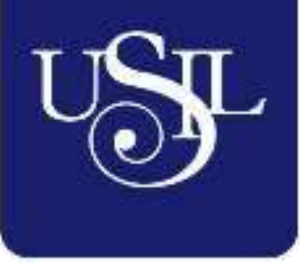

UNIVERSIDAD

SAN IGNACIO

DE LOYOLA

ESCUELA DE POSTGRADO

Maestría en Ciencias Empresariales

\title{
PLAN DE NEGOCIO EN LA IMPLEMENTACIÓN DE UNA EMPRESA PARA LA ELABORACIÓN Y COMERCIALIZACIÓN DE PAPA DIALIZADA
}

Tesis para optar el grado de Maestro en Ciencias Empresariales

\author{
IVET SONIA AGUIRRE FLORES \\ KAREN SILVIA CRESPO QUESADA \\ JORGE MANUEL DÍAZ PISCO \\ OSCAR LUIS FLORENCIO GONZALES VEGA
}

Asesor:

Dr. Edmundo Rafael Casavilca Maldonado

Lima - Perú

2017 
"Plan de negocio en la implementación de una empresa para la elaboración y comercialización de papa dializada" 


\section{Resumen Ejecutivo}

A continuación, desarrollaremos algunos de los aspectos más importantes y relevantes del proyecto, con el fin de dar a conocer en que consiste el proceso de dialización de la papa, su utilidad, las ventajas competitivas de este nuevo producto, como también los resultados financieros proyectados obtenidos e indicadores de factibilidad del proyecto.

El propósito del presente proyecto se dirige a implementar una empresa que se dedique a la elaboración y comercialización de papa que ha pasado por un proceso productivo al que se llamará comercialmente "dialización”.

Al igual que el proceso de diálisis en seres humanos, el cual es la "técnica extracorpórea que se basa en la difusión de solutos entre la sangre y el baño de diálisis a través de un hemodializador” (MINSA RM 845-2007), esto significa que mediante un tratamiento médico se elimina o reduce de manera artificial las toxinas y/o sustancias nocivas de la sangre, la dialización que se realizará a la papa será mediante la inmersión en agua natural sin ningún aditamento químico durante cuatro ciclos de seis horas, logrando así reducir los niveles de minerales que contiene este tubérculo, sobretodo los del potasio, ya que por ser un mineral se diluye en agua.

Gracias a la disminución del potasio, se logra mejorar el proceso de asimilación que realiza el cuerpo humano a través de los riñones (Animated Dissection of Anatomy for Medicine, 1990, "El potasio es necesario para que las células funcionen apropiadamente. Usted obtiene potasio a través de los alimentos. Los riñones eliminan el exceso de potasio a través de la orina para mantener un equilibrio adecuado de este mineral en el cuerpo. Si los riñones no están funcionando bien, es posible que no sean capaces de eliminar la cantidad adecuada de potasio. Como resultado de esto, el potasio 
se puede acumular en la sangre"), ya que después de los 25 años nuestro cuerpo envejece y nuestros órganos ya no son tan eficientes como en personas más jóvenes. (Ernesto Villalba Supka, 2012, “los humanos dejamos de crecer biológicamente entre los 25 y 27 años, porque la glándula pituitaria con el correr de los años disminuye la producción de HGH (Hormona del Crecimiento Humano), encargada de fortalecer y rejuvenecer nuestros tejidos y es a partir de entonces que se inicia una fase natural, intrínseca y universal de todo ser vivo: comenzamos a declinar", p. 139).

El plan de negocio propuesto está enfocado o dirigido a personas mayores de 25 años de edad, las cuales desean mantener un estilo de vida saludable y de calidad, y buscan un lento envejecimiento del organismo humano, ya que según la Organización Mundial de la Salud (OMS) la expectativa de vida ha aumentado y por consiguiente existen gran cantidad de personas mayores a 80 o 100 años.

Por ello la empresa CODIAL S.A.C. desarrollara la infraestructura y procesos necesarios para lograr una oportunidad de negocio que permita brindar una buena alimentación sin tener la necesidad de recurrir a trabajos caseros o artesanales. A su vez la empresa desarrollará un producto a base de papa perricholi, a la que se aplicará un proceso innovador en el campo comercial denominado “dialización”, para ser empacada y sellada al vacío, permitiendo así la facilidad, inmediatez y conservación de las propiedades del producto, tanto en su forma natural como en su preparación.

Resultados previstos

El plan de negocio se desarrollará durante cinco años, teniendo como zonas de influencia comercial los distritos de Lima Metropolitana (Lima y Callao), con una inversión total de S/. 386,983 soles. Los procesos operativos y comerciales se centralizarán en el distrito de Independencia, donde se ubicarán la planta y oficinas; 
además contará con un diseño organizacional muy plano que permite gran eficiencia en la gestión y estará conformado por nueve colaboradores, quienes contarán con los recursos y equipamientos especializados para lograr el objetivo proyectado sobre una Tasa Interna de Retorno Financiera (TIRF) de 25\% frente a un Costo de Oportunidad del Capital (COK) de 14.02\%, con un Valor Actual Neto Financiero de S/. 283,095, con un retorno de la inversión de 4 años, 0 meses y 29 días y un costo beneficio de 3.94 veces por cada sol invertido, al quinto año del proyecto. 
Tabla de Contenido

Introducción

Capítulo I. Generalidades .17

1.1. Antecedentes .17

1.2. Determinación del problema u oportunidad .22

1.3. Justificación del Proyecto. .23

1.4. Objetivos generales y específicos .24

1.4.1. Objetivo General .24

1.4.2. Objetivos Específicos .24

1.5. Alcances y limitaciones de la investigación .25

1.5.1. Alcance: .25

1.5.2. Limitación: .25

Capítulo II: Estructura Económica del Sector .26

2.1. Descripción del estado actual de la Industria .26

2.1.1. Segmentación de la industria. 31

2.1.2. Empresas que la conforman 32

2.2. Tendencias de la industria .36

2.3. Análisis Estructural del Sector Industria 37

2.3.1. Amenaza de entrada de nuevos competidores .38

2.3.2. Rivalidad entre competidores .45

2.3.3. Amenaza de servicios y productos sustitutos 45 
2.3.4. Poder de negociación de los clientes .46

2.3.5. Poder de negociación de los proveedores 47

2.4. Análisis de la Competencia 47

2.4.1. Empresas que ofrecen el mismo producto o servicio .48

2.4.2. Participación de mercado de cada uno de ellos .51

2.4.3. Matriz de perfil competitivo 52

2.4.4. Matriz de atractividad del sector .55

2.5. Análisis del Contexto Actual y Esperado. .57

2.5.1. Análisis Político-Gubernamental .58

2.5.2. Análisis Económico. .59

2.5.3. Análisis Legal .64

2.5.4. Análisis Cultural .65

2.5.5. Análisis Tecnológico. .66

2.5.6. Análisis Ecológico.

2.6. Oportunidades .68

Capítulo III: Estudio de Mercado. .70

3.1. Descripción del servicio o producto .70

3.2. Selección del segmento de mercado. .74

3.3. Investigación Cuantitativa .80

3.3.1. Proceso de Muestreo .81

3.3.2. Análisis y Procesamiento de Datos .87 


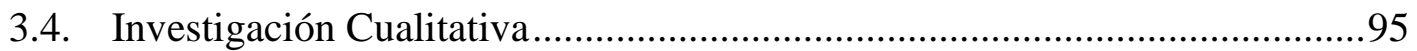

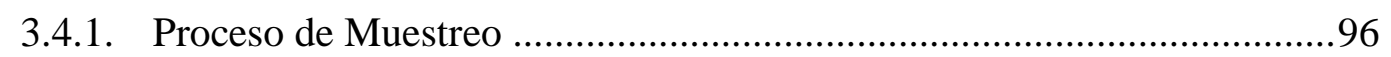

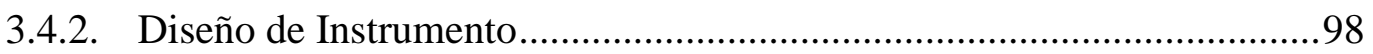

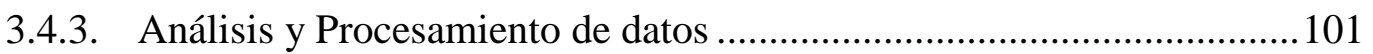

3.5. Conclusiones y recomendaciones del Estudio Cualitativo y Cuantitativo ...104

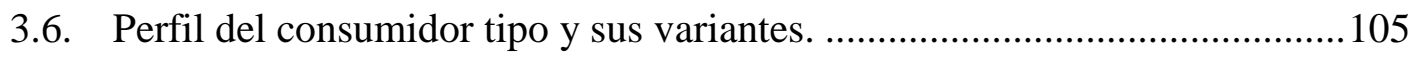

Capítulo IV: Proyección del Mercado Objetivo …………………………………....107

4.1. El ámbito de la proyección...........................................................................107

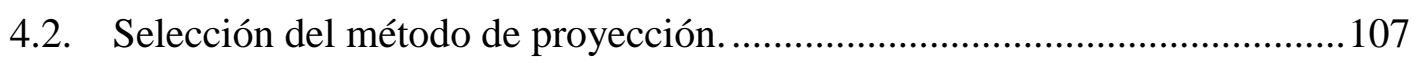

4.2.1. Mercado Potencial.................................................................................... 107

4.2.2. Mercado Disponible. ………………………………………………..... 110

4.2.3. Mercado Efectivo. ........................................................................ 110

4.2.4. Mercado Objetivo........................................................................... 111

4.3. Pronóstico de Ventas...................................................................................112

4.4. Aspectos críticos que impactan el pronóstico de ventas ................................119

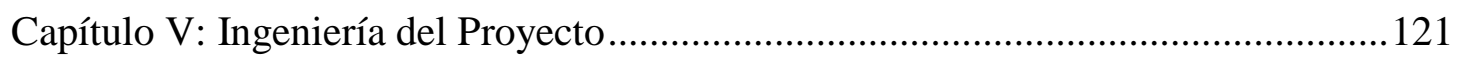

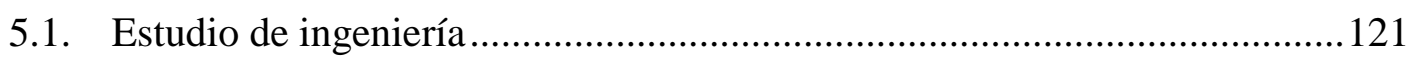

5.1.1. Modelamiento y selección de procesos productivos ...............................121

5.1.2. Selección del equipamiento ………………………………………....... 131

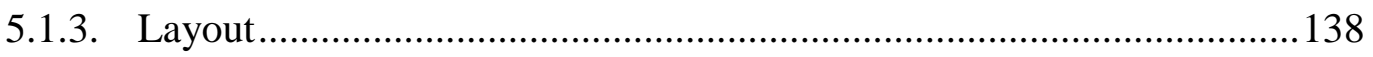

5.1.4. Distribución de equipos y maquinarias ....................................................139 
5.2. Determinación del Tamaño 146

5.2.1. Proyección de crecimiento 146

5.2.2. Recursos 149

5.2.3. Tecnología 152

5.2.4. Flexibilidad 153

5.2.5. Selección del tamaño ideal 155

5.3. Estudio de localización 161

5.3.1. Definición de factores locacionales 161

5.3.2. Consideraciones legales. 162

5.4. Determinación de la localización óptima.................................................. 170

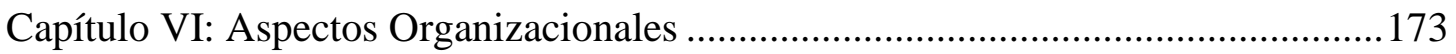

6.1. Caracterización de la cultura organizacional deseada ................................173

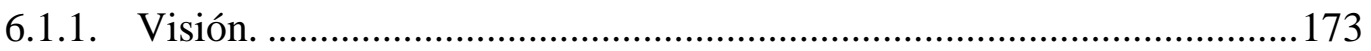

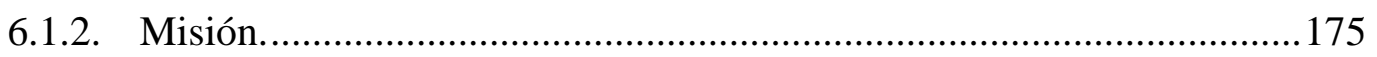

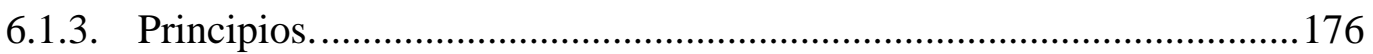

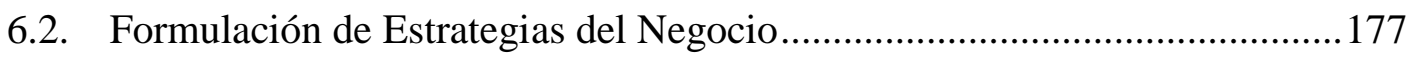

6.3. Determinación de las ventajas competitivas críticas....................................181

6.4. Diseño de la estructura organizacional deseada ......................................... 183

6.5. Diseño de los perfiles de puestos clave ..................................................... 184

6.6. Remuneraciones, compensaciones e incentivos ......................................... 194

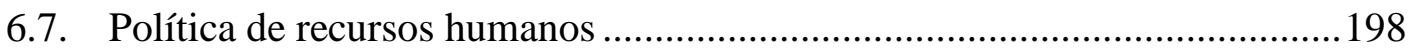




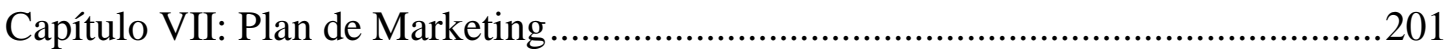

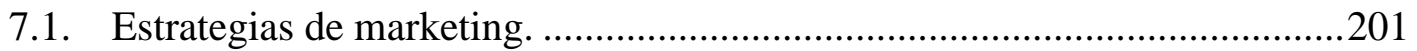

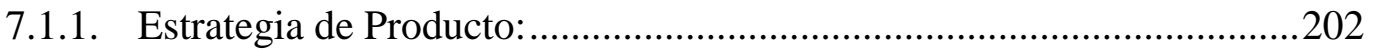

7.1.2. Estrategia de Precio: .............................................................................20

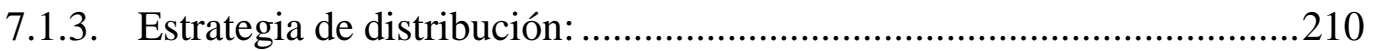

7.1.4. Estrategia de promoción y publicidad: .................................................211

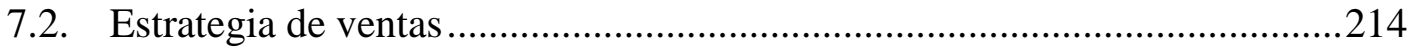

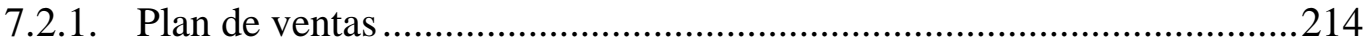

7.2.2. Políticas de servicios y garantías........................................................216

Capítulo VIII: Planificación Financiera................................................................219

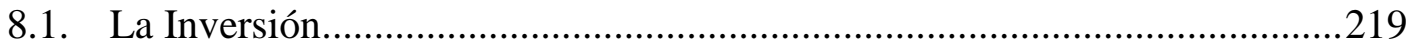

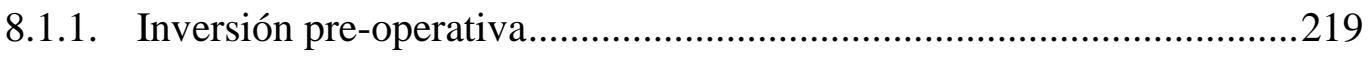

8.1.2. Inversión en capital de trabajo..........................................................223

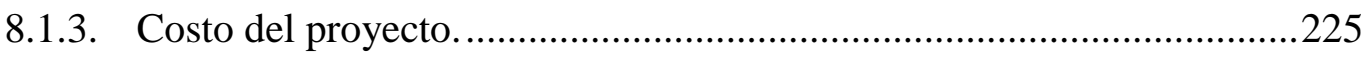

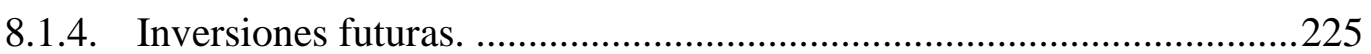

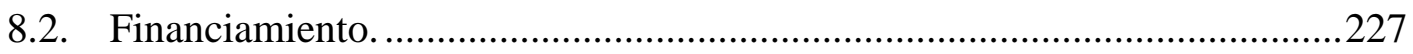

8.2.1. Endeudamiento y condiciones...........................................................22

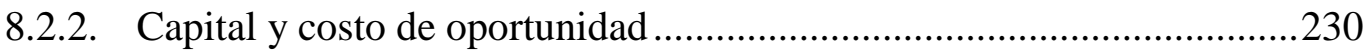

8.2.3. Costo de capital promedio ponderado ..................................................235

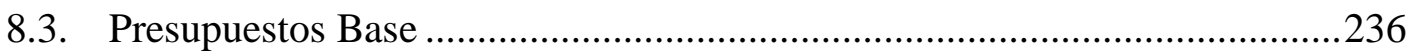

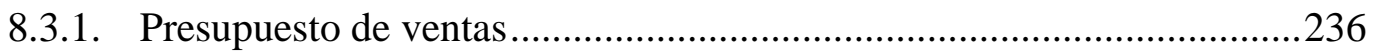


8.3.2. Presupuesto de costos de producción 237

8.3.3. Presupuesto de compras 238

8.3.4. Presupuesto de costo de ventas. 239

8.3.5. Presupuesto de gastos administrativos 241

8.3.6. Presupuesto de marketing y ventas 242

8.3.7. Presupuesto de gastos financieros 244

8.4. Presupuestos de Resultados..... 244

8.4.1. Estado de Resultados 244

8.4.2. Estado de situación finaciera proyectado 246

8.4.3. Flujo de caja proyectado 252

Capítulo IX: Evaluación Económico Financiera 255

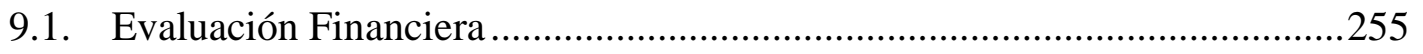

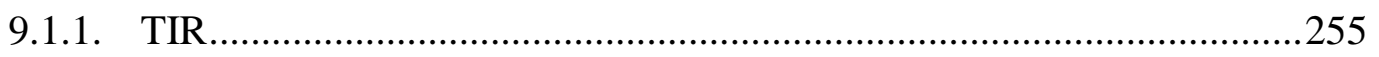

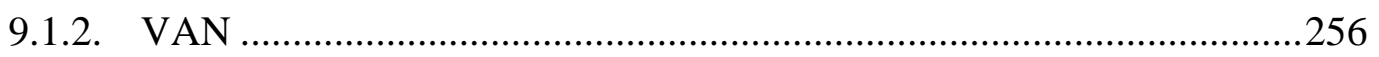

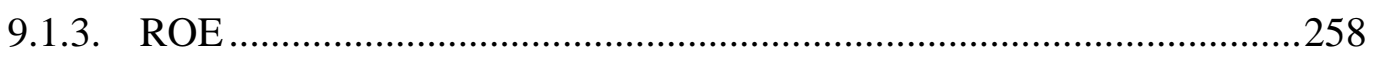

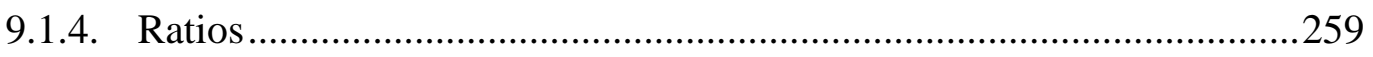

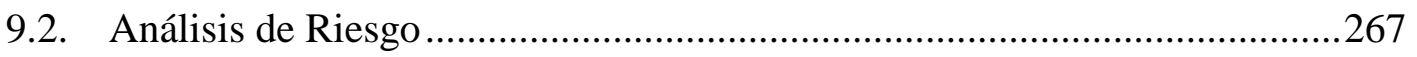

9.2.1. Análisis de punto de equilibrio........................................................267

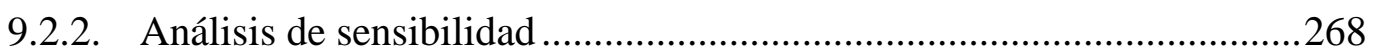

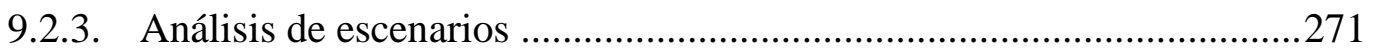

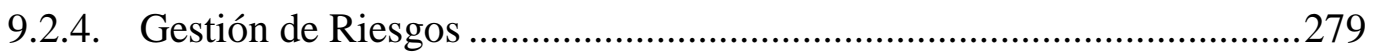


Capítulo X: Conclusiones y Recomendaciones 284

10.1. Conclusiones 284

10.2. Recomendaciones 287

Índice de Figuras 289

Índice de Tablas 295

Anexos 302

13.1. Anexo $\mathrm{N}^{\mathrm{o}} 01$ - Cartilla de Entrenamiento Focus Group 302

13.2. Anexo $\mathrm{N}^{\mathrm{o}} 02$ - Guia del Moderador del Focus Group 305

13.3. Anexo $\mathrm{N}^{\mathrm{o}} 03$ - Plantilla Focus Group 308

13.4. Anexo $\mathrm{N}^{\mathrm{o}} 04$ - Focus Group $\mathrm{N}^{\mathrm{o}} 1,2$ y 3

13.5. Anexo $\mathrm{N}^{\circ} 05$ - Ficha de Entrevista de Profundidad.

13.6. Anexo $\mathrm{N}^{\mathrm{o}} 06$ - Encuesta.

13.7. Anexo $\mathrm{N}^{\mathrm{o}} 07$ - Zonificaciòn de Lima Metropolitana 316

13.8. Anexo $N^{\circ} 09$ - Analisis Fisico Quimico

13.9. Anexo $\mathrm{N}^{\mathrm{o}} 10$ - Interes Promedio del Sistema Bancario

13.10. Anexo $N^{\circ} 11$ - Porjentaje de Depreciaciòn de Bienes

13.11. Anexo $\mathrm{N}^{\mathrm{o}} 12$ - Proyecciòn Prestamo Banco Continental 320

13.12. Anexo $\mathrm{N}^{\mathrm{o}} 13$ - Proyecciòn Prestamo Banco de Credito

13.13. Anexo $\mathrm{N}^{\circ} 14$ - Proyecciòn Prestamo Banco Interbank

13.14. Anexo $\mathrm{N}^{\circ} 15$ - Análisis de Sensibilidad. 323

13.15. Anexo $\mathrm{N}^{\mathrm{o}} 16$ - Ratios Año 1 325 
13.16. Anexo $\mathrm{N}^{\circ} 17$ - Ratios Año 2 .

13.17. Anexo $\mathrm{N}^{\mathrm{o}} 18$ - Ratios Año 3

13.18. Anexo $\mathrm{N}^{\circ} 19$ - Ratios Año 4

13.19. Anexo $\mathrm{N}^{\circ} 20$ - Ratios Año 5

13.20. Anexo $\mathrm{N}^{\mathrm{o}} 21$ - Beta del Sector de Alimentos en EE.UU. 345

13.21. Anexo $\mathrm{N}^{\circ} 22$ - Afiche Publicitario - Papa Sano 346

13.22. Anexo $\mathrm{N}^{\mathrm{o}} 23$ - Extracto del Libro ¿Cuántos Años Viviré?. 347

13.23. Anexo $\mathrm{N}^{\mathrm{o}} 24$ - Gasto Mensual Promedio por Persona. 348

13.24. Anexo $\mathrm{N}^{\mathrm{o}} 25$ - Licencias de Funcionamiento - Lima Metropolitana........349

13.25. Anexo $\mathrm{N}^{\mathrm{o}} 26$ - Licencia a Bodegas - Lima Metropolitana .... 350

13.26. Anexo $\mathrm{N}^{\mathrm{o}} 27$ - Casas Naturistas - Zona 2 351

Bibliografía. .352

Referencias Electrónicas . .353 


\section{Introducción}

El presente plan de negocios tiene como objetivo realizar una investigación para la implementación de una empresa encargada de la elaboración y comercialización de papa dializada; asignando el término “dialización” al proceso productivo que permitirá la reducción del nivel de potasio, para que logre ser fácilmente asimilado por los órganos vitales del ser humano (“Guía de alimentación del hospital universitario Donostia”, 2013).

La obtención de datos se ha logrado a través de un estudio de mercado, realizado a personas mayores de 25 años del segmento Zona 2 de Lima Metropolitana y de fuentes bibliográficas que han brindado información acerca del proceso y sus beneficios.

El plan de negocios presenta los siguientes capítulos:

En el capítulo I se presenta la descripción de los antecedentes del negocio, identificación del problema, descripción de la oportunidad de negocio, justificación, objetivos y alcances de la investigación.

En el capítulo II se describirá el estado financiero actual del sector, identificando y analizando a posibles empresas que lo conforman utilizando una serie de herramientas que nos puedan dar información relevante para toma de decisión con base en información financiera del sector.

En el capítulo III se desarrollará investigación de mercado con información cuantitativa y cualitativa, la cual brindará información a través de una serie de herramientas, de la opinión pública acerca de nuestra propuesta de valor al mercado.

En el capítulo IV se utilizarán los métodos de proyección para determinar el mercado potencial, disponible, efectivo y objetivo, además se realizará el pronóstico de venta. 
En el capítulo V se establecerá el modelamiento y selección del proceso productivo y la localización del centro de producción.

En el capítulo VI se definirá los objetivos principales de la organización, a través de la descripción de la misión, visión y principios de la empresa, además de definir las directrices que se van a regir dentro de la organización, las cuales van a ser aceptadas por todos los miembros de la empresa.

En el capítulo VII se definirá el plan de marketing a seguir por la empresa, para que pueda alcanzar los objetivos trazados y obtenga una competitividad sostenible dentro del mercado, abarcando las $4 \mathrm{p}$ del marketing: producto, precio, publicidad y plaza.

En el capítulo VIII se determinará la propuesta, evaluación y análisis de sensibilidad para conocer el balance proyectado y el presupuesto necesario para la puesta en marcha de la empresa.

En el capítulo IX se realizará una evaluación financiera obteniendo los indicadores financieros a través del VAN, TIR, ROE y ratios, a la vez realizar un análisis de riesgo mediante: punto de equilibrio, de sensibilidad y análisis de escenarios.

Finalmente se realizarán las conclusiones del proyecto de negocio, así como también se describirán las recomendaciones a tener en cuenta para su implementación y futuras aplicaciones. 


\section{Capítulo I. Generalidades}

\subsection{Antecedentes}

La papa (Solamum Tuberosum) es un producto de gran consumo a nivel mundial, su valor proteico y las variedades que posee la hace uno de los alimentos con más importancia después del maíz, trigo y arroz. Según un estudio de la Organización de las Naciones Unidas para la Alimentación y la Agricultura (FAO, 2008) señala que los continentes de Asia y Europa son las regiones con mayor producción de papa en el mundo, siendo en el 2007 el año en que alcanzaron a suministrar el $80 \%$ de la producción mundial; está situación no ha cambiado al año 2012 en el cual otro estudio realizado por la misma organización mantiene a los continentes de Asia y Europa como los principales productores de papa y sitúa al Perú en el décimo octavo lugar, la Tabla $\mathrm{N}^{\circ} 1$ presenta la información de producción de papa en el mundo.

\section{Tabla 1}

Producción de Papa en el Mundo

\begin{tabular}{|c|c|c|c|}
\hline Ranking & País & Producción & TM \\
\hline & 1 China & $85,860,000.00$ & \\
\hline & 2 India & $45,000,000.00$ & \\
\hline & 3 Estados Unidos & $19,165,865.00$ & \\
\hline & 4 Federación de Rusia & $29,532,530.00$ & \\
\hline & 5 Alemania & $10,665,600.00$ & \\
\hline & 6 Ucrania & $23,250,200.00$ & \\
\hline & 7 Bangladesh & $8,205,470.00$ & \\
\hline & 8 Paises Bajos & $6,765,618.00$ & \\
\hline & 9 Polonia & $9,091,900.00$ & \\
\hline & 10 Francia & $6,340,807.00$ & \\
\hline & 11 Iran & $5,400,000.00$ & \\
\hline & 12 Turquia & $4,822,000.00$ & \\
\hline & 13 Canada & $4,590,296.00$ & \\
\hline & 14 Argelia & $4,219,476.00$ & \\
\hline & 15 Egipto & $4,500,000.00$ & \\
\hline & 16 Reino Unido & $4,553,000.00$ & \\
\hline & 17 Pakistán & $4,104,400.00$ & \\
\hline & 18 Perú & $4,473,503.00$ & \\
\hline & 19 Brasil & $3,731,798.00$ & \\
\hline & 20 Malawi & $3,255,780.00$ & \\
\hline
\end{tabular}

Nota. Tomado de "Producción de papa en el mundo" (INEI, 2012), Adaptado de la Organización de las naciones unidas para la alimentación y la agricultura FAO. 
La papa juega un papel muy importante en la economía actual, la inversión que se realiza para obtener un producto de calidad elaborado con este insumo y a la vez su uso en la gastronomía de todo el mundo, le ha permitido ser considerado como uno de los productos commodity. Debido a la exigencia de las empresas dedicadas al sector gastronómico, el mercado de papa, se ha venido diversificando en diferentes partes del mundo.

Según la Escuela de Administración de Negocios para Graduados (ESAN, 2014), en el Perú las empresas dedicadas a la comida rápida o mejor conocidas como Fast Food, han iniciado sus operaciones desde la década de los 1980s, como se visualiza en la figura $\mathrm{N}^{\circ} 1$, siendo su despegue de este sector en la década de los 1990s, convirtiéndose en uno de los sectores con mayor dinamismo en el Perú en el contexto de un nuevo modelo económico nacional, dentro de este grupo de empresas existen aquellas que basan su comida en la utilización de la papa como parte principal de los productos que ofrecen.

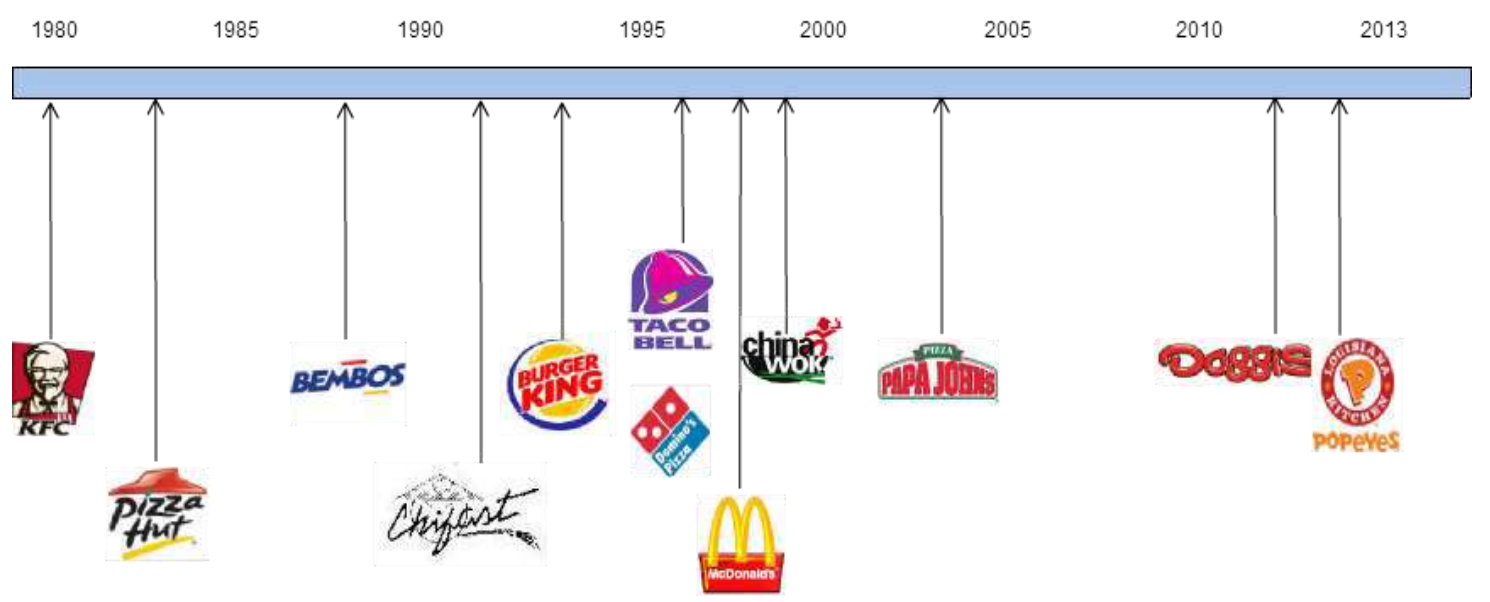

Figura 1. Evolución del mercado de fast food 1980 - 2013.

Tomado de Análisis prospectivo del sector de comida rápida en Lima: 2014 - 2030 (p.25), por L. A. Autor, M.C. Autor, O. C. Autor y G. L. Autor, Lima - Perú:

Editorial Cecosami Prepensa e Impresión Digital. 
En la actualidad el Perú es el mayor productor de papa en Sudamérica, figura $\mathrm{N}^{\circ}$, siendo la papa una planta alimenticia que procede de las culturas pre Incas e Incas. El país cuenta con las 3,000 variedades de papas de las 5,000 que existen a nivel mundial, es decir, tiene el $60 \%$ de variedades de este tubérculo a nivel mundial (Ministerio de Agricultura, 2011).

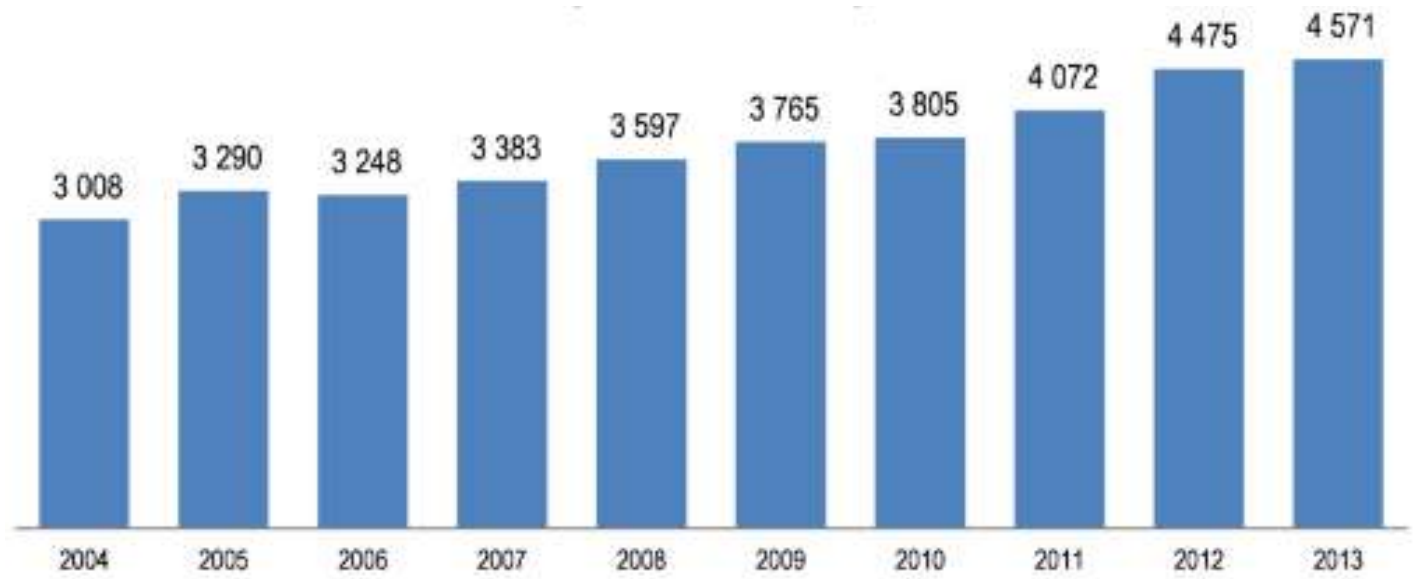

Figura 2. Producción de la papa entre los años 2004 y 2013 (Miles de toneladas), tomado de "PAPA Principales Aspectos Agroeconómicos" por el Ministerio de Agricultura y Riego (MINAGRI) 2013. Recuperado de https://www.inei.gob.pe/prensa/noticias/produccion-de-papa-crecio-45-7582/

Con base en un estudio del Ministerio de Agricultura del Perú (MINAGRI, 2013), el Producto Bruto Interno (PBI) de producción de papa representa el 25\% del sector agrícola, siendo las áreas de mayor producción Puno, Huánuco, Cusco, Junín, La Libertad, Apurímac, Cajamarca, Ayacucho, entre otras. De acuerdo a esta información, se deduce que el mayor cultivo de este tubérculo se presenta en la sierra del Perú con una suma del $90 \%$ de la producción total, figura $\mathrm{N}^{\circ} 3$. 


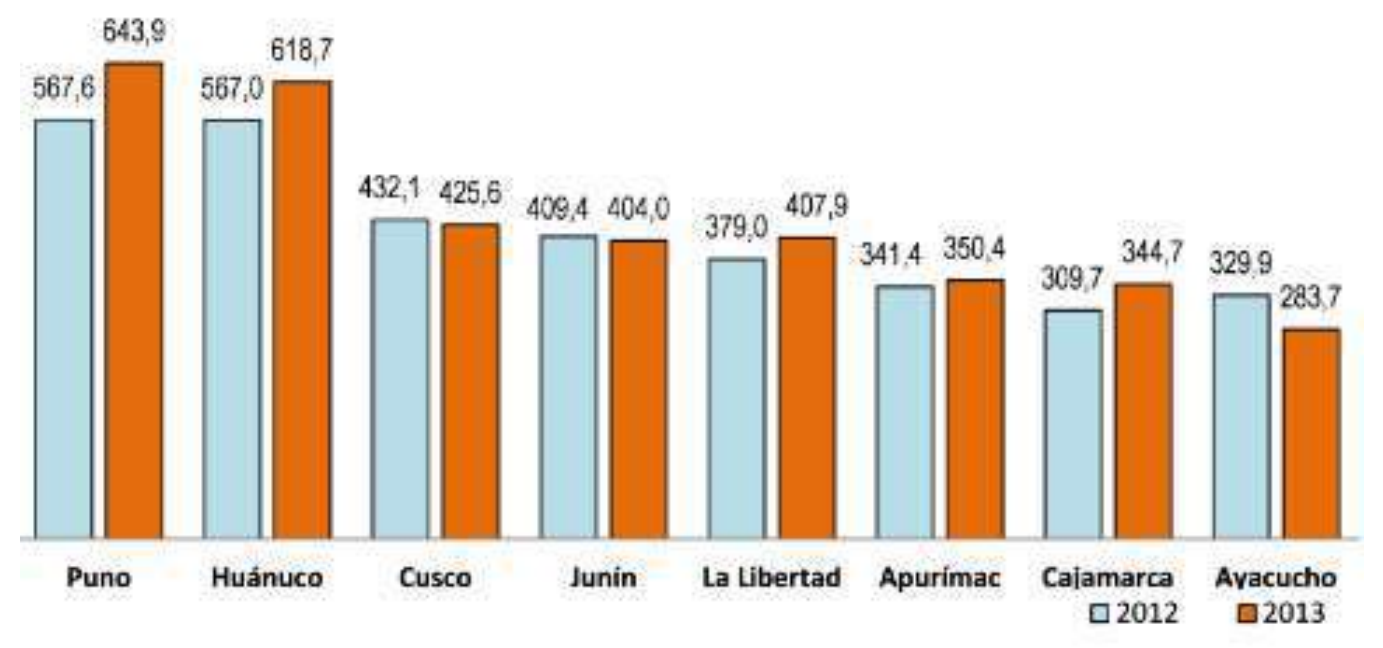

Figura 3. Principales departamentos productores de papa, 2013 - 2012 (Miles de toneladas), tomado de "PAPA Principales Aspectos Agroeconómicos" por el Ministerio de Agricultura y Riego (MINAGRI) 2013. Recuperado de https://www.inei.gob.pe/prensa/noticias/produccion-de-papa-crecio-45-7582/

La papa ha sido durante milenios uno de los productos fundamentales en la alimentación de todos los peruanos, la Organización de las Naciones Unidas para la Alimentación y la Agricultura (2008) señala que en el Perú se estima un consumo anual de $85 \mathrm{~kg}$ por persona, y caracteriza al tubérculo como un producto versátil con gran contenido de carbohidratos, vitamina $\mathrm{C}$, antioxidantes alimentarios (que ayuda a prevenir enfermedades como el envejecimiento), y con fibra, entre otros micronutrientes. En cuanto al valor nutricional, se precisa que una papa de 150 gramos consumida con su piel, aporta casi la mitad de nutrientes de las necesidades diarias de un adulto (100mg). 


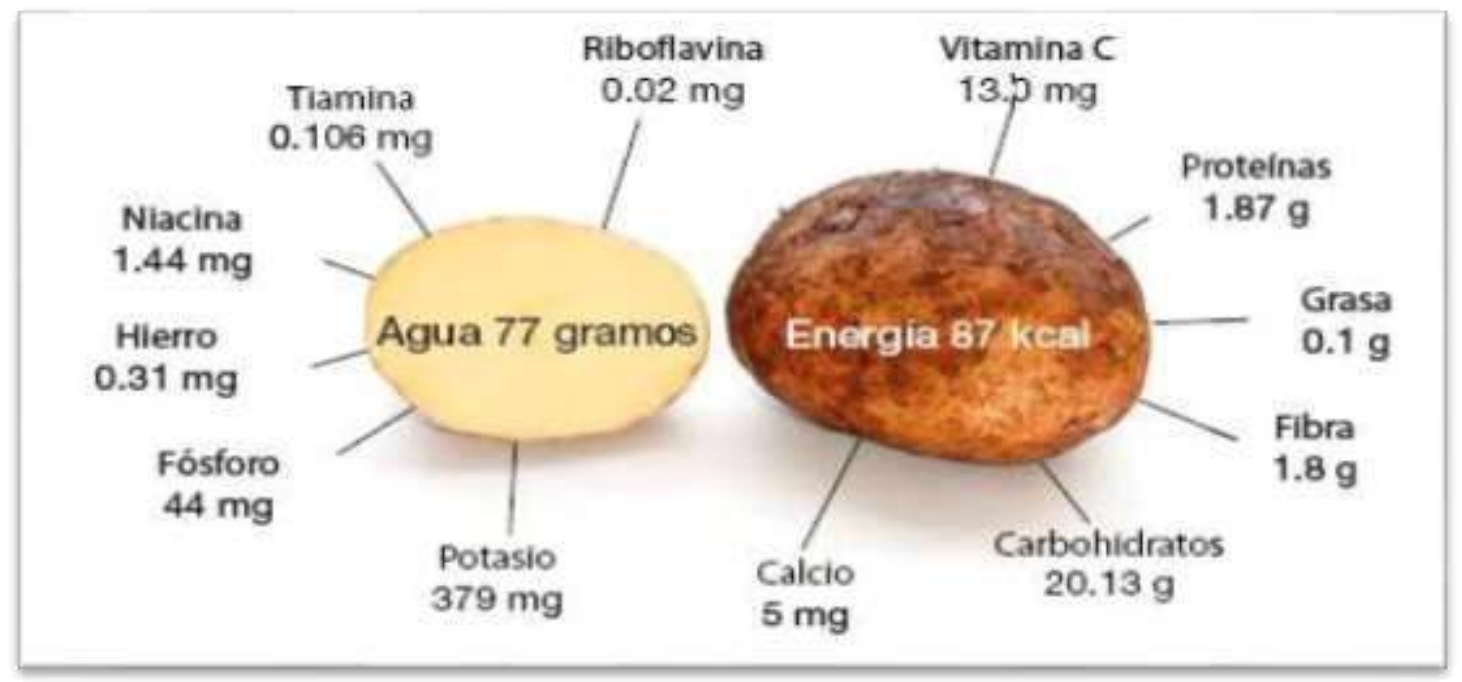

Figura 4. Nutrientes en 100gr de papa hervida y pelada antes del consumo. Año internacional de la Papa, 2008. Tomado de "Nutrientes de la papa" por la Organización de las Naciones Unidas para la Alimentación y la Agricultura (FAO), 2008. Recuperado de http://www.fao.org/potato-2008/es/lapapa/hojas.html

En la figura 4, se puede identificar que la papa contiene un alto valor de potasio, por cada $100 \mathrm{gr}$ de papa existe $379 \mathrm{mg}(9.718 \mathrm{mEq})$ de este mineral, muy importante en nuestra salud ya que permite, según el Artículo "Potasio en la Sangre" (salud.ccm.net, 2016), la transmisión de impulsos nerviosos, la contracción muscular y el funcionamiento adecuado de los órganos como el corazón y los riñones, entre otros.

Según la OMS (Organización Mundial de la Salud) en uno de sus artículos ("Directrices: Ingesta de potasio en adultos y niños", 2013) señala que un nivel normal de potasio en la sangre del ser humano debe estar en 3500mg por día, en ese sentido una papa de 100mg otorga el $11 \%$ aprox de lo que requiere el ser humano. El consumo per capita diario por persona es $253 \mathrm{gr}$ o 2.53 veces de papa de $100 \mathrm{gr}$ con $959 \mathrm{mg}$ de potasio, $27 \%$ del nivel normal; sin considerar la ingesta del potasio que tienen otros alimentos. 
Hoy en día existe un procedimiento, no industrializado, que contribuye en reducir el nivel de potasio que se encuentran en los tubérculos; este proceso al cual se llamará en adelante "Dialización", tiene como finalidad reducir el grado de porcentaje de algunos componentes, como es el caso del potasio, que al ser un mineral se disuelve fácilmente en el agua. Una propuesta del hospital universitario Virgen de las Nieves de España (2014), señala que, mediante el proceso de remojo, hervido y congelado, los alimentos pierden más del 50\% del potasio en su constitución, y las operaciones de remojo y doble cocción eliminan más del 70\% de este mineral, haciendo de los alimentos un producto más saludable y asimilable por el sistema humano; sin dejar de tener los nutrientes suficientes para una buena y correcta alimentación. Este proceso de dialización aplicado a los alimentos, que no es más que un proceso artesanal de remojo de los mismos, busca controlar los desechos que se logren acumular en la sangre y regular el nivel de potasio en la nutrición diaria.

\subsection{Determinación del problema u oportunidad}

En el Perú existe una evolución positiva por el consumo de alimentos saludables, a medida que el ritmo de vida de las personas va cambiando, tendiendo a ser más acelerada; estas buscan en los alimentos una forma de mantener o mejorar su calidad de vida, es por ello que se ve en el mercado diferentes productos que se ofrecen como saludables, por ejemplo se encuentran los aceites con cero colesterol, bebidas gaseosas, caracterizadas como cero azúcar, y productos que ayudan a facilitar el mejor funcionamiento de algún sistema del cuerpo humano, dentro de este grupo encontramos yogurts, denominados como pro bióticos, que contribuye a la correcta actividad del sistema digestivo. 
La propuesta del presente plan de negocio es ofrecer un producto saludable basado en la reducción de los minerales contenidos en los alimentos de consumo masivo, este se realizará mediante un proceso de remojo en agua entre 12 y 24 horas. Esta técnica que comercialmente se denominará “dialización” pretende industrializar el proceso mencionado.

Además, el proceso de dialización en alimentos no es conocido en el Perú, a pesar que hay una gran demanda por los alimentos con la finalidad de mejorar el funcionamiento integral del organismo humano. No existe aún un proceso industrializado que permite reducir los excesos de algún componente de los alimentos para que logren ser más saludables, manteniendo el nivel de nutrientes necesarios en una alimentación.

Esto nos permite identificar un mercado en el cual las personas tienen cierto cuidado en la adquisición de productos alimenticios, sobretodo porque contribuyen con una mejor calidad de la salud

\subsection{Justificación del Proyecto}

El proyecto busca cubrir una oportunidad de negocio de los consumidores con preferencia por productos saludables, especialmente por aquellos insumos que forman parte de la dieta diaria (como es el caso de los tubérculos) y con mayor atención en la dieta de aquellas personas que padecen de alguna enfermedad; para ellos una balanceada alimentación es necesaria y obligatoria para evitar complicaciones y llevarlos a un deterioro progresivo de sus órganos vitales.

Una buena opción para brindar un alimento saludable, se realizará por medio del proceso de dialización. Este proceso se aplicará en uno de los productos de mayor consumo en nuestro país, la papa; actualmente lo realizan de forma artesanal los 
centros médicos, para alimentar a sus pacientes, o también lo pueden realizar los familiares de estos en sus respectivos hogares; sin embargo, se busca industrializar este proceso para aumentar el volumen de la producción en un corto tiempo, introducirlo al mercado y cubrir la demanda en un tiempo real.

Con el proceso de dialización, poco conocido hoy en el mercado de productos saludables como tal; obtendremos un alimento, como la papa, con menor nivel de potasio; ya que un nivel adecuado de este elemento en la sangre permite el buen funcionamiento del sistema nervioso y muscular, y en su defecto su exceso puede provocar problemas cardiacos. (Animated Dissection of Anatomy for Medicine, 1990, "El potasio es necesario para que las células funcionen apropiadamente. Usted obtiene potasio a través de los alimentos. Los riñones eliminan el exceso de potasio a través de la orina para mantener un equilibrio adecuado de este mineral en el cuerpo. Si los riñones no están funcionando bien, es posible que no sean capaces de eliminar la cantidad adecuada de potasio. Como resultado de esto, el potasio se puede acumular en la sangre"). Este producto busca convertirse en uno de los alimentos saludables básicos de la dieta diaria.

\subsection{Objetivos generales y específicos}

\subsubsection{Objetivo General}

Elaborar un plan de negocio en la implementación de una empresa para la elaboración y comercialización de papa dializada

\subsubsection{Objetivos Específicos}

1. Analizar el entorno y/o el sector donde se desarrollará la empresa o negocio para identificar las oportunidades y amenazas que puedan afectar a este. 
2. Desarrollar un plan de marketing, en el que se describe la investigación de mercado y sus resultados, las estrategias de mercado y las ventas a proyectar.

3. Desarrollar un plan de operaciones, donde se considere costos de la operación e infraestructura de la empresa.

4. Desarrollar un plan organizacional, que incluya las estrategias de la empresa, sus costos administrativos, aspectos legales para su buen funcionamiento y la estructura organizacional.

5. Desarrollar un plan financiero, donde se detallarán los ingresos y egresos, en el que se evaluará la viabilidad de lo que resulte al término del tiempo proyectado.

\subsection{Alcances y limitaciones de la investigación.}

\subsubsection{Alcance:}

El proyecto en desarrollo tiene como alcance la implementación de una empresa para la elaboración y comercialización de papa dializada, en la ciudad de Lima - Perú.

\subsubsection{Limitación:}

1. Información limitada sobre dialización en tubérculos.

2. Información limitada sobre empresas que aplican el proceso de dialización en su elaboración.

3. Tiempo para el desarrollo del proyecto propuesto. 


\section{Capítulo II: Estructura Económica del Sector}

El sector en el cual se concentrará el estudio del producto a ofrecer es denominado industria alimenticia, la misma que forma parte de la industria manufacturera y donde se realizan actividades relacionadas a procesos de la cadena alimentaria.

\subsection{Descripción del estado actual de la Industria}

La industria manufacturera tiene como principales actividades, aquellas que se desarrollan en el sector de la industria alimenticia; siendo este un sector dinámico en la economía nacional, ya que comprende actividades dedicadas a la elaboración y procesamiento de productos para el consumo de hogares y empresas (Ver Tabla $\mathrm{N}^{\mathrm{o}} 2$ )

Los productos que genera en este tipo de industria son de vital importancia, ya que están dirigidos a cubrir las necesidades básicas de la población, en los aspectos de nutrición, salud y seguridad alimentaria.

La industria alimentaria es una de las más representativas en el país con 32\% del Producto Bruto Interno (PBI) industrial, y que comprende un rubro importante y estratégico para la economía a nivel nacional (Gestión, 2015). Así también señala la revista Industria Alimentaria (2015), que este sector representó en el 2014 el 5.7\% del Producto Bruto Interno (Ver Tabla $N^{\circ} 3$ ).

Tabla 2

Producto Bruto Interno de la industria manufacturera

\begin{tabular}{|c|c|c|c|c|c|}
\hline Clase de Actividad & $2008 \mathrm{Pl}$ & $2009 \mathrm{Pl}$ & $2010 \mathrm{Pl}$ & $2011 \mathrm{Pl}$ & $2012 \mathrm{E} /$ \\
\hline Industria Manufacturera & 29824560 & 27752911 & 31504629 & 33409865 & 33901311 \\
\hline Industria alimenticia & 8871942 & 8925488 & 9237942 & 10244827 & 10349588 \\
\hline Fabricación de productos lácteos & 718678 & 697174 & 788548 & 817539 & 872576 \\
\hline Elaboración y preservación de pescado & 727136 & 633070 & 531928 & 891686 & 866600 \\
\hline Elaboración harina y aceite pescado & 525586 & 503339 & 344577 & 631026 & 341967 \\
\hline Molineria y panadería & 1646639 & 1728631 & 1814189 & 1825416 & 1908953 \\
\hline Elaboración y refinación de azúcar & 258240 & 272937 & 266420 & 275951 & 281504 \\
\hline Fabricación otros productos alimenticios & 3640545 & 3696941 & 4001098 & 4223435 & 4432159 \\
\hline Fabricación de bebidas y productos de tabaco & 1355118 & 1393396 & 1491182 & 1579774 & 1645829 \\
\hline
\end{tabular}

Nota Adaptado de "Producto Bruto Interno en el sector de Industria Alimenticia 2008 - 2012 en miles de soles", por el Banco Central de Reserva del Perú 
Tabla 3

Producto Bruto Interno por Sector Productivo 2010-2015

\begin{tabular}{l|rrrrrr}
\hline & 2010 & 2011 & 2012 & 2013 & 2014 & 2015 \\
\hline Agropecuario & 21,766 & 22,658 & 23,991 & 24,362 & 24,814 & 25,518 \\
Pesca & 1,891 & 2,892 & 1,960 & 2,445 & 1,762 & 2,042 \\
Mineria & 50,714 & 51,043 & 52,473 & 55,035 & 54,554 & 59,615 \\
Manufactura & 59,255 & 64,330 & 65,265 & 68,508 & 66,041 & 64,939 \\
Electricidad y agua & 6,501 & 6,994 & 7,401 & 7,811 & 8,193 & 8,701 \\
Construcción & 23,993 & 24,848 & 28,779 & 31,353 & 31,956 & 30,081 \\
Comercio & 40,420 & 44,034 & 47,218 & 49,984 & 52,193 & 54,217 \\
Servicios 1/ & 177,840 & 190,253 & 204,186 & 217,022 & 227,890 & 237,515 \\
PRODUCTO BRUTO INTERNO & 382,380 & $\mathbf{4 0 7 , 0 5 2}$ & $\mathbf{4 3 1 , 2 7 3}$ & $\mathbf{4 5 6 , 5 2 0}$ & $\mathbf{4 6 7 , 4 0 4}$ & $\mathbf{4 8 2 , 6 2 7}$ \\
\hline
\end{tabular}

Nota Adaptado de "Producto Bruto Interno por Sector Productivo 2010-2015 en miles de soles", por el Instituto Nacional de Estadística e Informática (INEI)

A nivel nacional, algunos de los factores que impulsan el desarrollo de la industria alimentaria, especialmente el segmento de productos saludables, están: el mayor poder adquisitivo que ha adquirido la población debido al aumento de empleo y el incremento de créditos financieros que hoy brindan las entidades bancarias para el consumo, por ejemplo la entidad financiera Saga Falabella, muy conocida no solo en el sector Financiero, también en el Retail, tiene su propia tarjeta de crédito, la cual es muy utilizada en diferentes sectores de consumo uno de ellos es Tottus, Hipermercado que tiene una gran demanda en productos de consumo alimentario. Esta conclusión parte de la Figura 5 donde se identifica claramente que las personas en los últimos cinco años han incrementado significativamente sus gastos mensuales, en comparación a los años anteriores. 


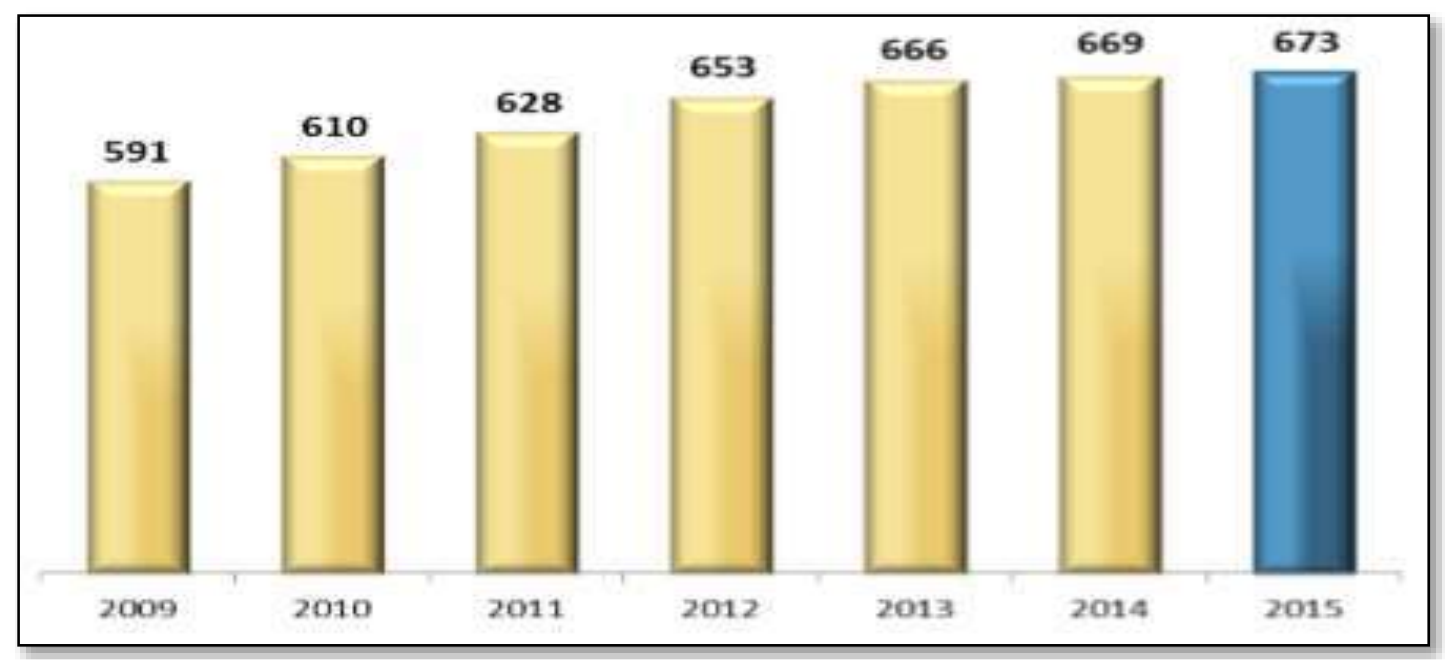

Figura 5. Evolución del gasto per cápita mensual 2009 - 2015

Soles, tomado de Evolución de la pobreza monetaria 2009 - 2015 (p. 13) por Instituto Nacional de Estadística e Informática 2016, Lima - Perú.

En la figura 6, se visualiza que las personas hoy en día invierten más en el consumo de alimentos, comparado a los otros grupos que cubren también las necesidades primarias y secundarias del ser humano y que dentro de dicho grupo hay mayor preferencia por el consumo de alimentos dentro del hogar, esto hace presumir que hay una mayor inversión en la compra de productos para la elaboración de alimentos en casa.

\begin{tabular}{l|rrrrrrrrrr}
\hline \multicolumn{1}{c}{ Grupos de gastos } & $\mathbf{2 0 0 9}$ & $\mathbf{2 0 1 0}$ & $\mathbf{2 0 1 1}$ & $\mathbf{2 0 1 2}$ & $\mathbf{2 0 1 3}$ & $\mathbf{2 0 1 4}$ & $\mathbf{2 0 1 5}$ & \multicolumn{2}{c}{ Variación Porcentual } \\
\hline Nacional & $\mathbf{5 9 1}$ & $\mathbf{6 1 0}$ & $\mathbf{6 2 8}$ & $\mathbf{6 5 3}$ & $\mathbf{6 6 6}$ & $\mathbf{6 6 9}$ & $\mathbf{6 7 3}$ & $\mathbf{0 , 6}$ & $\mathbf{1 3 , 9}$ \\
Alimentos & 255 & 263 & 269 & 272 & 278 & 275 & 278 & 1,2 & 9,1 \\
Alimentos dentro del hogar & 173 & 175 & 182 & 183 & 186 & 184 & 186 & 1,5 & 7,7 \\
Alimentos fuera del hogar & 82 & 87 & 87 & 89 & 92 & 91 & 92 & 0,6 & 12,1 \\
Vestido y calzado & 25 & 27 & 27 & 29 & 30 & 30 & 30 & 0,8 & 19,4 \\
Alquiler de vivienda y combustible & 96 & 97 & 105 & 112 & 118 & 121 & 125 & 2,9 & 29,3 \\
Muebles y enseres & 24 & 25 & 24 & 27 & 26 & 28 & 29 & 3,9 & 22,8 \\
Cuidados de la salud & 50 & 53 & 55 & 57 & 54 & 54 & 53 & $-1,0$ & 7,4 \\
Transporte y comunicaciones & 66 & 65 & 67 & 73 & 77 & 75 & 75 & 0,0 & 12,5 \\
Esparcimiento diversión y cultura & 50 & 53 & 55 & 56 & 55 & 57 & 54 & $-6,5$ & 7,4 \\
Otros gastos & 25 & 27 & 26 & 27 & 28 & 29 & 29 & 0,8 & 17,9 \\
\hline
\end{tabular}

Figura 6. Gasto real promedio per cápita mensual, por grupo de gastos 2009 - 2015. Tomado de Evolución de la pobreza monetaria 2009 - 2015 (p. 19) por Instituto Nacional de Estadística e Informática 2016, Lima - Perú. 
Entre los alimentos que siempre encontraremos en la canasta familiar de un peruano/a se encuentran los tubérculos, estos productos son sensibles a sufrir transformaciones en harinas, chuño, entre otros. Según el Instituto Nacional de Estadística e Investigación (INEI, 2009) menciona que, en el Perú, la papa es uno de los productos de mayor consumo promedio per cápita, con $63.5 \mathrm{~kg}$. al año y $5.3 \mathrm{~kg}$. al mes, siendo el consumo en Lima Metropolitana de $43.4 \mathrm{~kg}$., es decir, $29.2 \mathrm{~kg}$. al año menos de papa que en el resto del país (Ver tabla 4).

Tabla 4

Consumo promedio per cápita anual de tubérculos

\begin{tabular}{|c|c|c|c|c|c|c|c|c|}
\hline \multirow{2}{*}{$\begin{array}{c}\text { Principales tipos de tubérculos y } \\
\text { derivados }\end{array}$} & \multirow{2}{*}{ Total } & \multirow{2}{*}{$\begin{array}{c}\text { Lima } \\
\text { Matropolitana 1/ }\end{array}$} & \multirow{2}{*}{ Resto Pais } & \multicolumn{2}{|c|}{ Área } & \multicolumn{3}{|c|}{ Region natural } \\
\hline & & & & Urbana & Rural & Costa & Sierra & Selva \\
\hline Canote $(\mathrm{kg})$. & 3,4 & 3,6 & 3,3 & 3,4 & 3,5 & 4,1 & 2,6 & 2,6 \\
\hline Chuño entero (Kg.) & 22 & 0,0 & 3,1 & 0,5 & 7,7 & 0,1 & 6,4 & 0,1 \\
\hline Oluco (Kg.) & 28 & 2,1 & 3,2 & 1,6 & 7,0 & 1,6 & 5,8 & 0,6 \\
\hline Рapa (Kg.) & 63,5 & 43,4 & 72,6 & 47,0 & 120,1 & 39,4 & 116,5 & 29,9 \\
\hline Yuca (Kg.) & 6,6 & 2,2 & 8,6 & 3,5 & 17,2 & 3,3 & 5,0 & 24,3 \\
\hline Otros tuberaulos 21 & 1,3 & 0,1 & 1.8 & 0,3 & 4,5 & 0,1 & 3,5 & 0,3 \\
\hline
\end{tabular}

Nota. Adaptado de "Perú: Consumo Per Capita de los Principales Alimentos 2008 2009" por el Instituto Nacional de Estadística e Informática 2010 Consumo de Alimentos y Bebidas, (p. 32).

A nivel internacional, una de las variables que contribuye positivamente con esta industria es el crecimiento de las exportaciones y apertura a nuevos mercados (Ver tabla 5), debido a las mayores preferencias arancelarias que impacta en el comercio exterior de productos a nivel internacional con el fin de cubrir la demanda no satisfecha de productos alimenticios de cada país (Ver tabla 6), estos pueden ser tradicionales (insumos o materia prima) o no tradicionales (productos terminados con valor agregado) . 
Tabla 5

Producto Bruto Interno por Sector Productivo 2010-2015

\begin{tabular}{|c|c|c|c|c|c|c|}
\hline & 2010 & 2011 & 2012 & 2013 & 2014 & 2015 \\
\hline 1. Demanda Interna & 374,652 & 403,390 & 432,536 & 463,983 & 474,308 & 488,165 \\
\hline a. Consumo privado & 234,031 & 248,045 & 263,183 & 277,236 & 288,705 & 298,499 \\
\hline b. Consumo público & 42,036 & 44,063 & 47,634 & 50,802 & 55,914 & 61,210 \\
\hline c. Inversión bruta interna & 98,585 & 111,282 & 121,719 & 135,945 & 129,690 & 128,467 \\
\hline Inversion bruta fija & 97,824 & 103,541 & 120,419 & 129,164 & 126,466 & 120,139 \\
\hline - Privada & 75,841 & 84,028 & 97,020 & 103,266 & 101,064 & 96,645 \\
\hline -Pública & 21,982 & 19,513 & 23,399 & 25,898 & 25,392 & 23,494 \\
\hline Variación de inventarios & 761 & 7,741 & 1,300 & 6,781 & 3,234 & 8,318 \\
\hline 2. Exportaciones & 105,044 & 112,310 & 118,818 & 117,289 & 116,324 & 120,447 \\
\hline 4. Importaciones & 97,316 & 108,648 & 120,080 & 124,752 & 123,228 & 125,985 \\
\hline 3. Producto Bruto Interno & 382,380 & 407,052 & 431,273 & 456,520 & 467,404 & 482,627 \\
\hline
\end{tabular}

Nota. Adaptado de "Producto Bruto Interno por Sector Productivo 2010-2015 en miles de soles" por el Instituto Nacional de Estadística e Informática 2016. www.inei.gob.pe

Tabla 6

Exportaciones por $\mathrm{FOB}$

\begin{tabular}{|c|c|c|c|c|c|c|}
\hline & $2010^{n}$ & $2011^{2}$ & $2012^{\prime}$ & $2013^{2}$ & 2014 & 2015 \\
\hline TOTAL EXPORTACIONES & 35803 & 46376 & 47411 & 42861 & 39533 & 34236 \\
\hline \multicolumn{7}{|c|}{ ESTRUCTURA PORCENTUAL (\%) } \\
\hline Pesqueros & 5.3 & 4.6 & 4.9 & 4.0 & 4.4 & 4.2 \\
\hline Agrícolas & 2.7 & 3.6 & 2.3 & 1.8 & 2.1 & 2.1 \\
\hline Mineros & 61.2 & 59.4 & 57.9 & 55.5 & 52.0 & 55.0 \\
\hline Petróleo y derivados & 8.6 & 9.8 & 10.5 & 12.3 & 11.5 & 6.7 \\
\hline TRADICIONALES & 77.8 & 77.4 & 75.6 & 73.6 & 70.0 & 68.0 \\
\hline NO TRADICIONALES & 21.5 & 21.9 & 23.6 & 25.8 & 29.5 & 31.7 \\
\hline OTROS & 0.7 & 0.7 & 0.8 & 0.6 & 0.5 & 0.3 \\
\hline TOTAL & 100.0 & 100.0 & 100 & 100 & 100 & 100 \\
\hline
\end{tabular}

Nota. Adaptado de "Exportaciones por FOB en porcentaje 2010-2015" por el Banco Central de Reserva del Perú. www.bcrp.gob.pe

Sin embargo, con respecto a lo último mencionado, existe un riesgo ligado directamente con las consecuencias de la desaceleración de la economía mundial. Las empresas más vendedoras de la industria de alimentos (como se cita en la revista alimentos, 2012) indica que es preocupante la evolución negativa de los países que conforman la Unión Europea, así como la lenta recuperación de los Estados Unidos, lo que perjudicarían la demanda de los productos de agro exportación y por 
consiguiente decaerían las expectativas de la industria manufacturera, sobre la cual se acondiciona las perspectivas enfocadas en la evolución de la industria alimentaria.

\subsubsection{Segmentación de la industria.}

Según la Clasificación Industrial Internacional Uniforme (CIIU, 2016), la clasificación para la empresa que se desea implementar con el presente proyecto se ubicaría en la categoría de Industrias Manufactureras, Sección C, Grupo 103, Clase 1030 (Elaboración y conservación de frutas, legumbres y hortalizas).

El CIIU (Revisión 4, 2016) indica que la Clase 1030 contempla la elaboración y conservación de frutas, legumbres y hortalizas (Ver figura 7). Además, precisa que esta clase comprende las siguientes actividades:

1. Fabricación de alimentos compuestos principalmente de frutas, legumbres u hortalizas, excepto platos congelados o enlatados listos para consumir.

2. Conservación de frutas, nueces, legumbres y hortalizas: congelación, desecación, inmersión en aceite o en vinagre, enlatado, etcétera.

3. Fabricación de productos alimenticios a partir de frutas, legumbres u hortalizas.

4. Fabricación de jugos de frutas u hortalizas.

5. Fabricación de compotas, mermeladas y jaleas.

6. Elaboración y conservación de patatas: fabricación de patatas congeladas preparadas, fabricación de puré de patatas deshidratado, fabricación de aperitivos a base de patata, fabricación de patatas fritas, y fabricación de harina y sémola de patata.

7. Tostado de nueces. 
8. Fabricación de alimentos y pastas de nueces.

9. Se incluyen también las siguientes actividades: pelado industrial de patatas; producción de concentrados a partir de frutas y hortalizas frescas; y elaboración de productos perecederos de frutas, legumbres y hortalizas, como: ensaladas, hortalizas peladas o cortadas y tofu (cuajada de soja)

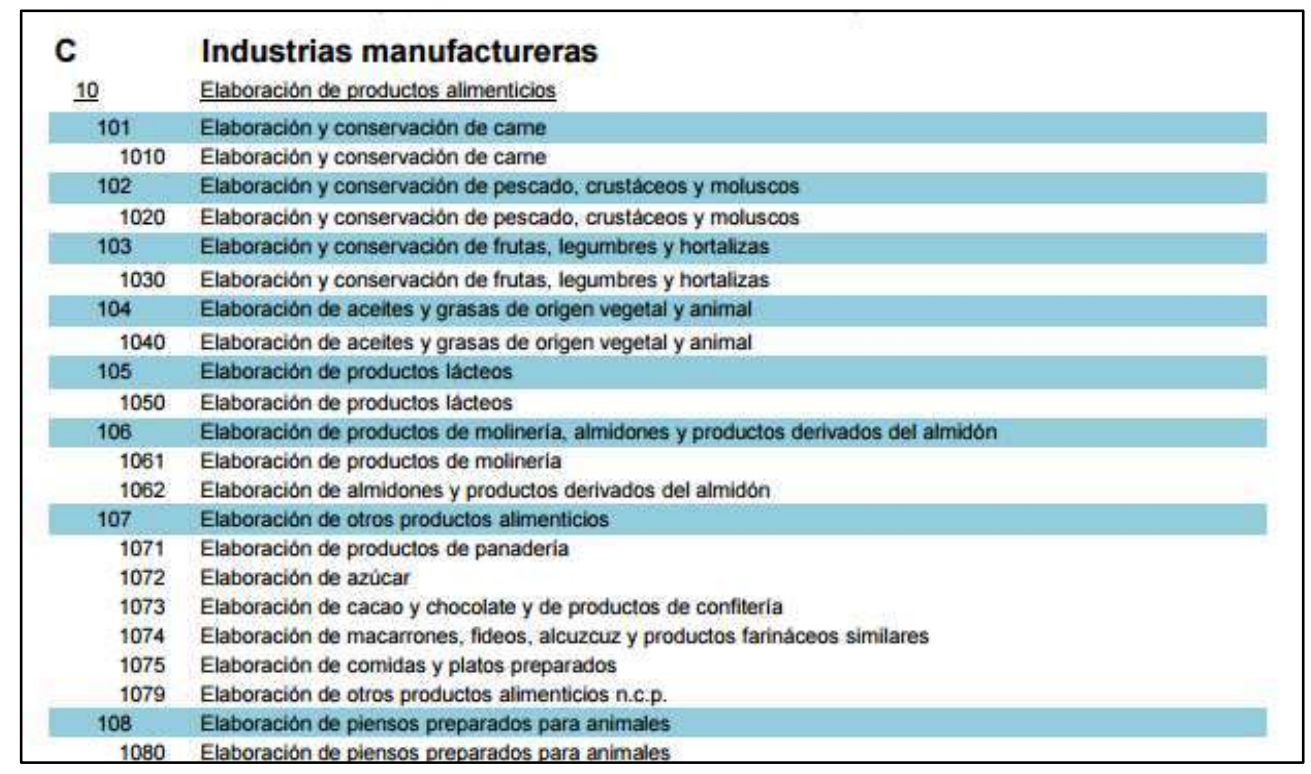

Figura 7. Clasificación Industrial Internacional Uniforme

Todas las Actividades Económicas, CIIU Revisión 4. Tomado de "Clasificación Industrial Internacional Uniforme de todas las Actividades Económicas Revisión 4" por el Instituto Nacional de Estadística e Informática (INEI), 2016 recuperado de https://www.inei.gob.pe/media/MenuRecursivo/publicaciones_digitales/Est/Li b0883/Libro.pdf.

\subsubsection{Empresas que la conforman}

América Economía (2013) lista a las siguientes empresas de alimentos más rentables del Perú (Ver figura 8), siendo Alicorp la que encabeza la lista: 


\begin{tabular}{|c|c|c|c|c|c|c|c|c|c|}
\hline$\frac{\pi}{20}$ & 바료 & 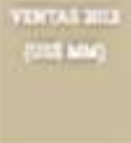 & $\frac{\cos }{\operatorname{mon} x}$ & 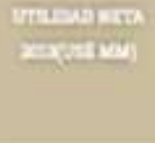 & 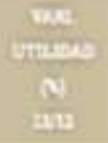 & $\frac{x+5}{x}$ & $\frac{m a}{2 x}$ & 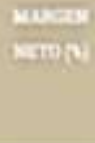 & $\frac{18}{20}$ \\
\hline 1 & Necouran & 2015 & $n$ & wo & $*$ & 194 & u & 0 & $a$ \\
\hline 2 & $\begin{array}{l}\text { matoos } \\
\text { casmavo } \\
\text { nocon }\end{array}$ & tains & $u$ & m & 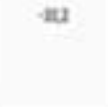 & w & v & v & u \\
\hline , & 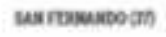 & Tes & as & $u$ & -4 & $v$ & u & at & w \\
\hline 4 & atintroes as & wet & v & No & $=$ & - & $=$ & - & $n$ \\
\hline 1 & mencetatis & $\mathrm{nu}$ & as & 4 & ow & 20 & is & $\omega$ & $n$ \\
\hline - & 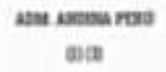 & wu & a & $x=$ & - & - & - & - & to \\
\hline 7 & amposes & $2 a 4$ & a & $\mathrm{ks}$ & - & - & - & $=$ & in \\
\hline 1 & mesmase & max & $4 a$ & in & - & - & - & - & Ist \\
\hline , & 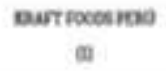 & ess & is & wo & - & - & - & - & $m$ \\
\hline 1 & wovt & os & a & $\alpha$ & $w$ & 7 & e & $2 s$ & an \\
\hline
\end{tabular}

Figura 8. Empresas de alimentos más rentables del Perú.

Tomado de "Revista América Económica (2013)" por américa Economía recuperado de http://rankings.americaeconomia.com/las500-mayores-empresas-de-peru-2014/

Alicorp

Empresa de marcas líderes con presencia regional, que busca generar valor y bienestar en la sociedad peruana; presenta un liderazgo en nuestro país con productos de consumo masivo, con marcas posicionadas: Don Vittorio, A la Cena, Negrita, Manty, Blanca Flor, Casino, Sayón, etc.; y en productos industriales tienen: Nicollini, Crisol, Harina para cocinar, papas congeladas (listas para freír).

Alicorp llega al consumidor por medio de los canales de venta: supermercados, bodegas y tiendas; y el consumo de sus productos se realiza también a través de los restaurantes o panaderías. 
Esta empresa busca llegar a todos los sectores socioeconómicos de nuestro país, así como extender su producción hacia el exterior, alcanzando hasta el momento colocarse en las regiones de Argentina, Brasil, Chile, Colombia y Ecuador para lograr abastecer la demanda considerable que hasta hoy han logrado entre los 23 países que ya se encuentran sus productos.

Alicorp además cuenta con otros negocios que responden a las necesidades y exigencias de los consumidores del sector acuicultura, es el caso de nutrición para animales.

Holding Alimentario del Perú

Holding Alimentario del Perú S.A. es propietario del 100\% de Jorge Rodríguez Banda S.A. (Jorbsa), este holding tiene el 75.64\% de las acciones de Gloria S.A., quien es la mayor empresa láctea de Perú (Ver figura 9); esta empresa está dedicada a la preparación, fabricación, compra, venta, importación, exportación y comercialización de diversos productos y derivados de lácteos.

Esta sociedad alimentaria además cuenta con acciones en diversas empresas como:

1. Grupo Gloria Holding Corporation, holding de Puerto Rico (100\%)

2. Racionalización Empresarial S.A. Perú, Raciemsa, empresa de transporte de carga $(28.24 \%)$

3. Lechería Andina Ecuador (100\%)

4. Distribuidor Exclusiva de Productos SAC Perú (99.99\%)

5. Inversiones Gloria Argentina S.A (100\%)

6. Inversiones Gloria Colombia (100\%)

7. Litrex S.A. Uruguay (100\%) 


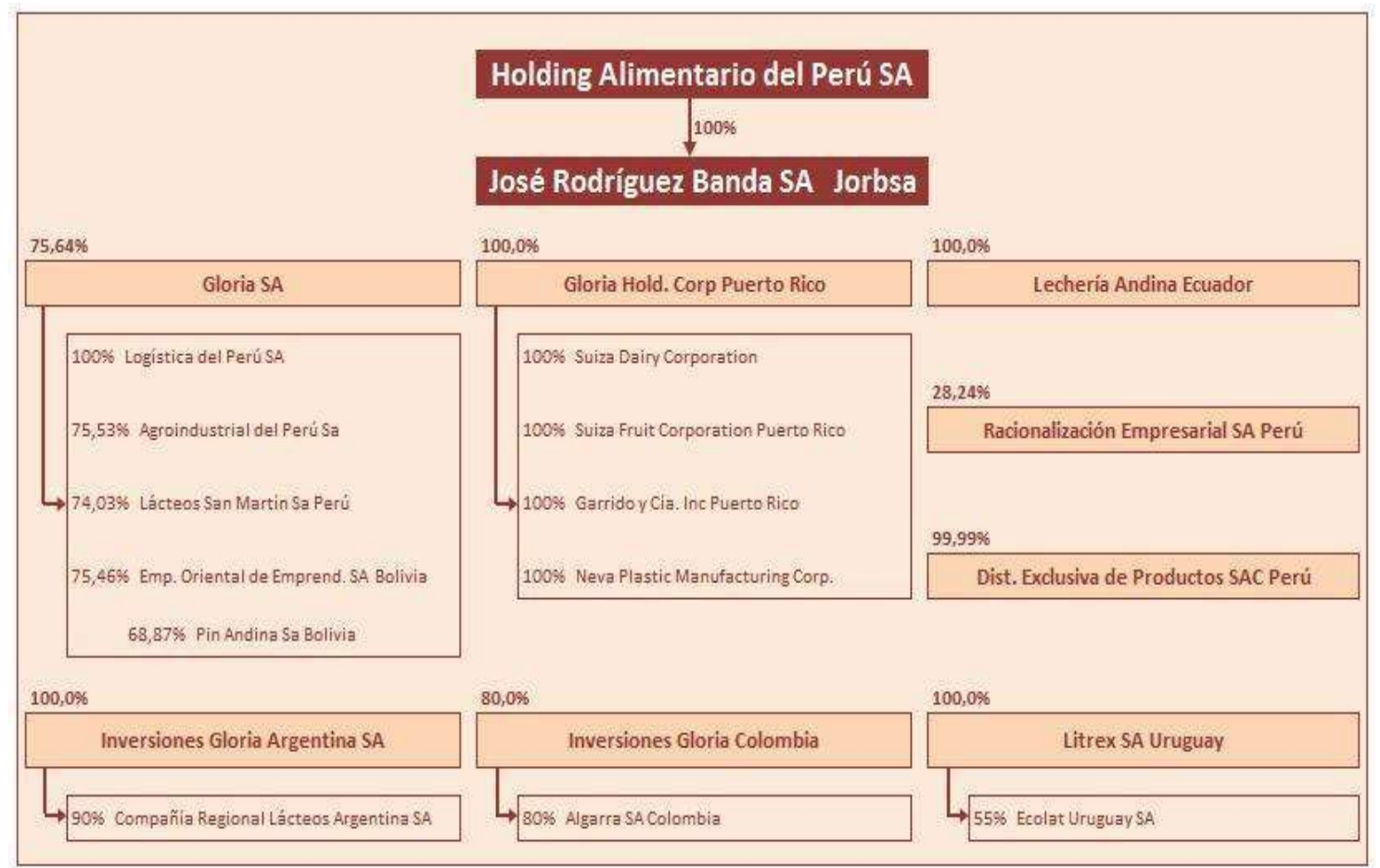

Figura 9. Distribución de acciones del Holding Alimentario del Perú S.A. 2012. Tomado del Diario de Fusiones \& Adquisiciones. Recuperado de San Fernando http://www.diariodefusiones.com

Es una empresa peruana dedicada a la producción y comercialización de alimentos de consumo masivo: líneas de pollo, pavo, cerdo, huevo y productos procesados. Esta empresa fue creada por la fusión de Molino Mayo con Avícola San Fernando.

San Fernando, es líder en el mercado con más de 65 años de experiencia (Ver figura 10), es el representante exclusivo de la línea genética "Cobb”, líder a nivel mundial, a través de su marca de genética Produss. 


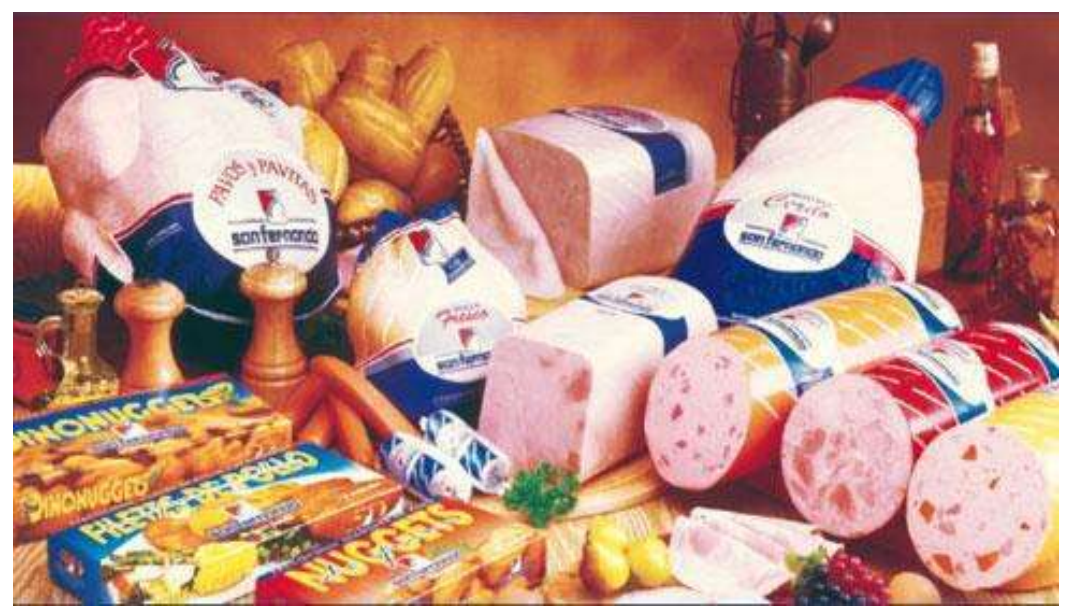

Figura 10. Productos desarrollados por San Fernando. Recuperado http://www.diariodefusiones.com

\subsection{Tendencias de la industria}

El ritmo de vida de las personas ha cambiado en los últimos diez años, caracterizado por una agitada vida cotidiana, una dinámica laboral y social; estos son algunos de los factores que acentúan la exigencia por la búsqueda de productos que beneficien la calidad de vida y que al mismo tiempo sean prácticos para su consumo.

Sobre esta premisa podemos identificar que existe la necesidad por buscar la practicidad en los productos alimenticios, que considere las siguientes características:

1. Capacidad en reducir su tiempo de preparación

2. Simplicidad para su consumo o uso

3. Facilidad para su transporte

4. Alcance inmediato por el consumidor

5. Eviten generar desechos que sean contraproducentes para el medio ambiente. Además, existe una gran tendencia por el consumo de productos saludables en la dieta diaria de toda persona, entendiéndose por productos saludables a todo aquel que aporte los siguientes beneficios:

1. Nutrientes necesarios para un correcto funcionamiento del organismo humano. 
2. Contribuir en la prevención de enfermedades

3. Fortalecer la dieta de los adultos mayores

4. Uso de envases orgánicos que permitan su correcta conservación

5. No contengan organismos genéticamente modificados

6. Proceso de elaboración natural

\subsection{Análisis Estructural del Sector Industria}

La inversión en la idea de negocio, obliga a realizar un estudio del entorno de la industria en la que se busca establecer la empresa. La estrategia a definir, va a estar soportada por la información que se obtenga como producto de este estudio, es decir, la estrategia competitiva va a depender del entorno social y económico y de cómo la empresa va a enfrentar la intensidad de la industria, es por ello que es importante este estudio.

Para analizar esta información se ha tomado como base las cinco fuerzas de Michael Porter (1980), las mismas que a continuación, a manera de resumen, se describe cada una de ellas y cómo son utilizadas para el análisis del sector:

1. Amenaza de entrada de nuevos competidores

Detecta, dentro de la industria, si los nuevos participantes tendrán barreras de entrada fáciles de franquear.

2. Rivalidad entre competidores

Muestra un panorama del posicionamiento de los competidores en la industria, con el fin de identificar las guerras de precio, campañas publicitarias, promociones y entrada de nuevos productos.

3. Amenaza de servicios y productos sustitutos 
Permite analizar en el mercado los productos sustitutos que existen y que pueden afectar la venta del bien. Se entiende como productos sustitutos, aquellos que tienen similares características y pueden satisfacer la misma necesidad.

4. Poder de negociación de los clientes

Da a conocer la característica de los compradores, con la finalidad de identificar que tan informados están a cerca del producto a ofrecer en el mercado, ya que esto puede determinar el precio del bien.

5. Poder de negociación de los proveedores

Permite analizar la organización de los proveedores, con la finalidad de determinar qué tan fuertes son para imponer sus precios de los insumos claves que suministran.

\subsubsection{Amenaza de entrada de nuevos competidores}

Partiendo de la premisa que, al ingresar nuevos competidores al mercado, la rentabilidad y el sector se tornan menos atractivo, dentro del sector manufacturero el negocio de productos saludables con proceso de dialización aún no tiene competidores directos, ya sea por el desconocimiento del proceso o porque en muchos casos son las mismas personas quienes realizan este proceso en sus alimentos de manera casera.

\subsubsection{Economías de Escala}

Según el análisis realizado actualmente, se tiene una baja barrera de entrada a los competidores mediante el concepto de economía de escala, no existe en el mercado peruano una empresa que se dedique a producir comida saludable mediante el proceso de 
dialización de manera industrial y en grandes cantidades que permita competir en el mercado en base a una reducción de costos, pero a la vez, esta se ve compensada por el desconocimiento que existe acerca del negocio y el proceso de dialización de alimentos, la finalidad de la empresa es justamente hacer que el negocio logre una economía de escala para que ello sirva de barrera para el ingreso de nuevos competidores ya que incrementando la producción y disminuyendo nuestros costos se lograría este fin.

\subsubsection{Diferenciación de Producto}

La empresa no tiene un competidor directo en el negocio, dentro del sector, que tenga una marca establecida en el mercado; si bien existen productos para el consumo dietético, no existen muchos productos que atiendan a un mercado en búsqueda de materias primas, como los tubérculos, con niveles adecuados de nutrientes; la empresa brindará, dentro de los empaques del producto, información nutricional, comparando a la papa, el antes y después de su proceso de dialización, adicionalmente informar al consumidor, como es que disminuyendo el potasio, el cuerpo humano obtendrá un beneficio en su funcionamiento. También se va a proporcionar una página web con toda la información necesaria, en donde el usuario podrá conocer acerca del proceso de dialización, nuestro sistema de empaquetamiento, valores nutricionales y beneficios para el cuerpo humano. 


\subsubsection{Necesidades de Capital}

Uno de los objetivos de la empresa es industrializar el proceso de dialización de la papa, que actualmente se hace de manera casera, para cumplir con este objetivo se deberá crear una tecnología que se encargue del proceso de diálisis, esta tecnología no existe en el mercado, lo que se suma al objetivo inicial es, el diseño y construcción de este sistema tecnológico para que posteriormente sea patentado, con la finalidad de dificultar o dilatar el ingreso para aquellos empresarios, que quisieran atender a este segmento de mercado; es por ello que uno de las primeras acciones a tener en cuenta es conseguir el capital para poder patentar el sistema de diálisis de la papa por los conocimientos especializados del proceso, lo que se conseguiría con esta patente, es elevar la barrera de ingreso al mercado para los nuevos competidores, con ello se ganará tiempo que será aprovechado para un posicionamiento de la marca dentro del público objetivo al que se desea llegar.

\subsubsection{Costos vinculados a los cambios}

Al ser una empresa que entra en un negocio poco o nada explotada, en donde el sistema de dialización de alimentos es un proceso poco conocido, a nivel industrial, se generaría una nueva marca de mercado, la misma que tendría un posicionamiento en los clientes potenciales. Si en el mercado apareciera un nuevo proveedor del producto tendría que superar el volumen de producción para que pueda competir en precio, el costo por parte de los clientes, será asumir 
el riesgo de cambiar de proveedor conociendo ya la calidad de la marca.

\subsubsection{Acceso a los canales de distribución}

La empresa realizará una distribución del nuevo producto en dos formas, indirecta, como inversión inicial y directa como una inversión futura del negocio (Ver figura 11).

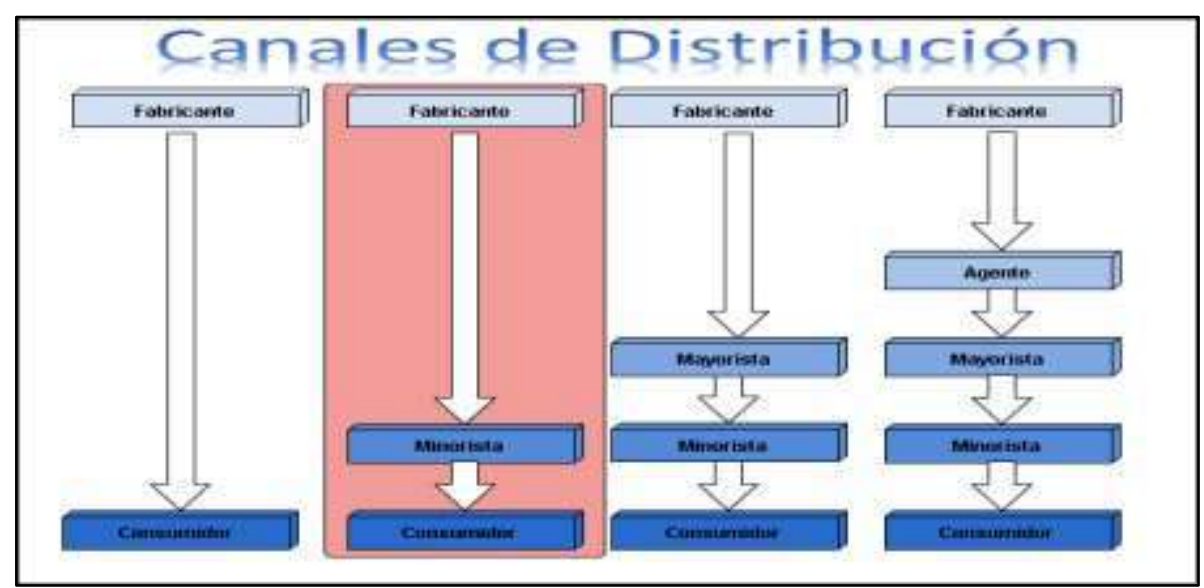

Figura 11. Tipos de canales de distribución 2

Tomado de Dirección de Marketing (p. 551) por Philip Kotler, 2016, México, Pearson Education, Copyright Prentice Hall Inc.

Para el caso de la distribución indirecta (Ver figura 12), esta se realizará a través de un minorista, como lo son las casas naturistas, minimarkets o tiendas de productos orgánicos. A quienes la empresa apoyará con la difusión del producto con la finalidad de cubrir la demanda que se presente, esta difusión se realizará a través de los siguientes medios:

1. La tecnología, a través de la Internet, nos brinda la oportunidad de estar más cerca de nuestros consumidores, es por ello que se desarrollará una campaña de difusión masiva, mediante las 
redes sociales, acerca de los beneficios de la papa dializada, indicando que se puede preparar en todos los platos como una papa normal.

2. Desarrollo de una página web con contenido principal de la papa dializada y el proceso por el cual este tubérculo pasa para convertirse en nuestro producto final, adicionalmente tendrá información nutricional y cuadro comparativo de las diferencias que tiene con una papa no dializada, con el objetivo que el consumidor pueda informarse de los beneficios de su consumo.

3. Impulsar y fortalecer el consumo de nuestro producto en los centros de abastos, mostrando las cualidades y los modos de preparación que se puede lograr con él.

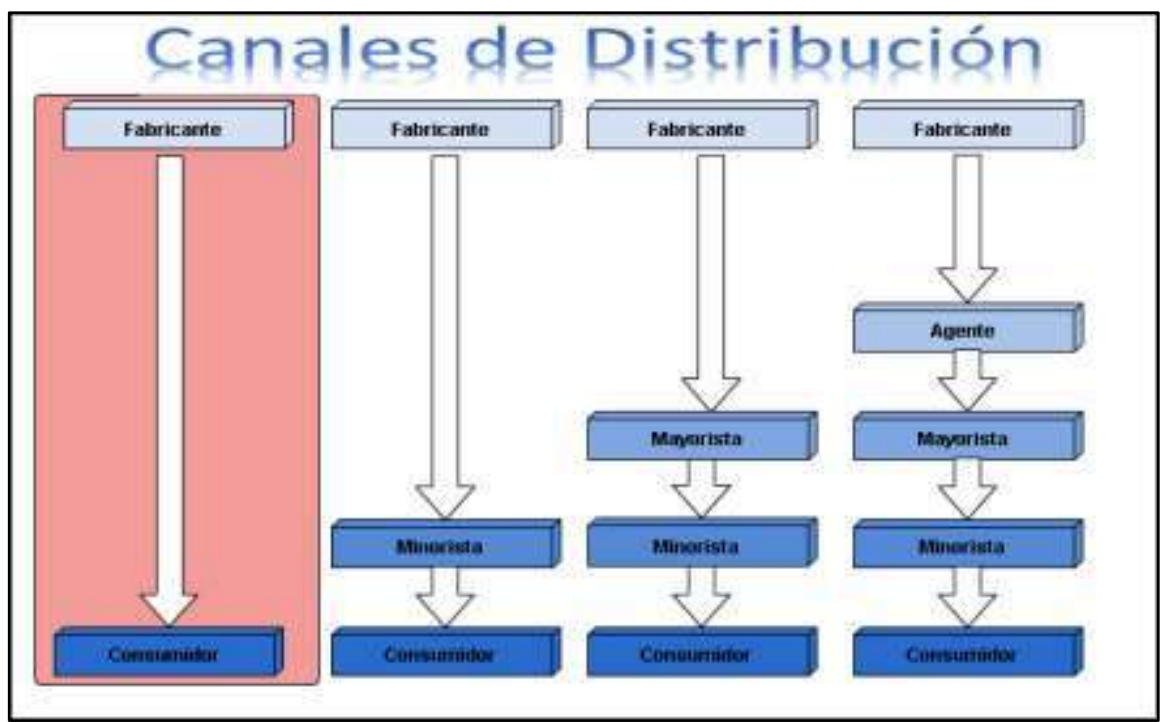

Figura 12. Tipos de canales de distribución Tomado de Dirección de Marketing (p. 551) por Philip Kotler, 2016, México, Pearson Education, Copyright Prentice Hall Inc.

En el caso de la distribución directa, la empresa no utilizará intermediarios, ya que se venderá directamente al consumidor final que 
puede ser el Estado (sector estatal) o centros de comida rápida llamados "Fast food" (sector privado).

Este último canal está considerado como una inversión futura del negocio, la cual se va a realizar luego de haber realizado el estudio de mercado respectivo.

La introducción del producto en el sector estatal se realizaría a través del siguiente proceso:

1. Registrar la empresa como proveedor del estado a través del Registro Nacional de Proveedores (RNP).

2. Participar en las adquisiciones o procesos de selección convocados que realizan las diferentes entidades estatales a través del Sistema Electrónico de Contrataciones del Estado (SEACE).

Como se ha mencionado en los antecedentes, existen muchas empresas en Lima metropolitana dedicadas al rubro de comida rápida "Fast food", donde la papa es un actor principal en el producto final que ellos ofrecen. Mediante un sistema de información acerca de los beneficios que se tiene con la papa dializada, la empresa utilizará las siguientes vías para llegar a este sector:

1. Construcción de una base de datos de empresas que se dediquen al servicio de venta de comidas, comunicando vía email o de manera personal acerca de las bondades que se tiene mediante el consumo de papa dializada. 
2. Desarrollar alianzas estratégicas con las empresas de comida rápida que utilicen la papa como alimento principal en los productos que ofrecen.

\subsubsection{Desventajas de los costos independientes del tamaño de la empresa}

La empresa, comparándola con cualquier otra que desee ingresar al mercado, tiene una ventaja que se encuentra apoyada en el conocimiento de la tecnología a utilizar para la dialización de alimentos. Sin embargo, al ser un producto nuevo a introducir, el volumen de producción en sus inicios será aún menor; una baja producción con capacidad ociosa de maquinaria resulta para la empresa incurrir en costos altos.

\subsubsection{Política del gobierno}

Según la Constitución Política del Perú (1993) todos los ciudadanos del Perú tienen derecho a la asistencia y protección de su salud y la de su entorno familiar, como política del estado es su obligación de brindar un ambiente que posibilite una mejor calidad de vida y a través de esta nueva tecnología de dialización de alimentos se tendrá la posibilidad de mejorar la salud, que por derecho debe tener cada uno de los ciudadanos, lo único que se debe cumplir es con las reglamentaciones que el estado exige para con los productos alimentarios. 


\subsubsection{Rivalidad entre competidores}

No existe una rivalidad entre competidores directa que puedan afectar al negocio actualmente, por ello podemos identificar este punto como bajo, a pesar que existe una tendencia en el mercado por el cuidado de la salud a través de productos que se venden por tiendas naturistas, pero estos no atienden a un mercado específico mediante un producto dializado, sino a clientes que relacionan la salud con el cuidado personal, como por ejemplo: productos bajos en grasa o con un nivel bajo en carbohidratos, pero no existe aún una industria alimentaria que procese los alimentos para atender a consumidores que desean un producto como la papa con bajo nivel de potasio, objetivo que se cumple dializando este tubérculo.

\subsubsection{Amenaza de servicios y productos sustitutos}

La amenaza de productos sustitutos ha sido identificada como muy alta, ya que los productos dializados que normalmente son consumidos, pueden ser tratados de manera casera, ahorrando así el dinero, pero no la inmediatez ni la facilidad de tener ingredientes aptos para el consumo que se encuentren en cualquier momento. Otros productos alternativos son los productos envasados como por ejemplo los productos Santa Natura o Fito sana que son complementos de los alimentos. Otro tipo de producto alternativo son de las conocidas redes de mercadeo como Herbalife o Fuxion, que tienen productos industrializados con agentes adicionales que ayudan en el funcionamiento de los sistemas del cuerpo humano. Se tiene que tener en cuenta que la dialización no implica agregar ningún componente a la papa, por 
el contrario de manera natural es disminuir el nivel de potasio en el tubérculo para que el cuerpo humano lo asimile mejor.

\subsubsection{Poder de negociación de los clientes}

La necesidad y búsqueda, por parte de los consumidores, de productos que brinden salud, de manera natural, se identifica como una oportunidad muy grande de negocio. Con el lanzamiento del producto de papa dializada, se atiende a este sector de mercado y que, además, a través de medios de información, se comunicaría las bondades y beneficios que tiene este producto; con ello se busca luchar contra el posible rechazo del producto por el precio adicional que tendrá, debido al procesamiento particular que se emplea. Así como tenemos una gran oportunidad, tenemos a la vez un reto aún más grande con las personas que no consideran importante el ahorro de tiempo generado en el trabajo y la dedicación que se le debe de dar al tratamiento casero de los productos.

Adicionalmente podemos declarar que estos productos dializados, está pensado para su venta al consumidor final que no está acostumbrado a la compra de grandes volúmenes, por lo general los productos para consumo humano, son adquiridos para ser consumidos como máximo dentro de la semana, por lo que, al no adquirir productos en masa, no exige reducir los costos unitarios del producto.

El cliente final no está en la posición de adquirir el producto, a ofrecer por parte de la empresa, a través de diferentes proveedores que produzcan el alimento como la papa dializada y pueda negociar hasta conseguir un mejor 
precio posible, ya que no existen aún en el mercado empresas que se dediquen a este tipo de negocio.

\subsubsection{Poder de negociación de los proveedores}

El poder de negociación de los proveedores es bajo, ya que se tiene muchas alternativas de compra de materia prima como por ejemplo el mercado de productores de Santa Anita, la Parada, Unicachi, Fiori o comprando directamente al agricultor; en cuanto a los equipos que se utilizarán para el proceso, se tiene la ventaja que es fácilmente ubicable en el mercado a través de internet y en tiendas locales, con un precio que es relativamente accesible, con opciones de mantenimiento y de servicio técnico también de bajo precio.

Otro factor que se debe de tener en cuenta es que nuestro insumo principal, la papa, no tiene una restricción para el acceso; es decir no es un producto privilegiado y a su vez no existen normativas gubernamentales que puedan restringir la inversión en este sector, pero al no ser un mercado explorado y explotado da una ventaja para poder acceder a implementar el formato de negocio que plantea este proyecto.

\subsection{Análisis de la Competencia}

Si bien es cierto el proyecto está basado en la elaboración y comercialización de papa dializada, tenemos que especificar que, en el Perú, no existen empresas que brinde el servicio de dialización u ofrezcan un producto ya dializado, como es el caso del presente proyecto.

En ese sentido tendríamos que hablar de una competencia indirecta, las cuales clasificaremos en tres grupos, como a continuación se indica: 
1. Empresas Primarias: Son las de acopio y comercialización donde están comprendidas los Mercados Mayoristas, Minoristas o Mercados de Barrio

2. Empresas Secundarias: También son de acopio y comercialización, pero en este caso están comprendidos los Supermercados e Hipermercados.

3. Empresas Procesadoras: En este caso son empresas que acopian, procesan y comercializan alimentos de consumo masivo.

Para todos los casos evaluaremos a todas las empresas que estén dentro de las que comercialicen la papa como uno de sus productos.

\subsubsection{Empresas que ofrecen el mismo producto o servicio}

A continuación, enunciamos por cada grupo las principales empresas que ofrecen un producto o servicio parecido o similar:

Empresas Primarias

En este punto se puede identificar a dos tipos de empresas o grupos empresariales, las cuales ofertan el producto de manera natural sin cambio o alteración, tampoco existe algún valor agregado al mismo o selección profunda del producto, comercializan directamente el producto y estos son:

1. Mercados Mayoristas $N^{\circ}$ 1, especializado en hortalizas, legumbres, tubérculos y raíces, la cual cuenta con el $80 \%$ del acopio de la papa nacional (MINAGRI, 2014) y no oferta ningún valor agregado al producto.

2. Los mercados Minoristas, los cuales están repartidos en todo Lima Metropolitana y mercados de barrio. 
Empresas Secundarias

En este punto se puede identificar las tres empresas más importantes que cuentan con supermercados e hipermercados en todo el Perú y estos son las siguientes:

1. Cencosud Retail Perú S.A.

La empresa Cencosud Retail Perú S.A. (Metro / Paris / Wong), es una empresa de capitales chilenos que en el 2007 y 2012 adquirió las tiendas del grupo Wong (Wong y Metro respectivamente), las cuales operan desde 1992 y hoy siguen en operación bajo el control de Cencosud.

La empresa Cencosud está dentro del rubro de supermercados e Hipermercados, en los cuales ofrecen productos de consumo masivo de la canasta familiar, llámense pan, fideos, lácteos, carnes, frutas y verduras entre otros, cuenta actualmente.

En este último rubro de verduras, que ofrece a sus clientes, se encuentra la papa blanca sin procesar, la cual compra directamente del productor, selecciona y comercializa en sus 78 tiendas ( 9 de Wong y 69 de Metro) a nivel nacional, siendo el volumen de comercialización

2. Supermercados Peruanos

Comienza en 1993 como cadena de tiendas Santa Isabel, luego en diciembre del 2003 el grupo financiero Interbank adquirió el total de sus acciones, y en marzo del 2004 cambiaron el nombre de Santa Isabel a Supermercados Peruanos la cual está compuesta por los supermercados Plaza Vea, Vivanda y Mass, esta cadena de tiendas también cuenta con un modelo de negocio basado en Supermercados e Hipermercados y hoy 
cuenta con un total de 72 locales (50 Plaza Vea, 8 Vivanda y 14 Mass) ubicándose principalmente en Lima, Piura, Chiclayo, Trujillo, Chimbote, Huancayo, Ica, Arequipa, Juliaca y Tacna, al igual que Cencosud ofrece a sus clientes productos de la canasta familiar, donde podemos encontrar a la papa blanca sin procesar, la cual compra directamente del productor, selecciona y comercializa.

3. Hipermercados Tottus S.A

Empresa perteneciente al grupo financiero Falabella de chile inicio sus operaciones en el 2002 en Perú y al igual que las arriba indicas esta también cuenta con supermercados e hipermercados, los cuales los tiene mayoritariamente en Lima, Arequipa, Piura, Cajamarca y Chimbote, con un total de 61 locales comerciales en los cuales también acopia y comercializa varios tipos de papa, dentro del rubro de productos de primera necesidad de la canasta familiar.

4. Makro Supermayorista S.A.

Empresa dedicada a la comercialización de productos alimenticios y no alimenticios con presencia internacional, dio comienzo a sus operaciones en el año 2009 agrupando Hoteles, Restaurantes, Caterings, Bodegas y Puestos de Mercado, actualmente cuenta con 11 locales a nivel nacional (Lima, Arequipa, Chiclayo, Trujillo y Piura), esta empresa es de capitales Holandeses y pertenece a Steenkool Handels Vereeniging la cual fue fundada en 1896 y opera en 62 países del mundo y emplea a 60,000 personas. 
Empresas Procesadoras

En este rubro se ubican a todas las empresas procesadoras formales e informales dentro del sector, estas empresas están dedicadas a procesamiento de alimentos para su comercialización en diversos lugares de Lima Metropolitana (es el principal lugar de distribución), y algunas provincias y departamentos del Perú.

\subsubsection{Participación de mercado de cada uno de ellos}

A continuación, se detalla la participación de mercado de cada uno de los competidores identificados en el punto 2.4 del presente trabajo, esta información se ha podido obtener tanto del Ministerio de Agricultura (MINAGRI), como del Instituto Nacional de Estadística e Informática (INEI) del año 2015, que a continuación revisaremos:

Tabla 7

Participación de Mercado 2015

\begin{tabular}{lcc}
\hline \multicolumn{1}{c}{ Distribuidor } & $\begin{array}{c}\text { Año } \\
2015\end{array}$ & $\begin{array}{c}\text { Participacion } \\
\%\end{array}$ \\
\hline $\begin{array}{l}\text { Mercado Mayorista } \\
\text { Mercado Minorista }\end{array}$ & 529.256 & $12,06 \%$ \\
$\quad$ Mercados de Barrio & & \\
$\begin{array}{l}\text { Supermercados } \\
\quad \text { Cencosud Retail } \\
\quad \text { Supermercados Peruanos } \\
\quad \text { Hipermercados Tottus } \\
\quad \text { Makro Supermayorista }\end{array}$ & 1.316 .610 & $30,00 \%$ \\
$\begin{array}{l}\text { Procesadores de Alimento } \\
\text { Exportaciones }\end{array}$ & & \\
Otros & 594.400 & $13,54 \%$ \\
\hline Total Nacional (**) & 1.948 .434 & $44,40 \%$ \\
\hline
\end{tabular}

Nota. Elaboración propia, Fuente de información MINAGRI e INEI 2015 
La información presentada en el Tabla $\mathrm{N}^{\mathrm{o}} 07$ es producto de recolección de información tanto del Ministerio de Agricultura (MINAGRI), como del Instituto Nacional de Estadística e Informática (INEI) tomando como referencia el año 2015, dado que información actualizada de la participación del mercado o del consumo de los diferentes sectores de negocio no existe o está incompleta, razón por la cual se entrega información agregada de la participación de mercado en función a la producción y su distribución mensual.

En consecuencia, como se puede observar, la participación de los Supermercados es bastante alta en relación al Mercado Mayorista $\mathrm{N}^{\mathrm{o}} 01$ y las Empresas Procesadoras de Alimento, en esta última no se ha podido precisar la participación dado que la cantidad de empresas procesadoras de alimentos formales son una minoría en función a las empresas procesadoras de alimentos informales, haciendo difícil la identificación real de su participación en el mercado, aun así referencia no formales indican que la cantidad de participación de mercado está alrededor de 100,000 a 150,000 toneladas por mes, teniendo tan solo una participación de entre $2.30 \%$ a $3.30 \%$.

Finalmente, el competidor más importante es el que agrupa a los distintos supermercados, y en especial los de Lima Metropolitana.

\subsubsection{Matriz de perfil competitivo}

A continuación, se desarrollará la matriz del perfil competitivo del sector, en la cual se comparará los principales factores de éxito identificados que este negocio debe de contar, esta comparación no está realizada con otras empresas específicas del sector, esto dado que, al no contar con competidores 
directos, se ha realizado la comparación respecto a los principales

competidores indirectos, divididos en tres grupos los cuales detallamos a continuación:

1. Supermercados e Hipermercados

2. Procesadoras de Alimentos

3. Mercados Mayoristas y Minoristas 
Tabla 8

Matriz del Posición de Competitividad - MPC

\begin{tabular}{|c|c|c|c|c|c|c|c|c|c|}
\hline \multirow[t]{2}{*}{ Factores Clawes de fixito } & \multirow[t]{2}{*}{ Peso } & \multicolumn{2}{|c|}{ CODIAL } & \multicolumn{2}{|c|}{ Procesadoras } & \multicolumn{2}{|c|}{$\begin{array}{l}\text { Supermecadore } \\
\text { Hipermecados }\end{array}$} & \multicolumn{2}{|c|}{$\begin{array}{c}\text { Mercados Mayorista y } \\
\text { Minorista }\end{array}$} \\
\hline & & Valor & Ponderado & Valor & Ponckerado & Valor & Ponderado & Valor & Ponderado \\
\hline 01 Orientaciòn Preventiva o de Salud de Principales Productos & 0,12 & 4 & 0,48 & 3 & 0,36 & 3 & 0,36 & 2 & 0,24 \\
\hline 02 Innovacion en los procesos productivos & 0,07 & 4 & 0,28 & 2 & 0,14 & 2 & 0,14 & 1 & 0,07 \\
\hline 03 Solido respaldo de capital social y financiero & 0,10 & 2 & 0,20 & 3 & 0,30 & 4 & 0,40 & 2 & 0,20 \\
\hline 04 Eficiencia en el proceso operacional & 0,08 & 3 & 0,24 & 3 & 0,24 & 4 & 0,32 & 1 & 0,08 \\
\hline 05 Estandares de Bioseguridad en Procesos, (certificaciones) & 0,07 & 4 & 0,28 & 2 & 0,14 & 4 & 0,28 & 1 & 0,07 \\
\hline 06 Mayor infraestructura comercial- Locales de Venta & 0,10 & 1 & 0,10 & 3 & 0,30 & 4 & 0,40 & 1 & 0,10 \\
\hline 07 Diversificaciòn de Productos & 0,15 & 2 & 0,30 & 3 & 0,45 & 4 & 0,60 & 3 & 0,45 \\
\hline 08 Infraestrutura Adecuada de Cadena de Frio & 0,16 & 2 & 0,32 & 2 & 0,32 & 3 & 0,48 & 2 & 0,32 \\
\hline 09 Mayor cartidad de Proveedores - Principal Materia Prima & 0,06 & 2 & 0,12 & 3 & 0,18 & 4 & 0,24 & 4 & 0,24 \\
\hline 10 Alanzas Comerciales en Segmentos Clave & 0,09 & 3 & 0,27 & 2 & 0,18 & 3 & 0,27 & 2 & 0,18 \\
\hline Total & 1,00 & & 2,59 & & 2,61 & & 3,49 & & 1,95 \\
\hline
\end{tabular}

1 = Debilidad grave $\quad-\quad 2$ = Debilidad menor

$\mathbf{3}=$ Fortale $z$ a menor $-\mathbf{4}=$ Fortaleza importante

Nota. Elaboración Propia 
Como se puede apreciar en la tabla $\mathrm{N}^{\circ} 8$ el grupo de supermercados e hipermercados cuenta con 3.49 puntos de perfil competitivo lo cual representa el $87 \%$ del sector en observación, pero debemos de recordar que este liderazgo corresponde solo al acopio y comercialización del producto en su estado natural sin contar con algún proceso especializado, contando solo con un proceso de selección de calidad, luego tenemos que los procesadores de alimentos han obtenido un puntaje de 2.61 lo cual representa un $65.25 \%$ de competitividad en el sector mientras que la empresa ha obtenido un puntaje de 2,59 lo que representa un $64.75 \%$ de competitividad dentro del sector, lo que es de resaltar dado que el grupo de procesadores no dan un valor agregado en función a un beneficio de salud o prevención de la salud, en este punto también debemos de tener en cuenta que hablamos nuevamente de competidores indirectos, esto dado que la diferencia entre este grupo y la empresa es principalmente que el proceso de producción está orientado al procesamiento de la papa para fines de prevención de todos los integrantes del hogar y la mejora en la dieta de las personas con enfermedades, con lo cual está colocada dentro de un océano azul, quedando rezagados están los mercados mayoristas y minoristas los cuales han obtenido un puntaje de 1,95 lo cual representa solo el $49 \%$ de competitividad dentro del sector esto dado que solo son acopiadores y comercializadores, y no generan ningún valor agregado ni efectos benéficos para la salud humana.

\subsubsection{Matriz de atractividad del sector}

Para lograr un mejor entendimiento de por qué el sector de manufactura es el ideal para el presente proyecto presentamos a continuación la matriz de atractividad del sector (Ver tabla 9) la cual a través de la 
evaluación de factores críticos de éxito organizados en cinco (5) segmentos de análisis como son:

1. Rivalidad entre competidores.

2. Amenaza de nuevos entrantes.

3. Poder de negociación de los proveedores.

4. Poder de negociación de los compradores.

5. Productos sustitutos.

A continuación, se presentarán los resultados obtenidos en la matriz de atractividad:

Tabla 9

Matriz de Atractividad del Sector

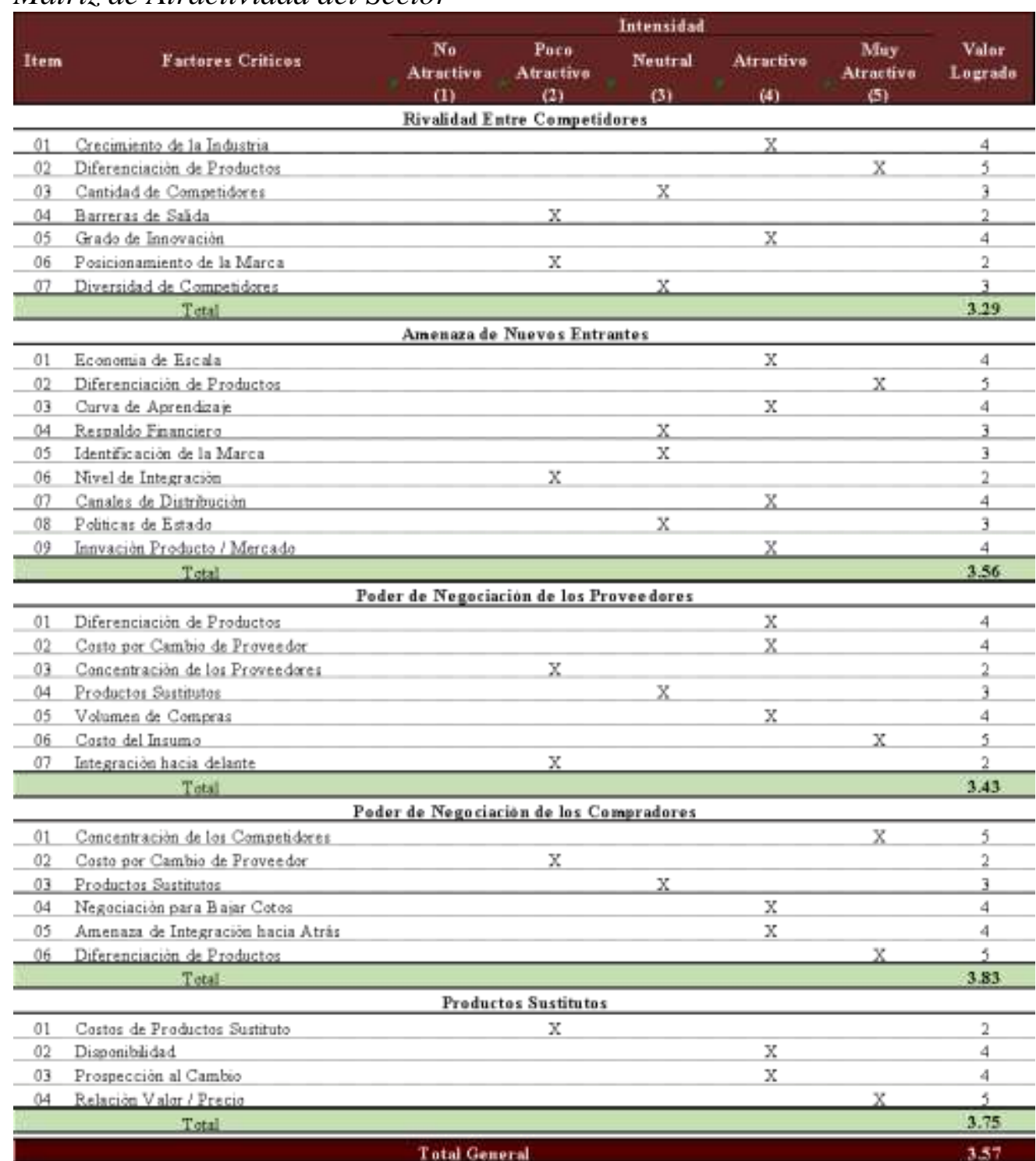

Nota: Elaboración Propia 
Como podemos observar de la evaluación realizada de los 5 segmentos se logra un promedio alto de 3.57 de los cuales los segmentos de poder de negociación de los compradores y productos son los más altos de evaluación, esto debido a que la influencia que puedan tener los compradores sobre el precio a ofertar es muy baja, garantizando el éxito en la comercialización del producto, como también la baja cantidad de productos sustitutos debido a que el producto ofertado es único, ya que no existen productos iguales o similares que ofrezcan un proceso totalmente saludable, logrando que sea muy atractivo el sector escogido (manufactura).

Por otro lado tenemos la rivalidad entre competidores la cual es totalmente baja (3.29) ya que el producto ofertado es único y con el valor agregado de crear salud, luego podemos observar que la negociación de los proveedores que está por debajo de la media general (3.43) y que representa un poder bajo debido a la existencia de gran cantidad de proveedores ofertantes del insumo a procesar, finalmente tenemos la amenaza de nuevos entretantos o competidores, los cuales pueden tener una restricción para su ingreso por la inversión a realizar la cual es alta, pero no obstante el proceso de operación es muy sencillo de lograr teniendo siempre consideración constantes de esta amenaza, finalmente como se puede apreciar se ha obtenido un promedio general de 3.57 de 5 lo que hace al sector un $71.4 \%$ atractivos para la realización del proyecto.

\subsection{Análisis del Contexto Actual y Esperado}

Aquí se analizará los factores externos que pueden impactar en el desarrollo normal de la empresa y la elaboración de su producto. 


\subsubsection{Análisis Político-Gubernamental}

En este punto se analizará el entorno político que actualmente vive el país y que puede afectar, ya sea directa o indirectamente, la actividad de la empresa.

En la actualidad el Perú está pasando por un proceso de transición gubernamental, en el cual está terminando un gobierno que apostó por una economía liberal, con una propuesta de política social, aunque los desaciertos fueron mayores, ya que el país vivió una desaceleración económica básicamente por factores externos que influenciaron en la situación económica, este año se ve marcado por la presencia de políticos que desean gobernar al Perú y que tienen la misma tendencia y cuya propuesta es la de reactivar la economía y dar normas que favorezcan a la pequeña y mediana empresa. Según el diario Gestión (2016), la propuesta del partido político de Fuerza Popular es que en los dos primeros años se va a crear una ley para dar origen a un plan de tributación cero para las pymes y del otro lado el partido político Peruanos Por el Kambio es la de otorgar a las pymes incentivos tributarios y a la vez simplificar trámites burocráticos para las nuevas inversiones en el país.

En el año 2004 se creó el programa nacional "Cómprale al Perú” creado por ley $\mathrm{N}^{\circ} 28312$ y que se ha mantenido hasta la actualidad y que promueve el apoyo a empresas nacionales para la adquisición de sus productos siempre y cuando cumplan con ciertas características, los bienes producidos por estas empresas nacionales tienen el respaldo del estado que aplican el sello 
de calidad "Hecho en Perú", con el respectivo logotipo que representa a los productos nacionales.

\subsubsection{Análisis Económico}

En los últimos 25 años el Perú ha consolidado su economía, la misma que ha sido reconocida por las principales agencias calificadoras de riesgo, a pesar que en el último quinquenio se ha visto afectado en su crecimiento económico por las crisis que se desató en los países europeos y Estados Unidos. El presidente del Banco Mundial, Yim Yong Kim (2015), señalo que el crecimiento de la economía peruana ha sido espectacular en los últimos 15 años destacando el crecimiento promedio anual del $6 \%$ que se ha obtenido en la última década, a pesar de la desaceleración que se ha presentado en los últimos dos años; actualmente se tiene una proyección de crecimiento para el 2016 de un 4\% en su PBI (Ver figura 13).

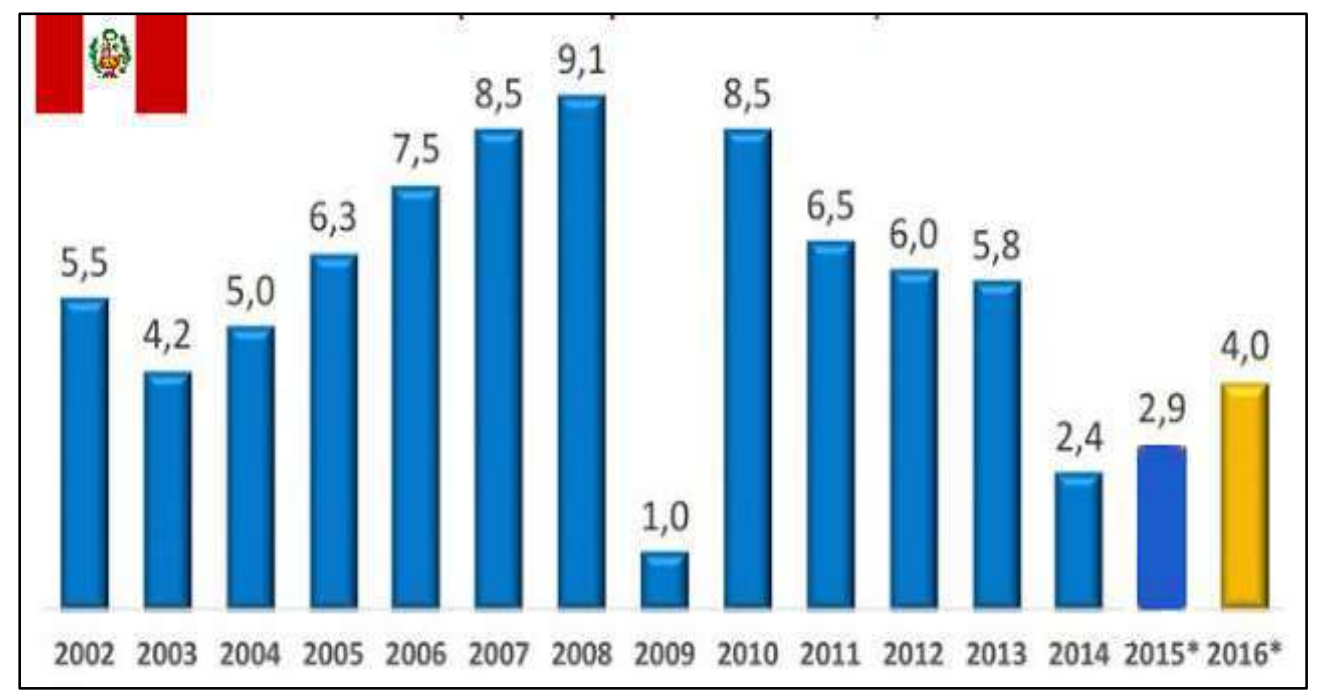

Figura 13. Crecimiento económico 2002 - 2016 tomado del Banco Central de Reserva, recuperado de http://econoblognet.blogspot.pe/2015/12/peru-2016-se-asoma-un-debilcrecimiento.html 
Este crecimiento del País se ha visto reflejado en la disminución de la pobreza gracias a la labor que se ha tenido en los diferentes gobiernos para incentivar y fortalecer la economía a través de políticas y estrategias en favor de los más necesitados. Con base en un informe emitido por el diario El Peruano (2016), el Perú ha reducido la pobreza de $58.7 \%$ a $22.7 \%$ entre los años 2004 y 2014, lo que refleja una disminución de 36 puntos porcentuales durante ese periodo. El Instituto Peruano de Economía (IPE, 2015) hace un análisis de la evolución de la reducción de la pobreza en el Perú y muestra que entre los años 2004 y 2007 (Ver figura 14), fue en donde mayores puntos porcentuales fue reducida la pobreza (5.4) anualmente en promedio, a partir de allí se dio una desaceleración, justamente por problemas externos.

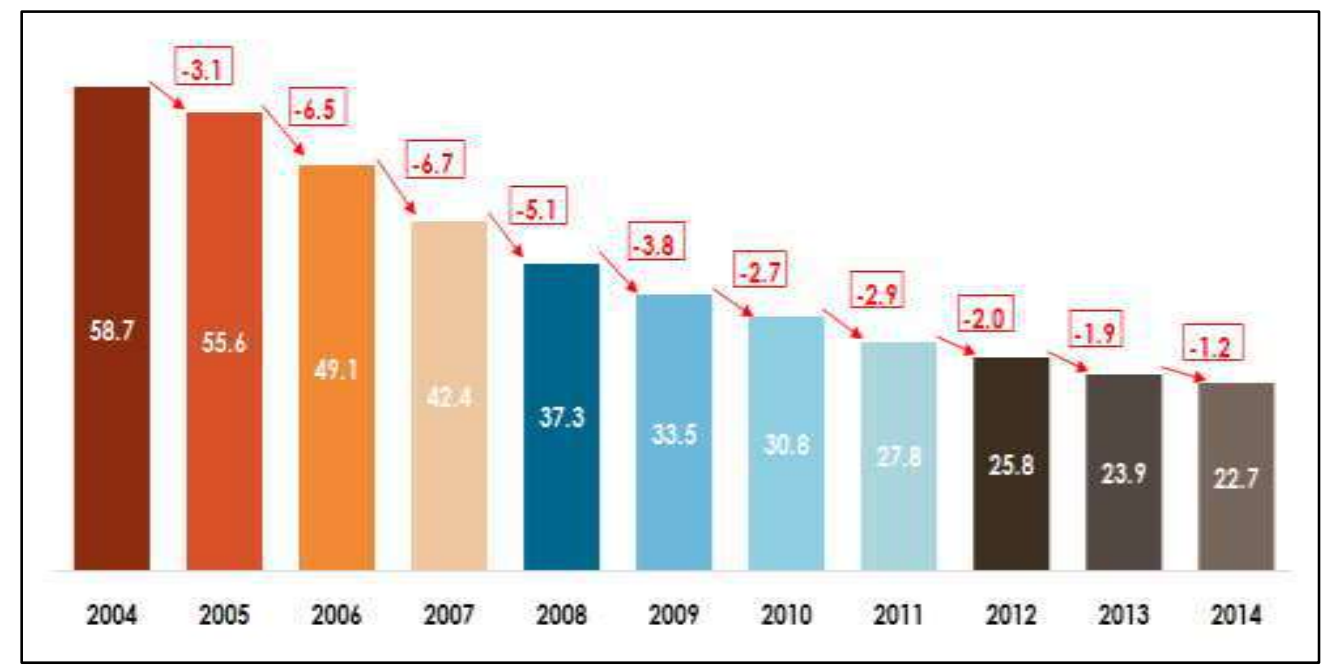

Figura 14. Desaceleración en la reducción de la pobreza Tomado de, "Perú: Pobreza total y disminución de la pobreza 2004 - 2014 (En porcentajes y puntos porcentuales respectivamente)", recuperado de http://www.ipe.org.pe/graficos/se-desacelera-la-reduccion-de-la-pobreza

El crecimiento del país ha dado pie a una mejora en los indicadores de empleo e ingresos de las personas a nivel nacional (Ver figura 15), lo que permite generar un movimiento económico a través del poder adquisitivo que se tiene, con base a un estudio del Instituto Nacional de Estadística e 
Informática (INEI, 2013), en todos los departamentos del país se ha dado un incremento importante de la población económicamente activa entre los años 2004 y 2012 (Ver figura 16), al 2004, ningún departamento sobrepasaba el 40\% en empleo adecuado, esta situación cambió al 2012, en donde, en tres departamentos, Madre de Dios, Lima y Callao y Arequipa, un 60\% de su población tenía un empleo adecuado.

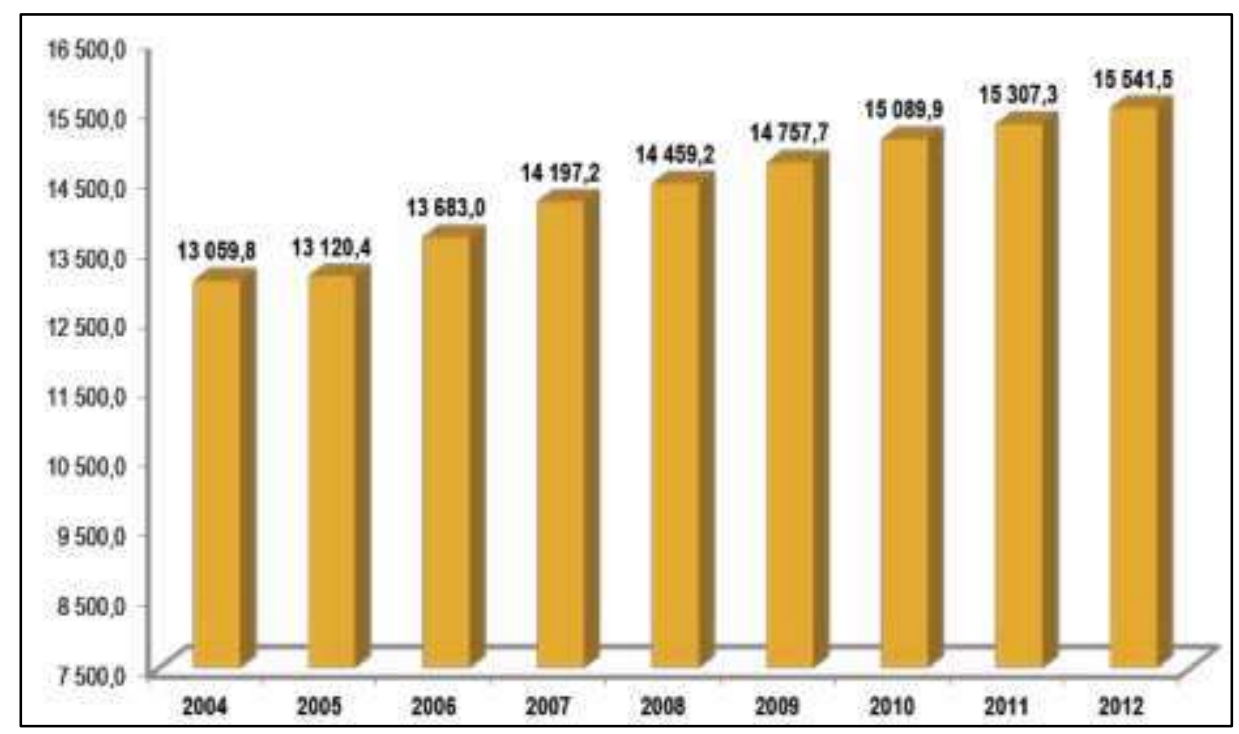

Figura 15. Evolución de la población ocupada, 2004 - 2012 Tomado de "Perú: evolución de los indicadores de empleo e ingreso por departamento 2004 - 2012" recuperado de https://www.inei.gob.pe/media/MenuRecursivo/publicaciones_digitales/Est/Li b1105/libro.pdf 


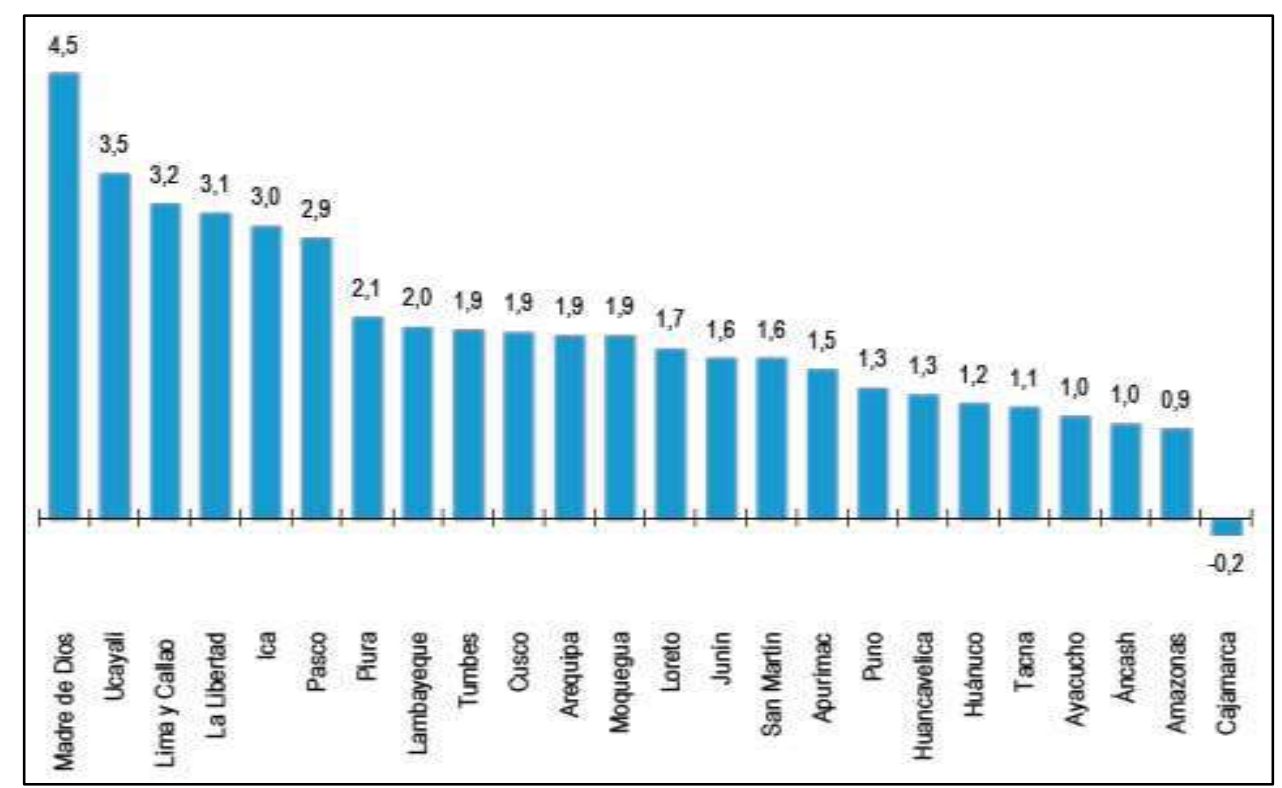

Figura 16. Tasa de crecimiento promedio anual de la población ocupada Según departamento: 2004 - 2012 Tomado de "Perú: evolución de los indicadores de empleo e ingreso por departamento 2004 - 2012" recuperado de https://www.inei.gob.pe/media/MenuRecursivo/publicaciones_digitales/Est/Li b1105/libro.pdf

Realizando un análisis a la situación actual en cuanto al crecimiento económico por sector se estima para este año un avance liderado por el sector pesquero $(9.5 \%)$ y minería $(5.0 \%)$, uno de los sectores que menos crecimiento va a tener es el manufacturero, principalmente afectado por el incremento en el precio de los comodities, se proyecta que este sector tendría un alcance solo del 2.3\% (Diario El Comercio, 2016). (Ver Figura 17). 


\begin{tabular}{|c|c|c|c|c|c|c|}
\hline & \begin{tabular}{|l|} 
Panderoc: \\
INEI 2007
\end{tabular} & 2012 & 2013 & 2014 & $2015^{*}$ & $2016^{\circ *}$ \\
\hline Global & 100.0 & 6.0 & 5.8 & 2.4 & 2.7 & 3.0 \\
\hline Agropecuario & 6.0 & 5.9 & 1.6 & 1.4 & 1.3 & 2.1 \\
\hline Pesca & 0.7 & -32.2 & 24.0 & -27.9 & 17.2 & 9.5 \\
\hline Minería e Hidrocarb. & 14.4 & 2.8 & 4.9 & -0.8 & 4.9 & 5.0 \\
\hline Manufactura & 16.5 & 1.5 & 5.0 & -3.3 & 0.4 & 2.3 \\
\hline Electricidad y Agua & 1.7 & 5.8 & 5.5 & 4.9 & 4.7 & 4.8 \\
\hline Construcción & 5.1 & 15.8 & 8.9 & 1.7 & -3.8 & 3.6 \\
\hline Comercio & 10.2 & 7.2 & 5.9 & 4.4 & 3.9 & 4.1 \\
\hline Otros Servicios & 37.1 & 7.4 & 6.2 & 5.9 & 5.1 & 4.7 \\
\hline VAB & 91.7 & 5.9 & 5.9 & 2.5 & 2.9 & 2.9 \\
\hline DM-Imp. a productos & 8.3 & 6.9 & 4.5 & 0.8 & 0.1 & 0.7 \\
\hline
\end{tabular}

Figura 17. PBI Global y Sectorial (Var \%) Tomado de "Banco Central de Reserva" recuperado de http://elcomercio.pe/visor/1836195/1184880-ccl-pbi-peru-creceria-solo-272015-y-3-2016-economia-peruana-noticia

Finalmente en el Perú desde el 2013 las cifras de crecimiento son muy alentadoras, la proyección que todavía se maneja para el 2016 es de 4.0\% para el Banco Central de Reserva, 3.8\% para el Ministerio de Economía y Finanzas, 3.7\% para el Fondo Monetario Internacional, 3.0\% para Apoyo Consultores y 3.0\% para Bank Of América Merrill Lynch, tomando en cuenta los problemas que todavía aqueja a Europa, pero no hay que dejar de observar el variación del tipo de cambio del dólar americano, el cual tiene una lenta pero constante subida con una proyección de llegar a 3.5 soles por cada dólar americano, lo cual podría ayudar a un mayor endeudamiento en soles, generando con ello una mejora de la economía interna o quizás una desaceleración mayor impulsando a una caída de nuestro PBI. 


\subsubsection{Análisis Legal}

En ámbito legal se cuenta con normas y reglamentos que protegen al producto que se comercializará, como por ejemplo los aranceles que permiten frenar el ingreso de productos con muy bajo precio al mercado interno, evitando con ello la competencia desleal que pueda existir; en este momento existen una serie de aranceles a la importación de tubérculos que impiden la colocación de precios por debajo de nuestros costos de producción, pero hay que tener sumo cuidado dado que como resultado de los Tratados de Libre Comercio estos aranceles pueden lograr ser cero, como el acuerdo que tienen los países de la Comunidad Andina los cuales han exonerado a alguna variedad de granos a fin de que ingrese con un arancel cero.

También existen los organismos reguladores y fiscalizadores, a través de los cuales se logra el controlar y ayudar en la utilización de productos alimenticios y obtener estándares de procesamiento de alimentos de alta calidad, unido a la atención con higiene y disciplinada del servicio, entre estos organismos tenemos al Ministerio de Salud con la Ley 27657 de Normativa Sanitaria de Alimentos, quien encarga a la Dirección General de Salud Ambiental e Inocuidad Alimentaria (DIGESA) la fiscalización y control del su cumplimiento.

Por otra parte, existen otras normas y reglamentos vinculados como, por ejemplo:

1. Ley $N^{a} 28015$ de Promoción y Formalización de La Micro y Pequeña Empresa que fue promulgada en Julio de 2003 por el Ministerio de Trabajo y Promoción del Empleo. 
2. RM 449-2006/MINSA para Norma Sanitaria para la aplicación del Sistema HACCP en la fabricación de alimentos y bebidas.

3. Decreto legislativo $\mathrm{N}^{\circ} 1086$ - SUNAT de Promoción y Formalización de La Micro y Pequeña Empresa.

4. Norma Sanitaria para el Funcionamiento de Restaurantes y Servicios Afines (Resolución Ministerial No 363-2005-MINSA).

5. Disposiciones sobre Establecimientos que expenden Comidas y Bebidas (Resolución Ministerial No 081-94-ITINCI/DM).

6. Certificado de Registro Sanitario de Alimentos y Bebidas industrializados otorgado por DIGESA.

7. Permisos otorgados por las Municipalidades del sector donde se piensa establecer el local, este permiso se le conoce como Licencia de Funcionamiento el cual tiene como base legal a la Ley $N^{\circ} 28976$.

Además de INDECOPI que nos ayuda al registro de la marca o nombre comercial el cual sirve para la comercialización del producto propuesto.

\subsubsection{Análisis Cultural}

La sociedad peruana está compuesta por una gran diversidad de etnias y razas, lo cual hace muy rico a este país, pero no hay que olvidar sus tradiciones, sobretodo su cultura Inca, de la cual hemos heredado tantas cosas buenas; gracias a las tierras muy fértiles que se posee y que permiten la siembra de diversas especies de semillas y de sus variedades, como el caso de la papa, la cual en el Perú tiene más de 2,800 variedades de este tubérculo.

Este tubérculo tiene el 13\% de la producción agrícola nacional, las preferencias alimenticias de la sociedad peruana hacen que $94 \%$ consuma este 
producto fresco y el $6 \%$ de forma procesada. La papa es un producto de alto valor nutritivo por su contenido de vitamina $\mathrm{C}$, potasio, fibra y antioxidantes, y no contiene grasas ni azúcares solubles.

En el año 2005, mediante Resolución Suprema Nº 009-2005-AG, se estableció el 30 de mayo como el "Día Nacional de la Papa", además importante destacar que la Organización de las Naciones Unidas para la Alimentación y la Agricultura - FAO declaró en el 2008, el Año Internacional de la Papa, gracias a una iniciativa peruana.

Los hábitos alimenticios que hoy en día tienen los peruanos, hacen de la papa uno de los principales tubérculos de mayor consumo en este país.

\subsubsection{Análisis Tecnológico}

Respecto al ámbito tecnológico en el que se desarrollará el producto, podemos mencionar que la técnica de dialización que se aplicará al tubérculo (papa) es innovadora, ya que pasará de ser un proceso artesanal a un proceso industrial. El proceso artesanal, es casero, se realiza de forma manual y repetitivo con varias horas de esfuerzo, siendo uno de los principales procedimientos el de pelado, el cual implica varias horas según la cantidad de papa a procesar, el segundo procedimiento es la sumersión en agua del producto y su posterior recambio de agua cada 6 horas, con una duración de hasta 24 horas (en su mejor momento) y en otros casos podría prolongarse por varios días, ya sea por falta de tiempo, por no completar el procedimiento o por la pérdida del producto por deterioro (donde se tendría que reiniciar el proceso) 
Para aplicar la técnica de dialización alimentaria se está utilizando una máquina peladora de papas que realiza el procedimiento de hasta $300 \mathrm{~kg}$ por hora, con lo que obtenemos una producción máxima aproximada de 52 toneladas por mes, luego tenemos el proceso de sumersión el cual también cuenta con una poza especialmente diseñada para tal fin y automatizado el flujo y recambio de agua que se debe realizar.

Finalmente, para darle un mayor tiempo de conservación se introduce el empaque al vacío con lo cual aseguramos que no pierda peso, ni grasas o líquidos, procedimiento muy higiénico y con un tiempo para conservarlos frescos por 3 a 5 veces más de su conservación normal, según lo señala una guía (conservación doméstica de alimentos al vacío).

Con toda la implementación de tecnología se asegura y reduce el tiempo, aumenta la cantidad producida, se reemplaza el proceso artesanal utilizado por miles de personas que realizan la dialización alimentaria, sobretodo en el plano médico.

\subsubsection{Análisis Ecológico}

El Perú se caracteriza por ser un país con una gran biodiversidad y con un ecosistema muy variado a nivel mundial, que por su geografía se permite tener diversos microclimas que han favorecido al país en sus diversos sectores económicos, el impacto del cambio climático en el mundo ha afectado también al Perú, el Ministerio del Ambiente (MINAM, 2016) indica que, uno de los países más afectado con el problema del cambio climático es nuestro país porque repercute en fenómenos hidrometeoro lógicos que se relacionan 
con el fenómeno del niño, esta situación trae como consecuencia problemas de salud y económicos.

Uno de los principales problemas que afecta al Perú, por las acciones del fenómeno del niño, es que genera pérdidas en diversos cultivos como el maíz, el arroz, la papa, entre otros, y es justamente la papa, principal insumo en nuestra actividad económica, la que se ve afectada no solo en su producción, también en el transporte ya que las principales carreteras que traen este producto hacia Lima muchas veces se ven bloqueadas por las intensas lluvias que el fenómeno del niño genera.

Uno de los problemas que podría afectar a la empresa son las plagas que puede contraer una cosecha de papa, a pesar de que los campesinos conocen diferentes técnicas para combatir este problema natural, puede afectar directamente a la empresa por ser el insumo principal, pero no lo podemos catalogar como un riesgo alto, ya que existen muchos proveedores de quienes se puede adquirir este producto en caso de emergencia.

\subsection{Oportunidades}

Las oportunidades que podemos encontrar de acuerdo al análisis actual son:

1. Del análisis gubernamental, se aprovechará la coyuntura y el cambio de gobierno que se hace presente con nuevas propuestas, las cuales apoya a las pequeñas y medianas empresas, con beneficios en tributos y formalización. A su vez considera con énfasis el programa nacional "cómprale al Perú", con el que se fomenta la compra a las empresas nacionales.

2. Del análisis económico, con la evolución del poder adquisitivo y la estabilidad laboral, se logra una canasta familiar sostenible que permite un 
mayor consumo de alimentos, siendo la papa uno de los principales y más importantes en la dieta diaria de las personas. En ese sentido, la demanda proyectada de la papa se verá incrementada, y de manera especial si este insumo cuenta con un valor de aspecto saludable.

3. Del análisis legal, se considerarán las leyes establecidas para la promoción de la micro y mediana empresa; así como las normas sanitarias y permisos municipales para el funcionamiento correcto de la empresa. Además, las normas que permitan patentar el diseño de una maquinaria para el proceso de dialización.

4. Del análisis cultural, se aprovechará el boom de la gastronomía para poder brindar este producto saludable (papa dializada) como insumo para la elaboración de los diversos platos.

5. Del análisis tecnológico, se tiene la oportunidad de diseñar una máquina especializada que automatice el proceso de dialización, para lograr rapidez en este proceso y obtener un volumen de producción.

6. Del análisis ecológico, basado en la diversidad de climas podemos captar una diversidad de proveedores a nivel nacional, lo que permitirá analizar y obtener costos competitivos para la compra del insumo (papa). 


\section{Capítulo III: Estudio de Mercado}

\subsection{Descripción del servicio o producto}

En esta sección del trabajo se realizará una descripción del producto, profundizando la forma de entrega al consumidor final.

La papa es un producto que tiene origen hace más de 8000 mil años, según un estudio del Centro Internacional de la Papa (2008) y que nace en el Altiplano Andino, entre los países del Perú y Bolivia, cerca del Lago Titicaca, este producto es un tubérculo comestible perteneciente a la familia de las Solanaceas, siendo su nombre científico Solanum Tuberosum.

Entre las variedades de papa que existen se ha seleccionado la papa perricholi (Ver Figura 18), para la elaboración del producto final, ya que de acuerdo a un estudio realizado por el Instituto Nacional de Innovación Agraria (INIA, 2012) establece que, entre sus particularidades de este tipo de papa, destaca que una vez pelada no tiende a oscurecerse rápidamente, logrando ser un producto que se puede emplear industrialmente

El proceso de dialización a aplicar en este tubérculo, ha sido denominado así debido a la similitud que existe con la dialización en los seres humanos, el mismo que tiene como finalidad extraer las toxinas y excesos de la sangre, y que según el Ministerio de Salud (MINSA RM 845, 2007) lo define como “técnica extracorpórea que se basa en la difusión de solutos en la sangre y el baño de diálisis a través de un hemodializador".

Esta técnica a la que se denomina "dialización" hoy en día no es aplicado más allá del sector médico; sin embargo, el presente proyecto asignará dicha técnica, innovadora en el campo comercial, al proceso que se encarga de reducir los niveles 
de minerales en alimentos, sobretodo el del potasio, controlando así los desechos que se pueden acumular en la sangre por su ingesta y regulando el nivel de la nutrición diaria.

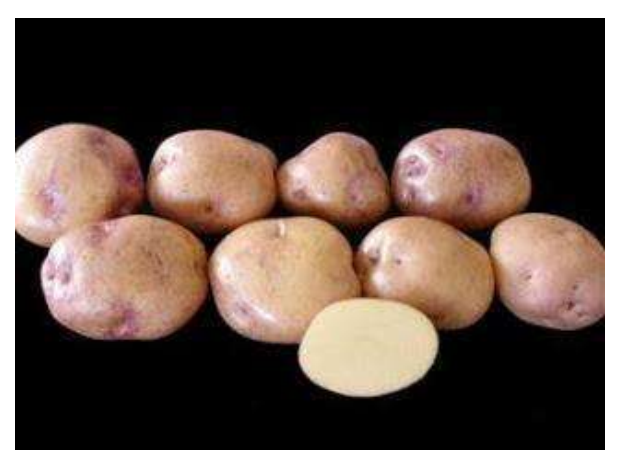

Figura 18. Papa perricholi, tomado de variedades de papa en el Perú. Recuperado de http://blogs.deperu.com/productosperuanos/variedades-de-papa-en-el-peru/

1. Características de la papa

a) Forma

Los cultivos modernos de papa suelen ser de forma redondeada, pero no uniforme.

b) Tamaño

El tamaño de este tubérculo varía entre los dos y ocho centímetros aproximadamente.

c) Color

El color de la cáscara de la papa puede variar, dependiendo del tipo, pero el color de su piel y pulpa es de color amarillo.

d) Sabor

La papa cruda tiene un sabor amargo, lo que cambia en su preparación, de acuerdo al gusto gastronómico de las personas.

e) Código CIIU 
La Clasificación Industrial Internacional Uniforme (CIIU), ofrece una clasificación de las actividades productivas con la finalidad de establecer un patrón estadístico al momento de estudiar el comportamiento de las entidades económicas (INEI, 2010). Ver tabla 10

Tabla 10

Clasificación Industrial Internacional Uniforme

A Agricultura, Ganadería, Caza, y silvicutura.

1 Agricultura, Ganadería, Caza y Actividades de servicios conexas.

11 Producción específicamente agrícola.

116 Producción especializada de Hortalizas

y Legumbres.

Nota. Estructura de la CIIU Revisión 4. Tomada de Clasificación Industrial Internacional Uniforme ( $p .21)$ por Instituto Nacional de Estadística e Informática, 2016

2. Propiedades de la papa

El balance nutritivo de la papa es relativamente bajo en niveles de grasa y calorías y por el contrario un nivel alto en niveles de potasio y vitamina $\mathrm{C}$, brinda grandes cantidades de energía por su composición de almidón y carbohidratos (Ver figura 19 y figura 20). 


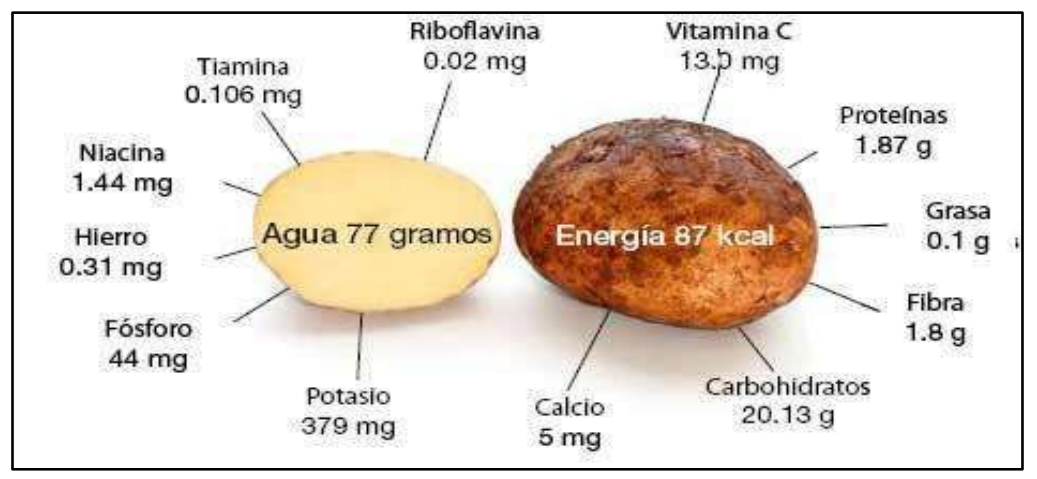

Figura 19. Nutrientes en $100 \mathrm{gr}$ de papa hervida y pelada antes del consumo. Año internacional de la Papa, 2008. Tomado de "Nutrientes de la papa" por la FAO (2008). Recuperado de http://www.fao.org/potato2008/es/lapapa/hojas.html

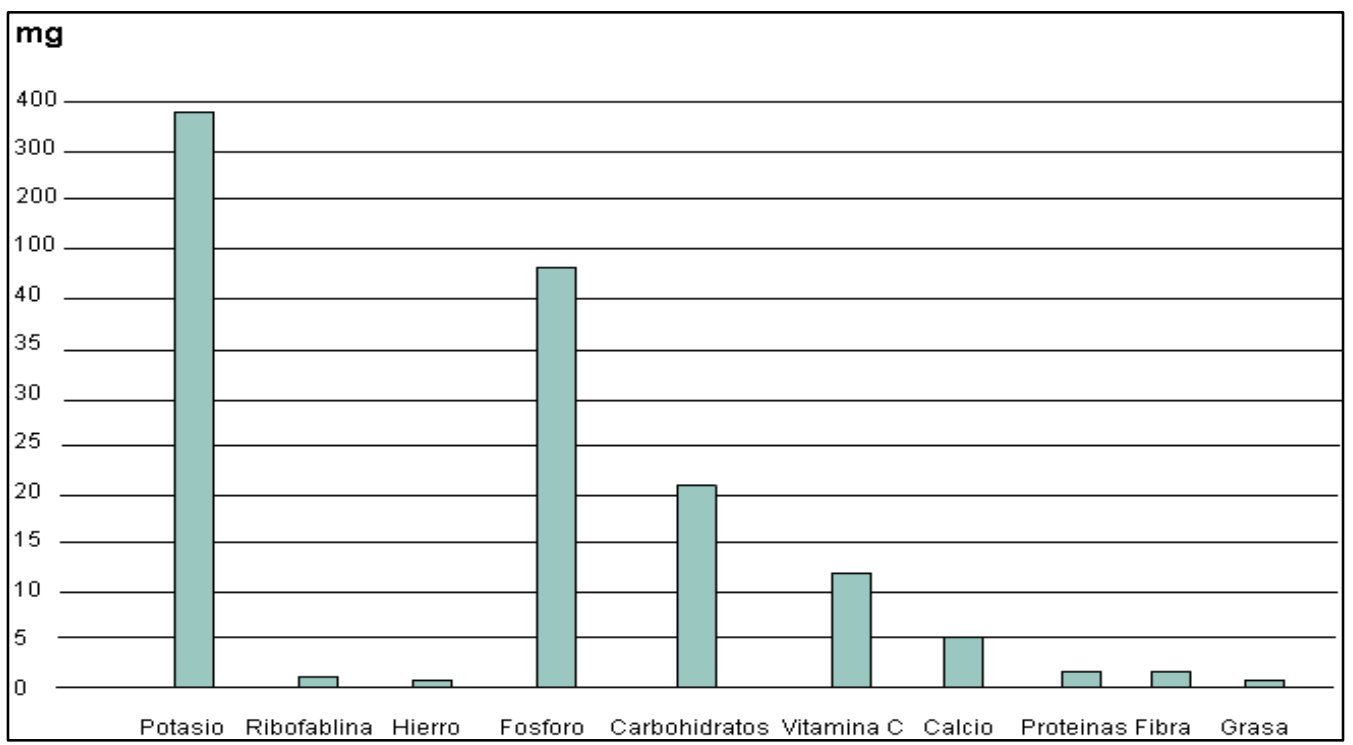

Figura 20. Nutrientes en 100gr de papa hervida y pelada antes del consumo. Año internacional de la Papa, 2008. Tomado de "Nutrientes de la papa" por la FAO (2008). Recuperado de http://www.fao.org/potato2008/es/lapapa/hojas.html

\section{Beneficios}

La papa es un tubérculo principalmente constituida por agua y en considerables cantidades de fibra, lo que lo hace un alimento con ciertos beneficios, los que se describen a continuación.

1. Por la cantidad de hierro que posee, es un alimento recomendado para personas que sufren de anemia, permitiendo tratar esta enfermedad y prevenirla. 
2. Los altos contenidos de minerales lo convierten en un alimento ideal para combatir inflamaciones.

3. Uno de los mayores minerales que posee la papa es el potasio, este permite disminuir la presión arterial en el organismo, sin embargo, un elevado nivel de dicho mineral en personas mayores de 30 años puede ser perjudicial, provocando hipertensión, arritmias cardiacas, infarto, entre otros problemas cardiacos.

4. El consumo diario de papa en jugo permite ayudar problemas del hígado como la hepatitis.

5. El contenido de fibra en la papa permite regular el tránsito intestinal en las personas, no es muy efectivo en el tratamiento de problemas graves de estreñimiento, como otros productos, pero ayuda a prevenirla.

\subsection{Selección del segmento de mercado}

El segmento del mercado al cual se dirige el producto a desarrollar con el presente proyecto, ha sido seleccionado bajo los siguientes criterios:

\section{Edades}

De la población total del Perú $(31,151,643)$, Lima departamento representa el $31.58 \%(9,838,251)$, la Provincia de Lima representa el $28.55 \%(8,894,412)$ y la Provincia Constitucional del Callao representa el 3.2\% (1, 010,315), con respecto a la población total del país peruano, según INEI (2015).

Lima Metropolitana está conformada por la Provincia de Lima y la Provincia Constitucional del Perú con un total de 9, 904,727 habitantes, indicado por el INEI 
(Una mirada a Lima Metropolitana, 2014). Esta sección corresponde al 31.80\% de la población total (Ver tabla 11 y 12).

Se identifica que este segmento concentra la mayor cantidad de población peruana en el ámbito urbano, de los cuales se seleccionarán personas que se encuentran entre un rango de edades y en ubicados en determinados distritos.

Tabla 11

Población estimada al 30 de junio, por sexo, según departamentos (2015)

\begin{tabular}{llrrr}
\multirow{2}{*}{ UBIGEO } & \multirow{2}{*}{ DEPARTAMENTO } & \multicolumn{3}{c}{$\mathbf{2 0 1 5}$} \\
\cline { 3 - 5 } & & & \multicolumn{1}{c}{ Total } \\
\hline $\mathbf{0 0 0 0 0 0}$ & PERÚ & $\mathbf{3 1 , 1 5 1 , 6 4 3}$ & $\mathbf{1 5 , 6 0 5 , 8 1 4}$ & $\mathbf{1 5 , 5 4 5 , 8 2 9}$ \\
\hline & & & & \\
010000 & AMAZONAS & 422,629 & 222,536 & 200,093 \\
020000 & ÁNCASH & $1,148,634$ & 582,978 & 565,656 \\
030000 & APURÍMAC & 458,830 & 234,224 & 224,606 \\
040000 & AREQUIPA & $1,287,205$ & 638,480 & 648,725 \\
050000 & AYACUCHO & 688,657 & 351,747 & 336,910 \\
060000 & CAJAMARCA & $1,529,755$ & 770,434 & 759,321 \\
070000 & CALLAO & $1,010,315$ & 502,923 & 507,392 \\
080000 & CUSCO & $1,316,729$ & 667,502 & 649,227 \\
090000 & HUANCAVELICA & 494,963 & 248,341 & 246,622 \\
100000 & HUÁNUCO & 860,537 & 437,223 & 423,314 \\
110000 & ICA & 787,170 & 395,398 & 391,772 \\
120000 & JUNÍN & $1,350,783$ & 682,129 & 668,654 \\
130000 & LA LIBERTAD & $1,859,640$ & 927,260 & 932,380 \\
140000 & LAMBAYEQUE & $1,260,650$ & 612,304 & 648,346 \\
150000 & LIMA & $9,838,251$ & $4,791,877$ & $5,046,374$ \\
160000 & LORETO & $1,039,372$ & 542,646 & 496,726 \\
170000 & MADRE DE DIOS & 137,316 & 78,863 & 58,453 \\
180000 & MOQUEGUA & 180,477 & 96,276 & 84,201 \\
190000 & PASCO & 304,158 & 161,372 & 142,786 \\
200000 & PIURA & $1,844,129$ & 925,765 & 918,364 \\
210000 & PUNO & $1,415,608$ & 709,705 & 705,903 \\
220000 & SAN MARTÍN & 840,790 & 457,187 & 383,603 \\
230000 & TACNA & 341,838 & 176,941 & 164,897 \\
240000 & TUMBES & 237,685 & 128,833 & 108,852 \\
250000 & UCAYALI & 495,522 & 262,870 & 232,652 \\
\hline
\end{tabular}

Nota, Población estimada al 30 de junio, por años calendario y sexo según departamento, 2012 - 2015 (p. 33) por el Instituto Nacional de Estadística e Informática 
Tabla 12

Población estimada al 30 de junio, según departamentos (2015)

\begin{tabular}{|c|c|}
\hline $\begin{array}{l}\text { DEPARTAMENTO, } \\
\text { PROVINCIA Y DISTRITO }\end{array}$ & Total \\
\hline PERÚ & $31,151,643$ \\
\hline LIMA & $8,894,412$ \\
\hline LIMA & 271,814 \\
\hline ANCON & 43,382 \\
\hline ATE & 630,086 \\
\hline BARRANCO & 29,984 \\
\hline BREÑA & 75,925 \\
\hline CARABAYLLO & 301,978 \\
\hline CHACLACAYO & 43,428 \\
\hline CHORRILLOS & 325,547 \\
\hline CIENEGUILLA & 47,080 \\
\hline COMAS & 524,894 \\
\hline EL AGUSTINO & 191,365 \\
\hline INDEPENDENCIA & 216,822 \\
\hline JESUS MARIA & 71,589 \\
\hline LA MOLINA & 171,646 \\
\hline LA VICTORIA & 171,779 \\
\hline LINCE & 50,228 \\
\hline LOS OLIVOS & 371,229 \\
\hline LURIGANCHO & 218,976 \\
\hline LURIN & 85,132 \\
\hline MAGDALENA DEL MAR & 54,656 \\
\hline MAGDALENA VIEJA & 76,114 \\
\hline MIRAFLORES & 81,932 \\
\hline PACHACAMAC & 129,653 \\
\hline PUCUSANA & 17,044 \\
\hline PUENTE PIEDRA & 353,327 \\
\hline PUNTA HERMOSA & 7,609 \\
\hline PUNTA NEGRA & 7,934 \\
\hline RIMAC & 164,911 \\
\hline SAN BARTOLO & 7,699 \\
\hline SAN BORJA & 111,928 \\
\hline SAN ISIDRO & 54,206 \\
\hline SAN JUAN DE & \\
\hline LURIGANCHO & $1,091,303$ \\
\hline SAN JUAN DE & \\
\hline MIRAFLORES & 404,001 \\
\hline SAN LUIS & 57,600 \\
\hline SAN MARTIN DE PORRES & 700,177 \\
\hline SAN MIGUEL & 135,506 \\
\hline SANTA ANITA & 228,422 \\
\hline SANTA MARIA DEL MAR & 1,608 \\
\hline SANTA ROSA & 18,751 \\
\hline SANTIAGO DE SURCO & 344,242 \\
\hline SURQUILLO & 91,346 \\
\hline VILLA EL SALVADOR & 463,014 \\
\hline VILLA MARIA DEL & \\
\hline TRIUNFO & 448,545 \\
\hline
\end{tabular}

Nota Población estimada al 30 de junio, por años calendario y sexo para el departamento de Lima, 2012 - 2015 (p. 269) por el Instituto Nacional de Estadística e Informática 
1. Segmento principal

Este segmento está conformado por aquellas personas que se encuentran en una edad de 40 a más, que representan el $33.10 \%$ (3,278,423) de Lima Metropolitana (9, 904,727) Ver tabla 13.

Estas personas se caracterizan por ser más sensibles a exigir una adecuada alimentación, más propensos a buscar alimentos saludables para mejorar su calidad de vida

Tabla 13

Población total al 30 de junio, por grupos quinquenales de edad, 2015

\begin{tabular}{|c|c|c|c|c|c|c|c|c|c|c|}
\hline \multirow{2}{*}{$\begin{array}{c}\text { DEPARTAMENTO, } \\
\text { PROVINCLAYDSTIRITO }\end{array}$} & \multirow{2}{*}{ Total } & \multicolumn{9}{|c|}{ GRLPUS QLINQLEXALES DE EDAD } \\
\hline & & $41 \cdot 4$ & $45 \cdot 49$ & 50.54 & $55 \cdot 59$ & $61 \cdot 64$ & $65 \cdot 69$ & $71 \cdot 74$ & $75 \cdot 79$ & Mints \\
\hline PRON CONST. JELCALAO & 349,738 & 71,481 & 64,433 & 56,892 & 45,354 & 36,303 & 26,805 & 19,839 & 14363 & 13,868 \\
\hline INA & 2928,685 & 580,034 & 530,716 & 475,296 & 3)9086 & 304,559 & 231,36 & 172714 & 126997 & 127,427 \\
\hline & $3,278,423$ & & & & & & & & & \\
\hline
\end{tabular}

Nota, Población estimada al 30 de junio, por grupos quinquenales de edad para el departamento, provincia y distrito de Lima 2015, tomado de Instituto Nacional de Estadística e Informática

2. Segmento secundario

Está conformado por aquellas personas que se encuentran entre las edades de 25 a 40 años, que representan el $24.51 \%(2,428,060)$ de Lima Metropolitana $(9,904,727)$ ver tabla 14.

Este grupo de personas se caracterizan porque buscan prevenir enfermedades, conscientes de que el sistema humano puede sufrir desgastes con el tiempo que no permita un proceso normal de su funcionamiento. 
Tabla 14

Población total al 30 de junio, por grupos quinquenales de edad, 2015

\begin{tabular}{l|rrrr}
\hline \multirow{2}{*}{ DEPARTAMENTO. PROVINCIA Y DISTRITO } & \multicolumn{3}{c}{ Total } & \multicolumn{3}{c}{ GRUPOS QUINQUENALES DE EDAD } \\
\cline { 3 - 5 } & & $\mathbf{2 5 - 2 9}$ & $\mathbf{3 0 - 3 4}$ & $\mathbf{3 5 - 3 9}$ \\
\cline { 2 - 5 } PROV. CONST. DEL CALLAO & 252,270 & 84,080 & 84,362 & 83,828 \\
LIMA & $2,175,790$ & 754,367 & 728,119 & 693,304 \\
& $\mathbf{2 , 4 2 8 , 0 6 0}$ & & &
\end{tabular}

Nota, Población estimada al 30 de junio, por grupos quinquenales de edad entre los 25 y 39 años para el departamento, provincia y distrito de Lima 2015, tomado de Instituto Nacional de Estadística e Informática

\section{Zonas de Lima Metropolitana}

Se segmentará la zona que agrupa los distritos de Lima Metropolitana con mayor concentración poblacional mayores a 25 años, para lo cual se utilizará clasificación por zonas según el APEIM (Ver Figura 21).

\begin{tabular}{|l|c|c|c|c|c|}
\hline \multirow{2}{*}{ Zona } & \multicolumn{5}{c|}{ Niveles Socioeconómicos } \\
\cline { 2 - 7 } & NSE "A" & NSE "B" & NSE "C" & NSE "D" & NSE "E" \\
\hline Total & 100.0 & 100.0 & 100.0 & 100.0 & 100.0 \\
\hline Zona 1 (Puente Piedra, Comas, Carabayllo) & 1.3 & 8.1 & 12.8 & 11.9 & 18.3 \\
\hline Zona 2 (Independencia, Los Olivos, San Martin de Porras) & 5.6 & 16.2 & 17.4 & 10.2 & 7.9 \\
\hline Zona 3 (San Juan de Lurigancho) & 2.7 & 5.8 & 12.3 & 17.2 & 13.8 \\
\hline Zona 4 (Cercado, Rimac, Breña, La Victoria) & 4.0 & 10.3 & 10.0 & 9.4 & 5.9 \\
\hline Zona 5 (Ate, Chaclacayo, Lurigancho, Santa Anita, San Luis, El Agustino) & 4.8 & 6.7 & 10.0 & 13.3 & 11.8 \\
\hline Zona 6 (Jesús Maria, Lince, Pueblo Libre, Magdalena, San Miguel) & 24.8 & 12.5 & 3.0 & 1.1 & 1.0 \\
\hline Zona 7 (Miraflores, San Isidro, San Borja, Surco, La Molina) & 45.6 & 16.8 & 3.1 & 1.6 & 2.0 \\
\hline Zona 8 (Surquillo, Barranco, Chorrillos, San Juan de Miraflores) & 7.7 & 8.5 & 7.7 & 8.0 & 8.9 \\
\hline Zona 9 (Villa El Salvador, Villa Maria del Triunfo, Lurin, Pachacamác) & 0.0 & 5.8 & 12.6 & 16.2 & 13.3 \\
\hline Zona 10 (Callao, Bellavista, La Perla, La Punta, Carmen de la Legua, Ventanilla) & 3.5 & 9.0 & 10.5 & 10.5 & 15.8 \\
\hline Otros & 0.0 & 0.3 & 0.6 & 0.6 & 1.3 \\
\hline
\end{tabular}

Figura 21. Distribución de niveles por zona APEIM 2015 Horizontal

Recuperado de http://www.apeim.com.pe/wpcontent/themes/apeim/docs/nse/APEIMNSE-2015.pdf

La zona 2, comprendida por los distritos de Independencia, Los Olivos y

San Martin de Porras, es la que tiene concentrada esa gran parte de la población.

Por esta razón el estudio de mercado del presente plan de negocio, se enfocará en esta zona de Lima Metropolitana 
Analizando los dos criterios de segmentación, edades y zonas que agrupan a los distritos de Lima Metropolitana y el Callao, para lograr determinar el segmento al cual se dirigirá el producto, y la cantidad de población que lo conforma.

Tabla 15

Población total al 30 de junio, por grupos quinquenales de edad, 2015

\begin{tabular}{l|c}
\hline $\begin{array}{c}\text { DEPARTAMENTO, } \\
\text { PROVINCIA Y } \\
\text { DISTRITO }\end{array}$ & \multicolumn{1}{c}{ Total } \\
\cline { 2 - 2 } & \\
INDEPENDENCIA & 216,822 \\
LOS OLIVOS & 371,229 \\
SAN MARTIN DE & 700,177 \\
PORRES & $1,288,228$
\end{tabular}

Nota. Población total al 30 de junio, por grupos quinquenales de edad, según departamento, provincia, distrito, 2015. Tomado de "Instituto Nacional de Estadística e Informática",

Según tabla 15, los distritos de la Zona 2 conformado por Independencia, Los Olivos San Martin de Porres, tienen el $13.01 \%$ respecto a Lima Metropolitana (1’2888 habitantes).

Tabla 16

Población total al 30 de junio, por grupos quinquenales de edad, 2015

\begin{tabular}{|c|c|c|c|c|c|c|c|c|c|c|c|c|c|}
\hline DEPARTAUESTO, & \multirow{2}{*}{ Tital } & \multicolumn{12}{|c|}{ GRLPOSQZTYQLEXALES DE EDAD } \\
\hline hOHINCLAY DSTRTIO & & $5 \cdot 8$ & $30 \cdot 34$ & $35 \cdot 34$ & H. H & 5.49 & $51 \cdot 5$ & 5. 5 & $66-4$ & $65 \cdot 6$ & $\pi \cdot 7$ & 73.79 & B) \\
\hline NEPENDEXOA & 155,24 & 17774 & 17800 & $18,3,4$ & 15,488 & 12,666 & 10,13 & 7,796 & 7,235 & 6574 & 5,458 & 3,624 & 2632 \\
\hline losoutros & 213,761 & 33218 & 30,56 & 27,931 & 24,056 & 3,005 & 2100 & 16,562 & 13,426 & 9225 & 62885 & 4,244 & 4,260 \\
\hline SAN MARTNDEPOARS & 406864 & 57,733 & $5385:$ & 55,056 & 49,742 & $46,2 \pi$ & 39,938 & 29,955 & 22,553 & 17,302 & 13,473 & 12,378 & 10,41 \\
\hline & 747,849 & & & & & & & & & & & & \\
\hline
\end{tabular}

Nota: Población total al 30 de junio, por grupos quinquenales de edad Para la provincia de lima zona 2 2015. Tomado de Instituto Nacional de Estadística e Informática.

De la Tabla $\mathrm{N}^{\circ} 16$, podemos visualizar que los habitantes que se encuentran entre las edades de 25 a más años y corresponden a la zona 2 de Lima Metropolitana es el $13.11 \%$ respecto a esta zona (747,849 habitantes). 
La selección del segmento de mercado está conformada por una población de 747,849 habitantes, de 25 años de edad a más y que pertenecen a la zona 2 de Lima Metropolitana, como se puede apreciar en la tabla $\mathrm{N}^{\circ} 17$.

Tabla 17

Distribución Poblacional por Zonas y Edades

\begin{tabular}{|c|c|c|c|c|}
\hline Zona & Población & $\%$ & $\begin{array}{l}\text { Mayores } \\
\text { a } 25 \text { años }\end{array}$ & $\%$ \\
\hline Zona 1 & $1,180,199$ & $11.92 \%$ & 639,570 & $11.21 \%$ \\
\hline Zona 2 & $1,288,228$ & $13.01 \%$ & 747,849 & $13.11 \%$ \\
\hline Zona 3 & $1,091,303$ & $11.02 \%$ & 585,405 & $10.26 \%$ \\
\hline Zona 4 & 684,429 & $6.91 \%$ & 427,203 & $7.49 \%$ \\
\hline Zona 5 & $1,369,877$ & $13.83 \%$ & 741,472 & $12.99 \%$ \\
\hline Zona 6 & 388,093 & $3.92 \%$ & 266,499 & $4.67 \%$ \\
\hline Zona 7 & 763,954 & $7.71 \%$ & 517,243 & $9.06 \%$ \\
\hline Zona 8 & 850,878 & $8.59 \%$ & 496,949 & $8.71 \%$ \\
\hline Zona 9 & $1,126,344$ & $11.37 \%$ & 601,154 & $10.53 \%$ \\
\hline Zona 10 & $1,010,315$ & $10.20 \%$ & 602,008 & $10.55 \%$ \\
\hline Otros & 151,107 & $1.53 \%$ & 81,131 & $1.42 \%$ \\
\hline Total & $9,904,727$ & $100.00 \%$ & $5,706,483$ & $100.00 \%$ \\
\hline
\end{tabular}

Nota : Elaboración Propia

\subsection{Investigación Cuantitativa}

La investigación cuantitativa tendrá como objetivos:

- Validar que el estudio se ha enfocado en personas mayores a 25 años

- Validar que el estudio se ha enfocado en personas de la zona 2 de Lima Metropolitana

- Identificar porcentaje de posibles consumidores

- Determinar la tendencia por consumo de producto saludable

- Determinar la frecuencia de consumo para la papa

- Determinar la demanda de las presentaciones del producto

- Identificar si el posible consumidor conoce de los beneficios de productos saludables y alimentos como la papa 


\subsubsection{Proceso de Muestreo}

El proceso de muestreo contará con cinco etapas o fases las cuales se interrelacionan entre sí y que sirven para la determinación de la investigación del mercado. (Ver Figura 22)

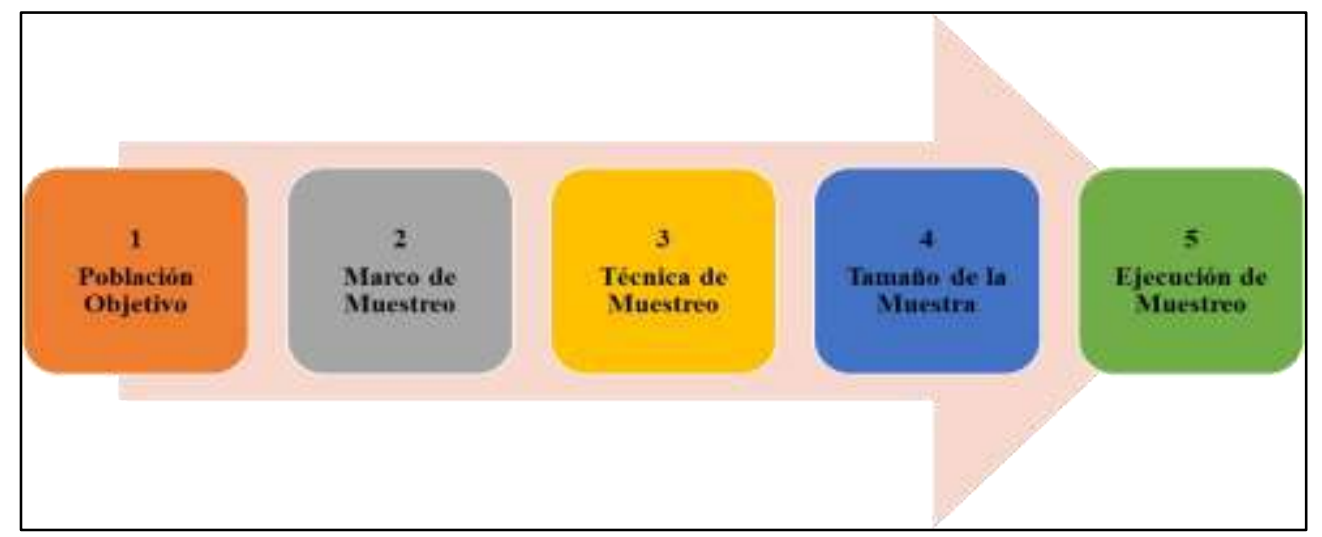

Figura 22. Proceso de muestreo cuantitativo

\section{Población Objetivo}

La población objetivo, determinada para el presente muestreo, son las personas mayores a 25 años, localizadas en la zona 2 de Lima Metropolitana

2. Marco de Muestreo

El marco muestral se construyó en base a la información obtenida del INEI, con respecto a los distritos de Lima Metropolitana y las Edades, según el APEIM 2015. 
3. Técnica de Muestreo

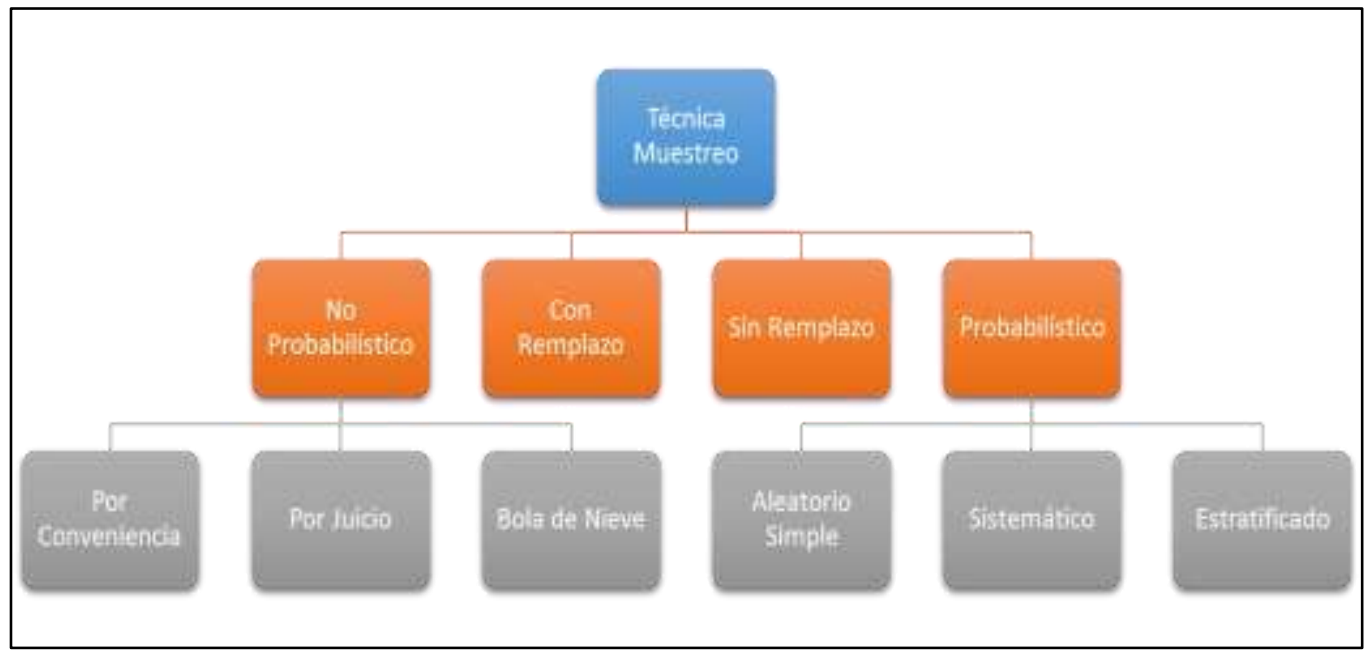

Figura 23. Teoría del muestreo cuantitativo

La estadística presenta varias técnicas, como se puede observar en la figura $\mathrm{N}^{\circ} 23$, para la realización del presente muestreo se utilizará la técnica probabilística estratificada proporcional, donde se divide la zona 2 de Lima Metropolitana en 3 estratos: (ver anexo 08)

- Los Olivos

- Independencia

- San Martin de Porres

4. Tamaño de la Muestra

Se tiene una población objetivo de 747,849 personas, mayores a 25 años de la Zona 2 de Lima Metropolitana. Para determinar el tamaño de la muestra se calculará aplicando la siguiente fórmula Gausseana (Ver Figura 24): 


$$
\mathrm{n}=\frac{N \cdot Z^{2} \cdot p \cdot(1-p)}{(N-1) \cdot \mathrm{e}^{2}+Z^{2} \cdot p \cdot(1-p)}
$$

Figura 24. Fórmula para el Tamaño de la Muestra

$\mathrm{n}=$ Tamaño de la Muestra.

$\mathrm{N}=$ Tamaño de la Población

$\mathrm{Z}=$ Es la desviación del valor medio que se aceptó para lograr el nivel de confianza deseado

e $=$ Es el margen de error máximo que admito

$\mathrm{p}=$ Es la proporción que esperamos encontrar.

Para el segmento estudiado se utilizó un nivel de confianza del $95 \%(Z=1,960)$, un margen de error permitido de $5.00 \%(e=0,05)$ y el porcentaje de heterogeneidad de la muestra o la proporción que esperamos encontrar es del 50\% ( $\mathrm{p}=0,50)$, este último parámetro representa el 50\% dado que la muestra no es muy homogénea y por lo tanto existe la posibilidad que estén de acuerdo o no con el consumo.

Debido a que el tamaño de la población es mayor a 100,000 personas; se aplicará la fórmula simplificada:

$$
\mathrm{n}=\frac{Z^{2} \cdot p \cdot(1-p)}{\mathrm{e}^{2}}
$$

Figura 25. Fórmula simplificada para el tamaño de la muestra. 
En la figura 25 se muestra la fórmula simplificada, la que no se tomará en cuenta el tamaño de la población, ya que esta es mayor a 100,000, obteniéndose el siguiente resultado:

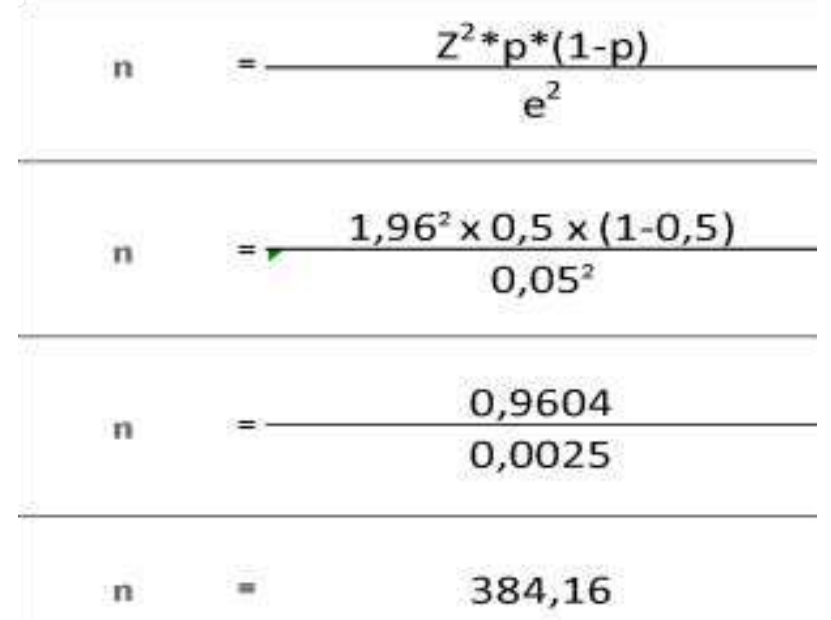

Figura 26. Resultando como tamaño de la muestra a utilizar.

Esta cifra de la Figura 26, cantidad mínima de muestra, será distribuida de forma proporcional entre los 3 estratos mencionados (Ver Tabla 18), considerando la cantidad de población por cada uno de ellos:

Tabla 18

Tamaño de Muestra Según Estratos

\begin{tabular}{lccc}
\hline \multicolumn{1}{c}{ Distrito } & Población & $\begin{array}{c}\text { Proporción } \\
\%\end{array}$ & $\begin{array}{c}\text { Tamaño de } \\
\text { Muestra }\end{array}$ \\
\hline Independencia & 125,404 & $16.77 \%$ & 64 \\
Los Olivos & 213,761 & $28.58 \%$ & 110 \\
San Martin De Porres & 408,684 & $54.65 \%$ & 210 \\
\hline \multicolumn{1}{c}{ Totales } & 747,849 & $100 \%$ & 384 \\
\hline
\end{tabular}

Diseño propio

Como se puede apreciar en la tabla $\mathrm{N}^{\circ} 18$, se ha estratificado según los distritos pertenecientes a la Zona $\mathrm{N}^{\mathrm{o}} 2$, a fin de determinar el tamaño de muestra para cada uno de ellos, cabe resaltar que se buscara encuestar en 
cada uno de estos distritos no solo a quienes puedan residir en ellos, sino también a los que puedan laborar, dado que el objetivo es encuestar a aquellos que su permanencia dentro de la Zona $\mathrm{N}^{\circ} 2$ es permanente y no golondrino.

Diseño de Instrumento

A continuación, se explicará el diseño del instrumento, el cual está soportado por la técnica de recolección de datos denominada la encuesta, la cual utiliza el instrumento de cuestionario de entrevistas, que según Camones y Moreno (1997) “La entrevista es un medio de recopilación de información mediante preguntas, a las que debe responder el interrogado", siendo así el soporte metodológico de la investigación cuantitativa del presente proyecto está soportado por una técnica valida, para lo cual se ha estructurado en tres partes: Capacitación del Encuestador, el Diseño de la Encuesta y la Ficha Técnica, que a continuación se detalla:

1. Capacitación de los Encuestadores

Para lograr un diseño adecuado del instrumento a utilizar, primero se seleccionará a los realizadores del levantamiento de información, así antes de terminar el diseño se obtendrá la retroalimentación necesaria de la persona que quizás pueda afectar, con sus preguntas o la falta de ellas, la toma de información. De esta manera se logrará un diseño adecuado en el cual no influya la intervención del encuestador. 
2. Desarrollo del Cuestionario

En esta segunda etapa es el desarrollo del cuestionario de preguntas que servían para la realización de la encuesta, esta contará con 15 preguntas de las cuales dos serán de carácter cualitativo de opción de múltiple selección y de 13 de carácter cuantitativo de selección cerrada, que solo podrá seleccionar una sola respuesta, permitiendo un adecuado estudio cuantitativo, la encuesta se podrá realizar de manera presencial y/o virtual a través de un diseño apoyado por el portal de Google, luego todas las respuesta será tabuladas en Excel y los resultados serán presentados tanto en forma numérica en tablas y también en forma gráfica.

\section{Ficha Técnica}

1. Ámbito de la Encuesta: Lima Metropolitana

2. Zona de Influencia: $\mathrm{N}^{\mathrm{o}} 2$

3. Distritos que la componen: Independencia, Los Olivos y San Martín de Porres.

4. Cantidad de Encuestadores: Cuatro encuestadores

5. Total, de Encuestas por encuestador: 96

6. Total, Personas a encuestar: 384 a más

7. La encuesta ser tomada los días viernes, sábado y domingo

8. La fecha de levantamiento de información será entre el 05 de julio y 09 de julio del 2016.

9. La hora de inicio será a partir de las 5 p.m.

10. La encuesta tendrá una duración máxima de 60 min. 
Una vez concluida la encuesta (Anexo $\left.\mathrm{N}^{\circ} 06\right)$ se procede con la tabulación de los datos en un archivo en formato Excel; luego se presenta los resultados obtenidos, así como las conclusiones y recomendaciones necesarias.

\subsubsection{Análisis y Procesamiento de Datos}

El proceso de análisis y procesamiento de datos se ha seguido bajo el esquema de Roberto Sampieri (Metodología de la Investigación, 2010) que nos propone lo siguientes

- Decidir el programa de análisis de datos que se utilizará, el programa utilizado es el SPSS, software estadístico que permite realizar un análisis predictivo de acuerdo a los datos obtenidos en la encuesta, adicionalmente se utilizó el Google forms, el cual permite realizar una encuesta de manera digital en la que podemos vaciar los datos y obtener de manera gráfica datos relevantes para el estudio.

- Descripción de los datos por variable, las cuales son tres

o Consumidor, pregunta 1 - 3

o Producto saludable, pregunta 4 - 6

o Consumo del producto, pregunta $7-15$

- La técnica estadística utilizada es descriptiva (medida de tendencia central), en la cual se describe los datos, los valores y las puntuaciones que los softwares utilizados han dado como resultado.

A continuación, se realizará el análisis de las encuestas obtenidas a través de un cuestionario de 15 preguntas, realizadas a 389 personas. Este 
cuestionario fue diseñado como una encuesta virtual soportado y apoyados por Google Doc. (Ver Figura 27)

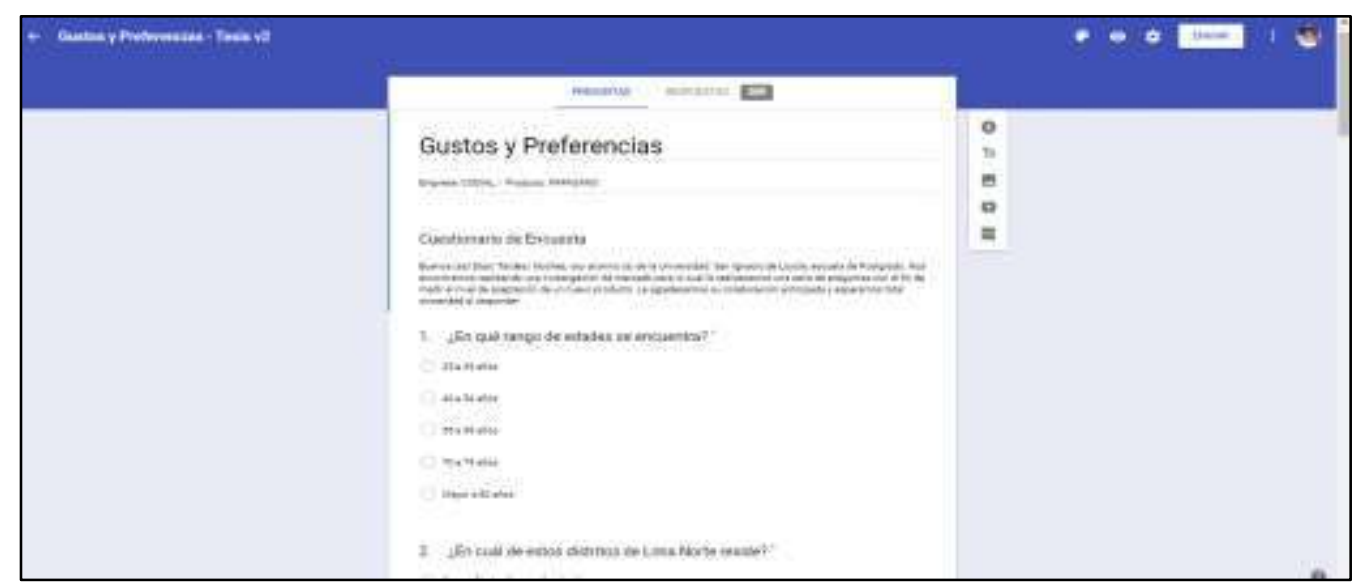

Figura 27. Encuesta Virtual, Diseño propio

Estas 389 encuestas realizadas fueron tabuladas de manera automática y están registradas en un archivo Excel que se encuentra adjunto al presente proyecto, a continuación, analizaremos cada una de las 15 preguntas realizadas:

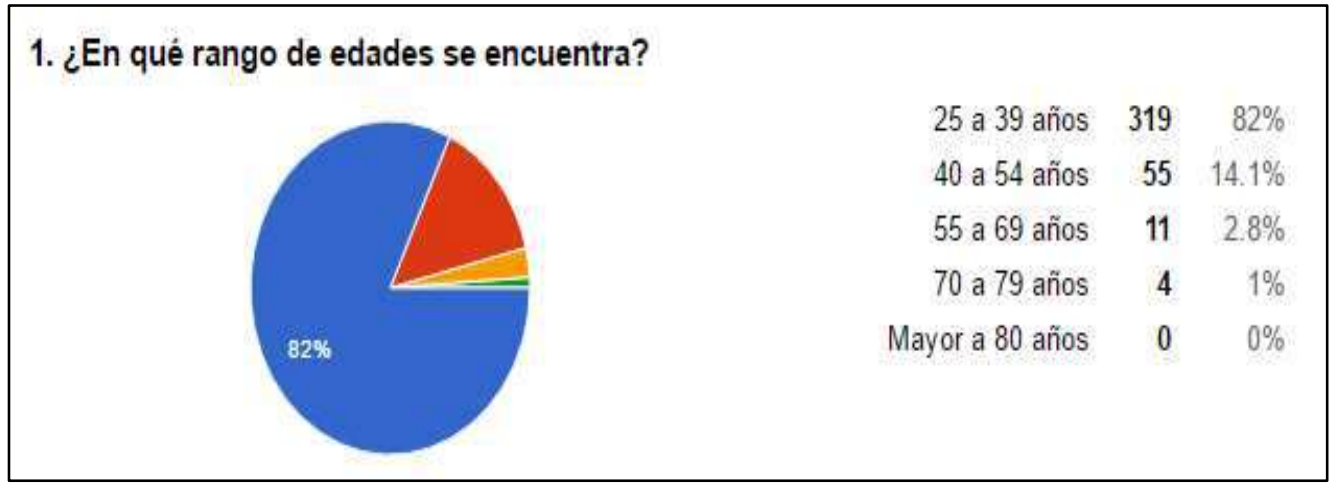

Figura 28. Encuesta Virtual, Diseño propio - Pregunta $\mathrm{N}^{\circ} 1$

Como se puede apreciar, la pregunta $\mathrm{N}^{\circ} 01$ (Figura $\mathrm{N}^{\circ} 28$ ) establece el rango de edad que se estableció para la encuesta, logrando obtener resultados ideales ya que el $96.1 \%$ de personas encuestadas se encuentran entre los rangos de 25 a 39 y 40 a 54 años de edad, edad ideal para la muestra, así también se aprecia que la mayoría de encuestados son de un perfil joven por el rango de edad preponderante, de 25 a 39 con $82 \%$ de los encuestados. 
2. ¿En cuál de estos distritos de Lima Norte reside?

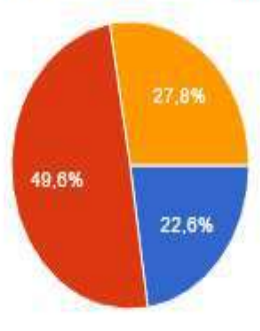

Puente Piedra, Comas, Carabayllo $88 \quad 22.6 \%$

Independencia, Los Olivos, SMP $193 \quad 49.6 \%$

Otro $108 \quad 27.8 \%$

Figura 29. Encuesta Virtual, Diseño propio - Pregunta $\mathrm{N}^{\circ} 2$

La pregunta $\mathrm{N}^{\circ} 02$ (Figura $\mathrm{N}^{\circ}$ 29) está relacionada con la ubicación geográfica de la vivienda del encuestado, siendo requisito la validación de la zona escogida para el trabajo teniendo una participación del 49.6\% (193 personas) que pertenecen a la zona 2 , donde se encuentran los distritos de Independencia, Los Olivos y San Martin de Porras, distrito escogidos en nuestro mercado objetivo, también podemos apreciar que en segundo lugar están los distritos de Puente Piedra, Comas y Carabayllo con 22.6\%, dando en consecuencia un $72.2 \%$ de todos los encuestado los cuales pertenecen a la zona norte de Lima Metropolitana y que son de área geográfica en evaluación.

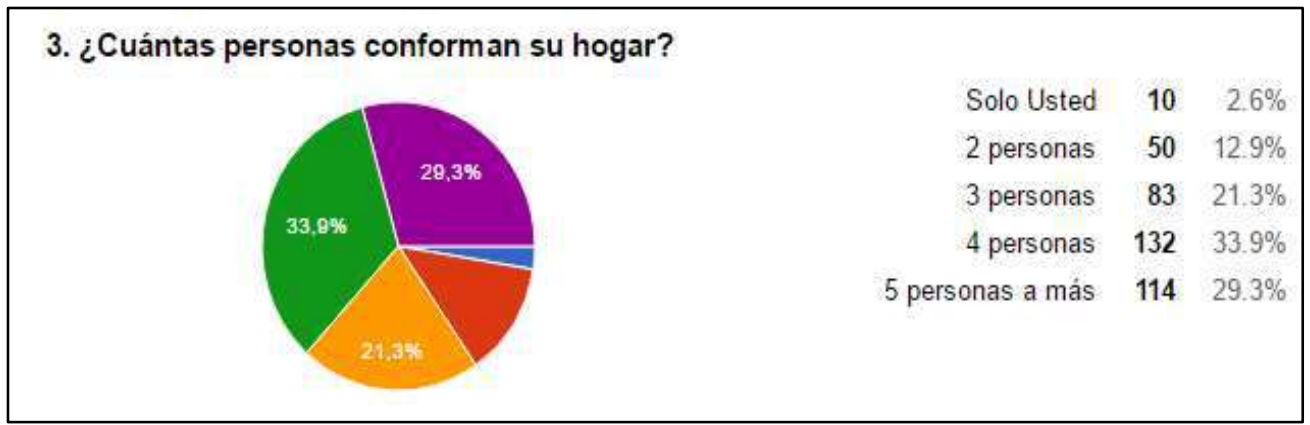

Figura 30. Encuesta Virtual, Diseño propio - Pregunta $\mathrm{N}^{\circ} 3$

La pregunta $\mathrm{N}^{\mathrm{o}} 03$ (Figura $\mathrm{N}^{\mathrm{o}} 30$ ) nos ayuda a identificar la cantidad de personas que integran el hogar y los resultados obtenidos nos indica que la cantidad de personas promedio por unidad familiar (hogar) están entre 4 y 5 personas, las cuales tienen una representación $63.2 \%$ del universo encuestado (246 personas), siendo las más relevantes. 


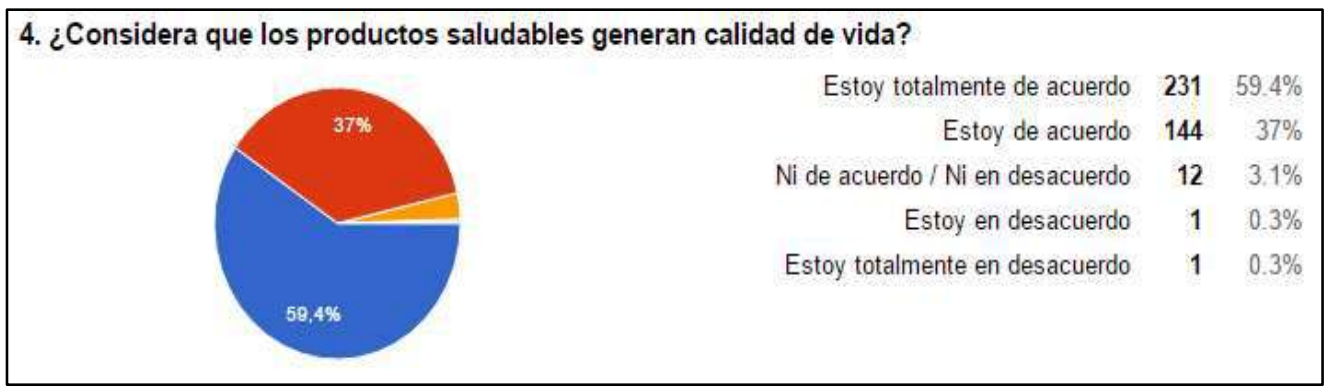

Figura 31. Encuesta Virtual, Diseño propio - Pregunta $\mathrm{N}^{\circ} 4$

La pregunta $\mathrm{N}^{\mathrm{o}} 04$ (Figura $\mathrm{N}^{\mathrm{o}} 31$ ) tiene la intención de validar si los encuestado tienen clara la idea que los productos saludables generan calidad de vida, logrando obtener un resultado bastante sorprendente ya que el $96.4 \%$ de los encuestados están de acuerdo o totalmente de acuerdo con la idea de que los productos saludables generan calidad de vida lo cual nos ayuda a posicionar bien el producto diseñado.

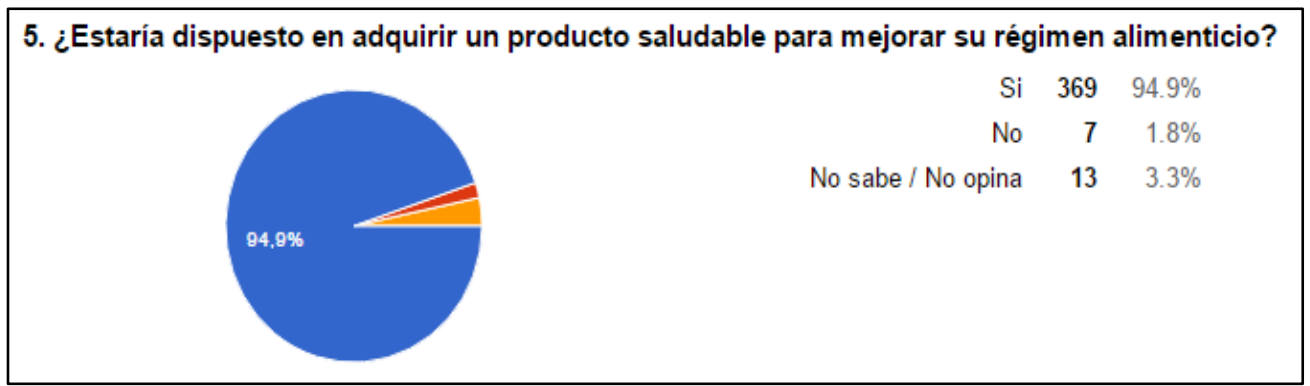

Figura 32. Encuesta Virtual, Diseño propio - Pregunta $\mathrm{N}^{\circ} 5$

La pregunta 5 (Figura $\mathrm{N}^{\circ} 32$ ) es una de nuestras preguntas filtro que nos permite identificar si la zona en estudio estaría dispuesta a adquirir productos de saludables para mejorar su régimen alimenticio, obteniendo un 94.9\% de respuestas que indican que estarían dispuesto a comprar, asegurando así que el mercado en estudio está dispuesto a comprar productos saludables. 
6. ¿Cree usted que la papa tiene beneficios para la salud?

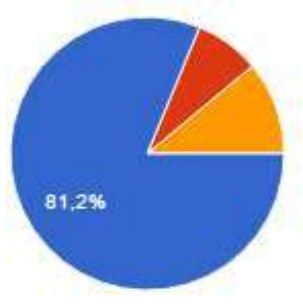

$\begin{array}{rrr}\text { No } & 316 & 81.2 \% \\ \text { No sabe/ No opina } & 43 & 7.7 \% \\ & & 11.1 \%\end{array}$

Figura 33. Encuesta Virtual, Diseño propio - Pregunta $\mathrm{N}^{\circ} 6$

La pregunta $\mathrm{N}^{\mathrm{o}} 06$ (Figura $\mathrm{N}^{\mathrm{o}} 33$ ) nos permite identificar si la

población encuestada conoce los beneficios que tiene o contiene la papa, dando como resultado que el $81.2 \%$ conocen de las bondades de la papa, situación que ayudaría enormemente a la comercialización del producto ofertado.

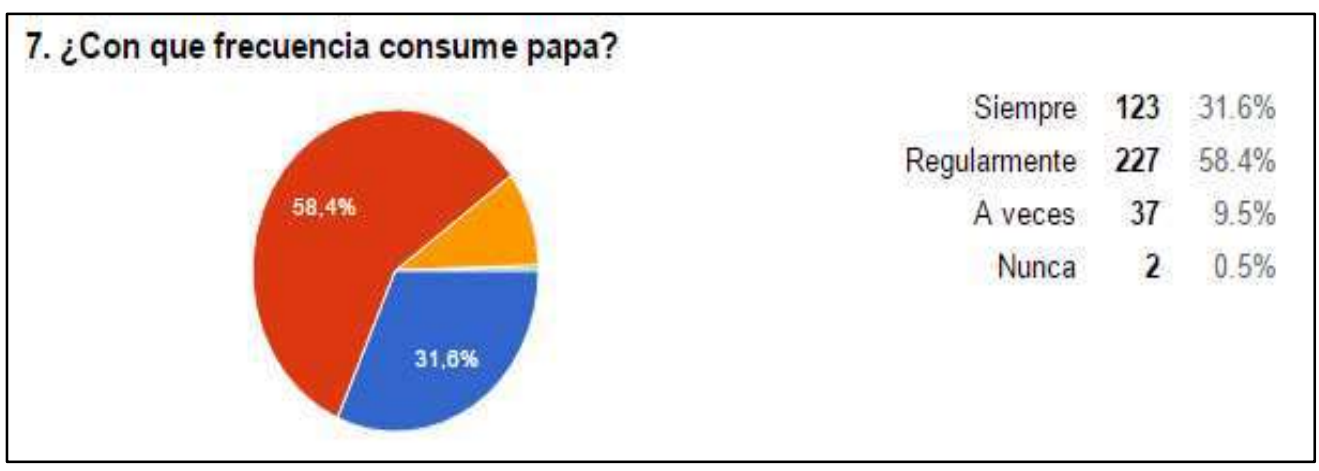

Figura 34. Encuesta Virtual, Diseño propio - Pregunta $N^{\circ} 7$

La pregunta $\mathrm{N}^{\mathrm{o}} 07$ (Figura $\mathrm{N}^{\mathrm{o}} 34$ ) nos permite identificar la frecuencia con la se consume o desean consumir el producto papa, dando como resultado que siempre consumen papa el $31.6 \%$ de los encuestados (123 personas) y el $58.4 \%$ consume regularmente (227 personas) dando en consecuencia que el $90 \%$ (350 personas) comen siempre o casi siempre papa, con lo que se puede afirmar que el consumo del producto se encuentra asegurado. 
8. ¿Ha tenido oportunidad de dializar algún alimento?Dialización: Proceso por el cual se reducen los niveles de potasio de un alimento, esto para controlar los desechos que se acumulan en la sangre por su ingesta y regular el nivel de potasio en la nutrición diaria.

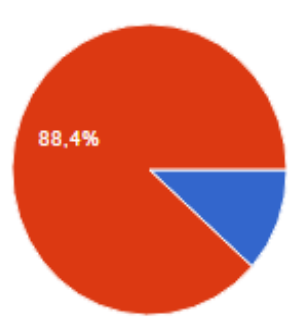

$\begin{array}{rrr}\text { Si } & 45 & 11.6 \% \\ \text { No } & 344 & 88.4 \%\end{array}$

Figura 35. Encuesta Virtual, Diseño propio - Pregunta $\mathrm{N}^{\circ} 8$

La pregunta $\mathrm{N}^{\circ} 08$ (Figura $\mathrm{N}^{\mathrm{o}} 35$ ) muestra claramente que el

conocimiento del proceso de dializaciòn de los alimentos no ha sido muy

difundido o no son conocido por lo que es necesario reforzar con mayor

cantidad de difusión, capacitación y publicidad que permita el recordamiento

del proceso de dializaciòn en alimentos a fin de que el proceso de fidelización

sea de manera natural y fácil de recordación.

\section{9. ¿Consumiría papa dializada?}

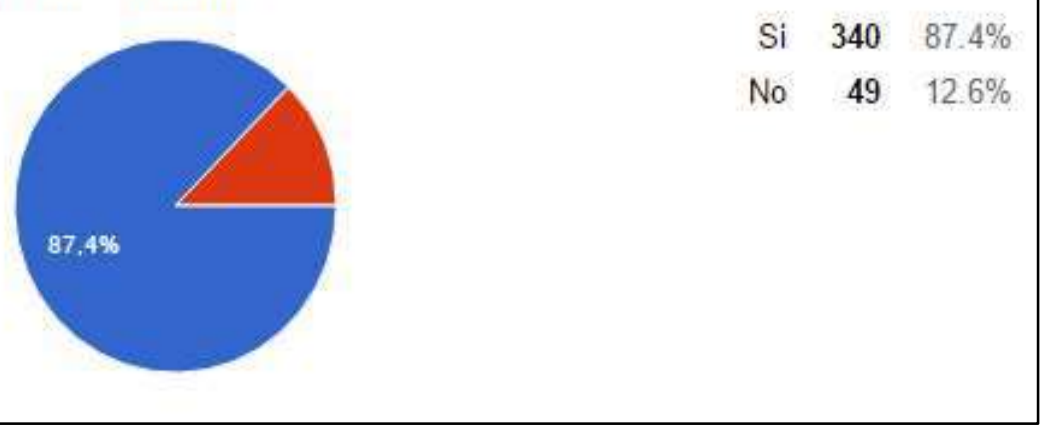

Figura 36. Encuesta Virtual, Diseño propio - Pregunta $\mathrm{N}^{\circ} 9$

La pregunta $\mathrm{N}^{\mathrm{o}} 09$ (Figura $\mathrm{N}^{\circ} 36$ ) es otra de nuestras preguntas filtros, ya que nos permite estar completamente seguros que las personas encuestadas estarían dispuestas a consumir la papa dializada, logrando obtener un $87.4 \%$ de aceptación frente al consumo de papa dializada, siendo un resultado muy aceptable para lograr el éxito de la comercialización del producto ofertado. 
10. ¿En cuál de estas presentaciones lo desearía adquirir?

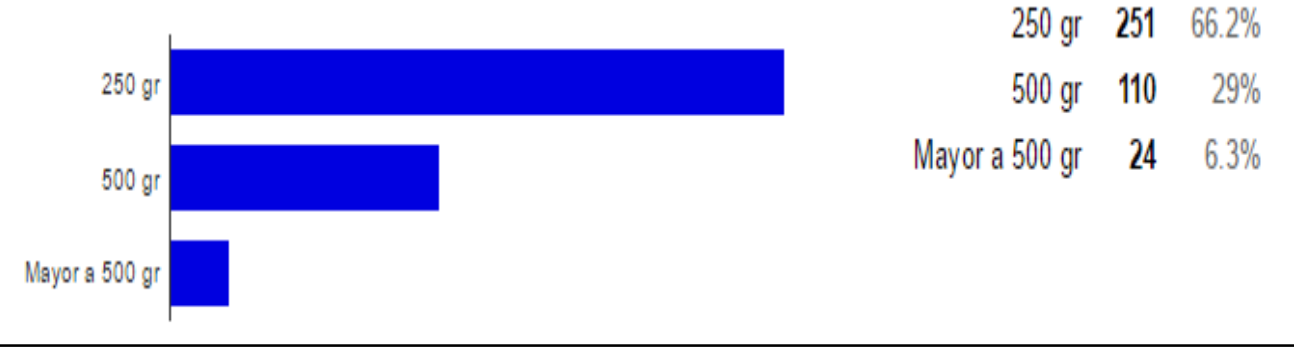

Figura 37. Encuesta Virtual, Diseño propio - Pregunta $\mathrm{N}^{\circ} 10$

La pregunta 10 (Figura $N^{\circ} 37$ ) permite identificar cuál de las

presentaciones diseñadas sería la más aceptada para la compra, obteniendo el $66.2 \%$ (251 personas) la presentación de 250 gr y un 29\% la presentación de 500 gr, siendo los resultados estar dentro de los parámetros proyectados.

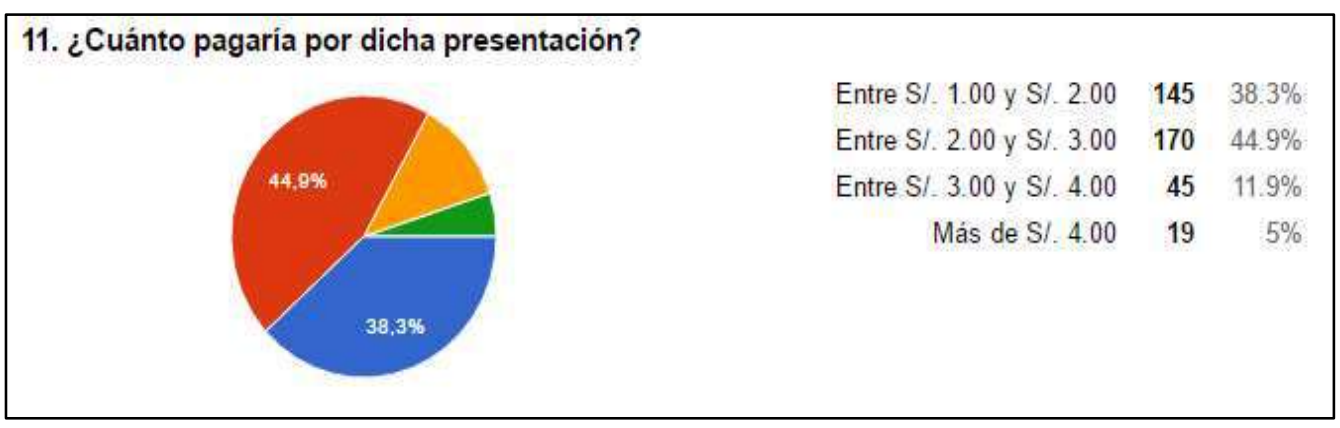

Figura 38. Encuesta Virtual, Diseño propio - Pregunta $\mathrm{N}^{\circ} 11$

La pregunta 11 (Figura 38) es una de la más importantes, ya que permitirán reforzar el precio a establecer por la venta de los productos ofertado en cualquiera de sus dos presentaciones, siendo el primer rango de precio más importante para los encuestados el que se encuentra entre S/.2.00 a S/.3.00 teniendo un 44.9\% de participación y el segundo rango de mayor importancia entre S/. 1.00 a S/. 2.00 con un $38.3 \%$, los cuales están dentro de los parámetros esperados. 


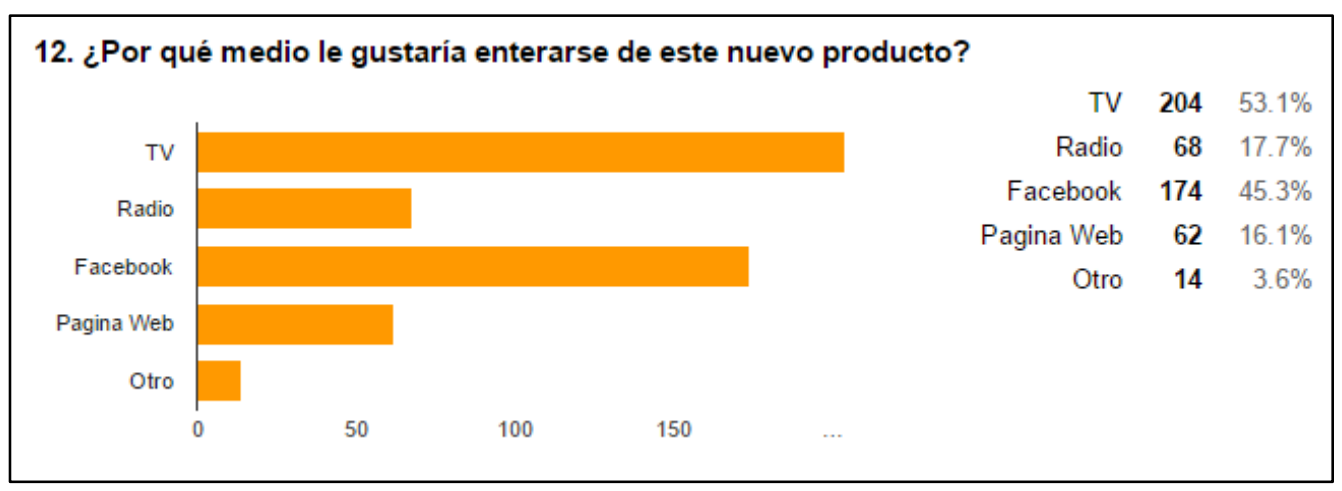

Figura 39. Encuesta Virtual, Diseño propio - Pregunta $N^{\circ} 12$

La pregunta número № 12 (Figura № 39) nos permite identificar los medios de difusión más relevantes para los consumidores por donde les gustaría tener conocimiento sobre el producto ofertado, siendo los dos más importantes la televisión con el 53.1\% y el Facebook con el $45.3 \%$, sirviendo esta información para el plan de marketing a ser diseñado.

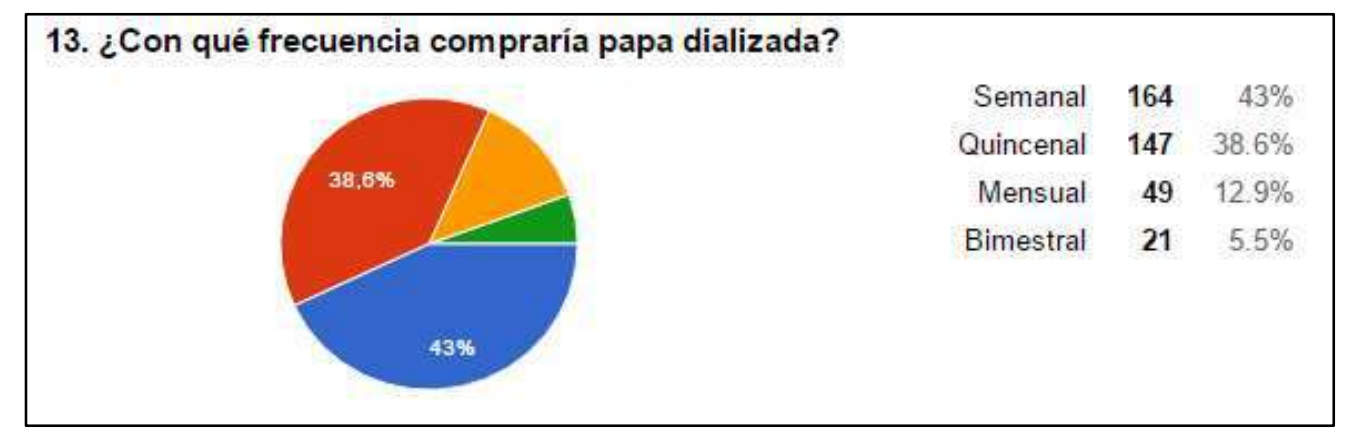

Figura 40. Encuesta Virtual, Diseño propio - Pregunta $\mathrm{N}^{\circ} 13$

La pregunta $\mathrm{N}^{\mathrm{o}} 13$ (Figura $\mathrm{N}^{\circ} 40$ ) nos ayudará a definir la frecuencia de compra del producto ofertado, prevaleciendo el consumo semanal con un $43 \%$ y quincenal con un $38.6 \%$, esta información nos permitirá realizar las proyecciones productivas y de ventas necesarias. 
14. ¿Lugar donde lo compraría?

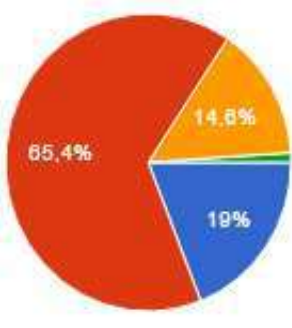

$$
\begin{array}{rrr}
\text { Tienda } & 73 & 19 \% \\
\text { Supermercado } & 251 & 65.4 \% \\
\text { Mercado } & 56 & 14.6 \% \\
\text { Otro } & 4 & 1 \%
\end{array}
$$

Figura 41. Encuesta Virtual, Diseño propio - Pregunta $\mathrm{N}^{\circ} 14$

La pregunta $\mathrm{N}^{\circ} 14$ (Figura $\mathrm{N}^{\circ} 41$ ) nos permite definir los canales de

\begin{tabular}{|c|c|c|c|}
\hline \multicolumn{4}{|c|}{ 15. ¿Cuál sería el motivo de compra de este nuevo producto? } \\
\hline & Precio asequible & 55 & $14.4 \%$ \\
\hline & Practicidad & 19 & $5 \%$ \\
\hline & Salud & 232 & $60.6 \%$ \\
\hline $60.8 \%$ & Seguridad & 2 & $0.5 \%$ \\
\hline & Todas las anteriores & 75 & $19.6 \%$ \\
\hline
\end{tabular}
distribución y venta a utilizar siendo el más importante los supermercados con un $65.4 \%$, teniendo como un importante socio de negocio a los retails los cuales deben de esta comprendidos en el Plan de Marketing.

Figura 42. Encuesta Virtual, Diseño propio - Pregunta $\mathrm{N}^{\circ} 15$

Finalmente, esta pregunta 15 (Figura $\mathrm{N}^{\mathrm{o}} 42$ ) nos ayuda a reforzar o posicionamiento del producto ofertado teniendo el $60.6 \%$ lo referido a la salud (232 personas), siendo lo más importante para los encuestados.

\subsection{Investigación Cualitativa}

La investigación cualitativa tendrá como objetivo identificar al consumidor, preferencias por alimento saludable y aceptación del producto a ofertar. 


\subsubsection{Proceso de Muestreo}

El proceso de muestreo contará con cinco etapas o fases las cuales se interrelacionan entre sí y que sirven para la determinación de la investigación del mercado. (Ver Figura $N^{\circ} 43$ )

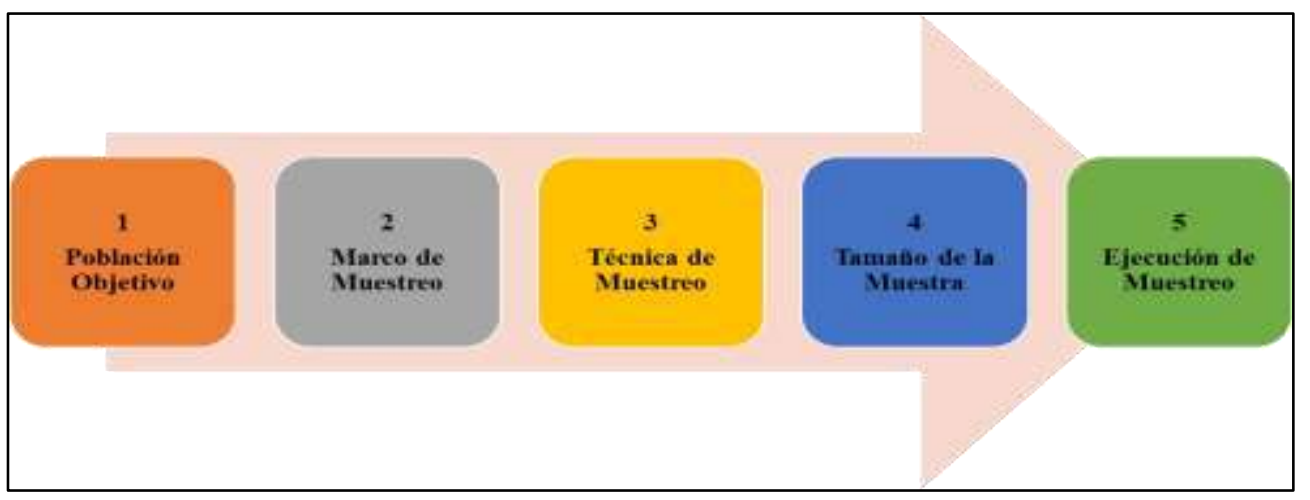

Figura 43. Proceso de Muestreo

1. Población Objetivo

La población objetivo determinada para la presente investigación, está conformada por personas mayores de 25 años, que se ubican en la zona 2 de Lima Metropolitana (Los Olivos, Independencia, San Martín).

2. Marco de Muestreo

El marco de muestreo está representado por personas que exijan un producto saludable en su dieta diaria, para evitar afectar directa o indirectamente el funcionamiento de sus órganos; o a personas mayores de 40 años que tengan la necesidad de contar con un buen estado de salud generando calidad de vida para su cuerpo humano. 
3. Técnica de Muestreo

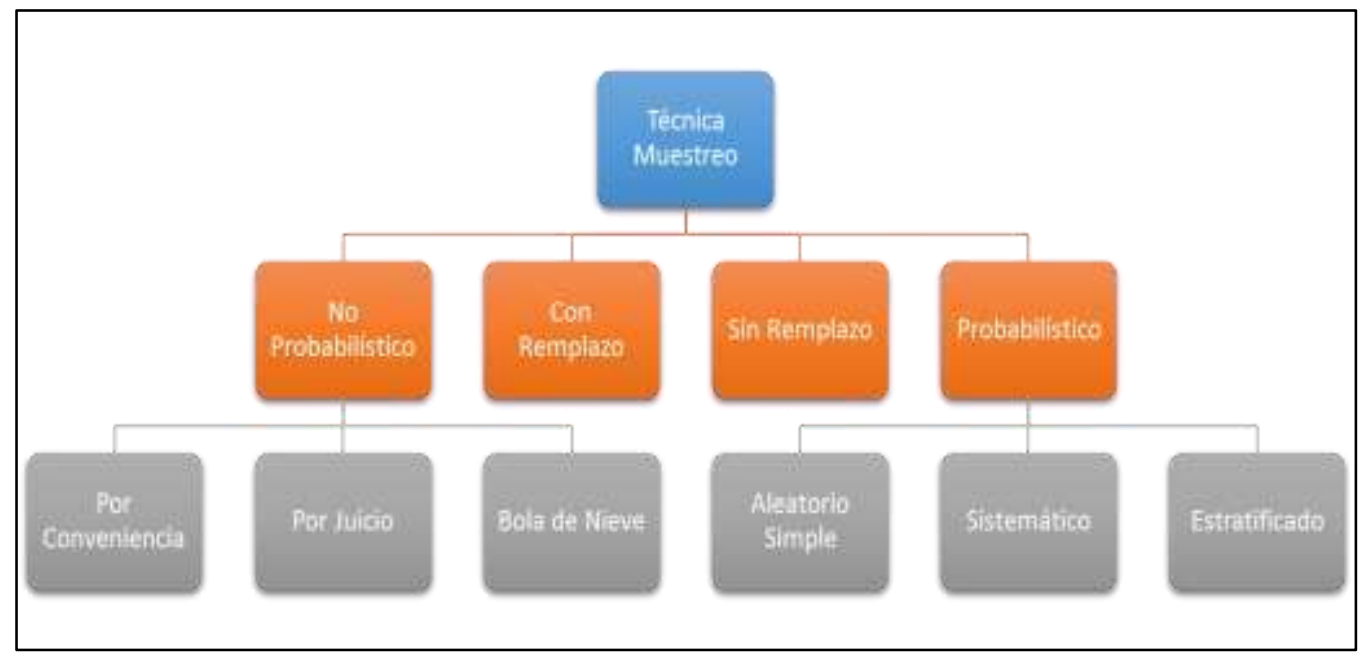

Figura 44. Organización de las Técnica de Muestreo

La estadística nos presenta varias técnicas, como se puede observar en la Figura $N^{\circ} 44$ arriba indicadas, para la realización del presente muestreo utilizaremos la técnica No Probabilística por Juicio, permitiendo que el investigador realice las preguntas necesarias a un grupo pre seleccionado de personas de la población objetivo.

La técnica a utilizar se realizará a través de dos instrumentos, las cuales serán la entrevista de Focus Group y Entrevistas de profundidad, las cuales detallaremos más adelante.

4. Tamaño de la Muestra

Se realizará la investigación utilizando dos tipos de técnicas:

\section{Focus Group}

Agrupará a seis personas del grupo objetivo determinado con edades mayores a 25 años y dentro de la zona 2 de Lima Metropolitana. 
Se realizarán cuatro eventos, para lograr una data más homogénea, con esta herramienta se busca profundizar el tema de producto saludable y papa dializada, para determinar si existe el conocimiento sobre este tipo de proceso e identificar cómo se percibe el producto como alimento saludable.

Entrevista en Profundidad

Para poder refrendar la calidad e importancia del producto que el presente proyecto desea comercializar, se realizaran dos entrevistas de profundidad a personas de distintos géneros, pero con conocimiento suficiente dentro de lo profesional, técnico y/o científico sobre los beneficios de la comida saludable y el proceso de dialización en los alimentos.

\subsubsection{Diseño de Instrumento}

A continuación, se detalla el diseño del instrumento, el cual estará dividido en dos partes o secciones, las cuales interactúan entre sí y son muy importantes y relevantes para el éxito del presente trabajo de investigación.

Estas partes o divisiones estarán compuestas por el manual para los moderadores y/o entrevistadores, y las preguntas a utilizar a través de las respectivas fichas.

1. Capacitación de los Moderadores

Para lograr un manejo adecuado del instrumento a utilizar, primero se seleccionará a las personas que realizaran el levantamiento de información, se continuará con su capacitación e involucrará en el propósito y finalidad de estos instrumentos; se orientará en la forma de cómo obtener la información para que el moderador y/o entrevistador no logre influir en las respuestas de los participantes. 
En ese sentido, se han elaborado dos documentos, la cartilla de entrenamiento del moderador (Anexo $\mathrm{N}^{\mathrm{o}}$ 02) y guía del moderador (Anexo $\mathrm{N}^{\circ}$ 03).

2. Desarrollo de las preguntas a debatir

En esta sección se desarrollará las preguntas para el Focus Group y para la entrevista de profundidad

\section{Focus Group}

El Focus Group estará dirigido a personas de la población objetivo y tendrá las siguientes características:

a) Se realizará un total de tres reuniones o Focus Group

b) Se convocará a seis personas, tres de cada género.

c) Las preguntas serán un total de ocho.

d) Cada entrevistador grabará el audio del debate

e) Todas las preguntas serán abiertas para lograr una mayor discusión y profundización del tema.

f) Las cuatro sesiones se realizarán el mismo día y a la misma hora, para asegurar la veracidad de cada grupo entrevistado.

g) Las personas que participarán en el Focus Group deberán de ser de la zona 2 del rango de edades mayores a 25 años.

h) El horario de ejecución del Focus Group se realizará a partir de las 5 pm., permitiendo lograr tener una participación plena de todos los participantes invitados y tendrá una duración de 1 hora aproximadamente. 


\section{Entrevista de Profundidad}

La entrevista de profundidad estará dirigida a dos personas que se encuentren involucradas en el sector de la prevención de la salud o trabajen alrededor del sector salud, que cuenten con una mayor especialización en los temas de alimentación saludable y deberá de tener las siguientes características:

a) Se realizará un total de dos entrevistas de profundidad

b) Se podrá convocar a cualquiera de los dos géneros.

c) Serán un total de ocho preguntas.

d) Cada entrevistador grabará el audio de la entrevista de profundidad.

e) Todas las preguntas serán abiertas y especializadas para lograr obtener la mayor cantidad de información técnica de calidad.

f) Las dos entrevistas de profundidad se realizarán el mismo día y a la misma hora, para asegurar la veracidad e imparcialidad de cada entrevistado.

g) Las personas que participarán en la entrevista de profundidad deberán de tener alguna especialización o conocimiento avanzado en referencia a la prevención de la salud, pudiendo ser nutricionistas, endocrinólogos o de medicina general.

h) El horario de ejecución de la Entrevista de Profundidad se realizará a partir de las 5 pm., permitiendo que los invitados a la entrevista puedan participar plenamente de la entrevista

i) La presente entrevista tendrá una duración mínima de 30 minutos y máxima de una hora aproximadamente. 
Una vez concluido el Focus Group y las entrevistas de profundidad serán registradas y tabuladas en un archivo Excel a fin de poder obtener los resultados cualitativos de las entrevistas, el diseño de la entrevista del Focus Group y la Entrevista de profundidad se encuentra en los Anexos Nº 04 y Anexo $N^{\circ} 05$ respectivamente del presente documento.

\subsubsection{Análisis y Procesamiento de datos}

\section{Focus Group}

De los datos recogidos de los tres focus group realizados, se identifica claramente que la percepción de alimentos saludables está presente y de manera clara en cada uno de los participantes, siendo para ellos que un producto saludable no se encuentra necesariamente dentro de lo farmacéutico y/o químicos, a pesar de tener una percepción clara sobre lo saludable que puede ser la papa, no cuentan con información precisa de sus propiedades o nutrientes que posee.

También se puede apreciar un rechazo inicial hacia el producto, esto dado por el nombre propuesto, en el cual el significado de dialización genera una fuerte relación con procesos o productos médicos, pero una vez explicado de manera clara y sencilla lo que este proceso realiza en la papa, la mayoría de los entrevistados aceptó el producto e identificaron que el proceso explicado era totalmente natural, habría que precisar que el concepto de dialización fue mejor entendido o conocido por la personas mayores (40 años a más) las cuales cuentan con mayor conocimiento de este proceso por referencia familiar o amical, no siendo de la misma manera en las personas menores. 
Finalmente, la mayoría de las personas entrevistadas presentaron una aceptación del producto y su identificación como saludable y/o contribuyente de calidad de vida, también se puede identificar que no existen dentro del mercado empresas que ofrezcan el mismo tipo de producto, el cual para todos los entrevistados era totalmente nuevo, pero una vez explicado los beneficios y cualidades, los entrevistados tenían disposición para comprarlos por lo menos una vez por semana y de preferencia en supermercados y/o centros minoristas.

Como se puede apreciar el desconocimiento del proceso de dialización produce un temor inicial que luego desaparece al ser explicado, dando como consecuencia una aceptación inmediata del beneficio y recomendación del mismo solo por ser saludable o de ayuda para la salud y por ello los participantes solicitaban se pueda incluir otros insumos o productos en el proceso a fin de poder adquirirlos o recomendarlos.

\section{Entrevista de Profundidad}

Se realizaron dos entrevistas de profundidad, la primera de ellas dirigida a un especialista en nutrición, al cual se le realizaron ocho preguntas relacionadas con el producto ofertado, pero con mayor detalle, para lograr obtener respuestas que nos permitan sustentar de manera adecuada el presente proyecto, con lo cual, para esta primera entrevista, se logró una comprensión de un $90 \%$ del proceso de dialización y un reconocimiento de lo saludable que este puede ser, no obstante el reconocimiento preciso para que pueda considerarse saludable este tiene que ser previamente evaluado o sometido a pruebas de laboratorio que 
permitan identificar de manera científica la reducción de potasio y otros componentes, también reconoció que no podría precisar todos los beneficios que tiene la papa, ni su composición, pero si estaba de acuerdo que su consumo es muy importante para el desarrollo del ser humano.

También reconoció el proceso, al cual el presente proyecto le ha denominado dialización de papa, que algunos centros de salud recomiendan realizar en casa para los pacientes con enfermedades renales o hepáticas, pero precisa que no sabe si este procedimiento es llevado a cabo por los hospitales del estado o alguna clínica en particular o empresa que se dedique a este servicio, finalmente recomendó que el producto ofertado esté acompañado por diferentes recetas de comidas saludable y balanceadas en el cual esté presente los beneficios que se obtiene al preparar el producto y los diferentes modos de preparación, así como lograr el respaldo de las entidades supervisoras de la salud y/o patrocinio del estado a fin de lograr la masificación y confianza en el producto.

La segunda entrevista de profundidad se realizó a un nefrólogo, especialista en riñones, el cual reconoció de manera inmediata el proceso y homologó fácilmente el nombre propuesto al producto, generando su interés y su disposición a participar de su difusión, al igual que la primera entrevista no sabía de la existencia de algún negocio u empresa que realice este tipo de servicio, más si acotó que existen algunos centros de salud del estado y de Essalud que recomiendan realizar dicho procedimiento y enseñan cómo realizarlos, se debe de precisar que el médico entrevistado se refería al área donde se desempeña, también comentó que la supervisión continua de los especialistas, empresas 
certificadoras u médicos calificados, es muy importante para lograr el respaldo de los profesionales médicos a los cuales, según el doctor, serán los que deban de ser convencidos antes que el público en general, por último explicó que este procedimiento es bastante antiguo y efectivamente nadie ha tenido la idea de industrializarlo y que le parece bien que existiera este y otros productos, pero recalcó que debe de contar con todos el respaldo de las entidades de control y supervisores de la salud (Municipalidades, Digesa, Ministerio de Salud, otros). Para concluir afirmó que de existir el producto lo recomendaría y consumiría siempre y cuando se realice el proceso descrito.

\subsection{Conclusiones y recomendaciones del Estudio Cualitativo y Cuantitativo}

Los resultados obtenidos mediante las diferentes técnicas de recolección de datos nos han permitido identificar que la aceptación al producto ofertado es muy alta dentro del universo evaluado, siendo muy importante para los encuestados todo lo relacionado con la salud y la mejora del producto de consumo humano, además la confirmación de que la papa (insumo) tubérculo que tiene una alta frecuencia de consumo.

Así también se ha identificado la necesidad una mayor difusión del proceso propuesto para la dialización de los alimentos, dado que se tiene una idea diferente o muy relacionada con unos productos medicinales y no un producto saludable, por lo cual es muy necesario un agresivo plan de marketing y difusión del nuevo, producto que aun teniendo una gran aceptación no existe un conocimiento real de que es posible lograr comer alimentos a través de su dialización. 
Por último, el plan de Marketing deberá de contemplar las preguntas referidas al precio seleccionado por los encuestados, los canales de distribución, los medios escogidos y la frecuencia de compra con que los futuros clientes estarían dispuestos a adquirir este nuevo producto a ofertar.

\subsection{Perfil del consumidor tipo y sus variantes.}

Para poder ingresar al mercado, se identificará las características que debe tener el consumidor a quien se dirigirá el producto, además de conocer sus hábitos de compra; con esta información, se desarrollará las estrategias para la aceptación del producto. Según Figura No 45 se detalla:

\section{Demográfico}

- Personas mayores a 25 años

\section{Conductual}

- Con inclinación a la adquisición de productos saludables y precios asequibles

- Frecuencia de consumo semanal

\section{Psicográfico}

- Preferencia por la papa

- Con tendencia a uso práctico de los productos

- Preferencia por una presentación de 250 gr

- Dispuestos pagar entre 2.00 y 3.00 soles por presentación de 250 gr

\section{Geográfico}

- Lima Metropolitana 


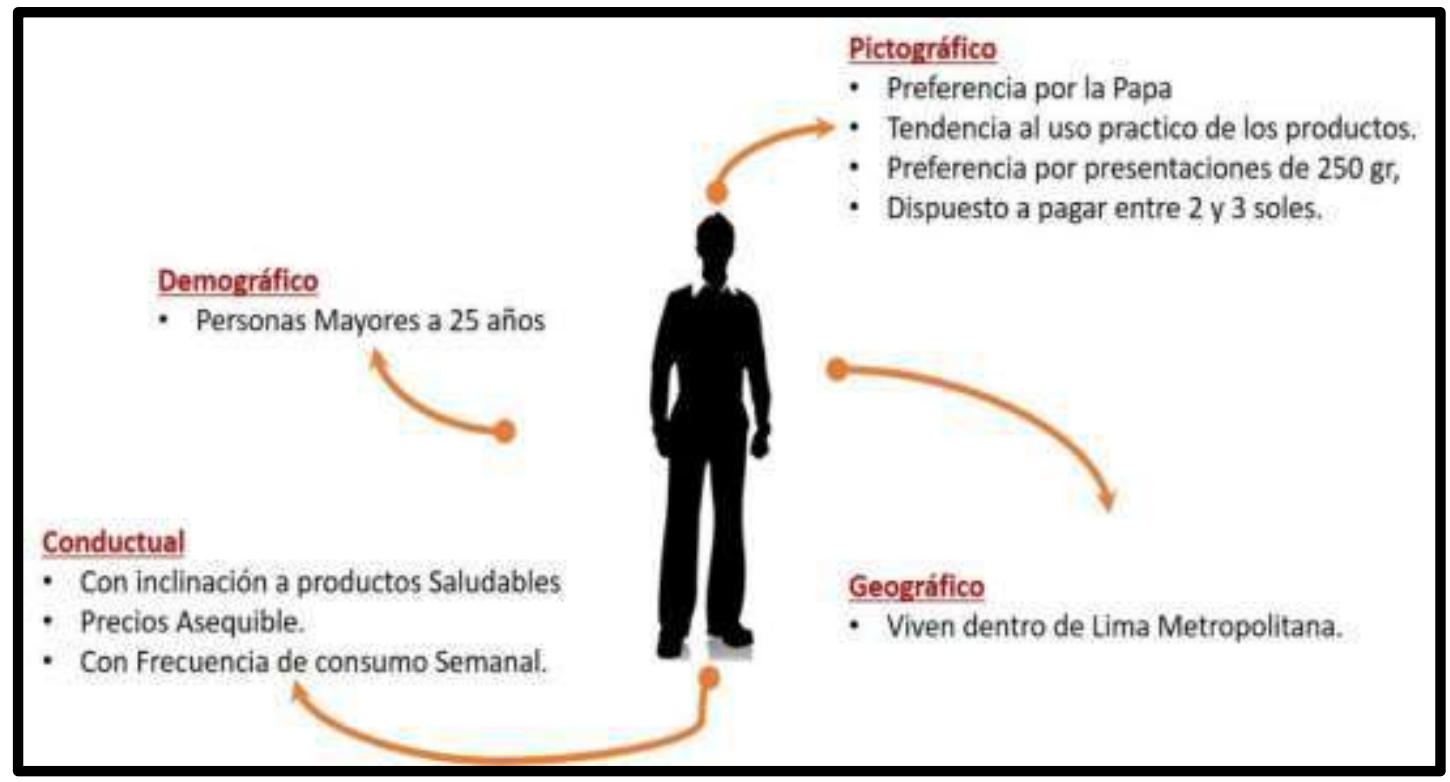

Figura 45. Perfil del Consumidor, diseño propio 


\section{Capítulo IV: Proyección del Mercado Objetivo}

\subsection{El ámbito de la proyección.}

Actualmente Lima Metropolitana (conformado por la Provincia de Lima y la Provincia Constitucional del Callao) representa el $31.80 \%$ de la población total del Perú (INEI 2015), de esta sección el 53.7\% en promedio es población económicamente activa, y este a su vez es el $31.5 \%$ del total de la PEA. Además, en Lima Metropolitana se concentran los principales mercados mayoristas y supermercados del país, como también se encuentran concentrados los principales centros médicos y de salud pública y privada.

Adicionalmente el ámbito de la presente proyección está a afectado por el perfil demográfico de nuestro consumidor el cual es mayor a los 25 años de edad, sin distinción de género y centralizados en la Zona 2 de Lima Metropolitana (APEIM 2015), esta zona está conformada por los distritos de Independencia, Los Olivos y San Martin de Porras, no obstante, debemos precisar que esta zonificación propuesta por APEIM está basada en la zonificación presentada por INEI (Lima Metropolitana, 2014) la cual clasifica en 5 zonas todo Lima Metropolitana y la Provincia Constitucional del Callao según Anexo $N^{\circ} 8$.

Como se puede visualizar en dicho Anexo, la zona 2 propuesta por APEIM 2015, se encuentra dentro de la Zona Norte, por lo tanto, el ámbito de la proyección también estaría acotado a la Zona Norte de Lima Metropolitana (Zona 2).

\subsection{Selección del método de proyección.}

\subsubsection{Mercado Potencial.}


El mercado potencial está definido por todas las personas mayores de 25 años, ubicadas en la zona 2 de Lima Metropolitana y que se encuentran afectados por el porcentaje de la población económicamente activa (PEA).

Según base de datos del INEI se tiene la proyección de población para los años 2000 a 2050, de ella se captura los correspondientes a los años 2017 hasta el 2021 para realizar la proyección respectiva. Además, tenemos que todas las personas que residen en Lima Metropolitana representan el $31.80 \%$ del Perú (INEI 2015). A esta cantidad de habitantes de Lima Metropolitana se aplica el $53.70 \%$, porcentaje promedio obtenido de los años 2010 - 2014, para determinar la población económicamente activa en esta parte del país (INEI, 2010 - 2014). De este último grupo de personas se ha seleccionado a todas aquellas que residen dentro de la Zona 2 que pertenecen a la Zona Norte de Lima (INEI 2015) representando un 13.01\% de Lima Metropolitana y la población mayor de 25 años de edad, está representado por el $58.05 \%$ respecto a la población de la zona 2 de Lima Metropolitana. (Ver Tabla 19)

Tabla 19

Proyección Poblacional 2017-2021

PROYECCION 2017 - 2021

\begin{tabular}{|c|c|c|c|c|c|c|c|c|c|}
\hline \multirow{2}{*}{$\begin{array}{l}\text { Añio } \\
2017\end{array}$} & \multirow{2}{*}{$\begin{array}{c}\text { INEI } \\
\text { Proy. Perù } \\
2000 \cdot 2050 \\
31,826,018\end{array}$} & \multicolumn{2}{|c|}{ Lima Metropolitana } & \multicolumn{2}{|c|}{ PEA \% } & \multicolumn{2}{|c|}{ Zona 2} & \multicolumn{2}{|c|}{$\begin{array}{l}\text { Personas mayores } \\
\text { a } 25 \text { años }\end{array}$} \\
\hline & & $31.80 \%$ & $10,120,674$ & $53.70 \%$ & $5,434,802$ & $13.01 \%$ & 707,068 & $58.05 \%$ & 410,453 \\
\hline 2018 & $32,162,184$ & $31.80 \%$ & $10,227,575$ & $53.70 \%$ & $5,492,208$ & $13.01 \%$ & 714,536 & $58.05 \%$ & 414,788 \\
\hline 2019 & $32,495,510$ & $31.80 \%$ & $10,333,572$ & $53.70 \%$ & $5,549,128$ & $13.01 \%$ & 721,942 & $58.05 \%$ & 419,087 \\
\hline 2020 & $32,824,358$ & $31.80 \%$ & $10,438,146$ & $53.70 \%$ & $5,605,284$ & $13.01 \%$ & 729,247 & $58.05 \%$ & 423,328 \\
\hline 2021 & $33,149,016$ & $31.80 \%$ & $10,541,387$ & $53.70 \%$ & $5,660,725$ & $13.01 \%$ & 736,460 & $58.05 \%$ & 427,515 \\
\hline
\end{tabular}

Nota. Adaptado de Información del INEI 2014

Finalmente resultando un mercado potencial para el primer año (2017) de 410,453 habitantes. (Ver Tabla 20) 
Tabla 20

Mercado Potencial

Mercado Potencial en

la Zona 2 de Lima

Metropolitana

(expresado en

\begin{tabular}{rr}
\hline Año & $\begin{array}{l}\text { Mercado } \\
\text { Potencial }\end{array}$ \\
\hline 2017 & 410,453 \\
\hline
\end{tabular}

Nota. Elaboración propia

Adicionalmente podemos visualizar en la Tabla $\mathrm{N}^{\circ} 21$ el mercado

potencial de Lima Metropolitana en el horizonte de evaluación en los cuatro años consecutivos $(2018-2021)$.

Tabla 21

Mercado Potencial 2018-2021

la Zona 2 de Lima

Metropolitana

(expresado en

\begin{tabular}{lr}
\hline Año & $\begin{array}{r}\text { Mercado } \\
\text { Potencial }\end{array}$ \\
\hline 2018 & 414,788 \\
2019 & 419,087 \\
2020 & 423,328 \\
2021 & 427,515 \\
\hline
\end{tabular}

Nota. Elaboración propia 


\subsubsection{Mercado Disponible.}

El mercado disponible está representado por todas las personas que están comprendidas dentro del mercado potencial y que están dispuesto a comprar productos saludables, dado que estos generan calidad de vida, para ello se tomará el porcentaje resultante de la pregunta filtro número cuatro de la encuesta realizada:

\section{¿Considera que los productos saludables generan calidad de vida?}

De donde el $59.4 \%$ de los encuestados contestaron que están totalmente de acuerdo con esta interrogante. Este porcentaje será aplicado al mercado potencial para hallar el mercado disponible para los años 2017 - 2021. (Ver Tabla 22)

Tabla 22

Mercado Disponible

\section{Mercado Disponible en la Zona 2 de Lima} Metropolitana (expresado en habitantes)

\begin{tabular}{rrrr}
\hline Año & $\begin{array}{c}\text { Mercado } \\
\text { Potencial }\end{array}$ & $\begin{array}{c}\text { \% Pregunta } \\
\text { filtro }\end{array}$ & $\begin{array}{c}\text { Mercado } \\
\text { Disponible }\end{array}$ \\
\hline 2017 & 410,453 & $59.40 \%$ & 243,809 \\
2018 & 414,788 & $59.40 \%$ & 246,384 \\
2019 & 419,087 & $59.40 \%$ & 248,938 \\
2020 & 423,328 & $59.40 \%$ & 251,457 \\
2021 & 427,515 & $59.40 \%$ & 253,944 \\
\hline
\end{tabular}

Nota. Elaboración propia

\subsubsection{Mercado Efectivo.}

Es una parte del mercado disponible que además de estar dispuesta en adquirir un producto saludable, tienen la intención de comprar nuestro producto, para ello se aplicará el porcentaje promedio resultante de las preguntas filtros número 10 y 11 de la encuesta realizada: 
10. ¿En cual de las presentaciones lo desearía adquirir?

De donde el $93.8 \%$ de los encuestados (361 encuestas) aceptan las presentaciones que se ofrecerá de 250 gr y 500 gr.

\section{1. ¿Cuánto pagarían por dicha presentación?}

De donde el $49.9 \%$ de los encuestados (189 encuestas) aceptan pagar por un precio de S/. 2.00 a más.

Se multiplicad a cada porcentaje la proporción de encuestas consideradas para su pregunta con respecto al total de encuestas consideradas de las preguntas 10 y 11 , y sumando ambos resultados se obtiene un porcentaje total de $78.68 \%$.

Este porcentaje será aplicado al mercado disponible para hallar el mercado efectivo para los años 2017 - 2021. (Ver Tabla 23)

\begin{tabular}{|c|c|c|c|}
\hline \multicolumn{4}{|c|}{$\begin{array}{l}\text { Mercado Efectivo en la Zona } 2 \text { de Lima } \\
\text { Metropolitana (expresado en habitantes) }\end{array}$} \\
\hline Año & $\begin{array}{c}\text { Mercado } \\
\text { Disponible }\end{array}$ & $\begin{array}{l}\% \text { Pregunta } \\
\text { filtro }\end{array}$ & $\begin{array}{l}\text { Mercado } \\
\text { Efectivo }\end{array}$ \\
\hline 2017 & 243,809 & $78.68 \%$ & 191,829 \\
\hline 2018 & 246,384 & $78.68 \%$ & 193,855 \\
\hline 2019 & 248,938 & $78.68 \%$ & 195,864 \\
\hline 2020 & 251,457 & $78.68 \%$ & 197,846 \\
\hline 2021 & 253,944 & $78.68 \%$ & 199,803 \\
\hline
\end{tabular}

Nota. Elaboración propia

\subsubsection{Mercado Objetivo.}

Por último, el mercado objetivo escogido para el presente proyecto está afectado por la capacidad operativa y de gestión de la empresa, por ello para el 
primer año de gestión, de un total de cinco que el presente proyecto plantea, se decide empezar con una oferta para el $2 \%$ del mercado efectivo dando como resultado la atención de 3,837 personas para este primer año, aumentando a razón de $2 \%$ por año la capacidad operativa, cifra que esta soportada por el cálculo proyectado del mercado objetivo apoyado por la estimación y proyección de población del 2000 al 2050 (INEI Boletín N³6). (Ver Tabla 24)

Tabla 24

Mercado Objetivo

Mercado Objetivo en la Zona 2 de Lima Metropolitana (expresado en habitantes)

\begin{tabular}{rrcr}
\hline Año & $\begin{array}{c}\text { Mercado } \\
\text { Efectivo }\end{array}$ & $\begin{array}{c}\text { \% de } \\
\text { estimación }\end{array}$ & $\begin{array}{r}\text { Mercado } \\
\text { Objetivo }\end{array}$ \\
\hline 2017 & 191,829 & $2 \%$ & 3,837 \\
2018 & 193,855 & $4 \%$ & 7,754 \\
2019 & 195,864 & $6 \%$ & 11,752 \\
2020 & 197,846 & $8 \%$ & 15,828 \\
2021 & 199,803 & $10 \%$ & 19,980 \\
\hline
\end{tabular}

Nota. Elaboración propia

\subsection{Pronóstico de Ventas}

El pronóstico de ventas tiene como base los datos referido al consumo per cápita de papa, $85 \mathrm{~kg}$ por persona al año (MINAGRI 2014). Asimismo, indica que cada persona consume un promedio de $1.6 \mathrm{Kg}$ semanalmente, en consecuencia, un consumo diario de 0.229 gr de papa por persona. Esta cifra servirá como parámetro de control a fin de que no exista una cifra de consumo no sustentada, además se apoyará con los resultados de la encuesta con lo que ayudará a determinar la frecuencia de consumo (pregunta $\mathrm{N}^{\mathrm{o}} 13$ de la encuesta), como también la cantidad de 
compra por tipo de producto ofertado (pregunta $\mathrm{N}^{\circ} 10$ de la encuesta), es así se podrá determinar lo siguiente:

1. El mercado objetivo obtenido representa la cantidad de personas que la empresa puede atender (3,837 personas en el primer año).

2. El $81.6 \%$ de este mercado objetivo estaría dispuesto a comprarlo una vez por semana o cada 15 días, mientras solo el $12.9 \%$ lo compraría de forma mensual y el 5.5\% bimestral, siendo de esta manera la frecuencia de compra del mercado objetivo afectada por todos estos resultados. (pregunta $\mathrm{N}^{\mathrm{o}} 13 \mathrm{de}$ la encuesta). (Ver Tabla 25)

\section{Tabla 25}

Según la pregunta 13 de la encuesta

13.- ¿Con que frecuencia compraría papa dializada?

\begin{tabular}{lcr}
\hline Semanal & 164 & $43.0 \%$ \\
Quincenal & 147 & $38.6 \%$ \\
Mensual & 49 & $12.9 \%$ \\
Bimestral & 21 & $5.5 \%$ \\
\hline & 381 & $100.00 \%$
\end{tabular}

Nota. Elaboración propia

3. Así también tenemos que, del mercado objetivo, según datos obtenidos de la encuesta realizada, el $65.2 \%$ prefiere comprar una presentación de 250 gr., mientras que el $28.6 \%$ prefiere una presentación de 500 gr, quedando solo el $6.2 \%$ los que prefieren una presentación mayor a 500 gr. (Pregunta $\mathrm{N}^{\mathrm{o}} 10 \mathrm{de}$ la encuesta). (Ver Tabla 26) 
Tabla 26

Según la pregunta 10 de la encuesta

\section{0.- ¿En cuál de estas presentaciones \\ lo desearía adquirir?}

\begin{tabular}{lcr}
\hline $250 \mathrm{gr}$ & 251 & $65.2 \%$ \\
$500 \mathrm{gr}$ & 110 & $28.6 \%$ \\
Mayor a $500 \mathrm{gr}$ & 24 & $6.2 \%$ \\
\hline & 385 &
\end{tabular}

Nota. Elaboración propia

4. Al combinar todas las variables antes indicadas permitirán saber

aproximadamente el consumo por cada una de las personas del mercado

objetivo según su intención de compra y la frecuencia de consumo,

obteniendo el promedio de compras al año (34.29 veces por año). (Ver Tabla

27)

Tabla 27

Según la pregunta 13 de la encuesta

\begin{tabular}{crrr} 
& Porcentaje & Compras al año & Promedio \\
\cline { 2 - 4 } Diario & $0.0 \%$ & 360 & \\
Semanal & $43.0 \%$ & 52 & 22.38 \\
Quincenal & $38.6 \%$ & 26 & 10.03 \\
Mensual & $12.9 \%$ & 12 & 1.54 \\
Bimestral & $5.5 \%$ & 6 & 0.33 \\
\cline { 2 - 4 } & \multicolumn{3}{c}{ Total }
\end{tabular}

Nota. Elaboración propia

Tabla 28

Cuantificación de la Demanda Proyectada

\begin{tabular}{|c|c|c|c|c|c|c|c|c|c|c|c|}
\hline \multirow{2}{*}{$\begin{array}{l}\text { Año } \\
2017\end{array}$} & \multirow{2}{*}{$\begin{array}{r}\text { Mercado } \\
\text { Objetivo }\end{array}$} & \multicolumn{2}{|c|}{$\begin{array}{c}\text { Producto } \\
\text { Bolsa } 500 \mathrm{gr} \\
\left.\text { Año ( } \mathrm{P} \mathrm{N}^{0} 10\right)\end{array}$} & \multicolumn{2}{|c|}{$\begin{array}{c}\text { Promedio de compras al } \\
\left.\text { año ( } \mathrm{P} \mathrm{N} \mathrm{N}^{\circ} 13\right)\end{array}$} & \multicolumn{2}{|c|}{$\begin{array}{c}\text { Producto } \\
\text { Bolsa } 250 \mathrm{gr} \\
\left.\text { Año (P } \mathrm{PN}^{\circ} 10\right)\end{array}$} & \multicolumn{2}{|c|}{$\begin{array}{l}\text { Promedio de compras al } \\
\left.\text { año ( } \mathrm{P} N^{0} 13\right)\end{array}$} & \multirow{2}{*}{$\begin{array}{l}\text { Total Kg } \\
40,256.21\end{array}$} & \multirow{2}{*}{$\begin{array}{r}\text { Total TN } \\
40.26\end{array}$} \\
\hline & & $28.60 \%$ & 1,097 & 34.29 & 37,625 & $65.20 \%$ & 2,501 & 34.29 & 85,775 & & \\
\hline 2018 & 7,754 & $28.60 \%$ & 2,218 & 34.29 & 76,045 & $65.20 \%$ & 5,056 & 34.29 & 173,361 & $81,362.85$ & 81.36 \\
\hline 2019 & 11,752 & $28.60 \%$ & 3,361 & 34.29 & 115,250 & $65.20 \%$ & 7,662 & 34.29 & 262,737 & $123,309.13$ & 123.31 \\
\hline 2020 & 15,828 & $28.60 \%$ & 4,527 & 34.29 & 155,221 & $65.20 \%$ & 10,320 & 34.29 & 353,861 & $166,075.99$ & 166.08 \\
\hline 2021 & 19,980 & $28.60 \%$ & 5,714 & 34.29 & 195,946 & $65.20 \%$ & 13,027 & 34.29 & 446,702 & $209,648.27$ & 209.65 \\
\hline
\end{tabular}

Nota. Elaboración propia 
Como se puede apreciar en tabla $\mathrm{N}^{\mathrm{o}} 28$ el total de toneladas a producir para el primer año será de 40.26, entre las dos presentaciones definidas en el presente plan de negocio, la cantidad de demanda proyectada tendrá un crecimiento promedio de 41 Tn por año, por último, se puede apreciar los kilos totales que la empresa deberá de producir para atender dicha demanda, la cual comenzará el primer año con un total de 40,256.21 kilos (40.26 Toneladas) y terminará en el quinto año con un total de 209,648.27 Kilos por año (209.65 Toneladas).

Para lograr una proyección más precisa, es necesario que la proyección antes mencionada en la tabla $\mathrm{N}^{\circ} 29$, esté afectada por las variaciones que la producción (factor exógeno) que tiene a lo largo del año, lo cual impactará en la cantidad a producir, así como también se deberá de tomar en cuenta la merma que existe durante el filtro de calidad al inicio, $3 \%$ de la compra del insumo y $2 \%$ del insumo después del proceso de pelado.

Tabla 29

Resumen de Ingreso al Mercado Mayorista de Lima Metropolitana

(expresado en tone ladas)

\begin{tabular}{|c|c|c|c|c|c|c|}
\hline & \multirow{3}{*}{$\begin{array}{l}\text { Promedio } \\
\text { Mensual } \\
\end{array}$} & \multirow{3}{*}{$\begin{array}{c}\text { Dif } \% \\
\text { P General }\end{array}$} \\
\hline \multirow{2}{*}{ Meses } & \multicolumn{4}{|c|}{ Años } & & \\
\hline & 2012 & 2013 & 2014 & 2015 & & \\
\hline Enero & 45.527 & 31.658 & 36.073 & 43.719 & 39.244 & $-3,10 \%$ \\
\hline Febrero & 42.240 & 37.569 & 33.128 & 41.829 & 38.692 & $-4,46 \%$ \\
\hline Marzo & 47.593 & 40.071 & 43.673 & 48.237 & 44.894 & $10,85 \%$ \\
\hline Abril & 43.565 & 37.326 & 42.813 & 45.510 & 42.304 & $4,46 \%$ \\
\hline Mayo & 46.617 & 35.762 & 42.314 & 47.062 & 42.939 & $6,02 \%$ \\
\hline Junio & 43.900 & 32.156 & 38.841 & 43.310 & 39.552 & $-2,34 \%$ \\
\hline Julio & 46.205 & 33.557 & 43.916 & 47.049 & 42.682 & $5,39 \%$ \\
\hline Agosto & 45.667 & 35.338 & 45.319 & 45.052 & 42.844 & $5,79 \%$ \\
\hline Septiembre & 40.546 & 34.374 & 41.285 & 43.138 & 39.836 & $-1,64 \%$ \\
\hline Octubre & 32.492 & 37.693 & 44.055 & 43.549 & 39.447 & $-2,60 \%$ \\
\hline Noviembre & 33.336 & 36.447 & 40.141 & 38.360 & 37.071 & $-8,46 \%$ \\
\hline Diciembre & 25.779 & 36.681 & & 42.441 & 34.967 & $-13,66 \%$ \\
\hline Total & 493.467 & 428.632 & 451.558 & 529.256 & 484.470 & \\
\hline Promedie General & 41.122 & 35.719 & 41.051 & 44.105 & 40.499 & \\
\hline Credimiente Anual & & $-13,14 \%$ & $\mathbf{5 , 3 5} \%$ & $17,21 \%$ & & \\
\hline
\end{tabular}

Nota. Elaboración propia - Fuente SISAP - Ministerio de Agricultura (MINAGRI) 
Como se puede apreciar en la tabla 30, se ha recolectado los volúmenes (expresado en toneladas) de papa ingresados en el Mercado Mayorista de Lima Metropolitana, logrando identificar los promedios de ingreso por mes y por año, resultado que servirá para identificar los meses que están por debajo de la producción promedio mensual y aquellos que se encuentran por encima de esta media, como se aprecia en la figura $\mathrm{N}^{\circ} 46$.

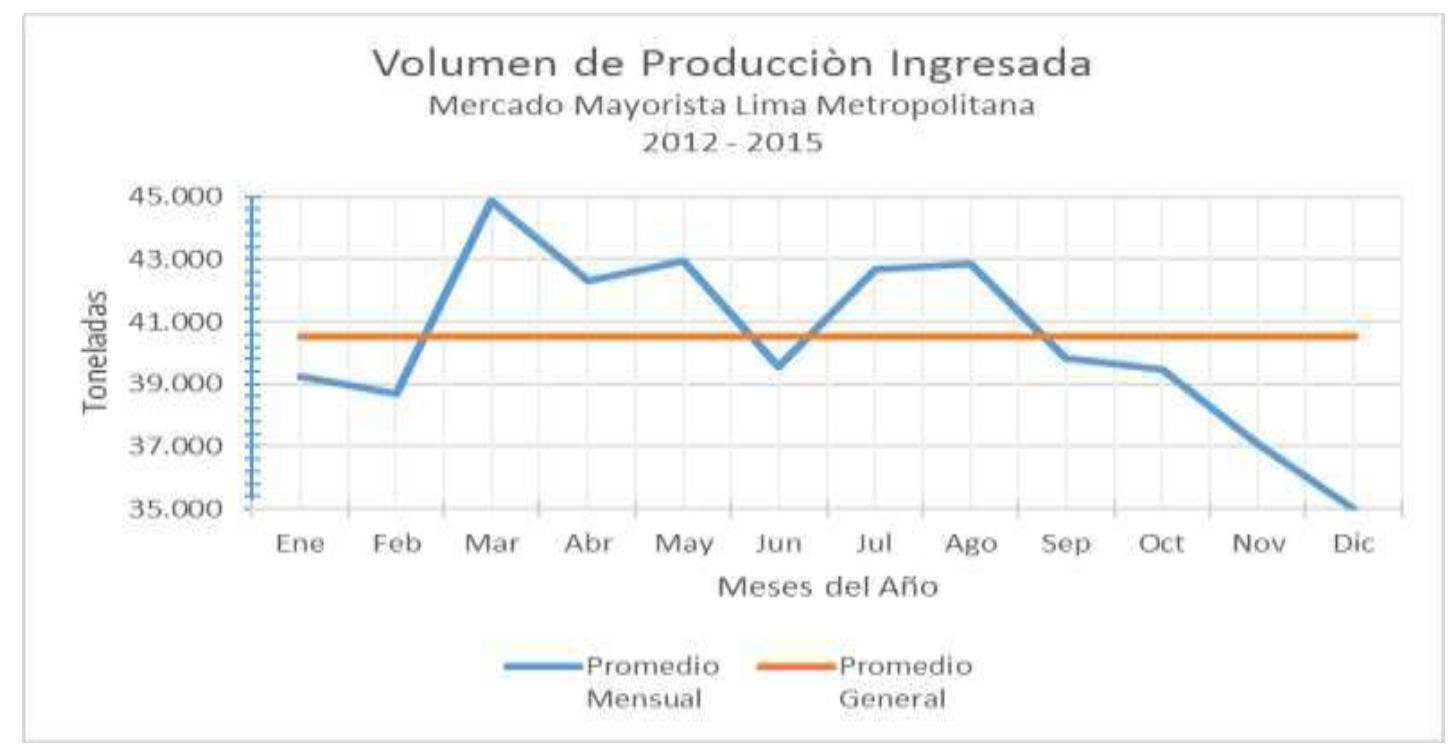

Figura 46. Volumen de Producción Ingresada - Mercado Mayorista

En la tabla $\mathrm{N}^{\circ} 29$, se puede observar la columna denominada Dif. \% del porcentaje general, la cual representa la variación con respecto al promedio general del volumen de producción que llega al mercado mayorista en Lima Metropolitana, y que servirá para la proyección de producción y ventas a realizar entre el 2017 y 2021. 
Tabla 30

Programa Mensual Proyectado de Producción y Ventas

Programa mensual de ventas por KILOS 2017

\begin{tabular}{lrccc}
\hline \multicolumn{1}{c}{ Meses } & $\begin{array}{c}\text { \% Ventas } \\
\text { regulares }\end{array}$ & $\begin{array}{c}\text { \% Logro } \\
\text { de ventas }\end{array}$ & \% ventas & $\begin{array}{c}\text { Ventas } \\
\text { Totales }\end{array}$ \\
\hline Enero & $8.10 \%$ & $85 \%$ & $6.9 \%$ & $2,771.75$ \\
Febrero & $7.99 \%$ & $85 \%$ & $6.8 \%$ & $2,732.85$ \\
Marzo & $9.27 \%$ & $85 \%$ & $7.9 \%$ & $3,170.78$ \\
Abril & $8.73 \%$ & $85 \%$ & $7.4 \%$ & $2,988.00$ \\
Mayo & $8.86 \%$ & $85 \%$ & $7.5 \%$ & $3,032.62$ \\
Junio & $8.16 \%$ & $85 \%$ & $6.9 \%$ & $2,793.49$ \\
Julio & $8.81 \%$ & $85 \%$ & $7.5 \%$ & $3,014.60$ \\
Agosto & $8.84 \%$ & $85 \%$ & $7.5 \%$ & $3,026.04$ \\
Septiembre & $8.22 \%$ & $85 \%$ & $7.0 \%$ & $2,813.51$ \\
Octubre & $8.14 \%$ & $85 \%$ & $6.9 \%$ & $2,786.05$ \\
Noviembre & $7.65 \%$ & $85 \%$ & $6.5 \%$ & $2,618.43$ \\
Diciembre & $7.22 \%$ & $85 \%$ & $6.1 \%$ & $2,469.69$ \\
\hline \hline Total & $100.00 \%$ & & $85.0 \%$ & $34,217.78$ \\
\hline Nota Elaboración propia & &
\end{tabular}

Como se aprecia en la tabla $\mathrm{N}^{\circ} 31$, se puede encontrar el porcentaje de proyección de ventas regulares, la que se encuentra en proporción con la producción que ingresa al mercado mayorista, este factor afectará al porcentaje que el presente proyecto busca lograr para el primer año, considerando que por ser un producto aún desconocido la empresa mantendrá un perfil conservador y buscará lograr el 85\% de la meta propuesta. Mostrándose el porcentaje de ventas por mes, permitiendo así establecer la proyección de ventas mensuales para el año 2017, el cual se mantendrá durante los próximos años de proyección (Ver Tabla 31). 
Tabla 31

Programa mensual de ventas proyectadas - 2018 al 2021

Programa mensual de ventas por KILOS 2018 al 2021

\begin{tabular}{|c|c|c|c|c|c|}
\hline Meses & $\begin{array}{c}\% \text { de } \\
\text { Ventas }\end{array}$ & 2018 & 2019 & 2020 & 2021 \\
\hline Enero & $8.10 \%$ & 6,591 & 9,988 & 13,453 & 16,982 \\
\hline Febrero & $7.99 \%$ & 6,498 & 9,848 & 13,264 & 16,744 \\
\hline Marzo & $9.27 \%$ & 7,539 & 11,426 & 15,389 & 19,427 \\
\hline Abril & $8.73 \%$ & 7,105 & 10,768 & 14,502 & 18,307 \\
\hline Мayo & $8.86 \%$ & 7,211 & 10,929 & 14,719 & 18,580 \\
\hline Junio & $8.16 \%$ & 6,642 & 10,067 & 13,558 & 17,115 \\
\hline Julio & $8.81 \%$ & 7,168 & 10,864 & 14,631 & 18,470 \\
\hline Agosto & $8.84 \%$ & 7,195 & 10,905 & 14,687 & 18,540 \\
\hline Septiembre & $8.22 \%$ & 6,690 & 10,139 & 13,655 & 17,238 \\
\hline Octubre & $8.14 \%$ & 6,625 & 10,040 & 13,522 & 17,070 \\
\hline Noviembre & $7.65 \%$ & 6,226 & 9,436 & 12,709 & 16,043 \\
\hline Diciembre & $7.22 \%$ & 5,872 & 8,900 & 11,987 & 15,131 \\
\hline Total & $100 \%$ & 81,363 & 123,309 & 166,076 & 209,648 \\
\hline
\end{tabular}

Nota. Elaboración propia

Finalmente se presenta el proyectado de las ventas a realizar por año y el total general de los 5 años de gestión proyectada. (Ver Tabla 32) 
Tabla 32

Proyección de Ventas Mensual 2018- 2021

Programa mensual de ventas por KILOS 2017 al 2021

\begin{tabular}{|c|c|c|c|c|c|c|}
\hline Meses & 2017 & 2018 & 2019 & 2020 & 2021 & $\begin{array}{c}\text { Total } \\
\text { General }\end{array}$ \\
\hline Enero & 2,772 & 6,591 & 9,988 & 13,453 & 16,982 & 49,786 \\
\hline Febrero & 2,733 & 6,498 & 9,848 & 13,264 & 16,744 & 49,087 \\
\hline Marzo & 3,171 & 7,539 & 11,426 & 15,389 & 19,427 & 56,953 \\
\hline Abril & 2,988 & 7,105 & 10,768 & 14,502 & 18,307 & 53,670 \\
\hline Mayo & 3,033 & 7,211 & 10,929 & 14,719 & 18,580 & 54,471 \\
\hline Junio & 2,793 & 6,642 & 10,067 & 13,558 & 17,115 & 50,176 \\
\hline Julio & 3,015 & 7,168 & 10,864 & 14,631 & 18,470 & 54,148 \\
\hline Agosto & 3,026 & 7,195 & 10,905 & 14,687 & 18,540 & 54,353 \\
\hline Septiembre & 2,814 & 6,690 & 10,139 & 13,655 & 17,238 & 50,536 \\
\hline Octubre & 2,786 & 6,625 & 10,040 & 13,522 & 17,070 & 50,043 \\
\hline Noviembre & 2,618 & 6,226 & 9,436 & 12,709 & 16,043 & 47,032 \\
\hline Diciembre & 2,470 & 5,872 & 8,900 & 11,987 & 15,131 & 44,360 \\
\hline Total & 34,218 & 81,363 & 123,309 & 166,076 & 209,648 & 614,614 \\
\hline \multicolumn{2}{|c|}{ Crecimiento Anual } & $137.78 \%$ & $51.55 \%$ & $34.68 \%$ & $26.24 \%$ & \\
\hline \multicolumn{2}{|c|}{ Crecimiento Acumulado $P$} & $137.78 \%$ & $260.37 \%$ & $385.35 \%$ & $512.69 \%$ & \\
\hline \multicolumn{2}{|c|}{ Participación } & $13.24 \%$ & $20.06 \%$ & $27.02 \%$ & $34.11 \%$ & \\
\hline
\end{tabular}

\subsection{Aspectos críticos que impactan el pronóstico de ventas}

Los cambios que puede experimentar la producción del producto a comercializar pueden generar cambios drásticos si algunos de estos son muy extremos y estos se pueden dar por las siguientes condiciones:

1. Efectos por el "Fenómeno del Niño"

Esto dado por los aumentos de temperatura del mar, el cual inicia hacia el final del mes de diciembre y puede durar varios meses (hasta tres meses), este desbalance de la naturaleza puede cuásar problemas en las cosechas, población y en el transporte, principalmente en la costa del Perú, esto podría afectar el abastecimiento normal del productos dando como consecuencia el tener que bajar los niveles de comercialización en los últimos meses del año, siendo la contingencia otras zonas productoras que pueden abastecer nuestra producción. 
2. Problemas en el Transporte

Este problema está enfocado básicamente a problemas de bloqueos de carreteras por disturbios y/o desastres naturales lo que haría casi imposible llegar a tiempo el abastecimiento para la capital de Lima Metropolitana, pero existen otras zonas productivas de las cuales podemos obtener el producto.

3. Cambios en la normativa sanitaria

Este punto básicamente dado por alertas de contaminadores o riesgos de plagas, dando como consecuencia que el gobierno pueda endurecer las normas de producción, recolección y venta del producto ofertado teniendo que adaptarnos rápidamente a los cambios generados. 


\section{Capítulo V: Ingeniería del Proyecto}

\subsection{Estudio de ingeniería}

El presente estudio de ingeniería tendrá como objetivo obtener el resultado optimizado del proceso productivo, así como también de la utilización de los recursos necesarios para lograr nuestro producto final a través de un uso eficiente de todos los insumos que intervienen en este proceso.

A través de un análisis de las diferentes opciones y condiciones para lograr una optimización de nuestro proceso productivo se originará el estudio de ingeniería, la misma que definirá los requerimientos de equipos y maquinarias y sus características de estas, finalmente también se determinará el ambiente necesario para su implementación y/o disposición en planta (layout).

\subsubsection{Modelamiento y selección de procesos productivos}

El modelo y esquema del proceso productivo, busca mostrar a todos los integrantes de la cadena productiva los cuales se mencionan en la siguiente lista:

1. Proceso de pelado de la papa

2. Proceso de control de calidad

3. Proceso de conservación y refrigeración

4. Proceso de dialización

5. Proceso de conservación post dialización

6. Proceso de corte, Empaque y sellado del producto final

El esquema está representado en la figura $\mathrm{N}^{\circ} 47$ la cual describe con precisión el proceso para la fabricación de la papa dializada 


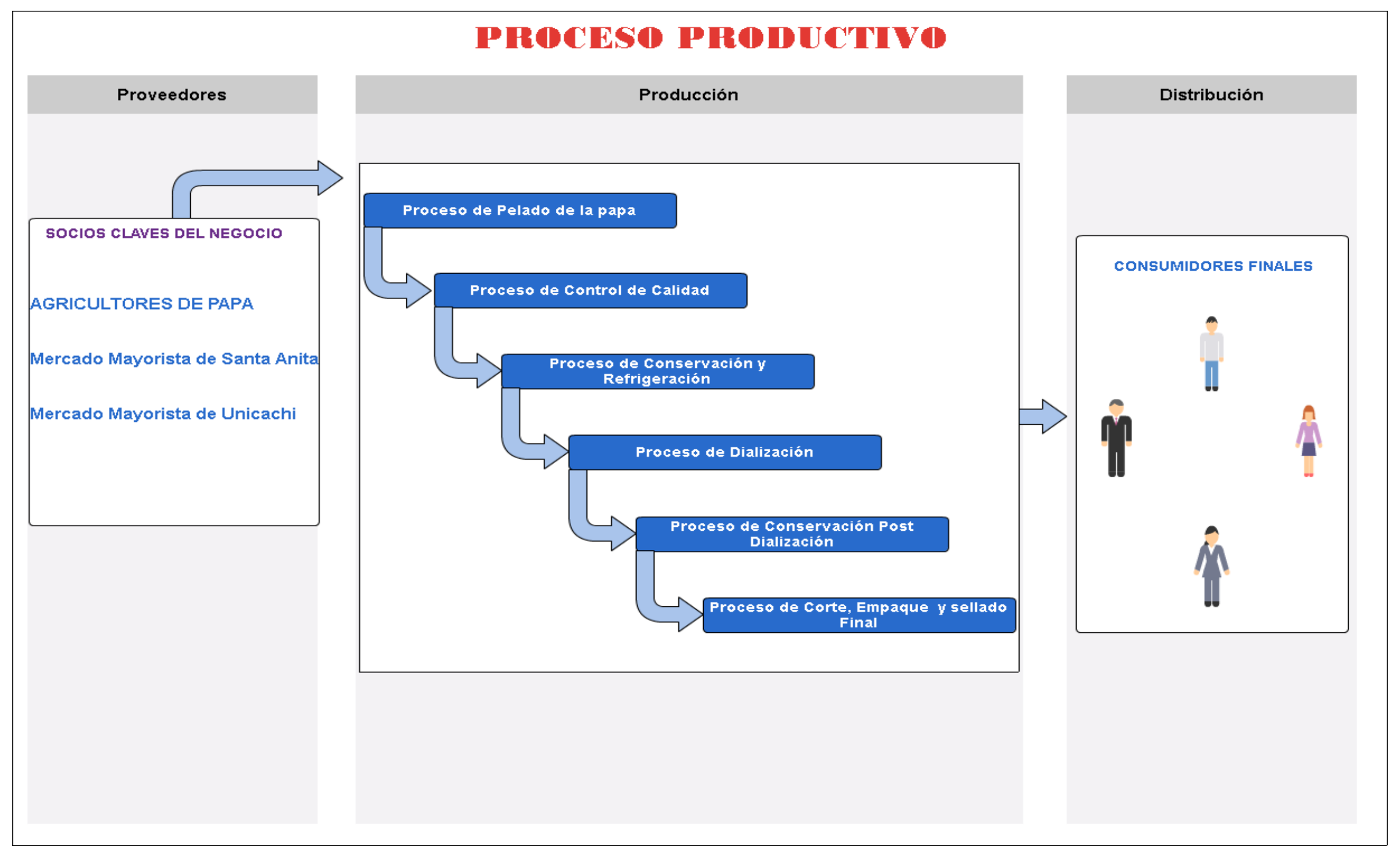

Figura 47. Proceso para la fabricación de la papa dializada, diseño propio 


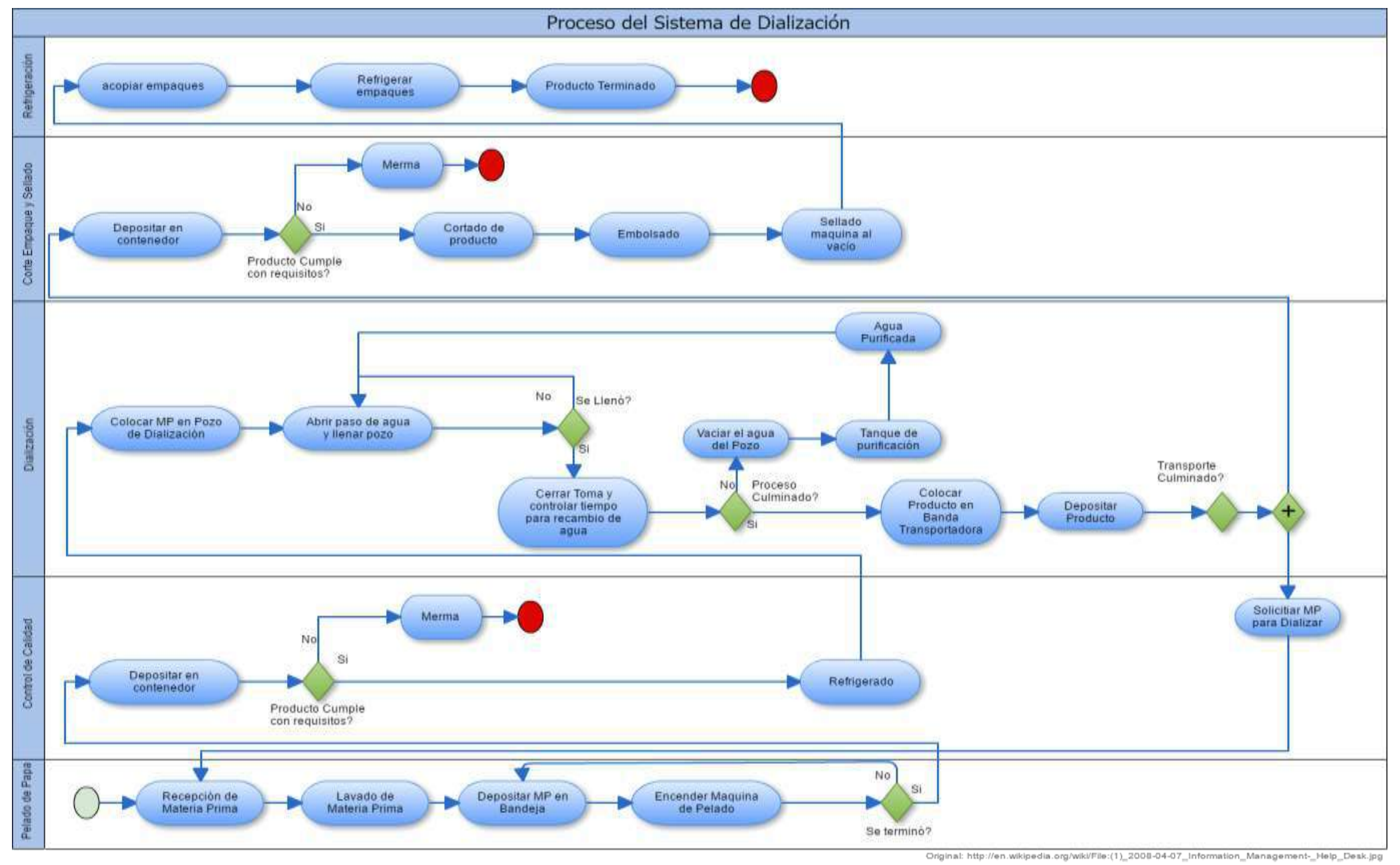

Figura 48. Proceso de la papa para cumplir ciclo de producción, diseño propio 
A continuación, se describirá cada uno de los procesos indicados en el figura $\mathrm{N}^{\circ}$ 48, la cual explica el proceso de la papa para cumplir ciclo de producción:

\section{Recepción de materia prima}

Como materia prima tenemos la papa, del tipo perricholi, la que será tomada desde el almacén de la empresa, el objetivo es que el proceso de dialización llegue a obtener 1,200 kilogramos de papa sin considerar la merma.

\section{Lavado de materia prima}

La papa pasará por un proceso de lavado en una poza con agua potable, quedando limpia y solo cubierta por su cascará natural.

\section{Depositar materia prima en bandeja}

Los operarios de la empresa llevarán la papa, hacia el depósito de la máquina peladora, en jaba, para comenzar el proceso de pelado.

\section{Encender máquina de pelado}

La máquina de pelado comenzará a realizar su trabajo, bajo la supervisión de un operario, quien se encargará de controlar el correcto funcionamiento y al finalizar cada lote, solicitará el siguiente lote a depositar en la bandeja de la máquina de pelado, todo ello hasta completar la totalidad de papa a dializar en el proceso de producción.

\section{Depositar en contenedor}

Habiendo culminado la máquina peladora, el pelado de cada lote de papa, el operario trasladará, mediante jabas, hacia un depósito donde se acumulará el papa, es aquí que un personal de control de calidad verificará su buen estado y 
decidirá cual continúa con el proceso y cual será considerada como merma, aquel producto que continúa con el proceso, será trasladado en jabas mediante stoka hacía la cámara frigorífica.

\section{Refrigerado}

Dentro de la cámara frigorífica, en un ambiente identificado como productos pre dializados, la papa reposará esperando acumular el total que se necesita para la producción del día, esto se hace con la finalidad de evitar que la papa pueda oxidarse previo al proceso de dialización.

\section{Depositar materia prima en pozo de dialización}

Habiéndose acumulado el total de papa que se necesita para el proceso del día, esta será trasladada hasta la posa dializadora, la que es capaz de acumular un peso de 3,000 kilogramos en total, esto será cubierto por 1,200 kilogramos de papa y la diferencia lo cubre el agua que se necesita para la dialización, 250 litros.

\section{Abrir paso de agua y llenar pozo}

El agua es un suministro principal en el proceso de dialización, esta será vertida en la poza dializadora cubriendo en su totalidad la papa que ha sido depositada previamente.

\section{Cerrar toma y controlar el tiempo para recambio de agua}

La máquina dializadora, deberá controlar, mediante sensor, que la poza tiene la cantidad suficiente de agua para empezar con el proceso, habiendo detectado ello, automáticamente se cerrará la toma de agua y comenzará con el proceso, esto dura un total de 24 horas, incluyendo los tiempos de recambios de 
agua que serán cada 5 horas 30 minutos, este tiempo de recambio de agua se estima que es de 30 minutos aproximadamente.

\section{Vaciar el agua del pozo}

Esto se realiza en cada recambio de agua, la tarea es vaciar totalmente el agua acumulada en la poza dializadora y llevarlo hacia un tanque que acumulará toda esta agua utilizada en el proceso.

\section{Purificar el agua}

Dentro del tanque que contiene el agua utilizada en cada proceso de dialización, mediante un filtro de purificación de agua se eliminará los minerales que se han obtenido del proceso.

\section{Agua purificada}

El agua purificada será nuevamente utilizada en el proceso y será llevada hacia la poza dializadora.

\section{Colocar producto en banda transportadora}

Al culminar con el proceso de dialización, la papa se trasladará mediante una banda transportadora, la que tendrá a la vez la tarea de limpiar la papa, es por ello que la banda deberá tener canales que rocíen agua en sus extremos laterales.

\section{Depositar producto}

La banda transportadora se encarga de depositar el producto en bandejas para su posterior inspección. El encargado de este proceso, será quien informe la culminación satisfactoria del proceso de dialización e indicará que la máquina se encuentra disponible para el siguiente proceso de producción. 


\section{Depositar en contenedor}

Habiendo acumulado toda la papa dializada, el operario de control de calidad se encargará de realizar la segunda inspección del tubérculo y determinará cual es el continúa con el proceso y cual será considerado como merma.

\section{Cortado de producto}

Este proceso se encarga de cortar la papa, en formas que el cliente haya solicitado, los cortes serán de dos tipos:

- Corte largo.

- Corte en rodajas.

\section{Embolsado}

El embolsado del producto será en dos presentaciones:

1. En bolsa de 250 gramos.

2. En bolsa de 500 gramos.

Este tipo será en base al tipo de solicitudes que realice los intermediarios, para despachar contra orden de compra.

\section{Sellado maquina al vacío.}

El sellado al vacío se realizará con la finalidad de conservar por más tiempo el producto, esto solo se va a realizar a las bolsas de $0.25 \mathrm{~kg}$. y $0.50 \mathrm{~kg}$.

\section{Acopiar empaques}

Todos los productos serán acumulados en jabas, de acuerdo a su tamaño previo a su traslado a la cámara frigorífica. 


\section{Refrigerar empaques}

El producto sellado será refrigerado en las cámaras frigoríficas en un ambiente denominado productos post dialización a la espera de su despacho.

\section{Producto terminado}

El producto terminado es aquel que ya está listo para su despacho hacia el nuestro canal indirecto, casas naturistas, minimarkets, tienes de alimentos orgánicos.

La Figura $N^{\circ} 49$, mostrará la descripción del proceso de administración, el cual tendrá la siguiente descripción. 


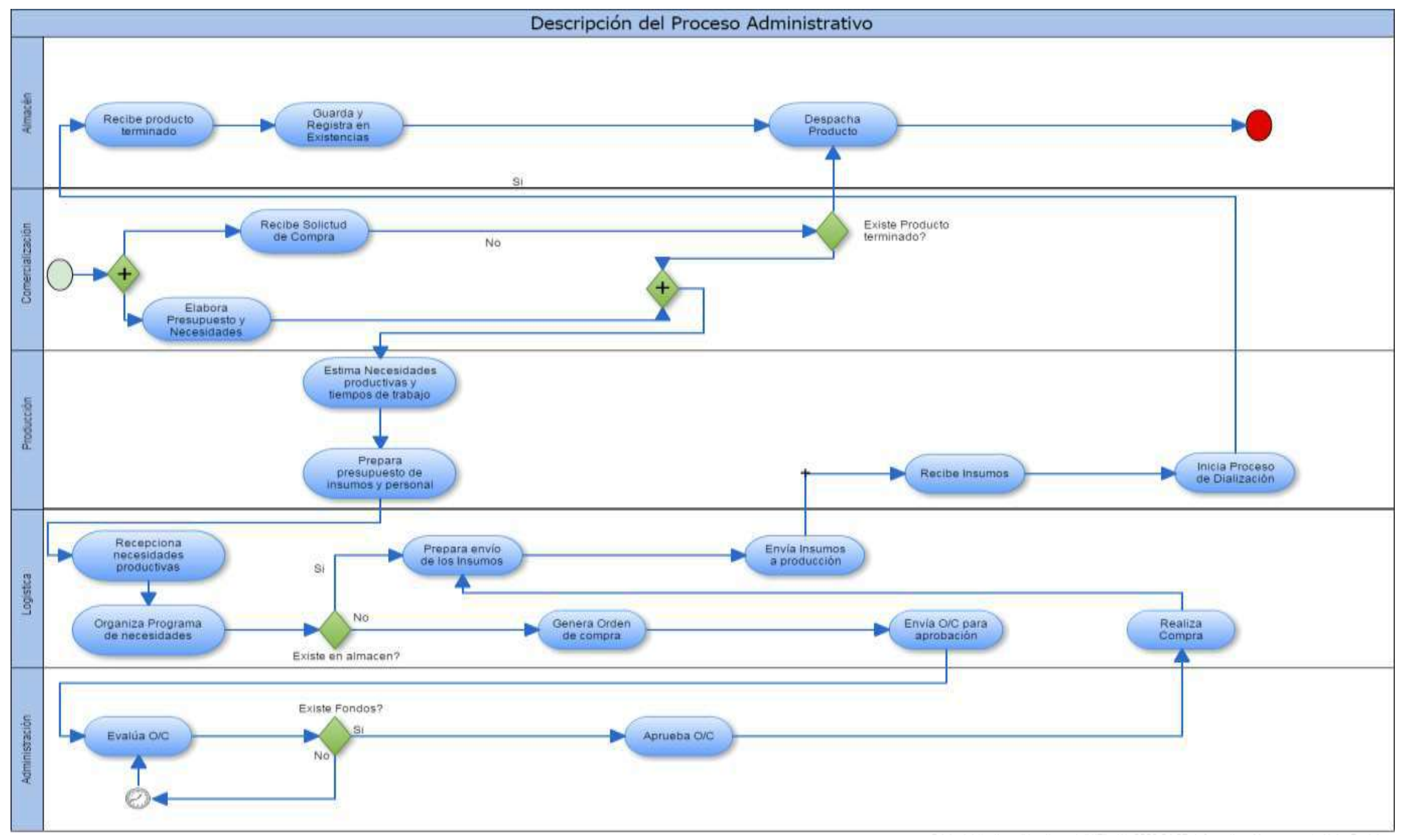

Figura 49. Descripción del Proceso Administrativo, diseño propio 
1. Administración

Establece los objetivos de la organización y coordina con las demás áreas funcionales de la empresa.

2. Logística

Genera compra de la materia prima según las necesidades de la organización, coordinando las necesidades con el área de producción.

3. Producción

Es el área encargada de estimar:

a. Necesidades productivas y tiempos de producción.

b. Preparar el presupuesto de los insumos requeridos y el personal necesario para la producción.

c. Responsable del proceso productivo y del control de calidad en la transformación de la papa en un producto dializado.

4. Comercialización

Área responsable de elaborar el presupuesto de las necesidades comerciales de la empresa, así mismo la encargada de atender los requerimientos de compra de parte de los clientes.

5. Almacén

Organiza y administra el almacenamiento del producto final, cumpliendo las siguientes tareas:

a. Recepción de materia prima y producto terminado

b. Registro de entradas y salidas del almacén.

c. Almacenamiento de materiales e insumos.

d. Mantenimiento de materiales y almacén.

a. Despacho de materiales e insumos. 
b. Coordinación del almacén con las áreas encargadas de control de inventarios y contabilidad.

\subsubsection{Selección del equipamiento}

\section{Máquina de pelado de papas}

En la figura $\mathrm{N}^{\circ} 50$, se describe el equipo el cual es el primero en nuestro proceso productivo, la especificación técnica del equipo está descrito bajo las siguientes características:

Detalles Técnicos

1. Capacidad $=10 \mathrm{~kg}$.

2. Producción $=150 \mathrm{~kg}$. por hora.

3. Voltaje $=220$ Voltios.

4. Potencia $=1 \mathrm{hp}$

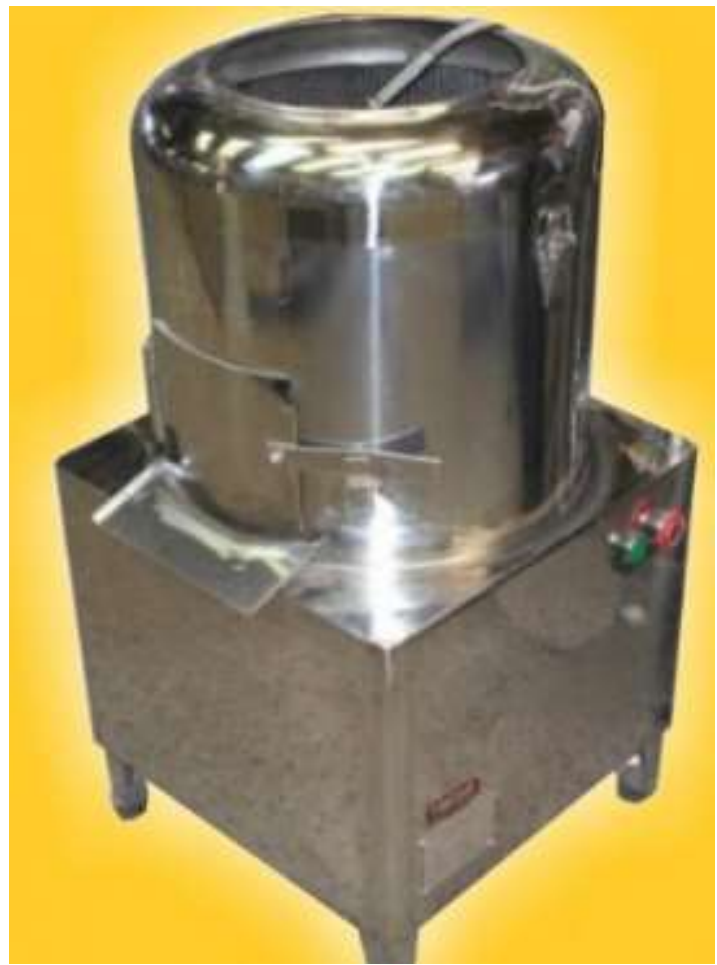

Figura 50. Máquina peladora de papa

Tomado de http://www. http://gastroequipos.com/ 


\section{Sistema de conservación y refrigeración}

Para el proceso de conservación del producto se necesitará de un sistema de refrigeración, la cual se muestra en la figura $\mathrm{N}^{\circ} 51$ el cual debe de tener las siguientes características:

Detalles técnicos

1. Cámara frigorífica desmontable, de $600 \mathrm{~cm}$ de largo x $300 \mathrm{~cm}$ de ancho $\mathrm{x}$ $200 \mathrm{~cm}$ de alto.

2. Termómetro indicador análogo

3. Puerta refrigerada, tipo corrediza con accionamiento manual.

4. Material con resistencia a impactos con alta durabilidad.

5. Colgadores y accesorios de sujeción al techo.

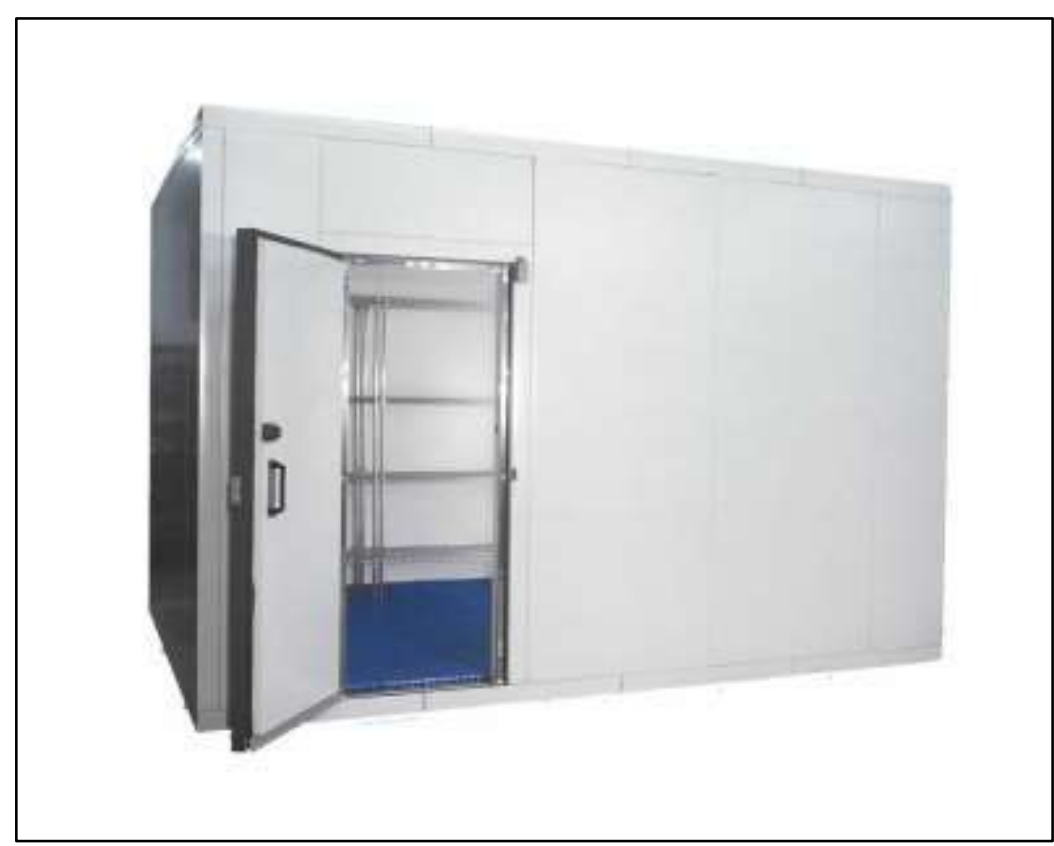

Figura 51. Cámara frigorífica

Tomado de. http://ciredeksa.cl/ 


\section{Sistema de bandas transportadoras}

Con la finalidad de agilizar el traslado del producto, se requiere la adquisición de fajas transportadoras la cual se indica en la figura $\mathrm{N}^{\circ} 52$ bajo las siguientes características:

1. Dos bandas transportadoras de PVC

2. Capacidad para soportar 20 kilogramos mínimo

3. Velocidad de $0.5 \mathrm{~m} / \mathrm{s}-1 \mathrm{~m} / \mathrm{s}$

4. Ancho de la línea $1000 \mathrm{~mm}$

5. Motor (con engranaje) reductor de 3 fases, $400 \mathrm{v} / 50 \mathrm{~Hz}$

6. Andamiaje en hoja plegada de acero con una altura de 10.2 ',

7. Convertidor de frecuencia para el control de velocidad

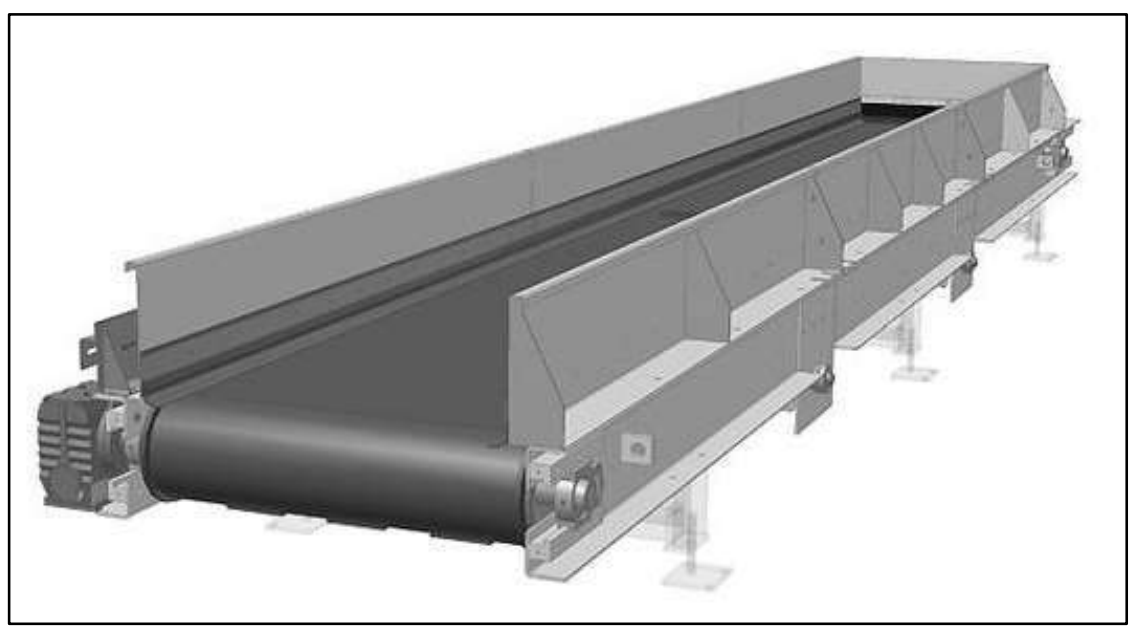

Figura 52. Banda Transportadora

Tomado de. http://www.axmann-fs.com/ 


\section{Máquina de empaque al vacío}

Como muestra la figura $\mathrm{N}^{\circ} 53$, esta máquina sirve para darle un mayor tiempo de duración al producto, con el mismo se empaquetará al vacío, esta máquina cumplirá esta función, sus características son las siguientes:

Detalles técnicos

1. Dimensiones cámara

2. Dimensiones máquina

3. Longitud de barra de soldadura $=2 \times 620 \mathrm{~mm}$

4. Capacidad de la bomba

5. Ciclo de la maquina
$=750 \times 620 \times 250 \mathrm{~mm}(\mathrm{~L} \times \mathrm{An} \times \mathrm{Al})$

$=1150 \times 1545 \times 1180 \mathrm{~mm}(\mathrm{~L} \times \mathrm{An} \times \mathrm{Al})$

$=160 \mathrm{~m} 3 / \mathrm{h}$

$=15-45 \mathrm{sec}$.

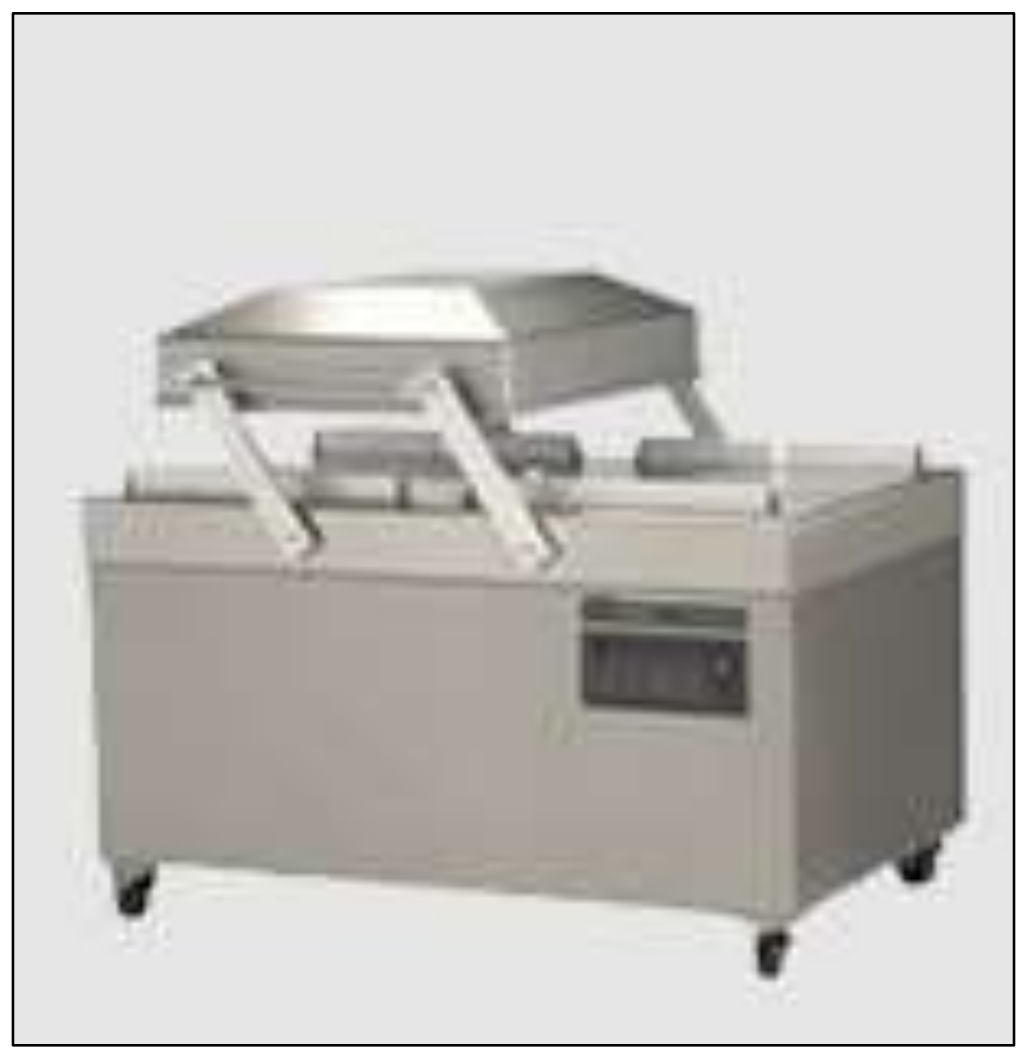

Figura 53. Máquina de empaque al vacío

Tomado de http://www.quickpackperu.com/EMPAQUE.html 


\section{Máquina de cortado}

Para las ventas en las diferentes presentaciones se requiere de una máquina especial para dar la forma al producto final, esta máquina contiene diversas cuchillas con las que se dará forma al producto, la misma se muestra en la figura $\mathrm{N}^{\circ} 54$, haciéndolo más atractivo para el mercado objetivo.

Detalles técnicos

1. Sistema de acero inoxidable

2. Corte centrífugo de cuchillas

3. Cortes fritas, rodajas y ondulados

4. Sistema de seguridad

5. Cuadro eléctrico incluido

6. Portátil

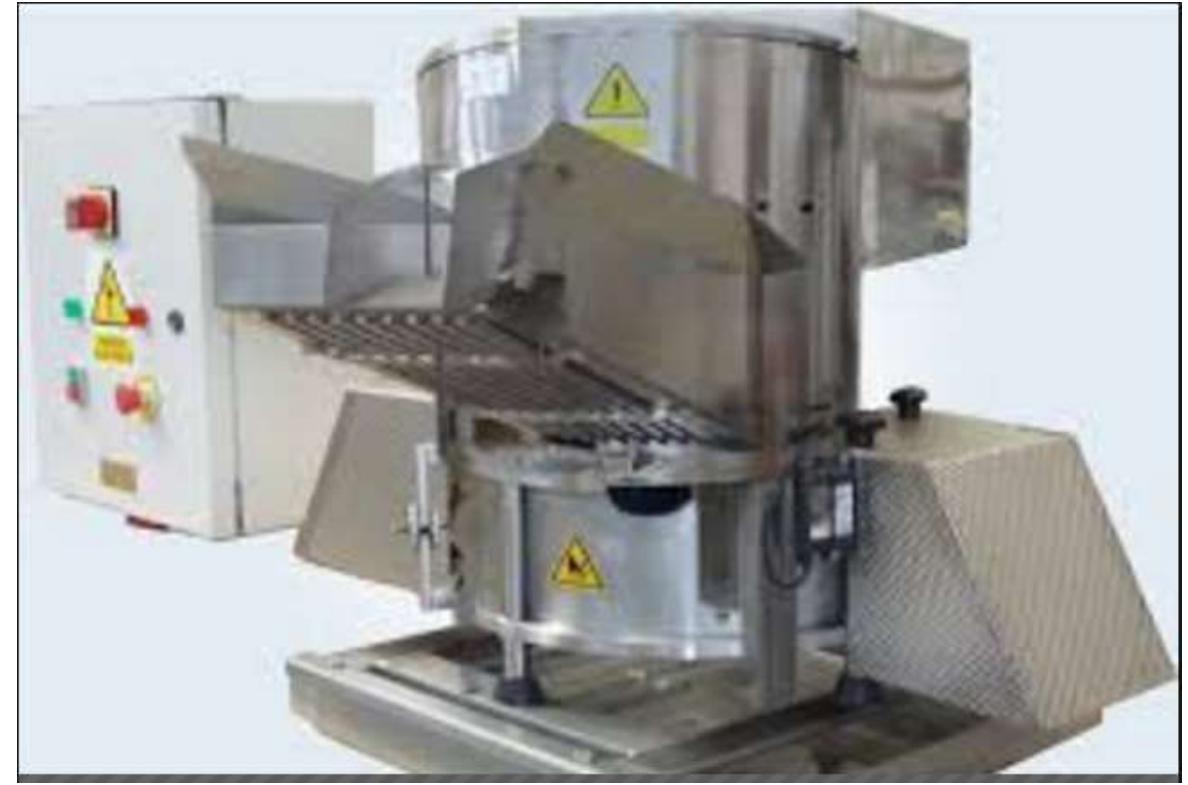

Figura 54. Máquina de cortado de papas Tomado de "http://www.solostocks.com/ventaproductos/equipamientos-hoteles-restaurantes/hornos-equipamientococina-industrial/cortador-de-patata-y-hortalizas-industrial-19173153" 


\section{Máquina de dialización}

Máquina principal que, mediante un proceso de inmersión en agua la papa podrá disminuir su nivel de potasio, esta máquina diagramada en la figura $\mathrm{N}^{\circ} 55$ está diseñada para un proceso de producción en masa, sus especificaciones son las siguientes:

Detalles técnicos

1. Peso seco

2. Capacidad máxima

3. Peso bruto

4. Sistema de control de peso

5. Sistema de control de tiempo

6. Sistema de entrada y salida de agua
$=100 \mathrm{~kg}$ aprox .

$=1200 \mathrm{~kg}$ (sin incluir agua).

$=1600 \mathrm{~kg}$ (incluyendo agua)

$=$ en toneladas

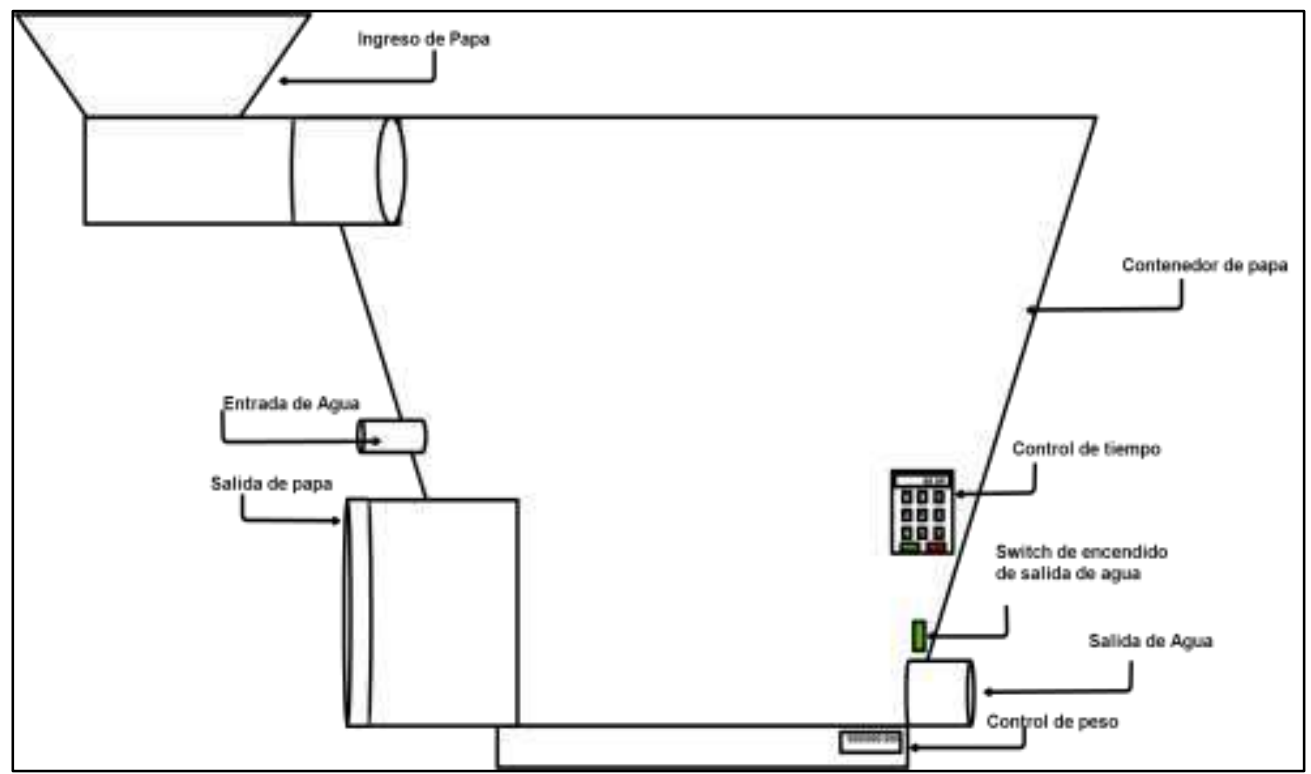

Figura 55. Máquina de dialización de papa, desarrollo propio 
El presupuesto del equipamiento se muestra en la tabla $\mathrm{N}^{\circ} 33$, la cual

indica el presupuesto del equipamiento necesario en la producción:

Tabla 33

Presupuesto del equipamiento necesario en la producción

Empresa CODIAL S.A.C.

\begin{tabular}{lrrrrr}
$\begin{array}{c}\text { Descripción de los } \\
\text { Equipos y Materiales }\end{array}$ & Cantida & $\begin{array}{c}\text { Precio } \\
\text { Unitario }\end{array}$ & \multicolumn{1}{c}{$\begin{array}{c}\text { Costo } \\
\text { Total }\end{array}$} & \multicolumn{1}{c}{ IGV } & $\begin{array}{c}\text { Total } \\
\text { Con IGV }\end{array}$ \\
\hline Pelador de Papas (20 Kg/ Min) & 1 & $2,288.14$ & $2,288.14$ & 411.86 & $2,700.00$ \\
Poza Dializadora & 1 & $1,694.92$ & $1,694.92$ & 305.08 & $2,000.00$ \\
Maquina Envasado al Vacio & 1 & $7,627.12$ & $7,627.12$ & $1,372.88$ & $9,000.00$ \\
Maquina cortadora de papa & 1 & $3,423.16$ & $3,423.16$ & 616.17 & $4,039.33$ \\
Banda Transportadora & 1 & $4,480.50$ & $4,480.50$ & 806.49 & $5,286.99$ \\
Bolsas para empaque de 500 grm & 100 & 0,35 & 35.00 & 6.30 & 41.30 \\
Bolsas para empaque de 250 grm & 100 & 0.30 & 30.00 & 5.40 & 35.40 \\
Botas Industriales para Agua & 4 & 20,00 & 80.00 & 14.40 & 94.40 \\
Mandiles Protectores & 4 & 45.00 & 180.00 & 32.40 & 212.40 \\
Mascarrillas & 4 & 5.08 & 20.34 & 3.66 & 24.00 \\
Guantes & 4 & 9.32 & 37.29 & 6.71 & 44.00 \\
Gorros y Protectores & 4 & 18.64 & 74.58 & 13.42 & 88.00 \\
Uniforme de Trabajo & 4 & 22.03 & 88.14 & 15.86 & 104.00 \\
Camioneta para ventas & 1 & $30,576.27$ & $30,576.27$ & $5,503.73$ & $36,080.00$ \\
Filtro & 1 & 203.39 & 203.39 & 36.61 & 240.00 \\
Cámara frigorífica & 1 & $205,865.96$ & $205,865.96$ & $37,055.87$ & $242,921.83$ \\
Jabas 15 Its área de empaque & 150 & 25.00 & $3,750.00$ & 675.00 & $4,425.00$ \\
Jabas 15 Its área de conservación & 150 & 25.00 & $3,750.00$ & 675.00 & $4,425.00$ \\
Jabas 15 Its área de despacho & 150 & 25.00 & $3,750.00$ & 675.00 & $4,425.00$ \\
stoka & 2 & $1,640.00$ & $3,280.00$ & 590.40 & $3,870.40$ \\
\hline & & $257,995.19$ & $271,234.79$ & $48,822.26$ & $320,057.05$
\end{tabular}

Nota. Elaboración propia. 


\subsubsection{Layout}

Las dimensiones y distribución del almacén se muestran en la figura $\mathrm{N}^{\circ} 56$

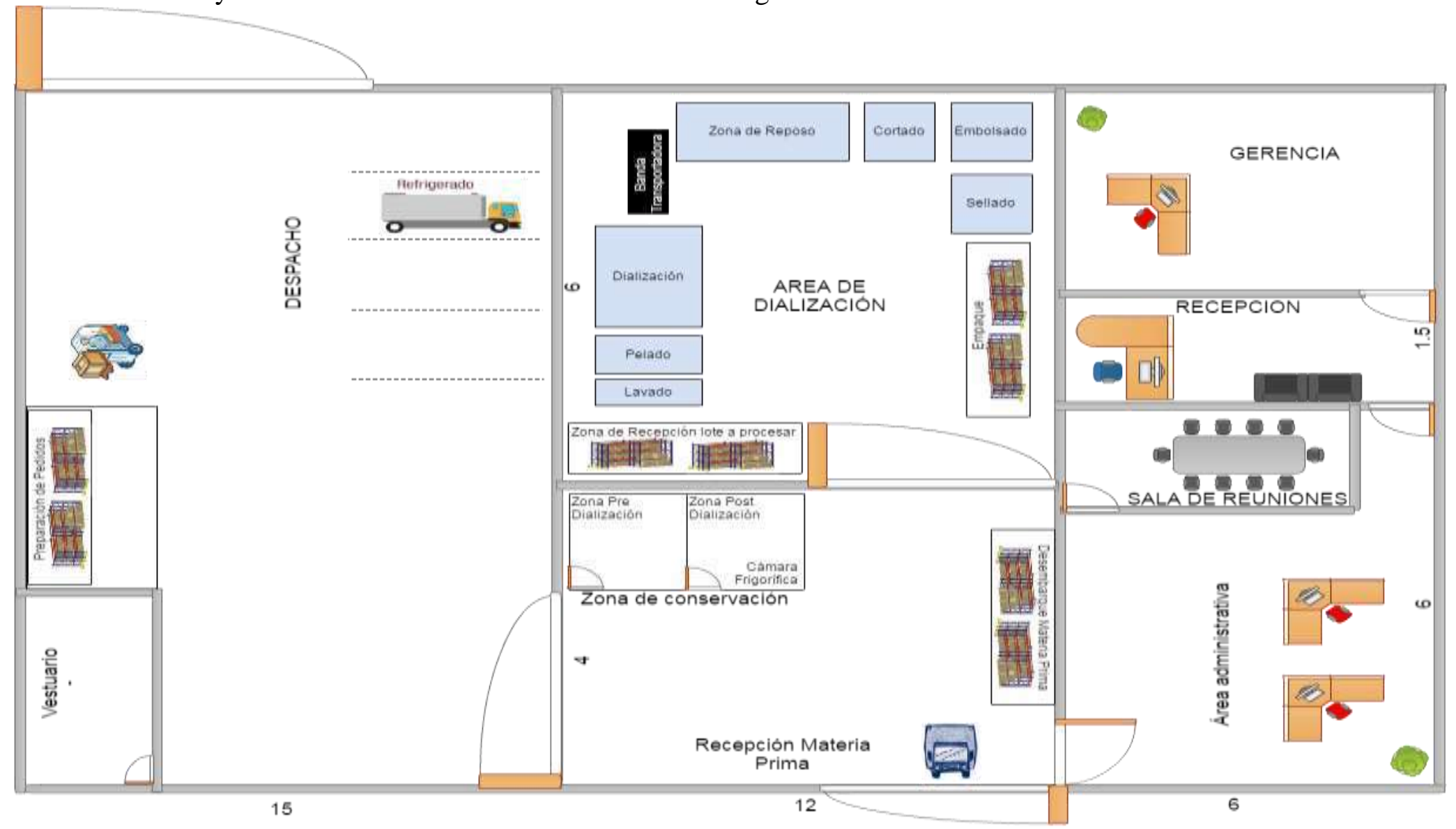

Figura 56. Diseño y Distribución de Ambientes - diseño propio 


\subsubsection{Distribución de equipos y maquinarias}

El centro de actividad económica, entiéndase como la disposición física dentro de la instalación de la empresa en donde se ejecutará todas las actividades de producción y administración, deberá permitir que todos los empleados, equipo y maquinaria puedan ejecutar sus labores con total eficiencia.

Teniendo como premisa lo expuesto anteriormente, se buscará tomar acción para conseguir las siguientes situaciones:

1. Utilización eficiente del espacio físico para evitar el congestionamiento.

2. Evitar que los materiales e insumos que se encuentren en proceso lleguen a acumularse y ocupar de manera excesiva el espacio físico.

3. Identificar las secuencias de los procesos para evitar distancias excesivas que puedan generar sobre tiempo en la ejecución del flujo de trabajo.

4. Establecer reglas, procedimientos y normas para evitar accidentes laborales.

5. Sistematizar el control del personal y horario de operación.

\section{Área de Gerencia}

El área de gerencia tendrá un área de 24 metros cuadrados, la misma que tendrá una división para la recepción de clientes u otras personas que necesiten información acerca de la empresa, de acuerdo al Layout, la representación gráfica se encuentra en la figura $\mathrm{N}^{\circ} 57$ : 


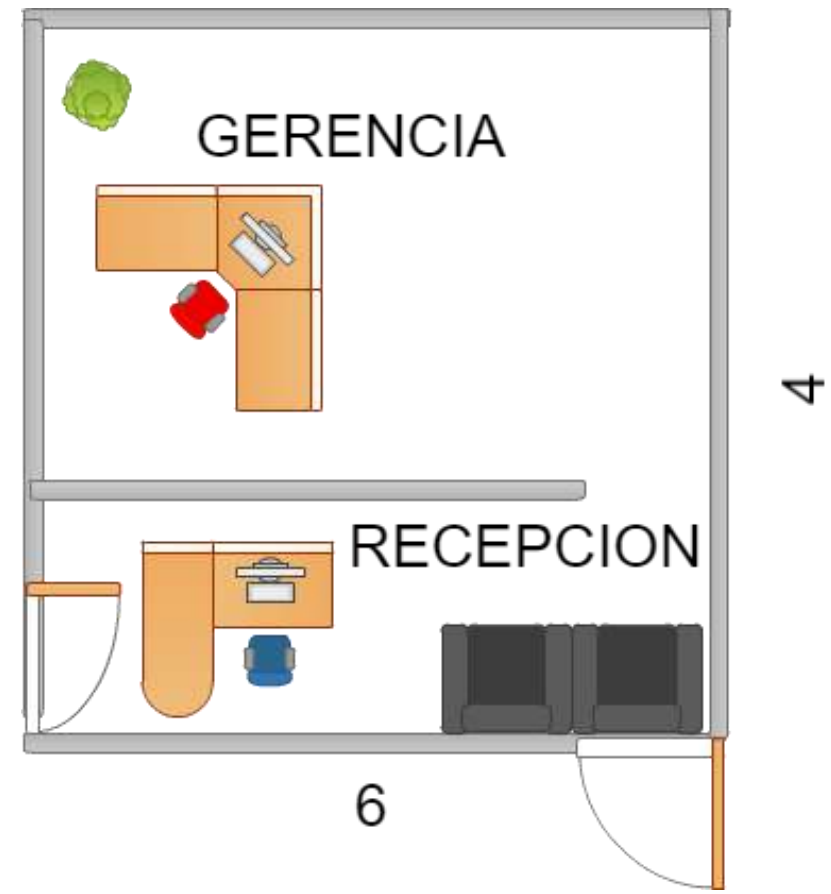

Figura 57. Gerencia, Diseño propio

El ambiente estará equipado por los siguientes muebles:

1. Un escritorio en L a base de melanina, precio S/. 480.00 .

2. Una silla giratoria S/. 209.00.

3. Archivador de $170 \mathrm{~cm}$ de alto $\mathrm{x} 40 \mathrm{~cm}$ de ancho, precio S/.550.00.

4. Una computadora Advance vission open V08155, Intel core i3-4170 3.70 GHz, 4GB DDR3, 500 GB SATA, precio S/. 1360.00.

5. Escritorio para el área de recepción de melanina, precio S/. 350.00.

6. Silla giratoria para el área de recepción de melanina, precio S/. 209.00.

7. Sofá de oficina para el área de recepción, precio S/. 850.00 


\section{Área de reuniones}

El área de reuniones tendrá una dimensión de 10 metros cuadrados, en donde se tomarán las decisiones en beneficio de la empresa, de acuerdo al layout, la descripción gráfica se muestra en la figura $\mathrm{N}^{\circ} 58$ :

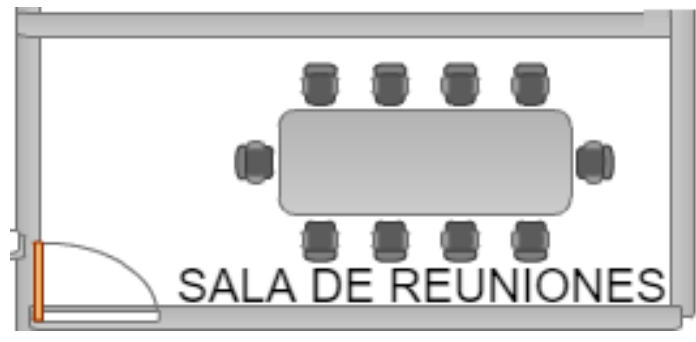

Figura 58. Sala de Reuniones, diseño propio

El ambiente será equipado por los siguientes muebles:

1. Escritorio en L a base de melanina, precio S/. 450.00.

2. Proyector ViewSonic, precio S/. 1599.00.

3. Mesa de reuniones con 10 sillas, precio S/. 1855.00

4. Computadora Advance vission open V08155, Intel core i3-4170 3.70 GHz, 4GB DDR3, 500 GB SATA, precio S/. 1360.00.

\section{Área administrativa}

El área administrativa cuenta con un área de 27 metros cuadrados, albergará a los empleados encargados de llevar a cabo todas las tareas administrativas de la empresa, la descripción gráfica se encuentra en la figura $\mathrm{N}^{\circ} 59$ : 


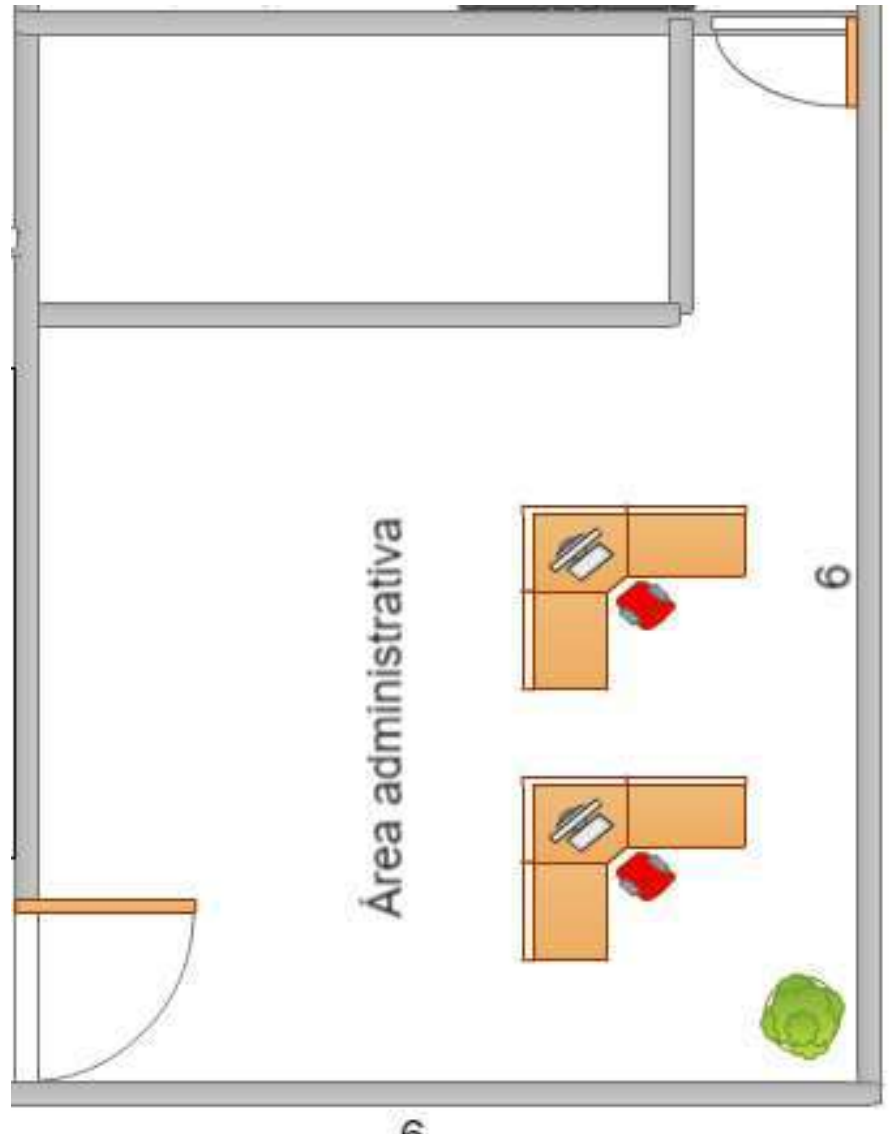

6

Figura 59. Área Administrativa, diseño propio

El ambiente será equipado por los siguientes muebles:

1. Dos escritorios en L a base de melanina, precio $\mathrm{S} / .480 .00 \mathrm{c} / \mathrm{u}$.

2. Dos sillas giratorias $\mathrm{S} / .209 .00 \mathrm{c} / \mathrm{u}$.

3. Dos archivadores de $170 \mathrm{~cm}$ de alto $\mathrm{x} 40 \mathrm{~cm}$ de ancho, precio $\mathrm{S} / .550 .00 \mathrm{c} / \mathrm{u}$

4. Dos computadoras Advance vission open V08155, Intel core i3-4170 3.70 GHz, 4GB DDR3, 500 GB SATA, precio S/. 1360.00 c/u.

5. Mesa para impresora, Precio S/. 250.00.

6. Impresora Epson Multifuncional L575Wi-Fi, Precio S/. 859.00 


\section{Área de dialización}

Dentro de esta área se encuentra el core del negocio, la misma que va a contar con una expansión de 72 metros cuadrados y que albergará toda la maquinaria que permitirá hacer funcionar el proceso productivo de la empresa. La descripción gráfica la podemos observar en la figura $\mathrm{N}^{\circ} 60$ :

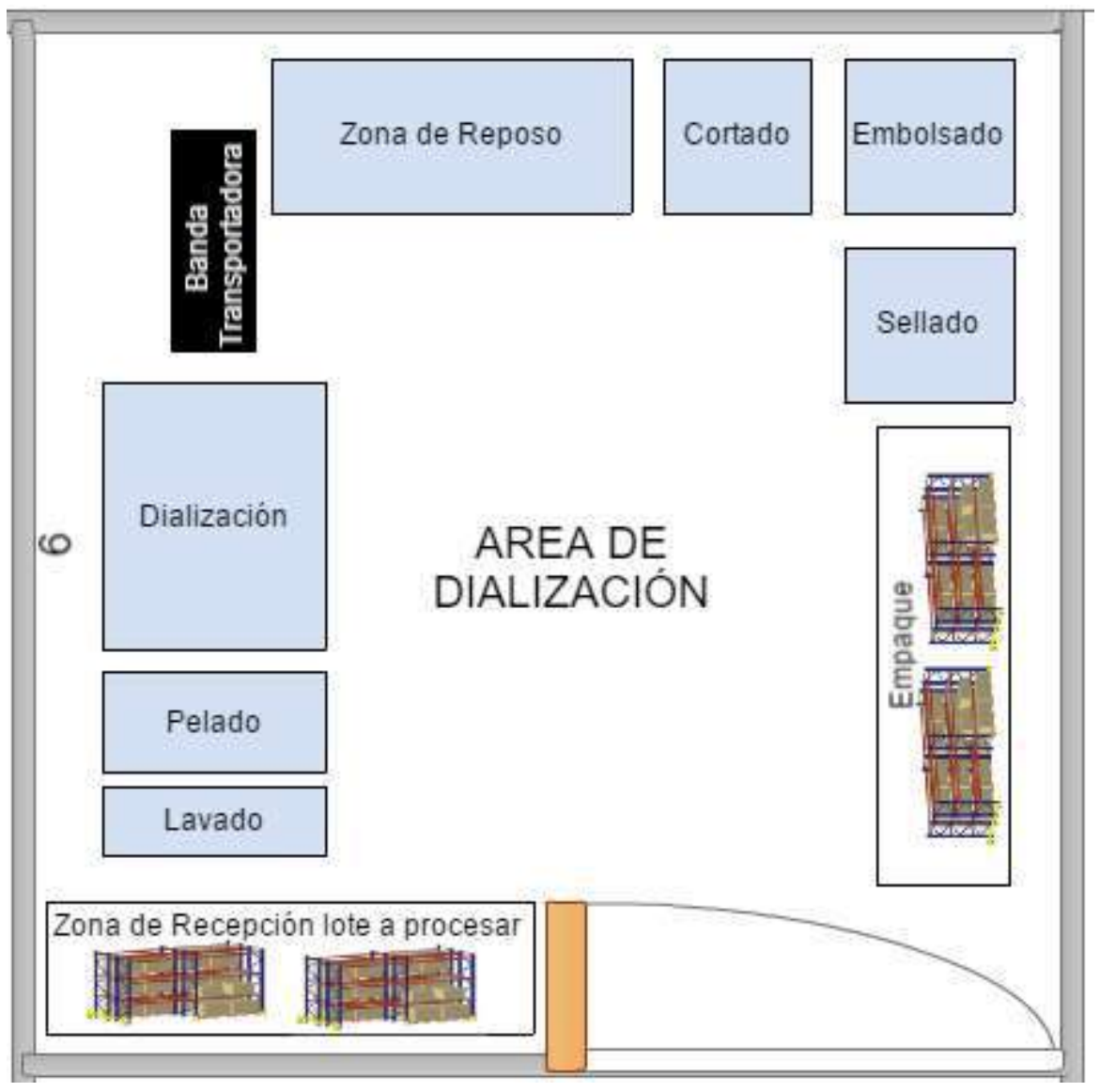

Figura 60. Área de Dializaciòn, diseño propio

El ambiente será equipado por los siguientes muebles:

1. Pozo de lavado

2. Maquina peladora de papa.

3. Máquina de dialización.

4. Bandas transportadoras.

5. Pozo de reposo. 
6. Máquina de cortado de papa.

7. Zona de embolsado

8. Máquina de sellado al vacío.

9. Zona de empaque producto terminado, albergará un total de 150 jabas de 15 lts. c/u.

\section{Área de conservación y recepción de materia prima}

El área cuenta con un espacio de 48 metros cuadrados, el cual se diagrama en la figura $\mathrm{N}^{\circ} 61$, la que albergará dos zonas:

1. Zona de conservación, aquí se almacenará el producto previo a su proceso de dialización y al culminar dicho proceso.

2. Zona de recepción de materia prima, esta será una zona de descarga del producto que proviene de los proveedores y será acumulado en jabas.

La descripción gráfica es la siguiente:

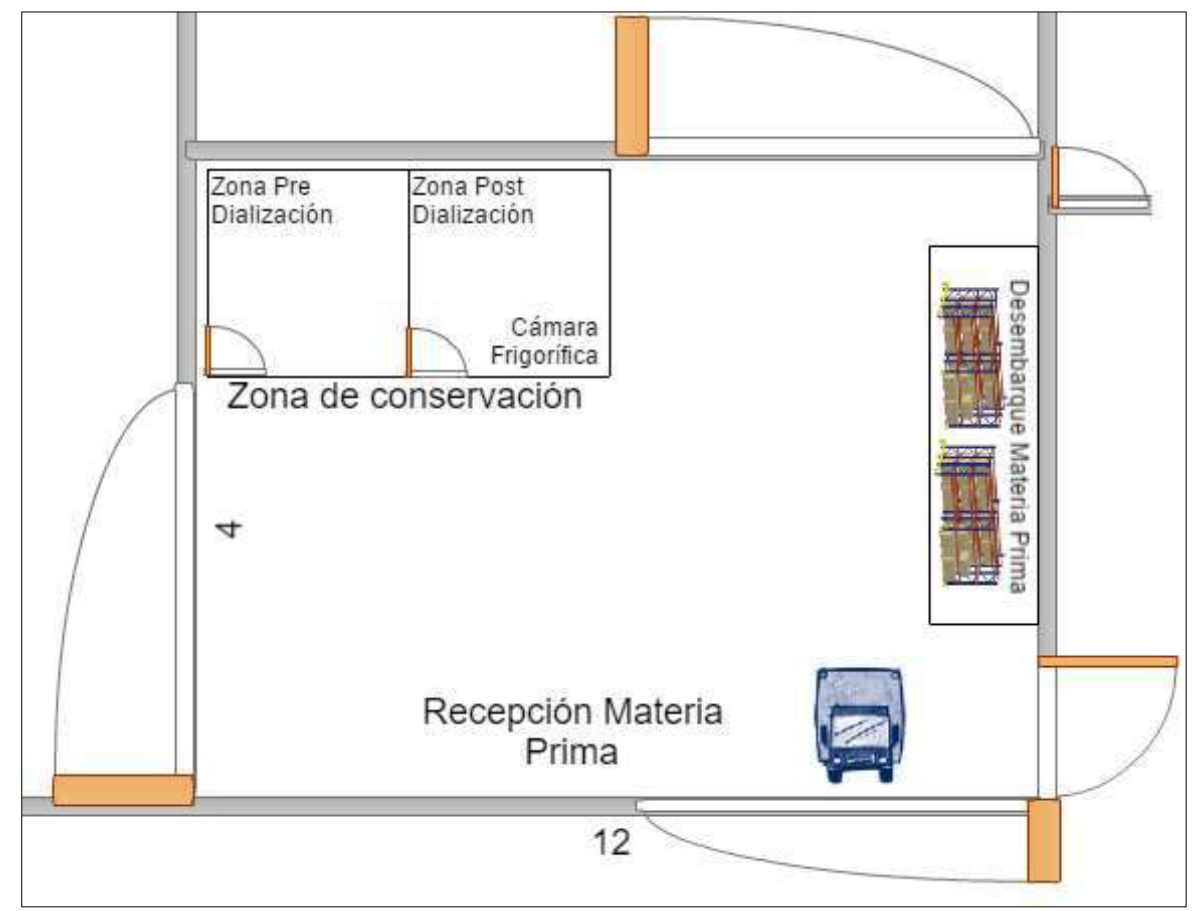

Figura 61. Zona de conservación y recepción, diseño propio 
El ambiente será equipado por los siguientes muebles:

1. 150 jabas de 15 lts. para transporte de tubérculos, precio $\mathrm{S} / .25 .00 \mathrm{c} / \mathrm{u}$.

2. 2 stokas hidráulicas para transporte de jabas con capacidad de carga de 2,000 kilogramos, precio S/. 1,640.00 c/u

3. Cámara frigorífica para conservación de verduras y tubérculos, precio S/. 205,826.96.

\section{Área de preparación de pedidos y distribución}

Este ambiente, el cual se encuentra diagramado en la figura $\mathrm{N}^{\circ} 62$ comprende un área total de 150 metros cuadrados, es la zona con más espacio de la empresa, por la necesidad que se tiene para maniobrar los camiones de carga liviana con capacidad de dos a ocho toneladas, la descripción gráfica es la siguiente:

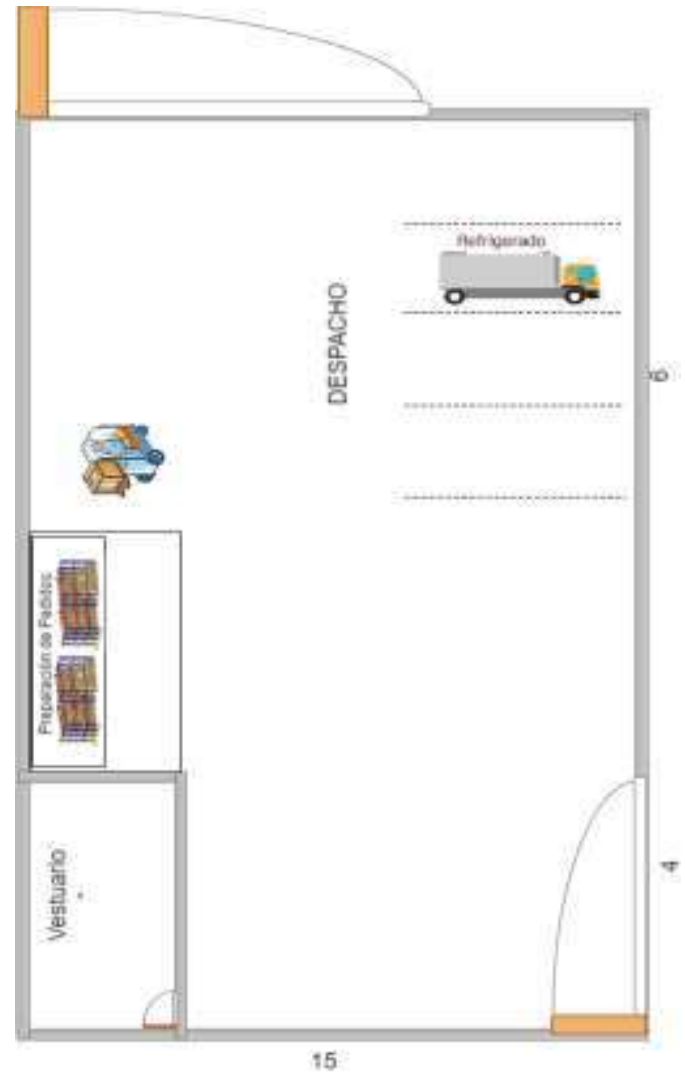

Figura 62. Despacho y Pedidos, diseño propio 
El ambiente será equipado por los siguientes muebles:

1. Montacargas liviano con capacidad de carga de carga de 3000 a 8000 lb, precio S/. 81,027.50.

2. 150 jabas de 40 lts. para transporte de tubérculo S/.25.00 c/u.

\subsection{Determinación del Tamaño}

En esta sección se determinará el tamaño del proyecto, para ello se considerará los siguientes factores: proyección de crecimiento, recursos, tecnología y flexibilidad. Para lo cual se analizará las variables de flujo y las variables de existencias, las que ayudaran a calcular de manera adecuada el tamaño de la planta o cantidad de trabajadores que se necesitan para determinada cantidad de flujo de producción en la operación, tanto en operativo como en lo administrativo y así poder determinar la superficie que se requiere para áreas de gerencia, recepción, sala de reuniones, área de dialización, área de almacenamiento, área de despacho y área de preparación de pedidos, asegurando la vida útil propuesta para el proyecto.

\subsubsection{Proyección de crecimiento}

La proyección de crecimiento está afectada por la variable de flujo denominada materia prima a procesar por año, la cual será igual a la venta proyectada por año, como se puede apreciar en la tabla $\mathrm{N}^{\circ} 34$

En la tabla $N^{\text {o }} 34$ se detalla el programa de producción mensual y el crecimiento que tendrá la empresa en los siguientes cuatro años proyectados, en este programa proyectado se encuentra incluido el 5\% de merma y el 10\% de stock de seguridad, teniendo así la cantidad a producir mensual. 
Tabla 34

Programa de Producción Mensual Proyectada 2017-2021

Expresado en Toneladas

\begin{tabular}{|c|c|c|c|c|c|c|c|c|c|c|}
\hline \multirow{2}{*}{ Mes } & \multicolumn{2}{|c|}{2017} & \multicolumn{2}{|c|}{2018} & \multicolumn{2}{|c|}{2019} & \multicolumn{2}{|c|}{2020} & \multicolumn{2}{|c|}{2021} \\
\hline & Vta. & Prod. & Vta. & Prod. & Vta. & Prod. & Vta. & Prod. & Vta. & Prod. \\
\hline Enero & 2.77 & 3.19 & 6.59 & 7.58 & 9.99 & 11.49 & 13.45 & 15.47 & 16.98 & 19.53 \\
\hline Febrero & 2.73 & 3.14 & 6.50 & 7.47 & 9.85 & 11.33 & 13.26 & 15.25 & 16.74 & 19.26 \\
\hline Marzo & 3.17 & 3.65 & 7.54 & 8.67 & 11.43 & 13.14 & 15.39 & 17.70 & 19.43 & 22.34 \\
\hline Abril & 2.99 & 3.44 & 7.10 & 8.17 & 10.77 & 12.38 & 14.50 & 16.68 & 18.31 & 21.05 \\
\hline Mayo & 3.03 & 3.44 & 7.21 & 8.17 & 10.93 & 12.38 & 14.72 & 16.68 & 18.58 & 21.05 \\
\hline Junio & 2.79 & 3.21 & 6.64 & 7.64 & 10.07 & 11.58 & 13.56 & 15.59 & 17.12 & 19.68 \\
\hline Julio & 3.01 & 3.47 & 7.17 & 8.24 & 10.86 & 12.49 & 14.63 & 16.83 & 18.47 & 21.24 \\
\hline Agosto & 3.03 & 3.48 & 7.20 & 8.27 & 10.90 & 12.54 & 14.69 & 16.89 & 18.54 & 21.32 \\
\hline Setiembre & 2.81 & 3.24 & 6.69 & 7.69 & 10.14 & 11.66 & 13.66 & 15.70 & 17.24 & 19.82 \\
\hline Octubre & 2.79 & 3.20 & 6.62 & 7.62 & 10.04 & 11.55 & 13.52 & 15.55 & 17.07 & 19.63 \\
\hline Noviembre & 2.62 & 3.01 & 6.23 & 7.16 & 9.44 & 10.85 & 12.71 & 14.61 & 16.04 & 18.45 \\
\hline Diciembre & 2.47 & 2.84 & 5.87 & 6.75 & 8.90 & 10.23 & 11.99 & 13.78 & 15.13 & 17.40 \\
\hline Total & 34.22 & 39.30 & 81.36 & 93.45 & 123.31 & 141.62 & 166.08 & 190.74 & 209.65 & 240.78 \\
\hline Promedio & & 3.27 & & 7.79 & & 11.80 & & 15.89 & & 20.07 \\
\hline Desviación Estánd & dar & 0.22 & & 0.52 & & 0.78 & & 1.05 & & 1.33 \\
\hline Capacidad Saco & & 0.05 & & 0.05 & & 0.05 & & 0.05 & & 0.05 \\
\hline Total Sacos & & 65 & & 156 & & 236 & & 318 & & 401 \\
\hline
\end{tabular}

Nota. Elaboración Propia

Como se puede apreciar en la tabla $\mathrm{N}^{\mathrm{o}} 34$ la producción promedio mensual para el primer año es de 3.27 toneladas con una desviación estándar de 0.22 toneladas, con lo cual se podría atender hasta 3.49 toneladas y un mínimo de 3.06 toneladas, con este dato se puede establecer la capacidad necesaria para el almacenamiento de la materia prima proyectado al quinto año como se presenta en la siguiente gráfica. 


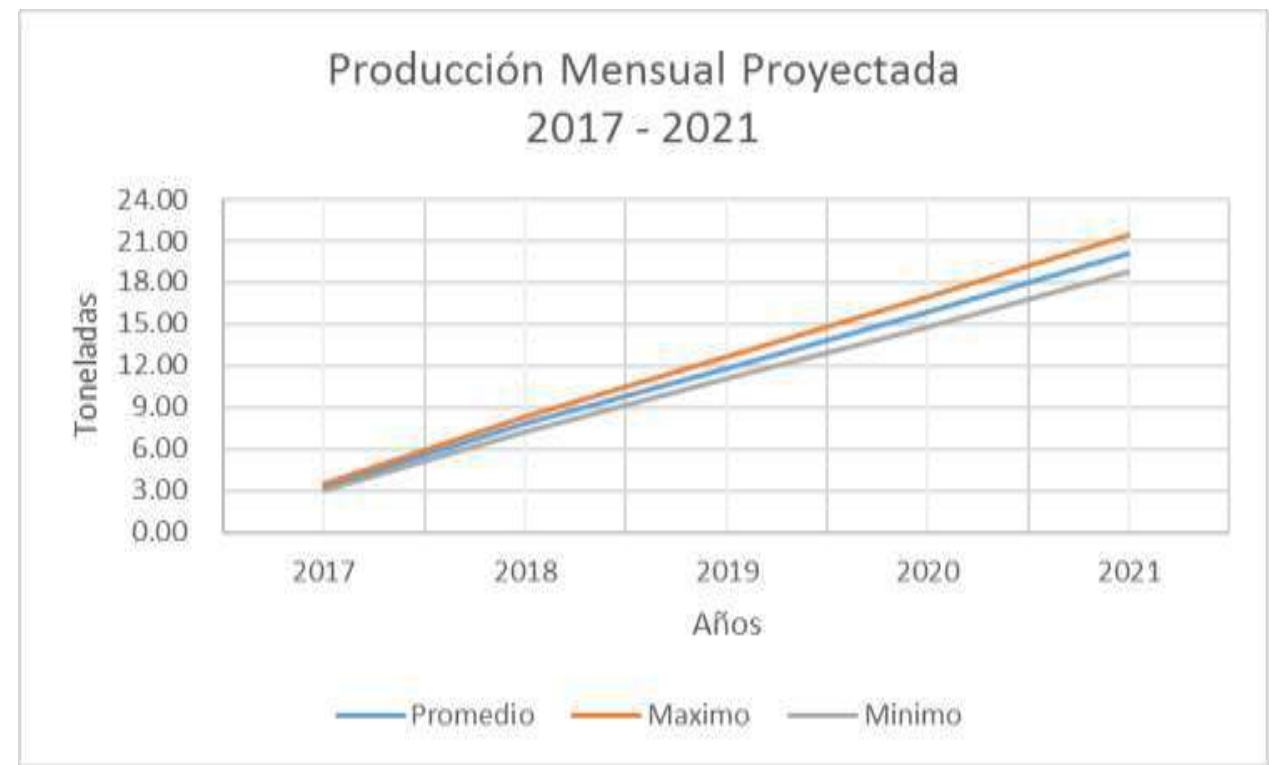

Figura 63. Producción Mensual Proyectada

A través de esta proyección (figura $\mathrm{N}^{\circ} 63$ ), se ha establecido de manera objetiva el flujo de materia prima a emplear durante todo el proceso productivo resultando 3.27 toneladas promedio mensual en el primer año, para terminar con 20.07 toneladas promedio mensual en el quinto año con lo que se logra un crecimiento del $414 \%$, también se debe tener en cuenta que el incremento mensual promedio por cada año 4.20 toneladas, siendo este un crecimiento muy conservador; finalmente observamos en la tabla $\mathrm{N}^{\circ} 35$ que el porcentaje de crecimiento respecto al año anterior va en disminución, esto se da debido a que el mercado objetivo crece en relación al crecimiento poblacional identificado en las proyecciones de crecimiento poblacional del INEI 2014 y no es un mercado estático como se pueda creer. 
Tabla 35

Crecimiento Mensual de Producción

\begin{tabular}{|c|c|c|c|c|}
\hline \multirow[t]{2}{*}{ Año } & \multicolumn{4}{|c|}{$\begin{array}{c}\text { Crecimiento } \\
\text { Promedio Mensual } \\
\text { por Año }\end{array}$} \\
\hline & tn & $\%$ & tn & $\%$ \\
\hline 2017 & 3.27 & $100 \%$ & 3.27 & $100 \%$ \\
\hline 2018 & 4.51 & $138 \%$ & 7.79 & $138 \%$ \\
\hline 2019 & 4.01 & $52 \%$ & 11.80 & $260 \%$ \\
\hline 2020 & 4.09 & $35 \%$ & 15.89 & $385 \%$ \\
\hline 2021 & 4.17 & $26 \%$ & 20.07 & $513 \%$ \\
\hline
\end{tabular}

Nota. Elaboración propia

\subsubsection{Recursos}

Para poder determinar adecuadamente los recursos de infraestructura, personal, materia e insumos determinaremos las capacidades de operación de cada uno de los diferentes procesos, los cuales se detallan a continuación:

1. Proceso de Lavado y Pelado

En este proceso se utilizará una máquina especializada en el lavado y pelado de la papa, la cual tiene una capacidad operativa de $150 \mathrm{Kg}$ por hora.

2. Proceso de Selección y Control de Calidad

El proceso de selección y control de calidad se realiza después del pelado de la papa para lograr identificar aquellos insumos que no están dentro de las características de productos deseado, como peso, color, forma, tamaño, entre otros y separarlos del proceso principal considerándolos con una de las mermas 
iniciales, este proceso tiene una duración 15 minutos por cada 200 $\mathrm{kg}$ de procesado por la peladora de papas.

\section{Proceso de Dialización}

Este es el proceso central del todo el ciclo de producción, en este proceso la materia prima (la papa) se mantendrá sumergida en agua en ciclos de 6 horas durante 24 horas de manera automática, en cada ciclo de 24 horas se podrá procesar 1.2 toneladas de papa.

4. Proceso de Corte

En este proceso se realiza con un equipo que tiene una capacidad de corte de $150 \mathrm{~kg}$ por hora

5. Proceso de Empaque al Vacío

En el proceso de empacado al vacío se utilizarán dos equipos especializados y se ha determinado el modelo de equipo adquirido tiene una capacidad productiva de 4 minutos por cada ciclo de empaque combinado con una capacidad de $10 \mathrm{~kg}$ por ciclo, con lo que se puede establecer que en 1 hora se procesara $150 \mathrm{Kg}$.

6. Proceso de Refrigeración.

El proceso de refrigerado es un proceso intermedio entre el producto terminado y la entrega al cliente final, y tendrá un tiempo de duración máxima de 12 horas hasta la salida del producto terminado y no está dentro del ciclo productivo.

Ahora que se conoce todos los tiempos que intervienen en el proceso productivo, se puede estimar e identificar los recursos a utilizar y las cantidades necesarias a emplear. 
Para la elaboración de una bolsa de papa en cualquiera de sus presentaciones ( 250 gr o 500 gr) se necesitarán los siguientes recursos:

1. 1.2 toneladas de papa por día.

2. 500 Lts. de agua por día. (esto debido a que se reutilizara el agua en cada cambio de ciclo pasándola por un proceso de purificación a través de filtros)

3. 1,400 voltios de electricidad por día de producción

4. Un total de nueve personas en un turno de 8 horas distribuidos de la siguiente manera:

a. Un (2) operario de producción para el proceso de pelado.

b. Dos (2) personas para el control de calidad, de los cuales uno (1) de ellos también estará ha cargado del proceso de cortado.

c. Un (1) personal para el control del almacenamiento.

d. Un (1) jefe comercial encargado de establecer los requerimientos comerciales que establecen las cantidades a producir.

e. Un (1) ejecutivo comercial el cual se hará cargo de las ventas y la canalización de los pedidos y seguimiento de los clientes.

f. Un (1) personal de apoyo encargado del despacho

g. Un (1) administrador general de la gestión.

Todos estos recursos serán utilizados un ciclo de producción diaria de 8 horas, durante 6 días a la semana y 26 días al mes, con un total de 9 trabajadores. 
En la tabla $\mathrm{N}^{\circ} 36$ se presentará el resumen de la estimación del primer año, y los 4 años subsiguientes de la duración total del presente proyecto:

Tabla 36

Cuadro Resumen de Recursos

\begin{tabular}{|c|c|c|c|c|c|c|}
\hline Descripciòn de Etapa & $\begin{array}{c}\text { Unidad } \\
\text { de Medida }\end{array}$ & $\begin{array}{c}\text { Año } 1 \\
2017\end{array}$ & $\begin{array}{c}\text { Año } 2 \\
2018\end{array}$ & $\begin{array}{c}\text { Año } 3 \\
2019\end{array}$ & $\begin{array}{c}\text { Año } 4 \\
2020\end{array}$ & $\begin{array}{c}\text { Año } 5 \\
2021\end{array}$ \\
\hline Ventas Prom. Mensual & Tonelada $(\mathrm{t})$ & 2.85 & 6.78 & 10.28 & 13.84 & 17.47 \\
\hline Producciòn Prom. Mensual & Tonelada $(\mathrm{t})$ & 3.27 & 7.79 & 11.80 & 15.89 & 20.07 \\
\hline Producciòn total diaria & Tonelada $(\mathrm{t})$ & 1.2 & 1.2 & 1.2 & 1.2 & 1.2 \\
\hline Producciòn total Mensual & Tonelada $(\mathrm{t})$ & 31.2 & 31.2 & 31.2 & 31.2 & 31.2 \\
\hline Capacida Productiva Ocupada & $\%$ & $10.50 \%$ & $24.96 \%$ & $37.83 \%$ & $50.95 \%$ & $64.31 \%$ \\
\hline \multicolumn{7}{|l|}{ Procesos } \\
\hline Lavado y Pelado & Tonelada $(\mathrm{t})$ & 31.2 & 31.2 & 31.2 & 31.2 & 31.2 \\
\hline Equipamiento & Unidad & 1 & 1 & 1 & 1 & 1 \\
\hline Personal & Persona & 1 & 1 & 1 & 1 & 1 \\
\hline Selecciòn y Control de Calidad & Tonelada $(\mathrm{t})$ & 249.6 & 249.6 & 249.6 & 249.6 & 249.6 \\
\hline Personal & Persona & 2 & 2 & 2 & 2 & 2 \\
\hline Dializaciòn & Tonelada $(\mathrm{t})$ & 31.2 & 31.2 & 31.2 & 31.2 & 31.2 \\
\hline Equipamiento & Unidad & 1 & 1 & 1 & 1 & 1 \\
\hline Personal & Persona & 1 & 1 & 1 & 1 & 1 \\
\hline Corte & Tonelada $(\mathrm{t})$ & 31.2 & 31.2 & 31.2 & 31.2 & 31.2 \\
\hline Equipamiento & Unidad & 1 & 1 & 1 & 1 & 1 \\
\hline Personal & Persona & 1 & 1 & 1 & 1 & 1 \\
\hline Empaque al Vacio & Tonelada $(\mathrm{t})$ & 31.2 & 31.2 & 31.2 & 31.2 & 31.2 \\
\hline Equipamiento & Unidad & 2 & 2 & 2 & 2 & 2 \\
\hline Personal & Persona & 1 & 1 & 1 & 1 & 1 \\
\hline Refigeraciòn & Tonelada (t) & 35 & 35 & 35 & 35 & 35 \\
\hline Equipamiento & Unidad & 1 & 1 & 1 & 1 & 1 \\
\hline
\end{tabular}

Nota. Elaboración propia

Como se puede apreciar en tabla $\mathrm{N}^{\mathrm{o}} 36$, los recursos estimados para el primer año productivos son suficiente para soportar el proceso productivo de los 5 años de duración del presente proyecto.

\subsubsection{Tecnología}

Para la producción de papa dializada, se requerirá las siguientes maquinarias electromecánicas:

1. Equipo de pelado de papas

Este equipo será empleado para retirar la cascará de la papa,

funcionará 8 horas produciendo 1.2 t de papa por día.

2. Equipo de Cortado de papas. 
Este equipo será empleado para cortar las papas en largas y rodajas, tendrá un funcionamiento de 8 horas, produciendo total de 1.2 toneladas de papa por día.

3. Equipo de empaque al vacío

Este equipo realizará el envasado del producto en las presentaciones de 250 gr y 500 gr, aplicando el proceso de "al vacío" ya que se retirará el oxígeno del empaque para dilatar el tiempo de caducidad del alimento y tendrá una producción total de 1.2 toneladas papas empacadas por día.

4. Equipo de dialización

Este equipo realizará el proceso principal del proyecto, el cual consiste en remojo de las papas por cuatro ciclos controlados con cambios de agua de 6 horas cada uno y tendrá una producción total de 1.2 toneladas papas dializadas por día.

\subsubsection{Flexibilidad}

A continuación, explicaremos las razones por la que consideramos que, si se requiera realizar un aumento de la producción durante la ejecución del proyecto esto no afectaría al diseño realizado, ya que el diseño está pensado en un solo ciclo de trabajo de 8 horas continuas, durante seis días por semana y con un día de descanso semanal, de los tres ciclos o turnos que se podrían realizar, esto ya que las condiciones técnicas; gracias a los equipos nuevos y de gran capacidad productiva genera una mayor eficiencia del proceso de producción, como se puede apreciar en la tabla $\mathrm{N}^{\circ} 37$ se describe la capacidad ociosa de los diferentes equipos que sostienen el proceso productivo: 
Tabla 37

Capacidad Ociosa de la Planta Productiva

\begin{tabular}{lccccc}
\hline \multicolumn{1}{c}{ Derscripción } & Año 1 & Año 2 & Año 3 & Año 4 & Año 5 \\
& $\mathbf{2 0 1 7}$ & $\mathbf{2 0 1 8}$ & $\mathbf{2 0 1 9}$ & $\mathbf{2 0 2 0}$ & $\mathbf{2 0 2 1}$ \\
\hline Papa Dializada - 500 Grm & $13,676.10$ & $32,518.95$ & $49,283.96$ & $66,376.94$ & $83,791.82$ \\
\hline Papa Dializada - 250 Grm & $25,623.04$ & $60,926.31$ & $92,336.62$ & $124,361.39$ & $156,989.28$ \\
\hline \hline Total Kilos a Producir & $39,299.13$ & $93,445.26$ & $141,620.58$ & $190,738.33$ & $240,781.10$ \\
\hline \hline Peladora - Kg & 374,400 & 374,400 & 374,400 & 374,400 & 374,400 \\
\hline \hline Cpacidad Ociosa & $\mathbf{9 0 \%}$ & $\mathbf{7 5 \%}$ & $\mathbf{6 2 \%}$ & $\mathbf{4 9 \%}$ & $\mathbf{3 6 \%}$ \\
\hline Poza Dializadora & 374,400 & 374,400 & 374,400 & 374,400 & 374,400 \\
\hline \hline Cpacidad Ociosa & $\mathbf{9 0 \%}$ & $\mathbf{7 5 \%}$ & $\mathbf{6 2 \%}$ & $\mathbf{4 9 \%}$ & $\mathbf{3 6 \%}$ \\
\hline Cortadora - Kg & 374,400 & 374,400 & 374,400 & 374,400 & 374,400 \\
\hline \hline Cpacidad Ociosa & $\mathbf{9 0 \%}$ & $\mathbf{7 5 \%}$ & $\mathbf{6 2 \%}$ & $\mathbf{4 9 \%}$ & $\mathbf{3 6 \%}$ \\
\hline Envasadora al Vacio - Kg & 374,400 & 374,400 & 374,400 & 374,400 & 374,400 \\
\hline \hline Cpacidad Ociosa & $\mathbf{9 0 \%}$ & $\mathbf{7 5 \%}$ & $\mathbf{6 2 \%}$ & $\mathbf{4 9 \%}$ & $\mathbf{3 6 \%}$ \\
\hline \hline Cpacidad Ociosa - Promedio & $\mathbf{9 0 \%}$ & $\mathbf{7 5 \%}$ & $\mathbf{6 2 \%}$ & $\mathbf{4 9 \%}$ & $\mathbf{3 6 \%}$ \\
\hline
\end{tabular}

Nota. Elaboración propia

Como se puede apreciar el primer año la capacidad ociosa de operación de la planta es de $90 \%$ y una capacidad operativa de $10 \%$, para terminar con un $36 \%$ de capacidad ociosa y un $64 \%$ de capacidad operativa en el quinto año de ejecución.

A fin de poder apreciar la flexibilidad del diseño de planta realizado se ejecutó una simulación en la cual se aumentaba los kilos a producir en 2.27 veces más la producción por cada año, siendo el resultado demostrado en la tabla $\mathrm{N}^{\circ} 38$.

Tabla 38

Simulación de Mayor Capacidad Productiva

\begin{tabular}{|c|c|c|c|c|c|}
\hline Derscripción & $\begin{array}{c}\text { Año } 1 \\
2017 \\
\end{array}$ & $\begin{array}{c}\text { Año } 2 \\
2018 \\
\end{array}$ & $\begin{array}{c}\text { Año } 3 \\
2019 \\
\end{array}$ & $\begin{array}{c}\text { Año } 4 \\
2020 \\
\end{array}$ & $\begin{array}{c}\text { Año } 5 \\
2021 \\
\end{array}$ \\
\hline Papa Dializada - 500 Grm & $21,197.95$ & $50,404.37$ & $76,390.14$ & $102,884.26$ & $129,877.33$ \\
\hline Papa Dializada - 250 Grm & $39,715.70$ & $94,435.78$ & $143,121.76$ & $192,760.16$ & $243,333.38$ \\
\hline Total Kilos a Producir & $60,913.66$ & $144,840.15$ & $219,511.89$ & $295,644.41$ & $373,210.70$ \\
\hline Peladora - Kg & 374,400 & 374,400 & 374,400 & 374,400 & 374,400 \\
\hline Cpacidad Ociosa & $84 \%$ & $61 \%$ & $41 \%$ & $21 \%$ & $0 \%$ \\
\hline Poza Dializadora & 374,400 & 374,400 & 374,400 & 374,400 & 374,400 \\
\hline Cpacidad Ociosa & $84 \%$ & $61 \%$ & $41 \%$ & $21 \%$ & $0 \%$ \\
\hline Cortadora - Kg & 374,400 & 374,400 & 374,400 & 374,400 & 374,400 \\
\hline Cpacidad Ociosa & $84 \%$ & $61 \%$ & $41 \%$ & $21 \%$ & $\mathbf{0 \%}$ \\
\hline Envasadora al Vacio - Kg & 374,400 & 374,400 & 374,400 & 374,400 & 374,400 \\
\hline Cpacidad Ociosa & $84 \%$ & $61 \%$ & $41 \%$ & $21 \%$ & $0 \%$ \\
\hline Cpacidad Ociosa - Promedio & $84 \%$ & $61 \%$ & $41 \%$ & $21 \%$ & $0 \%$ \\
\hline
\end{tabular}

Nota. Elaboración propia 
Como se puede apreciar la capacidad operativa del diseño de planta no se ve afectada en cualquiera de los cinco años de ejecución, tan solo en el quinto año la capacidad operativa proyectada seria el máximo que la planta pudiera soportar dado que en ese último año la capacidad ociosa seria de $0 \%$, asegurando la capacidad máxima de producción, con lo cual queda demostrado la flexibilidad y capacidad de crecimiento que tiene el diseño de planta.

\subsubsection{Selección del tamaño ideal}

La selección del tamaño de planta se ha realizado en base al análisis de la proyección de ventas (figura $\mathrm{N}^{\circ} 64$ ), capacidades productivas, dimensiones a utilizar por la tecnología o equipamiento y cantidad de recursos necesarios para cubrir la demanda en los próximos cinco años.

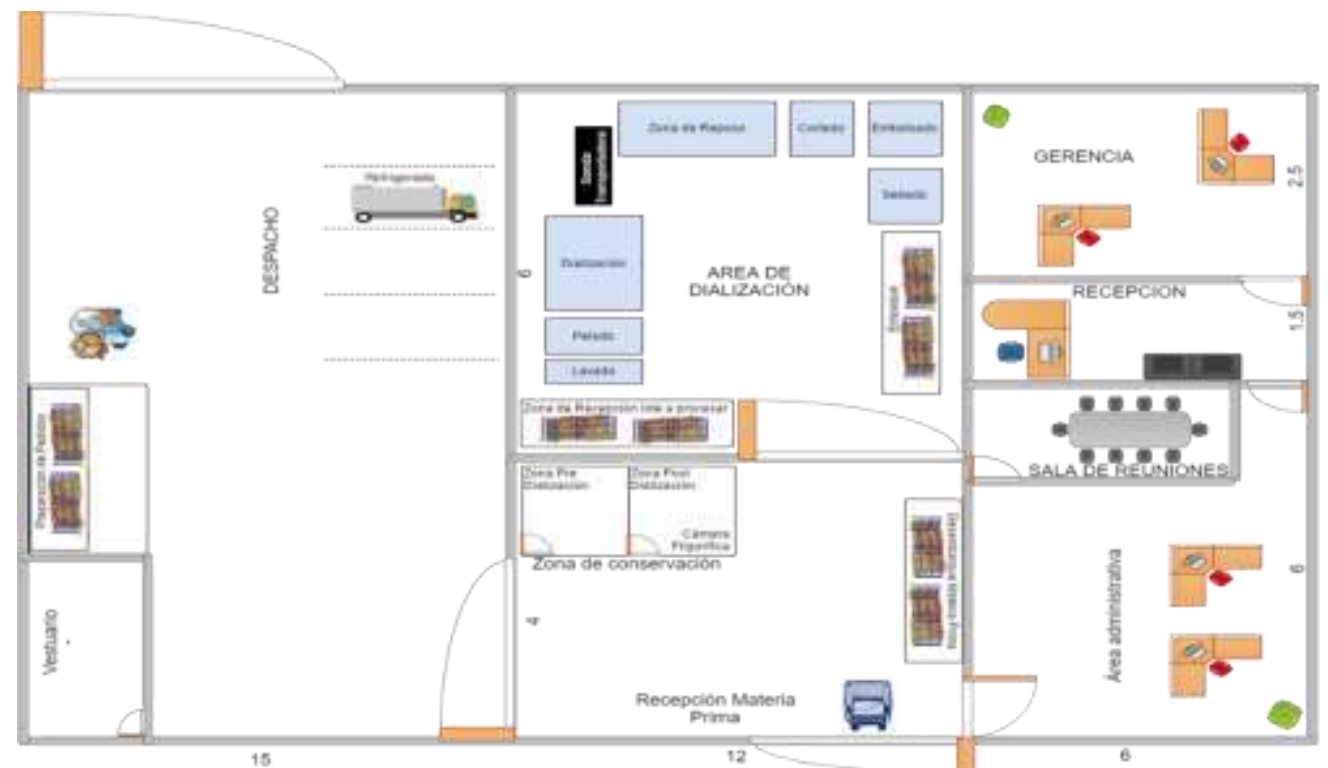

Figura 64. Área por Departamento, diseño propio

La selección del tamaño ideal está soportada por la determinar de los espacios que deberá de utilizar cada uno de los ambientes que intervienen en todo el proceso productivo, para lo cual se tomará los siguiente criterios o variables: 
1. Capacidad total por cada saco:

$50 \mathrm{~kg}(0.05 \mathrm{t})$

2. Dimensión de cada saco lleno:

Largo: $1.20 \mathrm{~cm}$.

Ancho: $0.50 \mathrm{~cm}$.

3. Capacidad total por cada jaba:

$16 \operatorname{Kg}(0.016 \mathrm{t})$

4. Dimensión de cada jaba:

Largo $=60 \mathrm{~cm}$.

Ancho $=40 \mathrm{~cm}$.

Altura $=20 \mathrm{~cm}$.

5. Dimensión de Equipo Dializador:

Largo $=3 \mathrm{~m}$.

Ancho $=2 \mathrm{~m}$.

Altura $=4 \mathrm{~m}$.

Área $=6 \mathrm{~m} 2$

6. Dimensión de Equipo Cortadora:

Largo $=1.40 \mathrm{~m}$.

Ancho $=95 \mathrm{~cm}$.

Altura $=2 \mathrm{~m}$.

Área $=1.33 \mathrm{~m} 2$

7. Dimensión de Equipo Empacado al Vacío: $\quad$ Largo $=0.75 \mathrm{~cm}$.

Ancho $=0.70 \mathrm{~cm}$.

Altura $=1.03 \mathrm{~m}$.

Área $=0.525 \mathrm{~m} 2$

8. Dimensión de Cinta Transportadora: $\quad$ Largo $=3 \mathrm{~m}$.

Ancho $=60 \mathrm{~cm}$.

Área $=1.8 \mathrm{~m} 2$

9. Dimensión de Equipo de refrigeración

Largo $=6 \mathrm{~m}$.

Ancho $=3 \mathrm{~m}$. 
10. Pozas de reposo

$$
\begin{aligned}
& \text { Altura }=2 \mathrm{~m} . \\
& \text { Área }=18 \mathrm{~m} 2 \\
& \text { Largo }=3 \mathrm{~m} . \\
& \text { Ancho }=2 \mathrm{~m} . \\
& \text { Altura }=4 \mathrm{~m} . \\
& \text { Área }=6 \mathrm{~m} 2
\end{aligned}
$$

Con estos datos ahora debemos de calcular la cantidad de espacio necesario para cada uno de los ambientes necesarios para el proceso productivo y comenzaremos por el área de despacho y atención de pedidos como se muestra en la figura $\mathrm{N}^{\circ} 65$.

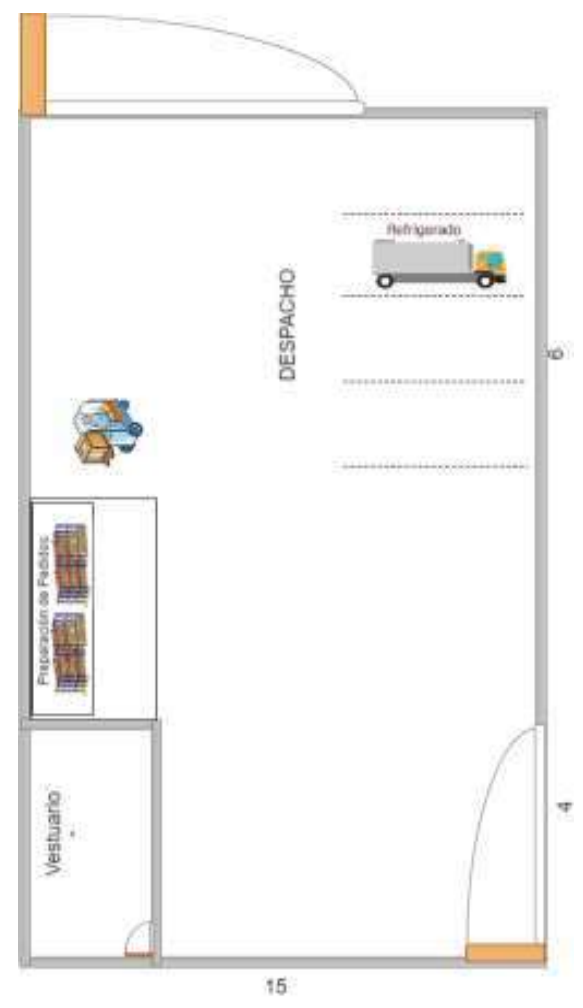

Figura 65. Despacho y Pedidos, diseño propio

En este ambiente tenemos un total de 150 metros cuadrados, la cual deberá de albergar hasta dos camiones para carga, utilizando los cinco primeros metros como se aprecia en la figura $\mathrm{N}^{\circ} 65$, para luego dar paso a la 
zona de preparación de pedidos, el cual cuanta con un total 75 metros cuadrados con una capacidad de 600 jabas de $16 \mathrm{~kg}$ cada una y con un total de 9.6 toneladas máxima por vez distribuidas en cinco camas, en caso de existir una mayor cantidad a despachar se puede duplicar la capacidad sin cambiar el espacio asignado a un total de 19.2 toneladas distribuidas en diez camas.

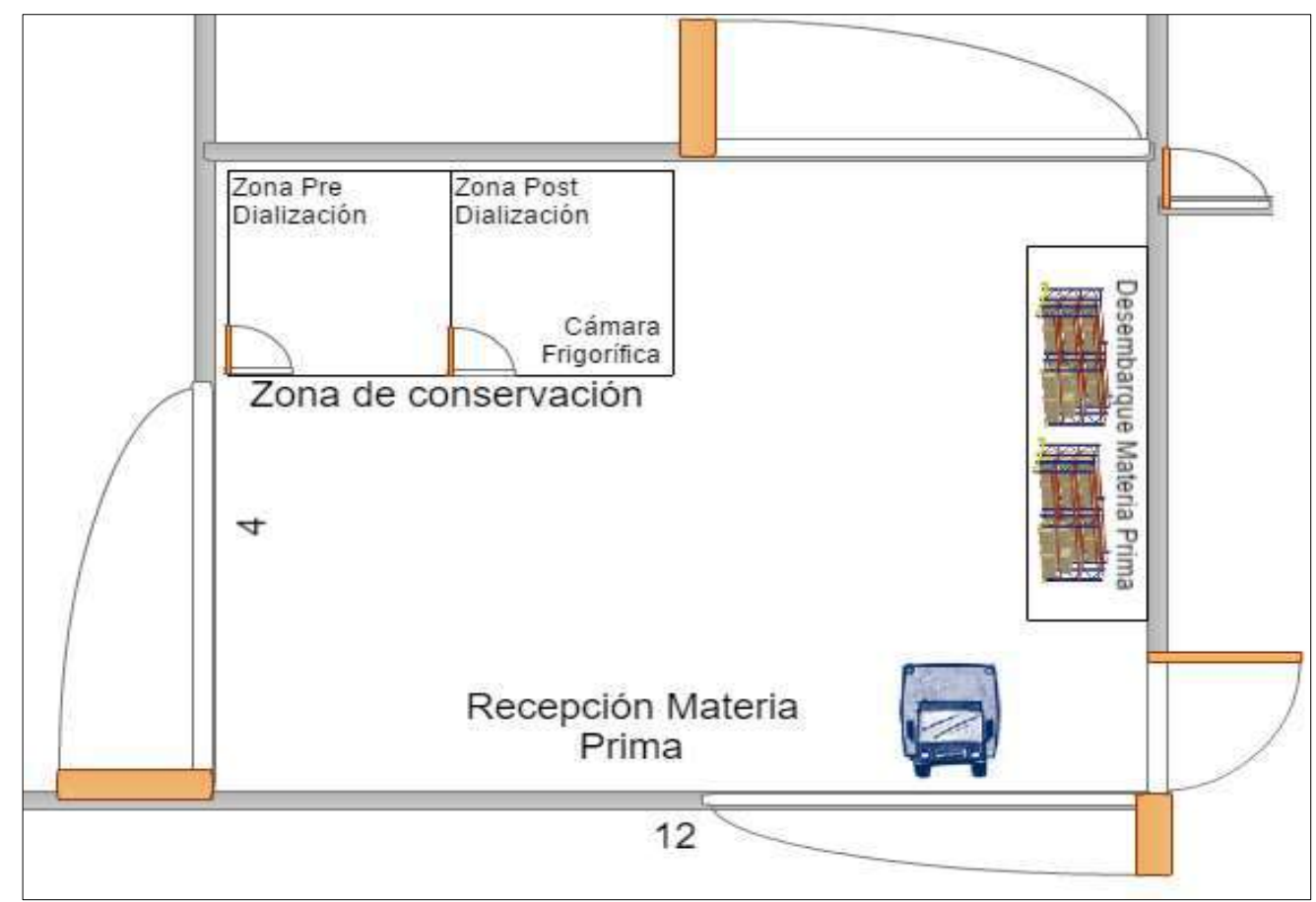

Figura 66. Almacén, diseño propio

En el espacio destinado al almacén (figura $\mathrm{N}^{\circ}$ 66), deberá de estar dispuesta una cámara de frio la cual necesita de 18 metros cuadrados de espacio para su funcionamiento, además de tener otro espacio libre para el almacenamiento del insumo (papa) en su estado natural dispuestas en sacos para lo cual se destinará 20 metros cuadrados donde se podría almacenar 1.2 toneladas en una cama y hasta 8 toneladas en cinco camas. 


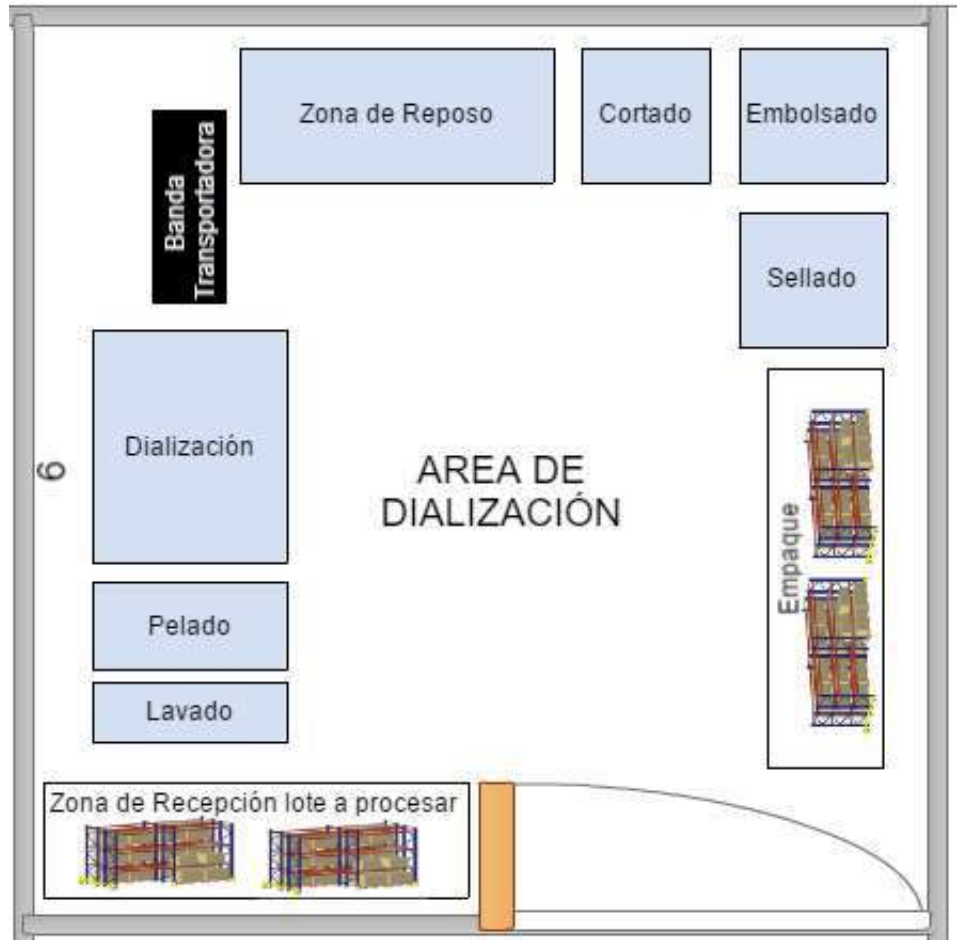

Figura 67. Área de Dialización, diseño propio

En el ambiente destinado al proceso de dialización (figura $\mathrm{N}^{\circ} 67$ ), tendrá que contener varios equipos destinados a este fin, los cuales son el equipo de dialización, la poza de reposo, la cinta transportadora, el equipo de cortado y finalmente el equipo de empaque, todos estos equipos juntos requieren un total de 16.18 metros cuadrados para su operación por lo cual el ambiente destinado a la dialización tendrá una total de 24 metros cuadrados ya que deberá de contar con espacios para desplazamiento. 


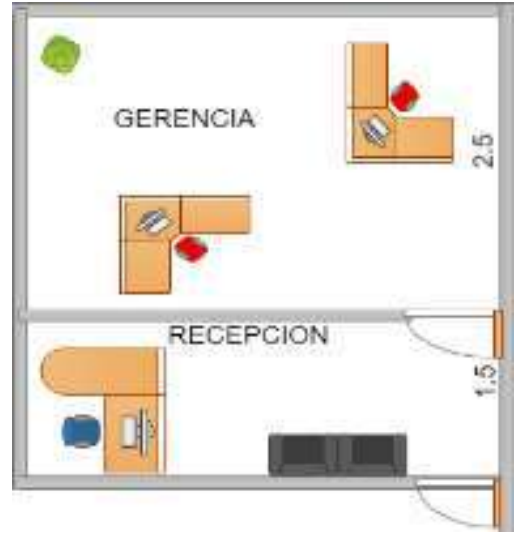

Figura 68. Gerencia

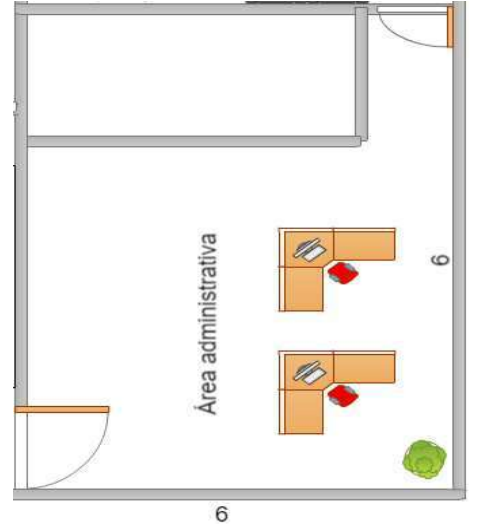

Figura 69. Sala de Reuniones

En la figura 68 y 69, están los ambientes destinados a la gestión administrativa donde trabajaran el administrador general y un asistente con un total de 24 metros cuadrados y un área multiusos denominada sala de reuniones que contará con 36 metros cuadrados y podrá alojar al personal comercial, control de calidad y operaciones, además de servir de espacio para las reuniones de trabajo, como se puede apreciar en las figuras $\mathrm{N}^{\circ} 68$ y $\mathrm{N}^{\circ} 69$.

Finalmente presentamos en la tabla $\mathrm{N}^{\circ} 39$ los metrajes que se necesitan por cada una de las operaciones del presente proyecto, así como los metros cuadrados dispuestos, dando como resultado la necesidad de contar como tamaño ideal de planta 330 metros cuadrados para poder atender las necesidades productivas y de comercialización del presente proyecto.

Tabla 39

Dimensiones de Local de Funcionamiento

\begin{tabular}{lrrr}
\hline \multicolumn{1}{c}{ Ubicación } & Largo & Ancho & M2 \\
\hline Despacho y Preparación de Pedidos & 15 & 10 & 150 \\
Área de Dializaciòn & 12 & 6 & 72 \\
Almacenamiento & 12 & 4 & 48 \\
Gerencia & 6 & 4 & 24 \\
Sala de Reuniones & 6 & 6 & 36 \\
\hline Área Total & $\mathbf{3 3}$ & $\mathbf{1 0}$ & $\mathbf{3 3 0}$ \\
\hline
\end{tabular}

Nota. Elaboración propia 


\subsection{Estudio de localización.}

\subsubsection{Definición de factores locacionales}

Se entiende por localización al análisis que se debe realizar de los diferentes lugares donde es posible ubicar el proyecto el cual se está trabajando en la presente tesis, con el fin de establecer el lugar que ofrece los máximos beneficios, los mejores costos; es decir, esta elección que la empresa realizará debe ser con la finalidad de obtener una mayor ganancia con el mínimo costo (http://soda.ustadistancia.edu.co, 2016).

Para este estudio y análisis se considerarán dos aspectos:

Macro localización

La cual consiste en evaluar el sitio que ofrece las mejores condiciones para la ubicación del proyecto, en el país o en el espacio rural o urbano de una región.

Entre los factores que se deben analizar para esta elección tenemos:

1. Ubicación de los consumidores o usuarios

2. Localización de materia prima y demás insumos

3. Vías de comunicación y medios de transporte

4. Infraestructura de servicios públicos

5. Políticas, planes o programas de desarrollo

6. Normas y regularizaciones específicas

7. Tendencia de desarrollo de la región

8. Condiciones climáticas, ambientales y suelos

9. Intereses de fuerzas sociales y comunitarias 
Micro localización

Es la determinación del punto preciso donde se construirá la empresa dentro de la región y donde se realizará la distribución de las instalaciones en el terreno elegido.

Entre los factores que se analizan para esta elección tenemos:

1. Disponibilidad y costo de recursos: mano de obra, materias primas, servicios y comunicaciones

2. Otros factores: ubicación de la competencia, limitaciones tecnológicas y consideraciones ecológicas

3. Costo de transporte de insumos y de productos, por ejemplo, costos de transferencia a la cuenta de fletes: comprende la suma de costos de transporte de insumos y de productos

\subsubsection{Consideraciones legales.}

\subsubsection{Identificación del marco legal}

- Forma Societaria

La empresa tendrá como razón social CODIAL SAC y contará con cinco accionistas quienes se distribuirán equitativamente el capital representado en acciones. La distribución en porcentaje se muestra en la tabla $\mathrm{N}^{\circ} 40$, la misma será la siguiente: 
Tabla 40

Participación de Accionistas

\begin{tabular}{lc}
\hline \multicolumn{2}{c}{ Participación de los accionistas } \\
\hline \multicolumn{1}{c}{ Accionistas } & Porcentajes \\
\hline Ivet Sonia Aguirre Flores & $25 \%$ \\
Karen Silvia Crespo Quesada & $25 \%$ \\
Jorge Manuel Diaz Pisco & $25 \%$ \\
Oscar Luis F. Gonzales Vega & $25 \%$ \\
\hline
\end{tabular}

Nota. Elaboración propia

Etapas para seguir la constitución:

- Definir el nombre de la empresa: CODIAL S.A.C

- Búsqueda y reserva del nombre en SUNARP. La reserva de la razón social es por 30 días.

- Elaborar la minuta de la constitución de la empresa en notaria

- Si se colocará dinero como capital social, primero se debe abrir una cuenta bancaria a nombre de la empresa.

- Si se colocará activos no monetarios, es necesario que se firme una declaración jurada de bienes

- Elevar la minuta a escritura pública

- Inscripción en Registros Públicos

- El notario levantará la Escritura Pública en el Registro de Personas Jurídicas de la Superintendencia Nacional de los Registros Públicos (SUNARP). Se deberá abonar un monto de $1.08 \%$ de una UIT más S/. 1,000 del capital social

Obtención del Registro Único de Contribuyentes (RUC) 
Antes de iniciar operaciones se debe tramitar el RUC ante la Superintendencia Nacional de Administración Tributaria (SUNAT), este número es el usado para el pago de impuesto ante esta entidad. Para obtener el RUC debemos acudir a la SUNAT y presentar los siguientes documentos:

1. Copia de la escritura pública de constitución, inscrita en Registros Públicos.

2. Recibo de agua, luz o teléfono del domicilio fiscal.

3. Documento de identidad en original del representante legal.

4. Vigencia de poder del representante legal.

5. Formato de inscripción de RUC de la SUNAT, según el tipo de régimen tributario al que se ha acogido.

6. Respecto al régimen tributario estaremos en el Régimen Especial de Impuesto a la Renta (RER), por los dos primeros años ya que nuestra facturación no superará las 150 UIT $(150 * 3950=\mathrm{S} / .592,500)$

7. Una vez que contemos con nuestro número de RUC, y elegido el régimen tributario al cual acogernos, podemos imprimir los comprobantes de pago (boleta y/o factura) que vamos a utilizar.

Libros contables

En este paso se procederá a realizar la compra del software para emitir los libros contables y legalizarlos a través de un notario público. Registro de marcas y patentes. 
El registro de la marca PAPA SANO deberá de será tramitada en la dirección de signos distintivos del Instituto Nacional de Defensa al Consumidor y a la propiedad intelectual (INDECOPI).

El registro de la marca tiene una vigencia de 10 años renovable, la duración del trámite de registro que se contabilizan desde la presentación de la solicitud a INDECOPI hasta la conclusión del mismo, con la obtención del certificado o título de propiedad, es de 120 días aproximadamente, siempre que no exista alguna oposición por parte de un tercero. Teniendo como derecho de prioridad con el registro de la solicitud o depósito realizado a INDECOPI.

Los principales requisitos para registrar la marca son los siguientes:

1. Pagar el derecho de trámite en la caja del Indecopi.

2. Presentar el formato de solicitud consignando datos de identificación del solicitante.

3. Indicar cuál es el signo que se registrará, si el signo posee elementos gráficos, presentar la descripción del mismo y adjuntar su reproducción (cinco reproducciones de 5x5 cm y a colores si también se desea protegerlos colores).

4. Indicar expresamente cuáles son los productos, servicios o actividades económicas que desea registrar, así como cuál es la clase en la que se solicita dicho registró.

5. Una vez aceptada la Solicitud de Registro, usted deberá acercarse a la Oficina del Diario oficial "El Peruano" y solicitar la publicación por única vez. Si el signo solicitado 
está constituido por un logotipo, envase o envoltura debe adjuntarlo en un tamaño de $3 \times 3 \mathrm{~cm}$.

Con respecto al registro de la patente, no realizaremos su registro ya que es un producto del cual se conoce su composición.

Licencias y autorizaciones.

Licencia de Funcionamiento Municipal

La licencia de funcionamiento es otorgada por el municipio en donde se encontrarán las instalaciones del negocio. El municipio cobra una tasa dependiendo del giro de la actividad y el área que ocupará el inmueble.

Al inicio del trámite se puede solicitar Licencia Provisional o definitiva, para el local del presente proyecto se aplicará la segunda. Al inicio, la municipalidad entregará una licencia provisional luego de 12 meses emite la Licencia Municipal definitiva.

Requisitos para licencia de funcionamiento definitiva:

1. Solicitud de licencia de funcionamiento definitiva.

2. Certificado de Zonificación y Compatibilidad de Uso

3. Copia del RUC

4. Copia del Título de Propiedad o documento equivalente que acredite la propiedad o Copia del contrato de alquiler.

5. Copia de la Escritura Pública de Constitución.

6. Informe favorable de Defensa Civil.

7. Pago por derecho de trámite. 
8. En el caso de autorizaciones sectoriales, copia de la autorización y/o certificación del sector competente según actividad.

9. Algún otro documento requerido por la Municipalidad. Para continuar con la Licencia Permanente, cada año se requiere que los contribuyentes presenten ante la Municipalidad de su jurisdicción una declaración jurada anual, simple y sin costo alguno, para informar que contribuyentes presenten ante la Municipalidad de su jurisdicción una declaración jurada anual, simple y sin costo alguno, para informar que continúan en el giro autorizado para el establecimiento.

Habilitación Sanitaria de Fábrica

Según Base Legal D.S. N ${ }^{a}$ 007-98-SA, Arts. $5^{\circ}$ y 94º del 25/09/98, señala que entre los requisitos se debe cumplir:

1. Solicitud dirigida al Director Ejecutivo de Higiene Alimentaria y Zoonosis de la DIGESA, con carácter de Declaración Jurada, que contenga $\mathrm{N}^{\mathrm{o}}$ de RUC, firmada por el Representante Legal.

2. Plan HACCP, Programas de Higiene, Saneamiento y Buenas Prácticas de Manufactura (BPM), por línea de producción.

3. Comprobante de Pago de Derecho de Trámite.

Registro Sanitario para alimentos y bebidas de consumo humano 
Entre los requisitos que solicita la entidad de Dirección General de Salud Ambiental e Inocuidad Alimentaria (DIGESA) se debe presentar:

1. Solicitud Única de Comercio Exterior - SUCE, www.vuce.gob.pe

2. Resultados de los análisis físico, químico y microbiológico del producto terminado, confirmando Su aptitud de acuerdo a la normatividad sanitaria vigente, otorgado por un laboratorio acreditado o del laboratorio del control de calidad de la fábrica.

3. Certificado de Libre Comercialización o similar o Certificado Sanitario emitido por la Autoridad Competente del país de origen, en original o copia refrendada por el consulado respectivo, cuando el alimento o bebida sea importado.

4. Información que contendrá el rotulado o etiquetado.

5. Análisis bromatológico practicado por laboratorio acreditado por INDECOPI para los Alimentos y Bebidas de regímenes especiales, los mismos que deberán señalar sus propiedades nutricionales.

6. Comprobante de Pago de Derecho de Trámite.

\subsubsection{Ordenamiento jurídico de la empresa}

El ordenamiento jurídico determinado para la empresa CODIAL SAC, será como persona jurídica bajo el régimen de 
sociedad cerrada (SAC). Según una analista legal de la Sociedad Nacional de Industrias (www.pqs.pe, 2016) indica que la dinámica de este tipo de sociedad es la más recomendable para una empresa familiar, pequeña o mediana

Ventajas

1. Se tendrá una responsabilidad limitada por socio, el cual equivale al capital que cada uno aportaría para iniciar el negocio.

2. Se contará con cuatro socios de los cuales cada uno tendrá el $25 \%$ de participación en la empresa.

3. Al contar con clientes a empresas, se considerará como opción la Sociedad Anónima Cerrada (SAC).

4. Se tendrá el apoyo de los bancos ya que se emitirá un préstamo bancario a nombre de la empresa.

Desventajas

1. Se asumirá gastos de constitución tanto en notaria como registros públicos para inscripción ante la Superintendencia Nacional de Registros Públicos (SUNARP).

2. No puede acogerse al Nuevo RUS, solo al régimen especial o régimen especial de impuesto a la renta.

3. Si se decide cerrar la empresa o cambio de razón social se debe realizar mediante un libro de actas y este genera un costo mayor modificación y cambio que será asumido por la empresa 


\subsection{Determinación de la localización óptima.}

\section{Localización de la planta CODIAL S.A.C}

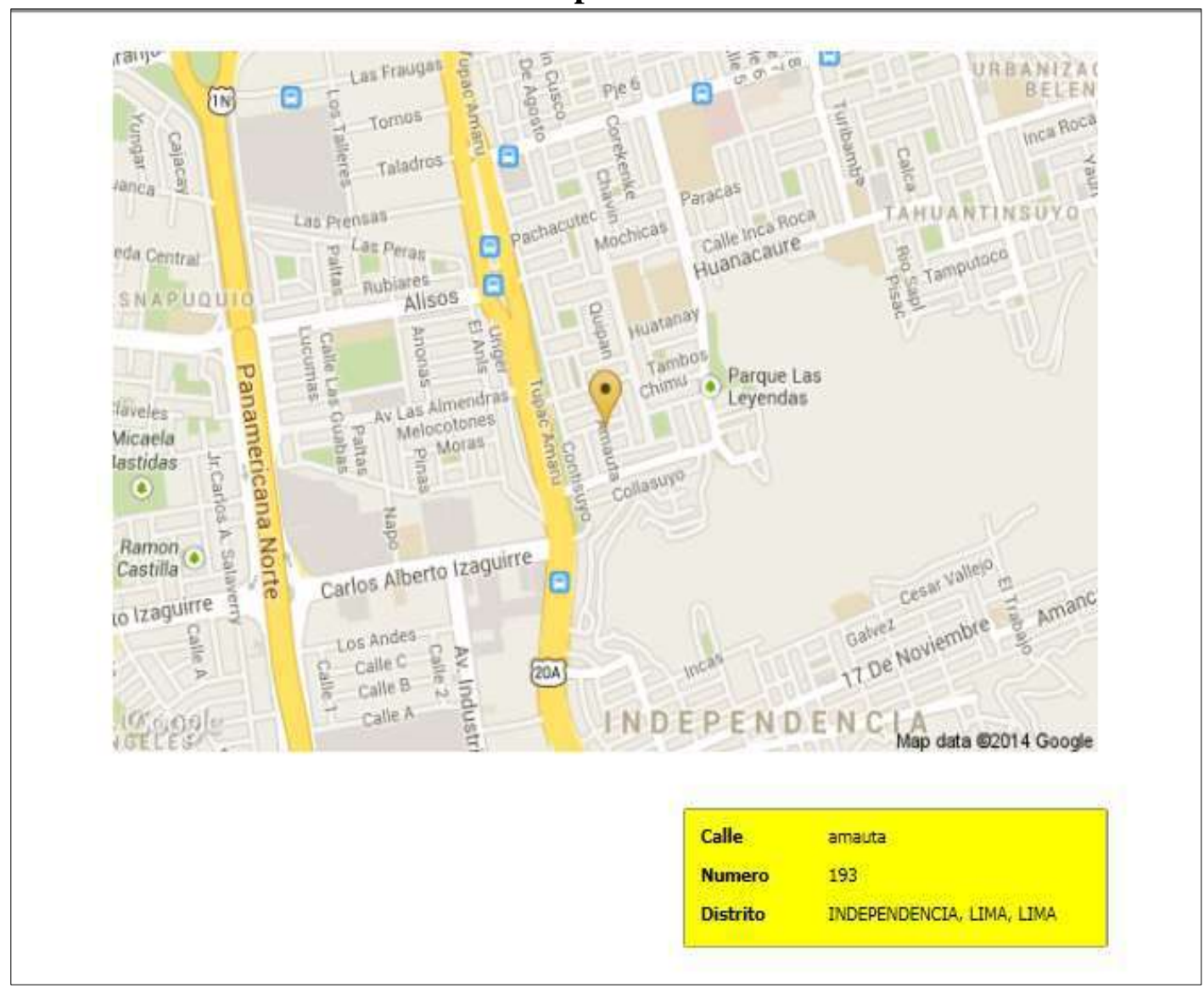

Figura 70. Mapa de Localización, diseño propio

Macro Localización

Las instalaciones de la empresa CODIAL S.A.C, donde se elaborarán los productos, se encuentra ubicado en la calle Amauta 193 - Tahuantinsuyo 1era zona Independencia y cuenta con una extensión de 330 metros cuadrados de área, como muestra la figura $\mathrm{N}^{\circ} 70$.

Micro Localización

El local de la empresa tiene una ubicación prevista en la avenida Túpac, en el distrito de Independencia, la cual ha sido elegida por ser propiedad de uno de los 
accionistas, con tendencia a tener menor costo de instalación y de alquiler. Además de ser una ubicación estratégica por la cercanía a los clientes objetivos.

Adicional se consideró esta ubicación por estar en el centro del área que se atenderá en una primera etapa del proyecto, contará con vías adecuadas y tendrá a proveedores cerca de la zona (Productores de Fiori). Adicional a esta ubicación se evalúo también una locación en Puente Piedra, así como muestra la tabla $\mathrm{N}^{\circ} 41$.

La elección de la ubicación de nuestro local fue sustentada bajo el análisis de otros aspectos como el método de evaluación por factores, así como muestra la tabla $\mathrm{N}^{\circ} 42$.

Tabla 41

Matriz de Factores de Micro Localización

MATRIZ DE FACTORES DE MICRO LOCALIZACION

\begin{tabular}{lccccc}
\cline { 3 - 6 } & & \multicolumn{2}{c}{ INDEPENDENCIA } & \multicolumn{2}{c}{ PUENTE PIEDRA } \\
\hline \multicolumn{1}{c}{ VARIABLES } & PESO & ESCALA & CALIFICACIÓN & ESCALA & CALLFICACIÓN \\
\hline Tamaño del Local & 0.13 & 6 & 0.78 & 7 & 0.91 \\
Precio de Alquiler & 0.2 & 6 & 1.2 & 6 & 1.2 \\
Accesibilidad & 0.11 & 6 & 0.66 & 4 & 0.44 \\
Seguridad de la Zona & 0.11 & 6 & 0.66 & 4 & 0.44 \\
Cercania de Proveedore & 0.1 & 7 & 0.7 & 3 & 0.3 \\
Costos de Servicios & 0.2 & 5 & 1 & 5 & 1 \\
Cercanía a clientes & 0.15 & 6 & 0.9 & 4 & 0.6 \\
\hline \multicolumn{1}{c}{ TOTALES } & 1 & & 5.9 & & 4.89 \\
\hline
\end{tabular}

Nota. Adaptado de "Métodos de localización de planta" http://www.ingenieriaindustrialonline.com/herramientas-para-el-ingenieroindustrial/diseño-y-distribución-en-planta/métodos-de-localización-de-planta/ 
Tabla 42

Calificación de Factores

\begin{tabular}{cc}
\hline \multicolumn{2}{c}{ CALIFICACION DE FACTORES } \\
\hline Leyenda & Escala \\
\hline Pésima & 1 \\
Muy Mala & 2 \\
Mala & 3 \\
Regular & 4 \\
Buena & 5 \\
Muy Buena & 6 \\
Excelente & 7 \\
\hline
\end{tabular}

Adaptado de Métodos de localización de planta de http://www.ingenieriaindustrialonline.com/herramientas-para-elingeniero-industrial/diseño-y-distribución-en-planta/métodos-delocalización-de-planta/ 


\section{Capítulo VI: Aspectos Organizacionales}

\subsection{Caracterización de la cultura organizacional deseada}

\subsubsection{Visión.}

Define las metas que la empresa pretende lograr en el futuro, estas deben ser realistas y alcanzables, puesto que la propuesta debe tener un carácter inspirador y motivador ("Welcome to the new marketing", 2012).

Se determinó la siguiente visión para la empresa:

"Lograr en cinco años ser una empresa líder y competitiva en la elaboración de alimentos dializados, buscando satisfacer la necesidad de nuestros consumidores y posicionarnos en su mente como la mejor opción de alimentos saludables"

Basada en el análisis de los siguientes criterios, según indica la tabla $\mathrm{N}^{\circ} 43$ : 
Tabla 43

Criterios que definen la visión

\begin{tabular}{|c|c|c|}
\hline Característica & Descripción & Análisis \\
\hline Gráfica & $\begin{array}{l}\text { Presenta una imagen de la clase de } \\
\text { empresa que la diretiva intenta crear y } \\
\text { de la posicion o posición en el mercado } \\
\text { que se esfuerza en conseguir }\end{array}$ & $\begin{array}{l}\text { Como podemos observar la } \\
\text { visión se presenta una imagen } \\
\text { contundente de lo que quieren } \\
\text { ser líder y competitiva", con lo } \\
\text { cual cumple con esta } \\
\text { característica. }\end{array}$ \\
\hline Direccional & $\begin{array}{l}\text { Mira hacia adelante. Describe el curso } \\
\text { estrategico que trazó la directiva y las } \\
\text { clases de cambios de producto/ } \\
\text { mercado/ cliente/ tecnología que } \\
\text { ayudarán a la compañía a prepararse } \\
\text { para el futuro }\end{array}$ & $\begin{array}{l}\text { Podemos identificar esta } \\
\text { característica que esta } \\
\text { especificada en la palabra } \\
\text { "elaboración de alimentos } \\
\text { dializados", cual represnta el } \\
\text { futuro que la compañía pretende } \\
\text { perseguir. }\end{array}$ \\
\hline
\end{tabular}

Presenta una imagen de la clase de empresa que la diretiva intenta crear y de la posicion o posición en el mercado que se esfuerza en conseguir
Podemos ver que está dentro del testimonio de " mejor opción de alimentos saludables"

\begin{tabular}{lll}
\hline & $\begin{array}{l}\text { No es una declaración eterna. El curso } \\
\text { que trazó la directiva quizá deba } \\
\text { ajustarse conforme cambien las } \\
\text { circunstancias del producto/ mercado / } \\
\text { cliente/ tecnología viable, está dentro } \\
\text { de las posibilidades razonables de lo } \\
\text { que la empresa puede esperar lograr a } \\
\text { su debido tiempo. }\end{array}$ & $\begin{array}{l}\text { Identicamos que centraliza sus } \\
\text { siendo este de cualquier tipo } \\
\text { (que contenga minerales) y que } \\
\text { circunstancias que la población } \\
\text { necesite o requiera de manera } \\
\text { razonable. }\end{array}$ \\
\hline
\end{tabular}

Indica por qué el rumbo elegido es comercialmente sensato y convertirte

Deseable para los intereses de largo plazo de los inversionistas (en especial de los accionistas empleados y clientes)
Esta característica es una de las más importantes dado que la visión se centrará en uno de los deseos más necesarios del ser humano, el alimentarse de forma saludable, dando por consecuencia que sea muy atractivo para cualqiuer inversionista la participación en esta empresa.

Definitivamente es muy facil de compartir la visión en pocas palabras a la comunidad, además de la utilización de un lexico natural
Fácil de comunicar
Se explica en cinco o diez minutos e idealmente se reduce a un lema sencillo y atractivo.

Nota. Kotter P, John, Leading Change, Boston, Harvard Business School Press, 1996, p. 72. 


\subsubsection{Misión.}

Consiste en la labor o actividad que tiene que realizar la empresa en el mercado, teniendo presente el público objetivo al cual se dirigirá y el valor diferencial que le piensa brindar ("Welcome to the new marketing", 2012).

Se determinó la siguiente misión para la empresa:

"Desarrollar un producto dializado a nivel nacional, mediante un proceso industrial que utiliza una técnica natural, generando un bien de consumo alimenticio que satisfaga las necesidades nutricionales de las personas, contribuyendo así con su calidad de vida y salud"

Basada en el análisis que muestra la tabla $N^{\circ} 44$ de los siguientes criterios: 
Tabla 44

Criterios que definen la Misión

\begin{tabular}{|c|c|c|}
\hline Característica & Descripción & Análisis \\
\hline Clientes & ¿Quiénes son ellos? & $\begin{array}{l}\text { Definitivamente está bien } \\
\text { identificado quien es el cliente en } \\
\text { este caso está referido a la } \\
\text { "personas" }\end{array}$ \\
\hline Productos o servicios & $\begin{array}{l}\text { ¿Cuáles son los productos o } \\
\text { servicios de la compañía? }\end{array}$ & $\begin{array}{l}\text { Se puede observar que desea } \\
\text { cumplir ampliamente esta } \\
\text { característica "producto } \\
\text { dializado" }\end{array}$ \\
\hline Ubicación & ¿Dónde compite la compañía? & $\begin{array}{l}\text { Está definiendo su ubicación } \\
\text { como nivel nacional. }\end{array}$ \\
\hline Tecnología & $\begin{array}{l}\text { ¿Cuál es la tecnología básica } \\
\text { de la empresa? }\end{array}$ & $\begin{array}{l}\text { Se Identifica claramente este } \\
\text { Punto "mediante un proceso } \\
\text { industrial" }\end{array}$ \\
\hline $\begin{array}{l}\text { Preocupación por la } \\
\text { supervivencia }\end{array}$ & $\begin{array}{l}\text { ¿Cuáles son los objetivos } \\
\text { económicos de la compañía? }\end{array}$ & $\begin{array}{l}\text { No se Identifica Claramente este } \\
\text { Punto. }\end{array}$ \\
\hline Filosofía & $\begin{array}{l}\text { ¿Cuáles son las creencias } \\
\text { básicas, valores, aspiraciones } \\
\text { y prioridades filosóficas de la } \\
\text { empresa? }\end{array}$ & $\begin{array}{l}\text { Está definida en "contribuyendo } \\
\text { así con su calidad de vida y } \\
\text { salud" }\end{array}$ \\
\hline Concepto propio & $\begin{array}{l}\text { ¿Cuáles son las principales } \\
\text { fortalezas y ventajas } \\
\text { competitivas de la compañía? }\end{array}$ & $\begin{array}{l}\text { Su fortaleza está dada en "utiliza } \\
\text { una técnica natural" }\end{array}$ \\
\hline $\begin{array}{l}\text { Preocupación por la } \\
\text { imagen pública }\end{array}$ & $\begin{array}{l}\text { ¿Cuál es la responsabilidad } \\
\text { pública de la empresa y qué } \\
\text { imagen desea? }\end{array}$ & $\begin{array}{l}\text { El hecho de querer buscar el } \\
\text { bienestar en la calidad de vida de } \\
\text { las personas, es una posición que } \\
\text { sostendrá a la organización }\end{array}$ \\
\hline $\begin{array}{l}\text { Preocupación de los } \\
\text { empleados }\end{array}$ & $\begin{array}{l}\text { ¿Cuál es la actitud de la } \\
\text { compañía hacia } \\
\text { sus empleados? }\end{array}$ & $\begin{array}{l}\text { No se identifica claramente este } \\
\text { Punto }\end{array}$ \\
\hline
\end{tabular}

Nota. F. R. David, "How companies define their mission", Long Range

Planning, vol 22, número 1, 1989, pp. 90-97

\subsubsection{Principios.}

1. Limpieza: Involucrar a todos los participantes del proceso productivo con el cuidado de higiene personal y laboral. 
2. Responsabilidad: Desarrollar el sentido de la responsabilidad en todos los trabajadores de la empresa, con la finalidad de lograr cada una de las metas trazadas.

3. Honestidad: Comunicar de manera clara a los consumidores acerca del producto que se está generando, con la finalidad de que no exista dudas ni temores para consumir el nuevo producto propuesto

4. Trabajo en equipo: Concientizar y fortalecer la visión empresarial en los trabajadores para construir una sinergia que permita alcanzar los objetivos trazados de la organización.

\subsection{Formulación de Estrategias del Negocio}

Las estrategias del negocio se basarán en cuatro pilares, cada uno se aplicará en el tiempo que le corresponda, estos se ordenan y mencionan en la figura $\mathrm{N}^{\circ} 71$ :

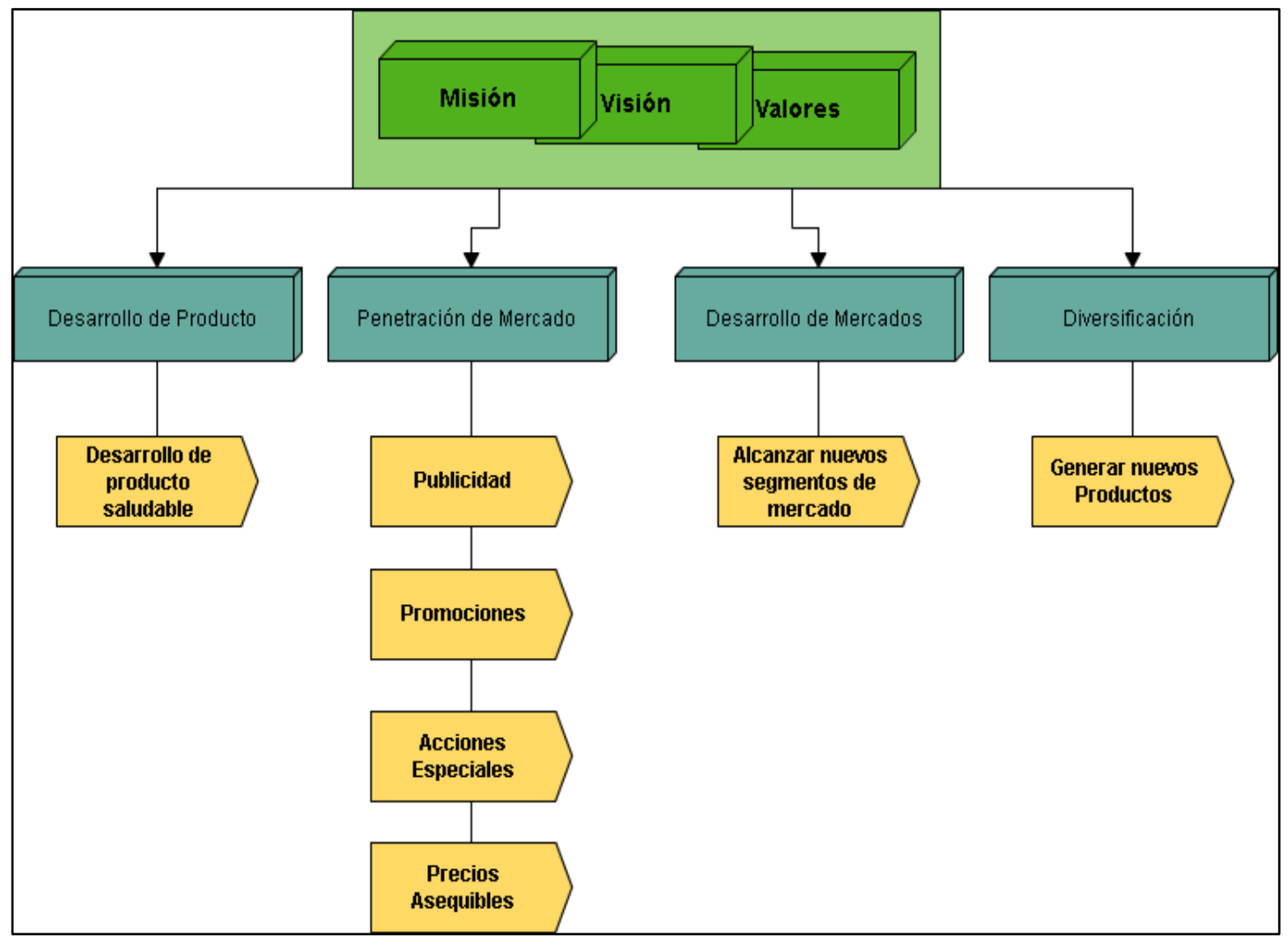

Figura 71. Estrategia de negocio empresa Codial, diseño propio 


\section{Desarrollo de producto}

El producto bandera de la empresa es la papa dializada, tubérculo que, al pasar por un proceso natural de sumersión en agua, logra disminuir su nivel de potasio, lo que permite al organismo humano procesarlo de mejor manera.

Para poder lograr este producto la empresa involucra dos procesos en paralelo, que son:

Ingeniería del proceso: Desarrollar el proceso, a través de máquinas y herramientas, que ayude a obtener el producto deseado bajo un estricto control de calidad.

Análisis del mercado: Identificación de la necesidad de un producto, como el que la empresa busca poner en el mercado, con el suficiente grupo de consumidores que la empresa pueda sostener en el tiempo, con un proceso de producción y atención, cubriendo así la demanda existente.

\section{Penetración de mercado}

Una vez que la empresa haya desarrollado el producto, buscará incrementar su participación en el mercado existente a través de las cuatro estrategias básicas

\section{Publicidad}

La zona 2, segmento en el cual se iniciará la introducción del producto, papa dializada; cuenta en gran porcentaje con acceso al internet, es por esta razón que la empresa diseñará estrategias basadas en: 
a.Comunicación del producto a través de las redes sociales.

b.Desarrollo de videos para mostrar en canales de youtube.com, que transmita al consumidor el proceso de dialización de la papa y sus beneficios.

c.Diseño y presentación de página web, que comunique al consumidor de los beneficios de la papa dializada y a la vez sirva como medio de comunicación entre el consumidor y la empresa.

Considerando que existe una parte de dicho segmento que no tiene acceso o no conoce de las herramientas en internet, se buscará difundir el producto a través de dos medios de comunicación masiva:

a. La radio, medio de difusión masiva en donde se publicitará el producto en programas de salud y bienestar personal.

b. Periódicos, se publicitará el producto en este medio, dando a conocer: la empresa, el producto y sus beneficios

\section{Promociones}

Habiendo informando al consumidor acerca del producto, se trabajará en una campaña de promoción del producto a través de dos acciones:

a. Establecer una alianza estratégica con una empresa de consumo alimenticio, que también tenga dentro de sus productos de consumo, aquellos denominados saludables; para que el consumidor pueda adquirir ambos productos como un paquete de oferta. 
b. Presentar el producto con un recetario de regalo para que el consumidor pueda usarlo en su preparación.

Ambas acciones tendrán un plazo determinado, solo hasta encontrar una mayor masificación de venta del producto.

\title{
Acciones especiales
}

Una de las estrategias adicionales que la empresa aplicará a mediano plazo es el de la asistencia social, orientando a los consumidores potenciales sobre la relación directa que existe entre el consumo de productos saludables con la calidad de vida.

\section{Precios Asequibles}

La empresa ofrecerá un producto a precio accesible, con la finalidad de ganar participación en el mercado, colocando grandes volúmenes de venta.

\section{Desarrollo de mercado}

Habiendo logrado un posicionamiento en el mercado de Lima Metropolitana y teniendo una gran aceptación por parte del consumidor, la empresa buscará acceder a otros mercados en el futuro que están clasificados en:

\author{
Mercado Interno \\ Ingresar, dentro del país, a las principales ciudades ofreciendo \\ nuestro producto. \\ Mercado Externo
}


El cuidado de la salud es una necesidad a nivel mundial, es por

ello que se buscará atender a otros países por medio de exportaciones.

\section{Diversificación}

El producto bandera de la empresa es la papa dializada, se ha elegido este producto porque estadísticamente es uno de los tubérculos que más se consumen en el Perú. El proceso de dialización que realizará la empresa, también puede ser aplicado en otros productos, lo que permite abrir un abanico de posibilidades de comercialización de productos similares u otros tubérculos con las mismas bondades que las que se consigue con la papa dializada.

\subsection{Determinación de las ventajas competitivas críticas}

Siguiendo la teoría de estrategia competitiva (Michael Porter, 2013) donde señala tres estrategias genéricas: liderazgo global en costos, diferenciación y enfoque o concentración (figura $\mathrm{N}^{\circ} 72$ ), con las cuales una empresa a través de ella puede hacer frente a las cinco fuerzas que moldean la competencia en un sector y conseguir una ventaja competitiva sostenible que le permita superar a las firmas rivales.
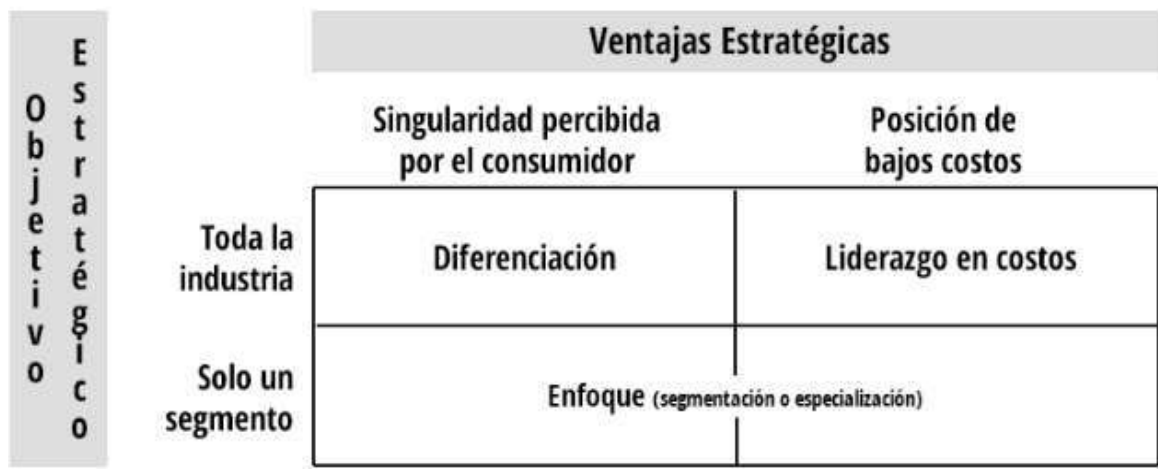

Figura 72. Ventajas Estratégicas

http://infomipyme.tmp.vis

Hosting.com/Docs/GT/Offline/marketing/marketing.htm 
1. Estrategia de liderazgo global en costos

La empresa debe tener la capacidad de reducir costos en todos los eslabones de su cadena de valor, de tal manera que la disminución de gastos redunde en un mejor precio para el consumidor y en consecuencia en una mayor participación de mercado.

2. Estrategia de diferenciación

La empresa debe producir servicios o productos exclusivos que sean percibidos así de especiales por los consumidores, quienes están en disposición de pagar más por tenerlos.

3. Estrategia de enfoque o concentración (segmentación o especialización)

La empresa se concentra en satisfacer segmentos bien definidos, de población, de productos o geográficos.

Las dos primeras, liderazgo en costos y diferenciación, buscan una ventaja general en su sector; mientras que la tercera, enfoque o concentración, busca tener una ventaja dentro de un mercado objetivo.

Para el presente proyecto se considerará la estrategia de Diferenciación, ya que el producto bandera "papa dializada", es un producto industrial diferenciado (no existente aún en le mercado como tal) y por el cual los consumidores potenciales pueden pagar un poco más que por la papa regular. Con esta estrategia se puede lograr la ventaja competitiva que consiste en contar con una técnica innovadora que permite de manera natural reducir los niveles de minerales en el producto ofertado. Las características de la ventaja competitiva son:

- Singularidad percibida del producto por el consumidor

- Proceso de producción ágil en comparación con el proceso casero 
- Obtención de un producto práctico, ya que estará listo para su preparación

\subsection{Diseño de la estructura organizacional deseada}

El diseño de la estructura organizacional deseada tendrá una orientación mixta (vertical y horizontal), el sentido vertical debido a que se despliega de arriba hacia abajo, ubicándose el puesto más crítico en el extremo superior, y de forma escalonada se van ubicando los distintos departamentos debajo de aquel, esto por un tema de orden al cual se le adicionará la característica de la flexibilidad hacia los lados horizontales, ya que a pesar de existir una jerarquía y orden de mando, logrará tener el menor número de niveles jerárquicos para integrar todas las unidades, orientando a la empresa a actuar como equipo de trabajo, movilizando de forma sistemática la inteligencia de todos sus recursos humanos, para obtener sus grandes aportes y haciéndolos agentes activos en los proyectos que la empresa proponga, así como muestra la figura $\mathrm{N}^{\circ} 73$.

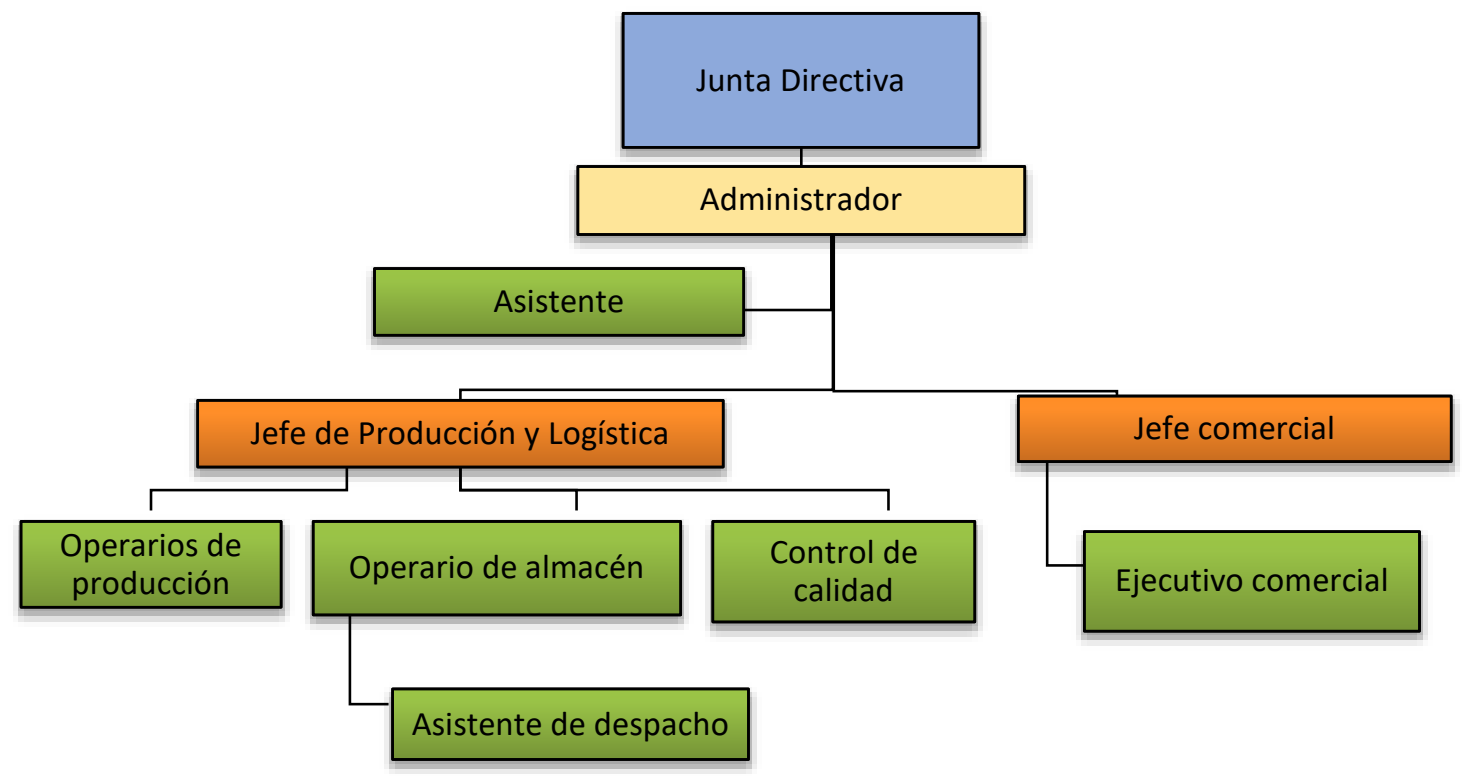

Figura 73. Organigrama Empresarial.

adaptado de "La organización en la empresa" por Salazar Molina Adafrancys, 2015, recuperado de http://datateca.unad.edu.co/contenidos/206041/AVA_2015-

2/Lecturas/Estructuras_organizacionales_y_tipos_de_organigramas.pdf 


\subsection{Diseño de los perfiles de puestos clave}

Los puestos que se detallan a continuación deberán cumplir con las funciones asignadas a fin de garantizar el nivel de producción y calidad que se necesita para asegurar el nivel de servicio requerido por el cliente.

La Junta Directiva como máxima autoridad, conformada por los accionistas o directores, está en la facultad de orientar (sin involucrarse en la administración rutinaria de la compañía), de supervisar y cuestionar las decisiones y acciones que se vayan a realizar con el fin de salvaguardar los beneficios de la empresa. Son los encargados de brindar los recursos financieros para el buen desarrollo de las operaciones de la empresa.

En la tabla $\mathrm{N}^{\circ} 45$ a la 54 se detallan los puestos, tareas, funciones y responsabilidades que desarrollarán las áreas que se encuentran en el organigrama presentado: 
Tabla 45

Funciones de los Puesto o Cargos

Representante legal de la empresa.
Encargado de planear, organizar, y
dirigir el funcionamiento
administrativo y operativo de la
empresa.

ADMINISTRADOR empresa, asegurando el cumplimiento de los objetivos de ventas, contribución y merma.

Diseñar y velar por la implementación de los planes de acción que faciliten la gestión y control de las diferentes

operaciones administrativas de la empresa de acuerdo a los parámetros establecidos.

manteniendo un adecuado control y registro de las actividades financieras y tributarias.
Establecer planes de trabajo para el alcance de las metas esperada por los accionistas.

Reporte de Ventas diarias.

Velar por el buen funcionamiento de la gestión comercial, financiera y administrativa.

Analizar constantemente el mercado a fin de identificar oportunidades de negocio.

Garantizar el funcionamiento y mejora del sistema de gestión de alta calidad a través del manejo y análisis de la información de todos los procesos.

Supervisar constantemente los resultados.

Analizar los Estados Financieros y los presupuestos de la empresa en forma completa y oportuna.

Controlar la disponibilidad de los recursos presupuestarios y el incremento o variación del estado financiero presupuestal o patrimonial.

Elaborar y presentar periódicamente la

información de la gestión administrativa a su cargo.

Realizar el proceso de reclutamiento y

selección de acuerdo a los perfiles

requeridos, garantizando la efectividad del

proceso.
Reporte de Evolución de

Ventas Mensuales.

Análisis de Resultado de Ventas.

Informe de Cobertura.

Presupuesto de Compras.

Flujos de provisión.

Estados de cuenta. 
Tabla 46

Funciones de los Puesto o Cargos - Continuación 1

\begin{tabular}{|c|c|c|c|c|}
\hline NOMBRE DEL PUESTO & OB.JETIVO & TAREAS & FUNCIONES & DOCUMENTACION \\
\hline \multirow{5}{*}{ ASISTENTE } & \multirow{5}{*}{$\begin{array}{l}\text { Apoyo administrativo en las } \\
\text { actividades y procesos que } \\
\text { garanticen el funcionamiento y } \\
\text { control. }\end{array}$} & \multirow{5}{*}{ Gestión y Análisis } & $\begin{array}{l}\text { Controlar y realizar la emisión de cheques, } \\
\text { velando porque se cumplan con los } \\
\text { cronogramas de cobro y pago } \\
\text { preestablecidos. }\end{array}$ & Reporte de cheques emitidos. \\
\hline & & & $\begin{array}{l}\text { Validar y suministrar información confiable } \\
\text { sobre las disponibilidades bancarias de la } \\
\text { Empresa }\end{array}$ & Reporte de caja chica. \\
\hline & & & $\begin{array}{l}\text { Analizar y entregar información financiera } \\
\text { para la toma de decisiones, así como para } \\
\text { solicitudes de créditos que la empresa } \\
\text { necesite. } \\
\text { Revisar los gastos de caja chica, asegurando } \\
\text { que los pagos emitidos correspondan a } \\
\text { conceptos preestablecidos y estén } \\
\text { previamente autorizados. }\end{array}$ & $\begin{array}{l}\text { Reporte de créditos y } \\
\text { cobranzas. }\end{array}$ \\
\hline & & & $\begin{array}{l}\text { Cualquier actividad encomendada por su } \\
\text { superior inmediato dentro de sus } \\
\text { competencias, inherente al cargo. }\end{array}$ & \\
\hline & & & $\begin{array}{l}\text { Realizar llamadas según lo solicite su } \\
\text { superior. }\end{array}$ & \\
\hline
\end{tabular}


Tabla 47

Funciones de los Puesto o Cargos - Continuación 2

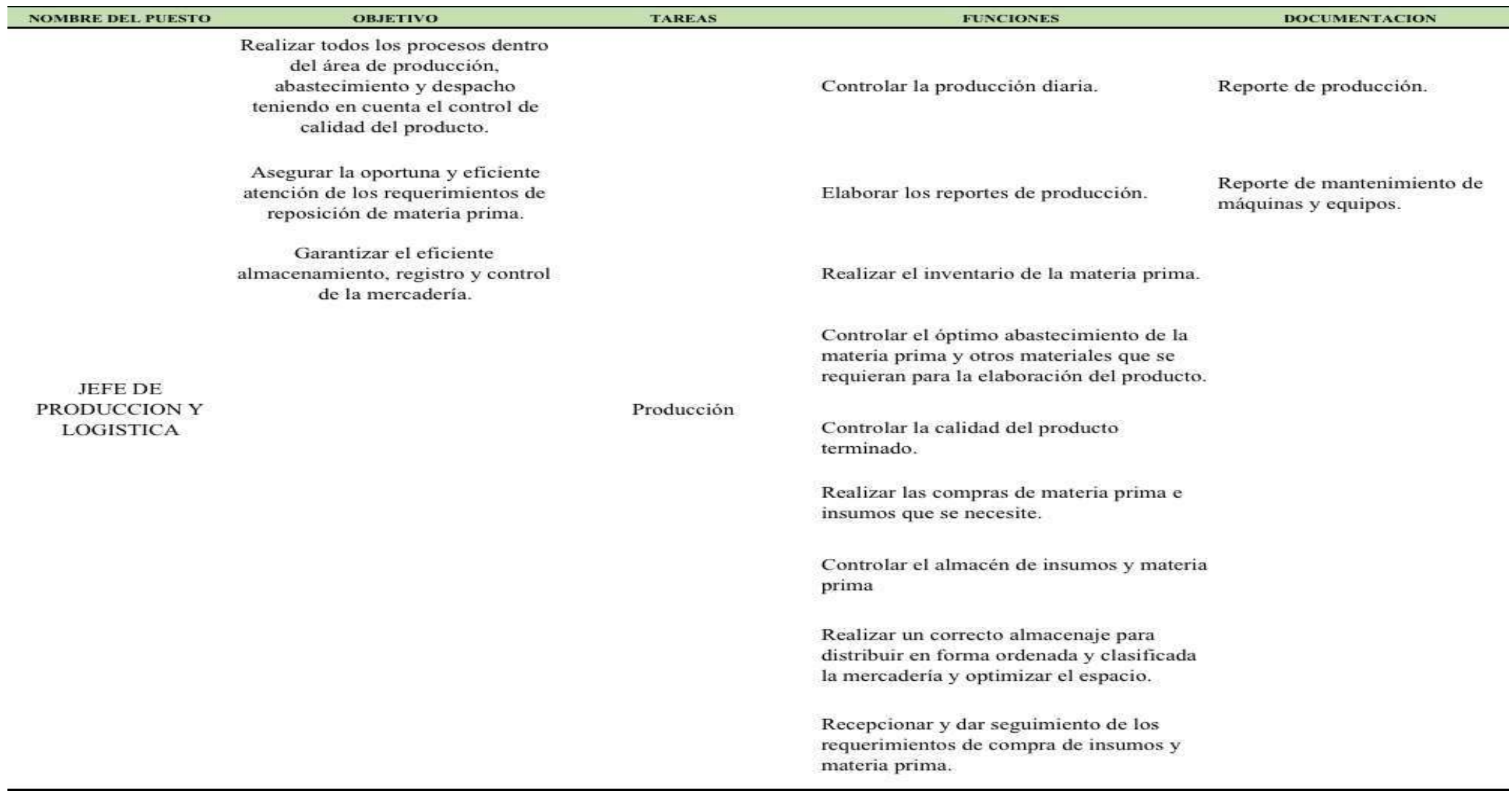


Tabla 48

Funciones de los Puesto o Cargos - Continuación 3

\begin{tabular}{|c|c|c|c|c|}
\hline NOMBRE DEL PUESTO & OBJETIVO & TAREAS & FUNCIONES & DOCUMENTACION \\
\hline \multirow{4}{*}{$\begin{array}{l}\text { PERSONAL DE } \\
\text { PRODUCCION }\end{array}$} & \multirow{4}{*}{$\begin{array}{c}\text { Encargado de elaborar la } \\
\text { producción }\end{array}$} & \multirow{4}{*}{ Producción } & $\begin{array}{l}\text { Elaborar las papas dializadas de acuerdo al } \\
\text { programa enviado por el Jefe de } \\
\text { Producción y Logistica. }\end{array}$ & \\
\hline & & & $\begin{array}{l}\text { Dar mantenimiento y limpieza a los } \\
\text { utensilios que usa en la elaboración del } \\
\text { producto. }\end{array}$ & \\
\hline & & & $\begin{array}{l}\text { Programar los horarios del proceso de } \\
\text { dialización para cada lote, de acuerdo al } \\
\text { orden de elaboración. }\end{array}$ & \\
\hline & & & $\begin{array}{l}\text { Reportar y coordinar con el Jefe de } \\
\text { Producción y Logística el mantenimiento } \\
\text { de las maquinarias. }\end{array}$ & \\
\hline
\end{tabular}


Tabla 49

Funciones de los Puesto o Cargos - Continuación 4

\begin{tabular}{|c|c|c|c|c|}
\hline NOMBRE DEL PUESTO & OBIETIVO & TAREAS & FUNCIONES & DOCUMENTACION \\
\hline \multirow{3}{*}{$\begin{array}{l}\text { PERSONAL DE } \\
\text { ALMACEN Y } \\
\text { DESPACHO }\end{array}$} & $\begin{array}{l}\text { Realizar la entrega oportuna de los } \\
\text { productos a nuestros distribuidores } \\
\text { y supermercados. }\end{array}$ & \multirow{3}{*}{ Despacho } & $\begin{array}{l}\text { Elaborar las rutas de entrega buscando la } \\
\text { optimización de los tiempos. }\end{array}$ & \multirow[t]{3}{*}{$\begin{array}{l}\text { Reporte de despachos } \\
\text { realizados. }\end{array}$} \\
\hline & $\begin{array}{c}\text { Responsable de la planificación, } \\
\text { organización y del control de los } \\
\text { productos de almacén. }\end{array}$ & & $\begin{array}{l}\text { Entrega de los productos en perfectas } \\
\text { condiciones. }\end{array}$ & \\
\hline & $\begin{array}{l}\text { Dirigir y coordinar la entrada y } \\
\text { salida de mercancia, desde el } \\
\text { centro de operaciones de la } \\
\text { organización hasta el destino final. }\end{array}$ & & $\begin{array}{l}\text { Realizar el reporte de los despachos } \\
\text { realizados durante el dia. }\end{array}$ & \\
\hline
\end{tabular}


Tabla 50

Funciones de los Puesto o Cargos - Continuación 5

\begin{tabular}{|c|c|c|c|c|}
\hline NOMBRE DEL PUESTO & OB.JETIVO & TAREAS & FUNCIONES & DOCUMENTACION \\
\hline \multirow{4}{*}{$\begin{array}{l}\text { CONTROL DE } \\
\text { CALIDAD }\end{array}$} & & \multirow{4}{*}{ Análisis } & $\begin{array}{l}\text { Coordinar y supervisar la correcta } \\
\text { ejecución de los procesos de } \\
\text { aseguramiento de control de calidad. }\end{array}$ & \multirow{4}{*}{ Reporte de calidad de producto. } \\
\hline & $\begin{array}{l}\text { Garantizar la confiabilidad de los } \\
\text { productos en proceso, insumos, } \\
\text { productos terminados. }\end{array}$ & & $\begin{array}{l}\text { Disponer las acciones preventivas y } \\
\text { correctivas necesarias para cumplir los } \\
\text { requerimientos de calidad. }\end{array}$ & \\
\hline & & & $\begin{array}{l}\text { Administrar las NO conformidades } \\
\text { identificadas y tomar medidas como } \\
\text { rechazar y ordenar el retiro de materiales y } \\
\text { equipos por mala calidad. }\end{array}$ & \\
\hline & & & $\begin{array}{l}\text { Elaborar informes de indicadores de } \\
\text { calidad y control periódicamente. }\end{array}$ & \\
\hline
\end{tabular}


Tabla 51

Funciones de los Puesto o Cargos - Continuación 6

Evaluar y aprobar la estrategia de ventas planteando alternativas a la Administración General.

Transmitir la Estrategia de Ventas a los colaboradores a su cargo,

productividad de las Unidades de negocio con visión

multidisciplinaria para monitorear las áreas a su cargo y optimizar el uso de los recursos según el presupuesto.
Coordinar y monitorear al personal a su

cargo estableciendo los canales de

información para que contribuyan al mejor Ventas Diarias, Acumulado y

funcionamiento retroalimentando

oportunamente los resultados de cada

estrategia puesta en marcha.

Aprobar y gestionar capacitaciones segú las oportunidades de mejoras planteadas por el personal de Ventas.

\section{Resumen General del producto}

Coordinar las acciones de comunicación de Marketing.

\section{Brief de Marketing}

Monitorear los resultados de gestión comercial,

Evaluar el análisis de las ventas a fin de tomar decisiones correctivas de acuerdo a las variaciones que puedan ir presentando.

Diseñar y velar por la implementación de planes de acción que permitan hacer frente a cualquier desviación de la estrategia de ventas, retroalimentando a la

Administración General al respecto.

Cualquier actividad encomendada por su Jefe inmediato dentro de sus competencias, inherente al cargo. 
Tabla 52

Funciones de los Puesto o Cargos - Continuación 7

\begin{tabular}{|c|c|c|c|c|}
\hline NOMBRE DEL PUESTO & OB.JETIVO & TAREAS & FUNCIONES & DOCUMENTACION \\
\hline \multirow{8}{*}{$\begin{array}{l}\text { EJECUTIVO } \\
\text { COMERCIAL }\end{array}$} & $\begin{array}{l}\text { Responsable de la búsqueda de } \\
\text { clientes y venta del producto de la } \\
\text { empresa con la finalidad de ganar } \\
\text { una mayor participación en el } \\
\text { mercado y elevar las ventas de la } \\
\text { compañia. }\end{array}$ & \multirow{8}{*}{ Ventas } & $\begin{array}{l}\text { Identificar oportunidades de negocio } \\
\text { buscando nuevos clientes para incrementar } \\
\text { la cartera. }\end{array}$ & Reporte de ventas. \\
\hline & $\begin{array}{l}\text { Determinar, planificar y dirigir los } \\
\text { lineamientos y estrategias de } \\
\text { comunicación y marketing de la } \\
\text { organización con retorno a la } \\
\text { inversión }\end{array}$ & & $\begin{array}{l}\text { Efectuar reuniones con los posibles } \\
\text { clientes y ofrecerles el producto logrando } \\
\text { concretar las ventas. }\end{array}$ & Presupuesto de publicidad \\
\hline & & & Ingresar los pedidos al sistema. & $\begin{array}{l}\text { Instructivos para la } \\
\text { implementación de las } \\
\text { camnañas }\end{array}$ \\
\hline & & & $\begin{array}{l}\text { Hacer seguimiento a los pedidos en } \\
\text { coordinación con el área de producción de } \\
\text { la empresa. }\end{array}$ & Plan de medios de campaña \\
\hline & & & $\begin{array}{l}\text { Asegurarse de que el producto llegue al } \\
\text { cliente en el tiempo previsto. }\end{array}$ & \\
\hline & & & $\begin{array}{l}\text { Asegurar la cobranza a los clientes dentro } \\
\text { de los plazos establecidos. }\end{array}$ & \\
\hline & & & $\begin{array}{l}\text { Planificar, evaluar, disponer y coordinar } \\
\text { las acciones publicitarias. }\end{array}$ & \\
\hline & & & $\begin{array}{l}\text { Buscar y establecer alianzas y/o } \\
\text { patrocinios entre la Empresa y otras } \\
\text { Instituciones }\end{array}$ & \\
\hline
\end{tabular}

Nota. Elaboración propia 
Tabla 53

Tablas de Perfil por Cargo

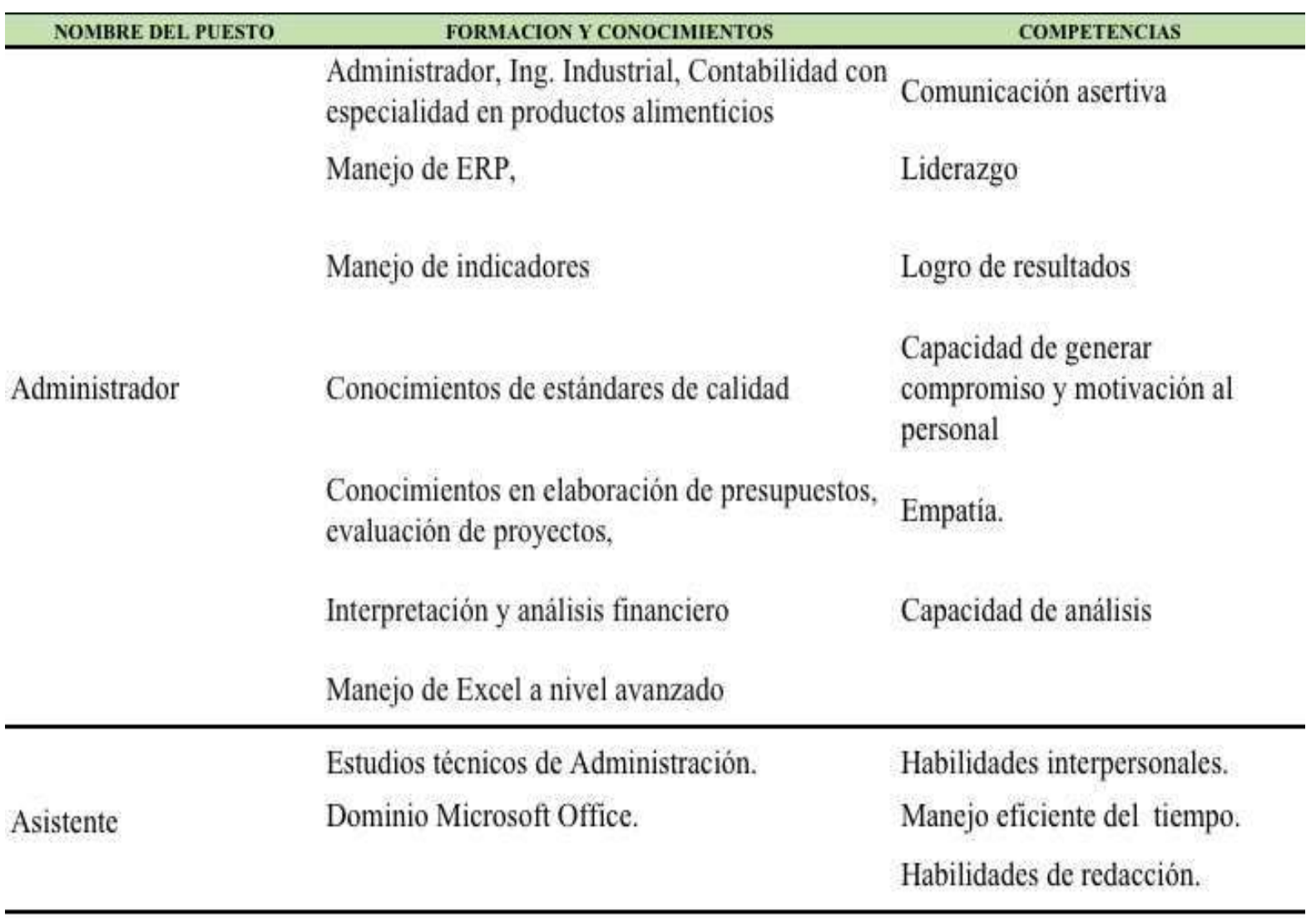

Carrera de administración o ingenieria industrial Orientación a resultados

Jefe de Producción y

Logística
Conocimiento del sector alimenticio

Conocimiento de proveedores
Trabajo bajo presión

Organizado y ordenado

Asertividad

Empatía

Estudios técnicos

Puntual

Personal de producción

Conocimientos del proceso de dialización Responsable

Conocimiento básico de Excel.

Comprometido, disciplinado 
Tabla 54

Tablas de Perfil por Cargo - Continuación 1

\begin{tabular}{|c|c|c|}
\hline NOMBRE DEL PUESTO & FORMACION Y CONOCIMIENTOS & COMPETENCLAS \\
\hline \multirow{3}{*}{$\begin{array}{l}\text { Personal de almacen y } \\
\text { despacho }\end{array}$} & Estudios técnicos & Puntual \\
\hline & Licencia de conducir & Responsable \\
\hline & Conocimiento básico de Excel & Comprometido, disciplinado \\
\hline \multirow{4}{*}{ Jefe Comercial } & $\begin{array}{l}\text { Profesional egresado de las carreras de } \\
\text { Ingenieria Industrial, Economia, Marketing, } \\
\text { Administración y/o afines }\end{array}$ & Dinámico \\
\hline & Conocimiento de office. & $\begin{array}{l}\text { Capacidad de relacionarse a todo } \\
\text { nivel de personas }\end{array}$ \\
\hline & Gestión comercial y manejo de personas & Persona empática \\
\hline & & Tolerancia al trabajo a presión. \\
\hline \multirow{4}{*}{ Ejecutivo comercial } & Téenico & Capacidad de análisis \\
\hline & Experiencia en ventas & Dinamismo \\
\hline & Conocimiento de manejo de office & $\begin{array}{l}\text { Comunicación a todo nivel } \\
\text { Compromiso }\end{array}$ \\
\hline & & Proactivo \\
\hline
\end{tabular}

Nota. Elaboración propia

\subsection{Remuneraciones, compensaciones e incentivos}

La empresa considerará la remuneración de acuerdo a las funciones y posición en las cuales se encuentran ubicados los trabajadores, en la tabla $\mathrm{N}^{\circ} 55$ se mostrará las remuneraciones fijas por los recursos humanos que se requerirán por cada departamento. 
Tabla 55

Planilla de Pago A Personal

PLANILLA DE PAGO A DE PERSONAL EN NUEVOS SOLES

PLANILLA DE PRODUCCION

\begin{tabular}{lcrrrrr}
\hline & & & \multicolumn{3}{c}{ Prestaciones } \\
\cline { 4 - 7 } Trabajador & Numero & Remuneración base & Gratificación & ESSALUD & CTS & Total \\
\hline Operario de producción & 1 & 850.00 & 70.83 & 89.25 & 35.42 & $1,045.50$ \\
\hline Control de Calidad & 1 & 850.00 & 70.83 & 89.25 & 35.42 & $1,045.50$ \\
\hline
\end{tabular}

Total Mano de Obra Directa

\begin{tabular}{lcrrrrr}
\hline & & & & \multicolumn{2}{c}{ Prestaciones } \\
\cline { 4 - 6 } \multicolumn{1}{c}{ Trabajador } & Numero & Remuneración base & Gratificación & ESSALUD & CTS & Total \\
\hline Jefe de Producción y Logistica & 1 & $1,000.00$ & 83.33 & 105.00 & 41.67 & $1,230.00$ \\
\hline Operario de Almacén & 1 & 850.00 & 70.83 & 89.25 & 35.42 & $1,045.50$ \\
\hline Asistente de despacho & 1 & 850.00 & 70.83 & 89.25 & 35.42 & $1,045.50$ \\
\hline
\end{tabular}

Total Mano de Obra Indirecta

PLANILLA VENTAS

\begin{tabular}{lcrrrrr}
\hline & & & & \multicolumn{2}{c}{ Prestaciones } \\
\cline { 4 - 7 } Trabajador & Numero & Remuneración base & Gratificación & ESSALUD & CTS & Total \\
\hline Jefe comercial & 1 & $1,200.00$ & 100.00 & 126.00 & 50.00 & $1,476.00$ \\
\hline Ejecutivo comercial & 1 & 850.00 & 70.83 & 89.25 & 35.42 & $1,045.50$ \\
\hline
\end{tabular}

Total Ventas

PLANILLA ADMINISTRATIVA

\begin{tabular}{|c|c|c|c|c|c|c|}
\hline \multirow[b]{2}{*}{ Trabajador } & \multirow[b]{2}{*}{ Numero } & \multirow[b]{2}{*}{ Remuneración base } & \multirow[b]{2}{*}{ Gratificación } & \multicolumn{2}{|c|}{ Prestaciones } & \multirow[b]{2}{*}{ Total } \\
\hline & & & & ESSALUD & CTS & \\
\hline Administrador & 1 & $2,000.00$ & 166.67 & 210.00 & 83.33 & $2,460.00$ \\
\hline Asistente & 1 & 900.00 & 75.00 & 94.50 & 37.50 & $1,107.00$ \\
\hline Total Administración & & & & & & $3,567,00$ \\
\hline
\end{tabular}

(*) Puestos serán implementados una vez que el proyecto esté en marcha y en crecimiento Nota. Elaboración propia

A continuación, se visualizará la tabla $\mathrm{N}^{\circ} 56$ la planilla para el pago mensual y

la tabla $\mathrm{N}^{\circ} 57$ donde se visualiza la planilla anual que corresponde al 2017 ,

considerando para el personal del departamento de ventas una comisión de acorde a

las ventas realizadas e incluidas como bono y parte de la remuneración: 
Tabla 56

Planilla de Pago Mensual Variable

\begin{tabular}{|c|c|c|c|c|c|c|c|c|c|c|c|c|}
\hline Tabajador & MES 1 & MES 2 & MES 3 & MES 4 & MES 5 & MES 6 & MES 7 & MES 8 & MES 9 & MES 10 & MES 11 & MES 12 \\
\hline \multicolumn{13}{|l|}{$\overline{\text { MOD }}$} \\
\hline Operario de producción & $2,091.00$ & $2,091.00$ & $2,091.00$ & $2,091.00$ & $2,091.00$ & $2,091.00$ & $2,091.00$ & $2,091.00$ & $2,091.00$ & $2,091.00$ & $2,091.00$ & $2,091.00$ \\
\hline \multirow[t]{2}{*}{ Control de Calidad } & $2,091.00$ & $2,091.00$ & $2,091.00$ & $2,091.00$ & $2,091.00$ & $2,091.00$ & $2,091.00$ & $2,091.00$ & $2,091.00$ & $2,091.00$ & $2,091.00$ & $2,091.00$ \\
\hline & $4,182.00$ & $4,182.00$ & $4,182.00$ & $4,182.00$ & $4,182.00$ & $4,182.00$ & $4,182.00$ & $4,182.00$ & $4,182.00$ & $4,182.00$ & $4,182.00$ & $4,182.00$ \\
\hline MOI & & & - & & & & & & & & & \\
\hline Jefe de Producción y Logistica & - & - & - & - & - & - & - & - & - & - & - & - \\
\hline Operario de Almacén & $1,045.50$ & $1,045.50$ & $1,045.50$ & $1,045.50$ & $1,045.50$ & $1,045.50$ & $1,045.50$ & $1,045.50$ & $1,045.50$ & $1,045.50$ & $1,045.50$ & $1,045.50$ \\
\hline \multirow[t]{2}{*}{ Asistente de despacho } & $1,045.50$ & $1,045.50$ & $1,045.50$ & $1,045.50$ & $1,045.50$ & $1,045.50$ & $1,045.50$ & $1,045.50$ & $1,045.50$ & $1,045.50$ & $1,045.50$ & $1,045.50$ \\
\hline & $2,091.00$ & $2,091.00$ & $2,091.00$ & $2,091.00$ & $2,091.00$ & $2,091.00$ & $2,091.00$ & $2,091.00$ & $2,091.00$ & $2,091.00$ & $2,091.00$ & $2,091.00$ \\
\hline VENTAS & & & - & & & & & & & & & \\
\hline Jefe comercial & $1,748.74$ & $1,744.91$ & $1,788.00$ & $1,770.02$ & $1,774.41$ & $1,750.88$ & $1,772.64$ & $1,773.76$ & $1,752.85$ & $1,750.15$ & $1,733.65$ & $1,719.02$ \\
\hline \multirow[t]{2}{*}{ Ejecutivo comercial } & $1,318.24$ & $1,314.41$ & $1,357.50$ & $1,339.52$ & $1,343.91$ & $1,320.38$ & $1,342.14$ & $1,343.26$ & $1,322.35$ & $1,319.65$ & $1,303.15$ & $1,288.52$ \\
\hline & $3,066.98$ & $3,059.32$ & $3,145.51$ & $3,109.54$ & $3,118.32$ & $3,071.26$ & $3,114.77$ & $3,117.02$ & $3,075.20$ & $3,069.79$ & $3,036.81$ & $3,007.53$ \\
\hline ADMINISTRATIVA & & - & - & & & & & & & & & \\
\hline Administrador & $2,460.00$ & $2,460.00$ & $2,460.00$ & $2,460.00$ & $2,460.00$ & $2,460.00$ & $2,460.00$ & $2,460.00$ & $2,460.00$ & $2,460.00$ & $2,460.00$ & $2,460.00$ \\
\hline \multirow[t]{2}{*}{ Asistente } & - & - & - & - & - & - & - & - & - & - & - & - \\
\hline & $2,460.00$ & $2,460.00$ & $2,460.00$ & $2,460.00$ & $2,460.00$ & $2,460.00$ & $2,460.00$ & $2,460.00$ & $2,460.00$ & $2,460.00$ & $2,460.00$ & $2,460.00$ \\
\hline & $11,799.98$ & $11,792.32$ & $11,878.51$ & $11,842.54$ & $11,851.32$ & $11,804.26$ & $11,847.77$ & $11,850.02$ & $11,808.20$ & $11,802.79$ & $11,769.81$ & $11,740.53$ \\
\hline
\end{tabular}


Tabla 57

Planilla de pago anual

\begin{tabular}{|c|c|c|c|c|c|}
\hline Trabajador & 2017 & 2018 & 2019 & 2020 & 2021 \\
\hline \multicolumn{6}{|l|}{ MOD } \\
\hline Operario de producción & $25,092.00$ & $25,092.00$ & $25,092.00$ & $25,092.00$ & $25,092.00$ \\
\hline \multirow[t]{2}{*}{ Control de Calidad } & $25,092.00$ & $25,092.00$ & $25,092.00$ & $25,092.00$ & $25,092.00$ \\
\hline & $50,184.00$ & $50,184.00$ & $50,184.00$ & $50,184.00$ & $50,184.00$ \\
\hline MOI & & & - & & \\
\hline Jefe de Producción y Logistica & - & $14,760.00$ & $14,760.00$ & $14,760.00$ & $14,760.00$ \\
\hline Operario de Almacén & $12,546.00$ & $12,546.00$ & $12,546.00$ & $12,546.00$ & $12,546.00$ \\
\hline \multirow[t]{2}{*}{ Asistente de despacho } & $12,546.00$ & $12,546.00$ & $12,546.00$ & $12,546.00$ & $12,546.00$ \\
\hline & $25,092.00$ & $39,852.00$ & $39,852.00$ & $39,852.00$ & $39,852.00$ \\
\hline VENTAS & & & - & & \\
\hline Jefe comercial & $21,079.03$ & $25,718.10$ & $29,845.62$ & $34,053.88$ & $38,341.39$ \\
\hline \multirow[t]{2}{*}{ Ejecutivo comercial } & $15,913.03$ & $20,552.10$ & $24,679.62$ & $28,887.88$ & $33,175.39$ \\
\hline & $36,992.06$ & $46,270.21$ & $54,525.24$ & $62,941.76$ & $71,516.78$ \\
\hline ADMINISTRATIVA & & - & - & & \\
\hline Administrador & $29,520.00$ & $29,520.00$ & $29,520.00$ & $29,520.00$ & $29,520.00$ \\
\hline \multirow[t]{2}{*}{ Asistente } & - & $13,284.00$ & $13,284.00$ & $13,284.00$ & $13,284.00$ \\
\hline & $29,520.00$ & $42,804.00$ & $42,804.00$ & $42,804.00$ & $42,804.00$ \\
\hline
\end{tabular}

Nota: Elaboración propia 


\subsection{Política de recursos humanos}

\section{Forma de Contratación}

Teniendo como base la legislación laboral del Perú, indicado en la tabla $\mathrm{N}^{\circ} 58$, se plantea tomar la contratación bajo la modalidad de contrato de trabajo para obra o servicio, en el cual al vencimiento tendrá derecho a la renovación luego de la evaluación y aprobación de su superior.

Según la ley de Productividad y Competitividad Laboral

(http://www.mintra.gob.pe, 1997) el contrato tendrá una fecha de inicio y una

fecha de vencimiento, lo que no impide a las partes resolverlo en cualquier momento por decisión unilateral.

Tabla 58

Cláusulas Contractuales

\begin{tabular}{|l|l|}
\hline $\begin{array}{l}\text { Contrato a plazo } \\
\text { indeterminado }\end{array}$ & $\begin{array}{l}\text { Estos contratos son utilizados para realizar labores } \\
\text { permanentes o continuas, no cuentan con un tiempo de } \\
\text { duración determinado y no es obligatorio (salvo algunos } \\
\text { casos) su presentación ante la Autoridad Administrativa } \\
\text { de trabajo ( Ministerio de trabajo) }\end{array}$ \\
\hline Contrato a tiempo parcial & $\begin{array}{l}\text { Estos contratos se celebran con personas que cumplen } \\
\text { una jornada inferior a 04 horas diarias y perciben el } \\
\text { equivalente de la parte proporcional de la } \\
\text { remuneración mínima vital. }\end{array}$ \\
\hline Contrato sujeto a modalidad & $\begin{array}{l}\text { Estos contratos cuentan con una fecha de inicio y una } \\
\text { fecha de término. }\end{array}$ \\
& Se dividen fundamentalmente en 03 modalidades. \\
& 3.1.- Contratos de naturaleza temporal \\
& 3.2.- Contratos de naturaleza accidental \\
3.3.- Contratos para obra o servicio.
\end{tabular}

Nota. Adaptado de http://www.trabajo.gob.pe/boletin/boletin_2_1.html

Existirá un periodo de prueba de tres meses en el cual se evaluará el desempeño, el compromiso y grado de responsabilidad que los trabajadores tienen para con el cumplimento de sus labores y funciones.

Una vez cumplido el periodo de prueba se analizará el desempeño a fin de renovar el contrato o dar por culminado la relación laboral. 
Cabe resaltar que las personas contratadas que ingresen a laborar en la compañía tendrán todos los beneficios que le corresponden por ley.

2. Régimen Laboral

Los contratos de trabajo serán bajo el Régimen Laboral de una Pequeña Empresa, con los beneficios sociales como la gratificación, CTS, ocho horas laborales, reconocimiento de horas extras, etc.

En la tabla $\mathrm{N}^{\circ} 59$ se detallan las características del tipo de empresa que se conformará con el presente proyecto, que es la de una pequeña empresa:

Tabla 59

Características de una Pequeña Empresa

\begin{tabular}{|c|c|c|}
\hline DESCRIPCION & MICROEMPRESA & PEQUEÑA EMPRESA \\
\hline Trabajadores & De 1 hasta 10 & De 1 hasta 100 \\
\hline Ventas brutas anuales & Hasta el monto máximo 150 UIT & $\begin{array}{l}\text { A partir del monto máximo sef̃alado en la } \\
\text { microempresa hasta } 1700 \text { UIT }\end{array}$ \\
\hline Remuneración mínima & 850 soles & 850 soles \\
\hline Jornada - Horario & 8 horas diarias 048 horas semanales & 8 horas diarias 648 horas semanales \\
\hline Descanso & Semanal y feriados & Semanal y feriados \\
\hline Vacaciones & 15 dias calendario al año & 15 dias calendario al año \\
\hline Despido injustificado & $\begin{array}{l}10 \text { dias de remuneración por año de } \\
\text { servicio, hasta } 3 \text { sueldos }\end{array}$ & $\begin{array}{l}20 \text { dias de remuneración por año de servicio, } \\
\text { hasta } 4 \text { sueldos. }\end{array}$ \\
\hline CTS & No aplica & $1 / 2$ sueldo por año \\
\hline Gratificaciones & No aplica & 1 sueldo por año \\
\hline Asignación familiar & No aplica & No especifica \\
\hline Póliza de Seguro & No aplica & $\begin{array}{l}\text { Cobertura de Seguro de Vida y Seguro } \\
\text { Complementario de trabajo de Riesgo (SCTR }\end{array}$ \\
\hline Utilidades & No participa & Participa \\
\hline Seguro Social & $\begin{array}{l}\text { Cobertura de seguridad social en salud a } \\
\text { través del SIS (SEGURO INTEGRAL DE } \\
\text { SALUD) }\end{array}$ & $\begin{array}{l}\text { Cobertura de seguridad social en salud a } \\
\text { través del ESSALUD }\end{array}$ \\
\hline Pensiones & $\begin{array}{l}\text { Empleador aportará el } 50 \% \text {, el estado el } \\
50 \%\end{array}$ & $13 \%$ ONP Ó AFP \\
\hline
\end{tabular}

Nota. Adaptado de http://perupymes.com/noticias/alcances-de-la--ley-de-micro-ypequena-empresapyme 
3. Horario de trabajo

La jornada laboral será de 8 horas de lunes a sábado, 48 horas, según lo indica la ley sin considerar el refrigerio y será efectiva de acuerdo al cronograma de actividades o plan de trabajo que se necesite en la empresa.

4. Beneficios Sociales

La empresa brindará todos los beneficios sociales al trabajador según lo indica la ley.

1. Descanso semanal obligatorio.

2. Descanso vacacional

3. Seguro social de Salud,

4. Régimen pensionario

5. Compensación por tiempo de servicio

6. Gratificaciones 


\section{Capítulo VII: Plan de Marketing}

\subsection{Estrategias de marketing.}

Tanto Ansoff (1957) como Kotler (Gary Armstrong y Philip Kotler, Marketing, 2012) cada cual en sus textos indican:

Ansoff en su artículo “Estrategias para la diversificación”, indica que existen cuatro opciones de crecimiento para una empresa formada, desarrollo de mercado, desarrollo de producto, penetración de mercado y diversificación.

Mientras que para Kotler en su texto (Gary Armstrong y Philip Kotler, Marketing, 2012), considera como estrategias, bajos costes, experiencia única para el cliente o consumidor, ofrecer máxima calidad en el producto, centrarse en nichos de mercado.

De las cuales, el presente proyecto desarrollará un plan basado en el concepto de "Desarrollo de producto", debido a la implementación de un proceso desconocido “dialización” que contribuye en brindar un producto con valor agregado para la salud, a un mercado existente, como es el caso de los consumidores de productos saludables.

Entre las acciones que van a contribuir a alcanzar la estrategia que el proyecto considerará, tenemos:

1. Introducir a la papa dializada, en el mercado objetivo, con el concepto de un producto significativo por los nutrientes y/o vitaminas que posee, pero además por ser fácilmente asimilable por el sistema humano.

2. Desarrollar una línea de productos, utilizando el mismo proceso de dialización en otros tubérculos, con la finalidad de ampliar el mercado. 
3. Ofertar al mercado objetivo un producto alimenticio certificado bajo los estándares de salud y calidad, enmarcado en la continua promoción nutricional por parte del gobierno.

\subsubsection{Estrategia de Producto:}

El producto que se ofrecerá en el presente plan de negocio utilizará como principal insumo a la papa perricholi natural, la cual mediante un proceso de remojo en agua (sin preservantes) sufrirá una desmineralización de sus componentes, a este proceso se le denominará "Dialización”, con lo que se obtendrá el producto "papa dializada” la cual tendrá marca propia de comercialización denominada "Papa Sano".

El mineral principal al cual se enfoca dicho proceso de dialización, es el potasio, este es un componente que resulta valioso para combatir algunas enfermedades crónicas como la presión arterial alta, debido a sus propiedades vasodilatadoras como diuréticas. Sin embargo, se debe tener en cuenta que un nivel elevado de este componente en la sangre puede llegar a ser perjudicial para las personas con problemas de hipertensión, obesidad, diabéticos y enfermos renales sometidos a diálisis; es por ello que el presente proyecto se enfoca al desarrollo de un producto basado en la papa (que tiene alto nivel de consumo en el país) con bajo nivel de potasio para que sea fácilmente asimilable por el organismo del ser humano.

El lugar de elaboración del producto contará con el respaldo del HACCP (Hazard Analysis and Critical Control Point System o Análisis de Peligros y Puntos Críticos de Control), el plan para la obtención de esta certificación se empezará a trabajar desde el primer mes para obtenerlo a fines 
del primer año de iniciada las operaciones, con él se garantizará la inocuidad del producto y sus procesos de elaboración los cuales deben ser seguros, eficientes y eficaces, a su vez disminuirá los posibles reclamos, devoluciones, reprocesos y/o rechazos, este valor será utilizado como herramienta de Marketing y contribuirá con la reducción de costos y ahorro de recursos.

Valor nutricional de papa perricholi según (Ministerio de Salud, 2008) cuenta con la siguiente composición, según como se puede apreciar en la tabla $\mathrm{N}^{\circ} 60$ :

Tabla 60

Valor Nutricional de la Papa por cada $100 \mathrm{gr}$.

\begin{tabular}{|c|c|}
\hline Nombre del Alimento & $\begin{array}{c}\text { Papa Blanca } \\
\text { (perricholi) }\end{array}$ \\
\hline 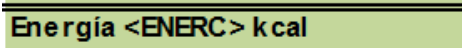 & 97.00 \\
\hline Energia <ENERC> kJ & 405.85 \\
\hline Agua $<$ WA TER $>$ g & 74.50 \\
\hline Proteinas $<$ PROCNT $>$ g & 2.10 \\
\hline Potasio $<\mathrm{K}>\mathrm{g}$ & 379.00 \\
\hline Gras a total $<\mathrm{FA} \mathrm{T}>\mathrm{g}$ & 0.10 \\
\hline $\begin{array}{l}\text { Carbohidratos totales } \\
\langle\text { CHOCDF }>\quad g\end{array}$ & 22.30 \\
\hline $\begin{array}{l}\text { Carbohidratos disponibles } \\
\langle\text { CHOAVL }>\quad g\end{array}$ & 19.90 \\
\hline Fibra cruda $\mathbf{g}$ & 0.60 \\
\hline Fibra die taria $<$ FIBTG $>$ g & 2.40 \\
\hline Cenizas $\langle\mathrm{ASH}\rangle \mathrm{g}$ & 1.00 \\
\hline Calcio $<\mathrm{CA}>\mathrm{mg}$ & 9.00 \\
\hline Fósforo $\langle\mathrm{P}\rangle \mathrm{mg}$ & 47.00 \\
\hline Zinc $<\mathrm{ZN} \triangleright \mathrm{mg}$ & 0.29 \\
\hline Hie rro <FE $>$ m g & 0.50 \\
\hline Retinol $\mu g$ & 3.00 \\
\hline Vitam ina $A$ equivalentes totales & \\
\hline$<$ VITA $>$ & 0.00 \\
\hline$\mu \mathrm{g}$ & \\
\hline Tiam ina $<$ THIA $>$ m g & 0.09 \\
\hline Riboflavina $<$ RIBF $>$ m g & 0.09 \\
\hline Niacina $<$ NIA $>$ m g & 1.67 \\
\hline Vitam ina $\mathrm{C}<\mathrm{VITC}>\mathrm{mg}$ & 14.00 \\
\hline
\end{tabular}

Elaboración propia, referencia tablas_peruanas_composición_alimentos_1023 http://www.ins.gob.pe/repositorioaps/0/5/jer/tab_cien_cenan/Tabla\%20 de\%20Alimentos.pdf 
A su vez la papa cuenta con Vitamina C; la cual presenta propiedades

antiescorbúticas y desintoxicantes, aunque como estas se localizan debajo de la piel, muchas de ellas se pierden en la cocción.

Asimismo, contiene calcio, fósforo y cantidades menores de beta carotenos, pero es especialmente rica en hidratos de carbono, que resulta junto con los azúcares, una fuente de energía para el correcto funcionamiento de sistema humano.

Se considera de gran importancia impulsar productos con alto valor nutricional que contribuyan con la buena alimentación del cliente, es por ello que "Papa Sano", posee beneficios para la nutrición humana como son los carbohidratos, calcio, fósforo y hierro.

Papa Sano cuenta con un nivel bajo de potasio, el cual ha sido sustentado por el laboratorio World Survey Services Perú SAC, demostrando que el proceso de remojo en agua natural, el cual ha sido denominado como dialización, reduce el nivel de potasio en un $40 \%$ aproximadamente, como se aprecia en la figura $\mathrm{N}^{\mathrm{o}} 74$.

\begin{tabular}{|c|c|c|}
\hline Nombre del Alimento & $\begin{array}{l}\text { Papa Blanca } \\
\text { (Perricholi) }\end{array}$ & PapaSano \\
\hline Ene rgla $\angle E N E R C>\mathrm{kcal}$ & 97.00 & 97.00 \\
\hline Agua $\triangle W A T E R>g$ & 74.50 & 74.50 \\
\hline Prote in as 4 PROCNT>g & 2.10 & 2.10 \\
\hline Potasio <K> g & 379.00 & 250.14 \\
\hline Grasa total $\angle F A T>g$ & 0.10 & 0.10 \\
\hline Carbo hldr at os totales $<\mathrm{CHOCDF}>\mathrm{g}$ & 22.30 & 22.30 \\
\hline Carbo hldrat os totales $<$ CHOAVL $>g$ & 19.90 & 19.90 \\
\hline Calclo $<C A>\mathrm{mg}$ & 4.00 & 4.00 \\
\hline Fósforo $4>>\mathrm{mg}$ & 30.00 & 30.00 \\
\hline RetInol $\mu \mathrm{g}$ & 3.00 & 3.00 \\
\hline Nlaclna $A$ NIA $>$ mg & 1.00 & 1.00 \\
\hline Vltamlna $\mathrm{C} \ll \mathrm{v} \pi \mathrm{C}>\mathrm{mg}$ & 5.60 & 5.60 \\
\hline
\end{tabular}

Figura 74. Diferencia entre Valor Nutricional (potasio) de papa perricholi natural vs. Papa Perricholi proceso de dialización, disminuye el $40 \%$ del valor inicial real. Figura elaboración propia en base a referencia, http://www.fao.org/potato-2008/es/lapapa/hojas.html 
El valor nutricional con el que contará Papa Sano, como se puede apreciar en la tabla $\mathrm{N}^{\mathrm{o}} 61$.

\begin{tabular}{|c|c|}
\hline Nombre del Alimento & $\begin{array}{l}\text { Papa Blanca } \\
\text { (perricholi) }\end{array}$ \\
\hline Energía <ENERC> kcal & 97.00 \\
\hline Agua $\langle$ WATER $>g$ & 74.50 \\
\hline Proteinas $<$ PROCNT $>\mathrm{g}$ & 2.10 \\
\hline Potas io $<\mathrm{K}>\mathrm{g}$ & 151.60 \\
\hline Grasa total $\langle F A T>g$ & 0.10 \\
\hline $\begin{array}{l}\text { Carbohidratos totales } \\
\text { <CHOCDF } \quad g\end{array}$ & 22.30 \\
\hline $\begin{array}{l}\text { Carbohidratos dis ponibles } \\
\langle\text { CHOAVL> } g\end{array}$ & 19.90 \\
\hline Calcio $<C A>m g$ & 4.00 \\
\hline Fósforo $\langle\mathrm{p}\rangle \mathrm{mg}$ & 30.00 \\
\hline Retinol $\mu g$ & 3.00 \\
\hline Niacina $<$ NIA $>\mathrm{mg}$ & 1.00 \\
\hline Vitam ina $C<$ VITC $>\mathrm{mg}$ & 5.60 \\
\hline
\end{tabular}

Adaptado del estudio realizado en laboratorio, cálculo aproximado de desmineralización del $40 \%$ en el potasio, y el resto de minerales.

Presentación y contenido de etiquetas:

Logo:

Será de color verde característico, induciendo al consumidor a la relación vida sana y cuidado del medio ambiente.

Etiqueta de valor nutricional:

Se visualizará en la parte posterior de la bolsa, con el detalle de la composición del producto a ofertar, segùn se aprecia en la tabla $\mathrm{N}^{\mathrm{a}} 62$. 
Rótulo:

Sobre el envase se adicionará una etiqueta o inject con los datos legales de la compañía, país de origen del producto, el permiso sanitario respectivo y la fecha de vencimiento; según la normativa vigente por la entidad Digesa, Figura $\mathrm{N}^{\mathrm{a}} 75$.

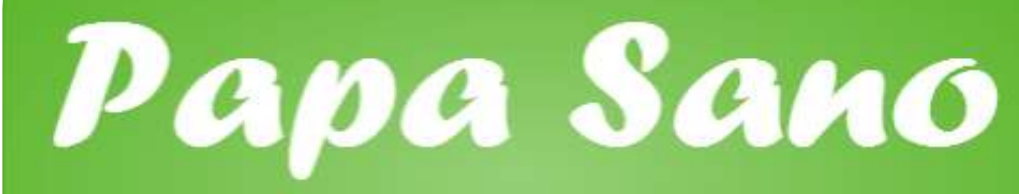

Papa Blonce

con proceso de dialíración

producto releceionado

Figura 75. Logo de Producto

Tabla 62

Valor Nutricional

\begin{tabular}{|c|c|}
\hline Nombre del Alimento & $\begin{array}{l}\text { Papa Blanca } \\
\text { (perricholi) }\end{array}$ \\
\hline$\overline{E \text { Energia }<\text { ENERC }>\text { kcal }}$ & 97.00 \\
\hline Agua $<W A T E R>$ g & 74.50 \\
\hline Proteinas $<$ PROCNT $>\mathrm{g}$ & 2.10 \\
\hline Potasio $<\mathrm{K}>\mathrm{g}$ & 151.60 \\
\hline Gras a total $<\mathrm{FAT}>\mathrm{g}$ & 0.10 \\
\hline $\begin{array}{l}\text { Carbohidratos totales } \\
\langle\text { CHOCDF } \quad \mathrm{g}\end{array}$ & 22.30 \\
\hline $\begin{array}{l}\text { Carbohidratos disponibles } \\
<\text { CHOAVL }>\quad \mathrm{g}\end{array}$ & 19.90 \\
\hline Calcio $<\mathrm{CA}>\mathrm{mg}$ & 4.00 \\
\hline Fósforo $\langle\mathrm{P}\rangle \mathrm{mg}$ & 30.00 \\
\hline Retinol $\mu g$ & 3.00 \\
\hline Niacina $<$ NIA $>$ m g & 1.00 \\
\hline Vitam ina $\mathrm{C}<\mathrm{VIITC}>\mathrm{mg}$ & 5.60 \\
\hline
\end{tabular}


Presentación del producto:

Se comercializará dos presentaciones, como se aprecia en la figura $\mathrm{N}^{\mathrm{a}} 76$, enfocadas al mercado objetivo, las cuales se mostrarán en bolsas de 250 gr y 500gr, las mismas que serán selladas al vacío, .
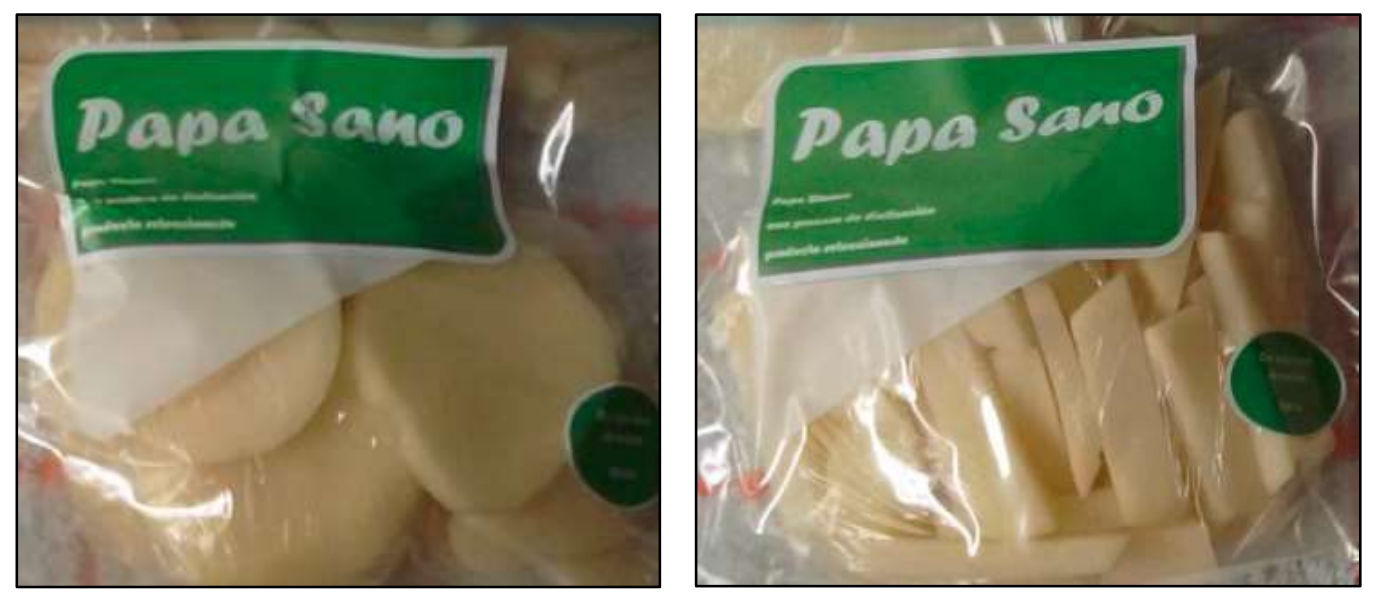

Figura 76. Presentación del Producto

En el futuro se evaluará la presentación de bolsas de polipropileno de $50 \mathrm{~kg}$., para la cual se aplicará un cocido con pabilo para que resista la cantidad del producto, dicha presentación estará orientada para la venta directa a hospitales y fast food, un próximo canal directo.

Envasado:

El producto será envasado en bolsas especiales de polietileno para el sellado al vacío, compatibles con la máquina de sellado adquirida, el cual permitirá que el producto se conserve fresco por un mayor tiempo, con una cantidad de humedad suficiente para que no se deshidrate y no sufra ninguna oxidación. 
Traslado

El producto en las presentaciones de 250 gr y de 500 gr, se trasladarán en jabas de plástico apilables, como se aprecia en la figura $\mathrm{N}^{\mathrm{o}} 77$ y 78 , cuyas medidas son de 40 cmts. ancho, 60 centímetros de largo y 20 centímetros de alto, para optimizar espacios y facilitar el retorno al almacén.

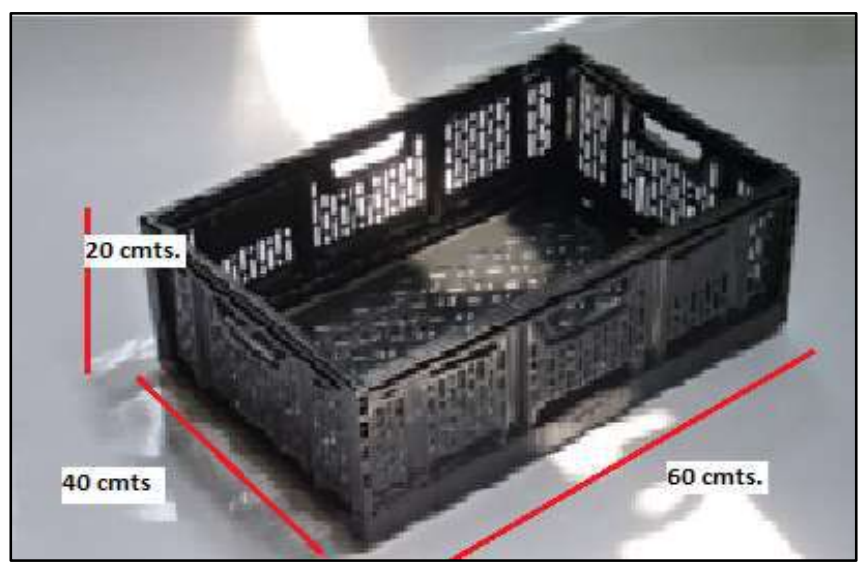

Figura 77. Jabas Nazca, proveedor Novatec apilable armada.

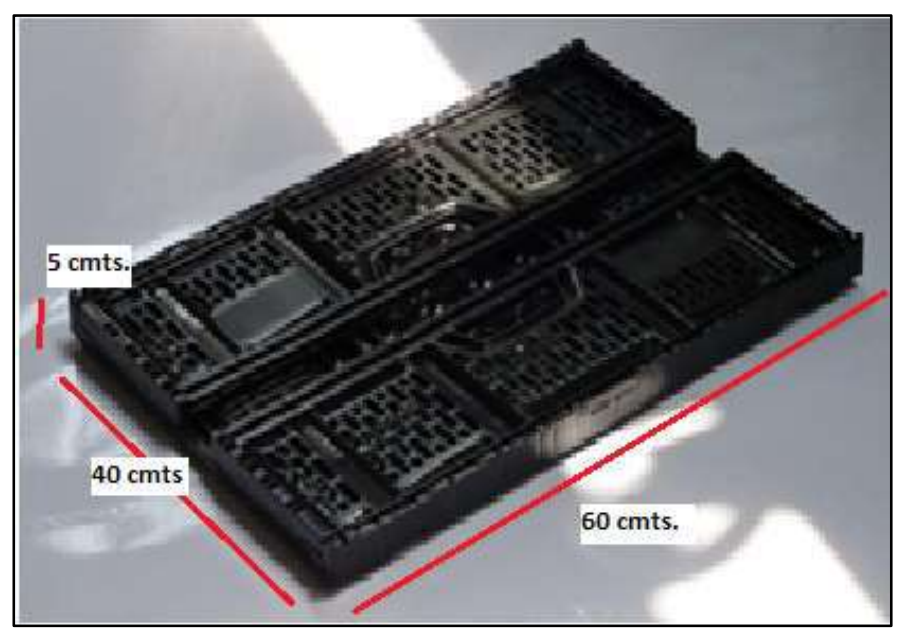

Figura 78. Jabas Nazca, proveedor Novatec, apilable, desarmada

\subsubsection{Estrategia de Precio:}

El mercado objetivo muestra disponibilidad de pagar un precio mayor al del mercado, por un producto sano y natural, como lo muestra la siguiente pregunta $\mathrm{N}^{\circ} 10$, según Figuras $\mathrm{N}^{\mathrm{o}} 79$ y 80, de la encuesta, teniendo presente 
que su preferencia como cliente siempre será el de obtener más por un precio bajo:

10. ¿En cuál de estas presentaciones lo desearía adquirir?

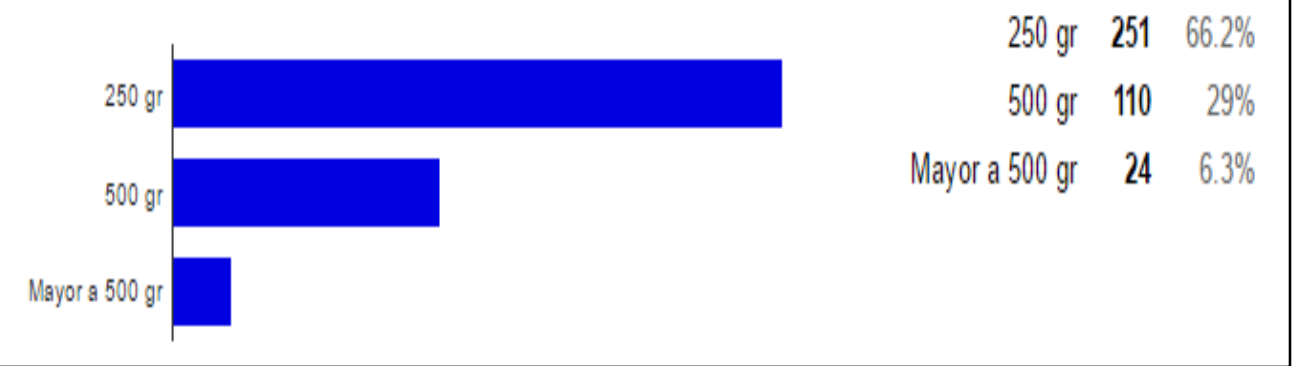

Figura 79. Respuesta Nº10 de la Encuesta

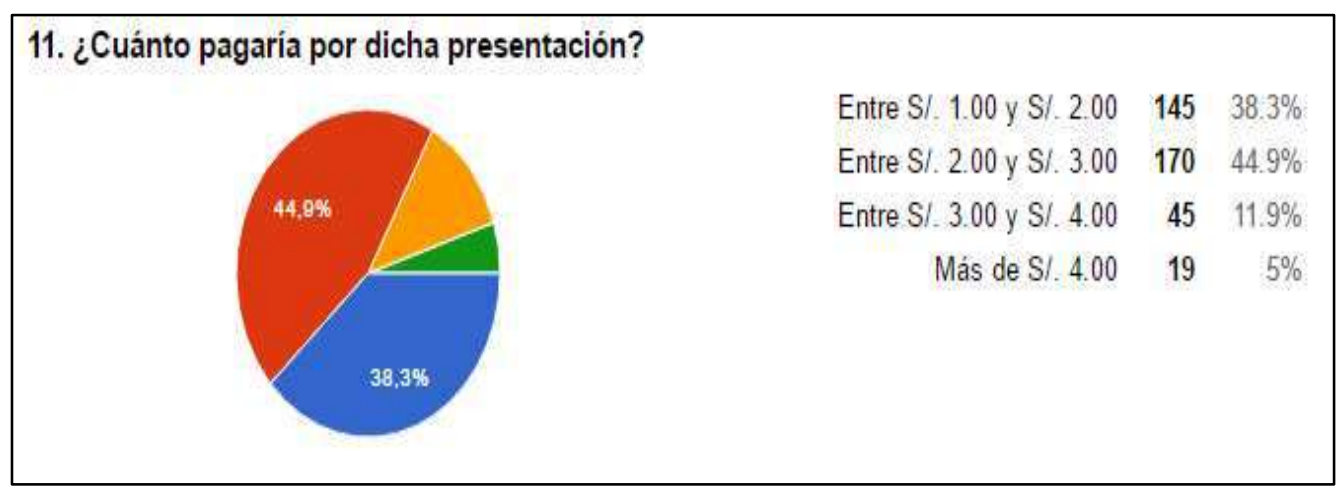

Figura 80. Respuesta $\mathrm{N}^{\circ} 11$ de la Encuesta

Para determinar el precio se ha tomado como referencia este análisis y el del costo de producción promedio por kilo (S/. 5.96), como se aprecia en la tabla $\mathrm{N}^{\circ} 63$, estableciendo un precio de venta para cada presentación con un margen promedio de utilidad para la empresa de $36 \%$ aproximadamente durante los cinco años:

1. S/. 2.00 para la presentación de 250 gr.,

2. S/. 4.00 soles para la de 500 gr. y

Tabla 63

Fijación de Precios

\begin{tabular}{|c|c|c|c|c|c|c|c|c|}
\hline & & & \multicolumn{3}{|c|}{ Margen Comercializador } & \multicolumn{3}{|c|}{ Margen Intermediario } \\
\hline & & Comercializador & $\%$ & S/. & Casa Intermediario & $\%$ & S/. & Consumidor \\
\hline \multirow{2}{*}{ PapaSano } & $250 \mathrm{gr}$ & 1.47 & 36 & 0.53 & 2.00 & 25 & 0.50 & 2.5 \\
\hline & $500 \mathrm{gr}$ & 2.94 & 36 & 1.06 & 4.00 & 25 & 1.00 & 5.0 \\
\hline
\end{tabular}


Cabe mencionar, que el precio implica el valor por las características, propiedades y beneficios que presenta el producto del presente proyecto, que es procesado de forma natural; en comparación con el producto de papas pre fritas que se ofrece en el mercado a S/.12.00 el kilo.

Se visualiza en la tabla que el precio de venta para el canal indirecto, como las casas naturistas, minimarkets y tiendas de productos orgánicos, será de S/. 2.00 para la presentación de 250 gr. y de S/. 4.00 para la presentación del 500 gr., brindándoles la opción de ganancia del 25\% sobre el costo del producto.

\subsubsection{Estrategia de distribución:}

El producto "Papa Sano” será comercializado a través de canales indirectos: casas naturistas, minimarkets y tiendas de productos orgánicos, para lograr llegar al consumidor final.

Como plan a futuro, parte del desarrollo de mercado que la empresa realizará previo estudio de mercado, se utilizará el canal directo; realizando ventas directas en volumen a hospitales y fast food.

Así mismo se aplicará las siguientes estrategias:

1. Ofrecer reposición de productos próximos a vencer

2. Ofrecer descuentos, dependiendo del volumen de compra

Con respecto a los supermercados se orienta a utilizar este medio de distribución a partir del tercer año de iniciada las operaciones, con un acuerdo comercial tolerante a la capacidad de producción y la capacidad de abastecimiento a una cadena retail. 
Para captar a estos intermediarios se aplicarán las siguientes estrategias:

1. Se establecerá bandas de adquisición por volumen, para aplicar descuentos graduales.

2. Se le ofrecerá transferencias gratuitas por alcanzar las ventas por volumen.

3. Ofrecer la reposición de productos próximos a vencer

\subsubsection{Estrategia de promoción y publicidad:}

Para llegar al objetivo anual de ventas, se desplegará una serie de estrategias basadas en actividades que logren atraer a los clientes, mejorar el reconocimiento del producto y mejorar la identidad de marca.

Para dicho objetivo se realizarán:

Material promocional:

Se contará con merchandising de la marca "Papa Sano", como lapiceros, mini recetarios, mandiles, gorros y caramelos, asimismo se entregarán muestras y degustación gratis en las casas naturistas, minimarkets y tiendas de productos orgánicos, y en su entorno.

Publicidad:

Se entregarán folletos y volantes a cargo de una señorita degustadora, se contarán con banners y afiches, los mismos que serán entregados a diversas instituciones de salud y venta masiva como mercados, supermercados, mercados naturistas y ferias.

Se realizará promoción televisiva en el programa Dr. TV en horario diurno. 
Promoción de ventas:

Se elaborará una página web que permitirá la difusión de las características del producto, además de promocionar y compartir los beneficios del producto.

Eventos:

Participación en ferias de alimentos con alta concurrencia, como el caso de Mistura en el mes de Setiembre.

Relaciones Públicas:

Se contactará con el personal del área comercial el cual promocionará el producto en ferias de nutrición, a fin de informar al público objetivo la introducción del producto en el mercado.

Se contará con un Gantt, tabla $\mathrm{N}^{\circ} 64$, de actividades promocionales y de publicidad, el mismo permitirá llevar un orden de la inversión que se realizará, como se puede apreciar en la tabla $\mathrm{N}^{\circ} 65$ : 
Tabla 64

Gantt mensual de actividades de Estrategias de Publicidad y Promoción

\begin{tabular}{|c|c|c|c|c|c|c|c|c|c|c|c|c|}
\hline \multirow{2}{*}{ MEDIOS DE COMUNICACIÓN } & \multicolumn{12}{|c|}{2017} \\
\hline & ENERO & FEBRERO & MARZO & ABRIL & MAYO & JUNIO & JULIO & AGOSTO & SEPTIEMBRE & OCTUBRE & NOVIEMBRE & DICIEMBRE \\
\hline \multicolumn{13}{|l|}{ PROMOCION DE VENTAS } \\
\hline Degustación en casa naturista, minimarket & $\mathrm{X}$ & $\mathrm{X}$ & $\mathrm{X}$ & $\mathrm{X}$ & $\mathrm{XX}$ & $\mathrm{X}$ & $\mathrm{X}$ & $\mathrm{X}$ & $\mathrm{X}$ & $\mathrm{X}$ & $\mathrm{X}$ & $\mathrm{X}$ \\
\hline \multicolumn{13}{|l|}{ Degustación en feria } \\
\hline \multicolumn{13}{|l|}{$\begin{array}{l}\text { PUBLICITY } \\
\text { Canal } 4 \text { (DR. TV) } \\
\text { Particinación en Ferias }\end{array}$} \\
\hline Participación en Ferias & & & & & & & & & & & & \\
\hline \multicolumn{13}{|l|}{ TRADE MARKETING } \\
\hline Banners & $\mathrm{X}$ & $\mathrm{X}$ & $\mathrm{X}$ & $\mathrm{X}$ & $\mathrm{xX}$ & $\mathrm{X}$ & $\mathrm{X}$ & $\mathrm{X}$ & $\mathrm{X}$ & $\mathrm{X}$ & $\mathrm{X}$ & $\mathrm{X}$ \\
\hline Folletos & $\mathrm{X}$ & $\mathrm{X}$ & $\mathrm{X}$ & $\mathrm{X}$ & $\mathrm{XX}$ & $\mathrm{X}$ & $\mathrm{X}$ & $\mathrm{X}$ & $\mathrm{X}$ & $\mathrm{X}$ & $\mathrm{X}$ & $\mathrm{X}$ \\
\hline Volantes & $\mathrm{X}$ & $\mathrm{X}$ & $\mathrm{X}$ & $\mathrm{X}$ & $\mathrm{XX}$ & $X$ & $\mathrm{X}$ & $\mathrm{X}$ & $\mathrm{X}$ & $\mathrm{X}$ & $\mathrm{X}$ & $\mathrm{X}$ \\
\hline Afiches & $\mathrm{X}$ & $\mathrm{X}$ & $\mathrm{X}$ & $\mathrm{X}$ & $\mathrm{XX}$ & $\mathrm{X}$ & $\mathrm{X}$ & $\mathrm{X}$ & $\mathrm{X}$ & $\mathrm{X}$ & $\mathrm{X}$ & $\mathrm{X}$ \\
\hline Merchandising & $\mathrm{X}$ & $X$ & $\mathrm{X}$ & $\mathrm{X}$ & $\mathrm{XX}$ & $\mathrm{X}$ & $X$ & $\mathrm{X}$ & $\mathrm{X}$ & $\mathrm{X}$ & $\mathrm{X}$ & $\mathrm{X}$ \\
\hline
\end{tabular}

Elaboración propia de acuerdo a las actividades a realizar en un año para la promoción del producto.

Tabla 65

Presupuesto Anual de Marketing

Degustación en casa naturista, minimarket

Degustación en feria

Canal 4 (DR. TV)

Participación en Ferias

Banners

Folletos

Volantes

Afiches

\begin{tabular}{|c|c|c|c|c|c|}
\hline 0 & 2017 & 2018 & 2019 & 2020 & 2021 \\
\hline & $23,010.00$ & $23,010.00$ & $23,010.00$ & $23,010.00$ & $23,010.00$ \\
\hline & - & $1,165.00$ & - & $1,165.00$ & - \\
\hline \multirow[t]{2}{*}{$24,000.00$} & - & - & $24,000.00$ & - & $24,000.00$ \\
\hline & - & $15,000.00$ & - & $15,000.00$ & - \\
\hline 216.00 & 936.00 & 948.00 & 936.00 & 948.00 & 936.00 \\
\hline 60.00 & 780.00 & 800.00 & 780.00 & 800.00 & 780.00 \\
\hline 180.00 & 780.00 & 800.00 & 780.00 & 800.00 & 780.00 \\
\hline 0 & 299.00 & 299.00 & 299.00 & 299.00 & 299.00 \\
\hline 875.00 & $9,750.00$ & $10,625.00$ & $9,750.00$ & $10,625.00$ & 9.750 .00 \\
\hline $25,331.00$ & $35,555.00$ & $52,647.00$ & $59,555.00$ & $52,647.00$ & $59,555.00$ \\
\hline
\end{tabular}

Nota: Elaboración propia 


\subsection{Estrategia de ventas}

\subsubsection{Plan de ventas}

Para la elaboración del plan de ventas en bolsas, se ha tomado como base la proyección de ventas en kilos de los años 2017 a 2021, como se aprecian en las tablas $\mathrm{N}^{\circ} 66,67,68,69$ y 70, para el mercado objetivo; a ello se le aplicará el porcentaje del mercado objetivo que prefiere bolsas de 250 gr y el porcentaje que prefiere las bolsas de 500gr a más, resultado de la pregunta 10 de la encuesta. Logrando obtener el siguiente plan mensual de bolsas por mes y por año:

\section{Tabla 66}

Plan de Ventas 2017

\begin{tabular}{|c|c|c|c|c|c|c|c|c|}
\hline \multicolumn{9}{|c|}{ Plan mensual de ventas 2017} \\
\hline Meses & Kilos & Bolsas de $250 \mathrm{gr}$ & Precio S/. & Sub total & Bolsas de $500 \mathrm{gr}$ & Precio S/. & Sub total & Ingresos \\
\hline Enero & 2,772 & 7,340 & 2.00 & 14,679 & 1,874 & 4.00 & 7,495 & 22,174 \\
\hline Febrero & 2,733 & 7,237 & 2.00 & 14,473 & 1,847 & 4.00 & 7,390 & 21,863 \\
\hline Marzo & 3,171 & 8,396 & 2.00 & 16,792 & 2,143 & 4.00 & 8,574 & 25,366 \\
\hline Abril & 2,988 & 7,912 & 2.00 & 15,824 & 2,020 & 4.00 & 8,080 & 23,904 \\
\hline Mayo & 3,033 & 8,030 & 2.00 & 16,061 & 2,050 & 4.00 & 8,200 & 24,261 \\
\hline Junio & 2,793 & 7,397 & 2.00 & 14,794 & 1,888 & 4.00 & 7,554 & 22,348 \\
\hline Julio & 3,015 & 7,983 & 2.00 & 15,965 & 2,038 & 4.00 & 8,151 & 24,117 \\
\hline Agosto & 3,026 & 8,013 & 2.00 & 16,026 & 2,046 & 4.00 & 8,182 & 24,208 \\
\hline Septiembre & 2,814 & 7,450 & 2.00 & 14,900 & 1,902 & 4.00 & 7,608 & 22,508 \\
\hline Octubre & 2,786 & 7,377 & 2.00 & 14,755 & 1,883 & 4.00 & 7,533 & 22,288 \\
\hline Noviembre & 2,618 & 6,934 & 2.00 & 13,867 & 1,770 & 4.00 & 7,080 & 20,947 \\
\hline Diciembre & 2,470 & 6,540 & 2.00 & 13,079 & 1,670 & 4.00 & 6,678 & 19,757 \\
\hline & 34,218 & 90,609 & & & 23,131 & & & $273,742.26$ \\
\hline
\end{tabular}

Elaboración: Propia

Tabla 67

Plan de Ventas 2018

\begin{tabular}{|c|c|c|c|c|c|c|c|c|}
\hline \multicolumn{9}{|c|}{ Plan mensual de ventas 2018} \\
\hline Meses & Kilos & Bolsas de $250 \mathrm{gr}$ & Precio S/. & Total & Bolsas de $500 \mathrm{gr}$ & Precio S/. & Total & Ingresos \\
\hline Enero & 6,591 & 17,452 & 2.00 & 34,904 & 4,455 & 4.00 & 17,821 & 52,725 \\
\hline Febrero & 6,498 & 17,207 & 2.00 & 34,414 & 4,393 & 4.00 & 17,571 & 51,985 \\
\hline Marzo & 7,539 & 19,964 & 2.00 & 39,929 & 5,097 & 4.00 & 20,387 & 60,316 \\
\hline Abril & 7,105 & 18,814 & 2.00 & 37,627 & 4,803 & 4.00 & 19,211 & 56,839 \\
\hline Mayo & 7,211 & 19,095 & 2.00 & 38,189 & 4,875 & 4.00 & 19,498 & 57,688 \\
\hline Junio & 6,642 & 17,589 & 2.00 & 35,178 & 4,490 & 4.00 & 17,961 & 53,139 \\
\hline Julio & 7,168 & 18,981 & 2.00 & 37,962 & 4,846 & 4.00 & 19,383 & 57,345 \\
\hline Agosto & 7,195 & 19,053 & 2.00 & 38,106 & 4,864 & 4.00 & 19,456 & 57,562 \\
\hline Septiembre & 6,690 & 17,715 & 2.00 & 35,430 & 4,522 & 4.00 & 18,090 & 53,520 \\
\hline Octubre & 6,625 & 17,542 & 2.00 & 35,084 & 4,478 & 4.00 & 17,913 & 52,997 \\
\hline Noviembre & 6,226 & 16,487 & 2.00 & 32,973 & 4,209 & 4.00 & 16,835 & 49,809 \\
\hline Diciembre & 5,872 & 15,550 & 2.00 & 31,100 & 3,970 & 4.00 & 15,879 & 46,979 \\
\hline & 81,363 & 215,449 & & & 55,001 & & & $650,902.81$ \\
\hline
\end{tabular}

Elaboración: Propia 
Tabla 68

Plan de Ventas 2019

\begin{tabular}{|c|c|c|c|c|c|c|c|c|}
\hline \multicolumn{9}{|c|}{ Plan mensual de ventas 2019} \\
\hline Meses & Kilos & Bolsas de $250 \mathrm{gr}$ & Precio S/. & Total & Bolsas de $500 \mathrm{gr}$ & Precio S/. & Total & Ingresos \\
\hline Enero & 9,988 & 26,449 & 2.00 & 52,899 & 6,752 & 4.00 & 27,009 & 79,907 \\
\hline Febrero & 9,848 & 26,078 & 2.00 & 52,156 & 6,657 & 4.00 & 26,630 & 78,786 \\
\hline Marzo & 11,426 & 30,257 & 2.00 & 60,514 & 7,724 & 4.00 & 30,897 & 91,411 \\
\hline Abril & 10,768 & 28,513 & 2.00 & 57,026 & 7,279 & 4.00 & 29,116 & 86,142 \\
\hline Mayo & 10,929 & 28,939 & 2.00 & 57,877 & 7,388 & 4.00 & 29,551 & 87,428 \\
\hline Junio & 10,067 & 26,657 & 2.00 & 53,314 & 6,805 & 4.00 & 27,221 & 80,534 \\
\hline Julio & 10,864 & 28,767 & 2.00 & 57,533 & 7,344 & 4.00 & 29,375 & 86,909 \\
\hline Agosto & 10,905 & 28,876 & 2.00 & 57,752 & 7,372 & 4.00 & 29,487 & 87,238 \\
\hline Septiembre & 10,139 & 26,848 & 2.00 & 53,696 & 6,854 & 4.00 & 27,416 & 81,111 \\
\hline Octubre & 10,040 & 26,586 & 2.00 & 53,172 & 6,787 & 4.00 & 27,148 & 80,320 \\
\hline Noviembre & 9,436 & 24,986 & 2.00 & 49,973 & 6,379 & 4.00 & 25,515 & 75,487 \\
\hline Diciembre & 8,900 & 23,567 & 2.00 & 47,134 & 6,016 & 4.00 & 24,065 & 71,199 \\
\hline & 123,309 & 326,523 & & & 83,357 & & & $986,473.06$ \\
\hline
\end{tabular}

Elaboración; Propia

Tabla 69

Plan de Ventas 2020

\begin{tabular}{|c|c|c|c|c|c|c|c|c|}
\hline \multicolumn{9}{|c|}{ Plan mensual de ventas 2020} \\
\hline Meses & Kilos & Bolsas de $250 \mathrm{gr}$ & Precio S/. & Total & Bolsas de $500 \mathrm{gr}$ & Precio S/. & Total & Ingresos \\
\hline Enero & 13,453 & 35,623 & 2.00 & 71,245 & 9,094 & 4.00 & 36,376 & 107,621 \\
\hline Febrero & 13,264 & 35,123 & 2.00 & 70,245 & 8,966 & 4.00 & 35,865 & 106,111 \\
\hline Marzo & 15,389 & 40,751 & 2.00 & 81,502 & 10,403 & 4.00 & 41,613 & 123,115 \\
\hline Abril & 14,502 & 38,402 & 2.00 & 76,804 & 9,804 & 4.00 & 39,214 & 116,018 \\
\hline Mayo & 14,719 & 38,975 & 2.00 & 77,951 & 9,950 & 4.00 & 39,800 & 117,750 \\
\hline Junio & 13,558 & 35,902 & 2.00 & 71,804 & 9,165 & 4.00 & 36,661 & 108,465 \\
\hline Julio & 14,631 & 38,744 & 2.00 & 77,488 & 9,891 & 4.00 & 39,563 & 117,051 \\
\hline Agosto & 14,687 & 38,891 & 2.00 & 77,782 & 9,928 & 4.00 & 39,713 & 117,495 \\
\hline Septiembre & 13,655 & 36,159 & 2.00 & 72,319 & 9,231 & 4.00 & 36,924 & 109,243 \\
\hline Octubre & 13,522 & 35,806 & 2.00 & 71,613 & 9,141 & 4.00 & 36,564 & 108,177 \\
\hline Noviembre & 12,709 & 33,652 & 2.00 & 67,304 & 8,591 & 4.00 & 34,364 & 101,668 \\
\hline Diciembre & 11,987 & 31,741 & 2.00 & 63,481 & 8,103 & 4.00 & 32,412 & 95,893 \\
\hline & 166,076 & 439,769 & & & 112,267 & & & $1,328,607.96$ \\
\hline
\end{tabular}

Elaboración: Propia

Tabla 70

Plan de Ventas 2021

\begin{tabular}{|c|c|c|c|c|c|c|c|c|}
\hline \multicolumn{9}{|c|}{ Plan mensual de ventas 2021} \\
\hline Meses & Kilos & Bolsas de $250 \mathrm{gr}$ & Precio S/. & Total & Bolsas de $500 \mathrm{gr}$ & Precio S/. & Total & Ingresos \\
\hline Enero & 16,982 & 44,969 & 2.00 & 89,938 & 11,480 & 4.00 & 45,920 & 135,857 \\
\hline Febrero & 16,744 & 44,338 & 2.00 & 88,675 & 11,319 & 4.00 & 45,275 & 133,951 \\
\hline Marzo & 19,427 & 51,443 & 2.00 & 102,885 & 13,133 & 4.00 & 52,531 & 155,416 \\
\hline Abril & 18,307 & 48,477 & 2.00 & 96,954 & 12,376 & 4.00 & 49,502 & 146,457 \\
\hline Mayo & 18,580 & 49,201 & 2.00 & 98,402 & 12,560 & 4.00 & 50,242 & 148,644 \\
\hline Junio & 17,115 & 45,321 & 2.00 & 90,643 & 11,570 & 4.00 & 46,280 & 136,923 \\
\hline Julio & 18,470 & 48,909 & 2.00 & 97,818 & 12,486 & 4.00 & 49,943 & 147,761 \\
\hline Agosto & 18,540 & 49,094 & 2.00 & 98,189 & 12,533 & 4.00 & 50,133 & 148,321 \\
\hline Septiembre & 17,238 & 45,646 & 2.00 & 91,293 & 11,653 & 4.00 & 46,612 & 137,904 \\
\hline Octubre & 17,070 & 45,201 & 2.00 & 90,402 & 11,539 & 4.00 & 46,157 & 136,558 \\
\hline Noviembre & 16,043 & 42,481 & 2.00 & 84,963 & 10,845 & 4.00 & 43,380 & 128,342 \\
\hline Diciembre & 15,131 & 40,068 & 2.00 & 80,136 & 10,229 & 4.00 & 40,916 & 121,052 \\
\hline & 209,648 & 555,149 & & & 141,722 & & & $1,677,186.13$ \\
\hline
\end{tabular}

Elaboración: Propia 
Se consolidará la proyección de unidades de bolsas a vender durante los cinco años del presente proyecto y la proyección de ingresos anualizado, como se aprecia en la tabla $\mathrm{N}^{\circ} 71$ :

Tabla 71

Plan de Ventas 2017 - 2021

\begin{tabular}{|crrr|}
\hline \multicolumn{4}{c|}{ Plan anual de ventas 2017 - 2021 } \\
\hline Años & Bolsas de 250 gr & Bolsas de 500 gr & Ingresos S/. \\
\hline 2017 & 90,609 & 23,131 & 273,742 \\
2018 & 215,449 & 55,001 & 650,903 \\
2019 & 326,523 & 83,357 & 986,473 \\
2020 & 439,769 & 112,267 & $1,328,608$ \\
2021 & 555,149 & 141,722 & $1,677,186$ \\
\hline Total & $1,627,498$ & 415,479 & $4,916,912$ \\
\hline
\end{tabular}

Elaboración propia

\subsubsection{Políticas de servicios y garantías.}

Dentro de la política de servicios y garantías que tendrá la empresa

CODIAL S.A.C. en lo sucesivo denominada La Empresa y El Cliente en lo sucesivo, los adquirientes del producto papa dializada, se regirá por las siguientes cláusulas:

1. La garantía del producto vendido por La Empresa se basa en la identificación del lote procesado del producto, el cual estará reflejado en la factura original de compra. Para hacer efectivo este proceso es indispensable que el Cliente presente la orden de compra, la factura original, la guía de remisión y el informe de recepción. Todos los productos deben venir acompañados de sus bolsas originales, etiquetas sin que muestre señales de violación o apertura, de lo contrario no serán aceptados por garantía. 
2. El Cliente debe revisar el producto adquirido al momento de la entrega y estar conforme al $100 \%$ en cuanto a la calidad y cantidad de los mismos, ya que cualquier daño físico, golpes, abolladuras o roturas no serán aceptados. Así como la violación de las bolsas selladas y etiquetas, dejará sin efectos la garantía del producto y no serán recibidos posteriormente por el Departamento de Almacén y despacho; esto incluye también aquellos daños ocasionados por el desconocimiento de manipulación al momento de la utilizar el producto.

3. El tiempo de vida del producto es de 20 días calendario, válida desde el momento del proceso de la misma, sin extensiones y en días corridos.

4. El proceso de garantía por la empresa está basado en el cambio por un producto nuevo, siempre y cuando la fecha de entrega esté muy cerca a la fecha de vencimiento del producto, cuya reposición será dentro de las 48 horas de reportado el incidente.

5. La entrega y recepción del producto se hará en repartos directos por una empresa de transporte tercera que asumirá la responsabilidad del traslado.

6. Para aquel producto que presente daños físicos no detectables a la vista, serán evaluado por el especialista en calidad antes de solicitar la reposición para evitar inconvenientes, el cliente estará sujeto al cumplimiento de la garantía por parte del fabricante y también al tiempo que este proceso amerite. 
7. La Empresa no se hace responsable de hurtos, robos, daños maltrato físico, mal uso, daños maliciosos o mal intencionados, motín o conmoción civil, daños causados por agua, lluvia, humedad, acción ácida de algunos elementos químicos, impacto de rayos, y/o mal uso por falta de conocimiento por manipulación. 


\section{Capítulo VIII: Planificación Financiera.}

\subsection{La Inversión}

\subsubsection{Inversión pre-operativa}

Se detallarán los costos pre operativos en los cuales se incurrirá antes del inicio de operaciones, estos están divididos en activos tangibles e intangibles.

Los activos tangibles se encuentran expresado en soles y no incluyen IGV, se detallan a continuación en las tablas $\mathrm{N}^{\circ} 72,73,74 \mathrm{y} 75$ :

Tabla 72

Inversión Pre Operativa - Tangibles

\begin{tabular}{lr}
\hline Inversión pre - operativa tangible & \multicolumn{1}{c}{ Costo } \\
\hline & \\
Maquinaria y equipos & $228,863.19$ \\
Implementos y accesorios & $13,470.81$ \\
Muebles de oficina & $16,650.70$ \\
\hline Total Activo Tangible & $\mathbf{2 5 8 , 9 8 4 . 7 0}$ \\
\hline
\end{tabular}

Elaboración propia

Tabla 73

Inversión Pre Operativa - Maquinarias y equipos

\begin{tabular}{|c|c|c|c|c|c|c|}
\hline Concepto & & Cantidad & $\begin{array}{c}\text { Costo Unitario } \\
\text { sin IGV } \\
\end{array}$ & $\begin{array}{c}\text { Total sin } \\
\text { IGV }\end{array}$ & IGV & $\begin{array}{c}\text { Total } \\
\text { con IGV }\end{array}$ \\
\hline Pelador de papas & Maquinaria & 1 & $2,288.14$ & $2,288.14$ & 411.87 & $2,700.01$ \\
\hline Poza dializadora & Maquinaria & 1 & $1,694.92$ & $1,694.92$ & 305.09 & $2,000.01$ \\
\hline Máquina envasado al Vacío & Maquinaria & 1 & $7,627.12$ & $7,627.12$ & $1,372.88$ & $9,000.00$ \\
\hline Máquina cortadora & Maquinaria & 1 & $3,423.16$ & $3,423.16$ & 616.17 & $4,039.33$ \\
\hline Banda transportadora & Maquinaria & 1 & $4,480.50$ & $4,480.50$ & 806.49 & $5,286.99$ \\
\hline Filtro & Maquinaria & 1 & 203.39 & 203.39 & 36.61 & 240.00 \\
\hline Cámara frigorífica & Maquinaria & 1 & $205,865.96$ & $205,865.96$ & $37,055.87$ & $242,921.83$ \\
\hline \multirow[t]{2}{*}{ Stoka } & Maquinaria & 2 & $1,640.00$ & $3,280.00$ & 590.40 & $3,870.40$ \\
\hline & & & & $228,863.19$ & $41,195.37$ & $270,058.56$ \\
\hline
\end{tabular}

Elaboración propia 
Tabla 74

Inversión Pre Operativa - Muebles y Enseres

\begin{tabular}{llrrrrr}
\hline \multicolumn{1}{c}{ Concepto } & & Cantidad & $\begin{array}{c}\text { Costo Unitario } \\
\text { sin IGV }\end{array}$ & $\begin{array}{r}\text { Total sin } \\
\text { IGV }\end{array}$ & IGV & $\begin{array}{c}\text { Total } \\
\text { con IGV }\end{array}$ \\
\hline \multicolumn{1}{c}{ Area de Producción } & & & & & & \\
Botas industriales para agua & Muebles y enseres & 6 & 20.00 & 120.00 & 21.60 & 141.60 \\
Mandiles protectores & Muebles y enseres & 6 & 45.00 & 270.00 & 48.60 & 318.60 \\
Javas & Muebles y enseres & 450 & 25.00 & $11,250.00$ & $2,025.00$ & $13,275.00$ \\
Mascarillas & Muebles y enseres & 6 & 5.08 & 30.48 & 5.49 & 35.97 \\
Guantes & Muebles y enseres & 12 & 9.32 & 111.84 & 20.13 & 131.97 \\
Gorros y protectores & Muebles y enseres & 6 & 18.64 & 111.84 & 20.13 & 131.97 \\
Uniforme de trabajo & Muebles y enseres & 6 & 22.03 & 132.18 & 23.79 & 155.97 \\
Extintores & Muebles y enseres & 5 & 69.41 & 347.05 & 62.47 & 409.52 \\
\hline \multirow{2}{*}{ Vestuario } & & & & & & \\
Juego de baño & Muebles y enseres & 1 & 68.64 & 68.64 & 12.36 & 81.00 \\
Espejo & Muebles y enseres & 1 & 15.17 & 15.17 & 2.73 & 17.90 \\
Dispensador de antibacterial & Muebles y enseres & 2 & 15.51 & 31.02 & 5.58 & 36.60 \\
Dispensador de jabón espuma & Muebles y enseres & 2 & 25.20 & 50.40 & 9.07 & 59.47 \\
Dispensador de papel higiénico & Muebles y enseres & 2 & 42.37 & 84.74 & 15.25 & 99.99 \\
Estantería metálica & Muebles y enseres & 2 & 211.86 & 423.72 & 76.27 & 499.99 \\
Gabinete para vestuario & Muebles y enseres & 1 & 423.73 & 423.73 & 76.27 & 500.00 \\
\hline & & & & 13,471 & 2,425 & $15,895.56$ \\
\hline
\end{tabular}

\section{Elaboración propia}

Tabla 75

Inversión Pre Operativa - Mueble de Oficina

\begin{tabular}{|c|c|c|c|c|c|c|}
\hline Concepto & & Cantidad & $\begin{array}{c}\text { Costo Unitario } \\
\text { sin IGV } \\
\end{array}$ & $\begin{array}{c}\text { Total sin } \\
\text { IGV }\end{array}$ & IGV & $\begin{array}{c}\text { Total } \\
\text { con IGV }\end{array}$ \\
\hline \multicolumn{7}{|l|}{ Area de Gerencia } \\
\hline Escritorio de melamina & Muebles y enseres & 1 & 480.00 & 480.00 & 86.40 & 566.40 \\
\hline Sillas giratorias & Muebles y enseres & 2 & 209.00 & 418.00 & 75.24 & 493.24 \\
\hline Estante archivador & Muebles y enseres & 1 & 550.00 & 550.00 & 99.00 & 649.00 \\
\hline Computadoras & Muebles y enseres & 2 & 1360.00 & $2,720.00$ & 489.60 & $3,209.60$ \\
\hline Escritorio para recepción & Muebles y enseres & 1 & 350.00 & 350.00 & 63.00 & 413.00 \\
\hline Sofa de oficina para recepción & Muebles y enseres & 1 & 850.00 & 850.00 & 153.00 & $1,003.00$ \\
\hline Caja fuerte & Muebles y enseres & 1 & 160.17 & 160.17 & 28.83 & 189.00 \\
\hline \multicolumn{7}{|l|}{ Area de Reuniones } \\
\hline Escritorio de melamina & Muebles y enseres & 1 & 450.00 & 450.00 & 81.00 & 531.00 \\
\hline Proyector & Muebles y enseres & 1 & 1599.00 & $1,599.00$ & 287.82 & $1,886.82$ \\
\hline Mesa de reuniones con 10 sillas & Muebles y enseres & 1 & 1855.00 & $1,855.00$ & 333.90 & $2,188.90$ \\
\hline Computadora & Muebles y enseres & 1 & 1360.00 & $1,360.00$ & 244.80 & $1,604.80$ \\
\hline Pizarra & Muebles y enseres & 2 & 42.29 & 84.58 & 15.22 & 99.80 \\
\hline \multicolumn{7}{|l|}{ Area Administrativa } \\
\hline Escritorio de melamina & Muebles y enseres & 2 & 480.00 & 960.00 & 172.80 & $1,132.80$ \\
\hline Sillas giratorias & Muebles y enseres & 2 & 209.00 & 418.00 & 75.24 & 493.24 \\
\hline Estante archivador & Muebles y enseres & 1 & 550.00 & 550.00 & 99.00 & 649.00 \\
\hline Computadoras & Muebles y enseres & 2 & 1360.00 & $2,720.00$ & 489.60 & $3,209.60$ \\
\hline Mesa para impresora & Muebles y enseres & 1 & 250.00 & 250.00 & 45.00 & 295.00 \\
\hline Impresora & Muebles y enseres & 1 & 859.00 & 859.00 & 154.62 & $1,013.62$ \\
\hline \multirow[t]{2}{*}{ Reloj pared } & Muebles y enseres & 1 & 16.95 & 16.95 & 3.05 & 20.00 \\
\hline & & & & $16,650.70$ & $2,997.13$ & $19,647.83$ \\
\hline
\end{tabular}

\section{Elaboración propia}

TOTAL ACTIVOS TANGIBLES

$258,984.70 \quad 46,617.25 \quad 305,601.95$

Entre los activos intangibles, como se puede apreciar en las tablas $\mathrm{N}^{\circ}$

$76,77,78,79$ y 80 , que se encuentran en soles y sin igv., se encuentran: 
Tabla 76

Inversión Pre Operativa - Intangibles

\begin{tabular}{lr}
\hline Inversión pre - operativa intangible & \multicolumn{1}{c}{ Costo } \\
\hline & \\
Constitución de la empresa & $1,150.33$ \\
Licencias y permisos municipales & $2,453.56$ \\
Recursos humanos (publicación) & 42.37 \\
Software y pagina web & $1,528.14$ \\
Marketing & $25,331.00$ \\
Otros gastos pre operativos & $8,627.80$ \\
\hline Total & $\mathbf{3 9 , 1 3 3 . 2 0}$ \\
\hline
\end{tabular}

Elaboración propia

Tabla 77

Inversión Pre operativa - Constitución de la Empresa

\begin{tabular}{|c|c|c|c|c|c|c|}
\hline Concepto & & Cantidad & $\begin{array}{c}\text { Costo Unitario } \\
\text { sin IGV } \\
\end{array}$ & $\begin{array}{c}\text { Total sin } \\
\text { IGV }\end{array}$ & IGV & $\begin{array}{c}\text { Total } \\
\text { con IGV }\end{array}$ \\
\hline Apertura de cuenta corriente & $\mathrm{BCP}$ & 1 & - & - & - & - \\
\hline $\begin{array}{l}\text { Certificado de búsqueda mercantil, solicitud } \\
\text { de reserva de nombre }\end{array}$ & SUNARP & 1 & 16.10 & 16.10 & 2.90 & 19.00 \\
\hline Elaboración de Minuta & SUNARP & 1 & 211.86 & 211.86 & 38.13 & 249.99 \\
\hline Elevación de escritura a Registros Públicos & Notaria Chavez Gil & 1 & 207.12 & 207.12 & 37.28 & 244.40 \\
\hline Pago de derecho de inscripción & Notaria Chavez Gil & 1 & 142.37 & 142.37 & 25.63 & 168.00 \\
\hline Inscripción de RUC & SUNARP & 1 & - & - & - & - \\
\hline Inscripción de marca en Indecopi & Indecopi & 1 & 430.51 & 430.51 & 77.49 & 508.00 \\
\hline Publicación en diario & El Peruano & 1 & 142.37 & 142.37 & 25.63 & 168.00 \\
\hline Total & & & & $1,150.33$ & 207.06 & $1,357.39$ \\
\hline
\end{tabular}

Elaboración propia

Tabla 78

Inversión Pre Operativa - Licencias y Permisos

\begin{tabular}{|c|c|c|c|c|c|c|}
\hline Concepto & & Cantidad & $\begin{array}{c}\text { Costo Unitario } \\
\text { sin IGV }\end{array}$ & $\begin{array}{c}\text { Total sin } \\
\text { IGV }\end{array}$ & IGV & $\begin{array}{c}\text { Total } \\
\text { con IGV }\end{array}$ \\
\hline Derecho de revisión de bomberos & Munic Independencii & 1 & 185.59 & 185.59 & 33.41 & 219.00 \\
\hline Derecho de licencia & Munic Independencii & 1 & 84.75 & 84.75 & 15.26 & 100.01 \\
\hline Licencia de funcionamiento & Munic Independencii & 1 & 290.75 & 290.75 & 52.34 & 343.09 \\
\hline Carnet de Sanidad & Munic Independencii & 6 & 14.00 & 84.00 & 15.12 & 99.12 \\
\hline Certificado de Defensa Civil & Indeci & 1 & $1,422.03$ & $1,422.03$ & 255.97 & $1,678.00$ \\
\hline Certificado de seguridad de Defensa Civil & Indeci & 1 & 81.36 & 81.36 & 14.64 & 96.00 \\
\hline Registro Sanitario & Digesa & 1 & 305.08 & 305.08 & 54.91 & 359.99 \\
\hline & & & & $2,453.56$ & 441.64 & $2,895.20$ \\
\hline
\end{tabular}

\section{Elaboración propia}


Tabla 79

Inversión Pre Operativa - RRHH - Software - Marketing

\begin{tabular}{ccccccr}
\hline Concepto & & \multirow{2}{*}{ Cantidad $\begin{array}{c}\text { Costo Unitario } \\
\text { sin IGV }\end{array}$} & $\begin{array}{c}\text { Total sin } \\
\text { IGV }\end{array}$ & \multicolumn{2}{c}{ IGV } & \multicolumn{2}{c}{ Total } \\
con IGV \\
\hline Publicación de clasificados (fin de semana) & El Comercio & 1 & 42.37 & 42.37 & 7.63 & 50.00 \\
\hline & & & & $\mathbf{4 2 . 3 7}^{2}$ & $\mathbf{7 . 6 3}$ & $\mathbf{5 0 . 0 0}$ \\
\hline
\end{tabular}

Inversión Pre operativa - Software

\begin{tabular}{llrrrrrr}
\hline & & \multirow{2}{*}{ Concepto } & \multicolumn{2}{c}{ Costo Unitario } & Total sin & \multicolumn{2}{c}{ Total } \\
& & & sin IGV & IGV & IGV & con IGV \\
\hline Office Estandar & Office & 1 & 697.63 & 697.63 & 125.57 & 823.20 \\
Página web & Infosis Perú & 1 & 830.51 & 830.51 & 149.49 & 980.00 \\
\hline & & & & $\mathbf{1 , 5 2 8 . 1 4}$ & $\mathbf{2 7 5 . 0 7}$ & $\mathbf{1 , 8 0 3 . 2 1}$ \\
\hline
\end{tabular}

Inversión Pre operativa - Marketing

\begin{tabular}{lccccccc}
\hline \multirow{2}{*}{ Concepto } & & \multicolumn{2}{c}{ Cantidad } & \multicolumn{2}{c}{ Costo Unitario } & Total sin & \multicolumn{2}{c}{ Total con } \\
& & & sin IGV & IGV & IGV & IGV \\
\hline Publicidad & TV & 1 & $25,331.00$ & $25,331.00$ & $4,559.58$ & $29,890.58$ \\
\hline & & & & $\mathbf{2 5 , 3 3 1 . 0 0}$ & $\mathbf{4 5 5 9 . 5 8}$ & $\mathbf{2 9 , 8 9 0 . 5 8}$ \\
\hline
\end{tabular}

\section{Elaboración propia}

Tabla 80

Inversión Pre Operativa - Otros

\begin{tabular}{llrrrrr}
\hline \multicolumn{1}{c}{ Concepto } & & \multirow{2}{*}{ Cantidad Costo Unitario } & Total sin & \multicolumn{2}{c}{ Total con } \\
& & & sin IGV & IGV & \multicolumn{2}{c}{$\begin{array}{c}\text { IGV } \\
\text { IGV }\end{array}$} \\
\hline Talonario de facturas y boletas & Imprenta Libertad & 1 & 144.07 & 144.07 & 25.93 & 170.00 \\
Legalización de libros contables & Notaria Chavez Gil & 1 & 203.39 & 203.39 & 36.61 & 240.00 \\
Autorización de planillas de pago & MTPE & 1 & 29.66 & 29.66 & 5.34 & 35.00 \\
Alquiler de local & & 2 & $3,630.00$ & $7,260.00$ & $1,306.80$ & $8,566.80$ \\
Agua & Sedapal & 1 & 254.24 & 254.24 & 45.76 & 300.00 \\
Luz & Edelnor & 1 & 635.59 & 635.59 & 114.41 & 750.00 \\
Teléfono+Internet & Telefónica & 1 & 100.85 & 100.85 & 18.15 & 119.00 \\
\hline & & & & $\mathbf{8 , 6 2 7 . 8 0}$ & $\mathbf{1 , 5 5 3 . 0 0}$ & $\mathbf{1 0 , 1 8 0 . 8 0}$ \\
\hline
\end{tabular}

\section{Elaboración propia}

Se puede observar que la inversión total sin IGV en activos tangibles e intangibles es de S/. 298,117.90. El financiamiento del mismo será con un $70 \%$ del capital propio, aportado por lo accionistas, y el 30\% será financiado por un préstamo. 


\subsubsection{Inversión en capital de trabajo}

El capital de trabajo, será la cantidad de recursos a corto plazo que necesitará la empresa para la realización de sus actividades. Para la obtención del monto considerado como capital de trabajo, se aplicará el método del máximo déficit acumulado.

Este método es el que se ajusta al tipo de negocio que se realizará con el presente proyecto, ya que se aplica para productos con estacionalidad.

El método del déficit acumulado máximo consiste en calcular para cada mes, durante el primer año de realizado el proyecto, la fila de ingresos y egresos proyectados y determinar su cuantía como el equivalente al déficit acumulado máximo; seleccionándose el menor de la proyección anual.

Para iniciar el proyecto, se necesitará un valor de S/. 88,865.00 como capital de trabajo, tal como se muestra en la tabla $\mathrm{N}^{\circ} 81$ líneas abajo: 
Tabla 81

Inversión de Capital de Trabajo

Inversión en Capital de Trabajo

Expresado en nuevos soles

\begin{tabular}{|c|c|c|c|c|c|c|c|c|c|c|c|c|}
\hline Flujo de caja mensual & Enero & Febrero & Marzo & Abril & Mayo & Junio & Julio & Agosto & Septiembre & Octubre & Noviembre & Diciembre \\
\hline \multicolumn{13}{|l|}{ Ingresos } \\
\hline Por ventas contado & 22,174 & 21,863 & 25,366 & 23,904 & 24,261 & 22,348 & 24,117 & 24,208 & 22,508 & 22,288 & 20,947 & 19,757 \\
\hline Total Ingresos & 22,174 & 21,863 & 25,366 & 23,904 & $\mathbf{2 4 , 2 6 1}$ & 22,348 & $\mathbf{2 4 , 1 1 7}$ & $\mathbf{2 4 , 2 0 8}$ & 22,508 & $\mathbf{2 2 , 2 8 8}$ & 20,947 & 19,757 \\
\hline \multicolumn{13}{|l|}{ Compras } \\
\hline MPD & 6,189 & 5,564 & 6,550 & 6,057 & 6,192 & 5,649 & 6,189 & 6,172 & 5,695 & 5,675 & 5,306 & 5,007 \\
\hline MPI & 240 & 236 & 274 & 258 & 262 & 242 & 261 & 262 & 243 & 241 & 226 & 214 \\
\hline Total compras & 6,429 & 5,801 & 6,824 & 6,315 & 6,454 & 5,891 & 6,450 & 6,434 & 5,938 & 5,916 & 5,533 & 5,220 \\
\hline \multicolumn{13}{|l|}{ Otros egresos } \\
\hline MOD & 4,182 & 4,182 & 4,182 & 4,182 & 4,182 & 4,182 & 4,182 & 4,182 & 4,182 & 4,182 & 4,182 & 4,182 \\
\hline MOI & 2,091 & 2,091 & 2,091 & 2,091 & 2,091 & 2,091 & 2,091 & 2,091 & 2,091 & 2,091 & 2,091 & 2,091 \\
\hline \multicolumn{13}{|c|}{ OTROS COSTOS IND DE FABRICACION } \\
\hline Luz y Agua & 600 & 600 & 600 & 600 & 600 & 600 & 600 & 600 & 600 & 600 & 600 & 600 \\
\hline Alquiler de planta & 3,630 & 3,630 & 3,630 & 3,630 & 3,630 & 3,630 & 3,630 & 3,630 & 3,630 & 3,630 & 3,630 & 3,630 \\
\hline Impuestos y tasas & 100 & 100 & 100 & 100 & 100 & 100 & 100 & 100 & 100 & 100 & 100 & 100 \\
\hline Seguro & 215 & 215 & 215 & 215 & 215 & 215 & 215 & 215 & 215 & 215 & 215 & 215 \\
\hline Telefono e internet & 250 & 250 & 250 & 250 & 250 & 250 & 250 & 250 & 250 & 250 & 250 & 250 \\
\hline Amortización & 25 & 25 & 25 & 25 & 25 & 25 & 25 & 25 & 25 & 25 & 25 & 25 \\
\hline Depreciación & 2,364 & 2,364 & 2,364 & 2,364 & 2,364 & 2,364 & 2,364 & 2,364 & 2,364 & 2,364 & 2,364 & 2,364 \\
\hline Combustible & 600 & 600 & 600 & 600 & 600 & 600 & 600 & 600 & 600 & 600 & 600 & 600 \\
\hline Planilla de ventas & 3,067 & 3,059 & 3,146 & 3,110 & 3,118 & 3,071 & 3,115 & 3,117 & 3,075 & 3,070 & 3,037 & 3,008 \\
\hline Transporte & 1,192 & 1,175 & 1,363 & 1,404 & 1,304 & 1,201 & 1,296 & 1,301 & 1,210 & 1,198 & 1,126 & 1,062 \\
\hline Marketing & 2,735 & 2,735 & 2,735 & 2,735 & 5,470 & 2,735 & 2,735 & 2,735 & 2,735 & 2,735 & 2,735 & 2,735 \\
\hline Total otros egresos & 23,512 & 23,487 & 23,762 & 23,767 & 26,410 & 23,525 & 23,664 & 23,671 & 23,538 & 23,520 & 23,415 & 23,322 \\
\hline
\end{tabular}

\begin{tabular}{|c|c|c|c|c|c|c|c|c|c|c|c|c|}
\hline A cuenta del IR & 0 & 333 & 328 & 380 & 359 & 364 & 335 & 362 & 363 & 338 & 334 & 314 \\
\hline Préstamo & 0 & 0 & 0 & 0 & 0 & 0 & 0 & 0 & 0 & 0 & 0 & 0 \\
\hline Total Egresos & $-29,941$ & $-29,620$ & $-30,914$ & $-30,462$ & $-33,223$ & $-29,780$ & $-30,449$ & $-30,466$ & $-29,839$ & $-29,774$ & $-29,282$ & $-28,857$ \\
\hline Ingresos - Egresos & $-7,767$ & $-7,758$ & $-5,547$ & $-6,558$ & $-8,962$ & $-7,432$ & $-6,332$ & $-6,258$ & $-7,331$ & $-7,486$ & $-8,335$ & $-9,099$ \\
\hline Saldo del mes & 0 & $-7,767$ & $-15,524$ & $-21,072$ & $-27,630$ & $-36,592$ & $-44,024$ & $-50,356$ & $-56,614$ & $-63,945$ & $-71,431$ & $-79,766$ \\
\hline
\end{tabular}

Capital de trabajo

$-88,865$ 


\subsubsection{Costo del proyecto.}

El costo del proyecto asciende a S/. 386,983.00 esta inversión se divide en $66.92 \%$ de activo fijo tangible, $10.11 \%$ de activo intangible y $22.96 \%$ de capital de trabajo, se estructura de la siguiente manera y se aprecia en la tabla $\mathrm{N}^{\circ} 82$ :

Tabla 82

Costo del Proyecto

COSTO DEL PROYECTO - AÑO 0

Monto

$\%$

\section{Inversión en Activo Tangible}

Maquinaria y equipos 228,863

Implementos y accesorios

13,471

Muebles de oficina

16,651

Total Activo Tangible

$\mathbf{2 5 8 , 9 8 5} 66.92 \%$

\section{Inversión en Activo Intangible}

Constitución de la empresa

1,150

Licencias y permisos municip:

2,454

Recursos humanos (publicacis

42

Software y pagina web

1,528

Marketing

25,331

Otros gastos pre operativos

8,628

Total Activo Intangible

$\mathbf{3 9 , 1 3 3} \quad 10.11 \%$

\begin{tabular}{|c|c|c|c|}
\hline \multicolumn{4}{|c|}{ Capital } \\
\hline Capital de Trabajo & 88,865 & 88,865 & $22.96 \%$ \\
\hline Total & & 386,983 & $100 \%$ \\
\hline
\end{tabular}

\subsubsection{Inversiones futuras.}

Para las inversiones futuras a partir del 2022, la empresa evaluará el equipamiento que se requiera, ya que hasta el año 2021 aún mantendrá una capacidad ociosa del $30 \%$ por explotar, como se aprecia de la combianción de información de las tabla № 83 y 84 . 
Tabla 83

Capacidad Máxima de Producción

Capacidad máxima de producción

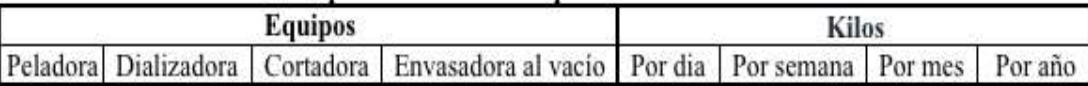

\begin{tabular}{|c|c|c|c|c|c|c|c|c|}
\hline Tiempo (horas) & 1 & 24 & 1 & 1 & & & & \\
\hline Capacidad (kg) & 150 & 1,200 & 150 & 150 & & & & \\
\hline Colaboradores & 1 & 1 & 1 & 1 & & & & \\
\hline Horas de trabajo & 8 & 24 & 8 & 8 & & & & \\
\hline Ciclos & 8 & 1 & 8 & 8 & & & & \\
\hline Capacidad maxima $(\mathrm{kg})$ & 1,200 & 1,200 & 1,200 & 1,200 & 1,200 & 7,200 & 28,800 & 345,600 \\
\hline
\end{tabular}

Elaboración propia

Según la capacidad de las maquinarias adquiridas, y que son las básicas para el diseño del proceso, se puede visualizar que con una producción máxima de 1.2 toneladas por día, logramos obtener en un año 345, $600 \mathrm{~kg}$ de papa, ver tabla $\mathrm{N}^{\mathrm{o}} 84$.

Tabla 84

Programa anual de Producción

\begin{tabular}{lrrrrr}
\hline & \multicolumn{1}{c}{$\mathbf{2 0 1 7}$} & \multicolumn{1}{c}{$\mathbf{2 0 1 8}$} & \multicolumn{1}{l}{$\mathbf{2 0 1 9}$} & \multicolumn{1}{l}{$\mathbf{2 0 2 0}$} & \multicolumn{1}{l}{$\mathbf{2 0 2 1}$} \\
\hline Producción anual $\mathrm{kg}$ & $36,175.64$ & $85,771.27$ & $141,805.50$ & $190,987.39$ & $241,095.51$ \\
Capacidad máxima kg & $345,600.00$ & $345,600.00$ & $345,600.00$ & $345,600.00$ & $345,600.00$ \\
\hline Porcentaje de utilización del proyecto & $10 \%$ & $25 \%$ & $41 \%$ & $55 \%$ & $70 \%$ \\
Capacidad ociosa & $90 \%$ & $\mathbf{7 5 \%}$ & $59 \%$ & $45 \%$ & $30 \%$
\end{tabular}

Elaboración propia

Por otro lado, al incrementar significativamente la producción a partir del 2022, la empresa necesitará realizar la contratación de más personal para evitar carga laboral que no permita continuar con los tiempos regulares de los procesos de producción o llamados cuellos de botella, ver tabla $\mathrm{N}^{\circ} 85$.

Tabla 85

Remuneración Base

\begin{tabular}{lcr}
\multicolumn{1}{c}{ Trabajador } & Numero & Remuneración base \\
\hline Operario de producción & 2 & 850.00 \\
\hline Control de Calidad & 2 & 850.00 \\
\hline Operario de Almacén & 1 & 850.00 \\
\hline Ejecutivo comercial & 1 & 850.00 \\
\hline Recepcionista & 1 & 850.00 \\
\hline
\end{tabular}


En el caso de las inversiones que se realizarán a partir del 2018 al 2021, tenemos:

1. Incremento de personal, una persona para el puesto de asistente administrativo y una persona para el puesto de Jefe de Producción y Logística, como se aprecia en la tabla $\mathrm{N}^{\circ} 86$.

2. Mantenimiento de Equipos, para el cual se destinará el 3\% del valor de las maquinarias.

Tabla 86

Recursos - Operaciones

\begin{tabular}{lccccc}
\hline \multicolumn{1}{c}{ Recurso } & $\mathbf{2 0 1 7}$ & $\mathbf{2 0 1 8}$ & $\mathbf{2 0 1 9}$ & $\mathbf{2 0 2 0}$ & $\mathbf{2 0 2 1}$ \\
\hline Jefe de Producción y Logistica & - & $14,760.00$ & $14,760.00$ & $14,760.00$ & $14,760.00$ \\
Asistente & - & $13,284.00$ & $13,284.00$ & $13,284.00$ & $13,284.00$ \\
Mantenimiento de Equipos & - & 6865.8957 & 6865.8957 & 6865.8957 & 6865.8957 \\
\hline
\end{tabular}

\subsection{Financiamiento.}

En esta sección se mostrará la estructura del monto a financiar, la empresa considera conveniente que el financiamiento debe ser por el $30 \%$ del costo del proyecto y el $70 \%$ deberá ser cubierto con el aporte de los socios, como se puede apreciar en la tabla $\mathrm{N}^{\circ} 87$.

\subsubsection{Endeudamiento y condiciones.}

La empresa financiará el monto de S/ 116,095, lo cual representa el $30 \%$ de la inversión total, este financiamiento lo manejará a través de un préstamo brindado por la institución financiera BBVA la cual ofrece una tasa para las pequeñas empresas que buscan financiamiento por un plazo mayor a 360 días, de $14.26 \%$ (Ver tabla $\mathrm{N}^{\circ} 88$ ) y el otro $70 \%$ será un aporte realizado por los socios de forma equitativa, como se aprecia en la tabla $\mathrm{N}^{\circ} 89$. 
En caso el financiamiento bancario no se haga efectivo de forma directa a la empresa, se optará por que cada socio solicite el préstamo a nombre personal, asumiendo el pago por impuesto a la renta que corresponda, el cual será deducido de sus utilidades por cobrar.

Las garantías que se utilizarán como respaldo del préstamo bancario, de forma directa o a nivel personal, serán garantías hipotecarias; las que recaerán sobre el inmueble en el que se realizará la operación productiva, ya que este es propiedad de uno de los socios accionista, el cual ha decidido ceder como garantía dicha propiedad en la cual está valorizada en US \$ 350,000.00.

Tabla 87

Estructura de Financiamiento

Cuadro de amortización expresado en nuevos soles

Estructura de financiamiento

(Nuevos Soles)

\begin{tabular}{|c|c|c|c|c|}
\hline Inversiones & $\begin{array}{l}\text { Total } \\
100 \% \\
\end{array}$ & $\begin{array}{c}\text { Aporte } \\
70 \%\end{array}$ & $\begin{array}{c}\text { Préstamo } \\
\mathbf{3 0 \%}\end{array}$ & $\%$ \\
\hline Activo tangible & 258,985 & 181,289 & 77,695 & $67 \%$ \\
\hline Activo intangible & 39,133 & 27,393 & 11,740 & $10 \%$ \\
\hline Capital de trabajo & 88,865 & 62,205 & 26,659 & $23 \%$ \\
\hline Totales & 386,983 & 270,888 & 116,095 & $100 \%$ \\
\hline
\end{tabular}


Tabla 88

Determinación del Préstamo en Cuotas

\begin{tabular}{|c|c|c|c|c|c|c|c|c|}
\hline $\begin{array}{l}\text { Monto: } \\
\text { Cuotas: } \\
\text { Sistema: }\end{array}$ & $\begin{array}{r}\text { S/. 116,094.82 } \\
60 \\
\text { Francés }\end{array}$ & $\begin{array}{l}\text { Soles } \\
\text { nensuales }\end{array}$ & Graci & $\begin{array}{l}\text { terés anual: } \\
\text { terés Men: } \\
\text { de capital: }\end{array}$ & $\begin{array}{r}14.26 \% \\
1.12 \% \\
0\end{array}$ & $\begin{array}{l}\text { TEA } \\
\text { TEM } \\
\text { neses }\end{array}$ & & \\
\hline Cuotas & Capital & Interés & $\begin{array}{l}\text { Importe de } \\
\text { Cuota }\end{array}$ & Saldo & $\begin{array}{l}\text { Importe } \\
\text { total a } \\
\text { pagar }\end{array}$ & & & \\
\hline $\begin{array}{l}\text { Saldo } \\
\text { Inicial }\end{array}$ & & & & $116,094.82$ & & & & \\
\hline 001 & $1,368.77$ & $1,296.87$ & $2,665.64$ & $114,726.05$ & $2,665.64$ & & & \\
\hline 002 & $1,384.06$ & $1,281.58$ & $2,665.64$ & $113,341.99$ & $2,665.64$ & & & \\
\hline 003 & $1,399.52$ & $1,266.12$ & $2,665.64$ & $111,942.47$ & $2,665.64$ & & & \\
\hline 004 & $1,415.16$ & $1,250.49$ & $2,665.64$ & $110,527.31$ & $2,665.64$ & & & \\
\hline 005 & $1,430.96$ & $1,234.68$ & $2,665.64$ & $109,096.35$ & $2,665.64$ & & & \\
\hline 006 & $1,446.95$ & $1,218.69$ & $2,665.64$ & $107,649.40$ & $2,665.64$ & & & \\
\hline 007 & $1,463.11$ & $1,202.53$ & $2,665.64$ & $106,186.28$ & $2,665.64$ & & & \\
\hline 008 & $1,479.46$ & $1,186.19$ & $2,665.64$ & $104,706.83$ & $2,665.64$ & & & \\
\hline 009 & $1,495.98$ & $1,169.66$ & $2,665.64$ & $103,210.84$ & $2,665.64$ & & & \\
\hline 010 & $1,512.70$ & $1,152.95$ & $2,665.64$ & $101,698.15$ & $2,665.64$ & & & \\
\hline 011 & $1,529.59$ & $1,136.05$ & $2,665.64$ & $100,168.55$ & $2,665.64$ & Intereses & Pagado & \\
\hline 012 & $1,546.68$ & $1,118.96$ & $2,665.64$ & $98,621.87$ & $2,665.64$ & $14,514.76$ & $31,987.71$ & Año 1 \\
\hline 013 & $1,563.96$ & $1,101.68$ & $2,665.64$ & $97,057.91$ & $2,665.64$ & & & \\
\hline 014 & $1,581.43$ & $1,084.21$ & $2,665.64$ & $95,476.49$ & $2,665.64$ & & & \\
\hline 015 & $1,599.09$ & $1,066.55$ & $2,665.64$ & $93,877.39$ & $2,665.64$ & & & \\
\hline 016 & $1,616.96$ & $1,048.69$ & $2,665.64$ & $92,260.43$ & $2,665.64$ & & & \\
\hline 017 & $1,635.02$ & $1,030.62$ & $2,665.64$ & $90,625.41$ & $2,665.64$ & & & \\
\hline 018 & $1,653.28$ & $1,012.36$ & $2,665.64$ & $88,972.13$ & $2,665.64$ & & & \\
\hline 019 & $1,671.75$ & 993.89 & $2,665.64$ & $87,300.38$ & $2,665.64$ & & & \\
\hline 020 & $1,690.43$ & 975.21 & $2,665.64$ & $85,609.95$ & $2,665.64$ & & & \\
\hline 021 & $1,709.31$ & 956.33 & $2,665.64$ & $83,900.64$ & $2,665.64$ & & & \\
\hline 022 & $1,728.41$ & 937.24 & $2,665.64$ & $82,172.23$ & $2,665.64$ & & & \\
\hline 023 & $1,747.71$ & 917.93 & $2,665.64$ & $80,424.52$ & $2,665.64$ & Intereses & Pagado & \\
\hline 024 & $1,767.24$ & 898.41 & $2,665.64$ & $78,657.28$ & $2,665.64$ & $12,023.12$ & $31,987.71$ & Año 2 \\
\hline 025 & $1,786.98$ & 878.66 & $2,665.64$ & $76,870.30$ & $2,665.64$ & & & \\
\hline 026 & $1,806.94$ & 858.70 & $2,665.64$ & $75,063.36$ & $2,665.64$ & & & \\
\hline 027 & $1,827.13$ & 838.52 & $2,665.64$ & $73,236.24$ & $2,665.64$ & & & \\
\hline 028 & $1,847.54$ & 818.11 & $2,665.64$ & $71,388.70$ & $2,665.64$ & & & \\
\hline 029 & $1,868.17$ & 797.47 & $2,665.64$ & $69,520.53$ & $2,665.64$ & & & \\
\hline 030 & $1,889.04$ & 776.60 & $2,665.64$ & $67,631.48$ & $2,665.64$ & & & \\
\hline 031 & $1,910.15$ & 755.50 & $2,665.64$ & $65,721.34$ & $2,665.64$ & & & \\
\hline 032 & $1,931.48$ & 734.16 & $2,665.64$ & $63,789.85$ & $2,665.64$ & & & \\
\hline 033 & $1,953.06$ & 712.58 & $2,665.64$ & $61,836.79$ & $2,665.64$ & & & \\
\hline 034 & $1,974.88$ & 690.77 & $2,665.64$ & $59,861.92$ & $2,665.64$ & & & \\
\hline 035 & $1,996.94$ & 668.71 & $2,665.64$ & $57,864.98$ & $2,665.64$ & Intereses & Pagado & \\
\hline 036 & $2,019.24$ & 646.40 & $2,665.64$ & $55,845.73$ & $2,665.64$ & $9,176.17$ & $31,987.71$ & Año 3 \\
\hline 037 & $2,041.80$ & 623.84 & $2,665.64$ & $53,803.93$ & $2,665.64$ & & & \\
\hline 038 & $2,064.61$ & 601.03 & $2,665.64$ & $51,739.32$ & $2,665.64$ & & & \\
\hline 039 & $2,087.67$ & 577.97 & $2,665.64$ & $49,651.65$ & $2,665.64$ & & & \\
\hline 040 & $2,110.99$ & 554.65 & $2,665.64$ & $47,540.66$ & $2,665.64$ & & & \\
\hline 041 & $2,134.58$ & 531.07 & $2,665.64$ & $45,406.08$ & $2,665.64$ & & & \\
\hline 042 & $2,158.42$ & 507.22 & $2,665.64$ & $43,247.66$ & $2,665.64$ & & & \\
\hline 043 & $2,182.53$ & 483.11 & $2,665.64$ & $41,065.13$ & $2,665.64$ & & & \\
\hline 044 & $2,206.91$ & 458.73 & $2,665.64$ & $38,858.21$ & $2,665.64$ & & & \\
\hline 045 & $2,231.57$ & 434.08 & $2,665.64$ & $36,626.65$ & $2,665.64$ & & & \\
\hline 046 & $2,256.49$ & 409.15 & $2,665.64$ & $34,370.15$ & $2,665.64$ & & & \\
\hline 047 & $2,281.70$ & 383.94 & $2,665.64$ & $32,088.45$ & $2,665.64$ & Intereses & Pagado & \\
\hline 048 & $2,307.19$ & 358.45 & $2,665.64$ & $29,781.26$ & $2,665.64$ & $5,923.24$ & $31,987.71$ & Año 4 \\
\hline 049 & $2,332.96$ & 332.68 & $2,665.64$ & $27,448.30$ & $2,665.64$ & & & \\
\hline 050 & $2,359.02$ & 306.62 & $2,665.64$ & $25,089.28$ & $2,665.64$ & & & \\
\hline 051 & $2,385.38$ & 280.27 & $2,665.64$ & $22,703.90$ & $2,665.64$ & & & \\
\hline 052 & $2,412.02$ & 253.62 & $2,665.64$ & $20,291.88$ & $2,665.64$ & & & \\
\hline 053 & $2,438.97$ & 226.68 & $2,665.64$ & $17,852.91$ & $2,665.64$ & & & \\
\hline 054 & $2,466.21$ & 199.43 & $2,665.64$ & $15,386.70$ & $2,665.64$ & & & \\
\hline 055 & $2,493.76$ & 171.88 & $2,665.64$ & $12,892.94$ & $2,665.64$ & & & \\
\hline 056 & $2,521.62$ & 144.02 & $2,665.64$ & $10,371.32$ & $2,665.64$ & & & \\
\hline 057 & $2,549.79$ & 115.86 & $2,665.64$ & $7,821.54$ & $2,665.64$ & & & \\
\hline 058 & $2,578.27$ & 87.37 & $2,665.64$ & $5,243.27$ & $2,665.64$ & & & \\
\hline 059 & $2,607.07$ & 58.57 & $2,665.64$ & $2,636.19$ & $2,665.64$ & Intereses & Pagado & \\
\hline 060 & $2,636.19$ & 29.45 & $2,665.64$ & 0.00 & $2,665.64$ & $2,206.45$ & $31,987.71$ & Año 5 \\
\hline
\end{tabular}




\subsubsection{Capital y costo de oportunidad}

\section{Capital}

El capital será un aporte equitativo realizado por los cuatro socios, por el monto de S/. 270,888; donde cada uno contribuirá con el $25 \%$ de este monto que corresponde a la suma de $\mathrm{S} / .67,722$, como se detalla en la tabla $\mathrm{N}^{\circ} 89$

Tabla 89

Aporte de Socios

Aportes por socios

(Nuevos Soles)

APORTE DE CADA SOCIO

\begin{tabular}{lr}
\hline & $\mathbf{2 5 \%}$ \\
\hline Ivet Aguirre & 67,722 \\
Karen Crespo & 67,722 \\
Jorge Díaz & 67,722 \\
Oscar Gonzales & 67,722 \\
\hline Total & $\mathbf{2 7 0 , 8 8 8}$ \\
\hline
\end{tabular}

Elaboración propia

\section{Costo de Oportunidad (Ke)}

El costo de oportunidad (Ke) conocido como la tasa mínima de rendimiento que se le exige a un proyecto de inversión en nuestro país, por ello se le considera como el rendimiento alternativo de la inversión al cual se renuncia para invertir en un proyecto de riesgo aceptable.

Para calcular el costo de oportunidad se utilizará variables que afectan directamente al mercado estadounidense, además para determinar este indicador se utilizará el método del Capital Asset Pricing Model (CAPM). Este método se basa en la teoría del portafolio que explica el riesgo de una inversión a través de la existencia de una relación positiva entre riesgo y retorno, así también en 
el supuesto que la única fuente de riesgo que afecta la rentabilidad de las inversiones es el riesgo del mercado, por lo que el riesgo de una inversión se mide a través de un factor llamado beta, que relaciona el riesgo del proyecto con el riesgo del mercado y donde este corresponde a las acciones de la industria americana de procesamiento de alimentos siendo de 0.72 (Damodaran, 2016), este valor indica que el sector es poco sensible a las variaciones del mercado, logrando ser una industria estable donde la demanda de dichos productos no se verá significativamente afectada en caso se altere los ingresos de los clientes. Al presentar la industria una volatilidad mediana, garantiza la seguridad a la inversión que se realice en ella.

Este índice es obtenido del mercado americano, ya que es el país que cuenta con las bolsas de valores más grandes a nivel internacional (Nasdaq omx, Nyse Euronext), las cuales están ubicadas en el estado de Nueva York, y donde cotizan las principales empresas y organizaciones de todo el mundo (comunidad de emprendedores ,2013), siendo una de las razones por la que se obtienen los indicadores del mercado americano, está dado por su menor volatilidad y logrando que el trabajo con dichas variables sea más estable.

Entre los datos estadísticos, variables que se necesitará para el cálculo del Ke en Perú, como se puede apreciar en las tablas № 90 y 91.

Tabla 90

Variables Estadísticas

\begin{tabular}{lcl}
\hline Variables & Valor & \multicolumn{1}{c}{ Fuente } \\
\hline Rendimiento de mercado de valores americano & $9.38 \%$ & Damodaran \\
Tasa libre de riesgo & $6.64 \%$ & Damodaran \\
Riesgo Pais & $1.84 \%$ & BCRP \\
Inflación USA & $0.84 \%$ & es.inflation.eu \\
Inflación Perú & $2.96 \%$ & BCRP \\
Beta del Sector & $\mathbf{0 . 7 2}$ & Damoradan \\
\hline
\end{tabular}

Elaboración propia 
Tabla 91

Estructura del costo del proyecto

\begin{tabular}{crr}
\hline D/C & MONTO S/ & PORCENTAJE \\
\hline Deuda & 116,095 & $30 \%$ \\
Capital & 270,888 & $70 \%$ \\
\hline TOTAL & $\mathbf{3 8 6 , 9 8 3}$ & $\mathbf{1 0 0 \%}$ \\
\hline
\end{tabular}

Tasa de Impuestos

$27 \%$

Fórmula para hallar Beta del sector:

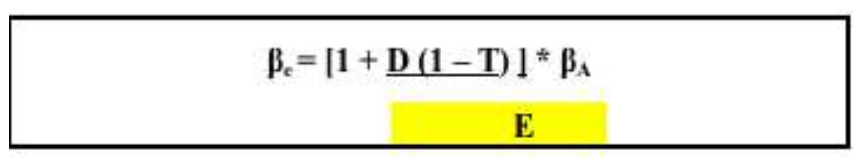

$$
\left.\beta_{c}=\left[1+\frac{0.30(1-0.27)}{1}\right] * 0.72\right)
$$

$\beta \mathrm{e}=1.16$

Figura 81. Beta del Sector

1. Apalancando USA

Aplicamos la siguiente fórmula de CAPM (ver figura $\mathrm{N}^{\circ} 84$ )

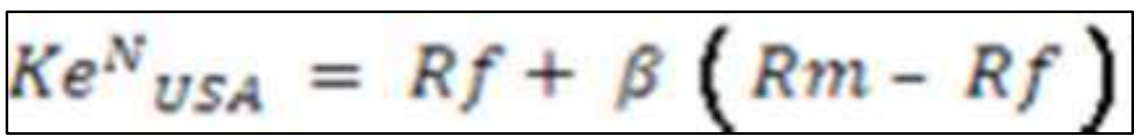

Figura 82. Formula del Costo de Oportunidad

Dónde:

$\mathrm{Ke}=$ Costo de oportunidad.

$\mathrm{B}=$ Promedio de beta del sector manufactura.

$\mathrm{Rf}=$ Tasa libre de riesgo

$\mathrm{Rm}=$ Rendimiento del mercado estadounidense

En esta fórmula del CAPM se ha tomado como variables a la tasa libre de riesgo $6.64 \%$ (Rf), el rendimiento del mercado de Estados Unidos 9.38\% (Rm) y el valor obtenido de $\beta=1.16$ (ver figura $\mathrm{N}^{\circ} 81$ ). 


\section{Haciendo Real}

Reemplazaremos los datos en la fórmula respectiva para hallar la tasa nominal en USA.

3. Calculo de tasa real Perú

Sumándole el riesgo país $1.84 \%$, se determina el costo de capital real de Perú $\mathrm{Ke}^{\mathrm{R}}$

4. Cálculo de la tasa del capital nominal del Perú

Por último, se aplica la inflación de Perú 2.96\%, dando como resultado el costo de capital nominal de Perú $\mathrm{Ke}^{\mathrm{N}}$ PERÚ (ver tabla $\mathrm{N}^{\circ}$ 92). 
Tabla 92

Cálculos WACC

Apalancando USA

$$
\begin{gathered}
\mathrm{K}_{\mathrm{c}}^{\mathrm{N}} \text { USA }=6.64 \%+1.16(9.38 \%-6.64 \%) \\
\mathrm{K}_{\mathrm{c} \text { USA }}^{\mathrm{N}}=9.81 \%
\end{gathered}
$$

$$
\mathbf{K}_{\mathrm{e}}^{\mathrm{R}} \text { USA }=\frac{1+\mathbf{K}_{\text {. NSA }}^{\mathrm{N}}-1}{1+\mathbf{f}}
$$

$$
\begin{gathered}
\mathrm{K}_{\text {e USA }}^{\mathrm{R}}=\frac{1+9.81 \%}{1+0.84 \%}-1 \\
\mathrm{~K}_{\mathrm{c}}^{\mathrm{R} \text { USA }}=8.90 \%
\end{gathered}
$$

Sumando Riesgo País para obtener la Tasa Real Perú

$$
\mathrm{Ke}_{\text {PERÙ- }}^{\mathrm{R}} \mathrm{Ke}_{\text {USA }}^{\mathrm{R}}+\text { Riesgo País }
$$

$\mathrm{Ke}_{\text {PERU }}^{\mathrm{R}}=8.90 \%+1.84 \%$

$$
\mathrm{Ke}^{\mathrm{R}}{ }_{\text {PERU }}=10.74 \%
$$

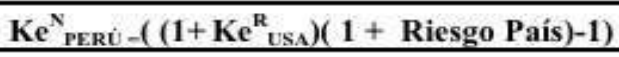

$$
\begin{array}{r}
\mathrm{Ke}_{\text {PERU }}^{\mathrm{N}}=[(1+10.74 \%)(1+1.84 \%)-1] \\
\operatorname{Ke}_{\text {PERÚ }}^{\mathrm{N}}=14.02 \%
\end{array}
$$

\begin{tabular}{|lr|}
\hline \multicolumn{2}{|c|}{$\begin{array}{c}\text { COSTO DE OPORTUNIDAD } \\
\text { (Expresado en Porcentaje) }\end{array}$} \\
\hline \multicolumn{2}{|c|}{ DATOS } \\
\hline$\beta_{\Lambda}$ & 0.72 \\
$\beta_{\epsilon}$ & 1.16 \\
$\mathrm{Rm}$ & $9.38 \%$ \\
$\mathrm{Rf}$ & $6.64 \%$ \\
Inflación Usa & $0.84 \%$ \\
Riesgo pais Perú & $1.84 \%$ \\
Inflacion peru & $2.96 \%$ \\
Ke Nominal Usa & $9.81 \%$ \\
Ke Real Usa & $8.90 \%$ \\
Ke Real Perú & $10.74 \%$ \\
Ke Nominal Perú & $14.02 \%$ \\
\hline
\end{tabular}

Figura 83. Costo de Oportunidad en Perú 


\subsubsection{Costo de capital promedio ponderado}

Para determinar el costo promedio ponderado de capital se identificará primero el costo de la deuda $(\mathrm{kd})$ y se tendrá presente el Costo de Capital u oportunidad (Ke) (ver figura $\mathrm{N}^{\circ} 83$ ).

El costo de la deuda (kd) es la tasa fue brindada por la entidad financiera BBVA, por lo tanto, el costo de la deuda será la tasa efectiva anual para el préstamo a pequeñas empresas, que es de $14.26 \%$, (ver Tabla $\mathrm{N}^{\circ} 93$ ).

Tabla 93

Costo de Deuda

CUADRO DE COSTO DE LA DEUDA

\begin{tabular}{cc}
\hline CONCEPTO & VALOR \\
\hline TEA $\%$ & $14.26 \%$ \\
TEM $\%$ & $1.12 \%$ \\
\hline
\end{tabular}

\begin{tabular}{cc} 
DATOS & $\%$ \\
\hline $\mathrm{COK}, \mathrm{Ke}$ & $14.02 \%$ \\
$\mathrm{We}=\mathrm{C} /(\mathrm{D}+\mathrm{C})$ & $70.00 \%$ \\
$\mathrm{Wd}=\mathrm{D} /(\mathrm{D}+\mathrm{C})$ & $30.00 \%$ \\
\hline
\end{tabular}

Para determinar este costo de capital promedio ponderado, se aplicará la fórmula del WACC, con lo que obtendremos la tasa de descuento para el flujo de caja económico, esta tasa es un promedio entre el coste y la rentabilidad exigida (ver figura $\mathrm{N}^{\circ} 84$ ).

WACC $=w_{e} r_{e}+w_{d} r_{d}\left(1-t_{c}\right)$

WACC $=[0.70 * 0.1402)+(0.30 * 0.1426 *[1-0.27])$

WACC $=12.93 \%$

$12.93 \%$

Figura 84. Cálculo del WACC 


\subsection{Presupuestos Base}

\subsubsection{Presupuesto de ventas}

A continuación, se visualizará el presupuesto de ventas y de ingresos para cada año del horizonte de evaluación, como se puede observar en las tablas $\mathrm{N}^{\circ} 94$ y 95 .

Tabla 94

Presupuesto Mensual de Ventas - 2017

Programa mensual de Ingresos - Expresado en soles

\begin{tabular}{|c|c|c|c|c|c|c|c|c|c|c|c|c|c|}
\hline & MES 1 & MES 2 & MES 3 & MES 4 & MES 5 & MES 6 & MES 7 & MES 8 & MES 9 & MES 10 & MES 11 & MES 12 & TOTAL \\
\hline Volumen de ventas & $2,771.75$ & $2,732.85$ & $3,170.78$ & $2,988.00$ & $3,032.62$ & $2,793.49$ & $3,014.60$ & $3,026.04$ & $2,813.51$ & $2,786.05$ & $2,618.43$ & $2,469.69$ & $34,217.78$ \\
\hline Valor de ventas $1 \mathrm{~kg}$ & 8.00 & 8.00 & 8.00 & 8.00 & 8.00 & 8.00 & 8.00 & 8.00 & 8.00 & 8.00 & 8.00 & 8.00 & 8.00 \\
\hline $\begin{array}{l}\text { Valor de ventas total } \\
\text { Elaboración propia }\end{array}$ & 22,173.98 & $21,862.77$ & $25,366.21$ & $23,903.96$ & $24,260.94$ & $22,347.89$ & $24,116.78$ & $24,208.31$ & $22,508.08$ & $22,288.40$ & $20,947.43$ & $19,757.50$ & $273,742.26$ \\
\hline
\end{tabular}

Tabla 95

Presupuesto Anual de Ventas 2017 - 2021

\section{Programa anual de Ingresos - Expresado en soles}

\begin{tabular}{lrrrrr}
\hline & $\mathbf{2 0 1 7}$ & $\mathbf{2 0 1 8}$ & $\mathbf{2 0 1 9}$ & $\mathbf{2 0 2 0}$ & $\mathbf{2 0 2 1}$ \\
\hline Volumen de ventas & $34,217.78$ & $81,362.85$ & $123,309.13$ & $166,075.99$ & $209,648.27$ \\
Valor de ventas 1kg & 8.00 & 8.00 & 8.00 & 8.00 & 8.00 \\
\hline Valor de ventas total & $\mathbf{2 7 3 , 7 4 2 . 2 6}$ & $\mathbf{6 5 0 , 9 0 2 . 8 1}$ & $\mathbf{9 8 6 , 4 7 3 . 0 6}$ & $\mathbf{1 , 3 2 8 , 6 0 7 . 9 6}$ & $\mathbf{1 , 6 7 7 , 1 8 6 . 1 3}$ \\
Elaboración propia & & & &
\end{tabular}




\subsubsection{Presupuesto de costos de producción}

En esta sección se hallará el costo unitario total y el costo de producción unitario, para el cálculo se ha considerado los costos de materia prima, la mano de obra directa, indirecta, los costos indirectos de fabricación, como se puede apreciar para presupuesto del primer año en la tabla N6, y el consolidado presupuestal de los años 2017 al 2021 en la tabla $\mathrm{N}^{\circ} 97$.

Tabla 96

Presupuesto Mensual de Costos de Producción 2017

Presupuesto de Costos Unitarios de Producción

\begin{tabular}{|c|c|c|c|c|c|c|c|c|c|c|c|c|c|}
\hline & MES 1 & MES 2 & MES 3 & MES 4 & MES 5 & MES 6 & MES 7 & MES 8 & MES 9 & MES 10 & MES 11 & MES 12 & TOTAL \\
\hline Matería prima directa & $6,189.49$ & $5,564.40$ & $6,549.88$ & $6,056.68$ & $6,191.82$ & $5,649.16$ & $6,189.35$ & $6,171.96$ & $5,695.15$ & $5,675.10$ & $5,306.12$ & $5,006.52$ & $70,245.63$ \\
\hline Mano de obra directa & $4,182.00$ & $4,182.00$ & $4,182.00$ & $4,182.00$ & $4,182.00$ & $4,182.00$ & $4,182.00$ & $4,182.00$ & $4,182.00$ & $4,182.00$ & $4,182.00$ & $4,182.00$ & $50,184.00$ \\
\hline CIF - Materia prima indirecta & 239.70 & 236.34 & 274.21 & 258.40 & 262.26 & 241.58 & 260.70 & 261.69 & 243.31 & 240.94 & 226.44 & 213.58 & $2,959.15$ \\
\hline CIF - Mano de obra indireta & $2,091.00$ & $2,091.00$ & $2,091.00$ & $2,091.00$ & $2,091.00$ & $2,091.00$ & $2,091.00$ & $2,091.00$ & $2,091.00$ & $2,091.00$ & $2,091.00$ & $2,091.00$ & $25,092.00$ \\
\hline CIF - Otros & $5,768.69$ & $5,768.69$ & $5,768.69$ & $5,768.69$ & $5,768.69$ & $5,768.69$ & $5,768.69$ & $5,768.69$ & $5,768.69$ & $5,768.69$ & $5,768.69$ & $5,768.69$ & $69,224.32$ \\
\hline Costos Totales de producción & $18,470.88$ & $17,842.43$ & $18,865.78$ & $18,356.78$ & $18,495.77$ & $17,932.43$ & $18,491.74$ & $18,475.35$ & $17,980.16$ & $17,957.73$ & $17,574.26$ & $17,261.79$ & $217,705.11$ \\
\hline Costo Unitario de Producción & 5.79 & 6.23 & 5.59 & 5.89 & 5.80 & 6.16 & 5.80 & 5.81 & 6.13 & 6.14 & 6.43 & 6.70 & 6.02 \\
\hline
\end{tabular}

Tabla 97

Presupuesto Anual de Costo de Producción 2017 - 2021

\section{Presupuesto de Costos Unitarios de Producción}

\begin{tabular}{|c|c|c|c|c|c|}
\hline & 2017 & 2018 & 2019 & 2020 & 2021 \\
\hline Matería prima directa & $70,245.63$ & $166,550.11$ & $275,357.04$ & $370,858.13$ & $468,157.75$ \\
\hline Mano de obra directa & $50,184.00$ & $50,184.00$ & $50,184.00$ & $50,184.00$ & $50,184.00$ \\
\hline CIF - Materia prima indirecta & $2,959.15$ & 7,036.26 & $10,663.77$ & $13,800.92$ & $18,130.38$ \\
\hline CIF - Mano de obra indireta & $25,092.00$ & $39,852.00$ & $39,852.00$ & $39,852.00$ & $39,852.00$ \\
\hline CIF - Otros & $69,224.32$ & $78,117.62$ & $80,246.39$ & $82,481.59$ & $80,691.27$ \\
\hline Costos Totales de producción & $217,705.11$ & $341,739.98$ & $456,303.20$ & $557,176.64$ & $657,015.40$ \\
\hline Costo Unitario de Producción x $\mathrm{kg}$ & 6.02 & 3.98 & 3.22 & 2.92 & 2.73 \\
\hline
\end{tabular}




\subsubsection{Presupuesto de compras}

Se detalla las compras realizadas por materia prima directa y materia prima indirecta (ver tablas $\mathrm{N}^{\circ} 98,99,100$ y 101 ).

Tabla 98

Presupuesto Mensual de Compras MD 2017

Presupuesto de compras MD

\begin{tabular}{lrrrrrrrrrrrrr}
\hline & MES 1 & \multicolumn{1}{c}{ MES 2 } & \multicolumn{1}{c}{ MES 3 } & MES 4 & MES 5 & MES 6 & \multicolumn{1}{c}{ MES 7 } & \multicolumn{1}{c}{ MES 8 } & MES 9 & MES 10 & MES 11 & MES 12 & TOTAL \\
\hline Papas & $6,183.77$ & $5,559.26$ & $6,543.83$ & $6,051.09$ & $6,186.10$ & $5,643.94$ & $6,183.63$ & $6,166.26$ & $5,689.89$ & $5,669.86$ & $5,301.22$ & $5,001.90$ & $70,180.74$ \\
Agua & 5.72 & 5.14 & 6.05 & 5.59 & 5.72 & 5.22 & 5.72 & 5.70 & 5.26 & 5.24 & 4.90 & 4.62 & 64.89 \\
\hline & $\mathbf{6 , 1 8 9 . 4 9}$ & $\mathbf{5 , 5 6 4 . 4 0}$ & $\mathbf{6 , 5 4 9 . 8 8}$ & $\mathbf{6 , 0 5 6 . 6 8}$ & $\mathbf{6 , 1 9 1 . 8 2}$ & $\mathbf{5 , 6 4 9 . 1 6}$ & $\mathbf{6 , 1 8 9 . 3 5}$ & $\mathbf{6 , 1 7 1 . 9 6}$ & $\mathbf{5 , 6 9 5 . 1 5}$ & $\mathbf{5 , 6 7 5 . 1 0}$ & $\mathbf{5 , 3 0 6 . 1 2}$ & $\mathbf{5 , 0 0 6 . 5 2}$ & $\mathbf{7 0 , 2 4 5 . 6 3}$
\end{tabular}

Tabla 99

Presupuesto Mensual de Compras MI 2017

Presupuesto de compras MI

\begin{tabular}{lrrrrrrrrrrrrr}
\hline & MES 1 & \multicolumn{1}{c}{ MES 2 } & \multicolumn{1}{c}{ MES 3 } & \multicolumn{1}{c}{ MES 4 } & \multicolumn{1}{c}{ MES 5 } & \multicolumn{1}{c}{ MES 6 } & \multicolumn{1}{c}{ MES 7 } & \multicolumn{1}{c}{ MES 8 } & \multicolumn{1}{c}{ MES 9 } & MES 10 & MES 11 & MES 12 & TOTAL \\
\hline Bolsas de 250 gr & 183.49 & 180.91 & 209.91 & 197.81 & 200.76 & 184.93 & 199.57 & 200.32 & 186.25 & 184.44 & 173.34 & 163.49 & 2265.22 \\
Bolsas de 500 gr & 56.21 & 55.42 & 64.30 & 60.60 & 61.50 & 56.65 & 61.14 & 61.37 & 57.06 & 56.50 & 53.10 & 50.09 & 693.94 \\
\hline & $\mathbf{2 3 9 . 7 0}$ & $\mathbf{2 3 6 . 3 4}$ & $\mathbf{2 7 4 . 2 1}$ & $\mathbf{2 5 8 . 4 0}$ & $\mathbf{2 6 2 . 2 6}$ & $\mathbf{2 4 1 . 5 8}$ & $\mathbf{2 6 0 . 7 0}$ & $\mathbf{2 6 1 . 6 9}$ & $\mathbf{2 4 3 . 3 1}$ & $\mathbf{2 4 0 . 9 4}$ & $\mathbf{2 2 6 . 4 4}$ & $\mathbf{2 1 3 . 5 8}$ & $\mathbf{2 . 9 5 9 . 1 5}$
\end{tabular}

Tabla 100

Presupuesto Anual de Compras MD 2017 - 2021

\section{Presupuesto de compras MD}

\begin{tabular}{|c|c|c|c|c|c|}
\hline & 2017 & 2018 & 2019 & 2020 & 2021 \\
\hline Papas & $70,180.74$ & $166,396.26$ & $275,102.67$ & $370,515.54$ & $467,725.28$ \\
\hline Agua & 64.89 & 153.85 & 254.36 & 342.58 & 432.47 \\
\hline & $70,245.63$ & $166,550.11$ & $275,357.04$ & 370,858.13 & $468,157.75$ \\
\hline
\end{tabular}


Tabla 101

Presupuesto Anual de Compras MI 2017 - 2021

\section{Presupuesto de compras MI}

\begin{tabular}{lcrrrr}
\hline & $\mathbf{2 0 1 7}$ & $\mathbf{2 0 1 8}$ & $\mathbf{2 0 1 9}$ & \multicolumn{1}{c}{$\mathbf{2 0 2 0}$} & \multicolumn{1}{c}{$\mathbf{2 0 2 1}$} \\
\hline Bolsas de 250 gr & $2,265.22$ & $5,386.22$ & $8,163.06$ & $10,994.23$ & $13,878.72$ \\
Bolsas de 500 gr & 693.94 & $1,650.04$ & $2,500.71$ & $2,806.68$ & $4,251.67$ \\
\hline & $\mathbf{2 , 9 5 9 . 1 5}$ & $\mathbf{7 , 0 3 6 . 2 6}$ & $\mathbf{1 0 , 6 6 3 . 7 7}$ & $\mathbf{1 3 , 8 0 0 . 9 2}$ & $\mathbf{1 8 , 1 3 0 . 3 8}$
\end{tabular}

\subsubsection{Presupuesto de costo de ventas}

Se detallará los costos del producto procesado, durante el horizonte de evaluación (ver tablas $\mathrm{N}^{\circ} 102$ y 103).

Tabla 102

Presupuesto Mensual de Costo de Ventas 2017

\section{Presupuesto Costo de Venta}

\begin{tabular}{lccccccccccccc}
\hline & MES 1 & MES 2 & MES 3 & MES 4 & MES 5 & MES 6 & MES 7 & MES 8 & MES 9 & MES 10 & MES 11 & MES 12 & T0TAL \\
\hline Inventario Inicial PT & 0.00 & $1,606.16$ & $1,701.59$ & $1,773.41$ & $1,758.51$ & $1,759.04$ & $1,721.89$ & $1,748.90$ & $1,758.92$ & $1,724.80$ & $1,711.87$ & $1,684.01$ & $18,949.10$ \\
MD & $6,189.49$ & $5,564.40$ & $6,549.88$ & $6,056.68$ & $6,191.82$ & $5,649.16$ & $6,189.35$ & $6,171.96$ & $5,695.15$ & $5,675.10$ & $5,306.12$ & $5,006.52$ & $70,245.63$ \\
MOD & $4,182.00$ & $4,182.00$ & $4,182.00$ & $4,182.00$ & $4,182.00$ & $4,182.00$ & $4,182.00$ & $4,182.00$ & $4,182.00$ & $4,182.00$ & $4,182.00$ & $4,182.00$ & $50,184.00$ \\
CIF & $8,099.39$ & $8,096.03$ & $8,133.90$ & $8,118.10$ & $8,121.95$ & $8,101.27$ & $8,120.40$ & $8,121.39$ & $8,103.01$ & $8,100.63$ & $8,086.14$ & $8,073.27$ & $97,275.47$ \\
(-) Inventario Final PT & $-1,606.16$ & $-1,701.59$ & $1,773.41$ & $-1,758.51$ & $-1,759.04$ & $-1,721.89$ & $-1,748.90$ & $-1,758.92$ & $-1,724.80$ & $1,711.87$ & $-1,684.01$ & $-1,653.46$ & $-20,602.57$ \\
\cline { 2 - 10 } & $\mathbf{1 6 , 8 6 4 . 7 2}$ & $\mathbf{1 7 , 7 4 7 . 0 1}$ & $\mathbf{1 8 , 7 9 3 . 9 5}$ & $\mathbf{1 8 , 3 7 1 . 6 8}$ & $\mathbf{1 8 , 4 9 5 . 2 5}$ & $\mathbf{1 7 , 9 6 9 . 5 8}$ & $\mathbf{1 8 , 4 6 4 . 7 3}$ & $\mathbf{1 8 , 4 6 5 . 3 3}$ & $\mathbf{1 8 , 0 1 4 . 2 7}$ & $\mathbf{1 7 , 9 7 0 . 6 7}$ & $\mathbf{1 7 , 6 0 2 . 1 2}$ & $\mathbf{1 7 , 2 9 2 . 3 4}$ & $\mathbf{2 1 6 , 0 5 1 . 6 4}$
\end{tabular}


Tabla 103

Presupuesto Anual de Costo de Ventas 2017 - 2021

\section{Presupuesto Costo de Ventas}

\begin{tabular}{|c|c|c|c|c|c|}
\hline & 2017 & 2018 & 2019 & 2020 & 2021 \\
\hline Inventario Inicial & 0.00 & $1,653.46$ & $2,339.75$ & $2,863.82$ & $3,496.92$ \\
\hline $\mathrm{MD}$ & $70,245.63$ & $166,550.11$ & $275,357.04$ & $370,858.13$ & $468,157.75$ \\
\hline MOD & $50,184.00$ & $50,184.00$ & $50,184.00$ & $50,184.00$ & $50,184.00$ \\
\hline CIF & $97,275.47$ & $125,005.88$ & $130,762.16$ & $136,134.51$ & $138,673.65$ \\
\hline \multirow[t]{2}{*}{ (-) Inventario Final } & $1,653.46$ & $2,339.75$ & $2,863.82$ & $3,496.92$ & $4,123.52$ \\
\hline & $216,051.64$ & $341,053.69$ & $455,779.13$ & $556,543.54$ & $656,388.80$ \\
\hline
\end{tabular}




\subsubsection{Presupuesto de gastos administrativos}

Entre los gastos administrativos se está considerando aquellos gastos que serán asumidos por el departamento de administración y que se incrementarán en un 5\% anual por variación del factor de inflación en el país, como se aprecia en las tablas $\mathrm{N}^{\circ} 104$ y 105 .

Tabla 104

Presupuesto de Gastos Mensuales de Administración 2017

Presupuesto de Gastos de Administración

\begin{tabular}{|c|c|c|c|c|c|c|c|c|c|c|c|c|c|c|}
\hline & & MES 1 & MES 2 & MES 3 & MES 4 & MES 5 & MES 6 & MES 7 & MES 8 & MES 9 & MES 10 & MES 11 & MES 12 & TOTAL \\
\hline Luz y agua & 90.00 & 90.00 & 90.00 & 90.00 & 90.00 & 90.00 & 90.00 & 90.00 & 90.00 & 90.00 & 90.00 & 90.00 & 90.00 & $1,080.00$ \\
\hline Alquiler de planta & 544.50 & 544.50 & 544.50 & 544.50 & 544.50 & 544.50 & 544.50 & 544.50 & 544.50 & 544.50 & 544.50 & 544.50 & 544.50 & $6,534.00$ \\
\hline Seguro & 24.00 & 24.00 & 24.00 & 24.00 & 24.00 & 24.00 & 24.00 & 24.00 & 24.00 & 24.00 & 24.00 & 24.00 & 24.00 & 288.00 \\
\hline \multirow[t]{2}{*}{ Telefono e internet } & 37.50 & 37.50 & 37.50 & 37.50 & 37.50 & 37.50 & 37.50 & 37.50 & 37.50 & 37.50 & 37.50 & 37.50 & 37.50 & 450.00 \\
\hline & & 696.00 & 696.00 & 696.00 & 696.00 & 696.00 & 696.00 & 696.00 & 696.00 & 696.00 & 696.00 & 696.00 & 696.00 & $8,352.00$ \\
\hline Planilla administrativa & $3,567.00$ & $2,460.00$ & $2,460.00$ & $2,460.00$ & $2,460.00$ & $2,460.00$ & $2,460.00$ & $2,460.00$ & $2,460.00$ & $2,460.00$ & $2,460.00$ & $2,460.00$ & $2,460.00$ & $29,520.00$ \\
\hline \multicolumn{2}{|c|}{ Total Gastos Administrativos } & $3,156.00$ & $3,156.00$ & $3,156.00$ & $3,156.00$ & $3,156.00$ & $3,156.00$ & $3,156.00$ & $3,156.00$ & $3,156.00$ & $3,156.00$ & $3,156.00$ & $3,156.00$ & $37,872.00$ \\
\hline IGV & $18 \%$ & 125.28 & 125.28 & 125.28 & 125.28 & 125.28 & 125.28 & 125.28 & 125.28 & 125.28 & 125.28 & 125.28 & 125.28 & $1,503.36$ \\
\hline & & $3,281.28$ & $3,281.28$ & $3,281.28$ & $3,281.28$ & $3,281.28$ & $3,281.28$ & $3,281.28$ & $3,281.28$ & $3,281.28$ & $3,281.28$ & $3,281.28$ & $3,281.28$ & $39,375.36$ \\
\hline
\end{tabular}

Tabla 105

Presupuesto de Gastos Anuales de Administración 2017 - 2021

\section{Presupuesto de Gastos de Administración}

\begin{tabular}{|c|c|c|c|c|c|c|}
\hline & & 2017 & 2018 & 2019 & 2020 & 2021 \\
\hline Luz y agua & 90.00 & $1,080.00$ & $1,134.00$ & $1,190.70$ & $1,250.24$ & $1,312.75$ \\
\hline Alquiler de planta & 544.50 & $6,534.00$ & $6,860.70$ & $7,203.74$ & $7,563.92$ & $7,942.12$ \\
\hline Seguro & 24.00 & 288.00 & 302.40 & 317.52 & 333.40 & 350.07 \\
\hline \multirow{2}{*}{ Telefono e internet } & 37.50 & 450.00 & 472.50 & 496.13 & 520.93 & 546.98 \\
\hline & & $8,352.00$ & $8,769.60$ & $9,208.08$ & $9,668.48$ & $10,151.91$ \\
\hline Planilla adminis trativa & & $29,520.00$ & $42,804.00$ & $42,804.00$ & $42,804.00$ & $42,804.00$ \\
\hline Total Gastos Administrativos & & $37,872.00$ & $51,573.60$ & $52,012.08$ & $52,472.48$ & $52,955.91$ \\
\hline \multirow[t]{2}{*}{ IGV } & & $1,503.36$ & $1,578.53$ & $1,657.45$ & $1,740.33$ & $1,827.34$ \\
\hline & & $39,375.36$ & $53,152.13$ & $53,669.53$ & $54,212.81$ & $54,783.25$ \\
\hline
\end{tabular}




\subsubsection{Presupuesto de marketing y ventas}

Entre los gastos de marketing, se incluyen todos los gastos necesarios para dar a conocer el producto del presente proyecto. Los gastos ventas son aquellos gastos asumidos por el departamento de ventas y se verá incrementado anualmente un 5\% por la variación del factor de inflación en el país, como se puede apreciar en las tablas N106, 107, 108 y 109.

Tabla 106

Presupuesto Mensual de Marketing 2017

\begin{tabular}{|c|c|c|c|c|c|c|c|c|c|c|c|c|c|}
\hline & ENERO & FEBRER0 & MARZO & ABRIL & MAYO & JUNI0 & JULO & AGOSTO & SEPTIEMBRE & OCTUBRE & NOVIEMBRE & DICIEMBRE & TOTAL \\
\hline Degustacín en casu naturisa, minimarkat & $1,770.00$ & $1,770.00$ & $1,770.00$ & $1,770.00$ & $3,540,00$ & $1,770.00$ & $1,770.00$ & $1,770,00$ & $1,770.00$ & $1,770.00$ & $1,770.00$ & $1,770,00$ & $23,010.00$ \\
\hline Degustacioin en feria & & & & & & & & & & & & & - \\
\hline Canal 4 (DR. TV) & & & & & & & & & & & & & - \\
\hline Participacionn en Ferias & & & & & & & & & & & & & . \\
\hline Banners & 72.00 & 72.00 & 72.00 & 7200 & 144.00 & 72.00 & 7200 & 72.00 & 72.00 & 7200 & 7200 & 72.00 & 936.00 \\
\hline Folletos: & 60.00 & 60.00 & 60.00 & 60.00 & 120.00 & 60.00 & 6000 & 60.00 & 60.00 & 6000 & 60.00 & 60.00 & 789.00 \\
\hline Volantes & 60.00 & 60,00 & 60.00 & 60.00 & 120.00 & 60.00 & 6000 & 60.00 & 60.00 & 6000 & 60.00 & 60.00 & 780.00 \\
\hline Afiches & 23,00 & 2300 & 23.00 & 23.00 & 46.00 & 23.00 & 2300 & 23.00 & 23.00 & 23.00 & 23,00 & 23,00 & 299.90 \\
\hline Merchiandising & 750.00 & 750.00 & 750.00 & 750.00 & $1,500,00$ & 750,00 & 75000 & 750.00 & 750.00 & 750.00 & 750.00 & 750.00 & $9,750.00$ \\
\hline Total & $2,735.00$ & $2,735.00$ & $2,735,00$ & 2735.00 & $5,470,00$ & $2,735,00$ & $2,735.00$ & $2,735.00$ & $2,735.00$ & $2,735.00$ & $2,735.00$ & $2,735.00$ & $35,555.10$ \\
\hline
\end{tabular}

Tabla 107

Presupuesto Anual de Marketing 2017 - 2021

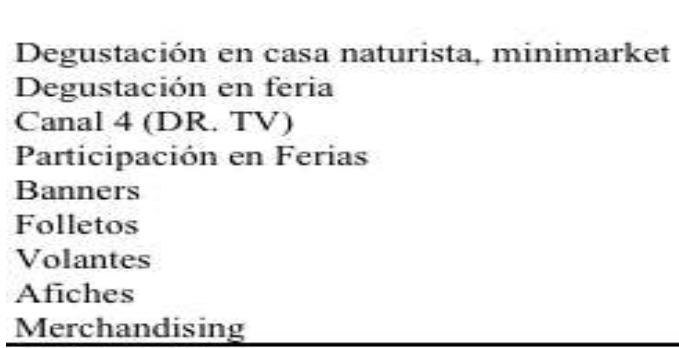

Degustación en casa naturista, minimarket Degustación en feria

Canal 4 (DR. TV)

Participación en Ferias

Banners

Folletos

Volantes

Afiches

Merchandising

\begin{tabular}{rrrrrr}
$\mathbf{0}$ & $\mathbf{2 0 1 7}$ & $\mathbf{2 0 1 8}$ & $\mathbf{2 0 1 9}$ & $\mathbf{2 0 2 0}$ & $\mathbf{2 0 2 1}$ \\
\hline & $23,010.00$ & $23,010.00$ & $23,010.00$ & $23,010.00$ & $23,010.00$ \\
$24,000.00$ & - & $1,165.00$ & - & $1,165.00$ & - \\
& - & - & $24,000.00$ & - & $24,000.00$ \\
216.00 & - & $15,000.00$ & - & $15,000.00$ & - \\
60.00 & 780.00 & 948.00 & 936.00 & 948.00 & 936.00 \\
180.00 & 780.00 & 800.00 & 780.00 & 800.00 & 780.00 \\
0 & 299.00 & 800.00 & 780.00 & 800.00 & 780.00 \\
875.00 & $9,750.00$ & $10,625.00$ & $9,750.00$ & $10,625.00$ & $9,750.00$ \\
\hline $\mathbf{2 5 , 3 3 1 . 0 0}$ & $\mathbf{3 5 , 5 5 5 . 0 0}$ & $\mathbf{5 2 , 6 4 7 . 0 0}$ & $\mathbf{5 9 , 5 5 5 . 0 0}$ & $\mathbf{5 2 , 6 4 7 . 0 0}$ & $\mathbf{5 9 , 5 5 5 . 0 0}$
\end{tabular}


Tabla 108

Presupuesto Mensual de Gasto de Ventas 2017

Presupuesto de Gastos de Ventas

\begin{tabular}{|c|c|c|c|c|c|c|c|c|c|c|c|c|c|c|}
\hline & & MES 1 & MES 2 & MES 3 & MES 4 & MES 5 & MES 6 & MES 7 & MES 8 & MES 9 & MES 10 & MES 11 & MES 12 & TOTAL \\
\hline Luz y agua & 90.00 & 90.00 & 90.00 & 90.00 & 90.00 & 90.00 & 90.00 & 90.00 & 90.00 & 90.00 & 90.00 & 90.00 & 90.00 & $1,080.00$ \\
\hline Combustible & 600.00 & 600.00 & 600.00 & 600.00 & 600.00 & 600.00 & 600.00 & 600.00 & 600.00 & 600.00 & 600.00 & 600.00 & 600.00 & $7,200.00$ \\
\hline Alquiler de planta & 544.50 & 544.50 & 544.50 & 544.50 & 544.50 & 544.50 & 544.50 & 544.50 & 544.50 & 544.50 & 544.50 & 544.50 & 544.50 & $6,534.00$ \\
\hline Seguro & 48.00 & 48.00 & 48.00 & 48.00 & 48.00 & 48.00 & 48.00 & 48.00 & 48.00 & 48.00 & 48.00 & 48.00 & 48.00 & 576.00 \\
\hline Telefono e internet & 37.50 & 37.50 & 37.50 & 37.50 & 37.50 & 37.50 & 37.50 & 37.50 & 37.50 & 37.50 & 37.50 & 37.50 & 37.50 & 450.00 \\
\hline Transporte & & $1,191.85$ & $1,175.12$ & $1,363.43$ & $1,404.36$ & 304.03 & $1,201.20$ & $1,296.28$ & $1,301.20$ & $1,209.81$ & $1,198.00$ & $1,125.92$ & $1,061.97$ & $14,833.17$ \\
\hline \multirow[t]{2}{*}{ Marketing } & & $2,735.00$ & $2,735.00$ & $2,735.00$ & $2,735.00$ & $5,470.00$ & $2,735.00$ & $2,735.00$ & $2,735.00$ & $2,735.00$ & $2,735.00$ & $2,735.00$ & $2,735.00$ & $35,555.00$ \\
\hline & & $5,246.85$ & 230.12 & $5,418.43$ & $5,459.36$ & $8,094.03$ & $5,256.20$ & $5,351.28$ & $5,356.20$ & $5,264.81$ & $5,253.00$ & $5,180.92$ & $5,116.97$ & $66,228.17$ \\
\hline Planilla de ventas & & $3,066.98$ & $3,059.32$ & $3,145.51$ & $3,109.54$ & $3,118.32$ & $3,071.26$ & $3,114.77$ & $3,117.02$ & $3,075.20$ & $3,069.79$ & $3,036.81$ & $3,007.53$ & $131,376.33$ \\
\hline Total Gastos de V & & $8,313.83$ & $8,289.45$ & $8,563.94$ & $8,568.90$ & $11,212.34$ & $8,327.46$ & $8,466.05$ & $8,473.22$ & $8,340.01$ & $8,322.80$ & $8,217.73$ & $8,124.50$ & $197,604.50$ \\
\hline
\end{tabular}

Tabla 109

Presupuesto Anual de Gastos de Ventas 2017 - 2021

\section{Presupuesto de Gastos de Ventas}

\begin{tabular}{|c|c|c|c|c|c|c|}
\hline & & 2017 & 2018 & 2019 & 2020 & 2021 \\
\hline Luz y agua & 90.00 & $1,080.00$ & $1,134.00$ & $1,190.70$ & $1,250.24$ & $1,312.75$ \\
\hline Combustible & 600.00 & $7,200.00$ & $7,560.00$ & $7,938.00$ & $8,334.90$ & $8,751.65$ \\
\hline Alquiler de planta & 544.50 & $6,534.00$ & $6,860.70$ & $7,203.74$ & $7,563.92$ & $7,942.12$ \\
\hline Seguro & 48.00 & 576.00 & 604.80 & 635.04 & 666.79 & 700.13 \\
\hline Telefono e internet & 37.50 & 450.00 & 472.50 & 496.13 & 520.93 & 546.98 \\
\hline Transporte & & $14,713.65$ & $34,986.03$ & $53,022.93$ & $71,412.68$ & $90,148.75$ \\
\hline \multirow[t]{2}{*}{ Marketing } & & $35,555.00$ & $52,647.00$ & $59,555.00$ & $52,647.00$ & $59,555.00$ \\
\hline & & $66,108.65$ & $104,265.03$ & $130,041.53$ & $142,396.46$ & $168,957.37$ \\
\hline Planilla de ventas & & $36,992.06$ & $46,270.21$ & $54,525.24$ & $62,941.76$ & $71,516.78$ \\
\hline Total Gastos de Ventas & & 103,100.71 & $150,535.23$ & $184,566.76$ & $205,338.21$ & $240,474.15$ \\
\hline
\end{tabular}




\subsubsection{Presupuesto de gastos financieros}

En estos gastos se están considerando los intereses generados por el préstamo bancario, a nivel mensual y anual, como se apreciar en la tabla $\mathrm{N}^{\circ}$ 110 y 111.

Tabla 110

Presupuesto Mensual de Gastos Financieros 2017

\begin{tabular}{lcccrc}
\hline Cuotas & Capital & Interes & $\begin{array}{c}\text { Importe de } \\
\text { Cuota }\end{array}$ & Saldo & $\begin{array}{l}\text { Importe } \\
\text { Total a } \\
\text { Pagar }\end{array}$ \\
\hline O01 & $1,368.77$ & $1,296.87$ & $2,665.64$ & $114,726.05$ & $2,665.64$ \\
O02 & $1,384.06$ & $1,281.58$ & $2,665.64$ & $113,341.99$ & $2,665.64$ \\
O03 & $1,399.52$ & $1,266.12$ & $2,665.64$ & $111,942.47$ & $2,665.64$ \\
O04 & $1,415.16$ & $1,250.49$ & $2,665.64$ & $110,527.31$ & $2,665.64$ \\
O05 & $1,430.96$ & $1,234.68$ & $2,665.64$ & $109,096.35$ & $2,665.64$ \\
O06 & $1,446.95$ & $1,218.69$ & $2,665.64$ & $107,649.40$ & $2,665.64$ \\
O07 & $1,463.11$ & $1,202.53$ & $2,665.64$ & $106,186.28$ & $2,665.64$ \\
O08 & $1,479.46$ & $1,186.19$ & $2,665.64$ & $104,706.83$ & $2,665.64$ \\
O09 & $1,495.98$ & $1,169.66$ & $2,665.64$ & $103,210.84$ & $2,665.64$ \\
O10 & $1,512.70$ & $1,152.95$ & $2,665.64$ & $101,698.15$ & $2,665.64$ \\
O11 & $1,529.59$ & $1,136.05$ & $2,665.64$ & $100,168.55$ & $2,665.64$ \\
O12 & $1,546.68$ & $1,118.96$ & $2,665.64$ & $98,621.87$ & $2,665.64$ \\
\hline
\end{tabular}

Tabla 111

Presupuestos Anual de Gastos Financieros 2017-2021

\begin{tabular}{lrrrrr}
\hline Conceptos & $\mathbf{2 0 1 7}$ & $\mathbf{2 0 1 8}$ & $\mathbf{2 0 1 9}$ & $\mathbf{2 0 2 0}$ & $\mathbf{2 0 2 1}$ \\
\hline Interes & $14,514.76$ & $12,023.12$ & $9,176.17$ & $5,923.24$ & $2,206.45$ \\
\hline Pago Total & $\mathbf{1 4 , 5 1 4 . 7 6}$ & $\mathbf{1 2 , 0 2 3 . 1 2}$ & $\mathbf{9 , 1 7 6 . 1 7}$ & $\mathbf{5 , 9 2 3 . 2 4}$ & $\mathbf{2 , 2 0 6 . 4 5}$
\end{tabular}

\subsection{Presupuestos de Resultados}

\subsubsection{Estado de Resultados}

Para la elaboración del estado de resultados del proyecto se ha considerado los siguientes puntos (ver tabla $\mathrm{N}^{\circ} 112$ ):

1. El impuesto a la renta utilizado es de $27 \%$.

2. Todas las cifras se encuentran expresadas en nuevos soles.

3. El horizonte de evaluación es de 5 años.

4. Ni las ventas y los costos incluyen IGV.

5. Se han considerado precios constantes para todos los años.

6. La estructura del capital está conformada por $70 \%$ con capital propio y $30 \%$ financiado. 
Tabla 112

Estado de resultados

\begin{tabular}{|c|c|c|c|c|c|c|c|c|c|c|}
\hline ESTADO DE RESULTADOS & 2017 & $\%$ & 2018 & $\%$ & 2019 & $\%$ & 2020 & $\%$ & 2021 & $\%$ \\
\hline Ventas & 273,742 & & 650,903 & & 986,473 & & $1,328,608$ & & $1,677,186$ & \\
\hline Costos de Ventas & 216,052 & $79 \%$ & 341,054 & $52 \%$ & 455,779 & $46 \%$ & 556,544 & $42 \%$ & 656,389 & $39 \%$ \\
\hline $\begin{array}{l}\text { Utilidad Bruta } \\
\end{array}$ & 57,691 & $21 \%$ & 309,849 & $48 \%$ & 530,694 & $54 \%$ & 772,064 & $58 \%$ & $1,020,797$ & $61 \%$ \\
\hline Gastos Administrativos & 37,872 & $14 \%$ & 51,574 & $8 \%$ & 52,012 & $5 \%$ & 52,472 & $4 \%$ & 52,956 & $3 \%$ \\
\hline Gastos Ventas & 103,101 & $38 \%$ & 150,535 & $23 \%$ & 184,567 & $19 \%$ & 205,338 & $15 \%$ & 240,474 & $14 \%$ \\
\hline Utilidad Operativa & $-83,282$ & $-30 \%$ & 107,740 & $17 \%$ & 294,115 & $30 \%$ & 514,254 & $39 \%$ & 727,367 & $43 \%$ \\
\hline Gastos Financieros & 14,515 & $5 \%$ & 12,023 & $2 \%$ & 9,176 & $1 \%$ & 5,923 & $0 \%$ & 2,206 & $0 \%$ \\
\hline Utilidad Antes de Impuestos & $-97,797$ & $-36 \%$ & 95,717 & $15 \%$ & 284,939 & $29 \%$ & 508,330 & $38 \%$ & 725,161 & $43 \%$ \\
\hline Impuesto a la Renta $(27 \%)$ & 0 & & 25,844 & $4 \%$ & 76,934 & $8 \%$ & 137,249 & $10 \%$ & 195,793 & $12 \%$ \\
\hline UTILIDAD NETA & $-97,797$ & $-36 \%$ & 69,874 & $11 \%$ & 208,005 & $21 \%$ & 371,081 & $28 \%$ & 529,367 & $32 \%$ \\
\hline
\end{tabular}




\subsubsection{Estado de situación finaciera proyectado}

A continuación, se presentará la situación financiera proyectada actual (ver tabla $\mathrm{N}^{\circ} 113$ ) y los cinco (5) situaciones financieras proyectadas de los cinco (5) años en los que se desarrollará el proyecto, como se puede aprecia en las tablas $\mathrm{N}^{\circ} 114,115,116,117$ y 118:

Situación financiera inicial

Tabla 113

Situación financiera inicial

ESTADO DE SITUACION FINANCIERA INICIAL AL O1 DE ENERO DEL 2017

\begin{tabular}{|c|c|c|c|}
\hline Activos & & Pasivos & \\
\hline $\begin{array}{l}\text { Activo Corriente } \\
\text { Caja y Bancos } \\
\text { Cuentas por Cobrar Clientes } \\
\text { Cuentas por Cobrar Accionistas y Personas } \\
\text { Cuentas por Cobrar Diversas } \\
\text { Provisiones por Cobranza Dudoza } \\
\text { Mercaderias }\end{array}$ & $386,982.74$ & $\begin{array}{l}\text { Pasivo Corriente } \\
\text { Tributos por Pagar } \\
\text { Remuneraciones y Participaciones por Pagar } \\
\text { Cuenta por Pagar Proveedores } \\
\text { Cuentas por Pagar Diversas }\end{array}$ & \\
\hline Total Activo Corriente & $386,982.74$ & Total Pasivo Corriente & $\mathbf{0 . 0 0}$ \\
\hline $\begin{array}{l}\text { Activo No Corriente } \\
\text { Valores } \\
\text { Inmuebles, Maquinarias y Equipos } \\
\text { Intangibles } \\
\text { Depreciaciòn y Amortizaciòn Acumulada }\end{array}$ & & $\begin{array}{l}\text { Pasivo No Corriente } \\
\text { Beneficio Sociales de los Trabajadores } \\
\text { Prestamos por Pagar } \\
\text { Total Pasivo No Corriente } \\
\text { Patrimonio } \\
\text { Capital } \\
\text { Resultado Acumulado } \\
\text { Resultado del Ejercicio }\end{array}$ & $\begin{array}{l}116,094.82 \\
116,094.82\end{array}$ \\
\hline Total Activo No Corriente & $\mathbf{0 . 0 0}$ & Total Patrimonio & $270,887.92$ \\
\hline Total Activo & $\mathbf{3 8 6 , 9 8 2 . 7 4}$ & Total Pasivo y Patrimonio & $386,982.74$ \\
\hline
\end{tabular}


Situación Financiera - Primer Año

Tabla 114

Situación Financiera - Primer Año

ESTADO DE SITUACION FINANCIERA AL 31 DE DICIEMBRE DEL 2017

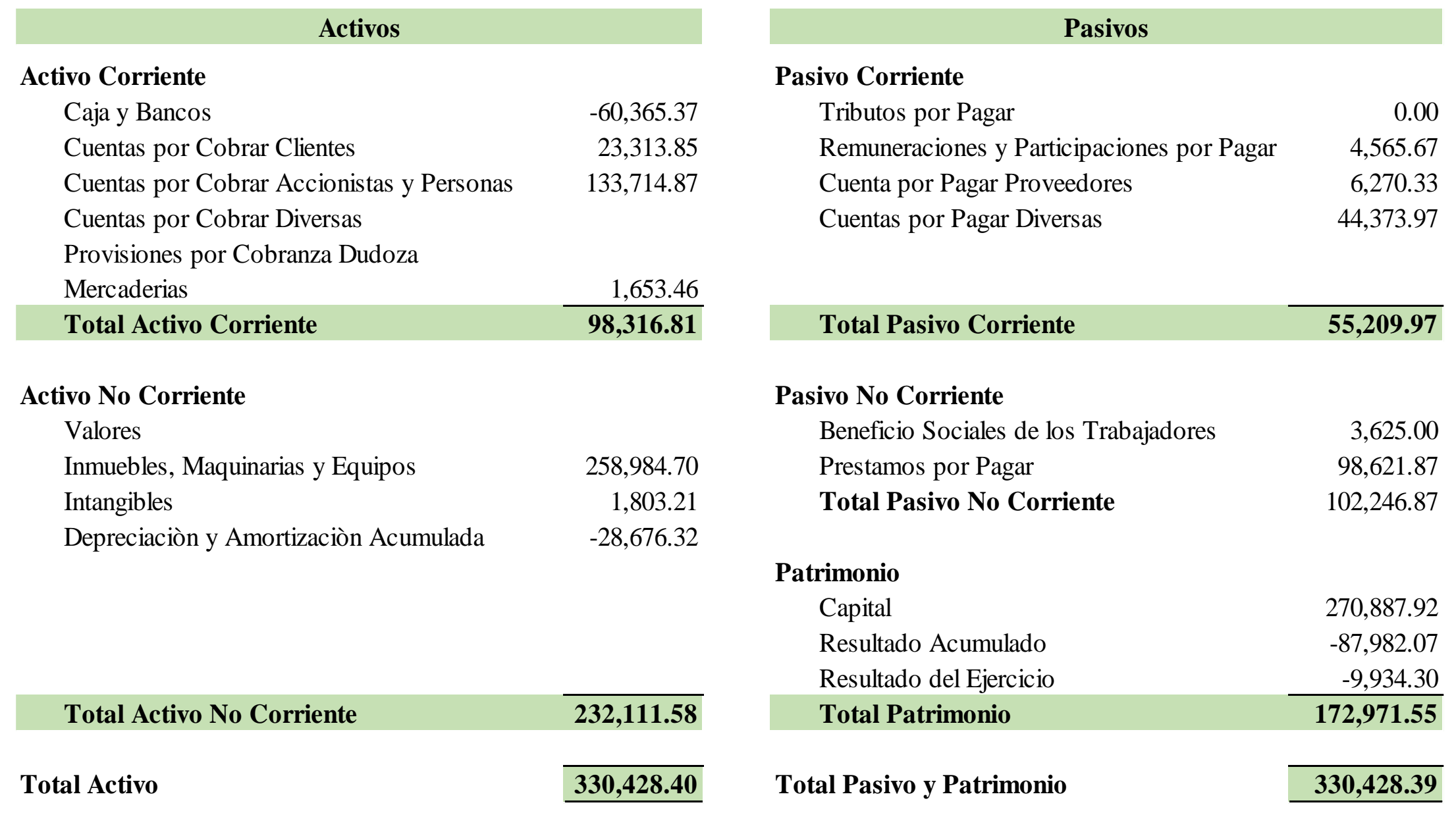


Situación Financiera - Segundo Año

Tabla 115

Situación Financiera - Segundo Año

ESTADO DE SITUACION FINANCIERA AL 31 DE DICIEMBRE DEL 2018

\begin{tabular}{|c|c|c|c|}
\hline \multicolumn{2}{|l|}{ Activos } & \multicolumn{2}{|l|}{ Pasivos } \\
\hline Activo Corriente & & Pasivo Corriente & \\
\hline Caja y Bancos & $119,650.22$ & Tributos por Pagar & $25,843.63$ \\
\hline Cuentas por Cobrar Clientes & $55,435.54$ & Remuneraciones y Participaciones por Pagar & $5,575.85$ \\
\hline Cuentas por Cobrar Accionistas y Personas & $94,232.28$ & Cuenta por Pagar Proveedores & $14,909.56$ \\
\hline Cuentas por Cobrar Diversas & & Cuentas por Pagar Diversas & $4,861.73$ \\
\hline \multicolumn{4}{|l|}{ Provisiones por Cobranza Dudoza } \\
\hline Mercaderias & $2,531.20$ & & \\
\hline Total Activo Corriente & $271,849.23$ & Total Pasivo Corriente & $51,190.77$ \\
\hline Activo No Corriente & & Pasivo No Corriente & \\
\hline Valores & & Beneficio Sociales de los Trabajadores & $4,675.00$ \\
\hline Inmuebles, Maquinarias y Equipos & $258,984.70$ & Prestamos por Pagar & $78,657.28$ \\
\hline Intangibles & $1,803.21$ & Total Pasivo No Corriente & $83,332.28$ \\
\hline \multirow[t]{4}{*}{ Depreciaciòn y Amortizaciòn Acumulada } & $-57,352.64$ & & \\
\hline & & Patrimonio & \\
\hline & & Capital & $270,887.92$ \\
\hline & & Resultado Acumulado del Ejercicio & $69,873.53$ \\
\hline Total Activo No Corriente & $203,435.26$ & Total Patrimonio & $340,761.45$ \\
\hline Total Activo & $475,284.50$ & Total Pasivo y Patrimonio & $475,284.49$ \\
\hline
\end{tabular}


Situación Financiera - Tercer Año

Tabla 116

Situación Financiera - Tercer Año

\section{ESTADO DE SITUACION FINANCIERA AL 31 DE DICIEMBRE DEL 2019}

\begin{tabular}{|c|c|c|c|}
\hline \multicolumn{2}{|l|}{ Activos } & \multicolumn{2}{|l|}{ Pasivos } \\
\hline Activo Corriente & & Pasivo Corriente & \\
\hline Caja y Bancos & $260,130.93$ & Tributos por Pagar & $76,933.51$ \\
\hline Cuentas por Cobrar Clientes & $84,015.10$ & Remuneraciones y Participaciones por Pagar & $5,832.84$ \\
\hline Cuentas por Cobrar Accionistas y Personas & $130,332.63$ & Cuenta por Pagar Proveedores & $24,799.71$ \\
\hline Cuentas por Cobrar Diversas & & Cuentas por Pagar Diversas & $5,071.06$ \\
\hline \multicolumn{4}{|l|}{ Provisiones por Cobranza Dudoza } \\
\hline Mercaderias & $3,029.04$ & & \\
\hline Total Activo Corriente & $477,507.69$ & Total Pasivo Corriente & $112,637.11$ \\
\hline Activo No Corriente & & Pasivo No Corriente & \\
\hline Valores & & Beneficio Sociales de los Trabajadores & $4,890.47$ \\
\hline Inmuebles, Maquinarias y Equipos & $258,984.70$ & Prestamos por Pagar & $55,845.73$ \\
\hline Intangibles & $1,803.21$ & Total Pasivo No Corriente & $60,736.20$ \\
\hline \multirow[t]{4}{*}{ Depreciaciòn y Amortizaciòn Acumulada } & $-86,028.96$ & & \\
\hline & & Patrimonio & \\
\hline & & Capital & $270,887.92$ \\
\hline & & Resultado Acumulado del Ejercicio & $208,005.41$ \\
\hline Total Activo No Corriente & $174,758.94$ & Total Patrimonio & $478,893.33$ \\
\hline Total Activo & $652,266.63$ & Total Pasivo y Patrimonio & $652,266.64$ \\
\hline
\end{tabular}


Situación Financiera - Cuarto Año

Tabla 117

Situación Financiera - Cuarto Año

\section{ESTADO DE SITUACION FINANCIERA AL 31 DE DICIEMBRE DEL 2020}

\begin{tabular}{|c|c|c|c|}
\hline \multicolumn{2}{|l|}{ Activos } & \multicolumn{2}{|l|}{ Pasivos } \\
\hline Activo Corriente & & Pasivo Corriente & \\
\hline Caja y Bancos & $424,976.83$ & Tributos por Pagar & $137,249.23$ \\
\hline Cuentas por Cobrar Clientes & $113,153.75$ & Remuneraciones y Participaciones por Pagar & $6,094.85$ \\
\hline Cuentas por Cobrar Accionistas y Personas & $167,911.42$ & Cuenta por Pagar Proveedores & $30,433.05$ \\
\hline Cuentas por Cobrar Diversas & & Cuentas por Pagar Diversas & $5,290.85$ \\
\hline \multicolumn{4}{|l|}{ Provisiones por Cobranza Dudoza } \\
\hline Mercaderias & $3,803.94$ & & \\
\hline Total Activo Corriente & $709,845.94$ & Total Pasivo Corriente & $179,067.98$ \\
\hline Activo No Corriente & & Pasivo No Corriente & \\
\hline Valores & & Beneficio Sociales de los Trabajadores & $5,110.15$ \\
\hline Inmuebles, Maquinarias y Equipos & $258,984.70$ & Prestamos por Pagar & $29,781.26$ \\
\hline Intangibles & $1,803.21$ & Total Pasivo No Corriente & $34,891.41$ \\
\hline \multirow[t]{4}{*}{ Depreciaciòn y Amortizaciòn Acumulada } & $-114,705.28$ & & \\
\hline & & Patrimonio & \\
\hline & & Capital & $270,887.92$ \\
\hline & & Resultado Acumulado del Ejercicio & $371,081.25$ \\
\hline Total Activo No Corriente & $146,082.62$ & Total Patrimonio & $641,969.17$ \\
\hline Total Activo & $855,928.56$ & Total Pasivo y Patrimonio & $855,928.56$ \\
\hline
\end{tabular}


Situación Financiera - Quinto Año

Tabla 118

Situación Financiera - Quinto Año

\section{ESTADO DE SITUACION FINANCIERA AL 31 DE DICIEMBRE DEL 2021}

\begin{tabular}{|c|c|c|c|}
\hline \multicolumn{2}{|l|}{ Activos } & \multicolumn{2}{|l|}{ Pasivos } \\
\hline Activo Corriente & & Pasivo Corriente & \\
\hline Caja y Bancos & $580,644.07$ & Tributos por Pagar & $195,793.42$ \\
\hline Cuentas por Cobrar Clientes & $142,841.16$ & Remuneraciones y Participaciones por Pagar & $6,361.80$ \\
\hline Cuentas por Cobrar Accionistas y Personas & $206,365.82$ & Cuenta por Pagar Proveedores & $38,417.57$ \\
\hline Cuentas por Cobrar Diversas & & Cuentas por Pagar Diversas & $5,521.64$ \\
\hline \multicolumn{4}{|l|}{ Provisiones por Cobranza Dudoza } \\
\hline Mercaderias & $4,426.36$ & & \\
\hline Total Activo Corriente & $934,277.41$ & Total Pasivo Corriente & $246,094.42$ \\
\hline Activo No Corriente & & Pasivo No Corriente & \\
\hline Valores & & Beneficio Sociales de los Trabajadores & $5,333.97$ \\
\hline Inmuebles, Maquinarias y Equipos & $258,984.70$ & Prestamos por Pagar & 0.00 \\
\hline Intangibles & $1,803.21$ & Total Pasivo No Corriente & $5,333.97$ \\
\hline \multirow[t]{4}{*}{ Depreciaciòn y Amortizaciòn Acumulada } & $-143,381.60$ & & \\
\hline & & Patrimonio & \\
\hline & & Capital & $270,887.92$ \\
\hline & & Resultado Acumulado del Ejercicio & $529,367.40$ \\
\hline Total Activo No Corriente & $117,406.30$ & Total Patrimonio & $800,255.32$ \\
\hline Total Activo & $\overline{1,051,683.71}$ & Total Pasivo y Patrimonio & $\overline{1,051,683.71}$ \\
\hline
\end{tabular}




\subsubsection{Flujo de caja proyectado}

\section{Flujo de caja operativo}

Para hallar el flujo de caja operativo (ver tabla $\mathrm{N}^{\circ} 119$ ) se procedió a restarle a las ventas todos los gastos incurridos en el proyecto (materia prima, mano de obra directa e indirecta, costos indirectos de fabricación, gastos de ventas, gastos de administración y el adelanto por el impuesto a la renta, que corresponde al $1.5 \%$ de las ventas mensuales realizadas).

Tabla 119

Flujo de Caja Operativo Proyectado

\begin{tabular}{|c|c|c|c|c|c|c|}
\hline \multicolumn{7}{|c|}{$\begin{array}{l}\text { Flujo de Caja Operativo ( } \sin \text { iGV) } \\
\text { Expresado en nuevos soles }\end{array}$} \\
\hline \multirow{2}{*}{ Elementos } & $\mathbf{0}$ & 1 & 2 & 3 & 4 & 5 \\
\hline & & 2017 & 2018 & 2019 & 2020 & 2021 \\
\hline Ingresos & & 273,742 & 650,903 & 986,473 & $1,328,608$ & $1,677,186$ \\
\hline \multicolumn{7}{|l|}{ Egresos } \\
\hline Mano de obra directa & & 50,184 & 50,184 & 50,184 & 50,184 & 50,184 \\
\hline CIF - MOI & & 25,092 & 39,852 & 39,852 & 39,852 & 39,852 \\
\hline CIF - OTROS & & 69,224 & 78,118 & 80,246 & 82,482 & 80,691 \\
\hline Gastos de administración & & 37,872 & 51,574 & 52,012 & 52,472 & 52,956 \\
\hline Gastos de Ventas & & 103,101 & 150,535 & 184,567 & 205,338 & 240,474 \\
\hline Costos Fijos & & 285,473 & 370,262 & 406,861 & 430,328 & 464,157 \\
\hline Materiales Directos & & 70,246 & 166,550 & 275,357 & 370,858 & 468,158 \\
\hline $\mathrm{CIF}-\mathrm{MI}$ & & 2,959 & 7,036 & 10,664 & 13,801 & 18,130 \\
\hline Pago a Cuenta Impuesto a la Renta & & 4,106 & 16,080 & 62,136 & 117,320 & 170,636 \\
\hline Costos Variables & & 77,311 & 189,666 & 348,157 & 501,979 & 656,924 \\
\hline Total Egresos & & 362,784 & 559,929 & 755,018 & 932,307 & $1,121,081$ \\
\hline Ebitda & & $-89,042$ & 90,974 & 231,455 & 396,301 & 556,105 \\
\hline Amortización & & 306 & 306 & 306 & 306 & 306 \\
\hline Depreciación & & 28,371 & 28,371 & 28,371 & 28,371 & 24,233 \\
\hline FLUJO DE CAJA OPERATIVO & & $-60,365$ & 119,650 & 260,131 & 424,977 & 580,644 \\
\hline
\end{tabular}

\section{Flujo de inversiones}

En el siguiente cuadro se apreciará que en año cero, se tendrá que hacer un fuerte desembolso por el valor de S/ 386,983 en los cuales incluyen la inversión en activo fijo, activo intangible y capital de trabajo (ver tabla $\mathrm{N}^{\mathrm{o}} 120$ ). 
Tabla 120

Flujo de Inversiones

\begin{tabular}{lcccccc}
\hline \multicolumn{1}{c}{ FLUJO DE INVERSIONES } & Año (0) & $\mathbf{2 0 1 7}$ & $\mathbf{2 0 1 8}$ & $\mathbf{2 0 1 9}$ & $\mathbf{2 0 2 0}$ & $\mathbf{2 0 2 1}$ \\
\hline Activo Fijo Tangible & $-258,985$ & & & & & \\
Activo Fijo Intangible & $-39,133$ & & & & & \\
Capital de Trabajo & $-88,865$ & $-122,437$ & $-108,936$ & $-111,067$ & $-113,159$ & 0 \\
Valor de Rescate Activos Fijos & & & & & & 121,167 \\
V.liquidacion en Capital de trabajo & & & & & & 544,464 \\
\hline FLUJO DE INVERSIONES & $\mathbf{- 3 8 6 , 9 8 3}$ & $\mathbf{- 1 2 2 , 4 3 7}$ & $\mathbf{- 1 0 8 , 9 3 6}$ & $\mathbf{- 1 1 1 , 0 6 7}$ & $\mathbf{- 1 1 3 , 1 5 9}$ & $\mathbf{6 6 5 , 6 3 1}$ \\
\hline
\end{tabular}

Flujo de caja económico proyectado

Para hallar el flujo de caja económico proyectado (ver tabla $\mathrm{N}^{\circ} 121$ ), se procedió a restar el flujo de caja operativo menos el flujo de caja capital, el cual se muestra a continuación.

Tabla 121

Flujo de Caja - Económico

Flujo de Caja Economico Proyectado

\begin{tabular}{llllllr}
\hline FLUJO DE CAJA ECONOMIC0 & Año (0) & $\mathbf{2 0 1 7}$ & $\mathbf{2 0 1 8}$ & \multicolumn{2}{c}{$\mathbf{2 0 1 9}$} & \multicolumn{2}{c}{$\mathbf{2 0 2 0}$} & \multicolumn{2}{c}{$\mathbf{2 0 2 1}$} \\
\hline Flujo de caja operativo & & $-60,365$ & 119,650 & 260,131 & 424,977 & 580,644 \\
Flujo de caja de inversión & $\mathbf{- 3 8 6 , 9 8 3}$ & $-122,437$ & $-108,936$ & $-111,067$ & $-113,159$ & 665,631 \\
\hline FLUJO DE CAJA ECONOMICO & $\mathbf{- 3 8 6 , 9 8 3}$ & $\mathbf{- 1 8 2 , 8 0 3}$ & $\mathbf{1 0 , 7 1 4}$ & $\mathbf{1 4 9 , 0 6 4}$ & $\mathbf{3 1 1 , 8 1 8}$ & $\mathbf{1 , 2 4 6 , 2 7 5}$ \\
\hline
\end{tabular}

Flujo de caja de la deuda

A continuación, se muestra el flujo del servicio de la deuda (ver tabla $\mathrm{N}^{\mathrm{o}}$ 122), el cual es el préstamo con el interés y la amortización, el préstamo que se está solicitando tiene un plazo de 5 años.

Tabla 122

Flujo de Servicio de la Deuda

\begin{tabular}{lcccccc}
\hline FLUJO DEL SERVICIO DE LA DEUDA & Año (0) & $\mathbf{2 0 1 7}$ & $\mathbf{2 0 1 8}$ & $\mathbf{2 0 1 9}$ & $\mathbf{2 0 2 0}$ & $\mathbf{2 0 2 1}$ \\
\hline Préstamo & 116,095 & & & & & \\
Servicio de la Deuda & & & & & & \\
Capital & & $-17,473$ & $-19,965$ & $-22,812$ & $-26,064$ & $-29,781$ \\
Intereses & & $-14,515$ & $-12,023$ & $-9,176$ & $-5,923$ & $-2,206$ \\
Cuota Total & $-31,988$ & $-31,988$ & $-31,988$ & $-31,988$ & $-31,988$ \\
\hline FLUJ0 DEL SERVICI0 DE LA DEUDA & $\mathbf{- 3 1 , 9 8 8}$ & $\mathbf{- 3 1 , 9 8 8}$ & $\mathbf{- 3 1 , 9 8 8}$ & $\mathbf{- 3 1 , 9 8 8}$ & $\mathbf{- 3 1 , 9 8 8}$ \\
\hline
\end{tabular}


Flujo de caja financiero

El flujo de caja financiero (ver tabla $\mathrm{N}^{\circ} 123$ ) se halló restando el flujo económico menos el servicio de deuda hallado anteriormente.

Tabla 123

Flujo de Caja - Financiero

\begin{tabular}{lcccccc}
\hline \multicolumn{1}{c}{ FLUJ0 DE CAJA FINANCIER0 } & Año (0) & 2017 & 2018 & 2019 & 2020 & \multicolumn{2}{c}{2021} \\
\hline Flujo de caja economico & $-386,983$ & $-182,803$ & 10,714 & 149,064 & 311,818 & $1,246,275$ \\
Flujo del servicio de la deuda & & $-31,988$ & $-31,988$ & $-31,988$ & $-31,988$ & $-31,988$ \\
\hline FLUJ0 DE CAJA FINANCIER0 & $-386,983$ & $-214,791$ & $-21,274$ & 117,076 & 279,830 & $1,214,288$ \\
\hline
\end{tabular}

Periodo de recuperación descontado (Payback descontado)

Este método permite determinar el tiempo exacto en que se recuperará el dinero de la inversión (ver tabla $\mathrm{N}^{\mathrm{o}} 124$ ).

Tabla 124

Payback Descontado

\begin{tabular}{|l|lllll}
\hline \multicolumn{1}{|c|}{ CPPC } & $12.93 \%$ \\
\cline { 1 - 1 } & & & \\
\multirow{2}{*}{ PRC } & $\underline{-182,803}$ & $\underline{10,714}$ & $\underline{149,064}$ & $\underline{311,818}$ & $\underline{1,246,275}$ \\
& $(1.1293)^{1}$ & $(1.1293)^{2}$ & $(1.1293)^{3}$ & $(1.1293)^{4}$ & $(1.1293) 5$
\end{tabular}

$\begin{array}{ll}\text { INVER.RECUPERADA } & 386,983 \\ \text { INVER.RECUPER.ACU. } & 386,983\end{array}$

\begin{tabular}{ccccccc}
\hline FLUJ0 DE CAJA ECONOMIC0 & Año $(0)$ & 2017 & 2018 & 2019 & 2020 & 2021 \\
\hline Flujo de caja económico & $-386,983$ & $-182,803$ & 10,714 & 149,064 & 311,818 & $1,246,275$ \\
Flujo de caja descontado & & $-182,567$ & 10,687 & 148,487 & 310,210 & $1,238,247$ \\
\hline \multicolumn{7}{|c|}{ Período de Recuperación del Capital 4 años, 0 meses y 29 días } \\
\hline
\end{tabular}




\section{Capítulo IX: Evaluación Económico Financiera}

\subsection{Evaluación Financiera}

\subsubsection{TIR}

La tasa interna de retorno es la máxima tasa de ganancia que se espera obtener de un proyecto. Matemáticamente se obtiene cuando el VAN equivale a cero, es decir, cuando la inversión inicial es igual a los flujos futuros descontados al periodo cero. La TIRE se halla en base a los flujos de caja económicos (ver tabla $\mathrm{N}^{\mathrm{o}}$ 125) y la TIRF se halla en base a los flujos de caja financieros (ver tabla $\mathrm{N}^{\circ}$ 126). El proyecto será considerado viable si la TIRE es mayor al WACC y la TIRF es mayor al Que.

Cuando la TIRE es mayor que el costo promedio ponderado de capital, conviene realizar el proyecto (ver tabla $\mathrm{N}^{\circ} 126$ ).

Tabla 125

Tasa Interna de Retorno Económico - TIRE

$$
I o=\sum \frac{f n}{(1+T I R)^{n}}
$$

TASA INTERNA DE RETORNO ECONOMICO

\begin{tabular}{|c|c|c|c|c|c|c|c|}
\hline & & Año $(0)$ & 2017 & 2018 & 2019 & 2020 & 2021 \\
\hline \multicolumn{2}{|c|}{ FLUJO DE CAJA ECONOMICO } & $-386,983$ & $-182,803$ & 10,714 & 149,064 & 311,818 & $1,246,275$ \\
\hline TIRE & WACC & & & & & & \\
\hline $29 \%$ & $12.93 \%$ & & & & & & \\
\hline
\end{tabular}

Tabla 126

Tasa Interna de Retorno Financiero - TIRF

TASA INTERNA DE RETORNO

FINANCIER0

\begin{tabular}{ccccccc}
\cline { 2 - 6 } & Año $(0)$ & 2017 & 2018 & 2019 & 2020 & 2021 \\
\hline FLUJO DE CAJA FINANCIER0 & $-386,983$ & $-214,791$ & $-21,274$ & 117,076 & 279,830 & $1,214,288$ \\
\hline
\end{tabular}

\begin{tabular}{rr} 
TIRF & Ke; COK \\
\hline $25 \%$ & $14.02 \%$ \\
\hline
\end{tabular}




\subsubsection{VAN}

El VAN es el valor actual neto de los flujos de caja generados por un proyecto durante su vida o años de evaluación. Se recomienda invertir en un proyecto de inversión cuando el VAN sea positivo o mayor a cero, por lo tanto, es preferible cuando el VAN es más elevado. El VANE se determina analizando los flujos de caja económicos por lo que se descuenta con el costo promedio ponderado de capital (WACC) (ver tabla $\mathrm{N}^{\circ}$ 127). Por otro lado, el VANF se determina analizando los flujos de caja financieros por lo que se descuenta con el costo de capital (Ke) (ver tabla $\left.\mathrm{N}^{\mathrm{o}} 128\right)$.

Tabla 127

Valor Actual Neto Económico - VANE

$V A N E=-I o+\sum \frac{f n}{(1+W A C C)^{n}}$

-Io: Inversión Inicial

n: Periodo

VALOR ACTUAL NETO ECONOMICO

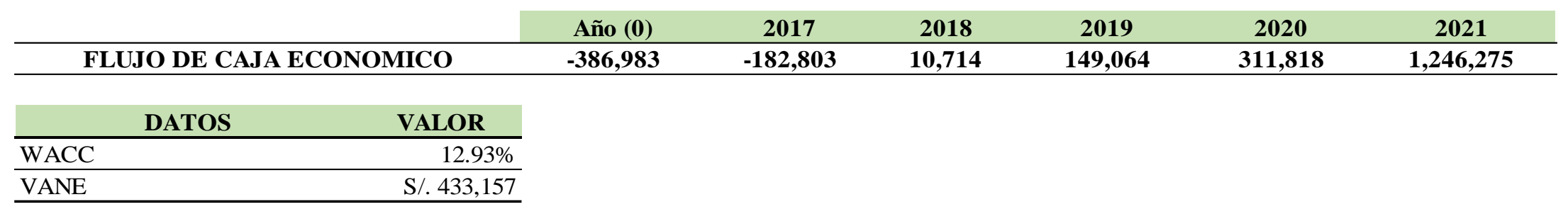


Tabla 128

Valor Actual Neto Financiero - VANF

VANF $=-I 0+\sum \frac{f n}{(1+K e)^{n}}$

-Io: Inversión Inicial

n: Periodo

VALOR ACTUAL NETO FINANCIERO

\begin{tabular}{ccccccc}
\cline { 2 - 6 } & Año $(0)$ & 2017 & 2018 & 2019 & 2020 & 2021 \\
\hline FLUJO DE CAJA FINANCIERO & $-386,983$ & $-214,791$ & $-21,274$ & 117,076 & 279,830 & $1,214,288$ \\
\hline
\end{tabular}

\begin{tabular}{|c|c|}
\hline DATOS & VALOR \\
\hline $\mathrm{Ke} ; \mathrm{COK}$ & $14.02 \%$ \\
\hline VANF & S/. 283,095 \\
\hline
\end{tabular}




\subsubsection{ROE}

El retorno sobre el capital (ROE) nos permite medir la rentabilidad del aporte de los accionistas sobre sus inversiones, para lo cual a continuación se presenta el resultado de los cinco (5) años proyectados en que desarrolla el proyecto (ver figura $\mathrm{N}^{\circ} 85$ ).

\begin{tabular}{|c|c|c|c|c|c|}
\hline \multicolumn{2}{|c|}{$\begin{array}{c}\text { Retorno Sobre el } \\
\text { Capital (ROE) } \\
\end{array}$} & & \multicolumn{2}{|c|}{ Utilidad Neta } & $\begin{array}{c}\text { Capital de } \\
\text { Accionistas }\end{array}$ \\
\hline $\begin{array}{l}\text { Resultado Base } \\
\text { INEI } 2007\end{array}$ & $\begin{array}{c}\text { Resultado Año } 1 \\
2017\end{array}$ & $\begin{array}{c}\text { Resultado Año } 2 \\
2018\end{array}$ & $\begin{array}{c}\text { Resultado Año } 3 \\
2019\end{array}$ & $\begin{array}{c}\text { Resultado Año } 4 \\
2020\end{array}$ & $\begin{array}{c}\text { Resultado Año } 5 \\
2021\end{array}$ \\
\hline $25.51 \%$ & $-36.10 \%$ & $25.79 \%$ & $76.79 \%$ & $136.99 \%$ & $195.42 \%$ \\
\hline
\end{tabular}

\section{Figura 85. Resultado ROE}

Como se puede apreciar el primer año el proyecto le da al inversionista un retorno negativo, esto dado que el primer año concluyo en perdida y por ello el retorno no se dio y en los siguientes años se pudo revertir esta situación logrando el segundo año un retorno de $25.79 \%$, el tercer año $76.79 \%$, el cuarto año $136.99 \%$ y terminar en el quinto año con una rentabilidad de $195.42 \%$ sobre el capital o aporte de los accionistas, además se ha agregado el indicadores financieros y económicos empresariales realizados por el instituto de estadística e informática (INEI 2010), y como se puede apreciar el ratio es de $25.51 \%$, del sector de manufactura, teniendo los dos primeros años resultados por debajo de este indicador para lograr a partir del tercer año muy por encima del ratio base, logrando en el quinto año cuadruplicar este indicador (ver figura $\mathrm{N}^{\circ} 85$ ). 


\subsubsection{Ratios}

A continuación, se presentarán indicadores económicos contables y financieros que ayudaran a comprender el comportamiento de los resultados del proyecto a lo largo de los cinco años de operación, con un solo índice o ratio no se podrá evaluar el estado de la empresa u organización por lo cual presentarán 15 ratios organizados en cuatro segmentos o grupos de evaluación que están referidos a la liquidez, gestión, apalancamiento financiero y rentabilidad (ver figura $\mathrm{N}^{\circ} 86$ ).

Liquidez

\begin{tabular}{cccccc|}
\hline \multicolumn{1}{|c}{ Disponibilidad Inmediata } & $=$ & Caja y Bancos & $/$ & Pasivo Corriente \\
\hline $\begin{array}{c}\text { Resultado Base } \\
\text { INEI 2007 }\end{array}$ & $\begin{array}{c}\text { Resultado Año 1 } \\
\mathbf{2 0 1 7}\end{array}$ & $\begin{array}{c}\text { Resultado Año 2 } \\
\mathbf{2 0 1 8}\end{array}$ & $\begin{array}{c}\text { Resultado Año 3 } \\
\mathbf{2 0 1 9}\end{array}$ & $\begin{array}{c}\text { Resultado Año } 4 \\
\mathbf{2 0 2 0}\end{array}$ & $\begin{array}{c}\text { Resultado Año 5 } \\
\mathbf{2 0 2 1}\end{array}$ \\
\hline 0.22 & -1.09 & 2.34 & 2.31 & 2.37 & 2.36 \\
\hline
\end{tabular}

Figura 86. Disponibilidad Inmediata

Como se puede observar el primer año se logra contar con un indicador de -1.09 que representa S/. -60,365 nuevos soles como saldo para poder realizar las operaciones de este primer año, no siendo un ideal para este primer año, luego, como se observa en la figura $\mathrm{N}^{\circ} 86$ se llega al término del quinto año con un capital de trabajo o capital de operación de S/. 580,644 nuevos soles monto suficiente que da sostenibilidad a la operación en cada año.

\begin{tabular}{|cccccc|}
\hline & Razón Corriente & Activo Corriente & Pasivo Corriente \\
\hline $\begin{array}{c}\text { Resultado Base } \\
\text { INEI 2007 }\end{array}$ & $\begin{array}{c}\text { Resultado Año 1 } \\
2017\end{array}$ & $\begin{array}{c}\text { Resultado Año } 2 \\
2018\end{array}$ & $\begin{array}{c}\text { Resultado Año } 3 \\
2019\end{array}$ & $\begin{array}{c}\text { Resultado Año } 4 \\
2020\end{array}$ & $\begin{array}{c}\text { Resultado Año } 5 \\
2021\end{array}$ \\
\hline 1.37 & 1.78 & 5.31 & 4.24 & 3.96 & 3.80 \\
\hline
\end{tabular}

Figura 87. Razón Corriente o Razón Circulante 
Este ratio permite evaluar la capacidad de pago de las deudas del proyecto durante cada año, y como se puede apreciar en la figura $\mathrm{N}^{\circ} 87$, el primer año se puede asumir las obligaciones de pagos en 1.78 veces, siendo esta una cifra no tan buena dado que se está muy cerca del no cumplimiento de las obligaciones, mientras que a partir del segundo año y hasta el quinto se logra en promedio hasta 3.80 veces asumir las obligaciones del proyecto cifra por demás muy buena, también podemos observar que aun teniendo el primer año un ratio no muy bueno este se encuentra por encima del ratio base de 0.84 el cual sirve para la comparación con el sector (manufactura).

\begin{tabular}{|c|c|c|c|c|c|}
\hline & \multirow{2}{*}{ Prueba ácida } & \multirow{2}{*}{$=$} & Activo Corriente & - & Inventario \\
\hline & & & \multicolumn{3}{|c|}{ Pasivo Corriente } \\
\hline Resultado Base & Resultado Año 1 & Resultado Año 2 & Resultado Año 3 & Resultado Año 4 & Resultado Año 5 \\
\hline INEI 2007 & 2017 & 2018 & 2019 & 2020 & 2021 \\
\hline 0.84 & 1.75 & 5.26 & 4.21 & 3.94 & 3.78 \\
\hline
\end{tabular}

Figura 88. Prueba Acida

Como se aprecia al igual que el ratio anterior, la prueba acida determina la capacidad de pago de las deudas en el corto plazo que la operación del proyecto genera, siendo la diferencia más importante es dada por quitar el stock de seguridad (inventarios) que se tiene en cada año, y como se puede apreciar en la figura $\mathrm{N}^{\circ} 88$ se comienza con un ratio algo ajustado pero al término del tercer año se tiene un ratio de 4.21 veces logrando con ello el sostenimiento de la capacidad de pago de las obligaciones a lo largo de todo el proyecto, también se observa que los ratios obtenidos en cada año supera fácilmente el ratio base del sector (manufactura). 
Gestión

\begin{tabular}{|cccccc|}
\hline \multicolumn{7}{|c|}{ Rotación de Inventarios } & & Costo de Venta & Inventario \\
\hline & & & & \\
\hline $\begin{array}{c}\text { Resultado Base } \\
\text { INEI 2007 }\end{array}$ & $\begin{array}{c}\text { Resultado Año 1 } \\
\mathbf{2 0 1 7}\end{array}$ & $\begin{array}{c}\text { Resultado Año 2 } \\
\mathbf{2 0 1 8}\end{array}$ & $\begin{array}{c}\text { Resultado Año 3 } \\
\mathbf{2 0 1 9}\end{array}$ & $\begin{array}{c}\text { Resultado Año } \\
\mathbf{2 0 2 0}\end{array}$ & $\begin{array}{c}\text { Resultado Añ 5 } \\
\mathbf{2 0 2 1}\end{array}$ \\
\hline 5.80 & 10.89 & 11.23 & 12.54 & 12.19 & 12.36 \\
\hline
\end{tabular}

Figura 89. Rotación de Inventarios

Como se puede aprecia el ratio de rotación de inventarios nos permite identificar la frecuencia que los inventarios (productos listos para la venta en los almacenes) salen para la venta, siendo este de 12 veces en promedio por año, con lo cual se puede afirmar que lo producido por mes se vende durante el mimo mes, más podemos observar que el sector tiene un ratio de 6 veces por año siendo este último una rotación muy larga en función a la rotación obtenida por el proyecto (ver figura $\mathrm{N}^{\circ} 89$ ).

\begin{tabular}{|c|c|c|c|c|c|c|}
\hline \multirow{2}{*}{\multicolumn{2}{|c|}{ Periodo Promedio de Inventar }} & & \multicolumn{4}{|c|}{ Inventario } \\
\hline & & & \multicolumn{2}{|c|}{ Costo de Venta } & I & 360 \\
\hline $\begin{array}{l}\text { Resultado Base } \\
\text { INEI } 2007\end{array}$ & $\begin{array}{c}\text { Resultado Año } 1 \\
2017\end{array}$ & $\begin{array}{c}\text { Resultado Año } 2 \\
\quad 2018\end{array}$ & $\begin{array}{c}\text { Resultado Año } 3 \\
2019\end{array}$ & Result & & $\begin{array}{c}\text { Resultado Año } 5 \\
2021\end{array}$ \\
\hline INEI 2007 & 33.06 & 32.06 & 28.71 & \multicolumn{2}{|c|}{29.53} & 29.53 \\
\hline
\end{tabular}

Figura 90. Periodo Promedio de Inventarios

Este ratio nos permite la confirmación de lo expuesto por el ratio de rotación de inventarios, teniendo como periodo promedio de inventarios un 30.58 días aproximadamente, lo cual está dentro de las políticas de gestión del proyecto, pero lamentablemente no se ha podido obtener el ratio base del sector por falta de información (ver figura $\mathrm{N}^{\mathrm{o}}$ 90). 


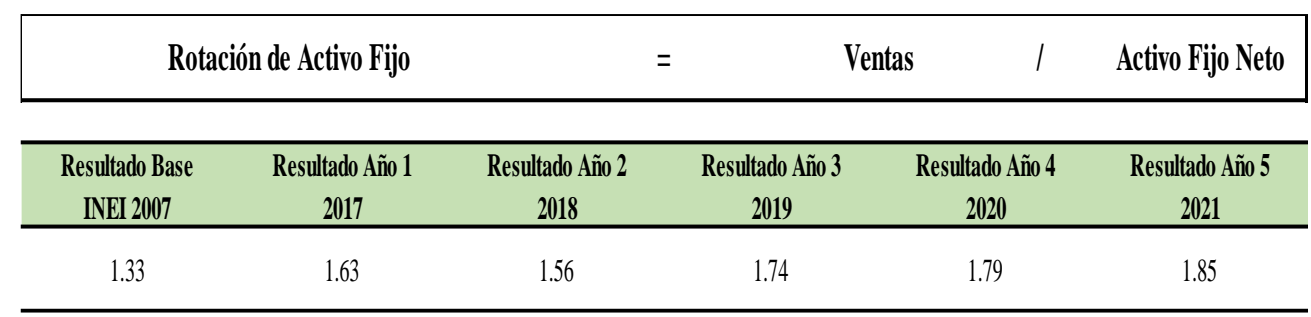

Figura 91. Rotación de Activo Fijo

Este ratio permite saber el monto de veces o proporción que las ventas están en relación a los activos fijos netos (inversión), en conclusión por cada solo invirtió las venta cuanto devuelve, en este cado el primer año se podría decir que se encuentra casi en su punto de equilibrio con 1.63 veces, lo ganado en el segundo año 1.56, el tercer año 1.74, el cuarto año 1.79, para finalizar el quinto año con un 1.85 con lo que se puede afirmar que las venta representa dos veces los activos fijos del proyecto, precisando que el activo fijo neto no incluye la depreciación de muebles y enseres y amortización de los intangibles, lo cual nos recordar que se está considerando que todos los muebles y enseres en cada año se estaría comprando, además de lograr superar a partir del primer año el ratio base de 1.33 de sector, teniendo el primer año un ratio ligeramente por debajo del ratio base del sector, esto debido a que el primer año el producto no tiene una buena penetración de mercado (ver figura $\left.\mathrm{N}^{\circ} 91\right)$.

\begin{tabular}{ccccccc|}
\hline \multicolumn{2}{c}{$\begin{array}{c}\text { Rotación de Activo } \\
\text { Fijo Total }\end{array}$} & & & Ventas & $/$ & Activo Total \\
\hline \multicolumn{1}{c}{$\begin{array}{c}\text { Resultado Base } \\
\text { INEI 2007 }\end{array}$} & $\begin{array}{c}\text { Resultado Año 1 } \\
\mathbf{2 0 1 7}\end{array}$ & $\begin{array}{c}\text { Resultado Año } 2 \\
\mathbf{2 0 1 8}\end{array}$ & $\begin{array}{c}\text { Resultado Año 3 } \\
\mathbf{2 0 1 9}\end{array}$ & $\begin{array}{c}\text { Resultado Año } 4 \\
\mathbf{2 0 2 0}\end{array}$ & $\begin{array}{c}\text { Resultado Año 5 } \\
\mathbf{2 0 2 1}\end{array}$ \\
\hline 1.33 & 1.39 & 1.37 & 1.51 & 1.55 & 1.59 \\
\hline
\end{tabular}

Figura 92. Rotación de Activo Fijo Total

Al igual que el ratio anterior, este ratio de rotación de activo fijo total nos permite saber si las ventas provocadas por el proyecto los activos totales, 
especificando la cantidad de veces, pero a diferencia que el anterior este dato está ajustado por la depreciación y amortización, aquí también podemos observar que a partir del segundo año se logra superar el ratio base del sector de 1.33 , logrando en el quinto año subir un $30 \%$ por encima del ratio base (ver figura $\mathrm{N}^{\circ}$ 92).

Apalancamiento Financiero

\begin{tabular}{ccccccc}
\hline & Endeudamiento & & Deuda Total & Activo Total \\
\hline $\begin{array}{c}\text { Resultado Base } \\
\text { INEI 2007 }\end{array}$ & $\begin{array}{c}\text { Resultado Año 1 } \\
2017\end{array}$ & $\begin{array}{c}\text { Resultado Año } \\
2018\end{array}$ & $\begin{array}{c}\text { Resultado Año 3 } \\
\mathbf{2 0 1 9}\end{array}$ & $\begin{array}{c}\text { Resultado Año } 4 \\
\mathbf{2 0 2 0}\end{array}$ & $\begin{array}{c}\text { Resultado Año 5 } \\
\text { 2021 }\end{array}$ \\
\hline 58.30 & 80.04 & 28.30 & 26.58 & 25.00 & 23.91 \\
\hline
\end{tabular}

Figura 93. Endeudamiento Financiero

Como se puede apreciar el apalancamiento financiero que se tiene es de $80.04 \%$ durante el primer año, ratio por ensima del ratio base (INEI 2007) de $58.30 \%$, pero a partir del segundo año y hasta el quinto los ratios logrados mejoran el ratio base hasta en un $40 \%$ menos, este resultado de $23.91 \%$ en el último año es positivo ya que la operación no está totalmente apalancada, y se encuentra por debajo del ratio base del sector de $58.30 \%$, logrando un endeudamiento eficiente durante todo el proyecto (ver figura $\mathrm{N}^{\circ} 93$ ).

\begin{tabular}{|c|c|c|c|c|c|}
\hline \multicolumn{2}{|c|}{ Deuda a Patrimonio } & & \multicolumn{2}{|c|}{ Deuda Total } & \multirow{2}{*}{$\begin{array}{l}\text { Patrimonio } \\
\text { Resultado Año } 5\end{array}$} \\
\hline $\begin{array}{l}\text { Resultado Base } \\
\text { INEI } 2007\end{array}$ & $\begin{array}{c}\text { Resultado Año } 1 \\
2017\end{array}$ & $\begin{array}{l}\text { Resultado Año } 2 \\
2018\end{array}$ & $\begin{array}{l}\text { Resultado Año } 3 \\
2019\end{array}$ & $\begin{array}{c}\text { Resultado Año } 4 \\
2020\end{array}$ & \\
\hline & 1.91 & 1.39 & 1.36 & 1.33 & 1.31 \\
\hline
\end{tabular}

Figura 94. Deuda a Patrimonio

Este ratio nos permite identificar cuanto del patrimonio financia la deuda total del proyecto por cada año, con lo que podemos apreciar que en el 
primer año tenemos que el patrimonio financia en $91 \%$ la deuda comprometida, pero podemos observar que esa relación o financiamiento baja al 39\%, el tercer año nuevamente baja al 36\%, en el cuarto año baja al 33\%, para en el último año situarse en $31 \%$ de deuda total financiada por el patrimonio, lamentablemente no se ha podido conseguir el ratio base del sector por falta de información (ver figura $\mathrm{N}^{\circ} 94$ ).

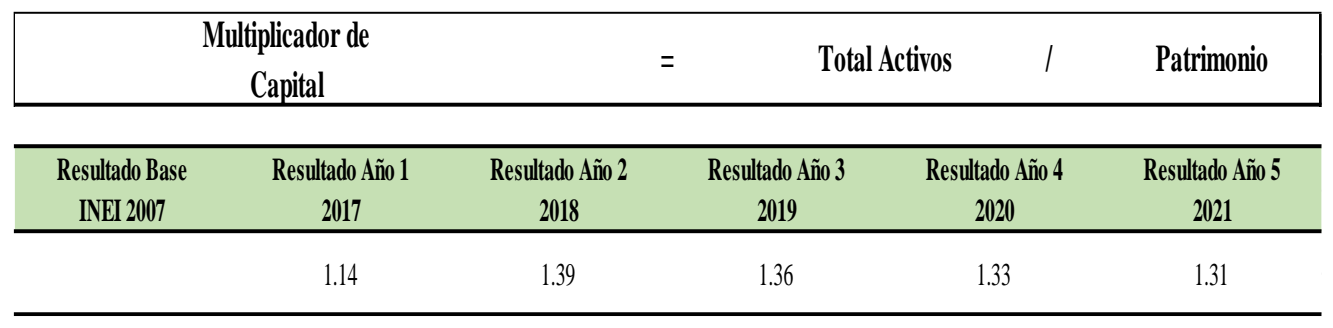

Figura 95. Multiplicador de Capital

El multiplicado de capital nos indica la participación del patrimonio (inversión de los accionistas) en la generación de activos y se puede apreciar que la participación inicial del patrimonio en el primer año es del 14\% una participación fuerte, para finalmente lograr en el quinto año una participación en la generación de activos de solo el $31 \%$ esto nos indica que con tan solo el $31 \%$ de aporte de los inversionistas se puede multiplicar los activos (ver figura $\left.\mathrm{N}^{\circ} 95\right)$.

\begin{tabular}{cccccc|}
\hline Cobertura de Intereses & & Utilidad Operativa & Gastos Financieros \\
\hline \multicolumn{1}{c}{ Resultado Base } \\
INEI 2007 & Resultado Año 1 & Resultado Año 2 & Resultado Año 3 & Resultado Año 4 & Resultado Año 5 \\
2017 & 2018 & 2019 & 2020 & 2021 \\
\hline & -5.74 & 8.96 & 32.05 & 86.82 & 329.65 \\
\hline
\end{tabular}

Figura 96. Cobertura de Intereses

Este ratio nos indica la cantidad de veces que el proyecto podrá pagar los intereses de la deuda comprometida con las ganancias antes de pago de intereses e impuestos, y cómo podemos ver el primer año se encuentra en 
negativo en -5.74 , esto quiere decir que no se podría pagar los intereses de este primer año, pero esto es debido a que este primer año es la inyección del préstamo y el resultado obtenido se encuentra en negativo, pero como se puede observar en la figura $\mathrm{N}^{\circ} 96$ a partir del según año se obtiene resultados positivos, siendo para este segundo año poder pagar los interese hasta 9 veces, en el tercer año 30 veces, en el cuarto año 86 veces, para llegar al quinto año poder pagar los interés que el proyecto genera hasta en 329 veces.

Rentabilidad

\begin{tabular}{|cccccc|}
\hline & Margen Bruto & & Utilidad Bruta & Ventas Totales \\
\hline & & & & & \\
\hline $\begin{array}{c}\text { Resultado Base } \\
\text { INEI 2007 }\end{array}$ & $\begin{array}{c}\text { Resultado Año 1 } \\
2017\end{array}$ & $\begin{array}{c}\text { Resultado Año 2 } \\
\mathbf{2 0 1 8}\end{array}$ & $\begin{array}{c}\text { Resultado Año 3 } \\
\mathbf{2 0 1 9}\end{array}$ & $\begin{array}{c}\text { Resultado Año 4 } \\
\mathbf{2 0 2 0}\end{array}$ & $\begin{array}{c}\text { Resultado Año 5 } \\
\mathbf{2 0 2 1}\end{array}$ \\
\hline 30.50 & 21.07 & 47.60 & 53.80 & 58.11 & 60.86 \\
\hline
\end{tabular}

Figura 97. Margen Bruto

Este ratio permite medir la rentabilidad de las ventas generadas frente a los costos generados por las ventas, cubriendo los gastos operativos del proyecto para la generación de utilidades, esto nos quiere decir que por cada sol vendido se gana $21.07 \%$ por cada centavos de utilidad, llegando al quinto año a ganar por cada sol el $60.86 \%$, también se puede observar que el ratio base es de $30.50 \%$ y desde el segundo año se lograr una ligera mejora, logrando a partir del tercer año y hasta el quinto año un aumento sobre del ratio base de $99 \%$ superando largamente el margen bruto del sector (ver figura $\mathrm{N}^{\circ}$ 97). 


\begin{tabular}{ccccccc}
\hline \multicolumn{2}{c}{$\begin{array}{c}\text { Margen de Utilidad } \\
\text { Neta }\end{array}$} & & Utilidad Neta & Ventas Totales \\
\hline & & & & & \\
\hline $\begin{array}{c}\text { Resultad0 Base } \\
\text { INEI 2007 }\end{array}$ & $\begin{array}{c}\text { Resultado Año 1 } \\
2017\end{array}$ & $\begin{array}{c}\text { Resultado Año 2 } \\
2018\end{array}$ & $\begin{array}{c}\text { Resultado Año 3 } \\
2019\end{array}$ & $\begin{array}{c}\text { Resultado Año 4 } \\
2020\end{array}$ & $\begin{array}{c}\text { Resultado Año 5 } \\
2021\end{array}$ \\
\hline 26.90 & -35.73 & 10.73 & 21.09 & 27.93 & 31.56 \\
\hline
\end{tabular}

Figura 98. Margen de Utilidad Neta.

Este indicador mide que porcentaje quedara de utiliza neta después de pagar los gastos de la operación y los impuestos, dando en consecuencia para el primer una pérdida de $35.73 \%$ en las utilidades, esto dado a que en el primera año de funcionamiento los gastos, publicidad e inversión inicial fueron bastante altas y agresivas debido a la campaña de difusión de los beneficios del producto, pero se puede observar que en el segundo año queda un $10.73 \%$ de utilidad neta, en el tercer año $21.09 \%$, el cuarto año $27.93 \%$, para llegar a un quinto año con un $31.56 \%$ de margen de utilidad neta, no obstante podemos observar que a pesar de los buenos resultados el sector nos pide un $27 \%$ de margen de utilidad neta siendo este mejoraro a partir del tercer año, pero como se puede apreciar al quinto año se puede decir que estamos dentro del parámetro esperado de margen de utilidad neta (ver figura $\mathrm{N}^{\circ}$ 98).

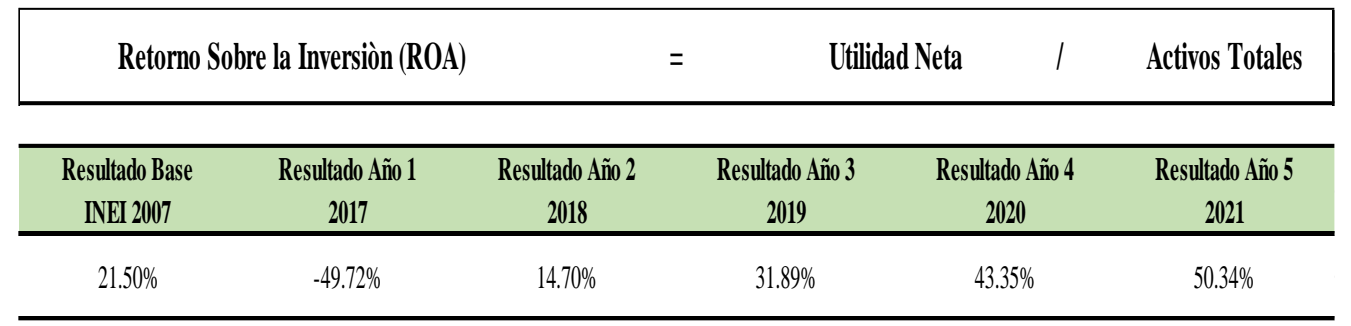

Figura 99. Retorno Sobre la Inversión

Este indicador nos muestra el retorno de la inversión por cada utilidad neta lograda y como se puede apreciar en la figura $\mathrm{N}^{\circ} 99$ el primer año este retorno es negativo en $46.72 \%$, por la ya expuesto anteriormente, que durante el primer año de salida la oferta fue baja y la demanda tenía que ser impulsada 
o alentada a través de publicidad y otras gestiones, para el segundo año este se revirtió siendo un $14.70 \%$ el retorno, para el tercer año creció a un $31.89 \%$, en cuarto año un $43.35 \%$, para terminar en el quinto año un retorno de $50.34 \%$ por cada sol del activo total, superando a partir del tercer año el ratio base del sector (manufactura), para llegar al quinto año por encima del ciento por encima del ratio base.

\subsection{Análisis de Riesgo}

\subsubsection{Análisis de punto de equilibrio}

El punto de equilibrio es aquel nivel de ventas que iguala el total de los costos, tanto variables como fijos. Por lo tanto, en este nivel de ventas, no existe ganancia ni pérdida (ver figura $\mathrm{N}^{\circ} 100$ ).

$$
\text { P.E. }=\frac{\text { Costos Fijos Totales }}{\text { Mg. de Contribución Ponderado }}
$$

Figura 100. Formula de Punto de Equilibrio

Tabla 129

Punto de Equilibrio

\begin{tabular}{crrrrr} 
& $\mathbf{2 0 1 7}$ & $\mathbf{2 0 1 8}$ & $\mathbf{2 0 1 9}$ & \multicolumn{1}{c}{$\mathbf{2 0 2 0}$} & \multicolumn{1}{c}{$\mathbf{2 0 2 1}$} \\
\hline Margen de Contribucion & 196,431 & 461,236 & 638,316 & 826,629 & $1,020,262$ \\
Mg Contribucion (\%ventas) & $71.8 \%$ & $70.9 \%$ & $64.7 \%$ & $62.2 \%$ & $60.8 \%$ \\
Mg Contribucion unitario & $\mathbf{5 . 7 4}$ & $\mathbf{5 . 6 7}$ & $\mathbf{5 . 1 8}$ & $\mathbf{4 . 9 8}$ & $\mathbf{4 . 8 7}$ \\
Costos Fijos mas Intereses & 299,988 & 382,286 & 416,037 & 436,252 & 464,157 \\
\hline Punto de Equilibrio (unidades) & $\mathbf{5 2 , 2 5 7}$ & $\mathbf{6 7 , 4 3 6}$ & $\mathbf{8 0 , 3 7 0}$ & $\mathbf{8 7 , 6 4 6}$ & $\mathbf{9 5 , 3 7 7}$
\end{tabular}

En la tabla $\mathrm{N}^{\circ} 129$ se visualiza en el cuadro las cantidades anuales en kilos que se necesita para cubrir los costos fijos. 


\subsubsection{Análisis de sensibilidad}

El presente proyecto tendrá dos tipos de análisis de sensibilidad, un análisis de sensibilidad con respecto al precio del insumo principal (la papa), para el cual se utilizará el método de Montecarlo, y el otro análisis de sensibilidad que realizará del precio del producto; todos ellos mostrarán el grado de riesgo que podría representar la inversión.

\section{Análisis de sensibilidad del precio del producto}

\section{Unidimensional}

Se analizará tanto las variables de ventas y precio del producto, donde se identificará que aun siendo distintas el VAN tiende a aumentar o disminuir según el sentido a donde se dirija ambas variables (ver tabla $\mathrm{N}^{\circ} 130$ ).

Se puede concluir que si el precio baja en un $20 \%$ se logrará obtener un VAN negativo.

En cambio, si el precio sube en un $20 \%$ resultará un VAN positivo y favorable para la empresa.

Tabla 130

Análisis de Sensibilidad por Variables - VANE

Analisis de sensibilidad por variables (Valores absolutos) VANE

\begin{tabular}{ccccc}
\hline Factor & Ventas(und) & Precio & Costos variables & Costos fijos \\
\hline 1.3 & $1,003,583$ & $1,258,003$ & 197,948 & 139,617 \\
1.2 & 817,500 & 983,054 & 276,351 & 237,464 \\
1.1 & 628,125 & 708,106 & 354,754 & 335,310 \\
1.0 & 433,157 & 433,157 & 433,157 & 433,157 \\
0.9 & 227,458 & 158,209 & 511,560 & 531,004 \\
0.8 & $-3,154$ & $-116,740$ & 589,963 & 628,851 \\
0.7 & $-317,478$ & $-391,688$ & 668,366 & 726,698 \\
\hline
\end{tabular}


En el caso de las ventas versus el TIRE del proyecto, concluimos que si las ventas descienden en un $30 \%$ resultaría una tasa de retorno positiva.

En el caso de incrementarse las ventas en un $30 \%$ resulta un TIRE muy positivo para la empresa (ver tabla $\mathrm{N}^{\mathrm{o}} 131$ ).

Tabla 131

Análisis de Sensibilidad por Variables -TIRE

Analisis de sensibilidad por variables (Valores absolutos) TIRE

\begin{tabular}{ccccc}
\hline Factor & Ventas (und) & Precio & Costos variables & Costos fijos \\
\hline 1.3 & 59 & 76 & 20 & 18 \\
1.2 & 49 & 58 & 23 & 22 \\
1.1 & 39 & 42 & 26 & 26 \\
1.0 & 29 & 29 & 29 & 29 \\
0.9 & 21 & 18 & 33 & 34 \\
0.8 & 13 & 9 & 36 & 38 \\
0.7 & 6 & 1 & 39 & 42 \\
\hline
\end{tabular}

En la tabla $\mathrm{N}^{\mathrm{a}} 132$ se mostrará los escenarios identificados al tener una variación en los elementos de sensibilidad:

Tabla 132

Escenarios

\begin{tabular}{lcc}
\hline \multicolumn{1}{c}{ Escenario } & VANE & TIRE \\
\hline Optimista & $1,258,003$ & 76 \\
Base & 433,157 & 29 \\
Pesimista & $-391,688$ & 1 \\
\hline
\end{tabular}

\section{Análisis de Sensibilidad utilizando el método Montecarlo}

Siendo la papa el insumo principal se realizará el análisis de sensibilidad utilizando el método Montecarlo.

Método Montecarlo según lo indicado por Madrid Org. en su artículo Análisis de Riesgo_Gestión de Riesgos, Análisis y Cuantificación; el mismo 
es un mecanismo que permite poner en práctica el método cuantitativo para el análisis de riesgo del proyecto.

Este método se aplicará para poder medir la probabilidad de ocurrencia del riesgo y el impacto que el mismo tendría, este impacto se mide con el beneficio obtenido del VAN.

Considerando 100 pruebas aleatorias se obtiene un VAN entre 328,272 a 344,502 para una variación en el precio, considerando que este resulte menor al precio de insumo considerado para el presente proyecto, como se puede observar en las tablas $\mathrm{N}^{\mathrm{a}} 133,134,135,136,137$ y 138.

Tabla 133

Prueba $N^{o} 01$

VANE del Plan S/. $433,157.25$

VANE Estimado S/. $328,272.95$

Tabla 134

Prueba $N^{o} 02$

VANE del Plan S/. 433,157.25

VANE Estimado S/. $330,037.06$

Tabla 135

Prueba $N^{o} 03$

VANE del Plan S/. $433,157.25$

VANE Estimado S/. $333,915.55$ 
Tabla 136

Prueba $N^{\circ} 04$

\begin{tabular}{lrr}
\hline VANE del Plan & S/. & $433,157.25$ \\
VANE Estimado & S/. & $333,915.55$ \\
\hline
\end{tabular}

Tabla 137

Prueba $N^{\circ} 05$

\begin{tabular}{lll}
\hline VANE del Plan & S/. & $433,157.25$ \\
VANE Estimado & S/. & $342,986.31$ \\
\hline
\end{tabular}

Tabla 138

Prueba $N^{\circ} 06$

\begin{tabular}{lrr}
\hline VANE del Plan & S/. & $433,157.25$ \\
VANE Estimado & S/. & $344,502.81$ \\
\hline
\end{tabular}

Con lo que se puede concluir que por un costo bajo de insumo se logra obtener un VAN positivo en cualquiera de las situaciones.

\subsubsection{Análisis de escenarios}

El análisis de escenario gira alrededor de identificar como cambia el estudio financiero realizado, cambiando 3 variables claves en la investigación, que han sido determinantes para identificar la viabilidad y rentabilidad proyectada del negocio de la papa dializada.

Estas variables que serán modificadas están identificadas como variables de entrada las que de acuerdo a la línea de estudio realizado se reflejarán como resultados de salida los que nos darán una apreciación de cómo afectará en el proyecto si estos escenarios se dan en el futuro. 
1. Variables de Entrada

Las variables de entrada que se han considerado como más relevantes para este análisis son tres:

a. Costos variables y costos fijos, existe alguna creencia que el volumen de ventas determina el aumento o disminución de utilidades para la empresa, es una visión incorrecta porque la rentabilidad que se puede obtener en el negocio se va a dar por un correcto control de los costos variables y fijos.

b. Precio de venta, es un instrumento competitivo muy poderoso, porque de acuerdo a esta variable, si se le asigna un correcto valor, se llegará a ser competitivo en el mercado y darles a los clientes la posibilidad de adquirir el producto.

c. El volumen de ventas en kilos, la capacidad de producción del producto se ha dado con base a atender un porcentaje del segmento de mercado al cual el producto se dirige, el escenario pesimista de nuestra producción en volumen se puede dar por diferentes factores que pueden incidir en el aprovisionamiento de nuestra materia prima que es la papa, en el otro lado, el escenario optimista de nuestra producción se da por la agresividad que pudiera tener la empresa para ingresar al mercado.

2. Variables de Salida

Las variables de salida son parámetros de sensibilidad que se van a afectar ante cualquier cambio en las variables de entrada anteriormente mencionadas. 
Por esta razón se ha considerado importante evaluar la sensibilidad del Valor Actual Neto Económico (VANE) y la Tasa Interna de Retorno Económico (TIRE).

\section{Escenario Base}

El escenario base del proyecto son los datos obtenidos del estudio realizado como se observa en la tabla No 139 y 140.

Tabla 139

Costos Variables

\begin{tabular}{crrrrrr}
\hline & \multicolumn{1}{c}{2017} & \multicolumn{1}{c}{2018} & \multicolumn{1}{c}{2019} & \multicolumn{1}{c}{2020} & \multicolumn{1}{c}{2021} & \multicolumn{1}{c}{ Total } \\
\hline Materia Prima & 70,246 & 166,550 & 275,357 & 370,858 & 468,158 & $1,351,169$ \\
C.I.F. (MI + 0TROS CIF) & 7,065 & 23,116 & 72,800 & 131,121 & 188,766 & 422,869 \\
\hline Total C.V. & $\mathbf{7 7 , 3 1 1}$ & 189,666 & 348,157 & $\mathbf{5 0 1 , 9 7 9}$ & $\mathbf{6 5 6 , 9 2 4}$ & $1,774,038$ \\
\hline
\end{tabular}

Nota. Elaboración propia

Tabla 140

Costos Fijos

\begin{tabular}{crrrrrr}
\hline & \multicolumn{1}{c}{2017} & \multicolumn{1}{c}{2018} & \multicolumn{1}{c}{2019} & \multicolumn{1}{c}{2020} & \multicolumn{1}{c}{ 2021 } & \multicolumn{1}{c}{ Total } \\
\hline M.0.D & 50,184 & 50,184 & 50,184 & 50,184 & 50,184 & $\mathbf{2 5 0 , 9 2 0}$ \\
C.I.F. (0TR0S CIF) & 69,224 & 78,118 & 80,246 & 82,482 & 80,691 & $\mathbf{3 9 0 , 7 6 1}$ \\
M.0.I. & 25,092 & 39,852 & 39,852 & 39,852 & 39,852 & 184,500 \\
Gtos. Administrativos & 37,872 & 51,574 & 52,012 & 52,472 & 52,956 & $\mathbf{2 4 6 , 8 8 6}$ \\
Gtos. De Ventas & 103,101 & 150,535 & 184,567 & 205,338 & 240,474 & $\mathbf{8 8 4 , 0 1 5}$ \\
\hline Total C.F. & $\mathbf{2 8 5 , 4 7 3}$ & $\mathbf{3 7 0 , 2 6 2}$ & $\mathbf{4 0 6 , 8 6 1}$ & $\mathbf{4 3 0 , 3 2 8}$ & $\mathbf{4 6 4 , 1 5 7}$ & $\mathbf{1 , 9 5 7 , 0 8 2}$ \\
\hline
\end{tabular}

Nota. Elaboración propia

El precio determinado para la venta es de S/. 8.00

El volumen de ventas es 45,003.95 
Resultados del Escenario Base

Estado de resultados (ver tabla $\mathrm{N}^{\circ} 141$ ) y sus indicadores financieros (ver tabla $\mathrm{N}^{\circ} 142$ ).

Tabla 141

Estado de Resultados por Año

\begin{tabular}{|c|c|c|c|c|c|c|c|c|c|c|}
\hline ESTADO DE RESULTADOS & 2017 & $\%$ & 2018 & $\%$ & 2019 & $\%$ & 2020 & $\%$ & 2021 & $\%$ \\
\hline Ventas & 273,742 & & 650,903 & & 986,473 & & $1,328,608$ & & $1,677,186$ & \\
\hline Costos de Ventas & 216,052 & $79 \%$ & 341,054 & $52 \%$ & 455,779 & $46 \%$ & 556,544 & $42 \%$ & 656,389 & $39 \%$ \\
\hline Utilidad Bruta & 57,691 & $21 \%$ & 309,849 & $48 \%$ & 530,694 & $54 \%$ & 772,064 & $58 \%$ & $1,020,797$ & $61 \%$ \\
\hline Gastos Administrativos & 37,872 & $14 \%$ & 51,574 & $8 \%$ & 52,012 & $5 \%$ & 52,472 & $4 \%$ & 52,956 & $3 \%$ \\
\hline Gastos Ventas & 103,101 & $38 \%$ & 150,535 & $23 \%$ & 184,567 & $19 \%$ & 205,338 & $15 \%$ & 240,474 & $14 \%$ \\
\hline Utilidad Operativa & $-83,282$ & $-30 \%$ & 107,740 & $17 \%$ & 294,115 & $30 \%$ & 514,254 & $39 \%$ & 727,367 & $43 \%$ \\
\hline Gastos Financieros & 14,515 & $5 \%$ & 12,023 & $2 \%$ & 9,176 & $1 \%$ & 5,923 & $0 \%$ & 2,206 & $0 \%$ \\
\hline Utilidad Antes de Impuestos & $-97,797$ & $-36 \%$ & 95,717 & $15 \%$ & 284,939 & $29 \%$ & 508,330 & $38 \%$ & 725,161 & $43 \%$ \\
\hline Impuesto a la Renta (27\%) & 0 & & 25,844 & $4 \%$ & 76,934 & $8 \%$ & 137,249 & $10 \%$ & 195,793 & $12 \%$ \\
\hline UTILIDAD NETA & $-97,797$ & $-36 \%$ & 69,874 & $11 \%$ & 208,005 & $21 \%$ & 371,081 & $28 \%$ & 529,367 & $32 \%$ \\
\hline
\end{tabular}

Nota. Elaboración propia

Tabla 142

Indicadores Financieros VANE - TIRE

\begin{tabular}{llll}
\hline & VANE & \multicolumn{2}{c}{ TIRE } \\
\hline DATOS & VALOR & DATOS & VALOR \\
WACC & $\mathbf{1 2 . 9 3 \%}$ & WACC & $\mathbf{1 2 . 9 3 \%}$ \\
VANE & S $/ . \mathbf{4 3 3 , 1 5 7}$ & TIRE & $\mathbf{2 9 \%}$
\end{tabular}

Nota. Elaboración propia 


\section{Escenario Pesimista}

Para el escenario pesimista el estudio se ubica dentro de dos posibilidades

1. Devaluación, en el último año, la moneda nacional se ha visto en una desventaja con respecto al dólar, su devaluación ha crecido de manera progresiva debido a una mejora económica en el sistema americano, debido a este factor es que se toma como posibilidad que pueda afectar este problema en el negocio (ver tabla $\mathrm{N}^{\mathrm{o}} 143$ ) y sus indicadores financieros (ver tabla $\mathrm{N}^{\mathrm{o}} 144$ ).

Características:

a. Por parte de la empresa ocurrirá una caída de las unidades vendidas en un $5 \%$.

b. Los costos variables aumentarán en un $10 \%$, por una subida en los precios de nuestra materia prima

c. El precio final aumentará en un $8 \%$. 


\section{Devaluación}

Tabla 143

Estado de Pérdidas y Ganancias - Devaluación

\begin{tabular}{|c|c|c|c|c|c|c|c|c|c|c|}
\hline ESTAD0 DE RESULTADOS & 2017 & $\%$ & 2018 & $\%$ & 2019 & $\%$ & 2020 & $\%$ & 2021 & $\%$ \\
\hline Ventas & 261,028 & & 668,362 & & $1,030,778$ & & $1,400,283$ & & $1,776,748$ & \\
\hline Costos de Ventas & 216,052 & $83 \%$ & 341,054 & $51 \%$ & 455,779 & $44 \%$ & 556,544 & $40 \%$ & 656,389 & $37 \%$ \\
\hline Utilidad Bruta & 44,977 & $17 \%$ & 327,308 & $49 \%$ & 574,998 & $56 \%$ & 843,740 & $60 \%$ & $1,120,359$ & $63 \%$ \\
\hline Gastos Administrativos & 37,872 & $15 \%$ & 51,574 & $8 \%$ & 52,012 & $5 \%$ & 52,472 & $4 \%$ & 52,956 & $3 \%$ \\
\hline Gastos Ventas & 102,788 & $39 \%$ & 150,965 & $23 \%$ & 185,657 & $18 \%$ & 207,101 & $15 \%$ & 242,923 & $14 \%$ \\
\hline Utilidad Operativa & $-95,683$ & $-37 \%$ & 124,770 & $19 \%$ & 337,330 & $33 \%$ & 584,166 & $42 \%$ & 824,480 & $46 \%$ \\
\hline Gastos Financieros & 13,725 & $5 \%$ & 11,369 & $2 \%$ & 8,677 & $1 \%$ & 5,601 & $0 \%$ & 2,086 & $0 \%$ \\
\hline Utilidad Antes de Impuestos & $-109,408$ & $-42 \%$ & 113,401 & $17 \%$ & 328,653 & $32 \%$ & 578,565 & $41 \%$ & 822,393 & $46 \%$ \\
\hline Impuesto a la Renta (27\%) & 0 & & 30,618 & $5 \%$ & 88,736 & $9 \%$ & 156,213 & $11 \%$ & 222,046 & $12 \%$ \\
\hline UTILIDAD NETA & $-109,408$ & $-42 \%$ & 82,783 & $12 \%$ & 239,917 & $23 \%$ & 422,352 & $30 \%$ & 600,347 & $34 \%$ \\
\hline
\end{tabular}

Nota. Elaboración propia

Tabla 144

Indicadores Financieros VAN y TIRE - Devaluación

\begin{tabular}{llll}
\hline & VANE & & \multicolumn{2}{c}{ TIRE } \\
\hline DATOS & VALOR & DATOS & VALOR \\
WACC & $\mathbf{1 2 . 9 3 \%}$ & WACC & $\mathbf{1 2 . 9 3 \%}$ \\
VANE & S/.469,546 & TIRE & $\mathbf{3 1 \%}$ \\
Nota. Elaboración propia & & &
\end{tabular}




\section{Escenario Optimista}

Para el escenario optimista el negocio se presenta en una posición de crecimiento y expansión del mercado por un buen manejo en la propuesta de marketing (ver tabla $\mathrm{N}^{\circ} 145$ ) y sus indicadores financieros (ver tabla $\mathrm{N}^{\circ} 146$ )

Características:

1. Aumento de las ventas en un $5 \%$.

2. El precio final al consumidor aumenta en un $3 \%$

3. Reducción de los costos variables en un $2 \%$ de las ventas por mayor productividad 


\section{Crecimiento y Expansión del mercado}

Tabla 145

Estado de Pérdidas y Ganancias - Crecimiento y Expansión

\begin{tabular}{|c|c|c|c|c|c|c|c|c|c|c|}
\hline ESTADO DE RESULTADOS & 2017 & $\%$ & 2018 & $\%$ & 2019 & $\%$ & 2020 & $\%$ & 2021 & $\%$ \\
\hline Ventas & 314,965 & & 703,441 & & $1,049,078$ & & $1,401,477$ & & $1,760,513$ & \\
\hline Costos de Ventas & 216,052 & $69 \%$ & 341,054 & $48 \%$ & 455,779 & $43 \%$ & 556,544 & $40 \%$ & 656,389 & $37 \%$ \\
\hline Utilidad Bruta & 98,914 & $31 \%$ & 362,387 & $52 \%$ & 593,299 & $57 \%$ & 844,933 & $60 \%$ & $1,104,124$ & $63 \%$ \\
\hline Gastos Administrativos & 37,872 & $12 \%$ & 51,574 & $7 \%$ & 52,012 & $5 \%$ & 52,472 & $4 \%$ & 52,956 & $3 \%$ \\
\hline Gastos Ventas & 104,115 & $33 \%$ & 151,828 & $22 \%$ & 186,107 & $18 \%$ & 207,131 & $15 \%$ & 242,524 & $14 \%$ \\
\hline Utilidad Operativa & $-43,073$ & $-14 \%$ & 158,986 & $23 \%$ & 355,180 & $34 \%$ & 585,330 & $42 \%$ & 808,644 & $46 \%$ \\
\hline Gastos Financieros & 14,219 & $5 \%$ & 11,778 & $2 \%$ & 8,989 & $1 \%$ & 5,802 & $0 \%$ & 2,161 & $0 \%$ \\
\hline Utilidad Antes de Impuestos & $-57,292$ & $-18 \%$ & 147,208 & $21 \%$ & 346,191 & $33 \%$ & 579,528 & $41 \%$ & 806,482 & $46 \%$ \\
\hline Impuesto a la Renta (27\%) & 0 & & 39,746 & $6 \%$ & 93,472 & $9 \%$ & 156,473 & $11 \%$ & 217,750 & $12 \%$ \\
\hline UTILIDAD NETA & $-57,292$ & $-18 \%$ & 107,462 & $15 \%$ & 252,719 & $24 \%$ & 423,055 & $30 \%$ & 588,732 & $33 \%$ \\
\hline
\end{tabular}

Nota. Elaboración propia

Tabla 146

Indicadores Financieros VAN y TIR - Crecimiento y Expansión

\begin{tabular}{lllc}
\hline & VanF & & TirF \\
\hline DATOS & VALOR & DATOS & VALOR \\
WACC & $\mathbf{1 2 . 9 3 \%}$ & WACC & $\mathbf{1 2 . 9 3 \%}$ \\
VANE & S/.479,721 & TIRE & $\mathbf{3 9 \%}$
\end{tabular}

En los escenarios analizados podemos identificar que tanto en el contexto pesimista y optimista, la empresa mantiene una rentabilidad, adicionalmente considerando los tres escenarios, base, optimista y pesimista, el VANE se mantiene positivo, esto nos lleva a la conclusión que el proyecto no presenta riesgo en su inversión. 


\subsubsection{Gestión de Riesgos}

A fin de que los resgos inherentes al plan de negocio presentado no afecten el desarrollo operativo y financiero del mismo se ha elaborado el plan de gestión de riesgos en cual veremos los Roles y Responsabiliades en la gestión, la evaluación cualitativa y el plan de respuesta frente a los riesgos.

\section{Roles y Responsabilidades}

A continuación se presenta los roles y responsabilidades que asignaran a cada una de las estapas de la gestión de riesgos, con ello se asgura el correcto desempeño para la elaboración del plan, ver tabla $\mathrm{N}^{\circ} 147$.

Tabla 147

Gestiòn de Riesgos - Roles y Responsabilidades

\begin{tabular}{|c|c|c|c|}
\hline Procesos & Roles & Cargos & Responsabilidades \\
\hline \multirow{3}{*}{ Planificaciòn } & Lider & $A D$ & Dirigir la Actividad, Responable Directo \\
\hline & Apoyo & $\mathrm{JP}, \mathrm{JC}$ & Proveer Definiciones \\
\hline & Miembros & $\mathrm{OP}, \mathrm{OA}, \mathrm{CC}, \mathrm{EC}$ & Ejecutar \\
\hline \multirow{3}{*}{ Identificaciòn } & Lider & $A D$ & Dirigir la Actividad, Responable Directo \\
\hline & Apoyo & $J P, J C$ & Proveer Definiciones \\
\hline & Miembros & $\mathrm{OP}, \mathrm{OA}, \mathrm{CC}, \mathrm{EC}$ & Ejecutar \\
\hline \multirow{3}{*}{$\begin{array}{c}\text { Analisis } \\
\text { Cualitativo }\end{array}$} & Lider & JP & Dirigir la Actividad, Responable Directo \\
\hline & Apoyo & $A D, C C, J C$ & Proveer Definiciones \\
\hline & Miembros & $\mathrm{OP}, \mathrm{OA}, \mathrm{EC}$ & Ejecutar \\
\hline \multirow{3}{*}{$\begin{array}{c}\text { Analisis } \\
\text { Cuantitativo }\end{array}$} & Lider & JP & Dirigir la Actividad, Responable Directo \\
\hline & Apoyo & $A D, C C, J C$ & Proveer Definiciones \\
\hline & Miembros & $\mathrm{OP}, \mathrm{OA}, \mathrm{EC}, \mathrm{CC}$ & Ejecutar \\
\hline \multirow{3}{*}{$\begin{array}{l}\text { Planificaciòn } \\
\text { de Respuestas }\end{array}$} & Lider & $A D$ & Dirigir la Actividad, Responable Directo \\
\hline & Apoyo & $J P, J C$ & Proveer Definiciones \\
\hline & Miembros & $\mathrm{OP}, \mathrm{OA}, \mathrm{CC}, \mathrm{EC}$ & Ejecutar \\
\hline \multirow{3}{*}{$\begin{array}{l}\text { Seguimiento } \\
\text { y Control }\end{array}$} & Lider & $A D$ & Dirigir la Actividad, Responable Directo \\
\hline & Apoyo & $J P, J C$ & Proveer Definiciones \\
\hline & Miembros & $\mathrm{OP}, \mathrm{OA}, \mathrm{CC}, \mathrm{EC}$ & Ejecutar \\
\hline
\end{tabular}

Nota: Elaboración Propia

Leyenda:
AD Administrador
JP Jefe de Producciòn
JC Jefe Comercial
OP Operario de Producciòn
OA Operario de Almacen
CC Control de Calidad
EC Ejecutivo Comercial 


\section{Evaluaciòn Cualitativa}

Para lograr una adecua identificación y determinación de los riesgos existentes en el plan de negocio presentado. se realizara la evaluación cualitativa de cada uno de ello y su afectación en alguna de la cuatro restricción (Costo, Tiempo, Alcance

y Calidad) siendo estos expuestos en las tablas $N^{\circ} 148$ y 149, la cual se puede ver continuación :

Tabla 148

Gestiòn de Riesgos - Evaluaciòn Cualitativa 1

\begin{tabular}{|c|c|c|c|c|c|c|c|c|c|}
\hline Código & Descripción & Causa Raíz & Disparador & Afecta a & $\begin{array}{r}\text { Objetivo } \\
\text { Afectado }\end{array}$ & $\begin{array}{c}\text { Estimación de } \\
\text { Probabilidad }\end{array}$ & $\begin{array}{l}\text { Estimación de } \\
\text { Impacto }\end{array}$ & $\begin{array}{l}\text { Probabilidad } \mathrm{x} \\
\text { Impacto }\end{array}$ & Tipo de Riesgo \\
\hline \multirow{5}{*}{ R001 } & \multirow{5}{*}{$\begin{array}{l}\text { Aumento de Poder } \\
\text { Adquisitivo de los } \\
\text { Consumidores }\end{array}$} & \multirow{5}{*}{$\begin{array}{c}\text { Auje } \\
\text { económico del } \\
\text { País }\end{array}$} & \multirow{5}{*}{$\begin{array}{c}\text { Mayor } \\
\text { demanda } \\
\text { de Nuestro } \\
\text { Productos }\end{array}$} & \multirow{5}{*}{$\begin{array}{l}\text { Producción y } \\
\text { Comercial }\end{array}$} & Alcance & & & 0.00 & \multirow{5}{*}{ Moderado } \\
\hline & & & & & Tiempo & & & 0.00 & \\
\hline & & & & & Costo & 0.30 & 0.50 & 0.15 & \\
\hline & & & & & Calidad & & & 0.00 & \\
\hline & & & & & & Total & & 0.15 & \\
\hline \multirow{5}{*}{ R002 } & \multirow{5}{*}{$\begin{array}{l}\text { Aumento de la necesidad } \\
\text { por parte de los } \\
\text { Consumidores de adquirir } \\
\text { productos saludables }\end{array}$} & \multirow{5}{*}{ Estilo de Vida } & \multirow{5}{*}{$\begin{array}{l}\text { Mejora de } \\
\text { Control de } \\
\text { Calidad }\end{array}$} & \multirow{5}{*}{$\begin{array}{l}\text { Control de Calidad } \\
\text { y Comercial }\end{array}$} & Alcance & & & 0.00 & \multirow{5}{*}{ Alto } \\
\hline & & & & & Tiempo & 0.50 & 0.10 & 0.05 & \\
\hline & & & & & Costo & 0.30 & 0.30 & 0.09 & \\
\hline & & & & & Calidad & 0.50 & 0.50 & 0.25 & \\
\hline & & & & & & Total & & 0.39 & \\
\hline \multirow{5}{*}{ R003 } & \multirow{5}{*}{$\begin{array}{c}\text { Nuevos } \\
\text { Competidores }\end{array}$} & \multirow{5}{*}{ Libre Mercado } & \multirow{5}{*}{$\begin{array}{l}\text { Menor } \\
\text { Volumen de } \\
\text { Ventas }\end{array}$} & \multirow{5}{*}{$\begin{array}{l}\text { Producción y } \\
\text { Comercial }\end{array}$} & Alcance & & & 0.00 & \multirow{5}{*}{ Alto } \\
\hline & & & & & Tiempo & & & 0.00 & \\
\hline & & & & & Costo & 0.90 & 0.40 & 0.36 & \\
\hline & & & & & Calidad & & & 0.00 & \\
\hline & & & & & & Total & & 0.36 & \\
\hline \multirow{5}{*}{ R004 } & \multirow{5}{*}{$\begin{array}{l}\text { Proceso Alternativo } \\
\text { (Casero) }\end{array}$} & \multirow{5}{*}{ Economía } & \multirow{5}{*}{ Marketing } & \multirow{5}{*}{ Comercial } & Alcance & & & 0.00 & \multirow{5}{*}{ Moderado } \\
\hline & & & & & Tiempo & 0.50 & 0.20 & 0.10 & \\
\hline & & & & & Costo & 0.50 & 0.40 & 0.20 & \\
\hline & & & & & Calidad & & & 0.00 & \\
\hline & & & & & & Total & & 0.3 & \\
\hline \multirow{5}{*}{ R005 } & \multirow{5}{*}{$\begin{array}{l}\text { Problemas en el } \\
\text { Funcionamiento de la } \\
\text { Maquina Dializadora }\end{array}$} & \multirow{5}{*}{$\begin{array}{c}\text { Falta de } \\
\text { Contingencias }\end{array}$} & \multirow{5}{*}{$\begin{array}{c}\text { Baja } \\
\text { Producción }\end{array}$} & \multirow{5}{*}{$\begin{array}{l}\text { Producción y } \\
\text { Comercial }\end{array}$} & Alcance & & & 0.00 & \multirow{5}{*}{ Muy Alto } \\
\hline & & & & & Tiempo & 0.30 & 0.20 & 0.06 & \\
\hline & & & & & Costo & 0.50 & 0.40 & 0.20 & \\
\hline & & & & & Calidad & 0.70 & 0.80 & 0.56 & \\
\hline & & & & & & Total & & 0.82 & \\
\hline
\end{tabular}


Tabla 149

Gestiòn de Riesgos - Evaluaciòn Cualitativa 2

\begin{tabular}{|c|c|c|c|c|c|c|c|c|c|}
\hline Código & Descripción & Causa Raíz & Disparador & Afecta a & $\begin{array}{l}\text { Objetivo } \\
\text { Afectado }\end{array}$ & $\begin{array}{l}\text { Estimación de } \\
\text { Probabilidad }\end{array}$ & $\begin{array}{l}\text { Estimación de } \\
\text { Impacto }\end{array}$ & $\begin{array}{l}\text { Probabilidad } \mathrm{x} \\
\text { Impacto }\end{array}$ & Tipo de Riesgo \\
\hline \multirow{5}{*}{ R006 } & \multirow{5}{*}{$\begin{array}{l}\text { Falta de Difusión del } \\
\text { Proceso de Idealización }\end{array}$} & \multirow{5}{*}{$\begin{array}{l}\text { Poco } \\
\text { Publicidad }\end{array}$} & \multirow{5}{*}{$\begin{array}{l}\text { Menor } \\
\text { Volumen de } \\
\text { Ventas }\end{array}$} & \multirow{5}{*}{ Comercial } & Alcance & & & 0.00 & \multirow{5}{*}{ Alto } \\
\hline & & & & & Tiempo & 0.50 & 0.20 & 0.10 & \\
\hline & & & & & Costo & 0.70 & 0.40 & 0.28 & \\
\hline & & & & & Calidad & & & 0.00 & \\
\hline & & & & & & Total & & 0.38 & \\
\hline \multirow{5}{*}{ R007 } & \multirow{5}{*}{$\begin{array}{c}\text { Aumento en } \\
\text { los Impuesto de Renta }\end{array}$} & \multirow{5}{*}{$\begin{array}{l}\text { Mayores } \\
\text { Ingresos }\end{array}$} & \multirow{5}{*}{$\begin{array}{l}\text { Aumento de } \\
\text { las Ventas }\end{array}$} & \multirow{5}{*}{$\begin{array}{l}\text { Producción y } \\
\text { Comercial }\end{array}$} & Alcance & & & 0.00 & \multirow{5}{*}{ Moderado } \\
\hline & & & & & Tiempo & & & 0.00 & \\
\hline & & & & & Costo & 0.70 & 0.20 & 0.14 & \\
\hline & & & & & Calidad & & & 0.00 & \\
\hline & & & & & & Total & & 0.14 & \\
\hline \multirow{5}{*}{ R008 } & \multirow{5}{*}{$\begin{array}{l}\text { Disminución de } \\
\text { Impuestos }\end{array}$} & \multirow{5}{*}{$\begin{array}{l}\text { Políticas de } \\
\text { Gobernó }\end{array}$} & \multirow{5}{*}{$\begin{array}{l}\text { Aumento de } \\
\text { los Ingresos }\end{array}$} & \multirow{5}{*}{$\begin{array}{l}\text { Producción, } \\
\text { Comercial y } \\
\text { Control de Calidad }\end{array}$} & Alcance & & & 0.00 & \multirow{5}{*}{ Muy Alto } \\
\hline & & & & & Tiempo & & & 0.00 & \\
\hline & & & & & Costo & 0.50 & 0.20 & 0.10 & \\
\hline & & & & & Calidad & 0.30 & 2.00 & 0.60 & \\
\hline & & & & & & Total & & 0.7 & \\
\hline \multirow{5}{*}{ R009 } & \multirow{5}{*}{$\begin{array}{c}\text { Preferencia por } \\
\text { Productos Sustitutos }\end{array}$} & \multirow{5}{*}{$\begin{array}{l}\text { Poco } \\
\text { Publicidad }\end{array}$} & \multirow{5}{*}{$\begin{array}{l}\text { Menor } \\
\text { Volumen de } \\
\text { Ventas }\end{array}$} & \multirow{5}{*}{ Comercial } & Alcance & & & 0.00 & \multirow{5}{*}{ Moderado } \\
\hline & & & & & Tiempo & & & 0.00 & \\
\hline & & & & & Costo & 0.70 & 0.40 & 0.28 & \\
\hline & & & & & Calidad & & & 0.00 & \\
\hline & & & & & & Total & & 0.28 & \\
\hline \multirow{5}{*}{ R010 } & \multirow{5}{*}{$\begin{array}{l}\text { Apertura de Nuevas } \\
\text { Ferias Alimentarias }\end{array}$} & \multirow{5}{*}{$\begin{array}{c}\text { Mejora del } \\
\text { Estilo de Vida }\end{array}$} & \multirow{5}{*}{$\begin{array}{l}\text { Mayor } \\
\text { Difusión del } \\
\text { Producto }\end{array}$} & \multirow{5}{*}{$\begin{array}{l}\text { Producción y } \\
\text { Comercial }\end{array}$} & Alcance & & & 0.00 & \multirow{5}{*}{ Moderado } \\
\hline & & & & & Tiempo & 0.50 & 0.20 & 0.10 & \\
\hline & & & & & Costo & 0.50 & 0.40 & 0.20 & \\
\hline & & & & & Calidad & & & 0.00 & \\
\hline & & & & & & Total & & 0.3 & \\
\hline
\end{tabular}

Nota: Elaboración Propia

\section{CUADROS DE VALORES}

\begin{tabular}{|c|c|c|c|c|c|}
\hline \multirow[b]{2}{*}{ Probabilidad } & \multirow[b]{2}{*}{ Valor } & & \\
\hline & & Impacto & Valor & $\begin{array}{c}\text { Tipo } \\
\text { de Riesgo }\end{array}$ & $\begin{array}{c}\text { Probabilidad } \\
\text { x Impacto }\end{array}$ \\
\hline Muy Improbable & 0.1 & Muy Bajo & 0.05 & Muy Alto & Mayor a 0.50 \\
\hline Relativamente Probable & 0.3 & Bajo & 0.10 & Alto & Menor a 0.50 \\
\hline Probable & 0.5 & Moderado & 0.20 & Moderado & Menor a 0.30 \\
\hline Muy Probable & 0.7 & Alto & 0.40 & Bajo & Menor a 0.10 \\
\hline Verdaderamente Probable & 0.9 & Muy Alto & 0.80 & Muy Bajo & Menor a 0.05 \\
\hline
\end{tabular}




\section{Plan de Respuesta}

Finalmente después de la indentificaciòn y análisis de los riesgos tabulados y calificados en la etapa de evaluación cualitativa, se ha elaborado el plan de respuestas, el cual esta orientado a la gestión adecuada de estos y su manejo, como se puede apreciar en la tablas $\mathrm{N}^{\mathrm{o}} 150$ y 151.

Tabla 150

Gestiòn de Riesgos - Plan de Respuestas

\begin{tabular}{|c|c|c|c|c|c|c|c|c|c|c|c|c|c|}
\hline Código & $\begin{array}{l}\text { Amenaza } \\
\text { Oportunidad }\end{array}$ & Descripción & Causa Ráiz & Disparador & Afecta a & $\begin{array}{l}\text { Probabilidad } \\
\text { de Impacto }\end{array}$ & $\begin{array}{l}\text { Tipode } \\
\text { Riesgo } \\
\text { (1) }\end{array}$ & Responsable & Respuesta & $\begin{array}{l}\text { Tipode } \\
\text { Respuesta } \\
\text { (2) }\end{array}$ & $\begin{array}{c}\text { Responsable } \\
\text { dela } \\
\text { Respuesta }\end{array}$ & Fecha & Plan de Contingencia \\
\hline \multirow[b]{2}{*}{ R005 } & \multirow[b]{2}{*}{ Amenaza } & \multirow{2}{*}{$\begin{array}{l}\text { Problemas en el Funcionamiento de la } \\
\text { Maquina Dializadora }\end{array}$} & \multirow{2}{*}{$\begin{array}{c}\text { Faltade } \\
\text { Contingencias }\end{array}$} & \multirow[b]{2}{*}{ Baja Producción } & \multirow{2}{*}{$\begin{array}{l}\text { Produccióny } \\
\text { Comercial }\end{array}$} & \multirow[b]{2}{*}{0.82} & \multirow[b]{2}{*}{ Muy Alto } & \multirow[b]{2}{*}{$A D$} & $\begin{array}{l}\text { Mejorar el Diseño de la Maquina } \\
\text { Dializadora }\end{array}$ & Mitiga & JP & $\begin{array}{l}\text { Acción } \\
\text { Continua }\end{array}$ & \multirow{2}{*}{$\begin{array}{l}\text { - Utilización de la Garantía } \\
\text { del Fabricante }\end{array}$} \\
\hline & & & & & & & & & $\begin{array}{l}\text { Revisión y Mantenimiento } \\
\text { Periódico de la Maquina } \\
\text { Dializadora }\end{array}$ & Evitar & JP & $\begin{array}{l}\text { Acción } \\
\text { Continua }\end{array}$ & \\
\hline ROOB & Oportunidad & $\begin{array}{l}\text { Disminución de } \\
\text { Impuestos }\end{array}$ & Polliticas de Gobernó & $\begin{array}{l}\text { Aumento de los } \\
\text { Ingresos }\end{array}$ & $\begin{array}{l}\text { Producción, Comercial } \\
\text { y Control de Calidad }\end{array}$ & 0.70 & Muy Alto & $A D$ & $\begin{array}{l}\text { Crear nuevos alternativas de } \\
\text { negocio (diversificación) }\end{array}$ & Explotar & $A D$ & Años Fiscal & $\begin{array}{l}\text { Reinversión en nueva } \\
\text { Maquinariay Equipos }\end{array}$ \\
\hline $\mathrm{ROO2}$ & Amenaza & $\begin{array}{l}\text { Aumento de la necesidad por parte de los } \\
\text { Consumidores de adquirir productos } \\
\text { saludables }\end{array}$ & Estilo de Vida & $\begin{array}{l}\text { Mejora de Control } \\
\text { de Calidad }\end{array}$ & $\begin{array}{l}\text { Control de Calidady } \\
\text { Comercial }\end{array}$ & 0.39 & Alto & $A D$ & $\begin{array}{l}\text { Mantenery Mejorar los } \\
\text { Estándares de la Calidad }\end{array}$ & Evitar & JP & $\begin{array}{l}\text { Acción } \\
\text { Continua }\end{array}$ & $\begin{array}{c}\text { Revalidaciones Periódicas } \\
\text { de las Certificaciones de } \\
\text { Calidad }\end{array}$ \\
\hline RO06 & Amenaza & $\begin{array}{l}\text { Falta de Difusión del Proceso de } \\
\text { Idealización }\end{array}$ & Poco Publicidad & $\begin{array}{l}\text { Menor Volumen } \\
\text { de Ventas }\end{array}$ & Comercial & 0.38 & Alto & $A D$ & $\begin{array}{l}\text { Mayor participación en eventos y } \\
\text { publicidad relacionada con lo } \\
\text { saludable }\end{array}$ & Mitiga & JC & $\begin{array}{l}\text { Al Final de Cada } \\
\text { Mes }\end{array}$ & $\begin{array}{l}\text { Convenio Estratégicos con } \\
\text { Instituciones y Empresas } \\
\text { relacionadas a la Salud }\end{array}$ \\
\hline ROO3 & Amenaza & $\begin{array}{c}\text { Nuevos } \\
\text { Competidores }\end{array}$ & Libre Mercado & $\begin{array}{l}\text { Menor Volumen } \\
\text { de Ventas }\end{array}$ & $\begin{array}{l}\text { Produccióny } \\
\text { Comercial }\end{array}$ & 0.36 & Alto & $A D$ & $\begin{array}{l}\text { Fomentar la económica de escala } \\
\text { de producto alimentarios } \\
\text { dializados. }\end{array}$ & Evitar & JP & $\begin{array}{l}\text { Al Final de Cada } \\
\text { Trimestre }\end{array}$ & $\begin{array}{c}\text { Alianza Estratégica con los } \\
\text { Productores }\end{array}$ \\
\hline
\end{tabular}

Nota: Elaboración Propia 
Tabla 151

Gestiòn de Riesgos - Plan de Respuesta 2

\begin{tabular}{|c|c|c|c|c|c|c|c|c|c|c|c|c|c|}
\hline Código & $\begin{array}{l}\text { Amenaza } \\
\text { Oportunidad }\end{array}$ & Descripción & Causa Raíz & Disparador & Afecta a & $\begin{array}{l}\text { Probabilidad } \\
\text { de Impacto }\end{array}$ & $\begin{array}{l}\text { Tipode } \\
\text { Riesgo } \\
\text { (1) }\end{array}$ & Responsable & Respuesta & $\begin{array}{l}\text { Tipode } \\
\text { Respuesta } \\
\text { (2) }\end{array}$ & $\begin{array}{c}\text { Responsable } \\
\text { dela } \\
\text { Respuesta }\end{array}$ & Fecha & Plan de Contingencia \\
\hline ROM & Amannzา & Proceso Alternativo & Ecrnomí & Marketing & Comarial & 030 & Madrardo & $A \cap$ & Mayor impulso al Marketing del & Miting & ic & Al Final de Cada & Mejorar la Presentación del \\
\hline 1004 & Alileliald & (Casero) & econiomind & Nuarkeling & cominerilal & 0.30 & Inouelado & AU & Producto & Militga & $\pi$ & Mes & Producto \\
\hline R010 & Oportunidad & $\begin{array}{l}\text { Apertura de Nuevas } \\
\text { Ferias Alimentarias }\end{array}$ & $\begin{array}{l}\text { Mejora del Estilo de } \\
\text { Vida }\end{array}$ & $\begin{array}{l}\text { Mayor Difusión } \\
\text { del Producto }\end{array}$ & $\begin{array}{l}\text { Produccióny } \\
\text { Comercial }\end{array}$ & 0.30 & Moderado & $A D$ & $\begin{array}{l}\text { Presentaciones Gastronómicas } \\
\text { del producto }\end{array}$ & Explotar & IC & $\begin{array}{l}\text { Acción } \\
\text { Continua }\end{array}$ & $\begin{array}{c}\text { Convenios con Restaurantes } \\
\text { de Comida Gourmet }\end{array}$ \\
\hline ROOg & Amenaza & $\begin{array}{c}\text { Preferencia por } \\
\text { Productos Sustitutos }\end{array}$ & Poco Publicidad & $\begin{array}{c}\text { Menor Volumen } \\
\text { de Ventas }\end{array}$ & Comercial & 0.28 & Moderado & $A D$ & $\begin{array}{l}\text { Aumentar las promociones y } \\
\text { descuento del producto }\end{array}$ & Mitiga & $J$ & $\begin{array}{c}\text { Al Final de Cada } \\
\text { Mes }\end{array}$ & $\begin{array}{l}\text { Mayor fuerza en campañas } \\
\text { publicitarias resaltando la } \\
\text { bondades del productos }\end{array}$ \\
\hline ROO1 & Oportunidad & $\begin{array}{l}\text { Aumento de Poder Adquisitivo de los } \\
\text { Consumidores }\end{array}$ & $\begin{array}{l}\text { Aujee económico del } \\
\text { País }\end{array}$ & $\begin{array}{l}\text { Mayor demanda } \\
\text { de Nuestro } \\
\text { Productos }\end{array}$ & $\begin{array}{l}\text { Produccióny } \\
\text { Comercial }\end{array}$ & 0.15 & Moderado & $A D$ & $\begin{array}{l}\text { Introducción de Nuevos } \\
\text { Productos }\end{array}$ & Explotar & JPyJC & $\begin{array}{l}\text { Acción } \\
\text { Continua }\end{array}$ & $\begin{array}{l}\text { Evaluar Periódicamente las } \\
\text { necesidades del Mercado }\end{array}$ \\
\hline R007 & Oportunidad & $\begin{array}{c}\text { Aumentoen } \\
\text { los Impuestode Renta }\end{array}$ & Mayores Ingresos & $\begin{array}{l}\text { Aumentode las } \\
\text { Ventas }\end{array}$ & $\begin{array}{l}\text { Produccióny } \\
\text { Comercial }\end{array}$ & 0.14 & Moderado & $A D$ & $\begin{array}{l}\text { Eliminación de Intermediarioy } \\
\text { Negociar con el Productor }\end{array}$ & Transfiere & $A D$ & $\begin{array}{l}\text { Acción } \\
\text { Continua }\end{array}$ & $\begin{array}{l}\text { Buscar Nuevos } \\
\text { Intermediarios }\end{array}$ \\
\hline
\end{tabular}

Nota: Elaboración Propia

\begin{tabular}{lll}
\multicolumn{1}{c}{$\begin{array}{c}\text { Tipo de } \\
\text { Rlesgo }\end{array}$} & & \multicolumn{1}{c}{$\begin{array}{c}\text { Tipo de } \\
\text { Respuesta }\end{array}$} \\
\cline { 1 - 1 } Muy Alto & & Evitar \\
Alto & & Mitigar \\
Moderado & & Transferir \\
Bajo & & Explotar \\
Muy Bajo & Compartir \\
\cline { 1 - 2 } & Mejorar \\
& Aceptar \\
\hline
\end{tabular}




\section{Capítulo X: Conclusiones y Recomendaciones}

A continuación, se expondrán las conclusiones y recomendaciones obtenidas en el desarrollo del presente proyecto y permitiendo se logren los objetivos planteados para su realización y así las distintas posibilidades de mercado que puede tener, sus capacidades productivas que para lograrán satisfacer la demanda planteada, y los resultados de los indicadores financieros, los cuales que nos permitirán sustentar la viabilidad del proyecto.

\subsection{Conclusiones}

La papa es un tubérculo que cuenta con una gran demanda a nivel mundial, siendo el Perú uno de sus principales productores con 3000 variedades de papa de 5000 que existen en el mundo y con un consumo anual per cápita de $85 \mathrm{~kg}$ por persona. En 100 gramos de papa se consume 379 mg aprox. de potasio, en 236 gr por consumo per cápita diario se ingiere 894 mg de potasio, el $26 \%$ de la cantidad normal sugerida sin considerar el nivel de potasio que se consume a través de otros alimentos.

Existen algunos estudios que sugieren el consumo de potasio, pero hay otros que precisan que el consumo en exceso puede traer daños al organismo del ser humano, considerando que a partir de los 25 años empieza el declive en el funcionamiento del organismo.

Es por ello que a este alimento se le aplicará una técnica innovadora en el campo comercial, denominada “dialización”, la cual se caracteriza por ser la ventaja competitiva de la empresa para aplicar la estrategia de diferenciación y a través de la cual se logrará reducir el nivel de minerales, entre ellos el 
potasio, obteniendo un producto que contribuya con la salud y calidad de vida del ser humano.

Para introducir este producto en el mercado actual se ha determinado un mercado objetivo para el primer año (2017) de 3,837 personas y para el quinto año (2021) 19,980 personas, con un aumento de $2 \%$ por año según la capacidad operativa con la que estima contar la empresa.

Se buscará posicionar el producto en el mercado a través de un plan de marketing agresivo para el año 0 con una inversión de S/. 25,331.00, ya que se empleará publicidad a través de programas televisivos.

La empresa iniciará sus actividades en un local de la zona de Independencia, con 9 colaboradores, este local contará con $330 \mathrm{~m} 2$ de área total que se distribuirá en zonas para realizar los procedimientos de pelado, dialización, cortado y empaque.

Para el primer año se trabajaran 39.30 toneladas de producción para cubrir una venta de 34 toneladas, para el segundo año 93.45 toneladas de producción para vender 81.36 toneladas, para el tercer año 141.62 toneladas de producción para vender 123.31 toneladas, para el cuarto año 190.74 toneladas de producción para vender 166.08 toneladas y para el quinto año 240.78 toneladas de producción para vender 209.65 toneladas; con una capacidad operativa $10 \%$ y $90 \%$ de capacidad ociosa para el primer año y al quinto año una capacidad operativa de $64 \%$ y $36 \%$ de capacidad ociosa.

Se brindará un producto en las presentaciones de 250 gr y 500 gr con precios para el consumidor final de S/. 2.50 y S/. 5.00 y para el intermediario 
S/. 2.00 y S/. 4.00 respectivamente, con un margen de ganancia para este del $25 \%$ y para la empresa un $36 \%$ sobre su costo.

El plan de negocio presentado tiene una inversión total de S/. 386,983.00 soles, de los cuales el $70 \%$ es inversión directa de los socios, teniendo un Costo de Oportunidad del Capital (COK) de $14.02 \%$ y un valor actual neto de 283,095.00 siendo muy competitivos dentro del mercado.

Al final de la implementación del plan de negocio se genera una eficiencia financiera en el quinto año de S/. 1,214,288 soles, teniendo con ello un retorno de la inversión en 4 años, 0 mes y 29 días, obteniendo un beneficio económico de 3.94, lo que significa que por cada sol invertido se ha logrado recuperar S/. 3.94 soles, logrando obtener un TIRF (Tas Interna de Retorno Financiero) del 25\% y VANF (Valor Actual Neto Financiero) de S/. 283,095.00 soles logrando que el Plan de Negocio sea viable.

Entre algunos de las ratios más importantes tenemos a la prueba acida la cual nos arroja, como era esperado, un resultado bastante bajo, pero no obstante alentador en relación a la referencia base del INEI, para lograr al quinto año un ratio de 3.78 dando seguridad en el compromiso de pago a proveedores.

Otro de los ratios importantes es el periodo promedio de inventario, los cual se mantienen de los 30 días en promedio, generando con ello un muy control mensual de la existencias.

El Apalancamiento Financiero que el plan de negocio presente durante el primer año presenta $47.65 \%$ de apalancamiento lo que representa un $81.74 \%$ del ratio base propuesto por INEI el cual presenta que el promedio del 
mercado es $58.30 \%$, logrando en el quinto año reducir nuestro nivel de apalancamiento a un 23.91 que solo representa un $41 \%$ del ratio base propuesto por INEI.

Dos de los dos indicadores más importantes de rentabilidad son el retorno Sobre la Inversión (ROA) y el retorno sobre el Capital (ROE), en el primero el ROA se puede apreciar que durante el primer año se obtiene un ROA negativo (-26.60\%) es debido a toda la inversión inicial realizada y el poco ingreso generado, pero en el quinto año podemos observar un ROA de 50.34 el cual dobla el resultado base propuesto por el INEI, mientras que en el ROE se puede apreciar un resultado en el primer año también en negativo ($36.10 \%$ ) pero al término del quinto año el Plan de Negocio logra revertir este resulta en $195 \%(169.91 \%)$.

\subsection{Recomendaciones}

1. Al término del 4to año proyectar la participación de otras zonas o mercados dado que la capacidad ociosa de la planta permitiría crecer en 2,27 veces sin cambio alguno y dentro de un solo turno, pero si es posible se debería evaluar si se puede crecer en uno (1) o dos (2) turnos más.

2. Incluir otros productos a parte de la papa, ya que existen tubérculos como el camote, yuca, zanahoria, beterraga entre otros que pueden ser incluidos en el proceso de dializaciòn logrando reducir también la cantidad de potasio, no necesariamente en la misma proporción, logrando otro producto saludable.

3. Participar en licitaciones públicas del estado, las cuales pueden asegurar una mayor cantidad a comercializar en por cliente y permanencia durante todo el año. 
4. Incursionar en empresas de comida rápida (fast food) a las cuales se les podría vender un nuevo producto de mayor peso y con un costo diferenciado.

5. Evaluar la posibilidad de patentar la maquinaria, con el fin de ofrecer el servicio y no el producto logrando tener muchos más clientes a los cuales se daría el servicio de dializaciòn de los productos que ellos proveen.

6. Certificar los procesos a fin de ser una empresa eco saludable, con lo que lograremos una utilización más eficiente de los equipos e insumos.

7. Considerar la donación y venta del producto merma a fin de lograr tener un ingreso marginal por ellos.

8. Evaluar la posibilidad de llevar el proyecto a otros países de la región con características similares como Ecuador, Bolivia, Argentina, Chile, Etc. 


\section{Índice de Figuras}

Figura 1. Evolución del mercado de fast food 1980 - 2013....................................18

Figura 2. Producción de la papa entre los años 2004 y 2013 .................................... 19

Figura 3. Principales departamentos productores de papa, 2013 - 2012 .....................20

Figura 4. Nutrientes en 100gr de papa hervida y pelada antes del consumo...............21

Figura 5. Evolución del gasto per cápita mensual 2009 - 2015.................................28

Figura 6. Gasto real promedio per cápita mensual, por grupo de gastos 2009 - 2015.28

Figura 7. Clasificación Industrial Internacional Uniforme ........................................ 32

Figura 8. Empresas de alimentos más rentables del Perú. ........................................33

Figura 9. Distribución de acciones del Holding Alimentario del Perú S.A. 2012.......35

Figura 10. Productos desarrollados por San Fernando................................................. 36

Figura 11. Tipos de canales de distribución 2 ..................................................... 41

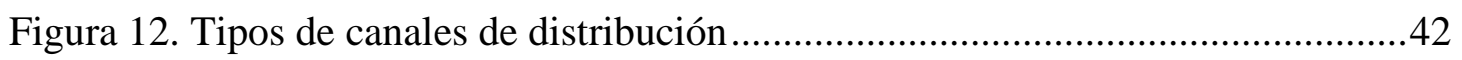

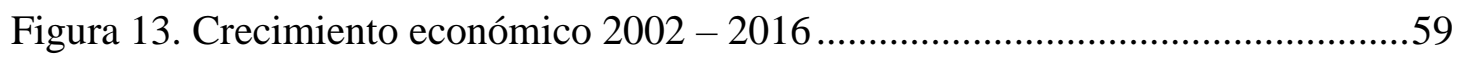

Figura 14. Desaceleración en la reducción de la pobreza ............................................60

Figura 15. Evolución de la población ocupada, 2004 - 2012 ....................................61

Figura 16. Tasa de crecimiento promedio anual de la población ocupada ..................62

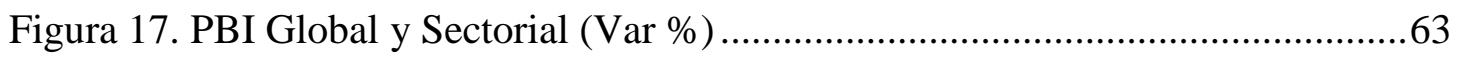

Figura 18. Papa perricholi, tomado de variedades de papa en el Perú..........................71

Figura 19. Nutrientes en 100gr de papa hervida y pelada antes del consumo. .............73

Figura 20. Nutrientes en 100gr de papa hervida y pelada antes del consumo.............73

Figura 21. Distribución de niveles por zona APEIM 2015 Horizontal ........................78

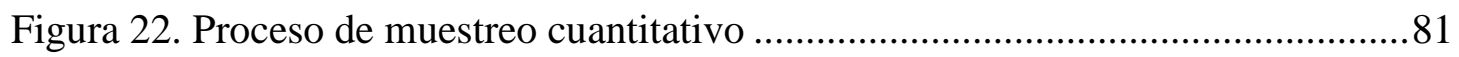

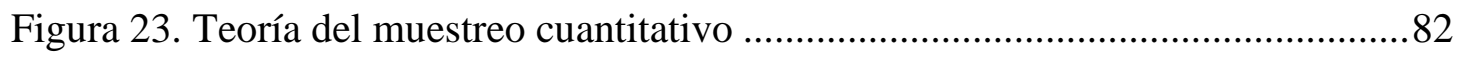

Figura 24. Fórmula para el Tamaño de la Muestra ......................................................8 
Figura 25. Fórmula simplificada para el tamaño de la muestra. .83

Figura 26. Resultando como tamaño de la muestra a utilizar. .84

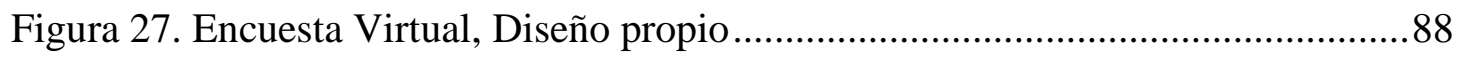

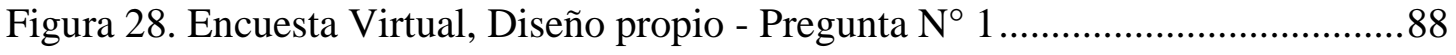

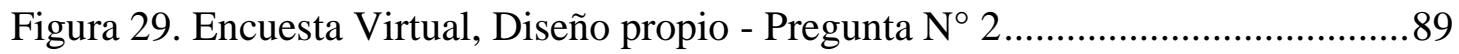

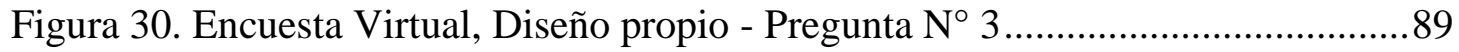

Figura 31. Encuesta Virtual, Diseño propio - Pregunta $\mathrm{N}^{\circ}$ 4 .....................................90

Figura 32. Encuesta Virtual, Diseño propio - Pregunta $\mathrm{N}^{\circ}$ 5 .................................... 90

Figura 33. Encuesta Virtual, Diseño propio - Pregunta $\mathrm{N}^{\circ}$ 6......................................91

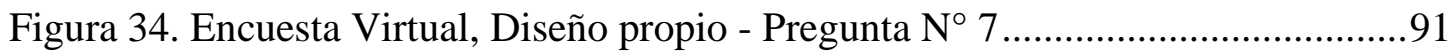

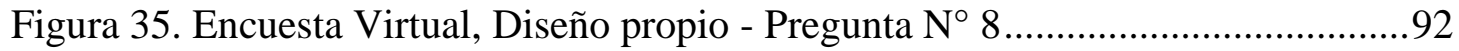

Figura 36. Encuesta Virtual, Diseño propio - Pregunta $\mathrm{N}^{\circ} 9$......................................92

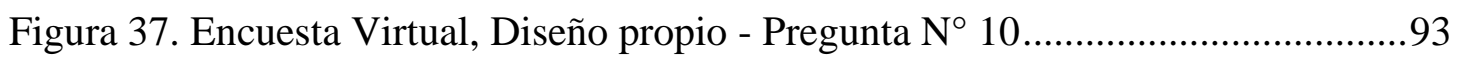

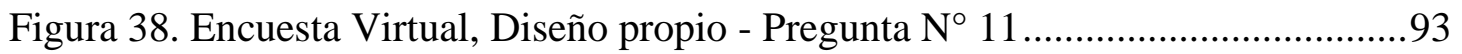

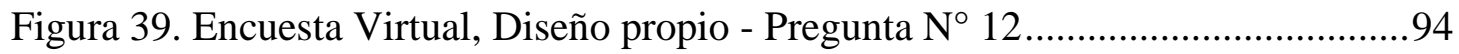

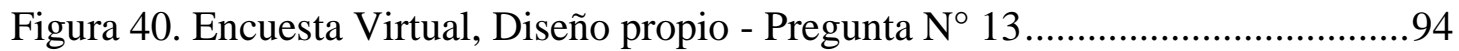

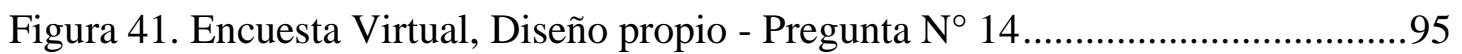

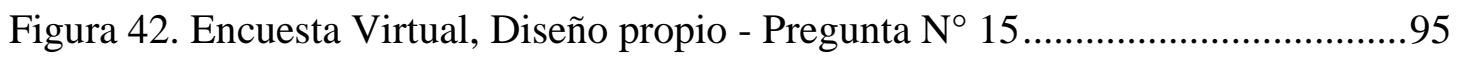

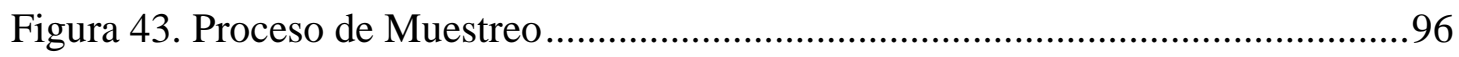

Figura 44. Organización de las Técnica de Muestreo ................................................97

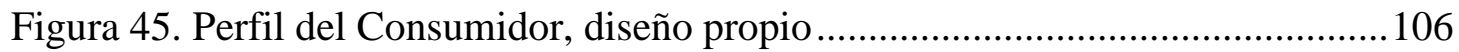

Figura 46. Volumen de Producción Ingresada - Mercado Mayorista .......................116

Figura 47. Proceso para la fabricación de la papa dializada, diseño propio ..............122

Figura 48. Proceso de la papa para cumplir ciclo de producción, diseño propio........123

Figura 49. Descripción del Proceso Administrativo, diseño propio ...........................129 
Figura 50. Máquina peladora de papa …............................................................. 131

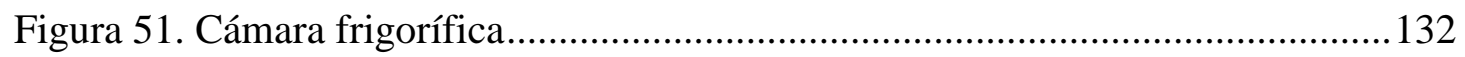

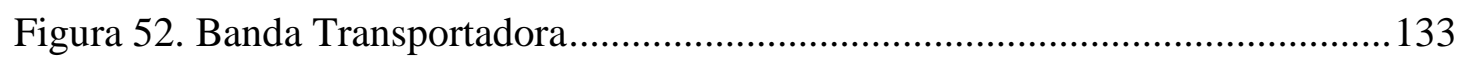

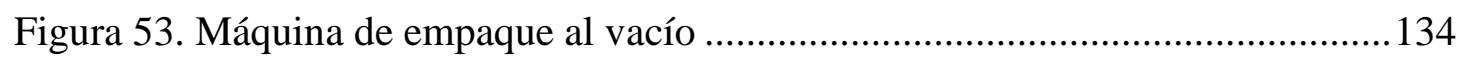

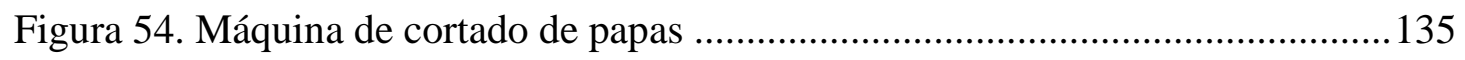

Figura 55. Máquina de dialización de papa, desarrollo propio ...................................136

Figura 56. Diseño y Distribución de Ambientes - diseño propio............................... 138

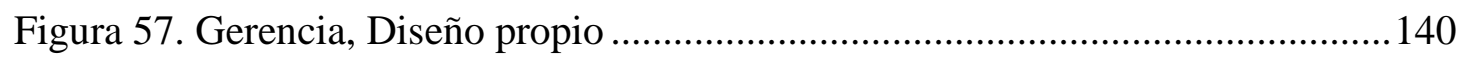

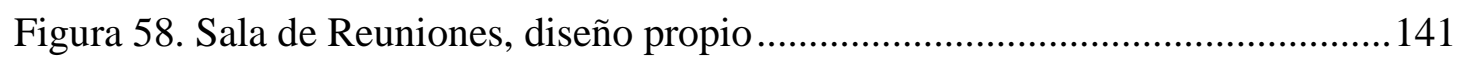

Figura 59. Área Administrativa, diseño propio........................................................ 142

Figura 60. Área de Dializaciòn, diseño propio ....................................................... 143

Figura 61. Zona de conservación y recepción, diseño propio.................................... 144

Figura 62. Despacho y Pedidos, diseño propio ................................................... 145

Figura 63. Producción Mensual Proyectada .......................................................... 148

Figura 64. Área por Departamento, diseño propio...................................................... 155

Figura 65. Despacho y Pedidos, diseño propio ...................................................... 157

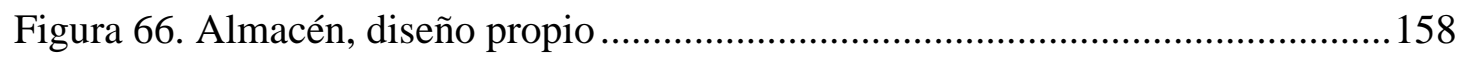

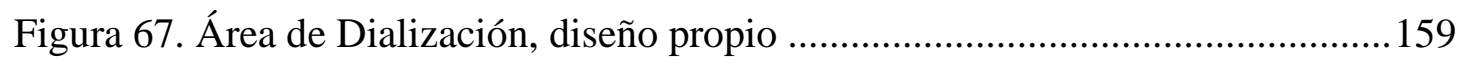

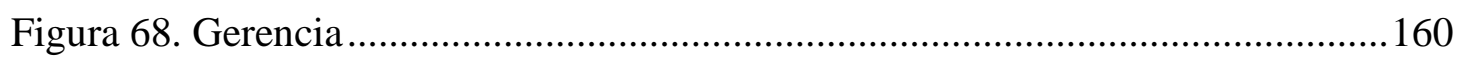

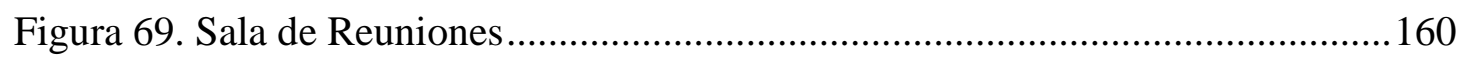

Figura 70. Mapa de Localización, diseño propio .................................................. 170

Figura 71. Estrategia de negocio empresa Codial, diseño propio ............................. 177

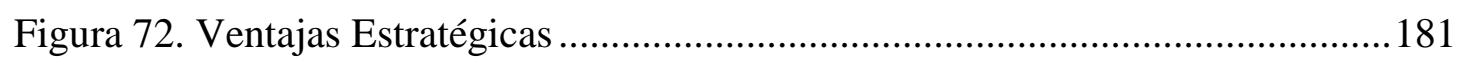

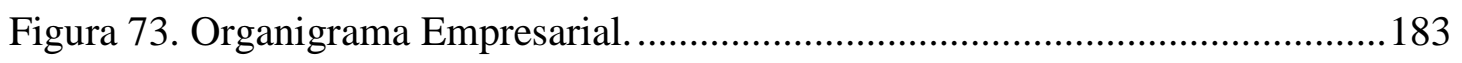

Figura 74. Diferencia entre Valor Nutricional (potasio) de papa..............................204 


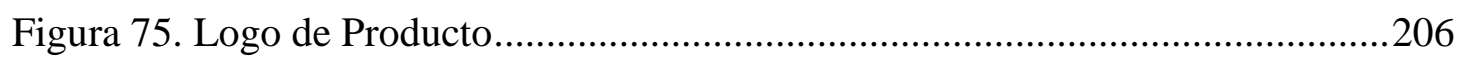

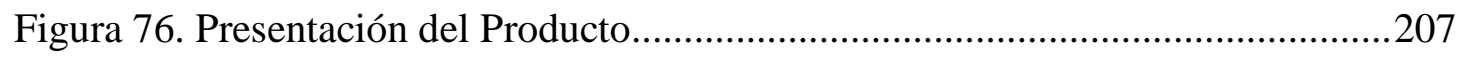

Figura 77. Jabas Nazca, proveedor Novatec apilable armada.................................208

Figura 78. Jabas Nazca, proveedor Novatec, apilable, desarmada .........................208

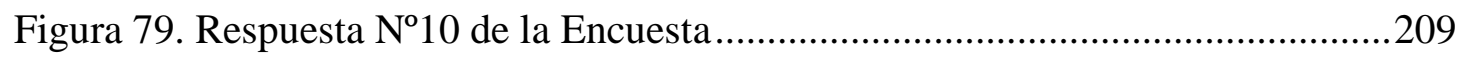

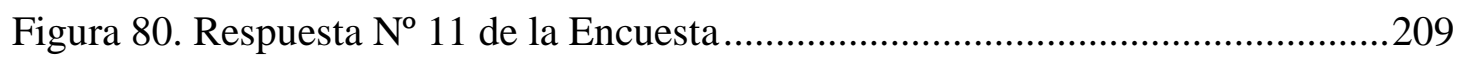

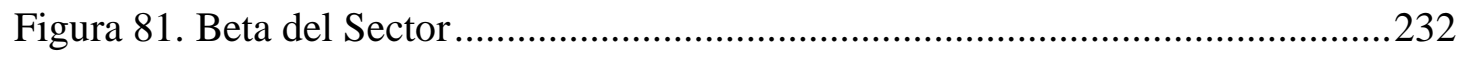

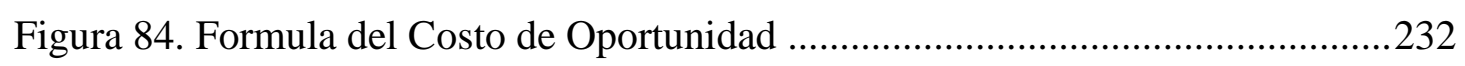

Figura 83. Costo de Oportunidad en Perú .............................................................2234

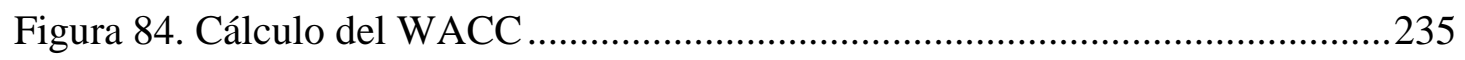

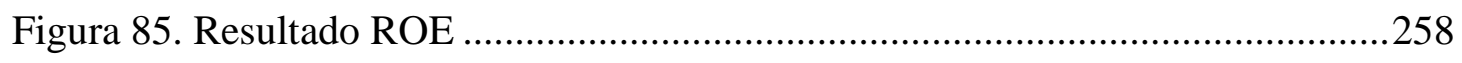

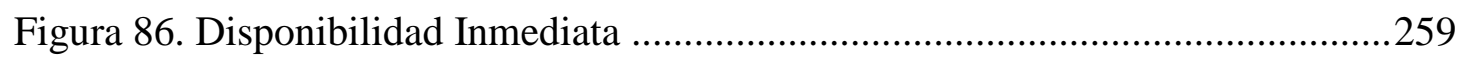

Figura 87. Razón Corriente o Razón Circulante ....................................................259

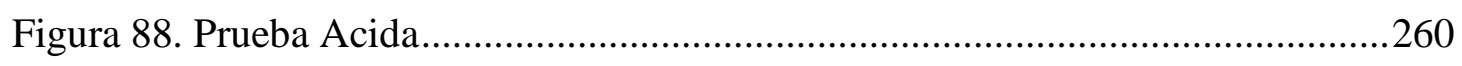

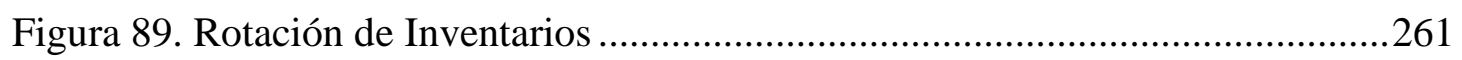

Figura 90. Periodo Promedio de Inventarios....................................................... 261

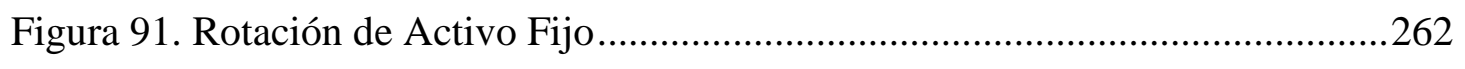

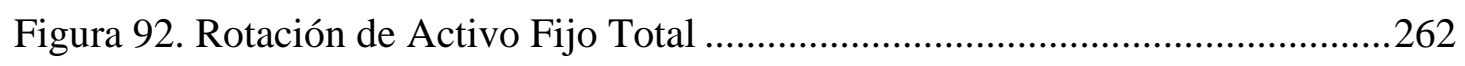

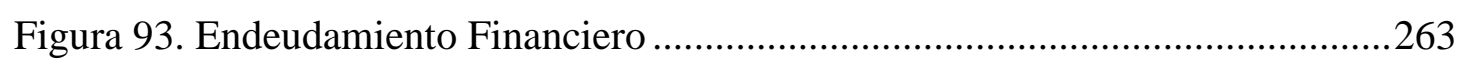

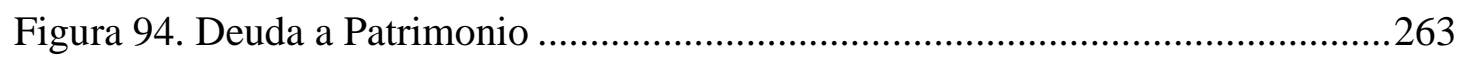

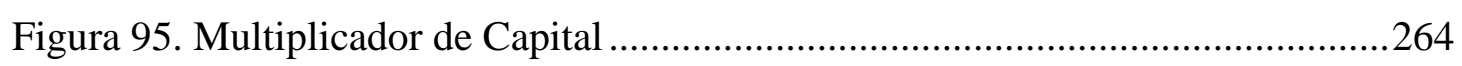

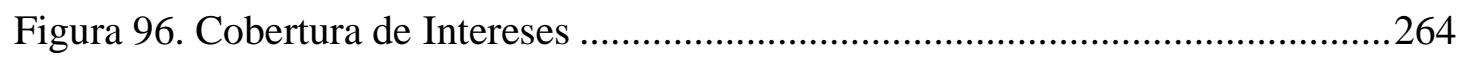

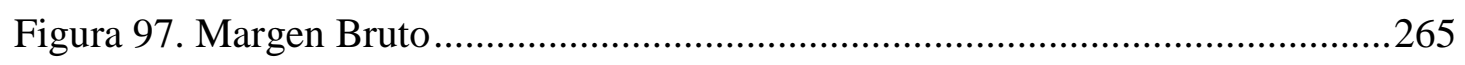

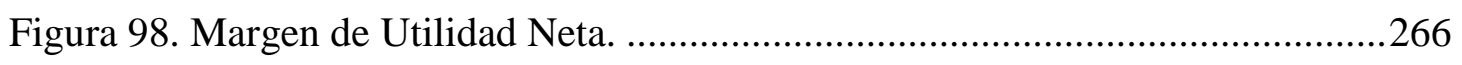

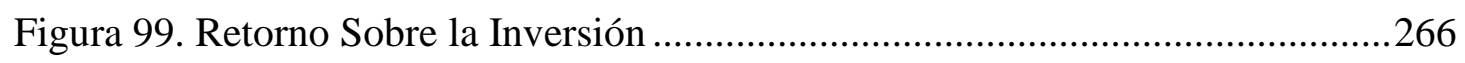


Figura 100. Formula de Punto de Equilibrio........................................................267

Figura 101.Una mirada a Lima Metropolitana, INEI (2014) .....................................

Figura 102. Resultado de Análisis Físico - Químico...............................................317

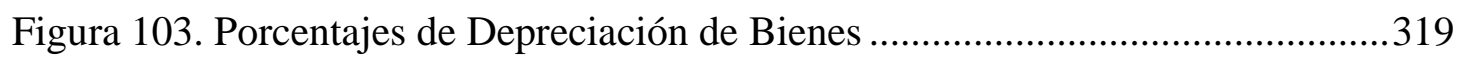

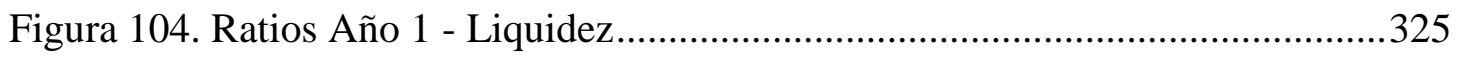

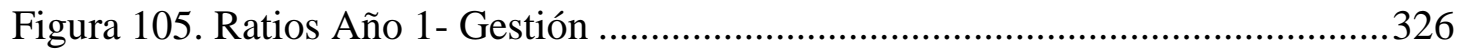

Figura 106. Ratios Año 1 - Apalancamiento Financiero..........................................327

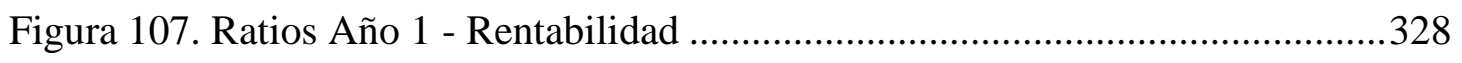

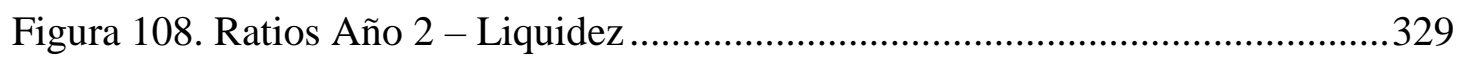

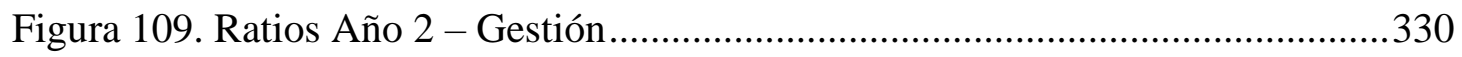

Figura 110. Ratios Año 2 - Apalancamiento Financiero ......................................... 331

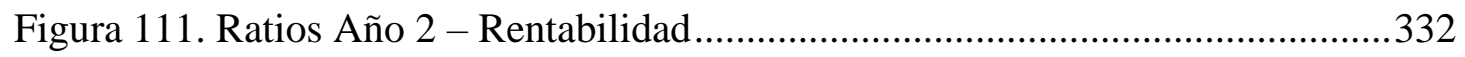

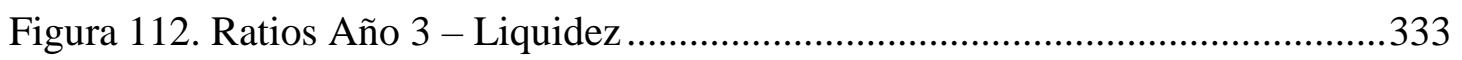

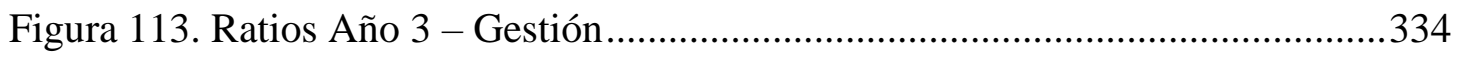

Figura 114. Ratios Año 3 - Apalancamiento Financiero ..........................................335

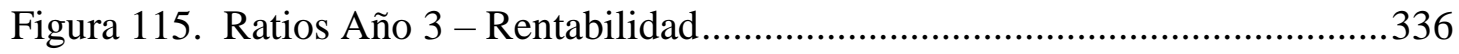

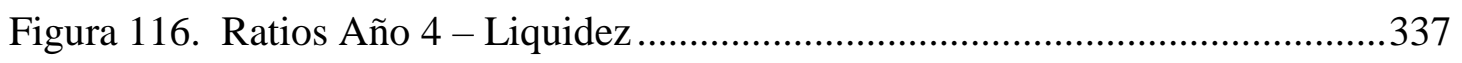

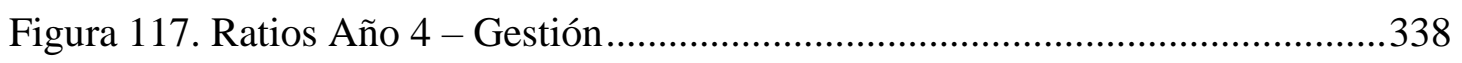

Figura 118. Ratios Año 4 - Apalancamiento Financiero ...........................................339

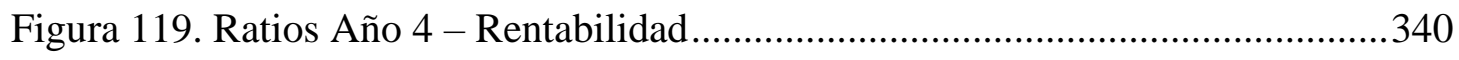

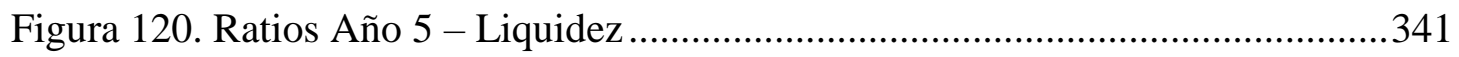

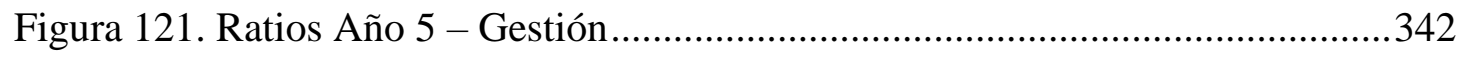

Figura 122. Ratios Año 5 - Apalancamiento Financiero ..........................................343

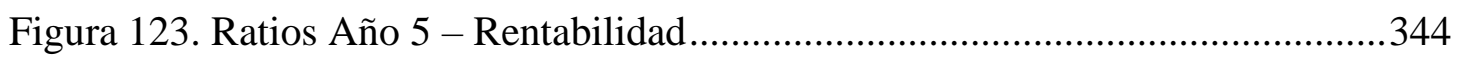

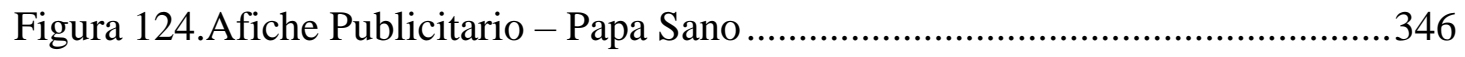


Figura 125. Extracto del Libro ¿Cuántos Años Viviré?..............................................347

Figura 126 Gasto Mensual Promedio por Persona.......................................................348

Figura 127 Licencias de Funcionamiento - Lima Metropolitana................................349

Figura 128 Licencia de Funcionamiento a Bodegas - Lima Metropolitana.................350 


\section{Índice de Tablas}

Tabla 1 Producción de Papa en el Mundo. .17

Tabla 2 Producto Bruto Interno de la industria manufacturera ..................................26

Tabla 3 Producto Bruto Interno por Sector Productivo 2010-2015 ...........................27

Tabla 4 Consumo promedio per cápita anual de tubérculos ......................................29

Tabla 5 Producto Bruto Interno por Sector Productivo 2010-2015 ............................30

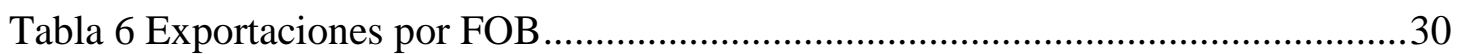

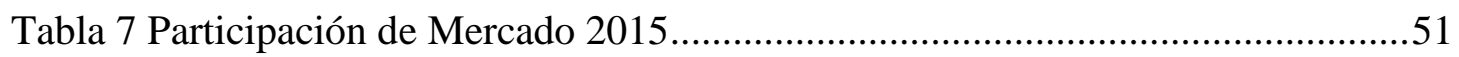

Tabla 8 Matriz del Posición de Competitividad - MPC ...............................................54

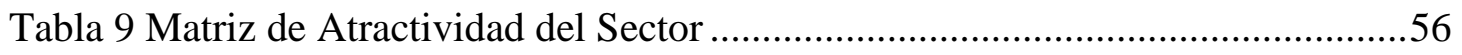

Tabla 10 Clasificación Industrial Internacional Uniforme …....................................72

Tabla 11 Población estimada al 30 de junio, por sexo, según departamentos (2015)..75

Tabla 12 Población estimada al 30 de junio, según departamentos (2015) ................76

Tabla 13 Población total al 30 de junio, por grupos quinquenales de edad, 2015 ......77

Tabla 14 Población total al 30 de junio, por grupos quinquenales de edad, 2015 .......78

Tabla 15 Población total al 30 de junio, por grupos quinquenales de edad, 2015 .......79

Tabla 16 Población total al 30 de junio, por grupos quinquenales de edad, 2015 .......79

Tabla 17 Distribución Poblacional por Zonas y Edades ............................................80

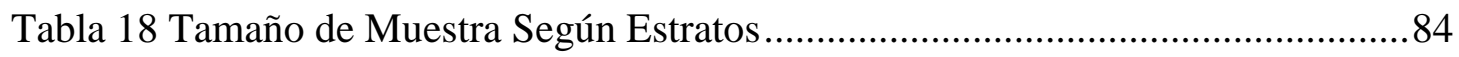

Tabla 19 Proyección Poblacional 2017-2021 .......................................................... 108

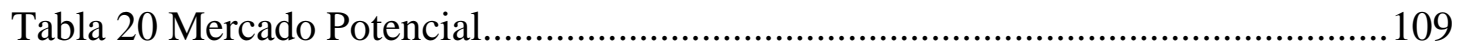

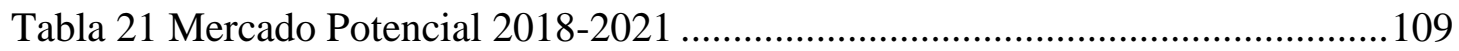

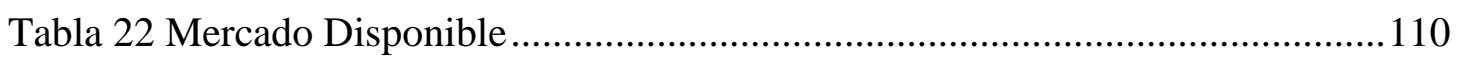

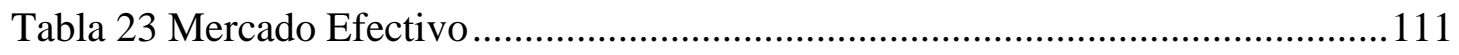

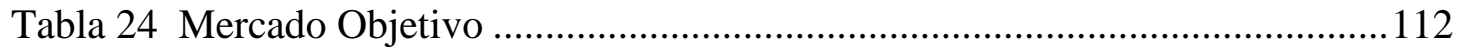




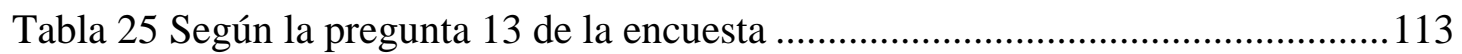

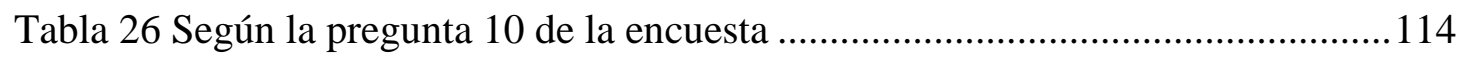

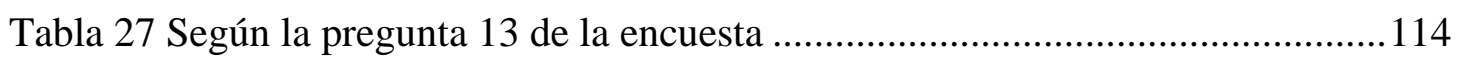

Tabla 28 Cuantificación de la Demanda Proyectada ............................................... 114

Tabla 29 Resumen de Ingreso al Mercado Mayorista de Lima Metropolitana...........115

Tabla 30 Programa Mensual Proyectado de Producción y Ventas .............................117

Tabla 31 Programa mensual de ventas proyectadas - 2018 al 2021 ......................... 118

Tabla 32 Proyección de Ventas Mensual 2018- 2021 ................................................ 119

Tabla 33 Presupuesto del equipamiento necesario en la producción..........................137

Tabla 34 Programa de Producción Mensual Proyectada 2017-2021 ......................... 147

Tabla 35 Crecimiento Mensual de Producción ............................................................ 149

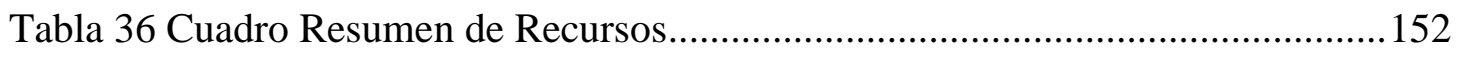

Tabla 37 Capacidad Ociosa de la Planta Productiva.................................................154

Tabla 38 Simulación de Mayor Capacidad Productiva..............................................154

Tabla 39 Dimensiones de Local de Funcionamiento ............................................... 160

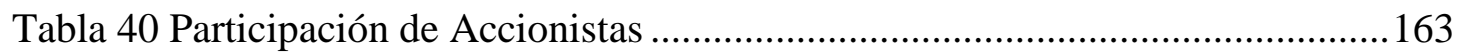

Tabla 41 Matriz de Factores de Micro Localización .................................................171

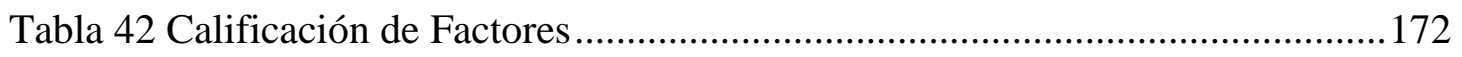

Tabla 43 Criterios que definen la visión ................................................................ 174

Tabla 44 Criterios que definen la Misión.................................................................. 176

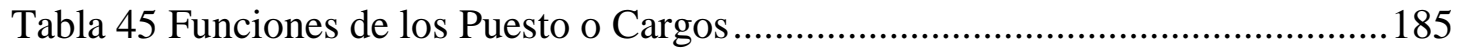

Tabla 46 Funciones de los Puesto o Cargos - Continuación 1 ....................................186

Tabla 47 Funciones de los Puesto o Cargos - Continuación 2 ................................187

Tabla 48 Funciones de los Puesto o Cargos - Continuación 3 .................................188

Tabla 49 Funciones de los Puesto o Cargos - Continuación 4 ..................................189 
Tabla 50 Funciones de los Puesto o Cargos - Continuación 5 ..................................190

Tabla 51 Funciones de los Puesto o Cargos - Continuación 6 .................................191

Tabla 52 Funciones de los Puesto o Cargos - Continuación 7 ..................................192

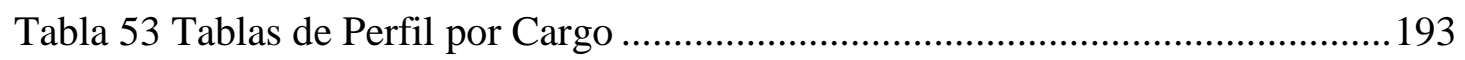

Tabla 54 Tablas de Perfil por Cargo - Continuación 1 .............................................. 194

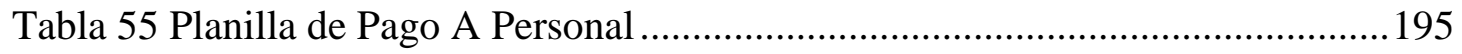

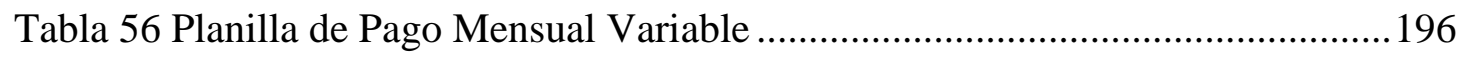

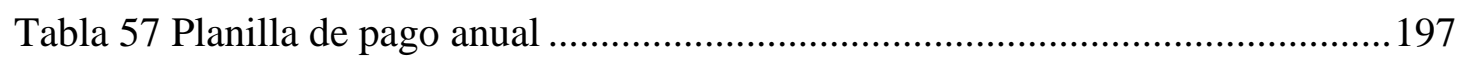

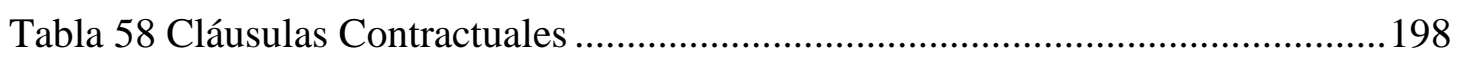

Tabla 59 Características de una Pequeña Empresa .................................................199

Tabla 60 Valor Nutricional de la Papa por cada 100 gr.........................................203

Tabla 61 Valor Nutricional de Papa Dializada por cada 100 gr. .............................205

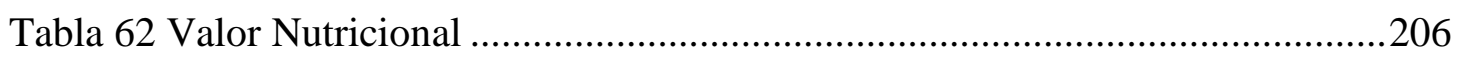

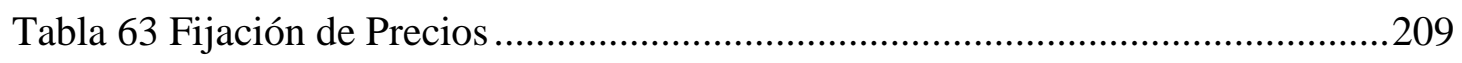

Tabla 64 Gantt mensual de actividades de Estrategias de Publicidad y Promoción..213

Tabla 65 Presupuesto Anual de Marketing ...........................................................213

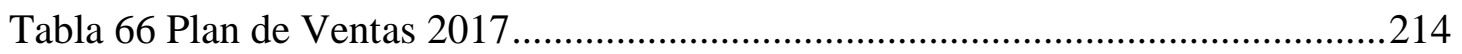

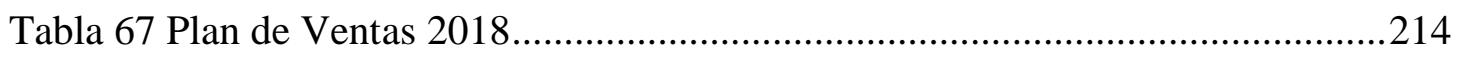

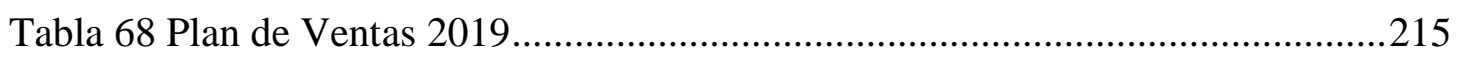

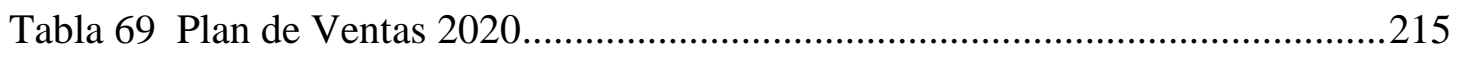

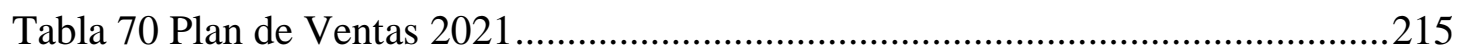

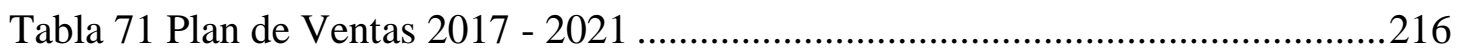

Tabla 72 Inversión Pre Operativa - Tangibles......................................................219

Tabla 73 Inversión Pre Operativa - Maquinarias y equipos ....................................219

Tabla 74 Inversión Pre Operativa - Muebles y Enseres .............................................220 
Tabla 75 Inversión Pre Operativa - Mueble de Oficina .............................................2220

Tabla 76 Inversión Pre Operativa - Intangibles....................................................222

Tabla 77 Inversión Pre operativa - Constitución de la Empresa ...............................221

Tabla 78 Inversión Pre Operativa - Licencias y Permisos .........................................221

Tabla 79 Inversión Pre Operativa - RRHH - Software - Marketing .........................222

Tabla 80 Inversión Pre Operativa - Otros .............................................................222

Tabla 81 Inversión de Capital de Trabajo ................................................................224

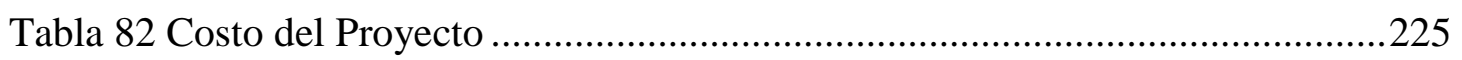

Tabla 83 Capacidad Máxima de Producción .........................................................226

Tabla 84 Programa anual de Producción ................................................................226

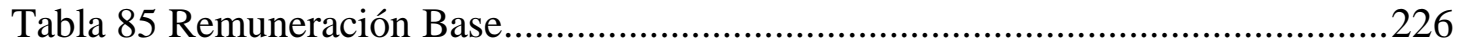

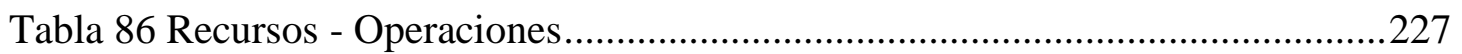

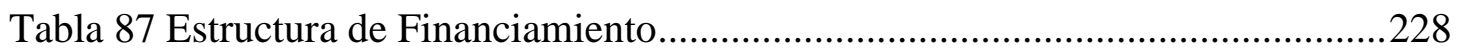

Tabla 88 Determinación del Préstamo en Cuotas ..................................................229

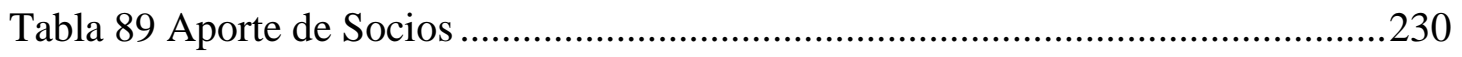

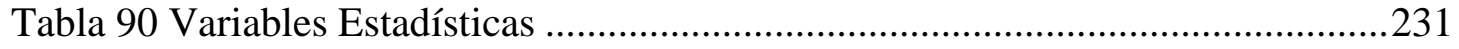

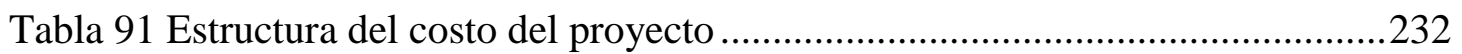

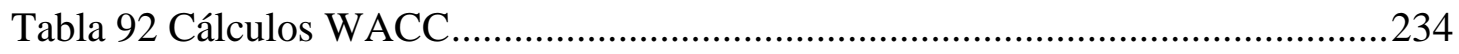

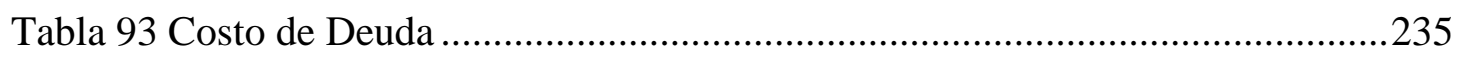

Tabla 94 Presupuesto Mensual de Ventas - 2017 ...................................................2236

Tabla 95 Presupuesto Anual de Ventas 2017 - 2021 ..............................................236

Tabla 96 Presupuesto Mensual de Costos de Producción 2017 .................................237

Tabla 97 Presupuesto Anual de Costo de Producción 2017 - 2021 ...........................237

Tabla 98 Presupuesto Mensual de Compras MD 2017 ............................................238

Tabla 99 Presupuesto Mensual de Compras MI 2017 ............................................238 
Tabla 100 Presupuesto Anual de Compras MD 2017 - 2021 ..................................238

Tabla 101 Presupuesto Anual de Compras MI 2017 - 2021 ....................................2239

Tabla 102 Presupuesto Mensual de Costo de Ventas 2017......................................239

Tabla 103 Presupuesto Anual de Costo de Ventas 2017 - 2021 ................................240

Tabla 104 Presupuesto de Gastos Mensuales de Administración 2017 .....................241

Tabla 105 Presupuesto de Gastos Anuales de Administración 2017 - 2021...............241

Tabla 106 Presupuesto Mensual de Marketing 2017 .................................................242

Tabla 107 Presupuesto Anual de Marketing 2017 - 2021 ........................................242

Tabla 108 Presupuesto Mensual de Gasto de Ventas 2017.....................................243

Tabla 109 Presupuesto Anual de Gastos de Ventas 2017 - 2021 .............................243

Tabla 110 Presupuesto Mensual de Gastos Financieros 2017 .................................244

Tabla 111 Presupuestos Anual de Gastos Financieros 2017-2021 ...........................244

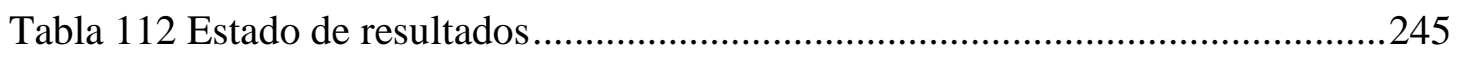

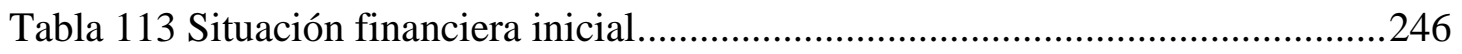

Tabla 114 Situación Financiera - Primer Año ........................................................247

Tabla 115 Situación Financiera - Segundo Año ....................................................248

Tabla 116 Situación Financiera - Tercer Año ........................................................249

Tabla 117 Situación Financiera - Cuarto Año......................................................250

Tabla 118 Situación Financiera - Quinto Año ……..............................................251

Tabla 119 Flujo de Caja Operativo Proyectado ......................................................252

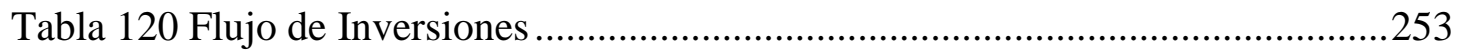

Tabla 121 Flujo de Caja - Económico .....................................................................253

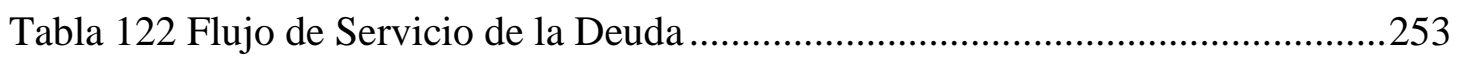

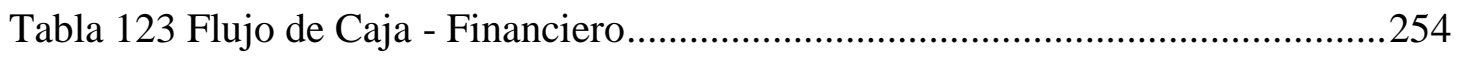

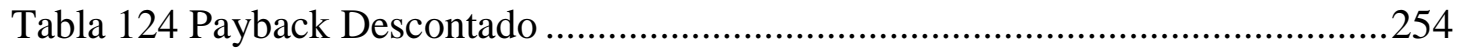


Tabla 125 Tasa Interna de Retorno Económico - TIRE ............................................255

Tabla 126 Tasa Interna de Retorno Financiero - TIRF ..........................................25

Tabla 127 Valor Actual Neto Económico - VANE ..................................................256

Tabla 128 Valor Actual Neto Financiero - VANF...............................................257

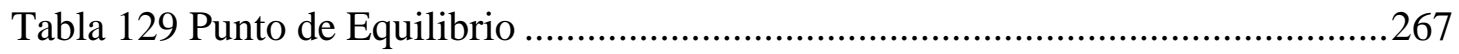

Tabla 130 Análisis de Sensibilidad por Variables - VANE .......................................268

Tabla 131 Análisis de Sensibilidad por Variables -TIRE ........................................269

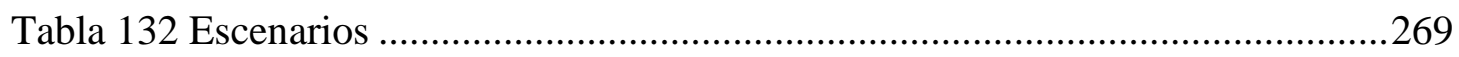

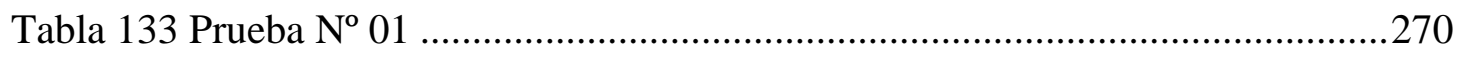

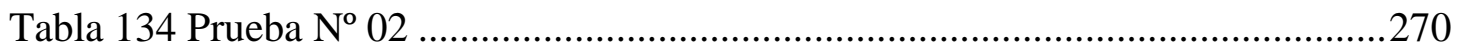

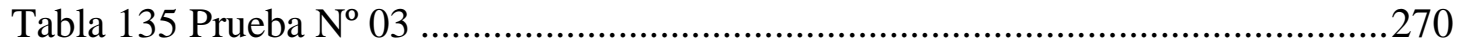

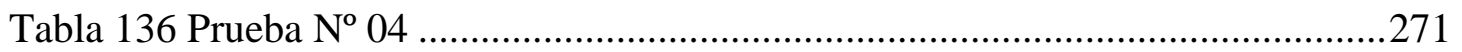

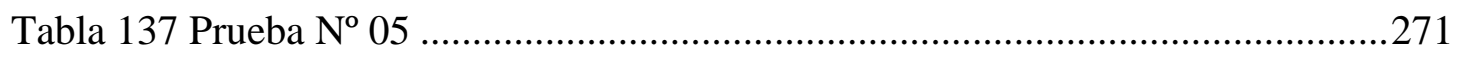

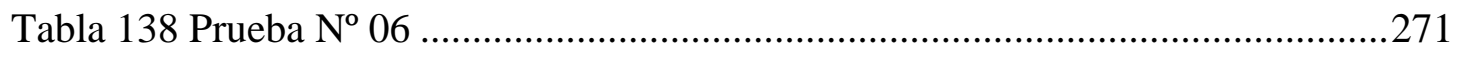

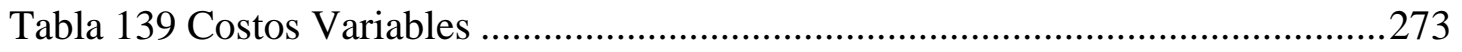

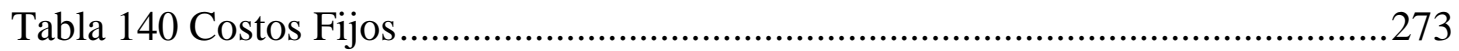

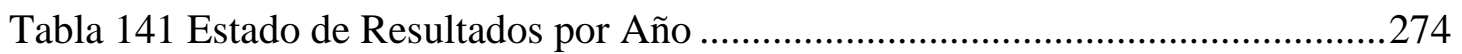

Tabla 142 Indicadores Financieros VANE - TIRE .............................................24

Tabla 143 Estado de Pérdidas y Ganancias - Devaluación .........................................2276

Tabla 144 Indicadores Financieros VAN y TIRE - Devaluación .............................276

Tabla 145 Estado de Pérdidas y Ganancias - Crecimiento y Expansión ....................278

Tabla 146 Indicadores Financieros VAN y TIR - Crecimiento y Expansión ...........278

Tabla 147 Gestiòn de Riesgos - Roles y Responsabilidades..................................2279

Tabla 148 Gestiòn de Riesgos - Evaluaciòn Cualitativa 1 ......................................280

Tabla 149 Gestiòn de Riesgos - Evaluaciòn Cualitativa 2 ........................................281 
Tabla 150 Gestiòn de Riesgos - Plan de Respuestas.................................................282

Tabla 151 Gestiòn de Riesgos - Plan de Respuesta 2 …..........................................283

Tabla 152 Tasa de Interés Promedio del Sistema Bancario - SBS ............................318

Tabla 153 Proyección Cuotas de Presta - Banco Continental......................................320

Tabla 154 Proyección Cuotas de Presta - Banco de Crédito del Perú ........................321

Tabla 155 Proyección Cuotas de Presta - Banco Interbank ........................................322

Tabla 156 Análisis de Sensibilidad Método Montecarlo ............................................323

Tabla 157 Análisis de Sensibilidad Método Montecarlo - Continuación ...................324

Tabla 158 Beta de Sector de Alimentos de EEUU …...............................................345

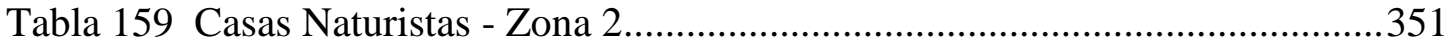




\section{Anexos}

\subsection{Anexo $\mathbf{N}^{\circ} 01$ - Cartilla de Entrenamiento Focus Group FOCUS GROUP: CARTILLA DE ENTRENAMIENTO DE MODERADOR}

Para el "Plan de negocio en la implementación de una empresa para la elaboración y comercialización de papa dializada", se desea conocer la opinión de las personas que desean llevar una dieta saludable, donde pueda incluir en su dieta diaria el producto propuesto.

Dicho producto es un el tubérculo comestible "Solanum tuberosum", conocido como "Papa", con la característica que atravesará por un proceso de dialización el cual consiste en la reducción del nivel de potasio que contiene mediante un ciclo de sumersión en agua cada seis horas durante dos días, pudiendo luego del proceso ser consumida por niños y adultos.

Sobre el producto ofertado "papa dializada" se puede indicar lo siguiente:

1. Dirigido a personas que incluyen en su dieta productos saludables.

2. Se presenta un producto con bajos niveles de potasio, el cual puede ayudar a la dieta de personas con problemas renales.

3. Disponible en paquetes de medio kilo y un kilo, empacados al vacío.

4. Papa Sano, posee 379 mg menos de potasio en su composición.

Para conocer las opiniones e impresiones de las personas, utilizaremos en el Focus Group y la Entrevista de Profundidad los siguientes puntos:

1. Selección y Segmentación del mercado objetivo. 
2. Seleccionara el tamaño de la muestra necesaria.

Se redactará una guía para que la persona que haga el papel de moderador, tenga en cuenta los siguientes puntos:
1. Presentación
2. Explicación Introductoria
3. Rompimiento del Hielo
4. Preguntas Generales o de Apertura
5. Preguntas de Transición
6. Preguntas Específicas
7. Preguntas de Cierre
8. Agradecimiento.

Segmento a Investigar:

Personas adultas de 25 años de edad en adelante; casados (as), viudos (as), solteros (as) con o sin hijos, con diferentes ingresos económicos, que gustan mantener una dieta saludable y llevar una vida en prevención de enfermedades sistémicas que deterioren los órganos debido a niveles no adecuados de minerales que contenga el producto y que residan en Lima Metropolitana, específicamente en los distritos de Independencia, Los Olivos y San Martín de Porras.

Proceso de Investigación:

Para lograr obtener un adecuado resultado del proceso de investigación se llevarán a cabo dos Instrumentos, el primero será un Focus Group, el cual se realizará en instalaciones que permitan reunir a las personas del segmento a investigar; la muestra a utilizar estará conformada por 32 personas divididas 
en cuatro grupos, las cuales se seleccionaran de acuerdo al segmento de investigación indicado anteriormente y realizándose un total de 6 preguntas por grupo.

El segundo instrumento será la Entrevista de Profundidad la cual estará dirigida a profesional y/o técnicos orientados en temas de salud, tanto como doctores y nutricionista, de profesiones como nutricionistas, endocrinólogos o doctores de la especialización de medicina general y técnicos especialistas en la salud, este segundo instrumento se realizará en instalaciones que permitan reunir a las personas seleccionadas; la muestra a utilizar estará conformada por dos personas divididas en dos grupos y realizándose un total de ocho preguntas por grupo. 


\subsection{Anexo $\mathrm{N}^{\circ} 02$ - Guia del Moderador del Focus Group \\ FOCUS GROUP: GUÍA DEL MODERADOR}

1. Presentación

a) Presentación del Moderador.

b) Motivo de la reunión

c) Presentación de los Integrantes, para que puedan entrar en un ambiente agradable y cómodo.

d) Duración del focus group de 1hora con 15 minutos.

2. Explicación Introductoria para la Sesión de Grupo

a) Se explicará de que se trata la sesión de grupo.

b) Se explicará que no hay respuestas correctas, sólo opiniones. Usted representa a muchas personas que piensan igual.

c) Se grabará la entrevista porque se necesita encontrar coherencia en lo que se dice y en lo que se escucha.

d) Por favor que solo hable una persona a la vez, y si desea dar una opinión puede levantar la mano.

e) Si usted tiene una opinión diferente a las demás personas del grupo, es importante que nos la haga saber.

f) ¿Tienen alguna pregunta?

3. Ruptura del Hielo 
a) Para romper el hielo se les realizarán preguntas libres sobre, profesión, como les gusta que los llamen, cuántos hijos tienen, que les gusta comer o qué tipo de preferencia de marcas por productos tiene para productos saludables.

4. Preguntas Generales o de Apertura

a) ¿Utiliza a diario la papa como parte de su dieta?

b) ¿Conoce alguna marca que venda papa libre de potasio?

c) ¿Qué clase de papa prefiere?

d) ¿Ha escuchado sobre la dialización de productos vegetales en especial la papa?

5. Preguntas de Transición

a) ¿Qué tipo de tubérculo prefiere que forme parte de su dieta diaria?, ¿Cual prefiere?

b) Si su respuesta fuera papa ¿Con qué frecuencia la consumiría?

c) ¿Me puede decir que piensa usted de los productos que sufren proceso de dialización?

d) ¿Ha escuchado que es papa dializada y que beneficios tiene?

e) ¿La papa dializada aparte de cuidar varios órganos del cuerpo, como el riñón, incluso en personas que son sometidas a diálisis inter diarias, con qué frecuencia cree usted que podría consumirla? 
6. Preguntas Específicas

Para llevar a cabo estas preguntas, se realizó preguntas directas acerca

a) ¿Qué opina usted sobre este nuevo producto?

En ese momento se les pasará un plato con una preparación que contenga papa blanca y que haya sufrido el proceso de dialización.

b) ¿Que opina acerca de este producto que cuida su salud previene enfermedades?

c) ¿Está dispuesto a pagar por ese producto y comprarlo para incluirlo en su gasto diario?

d) ¿Cuánto dinero estaría dispuesto a pagar por este producto que presenta características saludables?

7. Preguntas de Cierre

a) ¿Cuál sería su recomendación para el consumo frecuente del producto?

b) ¿Recomendaría a otros amigos acerca sobre este producto para la prevención de la salud?

8. Agradecimiento

Se les debe agradecer por la participación y por la calidad de respuestas que se obtendrán en las preguntas. Se les obsequiará una muestra de una unidad de papa empacada al vacío para que la puedan probar, incluido la preparación de un plato que contenga papa con el proceso de dialización. 


\subsection{Anexo $\mathbf{N}^{\circ} 03$ - Plantilla Focus Group}

\section{FICHA FOCUS GROUP ${ }^{\circ}$}

Fecha : Cantidad de Asistentes :

Nombre y Apellido del Moderador :

Hora de Inicio Hoa de Termino

Cantidad de Participantes : Femeninos - Masculinos

1. ¿Cuando consume cualquier tipo de alimento, ¿lo hace pensando en su salud?

2. ¿Sabe usted que productos puede comer para cuidar su salud ?

3. ¿Con que frecuencia consume usted productos saludables?

4. ¿Conoce las propiedades nutritivas de la papa?

5. ¿Ha escuchado del proceso de dialización de la papa?, Si su respuesta es afirmativa, detállenos su conocimiento

6. $i$ habiendo explicado las bondades del producto dializado, piensa que puede comprarlo y recomendarlo ? 
13.4. Anexo No 04 - Focus Group No 1, 2 y 3

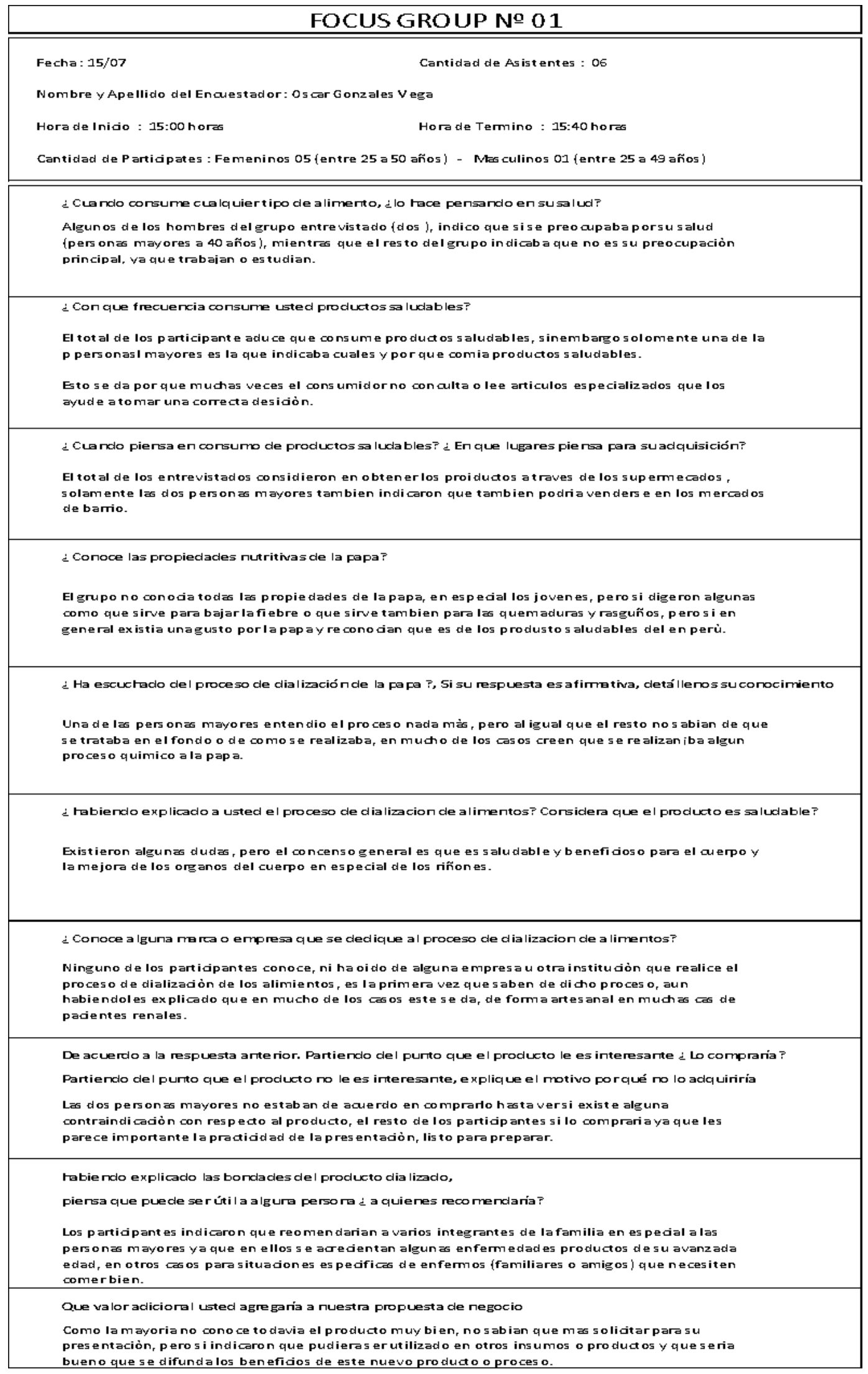




\begin{tabular}{|c|}
\hline FOCUS GROUP No 02 \\
\hline Fecha: $17 / 07$ \\
\hline Nombre y Apellido del Encuestador : Jorge Diaz Pisco \\
\hline Horade Inicio: $16: 00$ horas \\
\hline Cantidad de Participates: Femeninos 02 (entre 29 a 45 años) - Masculinos 03 (entre 35 a 60 años) \\
\hline $\begin{array}{l}\text { ¿Cuando consum e cualquier tip o de alim ento, ilo hace pensando en su salud? } \\
\text { Todos los participantes indicaron que habían consumido productos saludables, no farmacéuticos, como } \\
\text { por ejemplo, yogurts, aceites cero colesteroly Herbalife. }\end{array}$ \\
\hline ¿Con que frecuencia consume usted productos saludables? \\
\hline El consumo es semanal. \\
\hline ¿Cuando piensa en consumo de productos saludables? $\dot{c}$ En que lugarespiensa para su adquisición? \\
\hline El producto lo compran en su mayoría en el supermercado y los mercados minoristas locales. \\
\hline ¿Conoce las propiedades nutritivas de la papa? \\
\hline $\begin{array}{l}\text { Las personas no conocían de las propiedades nutritivas de la papa, pero sabían que era un alimento } \\
\text { importante en la mesay que podía ser aplicado en ciertas enfermedades, como por ejemplo para } \\
\text { disminuir la fiebre. }\end{array}$ \\
\hline ¿Ha escuchado delproceso de dialización de la papa?, Si su respuesta es afirm ativa, detállenos su conocim iento \\
\hline $\begin{array}{l}\text { Las personas mayores a } 40 \text { años conocían del proceso de dialización y lo explicaron claramente, las } \\
\text { personas entre los } 25 \text { y } 39 \text { años solo indicaron que habían escuchado acerca del proceso. }\end{array}$ \\
\hline ¿ habiendo explicado a usted el proceso de dializacion de alimentos? Considera que el producto es saludable? \\
\hline $\begin{array}{l}\text { Todos los participantes del focus group demostraron interés cuando se les explicó acerca del proceso } \\
\text { de dialización, al inicio tuvieron cierto rechazo, pensando que se le aplicaría insumos medicinales, al } \\
\text { final lo aceptaron cuando se les dijo que el producto final se obtendría de un proceso natural sin } \\
\text { ningún tipo de preservantes. }\end{array}$ \\
\hline ¿Conoce algunam arca ompresa que se dedique al proceso de dializacion de alimentos? \\
\hline Ningún participante conocía de empresa alguna que desarrollara este tipo de productos. \\
\hline De acuerdo a la respuesta anterior. Partiendo del punto que el producto le es interesante ¿ lo compraría? \\
\hline Partiendo del punto que el productono le es interesante, explique el motivo por qué no lo adquiriría \\
\hline $\begin{array}{l}\text { Los participantes de } 40 \text { años a mas indicaron que si comprarían el producto, los de } 25 \text { a } 39 \text { años no } \\
\text { sabían dar una respuesta afirm ativa. }\end{array}$ \\
\hline $\begin{array}{l}\text { habiendo explicado las bondades delproducto dializado, } \\
\text { piensa que puede ser útil a alguna persona c a quienesrecomendaría? }\end{array}$ \\
\hline Se recomendaría apersonas que sufren de insuficiencia renal, pacientes con diabetes e hipertensión. \\
\hline Que valor adicional usted agregaría a nuestra propuesta de negocio \\
\hline $\begin{array}{l}\text { Las personas propusieron que el proceso de dialización sea aplicado también a otros productos como } \\
\text { por el ejemplo, el camote y layuca. }\end{array}$ \\
\hline
\end{tabular}




\begin{tabular}{|l|}
\hline \multicolumn{2}{|c|}{ FOCUS GROUP No O3 } \\
\hline \hline $\begin{array}{l}\text { Fecha: } 19 / 07 \\
\text { Nombrey Apellido del Encuestador : Ivet Aguirre }\end{array}$ \\
$\begin{array}{l}\text { Horade Inicio : 14:00 horas } \\
\text { Cantidad de Participates: Femeninos 03 (entre } 30 \text { a } 35 \text { años) - Masculinos } 02 \text { (entre } 35 \text { a } 40 \text { años) }\end{array}$ \\
\hline
\end{tabular}

¿Cuando consum e cualquier tipo de alimento, ¿lo hace pensando en su salud?

En el caso de los hombresindican que no siempre, solo en casos de estar delicados de salud (por la exigencia de una dieta) o si su condición física lo exige

En el caso de las mujeres, mencionaron que si, ya que son las personas que dejan los alimentos hechos para consumo de sus hijos ofamiliares

¿Con que frecuencia consume usted productos saludables?

En caso de los hombre, esporadicamente

En caso de las mujeres, casi siempre

¿Cuando piensa en consumo de productossaludables? ¿ En que lugares piensa para su adquisición?

En ambos casos, mencionaron que casas naturistas o ferias donde se ofrecen productos parala salud

¿Conoce laspropiedades nutritivas de la papa?

No conocen exactamente que tipo de nutrientes contiene lapapaen si y que beneficios proporciona al ser humano, perotienen la idea de que en la cascara se concentra la m ayor cantidad de ellos.

Masloven como un producto con propiedades curativas

¿ Ha escuchado del proceso de dialización de la papa ?, si su respuesta es afirm ativa, detállenos su conocim iento

Dospersonas saben del proceso de dialización en el ser hum ano, pero nadie sabe de este proceso aplicado a alimentos

¿ habiendo explicado a usted el proceso de dializacion de alimentos? considera que el producto es saludable?

La mayoría lo considera así, y algunos lo consideran más un producto natural, en el que deberíamos precisar cuanto de este tipo de producto se debe consumir como máximo para que nos proporcione la cantidad de potasio que nuestro organism o pueda asimilar correctamente

¿Conoce alguna marca o empresa que se dedique al proceso de dializacion de alimentos?

Ninguno conoce

De acuerdo a la respuesta anterior. Partiendo del punto que el producto le es interesante $\dot{c}$ Lo compraría? Partiendo del punto que elproducto no le es interesante, explique el motivo por qué no lo adquiriría

Si les parece interesante, por el tema de practicidad y por tener lacaracterística de ser saludable, en principio lo adquiririan en lamenorpresentación paraver si cubren sus expectativas

habiendo explicado las bondades del producto dializado,

piensa que puede serútil a alguna persona $\dot{c}$ a quienes recomendaría?

Consideran que efectivamente es más util a las personas que se encuentran delicadas de salud, y a las personas que se encuentran en buen estado les ayudaría por la practicidad de la presentación

\section{Que valor adicional usted agregaría a nue stra propuesta de negocio}

Que se mencione en la etiqueta las composicion nutritivade lapapa dializadavs unapapanormal, Las mujeres destacaraon que la form a como se presente es lo primero que atraeray que el sabor no varie 


\subsection{Anexo $\mathbf{N}^{\circ} 05$ - Ficha de Entrevista de Profundidad}

\begin{tabular}{|l|}
\hline FICHA ENTREVISTA DE PROFUNDIDAD N ${ }^{\circ}$ \\
\hline Fecha : \\
Nombre y Apellido del Entrevistador : \\
Hora de Inicio : \\
Nombre del Entrevistado: \\
Profesión u Ocupación del Participante :
\end{tabular}

1. ¿ Podria decirnos que alimentos o productos recomienda que se debe de comer para cuidar salud?

2. ¿Conoce las propiedades nutritivas de la papa?

3. ¿Cuando piensa en consumo de productos saludables, ¿En qué lugares piensa para su adquisición?

4. ¿Ha escuchado del proceso de dialización en alimentos ? Si su respuesta es afirmativa, detállenos su conocimiento Si su respuesta es negativa, donde buscaria para saber más sobre este proceso'

5. ¿ Habiéndole explicado a usted el proceso de dialización de alimentos ?, considera que el producto es saludable

6. ¿Conoce de alguna marca, empresa u hospita que realice el proceso de dialización en alimentos?

7. ¿h habiendo explicado las bondades del producto dializado, piensa que puede comprarlo o recomendarlo ?

8. ¿Qué valor adicional agregaria usted a nuestra propuesta de negocio ? 
13.6. Anexo $N^{\circ} 06-$ Encuesta

\section{ENCUESTA: CUESTIONARIO}

Buenos (as) Días/ Tardes/ Noches, soy alumno (a) de la Universidad San Ignacio de Loyola, escuela de Postgrado. Nos encontramos realizando una investigación de mercado para lo cual le realizaremos una serie de preguntas con el fin de medir el nivel de aceptación de un nuevo producto. Le agradecemos su colaboración anticipada y esperamos total sinceridad al responder:

1. ¿En qué rango de edades se encuentra?
a. 25 a 39 años
b. 40 a 54 años
c. 55 a 69 años
d. 70 a 79 años
e. Mayor a 80 años

2. ¿En cuál de estos distritos de Lima Norte reside?
a. Puente Piedra, Comas, Carabayllo
b. Independencia, Los Olivos, SMP( )
c. Otro
d. Mencionar:

3. ¿Cuántas personas conforman su hogar?
a. Solo usted
b. 2 personas
( )
c. 3 personas
( )
d. 4 personas
( )
e. 5 personas a más ( )

4. ¿Considera que los productos saludables generan calidad de vida?
a. Estoy totalmente de acuerdo
b. Estoy de acuerdo
c. Ni de acuerdo / Ni en desacuerdo
d. Estoy en desacuerdo
e. Estoy totalmente en desacuerdo

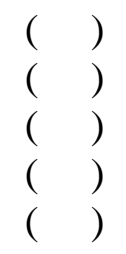

5. ¿Estaría dispuesto en adquirir un producto saludable para mejorar su régimen alimenticio?
a. $\mathrm{Si}$
b. No
c. No sabe/No opina( )

6. ¿Cree usted que la papa tiene beneficios para la salud? 

a. $\mathrm{Si}$
b. No
c. No sabe/No opina( )

7. ¿Con que frecuencia consume papa?
a. Siempre ( )
b. Regular ( )
c. A veces ( )
d. Nunca

8. ¿Ha tenido oportunidad de dializar algún alimento?

Dialización: Proceso por el cual se reducen los niveles de potasio de un alimento, esto para controlar los desechos que se acumulan en la sangre por su ingesta y regular el nivel de potasio en la nutrición diaria.
a. $\mathrm{Si}$
b. No

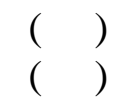

9. ¿Consumiría papa dializada?
a. $\mathrm{Si}$
b. No

10. ¿En cuál de estas presentaciones lo desearía adquirir?
a. $250 \mathrm{gr}$
b. $500 \mathrm{gr}$
c. Mayor a $500 \mathrm{gr}$
( )
$(\quad)$
)

11. ¿Cuánto pagaría por dicha presentación?
a. Entre S/. 1.00 y S/. 2.00
b. Entre S/. 2.00 y S/. 3.00
c. Entre S/. 3.00 y S/. 4.00
d. Más de S/. 4.00

12. ¿Por qué medio le gustaría enterarse de este nuevo producto?
a. TV
b. Radio
c. Facebook
d. Página Web
e. Otro

Mencionar:

13. ¿Con qué frecuencia compraría papa dializada? 

a. Semanal
b. Quincenal
c. Mensual
d. Bimestral

14. ¿Lugar donde lo compraría?
a. Tienda
$(\quad)$
b. Supermercado
c. Mercado
d. Otro
e. Mencionar:

15. ¿Cuál sería el motivo de compra de este nuevo producto?
a. Precio asequible
b. Practicidad
c. Salud
d. Seguridad
e. Todas las anteriores

$(\quad)$
$(\quad)$
$(\quad)$
$(\quad)$
$(\quad)$


13.7. Anexo $\mathbf{N}^{\circ} 07-$ Zonificaciòn de Lima Metropolitana

\section{LIMA METROPOLITANA}
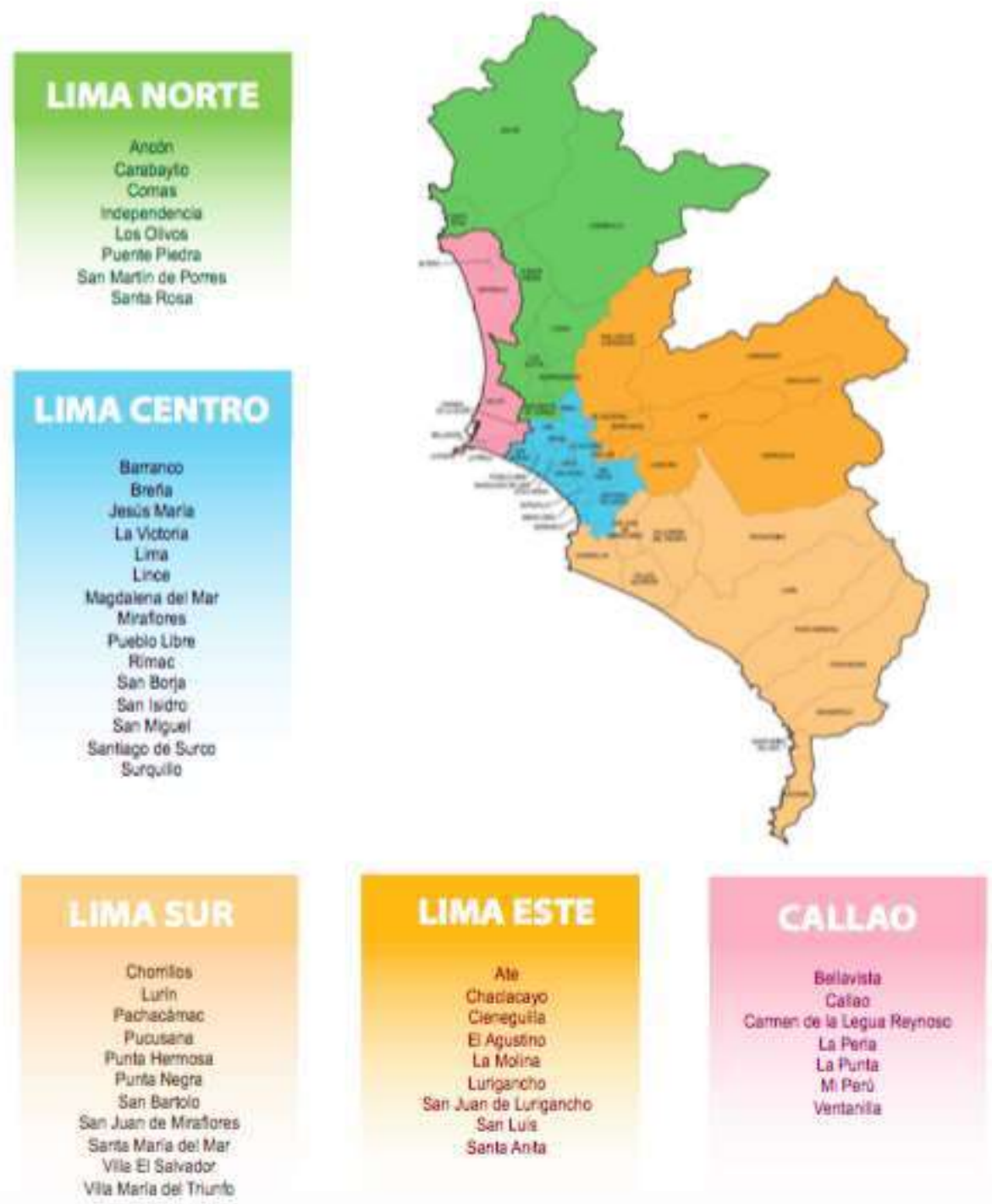

Figura 101.Una mirada a Lima Metropolitana, INEI (2014) 


\subsection{Anexo $\quad N^{\circ} 09$ - Analisis Fisico Quimico}

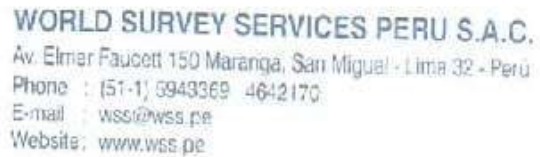

\section{INFORME DE ENSAYO N $460 / 16-\mathrm{L}$}

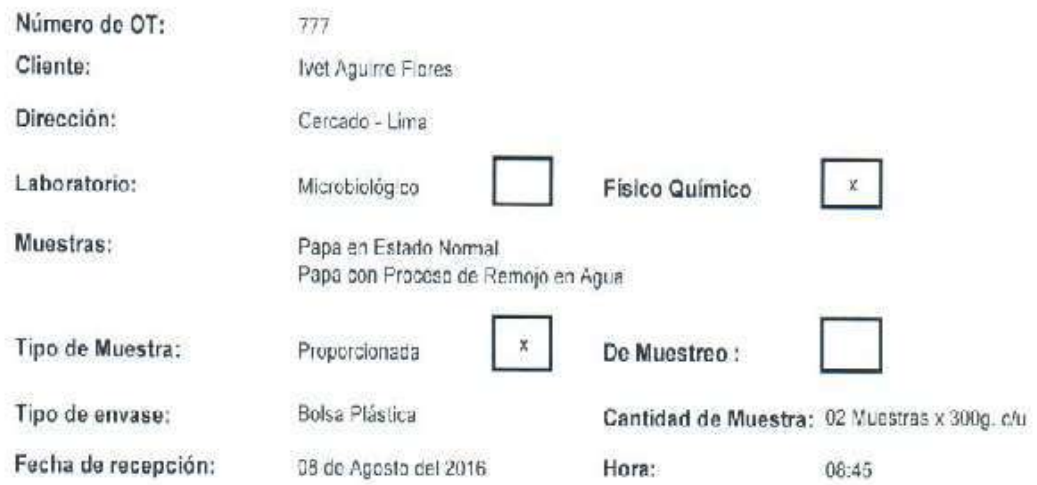

Fecha de inicio de Ensayo: 08 de Agcsto cel 2016 Fecha de término de ensayo: 13 de Agoslo del 2016

RESULTADOS

\begin{tabular}{|c|c|}
\hline Muestra - Descripción & $\begin{array}{l}\text { Potasio } \\
\text { (mg/kg) }\end{array}$ \\
\hline Papa cn Estado Normal & $4[0177$ \\
\hline $\begin{array}{c}\text { Papa } \\
\text { con Prasesa ca Remojo en Agua }\end{array}$ & 2833.5 \\
\hline
\end{tabular}

Mélodo de Ensayo:

Potasic $\quad$ AOAC 998,11

Observaciones:

Les racu todos oxrresfor den ten sclo a la muestra sarratida a ensayo

Le refroductión taral y'a parcial de este intorne nu es:a permitida sin ka astor zación por escrito de este laboratorio.

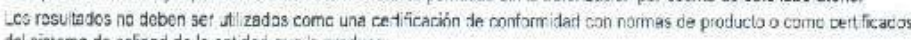
del sistema de calicad de la entidar que ba produce.

Lima, 13 de Agosto del 2016
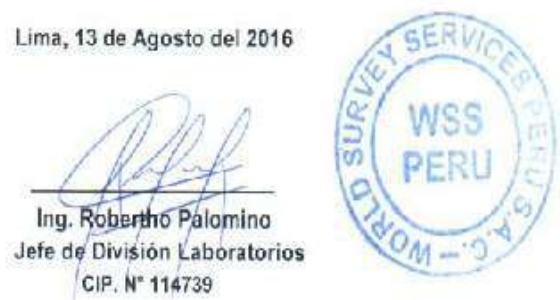

R LB 15 Rev $02 \quad 16062015$

Păg 1i,

\section{FiPSFA}

Figura 102. Resultado de Análisis Físico - Químico. 


\subsection{Anexo $\mathbf{N}^{\circ} 10$ - Interes Promedio del Sistema Bancario}

Tabla 152

Tasa de Interés Promedio del Sistema Bancario - SBS

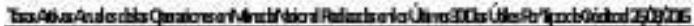

\begin{tabular}{|c|c|c|c|c|c|c|c|c|c|c|c|c|c|c|c|c|c|}
\hline Trandey & Cotrets & Doses & Gotin & firases & Ex & Sithen: & Oabis & netal & Nifaris & 208 & Etists & Srateria & noded. & Ateral: & Frand & (B) & Poued \\
\hline Gontha & 59 & . & (6) & $2 \mathrm{ZA}$ & 28 & 50 & 54 & 65 & - & - & . & $\mathscr{Z}$ &. & - & . & -1 & 65 \\
\hline Deats & $5 x$ & . & 65 & . & $\pi \Phi$ & 63 & $\approx$ & ॠ & $=$ & - & 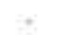 & 60 & . & + & $=$ & $\therefore$ & $\pi y$ \\
\hline Pátmelseatis & 58 & 2 & 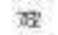 & 田 & 2 & 53 & 230 & 50 & - & 2 & . & - & 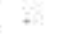 & - & - & - & 65 \\
\hline 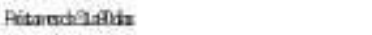 & 묘 & . & $\mathscr{P}$ & 29 & $\pi$ & SI & 포 & 뵤 & = & . & . & 22 & , & , & . & . & $5 E$ \\
\hline Petarudetaflids & Fis & - & 55 & $x$ & 55 & 50 & 63 & $\varpi 7$ & - & - & $=$ & का & - & - & - & - & $5 B$ \\
\hline Peturses Blatind & 58 & . & Ex & (3) & \& & - & - & 95 & - & - & - & $\Leftrightarrow$ & . & - & . & - & 72 \\
\hline Pétaleriatifintis & 71 & . & 241 & $6 \mathrm{~B}$ & II & . & . & $\Leftrightarrow$ & . & . & , & - & . & 8 & . & . & 27 \\
\hline Grituifess & ॠ & $D A$ & रतR & 82 & av & 659 & (W) & TS & - & क & . & EAtI & . & . & . & - & 73 \\
\hline Dasatx & 964 & $2 \pi n$. & an & GA & 24 & 69 & 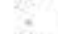 & 234 & . & 109 & . & eas & 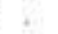 & 2 & . & 2 & $a s$ \\
\hline Petariasints & 59 & m & 822 & $\infty 0$ & - & 59 & 다 & 54 & - & 90 & . & 25 & . & - & - & - & 62 \\
\hline 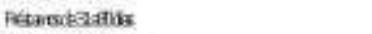 & 73 & $\mathrm{ED}$ & 35 & ab & as & 81 & 用 & 28 & - & 90 & - & क्ष & + & $=$ & - & $=$ & 77 \\
\hline Petromialatis & an & mon & $z J$ & 田 & 7 & 211 & 69 & $\infty$ & . & $\mathrm{mat}$ &. & 然 & . &. & . & . & $7 z$ \\
\hline Pelarodeflatids & 80 & $\because$ & 75 & 85 & 88 & 55 & $=$ & gक & - & 86 & - & 82 & - & - & - & - & TI \\
\hline Pstaisanatations: & 89 & - & en & 89 & $\mathscr{A}$ & $z x$ & - & 84: & 2 & 98 & - & 91 & 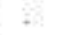 & $z$ & 2 & - & se. \\
\hline Natrufinpes & 1100 & 45. & 104 & DF & 962 & 907 & 68 & DE & DQ & 11108 & . & $\mathbb{A}$ & . & . & . & . & $D \theta$ \\
\hline Deasto: & 80 & 231 & 68 & 97 & $9 B$ & 99 & - & 98 & - & wis & $=$ & $8 \pi$ & . & - & - & - & I16 \\
\hline Petaristalis & 1100 & $D B$ & $9 x$ & (s) & 표 & प्रा & GA & IIP & . & IDI & + & [5] & . & . & . & . & 95 . \\
\hline Pétarortefifots & Dos & 131] & DS & 105 & 9 & 199 & $\ddot{m}$ & 112 & $=$ & 115 & - & 65) & - & $=$ & - & $=$ & Do \\
\hline Petaimoteatish & DS & 30 & 96 & DE: & ถ⿻ & 97) & - & III & DES & แक & . & $\theta$ & , & . & . & - & IS \\
\hline Petaritifinifinds & 00 & 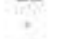 & 52 & 15 & HII & $2 D$ & 594 & IEP & Q8: & 290 & . & 7D & , & \% & . & . & 89 \\
\hline Pegrisariatotids & 09 & . & Dस & 34 & 115 & $9 d$ & 65ा & 1118 & 58 & 58 & . & 䨝 & . & . & - & - & Do \\
\hline Rapuituthipess & $n$ & EII & ga & 202 & 24 & 29 & $\therefore$ & $\mathrm{Ba}$ & 284 & mb & . & $\therefore$ & * & - & - & - & $2 \pi$ \\
\hline Denatas & 98 & - & \$ & $m$ & BD & BO & . & 92 & $=$ & - & . & 2 & . & . & $=$ & - & tas \\
\hline 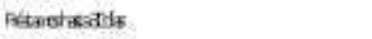 & 27 & 130 & का & min & - & 52 & $=$ & 1134 & अक & -. & $=$ & - & + & - & - & - & DB \\
\hline Petarsicatenis & $\mathrm{BD}$ & BII & 89 & 25 & 211 & 29 & . & Its & gा? & 100 & . & . & . & 2 & . & . & 90 \\
\hline Pesmodatifide & E71 & $=$ & ES & zxI & yI & 15 I5 & - & 155 & 35 & zin & - & - & : & $=$ & $=$ & - & $D E$ \\
\hline 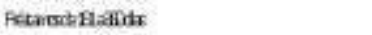 & 10 & . & 2e्e & 32 & กติ & 28 & $=$ & 20 & $2 \mathrm{EII}$ & 20 & 2 & $\therefore$ & - & - & $=$ & - & ne \\
\hline Petrivereatifits & 256 & , & MES & $20 \mathrm{~F}$ & 0 is & 399 & . & 88 & 289 & $\mathrm{~EB}$ & , & . & , & . & . & . & 278 \\
\hline Narupeses & $B B$ & 3n & 28 & क्क & 550 & $D$ & 2 & ZF & 335 & 5 & - & - & - & $=$ & - & $=$ & Eन \\
\hline Tayambiate & 319 & $m$ & I4 & ES & . & De & . & - & . & - & - & . & . & . & . & - & ats \\
\hline Denats & 18 & - & 80 & $=$ & ED & Ds & - & $\dddot{中}$ & - & - & - & - & + & $=$ & - & $=$ & $\mathbb{D P}$ \\
\hline Pecturifadertes & $B R$ & , & $\because$ & . & DOH & . & * & 91 & , & * & . & . & $\therefore$ & . & . & . & DR \\
\hline 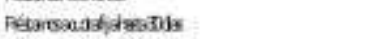 & 200 & - & $\Leftrightarrow$ & $=$ & - & 30 & - & 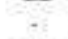 & $\omega$ & - & . & - & . & $=$ & - & $=$ & zका \\
\hline 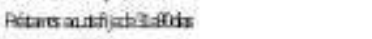 & 20 & . & 20 & $4 a$ & . & $\mathrm{ma}$ & . & $2 E$ & 58 & - & . & - & . & . & . & - & $4 \pi$ \\
\hline Petriesatafiactanifis & HFA & . & IS & 68 & $=$ & ail & $=$ & 205 & 527 & 迈 & $=$ & $=$ & $=$ & $=$ & $=$ & - & $\mathbb{P}$ \\
\hline Petrisandifablistids & ag & mI & 29 & $\operatorname{sen}$ & 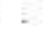 & 28 & - & 20 & ats & $-\therefore$ & 2 & - & . & $=$ & - & - & $\sin$ \\
\hline 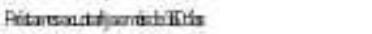 & 1100 & . & 84 & $\Phi 4$ & . & 233 & . & $2 D D$ & Bt & in & . & . & r & , & . & . & $m$ \\
\hline Gane & 5 & $E 9$ & $\exists G$ & 524 & $\mathrm{Dx}$ & $\Delta B$ & $\therefore$ & 60 & 594 & कृत & 50 & $=$ & 35 & $\mathrm{Bn}$ & $F D$ & - & ME \\
\hline Tajtedesto & 58 & 25 & 591 & 48 & min & 302 & - & 4 & - & an & qL & - & 67: & rear & a्य) & - & 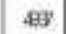 \\
\hline Pitrivpedrates: & 80 & 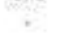 & $\therefore$ & . & 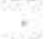 & 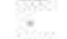 & . & 92 & . & . & . & . & . & 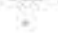 & . & . & os \\
\hline Répropedeterasabioks & $\mathrm{Hz}$ & - & 1 & - & DE & 107 & - & DB: & - & 밍 & ns: & - & . & . & . & - & un \\
\hline 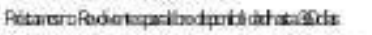 & IIs & $\mathrm{KE}$ & sil & aI & 19 & . & . & 20 & ㄸㅐㅛ & - & Bus & - & 40 & seat & . & . & TEA \\
\hline 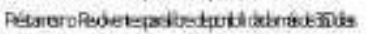 & DSA & DE & 68 & BDI & wa & का & - & 29 & $A Q$ & 88 & DEx & - & 35 & DE & - & - & IZA \\
\hline catrogoatr & 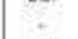 & $\operatorname{san}$ & 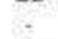 & $=$ & - & $\because$ & $\therefore$ & - & - & - & - & - & + & $=$ & - & - & 698 \\
\hline Hamis & al & 95 & $0 \%$ & 9 田 & 90 & 951 & . & 95 & EDO & 90 & . & . & . &. & $=$ & . & 69 \\
\hline Pstrotopaschanench & 87 & 99 & $\mathrm{~PB}$ & gृ & का & 95 & - & 95 & $B D$ & gn & - & - & . & . & - & - & 89 \\
\hline
\end{tabular}

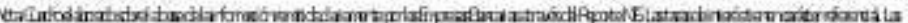

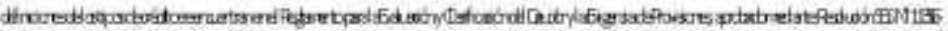

IIE) (endingares 
13.10. Anexo $N^{\circ} 11$ - Porjentaje de Depreciaciòn de Bienes

Los porcentajes de depreciación de acuerdo con el artículo $22^{\circ}$ del Reglamento de la Ley de Impuesto a la Renta D.S. No 122.94-EF, son los siguientes:

\begin{tabular}{|l|c|}
\hline \multicolumn{1}{|c|}{ BIENES } & $\%$ \\
\hline Ediricios y construcciones. & 3 \\
\hline Maquinarias. & 10 \\
\hline Maquinarias en act widades mineras petroleras y de construcción. & 10 \\
\hline Muebles y Enseres. & 10 \\
\hline Vehiculos de transporte. & 20 \\
\hline Equipos de procesamiento de datos. & 25 \\
\hline Ganados de trabajo y reproducción, redes de pesca. & 25 \\
\hline
\end{tabular}

Figura 103. Porcentajes de Depreciación de Bienes 
13.11. Anexo $\mathrm{N}^{\circ} 12$ - Proyecciòn Prestamo Banco Continental

Tabla 153

Proyección Cuotas de Presta - Banco Continental

\begin{tabular}{|c|c|c|c|c|c|c|c|c|}
\hline $\begin{array}{l}\text { Monto: } \\
\text { Cuotas: } \\
\text { Sistema: }\end{array}$ & $\begin{array}{r}\text { S/. 116,094.82 } \\
60 \\
\text { Francés }\end{array}$ & $\begin{array}{l}\text { Soles } \\
\text { mensuales }\end{array}$ & Grac & $\begin{array}{l}\text { terés anual: } \\
\text { nterés Men: } \\
\text { a de capital: }\end{array}$ & $\begin{array}{r}14.26 \% \\
1.12 \% \\
0\end{array}$ & $\begin{array}{l}\text { EA } \\
\text { EM } \\
\text { neses }\end{array}$ & & \\
\hline Cuotas & Capital & Interés & $\begin{array}{l}\text { Importe de } \\
\text { Cuota }\end{array}$ & Saldo & $\begin{array}{c}\text { Importe } \\
\text { total a } \\
\text { pagar }\end{array}$ & & & \\
\hline $\begin{array}{l}\text { Saldo } \\
\text { Inicial }\end{array}$ & & & & $116,094.82$ & & & & \\
\hline 001 & $1,368.77$ & $1,296.87$ & $2,665.64$ & $114,726.05$ & $2,665.64$ & & & \\
\hline 002 & $1,384.06$ & $1,281.58$ & $2,665.64$ & $113,341.99$ & $2,665.64$ & & & \\
\hline 003 & $1,399.52$ & $1,266.12$ & $2,665.64$ & $111,942.47$ & $2,665.64$ & & & \\
\hline 004 & $1,415.16$ & $1,250.49$ & $2,665.64$ & $110,527.31$ & $2,665.64$ & & & \\
\hline 005 & $1,430.96$ & $1,234.68$ & $2,665.64$ & $109,096.35$ & $2,665.64$ & & & \\
\hline 006 & $1,446.95$ & $1,218.69$ & $2,665.64$ & $107,649.40$ & $2,665.64$ & & & \\
\hline 007 & $1,463.11$ & $1,202.53$ & $2,665.64$ & $106,186.28$ & $2,665.64$ & & & \\
\hline 008 & $1,479.46$ & $1,186.19$ & $2,665.64$ & $104,706.83$ & $2,665.64$ & & & \\
\hline 009 & $1,495.98$ & $1,169.66$ & $2,665.64$ & $103,210.84$ & $2,665.64$ & & & \\
\hline 010 & $1,512.70$ & $1,152.95$ & $2,665.64$ & $101,698.15$ & $2,665.64$ & & & \\
\hline 011 & $1,529.59$ & $1,136.05$ & $2,665.64$ & $100,168.55$ & $2,665.64$ & Intereses & Pagado & \\
\hline 012 & $1,546.68$ & $1,118.96$ & $2,665.64$ & $98,621.87$ & $2,665.64$ & $14,514.76$ & $31,987.71$ & Año 1 \\
\hline 013 & $1,563.96$ & $1,101.68$ & $2,665.64$ & $97,057.91$ & $2,665.64$ & & & \\
\hline 014 & $1,581.43$ & $1,084.21$ & $2,665.64$ & $95,476.49$ & $2,665.64$ & & & \\
\hline 015 & $1,599.09$ & $1,066.55$ & $2,665.64$ & $93,877.39$ & $2,665.64$ & & & \\
\hline 016 & $1,616.96$ & $1,048.69$ & $2,665.64$ & $92,260.43$ & $2,665.64$ & & & \\
\hline 017 & $1,635.02$ & $1,030.62$ & $2,665.64$ & $90,625.41$ & $2,665.64$ & & & \\
\hline 018 & $1,653.28$ & $1,012.36$ & $2,665.64$ & $88,972.13$ & $2,665.64$ & & & \\
\hline 019 & $1,671.75$ & 993.89 & $2,665.64$ & $87,300.38$ & $2,665.64$ & & & \\
\hline 020 & $1,690.43$ & 975.21 & $2,665.64$ & $85,609.95$ & $2,665.64$ & & & \\
\hline 021 & $1,709.31$ & 956.33 & $2,665.64$ & $83,900.64$ & $2,665.64$ & & & \\
\hline 022 & $1,728.41$ & 937.24 & $2,665.64$ & $82,172.23$ & $2,665.64$ & & & \\
\hline 023 & $1,747.71$ & 917.93 & $2,665.64$ & $80,424.52$ & $2,665.64$ & Intereses & Pagado & \\
\hline 024 & $1,767.24$ & 898.41 & $2,665.64$ & $78,657.28$ & $2,665.64$ & $12,023.12$ & $31,987.71$ & Año 2 \\
\hline 025 & $1,786.98$ & 878.66 & $2,665.64$ & $76,870.30$ & $2,665.64$ & & & \\
\hline 026 & $1,806.94$ & 858.70 & $2,665.64$ & $75,063.36$ & $2,665.64$ & & & \\
\hline 027 & $1,827.13$ & 838.52 & $2,665.64$ & $73,236.24$ & $2,665.64$ & & & \\
\hline 028 & $1,847.54$ & 818.11 & $2,665.64$ & $71,388.70$ & $2,665.64$ & & & \\
\hline 029 & $1,868.17$ & 797.47 & $2,665.64$ & $69,520.53$ & $2,665.64$ & & & \\
\hline 030 & $1,889.04$ & 776.60 & $2,665.64$ & $67,631.48$ & $2,665.64$ & & & \\
\hline 031 & $1,910.15$ & 755.50 & $2,665.64$ & $65,721.34$ & $2,665.64$ & & & \\
\hline 032 & $1,931.48$ & 734.16 & $2,665.64$ & $63,789.85$ & $2,665.64$ & & & \\
\hline 033 & $1,953.06$ & 712.58 & $2,665.64$ & $61,836.79$ & $2,665.64$ & & & \\
\hline 034 & $1,974.88$ & 690.77 & $2,665.64$ & $59,861.92$ & $2,665.64$ & & & \\
\hline 035 & $1,996.94$ & 668.71 & $2,665.64$ & $57,864.98$ & $2,665.64$ & Intereses & Pagado & \\
\hline 036 & $2,019.24$ & 646.40 & $2,665.64$ & $55,845.73$ & $2,665.64$ & $9,176.17$ & $31,987.71$ & Año 3 \\
\hline 037 & $2,041.80$ & 623.84 & $2,665.64$ & $53,803.93$ & $2,665.64$ & & & \\
\hline 038 & $2,064.61$ & 601.03 & $2,665.64$ & $51,739.32$ & $2,665.64$ & & & \\
\hline 039 & $2,087.67$ & 577.97 & $2,665.64$ & $49,651.65$ & $2,665.64$ & & & \\
\hline 040 & $2,110.99$ & 554.65 & $2,665.64$ & $47,540.66$ & $2,665.64$ & & & \\
\hline 041 & $2,134.58$ & 531.07 & $2,665.64$ & $45,406.08$ & $2,665.64$ & & & \\
\hline 042 & $2,158.42$ & 507.22 & $2,665.64$ & $43,247.66$ & $2,665.64$ & & & \\
\hline 043 & $2,182.53$ & 483.11 & $2,665.64$ & $41,065.13$ & $2,665.64$ & & & \\
\hline 044 & $2,206.91$ & 458.73 & $2,665.64$ & $38,858.21$ & $2,665.64$ & & & \\
\hline 045 & $2,231.57$ & 434.08 & $2,665.64$ & $36,626.65$ & $2,665.64$ & & & \\
\hline 046 & $2,256.49$ & 409.15 & $2,665.64$ & $34,370.15$ & $2,665.64$ & & & \\
\hline 047 & $2,281.70$ & 383.94 & $2,665.64$ & $32,088.45$ & $2,665.64$ & Intereses & Pagado & \\
\hline 048 & $2,307.19$ & 358.45 & $2,665.64$ & $29,781.26$ & $2,665.64$ & $5,923.24$ & $31,987.71$ & Año 4 \\
\hline 049 & $2,332.96$ & 332.68 & $2,665.64$ & $27,448.30$ & $2,665.64$ & & & \\
\hline 050 & $2,359.02$ & 306.62 & $2,665.64$ & $25,089.28$ & $2,665.64$ & & & \\
\hline 051 & $2,385.38$ & 280.27 & $2,665.64$ & $22,703.90$ & $2,665.64$ & & & \\
\hline 052 & $2,412.02$ & 253.62 & $2,665.64$ & $20,291.88$ & $2,665.64$ & & & \\
\hline 053 & $2,438.97$ & 226.68 & $2,665.64$ & $17,852.91$ & $2,665.64$ & & & \\
\hline 054 & $2,466.21$ & 199.43 & $2,665.64$ & $15,386.70$ & $2,665.64$ & & & \\
\hline 055 & $2,493.76$ & 171.88 & $2,665.64$ & $12,892.94$ & $2,665.64$ & & & \\
\hline 056 & $2,521.62$ & 144.02 & $2,665.64$ & $10,371.32$ & $2,665.64$ & & & \\
\hline 057 & $2,549.79$ & 115.86 & $2,665.64$ & $7,821.54$ & $2,665.64$ & & & \\
\hline 058 & $2,578.27$ & 87.37 & $2,665.64$ & $5,243.27$ & $2,665.64$ & & & \\
\hline 059 & $2,607.07$ & 58.57 & $2,665.64$ & $2,636.19$ & $2,665.64$ & Intereses & Pagado & \\
\hline 060 & $2,636.19$ & 29.45 & $2,665.64$ & 0.00 & $2,665.64$ & $2,206.45$ & $31,987.71$ & Año 5 \\
\hline
\end{tabular}


13.12. Anexo $\mathbf{N}^{\circ} \mathbf{1 3}$ - Proyecciòn Prestamo Banco de Credito

Tabla 154

Proyección Cuotas de Presta - Banco de Crédito del Perú

\begin{tabular}{|c|c|c|c|c|c|c|c|c|}
\hline $\begin{array}{l}\text { Monto: } \\
\text { Cuotas: } \\
\text { Sistema: }\end{array}$ & $\begin{array}{r}\mathbf{S} / . \mathbf{1 1 6 , 0 9 4 . 8 2} \\
60 \\
\text { Francés }\end{array}$ & $\begin{array}{l}\text { Soles } \\
\text { mensuales }\end{array}$ & Ir & $\begin{array}{l}\text { terés anual: } \\
\text { nterés Men: } \\
\text { a de capital: }\end{array}$ & $\begin{array}{r}14.85 \% \\
1.16 \% \\
0\end{array}$ & & & \\
\hline Cuotas & Capital & Interés & $\begin{array}{c}\text { Importe de } \\
\text { Cuota }\end{array}$ & Saldo & $\begin{array}{c}\text { Importe } \\
\text { total a } \\
\text { pagar }\end{array}$ & & & \\
\hline $\begin{array}{l}\text { Saldo } \\
\text { Inicial }\end{array}$ & & & & $116,094.82$ & & & & \\
\hline 001 & $1,349.60$ & $1,347.27$ & $2,696.86$ & $114,745.23$ & $2,696.86$ & & & \\
\hline 002 & $1,365.26$ & $1,331.60$ & $2,696.86$ & $113,379.97$ & $2,696.86$ & & & \\
\hline 003 & $1,381.10$ & $1,315.76$ & $2,696.86$ & $111,998.87$ & $2,696.86$ & & & \\
\hline 004 & $1,397.13$ & $1,299.73$ & $2,696.86$ & $110,601.74$ & $2,696.86$ & & & \\
\hline 005 & $1,413.34$ & $1,283.52$ & $2,696.86$ & $109,188.39$ & $2,696.86$ & & & \\
\hline 006 & $1,429.74$ & $1,267.12$ & $2,696.86$ & $107,758.65$ & $2,696.86$ & & & \\
\hline 007 & $1,446.34$ & $1,250.53$ & $2,696.86$ & $106,312.31$ & $2,696.86$ & & & \\
\hline 008 & $1,463.12$ & $1,233.74$ & $2,696.86$ & $104,849.19$ & $2,696.86$ & & & \\
\hline 009 & $1,480.10$ & $1,216.76$ & $2,696.86$ & $103,369.09$ & $2,696.86$ & & & \\
\hline 010 & $1,497.28$ & $1,199.59$ & $2,696.86$ & $101,871.81$ & $2,696.86$ & & & \\
\hline 011 & $1,514.65$ & $1,182.21$ & $2,696.86$ & $100,357.16$ & $2,696.86$ & Intereses & Pagado & \\
\hline 012 & $1,532.23$ & $1,164.63$ & $2,696.86$ & $98,824.93$ & $2,696.86$ & $15,092.47$ & $32,362.36$ & Año 1 \\
\hline 013 & $1,550.01$ & $1,146.85$ & $2,696.86$ & $97,274.92$ & $2,696.86$ & & & \\
\hline 014 & $1,568.00$ & $1,128.86$ & $2,696.86$ & $95,706.92$ & $2,696.86$ & & & \\
\hline 015 & $1,586.20$ & $1,110.67$ & $2,696.86$ & $94,120.72$ & $2,696.86$ & & & \\
\hline 016 & $1,604.60$ & $1,092.26$ & $2,696.86$ & $92,516.12$ & $2,696.86$ & & & \\
\hline 017 & $1,623.22$ & $1,073.64$ & $2,696.86$ & $90,892.90$ & $2,696.86$ & & & \\
\hline 018 & $1,642.06$ & $1,054.80$ & $2,696.86$ & $89,250.84$ & $2,696.86$ & & & \\
\hline 019 & $1,661.12$ & $1,035.75$ & $2,696.86$ & $87,589.72$ & $2,696.86$ & & & \\
\hline 020 & $1,680.39$ & $1,016.47$ & $2,696.86$ & $85,909.32$ & $2,696.86$ & & & \\
\hline 021 & $1,699.90$ & 996.97 & $2,696.86$ & $84,209.43$ & $2,696.86$ & & & \\
\hline 022 & $1,719.62$ & 977.24 & $2,696.86$ & $82,489.80$ & $2,696.86$ & & & \\
\hline 023 & $1,739.58$ & 957.28 & $2,696.86$ & $80,750.23$ & $2,696.86$ & Intereses & Pagado & \\
\hline 024 & $1,759.77$ & 937.10 & $2,696.86$ & $78,990.46$ & $2,696.86$ & $12,527.89$ & $32,362.36$ & Año 2 \\
\hline 025 & $1,780.19$ & 916.67 & $2,696.86$ & $77,210.27$ & $2,696.86$ & & & \\
\hline 026 & $1,800.85$ & 896.02 & $2,696.86$ & $75,409.42$ & $2,696.86$ & & & \\
\hline 027 & $1,821.75$ & 875.12 & $2,696.86$ & $73,587.68$ & $2,696.86$ & & & \\
\hline 028 & $1,842.89$ & 853.98 & $2,696.86$ & $71,744.79$ & $2,696.86$ & & & \\
\hline 029 & $1,864.27$ & 832.59 & $2,696.86$ & $69,880.52$ & $2,696.86$ & & & \\
\hline 030 & $1,885.91$ & 810.96 & $2,696.86$ & $67,994.61$ & $2,696.86$ & & & \\
\hline 031 & $1,907.79$ & 789.07 & $2,696.86$ & $66,086.82$ & $2,696.86$ & & & \\
\hline 032 & $1,929.93$ & 766.93 & $2,696.86$ & $64,156.88$ & $2,696.86$ & & & \\
\hline 033 & $1,952.33$ & 744.53 & $2,696.86$ & $62,204.55$ & $2,696.86$ & & & \\
\hline 034 & $1,974.99$ & 721.88 & $2,696.86$ & $60,229.57$ & $2,696.86$ & & & \\
\hline 035 & $1,997.91$ & 698.96 & $2,696.86$ & $58,231.66$ & $2,696.86$ & Intereses & Pagado & \\
\hline 036 & $2,021.09$ & 675.77 & $2,696.86$ & $56,210.57$ & $2,696.86$ & $9,582.47$ & $32,362.36$ & Año 3 \\
\hline 037 & $2,044.55$ & 652.32 & $2,696.86$ & $54,166.02$ & $2,696.86$ & & & \\
\hline 038 & $2,068.27$ & 628.59 & $2,696.86$ & $52,097.75$ & $2,696.86$ & & & \\
\hline 039 & $2,092.27$ & 604.59 & $2,696.86$ & $50,005.48$ & $2,696.86$ & & & \\
\hline 040 & $2,116.56$ & 580.31 & $2,696.86$ & $47,888.92$ & $2,696.86$ & & & \\
\hline 041 & $2,141.12$ & 555.75 & $2,696.86$ & $45,747.80$ & $2,696.86$ & & & \\
\hline 042 & $2,165.97$ & 530.90 & $2,696.86$ & $43,581.84$ & $2,696.86$ & & & \\
\hline 043 & $2,191.10$ & 505.76 & $2,696.86$ & $41,390.74$ & $2,696.86$ & & & \\
\hline 044 & $2,216.53$ & 480.33 & $2,696.86$ & $39,174.21$ & $2,696.86$ & & & \\
\hline 045 & $2,242.25$ & 454.61 & $2,696.86$ & $36,931.96$ & $2,696.86$ & & & \\
\hline 046 & $2,268.27$ & 428.59 & $2,696.86$ & $34,663.68$ & $2,696.86$ & & & \\
\hline 047 & $2,294.60$ & 402.27 & $2,696.86$ & $32,369.09$ & $2,696.86$ & Intereses & Pagado & \\
\hline 048 & $2,321.22$ & 375.64 & $2,696.86$ & $30,047.87$ & $2,696.86$ & 6,199.65 & $32,362.36$ & Año 4 \\
\hline 049 & $2,348.16$ & 348.70 & $2,696.86$ & $27,699.70$ & $2,696.86$ & & & \\
\hline 050 & $2,375.41$ & 321.45 & $2,696.86$ & $25,324.29$ & $2,696.86$ & & & \\
\hline 051 & $2,402.98$ & 293.89 & $2,696.86$ & $22,921.32$ & $2,696.86$ & & & \\
\hline 052 & $2,430.86$ & 266.00 & $2,696.86$ & $20,490.45$ & $2,696.86$ & & & \\
\hline 053 & $2,459.07$ & 237.79 & $2,696.86$ & $18,031.38$ & $2,696.86$ & & & \\
\hline 054 & $2,487.61$ & 209.25 & $2,696.86$ & $15,543.77$ & $2,696.86$ & & & \\
\hline 055 & $2,516.48$ & 180.38 & $2,696.86$ & $13,027.29$ & $2,696.86$ & & & \\
\hline 056 & $2,545.68$ & 151.18 & $2,696.86$ & $10,481.60$ & $2,696.86$ & & & \\
\hline 057 & $2,575.23$ & 121.64 & $2,696.86$ & $7,906.38$ & $2,696.86$ & & & \\
\hline 058 & $2,605.11$ & 91.75 & $2,696.86$ & $5,301.27$ & $2,696.86$ & & & \\
\hline 059 & $2,635.34$ & 61.52 & $2,696.86$ & $2,665.93$ & $2,696.86$ & Intereses & Pagado & \\
\hline 060 & $2,665.93$ & 30.94 & $2,696.86$ & 0.00 & $2,696.86$ & $2,314.49$ & $32,362.36$ & Año 5 \\
\hline
\end{tabular}


13.13. Anexo No 14 - Proyecciòn Prestamo Banco Interbank

Tabla 155

Proyección Cuotas de Presta - Banco Interbank

\begin{tabular}{|c|c|c|c|c|c|c|c|c|c|}
\hline $\begin{array}{l}\text { Monto: } \\
\text { Cuotas: } \\
\text { Sistema: }\end{array}$ & $\mathrm{S} /$. & $\begin{array}{r}\mathbf{1 1 6 , 0 9 4 . 8 2} \\
60 \\
\text { Francés }\end{array}$ & $\begin{array}{l}\text { Soles } \\
\text { mensuales }\end{array}$ & Grac & $\begin{array}{l}\text { Iterés anual: } \\
\text { Interés Men: } \\
\text { ia de capital: }\end{array}$ & $\begin{array}{r}19.51 \% \\
1.50 \% \\
0\end{array}$ & & & \\
\hline Cuotas & & Capital & Interés & $\begin{array}{l}\text { Importe de } \\
\text { Cuota }\end{array}$ & Saldo & $\begin{array}{c}\text { Importe } \\
\text { total a } \\
\text { pagar }\end{array}$ & & & \\
\hline $\begin{array}{l}\text { Saldo } \\
\text { Inicial }\end{array}$ & & & & & $116,094.82$ & & & & \\
\hline 001 & & $1,208.10$ & $1,737.17$ & $2,945.27$ & $114,886.72$ & $2,945.27$ & & & \\
\hline 002 & & $1,226.18$ & $1,719.09$ & $2,945.27$ & $113,660.54$ & $2,945.27$ & & & \\
\hline 003 & & $1,244.53$ & $1,700.74$ & $2,945.27$ & $112,416.02$ & $2,945.27$ & & & \\
\hline 004 & & $1,263.15$ & $1,682.12$ & $2,945.27$ & $111,152.87$ & $2,945.27$ & & & \\
\hline 005 & & $1,282.05$ & $1,663.22$ & $2,945.27$ & $109,870.82$ & $2,945.27$ & & & \\
\hline 006 & & $1,301.23$ & $1,644.03$ & $2,945.27$ & $108,569.58$ & $2,945.27$ & & & \\
\hline 007 & & $1,320.70$ & $1,624.56$ & $2,945.27$ & $107,248.88$ & $2,945.27$ & & & \\
\hline 008 & & $1,340.47$ & $1,604.80$ & $2,945.27$ & $105,908.41$ & $2,945.27$ & & & \\
\hline 009 & & $1,360.52$ & $1,584.74$ & $2,945.27$ & $104,547.89$ & $2,945.27$ & & & \\
\hline 010 & & $1,380.88$ & $1,564.39$ & $2,945.27$ & $103,167.01$ & $2,945.27$ & & & \\
\hline 011 & & $1,401.55$ & $1,543.72$ & $2,945.27$ & $101,765.46$ & $2,945.27$ & Intereses & Pagado & \\
\hline 012 & & $1,422.52$ & $1,522.75$ & $2,945.27$ & $100,342.94$ & $2,945.27$ & $19,591.33$ & $35,343.21$ & Año 1 \\
\hline 013 & & $1,443.80$ & $1,501.47$ & $2,945.27$ & $98,899.14$ & $2,945.27$ & & & \\
\hline 014 & & $1,465.41$ & $1,479.86$ & $2,945.27$ & $97,433.74$ & $2,945.27$ & & & \\
\hline 015 & & $1,487.33$ & $1,457.93$ & $2,945.27$ & $95,946.40$ & $2,945.27$ & & & \\
\hline 016 & & $1,509.59$ & $1,435.68$ & $2,945.27$ & $94,436.81$ & $2,945.27$ & & & \\
\hline 017 & & $1,532.18$ & $1,413.09$ & $2,945.27$ & $92,904.63$ & $2,945.27$ & & & \\
\hline 018 & & $1,555.10$ & $1,390.16$ & $2,945.27$ & $91,349.53$ & $2,945.27$ & & & \\
\hline 019 & & $1,578.37$ & $1,366.89$ & $2,945.27$ & $89,771.16$ & $2,945.27$ & & & \\
\hline 020 & & $1,601.99$ & $1,343.28$ & $2,945.27$ & $88,169.16$ & $2,945.27$ & & & \\
\hline 021 & & $1,625.96$ & $1,319.30$ & $2,945.27$ & $86,543.20$ & $2,945.27$ & & & \\
\hline 022 & & $1,650.29$ & $1,294.97$ & $2,945.27$ & $84,892.91$ & $2,945.27$ & & & \\
\hline 023 & & $1,674.99$ & $1,270.28$ & $2,945.27$ & $83,217.92$ & $2,945.27$ & Intereses & Pagado & \\
\hline 024 & & $1,700.05$ & $1,245.22$ & $2,945.27$ & $81,517.87$ & $2,945.27$ & $16,518.14$ & $35,343.21$ & Año 2 \\
\hline 025 & & $1,725.49$ & $1,219.78$ & $2,945.27$ & $79,792.38$ & $2,945.27$ & & & \\
\hline 026 & & $1,751.31$ & $1,193.96$ & $2,945.27$ & $78,041.08$ & $2,945.27$ & & & \\
\hline 027 & & $1,777.51$ & $1,167.75$ & $2,945.27$ & $76,263.56$ & $2,945.27$ & & & \\
\hline 028 & & $1,804.11$ & $1,141.16$ & $2,945.27$ & $74,459.45$ & $2,945.27$ & & & \\
\hline 029 & & $1,831.11$ & $1,114.16$ & $2,945.27$ & $72,628.35$ & $2,945.27$ & & & \\
\hline 030 & & $1,858.51$ & $1,086.76$ & $2,945.27$ & $70,769.84$ & $2,945.27$ & & & \\
\hline 031 & & $1,886.31$ & $1,058.95$ & $2,945.27$ & $68,883.53$ & $2,945.27$ & & & \\
\hline 032 & & $1,914.54$ & $1,030.73$ & $2,945.27$ & $66,968.99$ & $2,945.27$ & & & \\
\hline 033 & & $1,943.19$ & $1,002.08$ & $2,945.27$ & $65,025.80$ & $2,945.27$ & & & \\
\hline 034 & & $1,972.26$ & 973.00 & $2,945.27$ & $63,053.54$ & $2,945.27$ & & & \\
\hline 035 & & $2,001.78$ & 943.49 & $2,945.27$ & $61,051.76$ & $2,945.27$ & Intereses & Pagado & \\
\hline 036 & & $2,031.73$ & 913.54 & $2,945.27$ & $59,020.03$ & $2,945.27$ & $12,845.37$ & $35,343.21$ & Año 3 \\
\hline 037 & & $2,062.13$ & 883.14 & $2,945.27$ & $56,957.90$ & $2,945.27$ & & & \\
\hline 038 & & $2,092.99$ & 852.28 & $2,945.27$ & $54,864.91$ & $2,945.27$ & & & \\
\hline 039 & & $2,124.31$ & 820.96 & $2,945.27$ & $52,740.61$ & $2,945.27$ & & & \\
\hline 040 & & $2,156.09$ & 789.18 & $2,945.27$ & $50,584.51$ & $2,945.27$ & & & \\
\hline 041 & & $2,188.35$ & 756.91 & $2,945.27$ & $48,396.16$ & $2,945.27$ & & & \\
\hline 042 & & $2,221.10$ & 724.17 & $2,945.27$ & $46,175.06$ & $2,945.27$ & & & \\
\hline 043 & & $2,254.33$ & 690.93 & $2,945.27$ & $43,920.73$ & $2,945.27$ & & & \\
\hline 044 & & $2,288.07$ & 657.20 & $2,945.27$ & $41,632.66$ & $2,945.27$ & & & \\
\hline 045 & & $2,322.30$ & 622.96 & $2,945.27$ & $39,310.36$ & $2,945.27$ & & & \\
\hline 046 & & $2,357.05$ & 588.21 & $2,945.27$ & $36,953.30$ & $2,945.27$ & & & \\
\hline 047 & & $2,392.32$ & 552.94 & $2,945.27$ & $34,560.98$ & $2,945.27$ & Intereses & Pagado & \\
\hline 048 & & $2,428.12$ & 517.15 & $2,945.27$ & $32,132.86$ & $2,945.27$ & $8,456.04$ & $35,343.21$ & Año 4 \\
\hline 049 & & $2,464.45$ & 480.81 & $2,945.27$ & $29,668.41$ & $2,945.27$ & & & \\
\hline 050 & & $2,501.33$ & 443.94 & $2,945.27$ & $27,167.08$ & $2,945.27$ & & & \\
\hline 051 & & $2,538.76$ & 406.51 & $2,945.27$ & $24,628.32$ & $2,945.27$ & & & \\
\hline 052 & & $2,576.75$ & 368.52 & $2,945.27$ & $22,051.57$ & $2,945.27$ & & & \\
\hline 053 & & $2,615.30$ & 329.97 & $2,945.27$ & $19,436.27$ & $2,945.27$ & & & \\
\hline 054 & & $2,654.44$ & 290.83 & $2,945.27$ & $16,781.84$ & $2,945.27$ & & & \\
\hline 055 & & $2,694.16$ & 251.11 & $2,945.27$ & $14,087.68$ & $2,945.27$ & & & \\
\hline 056 & & $2,734.47$ & 210.80 & $2,945.27$ & $11,353.21$ & $2,945.27$ & & & \\
\hline 057 & & $2,775.39$ & 169.88 & $2,945.27$ & $8,577.83$ & $2,945.27$ & & & \\
\hline 058 & & $2,816.91$ & 128.35 & $2,945.27$ & $5,760.91$ & $2,945.27$ & & & \\
\hline 059 & & $2,859.07$ & 86.20 & $2,945.27$ & $2,901.85$ & $2,945.27$ & Intereses & Pagado & \\
\hline 060 & & $2,901.85$ & 43.42 & $2,945.27$ & -0.00 & $2,945.27$ & $3,210.35$ & $35,343.21$ & Año 5 \\
\hline
\end{tabular}


13.14. Anexo $N^{\circ} 15$ - Análisis de Sensibilidad

Tabla 156

Análisis de Sensibilidad Método Montecarlo

\begin{tabular}{|c|c|c|c|c|c|c|c|c|c|}
\hline No & Aleatorio & Precio & Periodo o & Periodo1 & Periodo2 & Periodos & Periodo4 & Periodos & VAN \\
\hline & Orininal del proyecto & 1.94 & -312.259 .56 & $4,748.36$ & $310,235.75$ & $184,055.81$ & $280,079.80$ & $539,417.70$ & $371,957.97$ \\
\hline & 0.157475559 & 1,3 & $312,259.56$ & $35,198,90$ & $160,711.45$ & $255,673.96$ & $368,458,91$ & $644,946.55$ & $600,022.77$ \\
\hline 2 & 0,904784498 & 2.1 & 312.259 .56 & $-2,864.28$ & $97,616.83$ & $166,151.28$ & $257,935.02$ & $513,035.48$ & $314,941.77$ \\
\hline 3 & 0.449574011 & 1.4 & 312.259 .56 & $30,441.00$ & $152,824,63$ & $244,483.63$ & $354,643,43$ & $628,457.67$ & $564,387,64$ \\
\hline 4 & 0.570923239 & 1.6 & $312,259,56$ & $20,925.21$ & $137,050.97$ & $222,102.95$ & $327,012,46$ & $595,479.90$ & $493,117,39$ \\
\hline 5 & 0.498185646 & 1.5 & 312.259 .56 & $25,683.10$ & $144,937.80$ & $233,293.29$ & $340,827,94$ & $611,968.78$ & $528,752.52$ \\
\hline 6 & 0.732615452 & 1.8 & $312,259.56$ & $11,409.41$ & $121,277.31$ & $199,722.28$ & $299,381.48$ & $562,502.13$ & $421,847.15$ \\
\hline 7 & & 1.6 & $.312,259.56$ & $20,925.21$ & $137,050.97$ & $222,102.95$ & $327,012.46$ & $595,479.90$ & $493,117.39$ \\
\hline 8 & 0.307001791 & 1.3 & $-312,259.56$ & $35,198.90$ & $160,711,45$ & $255,673.96$ & $368,458.91$ & $644,946.55$ & $600,022.77$ \\
\hline 9 & 0.288081022 & 1.3 & $.312,259.56$ & $\begin{array}{r}35,198.90 \\
35.69 .10\end{array}$ & $160,711.45$ & $255,673.96$ & $368,458.91$ & $644,946.55$ & $600,022.77$ \\
\hline$\frac{10}{11}$ & $\begin{array}{l}0.510944771 \\
0.501352983\end{array}$ & $\frac{1.5}{1.5}$ & $\begin{array}{l}.312,259.56 \\
.312,259.56\end{array}$ & $\frac{25,683.10}{225.63 .10}$ & $\begin{array}{l}144,937.80 \\
144.937 .80\end{array}$ & 233,293.29 & $\begin{array}{l}340,827.94 \\
340.827 .94\end{array}$ & $\begin{array}{l}611,968.78 \\
611.968 .78\end{array}$ & $528,752.52$ \\
\hline 12 & 0.215863746 & $\frac{1.5}{1.3}$ & $\begin{array}{l}-312,259.56 \\
-312,259.56 \\
\end{array}$ & $\begin{array}{l}\frac{25,683.10}{35,198.90} \\
\end{array}$ & $\begin{array}{l}144,9317.80 \\
160,711.45\end{array}$ & $255,2973.96$ & $\begin{array}{l}340,827.94 \\
368,458.91\end{array}$ & $\begin{array}{l}611,968.78 \\
644,946.55\end{array}$ & $\begin{array}{l}528,752.52 \\
600,022.77\end{array}$ \\
\hline 13 & 0.275595385 & 1.3 & $-312,250.56$ & $35,198.90$ & $160,711.45$ & $255,673.96$ & $368,458.91$ & $644,946.55$ & $600,022.77$ \\
\hline 14 & 0.449900097 & 1.4 & $.312,250,56$ & $30,441.00$ & $152,8124.63$ & $244,483.63$ & $354,643.43$ & $628,457.67$ & $564,387.64$ \\
\hline 15 & 0.340042746 & 1.4 & $-312,259.56$ & $30,441.00$ & $152,924.63$ & 244,4113.63 & 154,643,43 & $628,457.67$ & $56 A, 387.64$ \\
\hline 10 & 0.056 ถาและ 79 & 1.3. & $-312,250.56$ & $35,190 \mathrm{n} .90$ & $160,711.45$ & $255,673.96$ & $368,458.91$ & $644,946.55$ & $600,022.77$ \\
\hline 17 & 0.786111538 & 2.1 & $-312,259,56$ & $-2,864.28$ & $97,616.83$ & $166,151.21$ & $257,935,02$ & $513,035.41$ & $314,941.77$ \\
\hline 18 & 0.314906864 & 1.4 & $-312,259,56$ & $30,441.00$ & $152,824,63$ & $244,483.63$ & $354,643,43$ & $621,457.67$ & $564,387,64$ \\
\hline$\frac{19}{200}$ & 0.693099783 & 1.8 & $\begin{array}{r}-312,259,56 \\
-312,250.56\end{array}$ & $\frac{11,409,41}{30025,21}$ & $\begin{array}{r}121,277,31 \\
137.050 .97\end{array}$ & $\frac{199,722.218}{7720}$ & 299,381.48 & $\frac{562,502.13}{505.170 .00}$ & $421,847,15$ \\
\hline$\frac{20}{21}$ & $\frac{0.553129272}{0.979135414}$ & $\frac{1.6}{2.1}$ & $\begin{array}{r}-312,259,56 \\
-312,259.56\end{array}$ & $\frac{20,925.21}{.2,864.28}$ & $\begin{array}{r}137,050.97 \\
97,616.83\end{array}$ & $\frac{222,102.95}{166,151.28}$ & $\mid \begin{array}{l}327,012.46 \\
257,935.02\end{array}$ & $\begin{array}{l}\frac{595,479,90}{513,035.48} \\
\end{array}$ & $\begin{array}{l}4933,117,39 \\
314,941,77\end{array}$ \\
\hline 22 & 0.637668843 & 1.8 & 312.259 .56 & $11,409.41$ & $121,277,31$ & $199,722,28$ & $299,381,48$ & $562,502,13$ & $421,847,15$ \\
\hline 23 & 0,924088667 & 2.1 & 312.259 .56 & $2,864.28$ & $97,616.83$ & $166,151,28$ & $257,935.02$ & $513,035,48$ & $314,941.77$ \\
\hline 24 & 0.575270072 & 1.6 & $312,259.56$ & $20,925.21$ & $137,050.97$ & $222,102.95$ & $327,012,46$ & $595,479.90$ & $493,117,39$ \\
\hline 25 & 0.84399952 & 2.1 & 312.259 .56 & $-2,864,28$ & $97,616.83$ & $166,151,28$ & $257,935.02$ & $513,035.48$ & $314,941.77$ \\
\hline 26 & 0.332893446 & 1.3 & .312 .259 .56 & $35,198,90$ & $160,711,45$ & $255,673.96$ & $368,458.91$ & $644,946.55$ & $600,022.77$ \\
\hline 27 & 0.650602872 & 1.8 & $-312,259.56$ & $11,409.41$ & $121,277.31$ & $199,722.28$ & $299,381.48$ & $562,502.13$ & $421,847.15$ \\
\hline 28 & 0.189630655 & 1.3 & $.312,259.56$ & $35,198.90$ & $160,711.45$ & $255,673.96$ & $368,458.91$ & $644,946.55$ & $600,022.77$ \\
\hline 29 & 0.404048529 & 1.4 & $\begin{array}{r}-312,259.56 \\
\end{array}$ & $30,441.00$ & $\begin{array}{r}152,824.63 \\
\end{array}$ & $\begin{array}{l}244,483.63 \\
190.723 .29\end{array}$ & $354,643,43$ & $628,457.67$ & $564,387,64$ \\
\hline 30| & $\frac{0.672716171}{0.019911865}$ & $\frac{1.8}{1.3}$ & $\frac{-312,259.56}{312.259 .56}$ & $\begin{array}{l}11,409.41 \\
35.198 .90\end{array}$ & $\begin{array}{l}121,277.31 \\
160.711 .45\end{array}$ & $\frac{199,722.28}{255.673 .96}$ & $\begin{array}{l}299,381.48 \\
368.458 .91\end{array}$ & $562,502.13$ & $\begin{array}{l}421,847.15 \\
600,022.77\end{array}$ \\
\hline 32 & $\begin{array}{l}0.01791185 \\
0.531693996\end{array}$ & $\frac{1.3}{1.5}$ & $\begin{array}{l}-312,259.56 \\
.312,259.56\end{array}$ & $\frac{35,198.90}{25,683.10}$ & $\begin{array}{l}160,712.45 \\
144,937.80\end{array}$ & $\begin{array}{l}235,67.69 \\
233,293.29\end{array}$ & $\begin{array}{l}338,4088.91 \\
340,827.94\end{array}$ & 6 611,968.78 & 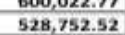 \\
\hline 33 & 0.91461627 & 2.1 & $.312,250.56$ & $.2,864.28$ & $97,616.83$ & $166,151.28$ & $257,935.02$ & $513,035.48$ & $314,941.77$ \\
\hline 34 & 0.844226056 & 2.1 & $-312,259.56$ & $.2,864.28$ & $97,616.83$ & $186,151.28$ & $257,935.02$ & $513,035.48$ & $314,941.77$ \\
\hline 35 & 0.344667648 & 1.4 & $-312,259.56$ & $30,441.00$ & $152,824.63$ & 244,483.63 & $354,643.43$ & $628,457.67$ & $564,387.64$ \\
\hline 36 & 0.380000053 & 1.4 & $-312,250,56$ & $30,441.00$ & $152,824.63$ & $244,483.63$ & $354,643.43$ & $628,457.67$ & $564,387.64$ \\
\hline 3) & 0.258534686 & 13 & $-312,250,56$ & $35,1919.90$ & $160,711.45$ & $255,673.96$ & $368,4518.91$ & 64a,946.55 & $600,022.77$ \\
\hline 3i: & 0.010965499 & 1,3 & $-312,259.56$ & $35,1901.90$ & $160,711.45$ & $255,673.96$ & $368,458.91$ & $644,246.55$ & $600,022.77$ \\
\hline 39) & 0.950939237 & 2,1 & $\begin{array}{r}-312,259: 56 \\
\end{array}$ & $\begin{array}{r}-2,864.28 \\
-30,210\end{array}$ & $\begin{array}{r}97,616.83 \\
\end{array}$ & $166,151.213$ & $257,935,02$ & $513,035.44$ & $314,941.77$ \\
\hline $\begin{array}{ll}40 \\
41\end{array}$ & $\frac{0.403458541}{0.028906406}$ & $\frac{1.4}{1.3}$ & $\begin{array}{r}-312,259,56 \\
-312,250,55\end{array}$ & $\begin{array}{r}30,441,00 \\
7,1,990.90\end{array}$ & $152,024,63$ & $244,4183.63$ & \begin{tabular}{|l}
$354,643.43$ \\
368.453 .92
\end{tabular} & $628,457.67$ & $564,3177,64$ \\
\hline 42 & $\begin{array}{l}0.028906040 \\
0.691156544\end{array}$ & $\frac{1.3}{1.8}$ & $\begin{array}{r}-312,259.56 \\
-312,259,56\end{array}$ & $\begin{array}{l}\frac{33,988.90}{11,409,41} \\
\end{array}$ & $\begin{array}{l}160,71.45 \\
121,277,31\end{array}$ & $\begin{array}{l}\frac{255,673.96}{199,722.28} \\
\end{array}$ & $\frac{366,458.91}{299,381.48}$ & $\begin{array}{l}564,946,53 \\
562,502,13\end{array}$ & $400,021,877,15$ \\
\hline 43 & 0.892002282 & 2.1 & $-312,259.56$ & $.2,864.28$ & $97,616.83$ & $166,151.28$ & $257,935,02$ & 513.035 .48 & $314,941.77$ \\
\hline 44 & 0.105746721 & 1.3 & 312.259 .56 & $35,198.90$ & $160,711.45$ & $255,673.96$ & $368,458.91$ & $644,946,55$ & $600,022.77$ \\
\hline 45 & 0.855630715 & 2.1 & 312.259 .56 & $-2,864.28$ & $97,616.83$ & $166,151,28$ & $257,935,02$ & $513,035,48$ & $314,941,77$ \\
\hline 46 & 0.655746356 & 1.8 & 312.259 .56 & $11,409.41$ & $121,277,31$ & $199,722.28$ & 299,381.48 & $562,502,13$ & $421,847,15$ \\
\hline 477 & 0.471708948 & $1.5]$ & $-312,259.56$ & $25,683.10$ & $144,937,80$ & 233,293.29 & $340,827,94$ & $611,968.78$ & $528,752.52$ \\
\hline 48. & 0.615268636 & 1.8 & $312,259.56$ & $11,409.41$ & $121,277.31$ & $199,722.28$ & $299,381,48$ & $562,502: 13$ & $421,847,15$ \\
\hline 49) & 0.443146727 & 1.4 & $\begin{array}{r}312,259.56 \\
3125056\end{array}$ & $30,441.00$ & $152,824.63$ & $244,483.63$ & $\begin{array}{r}354,643.43 \\
369.458 .98\end{array}$ & $628,457.67$ & $564,387.64$ \\
\hline 50] & 0.040875202 & $1.3]$ & $-312,259.56$ & $35,198.90$ & $160,711.45$ & $255,673.96$ & $368,458.91$ & $644,946.55$ & $600,022.77$ \\
\hline
\end{tabular}


Tabla 157

Análisis de Sensibilidad Método Montecarlo - Continuación

\begin{tabular}{|c|c|c|c|c|c|c|c|c|c|}
\hline 51 & 0.494839323 & 1.5 & $-312,259.56$ & $25,683.10$ & $\begin{array}{l}144,937.80 \\
\end{array}$ & $233,293.29$ & \begin{tabular}{|l|}
$340,827.94$ \\
\end{tabular} & $611,968.78$ & $528,752.52$ \\
\hline 52 & 0.211811822 & 1.3 & $-312,259.56$ & $35,198.90$ & $160,711.45$ & $\begin{array}{l}255,673.96 \\
\end{array}$ & \begin{tabular}{|l|l|}
$368,458.91$ \\
\end{tabular} & $644,946.55$ & $600,022.77$ \\
\hline 53 & 0.014424975 & 1.3 & $-312,259.56$ & $35,198.90$ & $160,711.45$ & $255,673.96$ & $368,458.91$ & $644,946.55$ & $600,022.77$ \\
\hline 54 & 0.875527284 & 2.1 & $-312,259.56$ & $-2,864.28$ & $97,616.83$ & $166,151.28$ & $257,935.02$ & $513,035.48$ & 314,941.77 \\
\hline 55 & 0.819336971 & 2.1 & $-312,259.56$ & $-2,864.28$ & $97,616.83$ & $166,151.28$ & $257,935.02$ & $513,035.48$ & $314,941.77$ \\
\hline 56 & 0.705947819 & 1.8 & $\begin{array}{r}-312,259.56 \\
\end{array}$ & $11,409.41$ & $121,277.31$ & $199,722.28$ & \begin{tabular}{|l|}
$299,381.48$ \\
\end{tabular} & $562,502.13$ & $421,847.15$ \\
\hline 57 & 0.367573441 & 1.4 & $-312,259.56$ & $30,441.00$ & $152,824.63$ & $244,483.63$ & $354,643.43$ & $628,457.67$ & $564,387.64$ \\
\hline 58 & 0.192654792 & 1.3 & $-312,259.56$ & $35,198.90$ & $160,711.45$ & $255,673.96$ & $368,458.91$ & $644,946.55$ & $600,022.77$ \\
\hline 59 & 0.586466068 & 1.6 & $-312,259.56$ & $20,925.21$ & $137,050.97$ & $222,102.95$ & $327,012.46$ & $595,479.90$ & $493,117.39$ \\
\hline 60 & 0.265716295 & 1.3 & $.312,259.56$ & $35,198.90$ & $160,711.45$ & $255,673.96$ & $368,458.91$ & $644,946.55$ & $600,022.77$ \\
\hline 61 & 0.512747451 & 1.5 & $.312,259.56$ & $25,683.10$ & $144,937.80$ & $233,293.29$ & $340,827.94$ & $611,968.78$ & $528,752.52$ \\
\hline 62 & 0.251458403 & 1.3 & $-312,259.56$ & $35,198.90$ & $160,711.45$ & $255,673.96$ & $368,458.91$ & $644,946.55$ & $600,022.77$ \\
\hline 63 & 0.49440961 & 1.5 & $-312,259.56$ & $25,683.10$ & $144,937.80$ & $233,293.29$ & $340,827.94$ & $611,968.78$ & $528,752.52$ \\
\hline 64 & 0.927085076 & 2.1 & $-312,259.56$ & $-2,864.28$ & $97,616.83$ & $166,151.28$ & $257,935.02$ & $513,035.48$ & $314,941.77$ \\
\hline 65 & 0.127337622 & 1.3 & $-312,259.56$ & $35,198.90$ & $160,711.45$ & $255,673.96$ & $368,458.91$ & $644,946.55$ & $600,022.77$ \\
\hline 66 & 0.370816096 & 1.4 & $-312,259.56$ & $30,441.00$ & $152,824.63$ & $244,483.63$ & $354,643.43$ & $628,457.67$ & $564,387.64$ \\
\hline 67 & 0.218521004 & 1.3 & $-312,259.56$ & $35,198.90$ & $160,711.45$ & $255,673.96$ & $368,458.91$ & $644,946.55$ & $600,022.77$ \\
\hline 68 & 0.184209108 & 1.3 & $-312,259.56$ & $35,198.90$ & $160,711.45$ & $255,673.96$ & $368,458.91$ & $644,946.55$ & $600,022.77$ \\
\hline 69 & 0.850800094 & 2.1 & $-312,259.56$ & $-2,864.28$ & $97,616.83$ & $166,151.28$ & $257,935.02$ & $513,035.48$ & $314,941.77$ \\
\hline 70 & 0.32466746 & 1.3 & $-312,259.56$ & $35,198.90$ & $160,711.45$ & $255,673.96$ & $368,458.91$ & $644,946.55$ & $600,022.77$ \\
\hline 71 & 0.792751123 & 2.1 & $-312,259.56$ & $-2,864.28$ & $97,616.83$ & $166,151.28$ & $257,935.02$ & $513,035.48$ & $314,941.77$ \\
\hline 72 & 0.854965336 & 2.1 & $-312,259.56$ & $-2,864.28$ & \begin{tabular}{|l|l|}
$97,616.83$ \\
\end{tabular} & $166,151.28$ & $257,935.02$ & $513,035.48$ & $314,941.77$ \\
\hline 73 & 0.94707362 & 2.1 & $-312,259.56$ & $-2,864.28$ & $97,616.83$ & $166,151.28$ & $257,935.02$ & $513,035.48$ & 314,941.77 \\
\hline 74 & 0.085664328 & 1.3 & $-312,259.56$ & $35,198.90$ & $160,711.45$ & $255,673.96$ & $368,458.91$ & $644,946.55$ & $600,022.77$ \\
\hline 75 & 0.420255159 & 1.4 & $-312,259.56$ & $30,441.00$ & $152,824.63$ & $244,483.63$ & $\begin{array}{l}354,643.43 \\
\end{array}$ & $628,457.67$ & $564,387.64$ \\
\hline 76 & 0.915668036 & 2.1 & $-312,259.56$ & $-2,864.28$ & $97,616.83$ & $166,151.28$ & $257,935.02$ & $513,035.48$ & $314,941.77$ \\
\hline 77 & 0.037010521 & 1.3 & $-312,259.56$ & $35,198.90$ & $160,711.45$ & $255,673.96$ & $368,458.91$ & $644,946.55$ & $600,022.77$ \\
\hline 78 & 0.901268692 & 2.1 & $.312,259.56$ & $-2,864.28$ & \begin{tabular}{|l|}
$97,616.83$ \\
\end{tabular} & $166,151.28$ & $257,935.02$ & $513,035.48$ & $314,941.77$ \\
\hline 79 & 0.410281663 & 1.4 & $-312,259.56$ & $30,441.00$ & $152,824.63$ & $244,483.63$ & $\begin{array}{l}354,643.43 \\
\end{array}$ & $628,457.67$ & $564,387.64$ \\
\hline 80 & 0.797869827 & 2.1 & $-312,259.56$ & $-2,864.28$ & $97,616.83$ & $166,151.28$ & $257,935.02$ & $513,035.48$ & $314,941.77$ \\
\hline 81 & 0.922977264 & 2.1 & $-312,259.56$ & $-2,864.28$ & \begin{tabular}{|l|l|}
$97,616.83$ \\
\end{tabular} & $166,151.28$ & $257,935.02$ & $513,035.48$ & $314,941.77$ \\
\hline 82 & 0.252345192 & 1.3 & $-312,259.56$ & $35,198.90$ & $160,711.45$ & $255,673.96$ & $368,458.91$ & $644,946.55$ & $600,022.77$ \\
\hline 83 & 0.092646968 & 1.3 & $-312,259.56$ & $35,198.90$ & $160,711.45$ & $255,673.96$ & $368,458.91$ & $644,946.55$ & $600,022.77$ \\
\hline 84 & 0.329647636 & 1.3 & $-312,259.56$ & $35,198.90$ & $160,711.45$ & $255,673.96$ & $368,458.91$ & $644,946.55$ & $600,022.77$ \\
\hline 85 & 0.008325319 & 1.3 & $.312,259.56$ & $35,198.90$ & $160,711.45$ & $255,673.96$ & $368,458.91$ & $644,946.55$ & $600,022.77$ \\
\hline 86 & 0.501085593 & 1.5 & $-312,259.56$ & $25,683.10$ & $144,937.80$ & $233,293.29$ & $340,827.94$ & $611,968.78$ & $528,752.52$ \\
\hline 87 & 0.3473627 & 1.4 & $-312,259.56$ & $30,441.00$ & $152,824.63$ & $244,483.63$ & $354,643.43$ & $628,457.67$ & $564,387.64$ \\
\hline 88 & 0.003824741 & 1.3 & $-312,259.56$ & $35,198.90$ & $160,711.45$ & $255,673.96$ & $368,458.91$ & $644,946.55$ & $600,022.77$ \\
\hline 89 & 0.137508536 & 1.3 & $.312,259.56$ & $35,198.90$ & $160,711.45$ & $255,673.96$ & $368,458.91$ & $644,946.55$ & $600,022.77$ \\
\hline 90 & 0.777362949 & 2.1 & $-312,259.56$ & $-2,864.28$ & \begin{tabular}{|c|}
$97,616.83$ \\
\end{tabular} & $166,151.28$ & $257,935.02$ & $513,035.48$ & $314,941.77$ \\
\hline 91 & 0.191314848 & 1.3 & $-312,259.56$ & $35,198.90$ & $160,711.45$ & $255,673.96$ & $368,458.91$ & $644,946.55$ & $600,022.77$ \\
\hline 92 & 0.541822974 & 1.6 & $-312,259.56$ & $20,925.21$ & $137,050.97$ & $222,102.95$ & $327,012.46$ & $595,479.90$ & $493,117.39$ \\
\hline 93 & 0.140907345 & 1.3 & $-312,259.56$ & $35,198.90$ & $160,711.45$ & $255,673.96$ & $368,458.91$ & $644,946.55$ & $600,022.77$ \\
\hline 94 & 0.946601895 & 2.1 & $-312,259.56$ & $-2,864.28$ & \begin{tabular}{|l|}
$97,616.83$ \\
\end{tabular} & $166,151.28$ & $257,935.02$ & $513,035.48$ & $314,941.77$ \\
\hline 95 & 0.872433869 & 2.1 & $-312,259.56$ & $-2,864.28$ & \begin{tabular}{|l|l|}
$97,616.83$ \\
\end{tabular} & $166,151.28$ & $257,935.02$ & $513,035.48$ & $314,941.77$ \\
\hline 96 & 0.941407428 & 2.1 & $-312,259.56$ & $-2,864.28$ & \begin{tabular}{|l|l|}
$97,616.83$ \\
\end{tabular} & $166,151.28$ & $257,935.02$ & $513,035.48$ & $314,941.77$ \\
\hline 97 & 0.871942314 & 2.1 & $-312,259.56$ & $-2,864.28$ & \begin{tabular}{|l|}
$97,616.83$ \\
\end{tabular} & $166,151.28$ & $257,935.02$ & $513,035.48$ & 314,941.77 \\
\hline 98 & 0.268441827 & 1.3 & $-312,259.56$ & $35,198.90$ & $160,711.45$ & $255,673.96$ & $368,458.91$ & $644,946.55$ & $600,022.77$ \\
\hline 99 & 0.064532715 & 1.3 & $-312,259.56$ & $35,198.90$ & $160,711.45$ & $255,673.96$ & $368,458.91$ & $644,946.55$ & $600,022.77$ \\
\hline 100 & 0.493108147 & 1.5 & $.312,259.56$ & $25,683.10$ & $144,937.80$ & $233,293.29$ & $340,827.94$ & $611,968.78$ & $528,752.52$ \\
\hline
\end{tabular}


13.15. Anexo $N^{\circ} 16$ - Ratios Año 1

\section{LIQUIDEZ}

\begin{tabular}{|ccccc|}
\hline $\begin{array}{c}\text { Disponibilidad } \\
\text { Inmediata }\end{array}$ & $=$ & Caja y Banco & $/$ & Pasivo Corriente \\
-1.09 & $=$ & $-60,365.37$ & $/$ & $55,209.97$ \\
\hline
\end{tabular}

\begin{tabular}{|c|c|c|}
\hline Razón Corriente & $=$ Activo Corriente & Pasivo Corriente \\
\hline 1.78 & $98,316.81$ & $55,209.97$ \\
\hline
\end{tabular}

\begin{tabular}{|c|c|c|}
\hline \multirow{3}{*}{ Prueba ácida } & Activo Corriente & Inventario \\
\hline & \multicolumn{2}{|c|}{ Pasivo Corriente } \\
\hline & $98,316.81$ & $1,653.46$ \\
\hline 1.75 & \multicolumn{2}{|c|}{$55,209.97$} \\
\hline
\end{tabular}

Figura 104. Ratios Año 1 - Liquidez 


\section{GESTION}

\begin{tabular}{|ccccc|}
\hline Rotación de Inventarios & $=$ & Costo de Venta & $/$ & Inventario \\
10.89 & $=$ & 18,004 & $/$ & $1,653.46$ \\
\hline
\end{tabular}

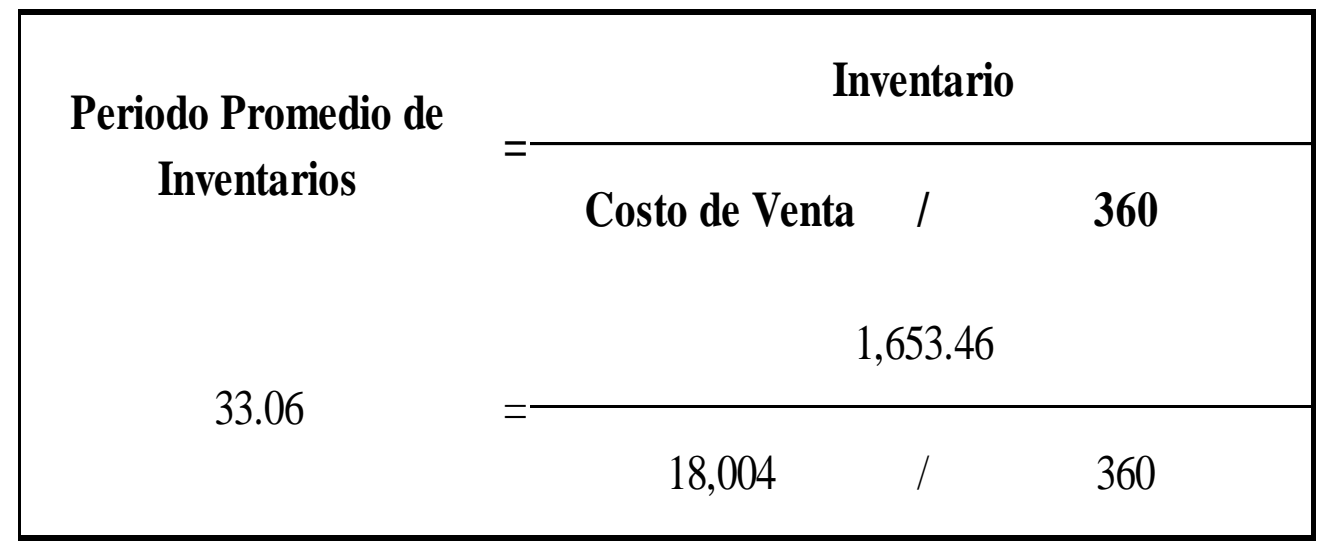

\begin{tabular}{|clccc|}
\hline Rotación de Activo Fijo & $=$ & Ventas & $/$ & Activo Fijo Neto \\
0.91 & $=$ & $273,742.26$ & $/$ & $301,752.08$ \\
& & & & \\
\hline
\end{tabular}

\begin{tabular}{|ccccc|}
\hline Rotación de Activo & $=$ & Ventas & $/$ & Activo Total \\
0.83 & $=$ & $273,742.26$ & $/$ & $330,428.40$ \\
\hline
\end{tabular}

Figura 105. Ratios Año 1- Gestión 
APALANCAMIENTO FINANCIERO

\begin{tabular}{|ccccc|}
\hline Endeudamiento & $=$ Deuda Total & $/$ & Activo Total \\
47.65 & $=157,456.85$ & $/$ & $330,428.40$
\end{tabular}

\begin{tabular}{|ccccc|}
\hline Deuda a Patrimonio & $=$ & Deuda Total & $/$ & Patrimonio \\
1.91 & $=330,428.39$ & $/$ & $172,971.55$ \\
\hline
\end{tabular}

\begin{tabular}{|ccccc|}
\hline $\begin{array}{c}\text { Multiplicador de } \\
\text { Capital }\end{array}$ & $=$ & Total Activos & $/$ & Patrimonio \\
1.91 & $=$ & 330,428 & $/$ & $172,971.55$ \\
\hline
\end{tabular}

Cobertura de Intereses = Utilidad Operativa / Gastos Financieros

$\begin{array}{lllll}-5.74 & = & -83,282 & / & 14,514.76\end{array}$

Figura 106. Ratios Año 1 - Apalancamiento Financiero 
RENTABILIDAD

\begin{tabular}{|ccccc|}
\hline Margen Bruto & $=$ & Utilidad Bruta & $/$ & Ventas Totales \\
21.07 & $=$ & 57,691 & $/$ & 273,742 \\
\hline
\end{tabular}

\begin{tabular}{|ccccc|}
\hline $\begin{array}{c}\text { Margen de Utilidad } \\
\text { Neta }\end{array}$ & $=$ & Utilidad Neta & $/$ & Ventas Totales \\
-35.73 & $=$ & $-97,797$ & $/$ & 273,742 \\
\hline
\end{tabular}

$\begin{aligned} & \text { Retorno Sobre la } \\ & \text { Inversiòn }(\text { ROA })\end{aligned}=$ Utilidad Neta $/ \quad$ Activos Totales

$-30 \%=-97,797 \quad / \quad 330,428$

\begin{tabular}{|ccccc}
$\begin{array}{c}\text { Retorno Sobre el } \\
\text { Capital (ROE) }\end{array}$ & $=$ & Utilidad Neta & $/$ & Capital de Accionistas \\
$-36 \%$ & $=$ & $-97,797$ & $/$ & 270,888
\end{tabular}

$\begin{array}{ccccc}\begin{array}{c}\text { Retorno Sobre la } \\ \text { Inversiòn (ROA) }\end{array} & \text { Utilidad Neta } / & \text { Activos Totales } \\ -30 \% & = & -26,771,131,382 \quad / & 90,452,216,481\end{array}$

Figura 107. Ratios Año 1 - Rentabilidad 
13.16. Anexo $N^{\circ} 17$ - Ratios Año 2

\section{LIQUIDEZ}

\begin{tabular}{|ccccc|}
\hline $\begin{array}{c}\text { Disponibilidad } \\
\text { Inmediata }\end{array}$ & $=$ & Caja y Banco & $/$ & Pasivo Corriente \\
2.34 & $=$ & $119,650.22$ & $/$ & $51,190.77$ \\
\hline
\end{tabular}

\section{Razón Corriente $=$ Activo Corriente $/$ Pasivo Corriente}

5.31 $=\quad 271,849.23$

$51,190.77$

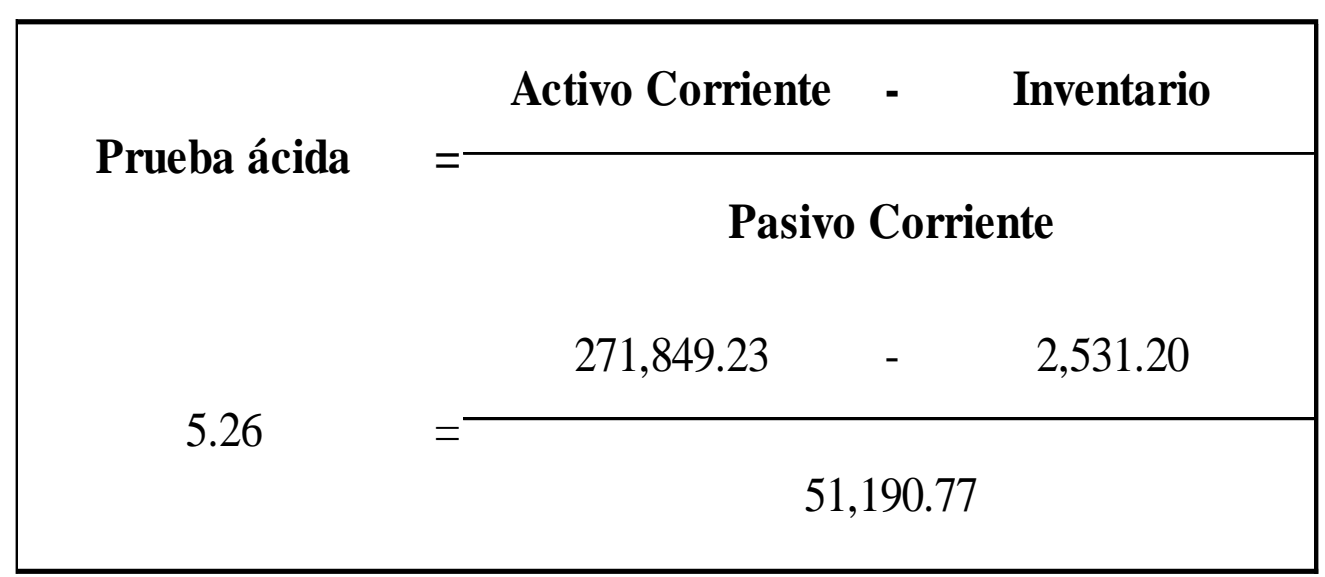

Figura 108. Ratios Año 2 - Liquidez 


\section{GESTION}

\begin{tabular}{|ccccc|} 
Rotación de Inventarios & $=$ & Costo de Venta & $/$ & Inventario \\
11.23 & $=$ & 28,421 & $/$ & $2,531.20$ \\
\hline
\end{tabular}

\begin{tabular}{|c|c|c|c|}
\hline \multirow{2}{*}{$\begin{array}{l}\text { Periodo Promedio de } \\
\text { Inventarios }\end{array}$} & \multicolumn{3}{|c|}{ Inventario } \\
\hline & Costo de Venta & I & 360 \\
\hline \multirow{2}{*}{32.06} & \multicolumn{3}{|c|}{$2,531.20$} \\
\hline & 28,421 & l & 360 \\
\hline
\end{tabular}

\begin{tabular}{|ccccc|}
\hline Rotación de Activo Fijo & $=$ & Ventas & $/$ & Activo Fijo Neto \\
1.56 & $=$ & $650,902.81$ & $/$ & $417,931.86$ \\
& & & & \\
\hline
\end{tabular}

\begin{tabular}{|ccccc|}
\hline Rotación de Activo & $=$ & Ventas & $/$ & Activo Total \\
1.37 & $=$ & $650,902.81$ & $/$ & $475,284.50$ \\
\hline
\end{tabular}

Figura 109. Ratios Año 2 - Gestión 
APALANCAMIENTO FINANCIERO

\begin{tabular}{|ccccc|}
\hline Endeudamiento & $=$ & Deuda Total & $/$ & Activo Total \\
28.30 & $=$ & $134,523.05$ & $/$ & $475,284.50$ \\
\hline
\end{tabular}

Deuda a Patrimonio $=$ Deuda Total $/$ Patrimonio

$1.39=475,284 \quad / \quad 340,761.45$

\begin{tabular}{|ccccc|}
\hline $\begin{array}{c}\text { Multiplicador de } \\
\text { Capital }\end{array}$ & $=$ & Total Activos & $/$ & Patrimonio \\
1.39 & $=$ & 475,284 & $/$ & $340,761.45$ \\
\hline
\end{tabular}

Cobertura de Intereses = Utilidad Operativa $/$ Gastos Financieros
8.96
$=\quad 107,740$
l
$12,023.12$

Figura 110. Ratios Año 2 - Apalancamiento Financiero 


\section{RENTABILIDAD}

\begin{tabular}{|ccccc|}
\hline Margen Bruto & $=$ & Utilidad Bruta & $/$ & Ventas Totales \\
47.60 & $=$ & 309,849 & $/$ & 650,903 \\
\hline
\end{tabular}

\begin{tabular}{|ccccc|}
\hline $\begin{array}{c}\text { Margen de Utilidad } \\
\text { Neta }\end{array}$ & $=$ & Utilidad Neta & $/$ & Ventas Totales \\
10.73 & $=$ & 69,874 & $/$ & 650,903 \\
\hline
\end{tabular}

$\begin{gathered}\text { Retorno Sobre la } \\ \text { Inversiòn }(\text { ROA })\end{gathered}=$ Utilidad Neta / Activos Totales

$15 \% \quad 69,874 \quad / \quad 475,284$

$\begin{array}{|ccccc|}\begin{array}{c}\text { Retorno Sobre el } \\ \text { Capital }(\text { ROE) }\end{array} & = & \text { Utilidad Neta } & / & \text { Capital de Accionistas } \\ 26 \% & = & 69,874 & / & 270,888\end{array}$

$\begin{array}{ccccc}\begin{array}{c}\text { Retorno Sobre la } \\ \text { Inversiòn }(\text { ROA) }\end{array} & =\text { Utilidad Neta } & / & \text { Activos Totales } \\ 15 \% & = & 45,480,873,868 & / & 309,364,012,912\end{array}$

Figura 111. Ratios Año 2 - Rentabilidad 
13.17. Anexo $N^{\circ} 18$ - Ratios Año 3

\section{LIQUIDEZ}

\begin{tabular}{|ccccc|}
\hline $\begin{array}{c}\text { Disponibilidad } \\
\text { Inmediata }\end{array}$ & $=$ Caja y Banco & $/$ & Pasivo Corriente \\
2.31 & $=$ & $260,130.93 \quad /$ & $112,637.11$ \\
\hline
\end{tabular}

$\begin{aligned} \text { Razón Corriente } & =\text { Activo Corriente } / \text { Pasivo Corriente } \\ 4.24 & =477,507.69 \quad / \quad 112,637.11\end{aligned}$

\begin{tabular}{|c|c|}
\hline Prueba ácida & $=\frac{\text { Activo Corriente }-\quad \text { Inventario }}{\text { Pasivo Corriente }}$ \\
4.21 & $=\frac{477,507.69 \quad-}{3,029.04}$ \\
\end{tabular}

Figura 112. Ratios Año 3 - Liquidez 


\section{GESTION}

\begin{tabular}{|ccccc|}
\hline Rotación de Inventarios & $=$ & Costo de Venta & $/$ & Inventario \\
12.54 & $=$ & 37,982 & $/$ & $3,029.04$ \\
\hline
\end{tabular}

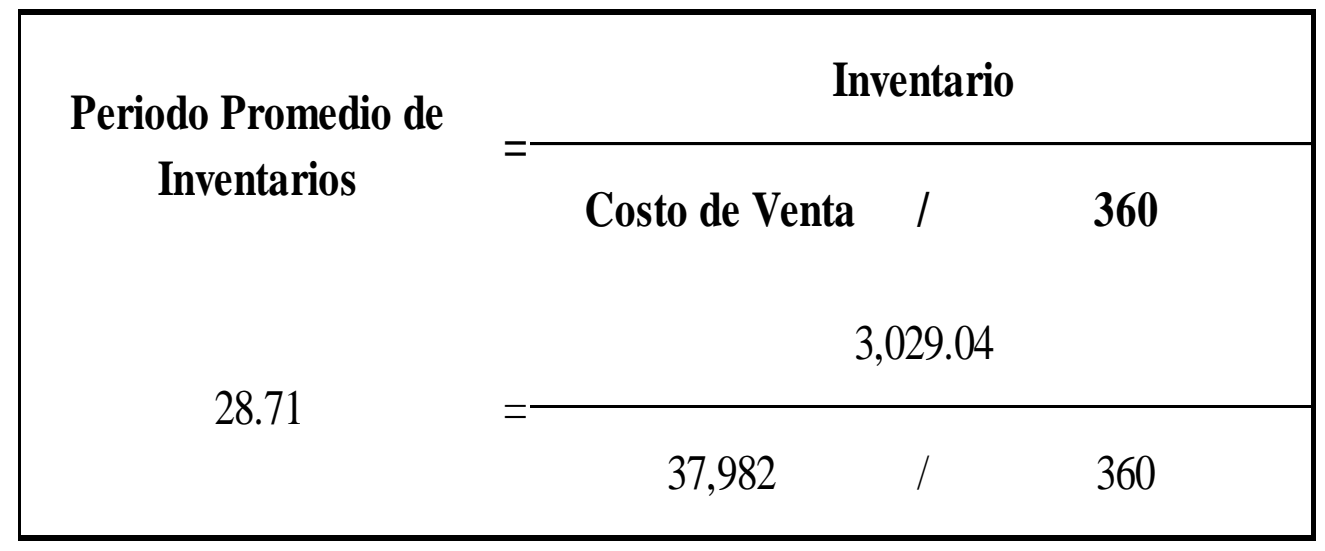

\begin{tabular}{|ccccc|}
\hline Rotación de Activo Fijo & $=$ & Ventas & $/$ & Activo Fijo Neto \\
1.74 & $=$ & $986,473.06$ & $/$ & $566,237.67$ \\
& & & & \\
\hline
\end{tabular}

\begin{tabular}{|ccccc|}
\hline Rotación de Activo & $=$ & Ventas & $/$ & Activo Total \\
1.51 & $=$ & $986,473.06$ & $/$ & $652,266.63$ \\
\hline
\end{tabular}

Figura 113. Ratios Año 3 - Gestión 
APALANCAMIENTO FINANCIERO

\begin{tabular}{|ccccc|}
\hline Endeudamiento & $=$ Deuda Total & $/$ & Activo Total \\
26.58 & $=173,373.31$ & $/$ & $652,266.63$ \\
\hline
\end{tabular}

\begin{tabular}{|ccccc|}
\hline Deuda a Patrimonio & $=$ & Deuda Total & $/$ & Patrimonio \\
1.36 & $=652,267$ & $/$ & $478,893.33$ \\
\hline
\end{tabular}

\begin{tabular}{|ccccc|}
\hline $\begin{array}{c}\text { Multiplicador de } \\
\text { Capital }\end{array}$ & $=$ & Total Activos & $/$ & Patrimonio \\
1.36 & $=$ & 652,267 & $/$ & $478,893.33$ \\
\hline
\end{tabular}

Cobertura de Intereses $=$ Utilidad Operativa / Gastos Financieros

$\begin{array}{llll}32.05 & = & 294,115 & /\end{array}$

Figura 114. Ratios Año 3 - Apalancamiento Financiero 
RENTABILIDAD

\begin{tabular}{|ccccc|}
\hline Margen Bruto & $=$ & Utilidad Bruta & $/$ & Ventas Totales \\
53.80 & $=$ & 530,694 & $/$ & 986,473 \\
\hline
\end{tabular}

\begin{tabular}{|ccccc|}
\hline $\begin{array}{c}\text { Margen de Utilidad } \\
\text { Neta }\end{array}$ & Utilidad Neta & $/$ & Ventas Totales \\
21.09 & $=$ & 208,005 & $/$ & 986,473 \\
\hline
\end{tabular}

$\begin{gathered}\text { Retorno Sobre la } \\ \text { Inversiòn }(\text { ROA })\end{gathered}=$ Utilidad Neta $/$ Activos Totales

$32 \%=208,005 \quad / \quad 652,267$

\begin{tabular}{ccccc|}
$\begin{array}{c}\text { Retorno Sobre el } \\
\text { Capital (ROE) }\end{array}$ & $=$ & Utilidad Neta & $/$ & Capital de Accionistas \\
$77 \%$ & $=$ & 208,005 & $/$ & 270,888
\end{tabular}

$\begin{array}{ccccc}\begin{array}{c}\text { Retorno Sobre la } \\ \text { Inversiòn (ROA) }\end{array} & \text { Utilidad Neta } / & \text { Activos Totales } \\ 32 \% & =205,191,729,600 / & 643,443,459,801\end{array}$

Figura 115. Ratios Año 3 - Rentabilidad 
13.18. Anexo $N^{\circ} 19$ - Ratios Año 4

\section{LIQUIDEZ}

\begin{tabular}{|ccccc|}
\hline $\begin{array}{c}\text { Disponibilidad } \\
\text { Inmediata }\end{array}$ & $=$ & Caja y Banco & / & Pasivo Corriente \\
2.37 & $=$ & $424,976.83$ & $/$ & $179,067.98$ \\
\hline
\end{tabular}

$$
\begin{array}{ccccc}
\text { Razón Corriente } & =\text { Activo Corriente } & / & \text { Pasivo Corriente } \\
3.96 & = & 709,845.94 & / & 179,067.98
\end{array}
$$

$$
\begin{gathered}
\text { Prueba ácida }=\frac{\text { Activo Corriente }-}{\text { Inventario }} \\
\text { Pasivo Corriente } \\
709,845.94 \quad-\quad 3,803.94
\end{gathered}
$$

3.94

$$
179,067.98
$$

Figura 116. Ratios Año 4 - Liquidez 


\section{GESTION}

\begin{tabular}{|ccccc|}
\hline Rotación de Inventarios & $=$ & Costo de Venta & $/$ & Inventario \\
12.19 & $=$ & 46,379 & $/$ & $3,803.94$ \\
\hline
\end{tabular}

\begin{tabular}{|c|c|c|c|c|}
\hline \multirow{2}{*}{$\begin{array}{l}\text { Periodo Promedio de } \\
\text { Inventarios }\end{array}$} & \multicolumn{4}{|c|}{ Inventario } \\
\hline & & Costo de Venta & I & 360 \\
\hline \multirow{2}{*}{29.53} & \multicolumn{4}{|c|}{$3,803.94$} \\
\hline & & 46,379 & l & 360 \\
\hline Rotación de Activo Fijo & $=$ & Ventas & I & Activo Fijo Neto \\
\hline 1.79 & $=$ & $1,328,607.96$ & l & $741,223.28$ \\
\hline Rotación de Activo & $=$ & Ventas & I & Activo Total \\
\hline 1.55 & $=$ & $1,328,607.96$ & l & $855,928.56$ \\
\hline
\end{tabular}

Figura 117. Ratios Año 4 - Gestión 


\section{APALANCAMIENTO FINANCIERO}

\begin{tabular}{|ccccc|}
\hline Endeudamiento & $=$ Deuda Total & $/$ & Activo Total \\
25.00 & $=213,959.39$ & $/$ & $855,928.56$ \\
\hline
\end{tabular}

\begin{tabular}{|ccccc|}
\hline Deuda a Patrimonio & $=$ & Deuda Total & $/$ & Patrimonio \\
1.33 & $=855,929$ & $/$ & $641,969.17$ \\
\hline
\end{tabular}

\begin{tabular}{|ccccc|}
\hline $\begin{array}{c}\text { Multiplicador de } \\
\text { Capital }\end{array}$ & $=$ & Total Activos & $/$ & Patrimonio \\
1.33 & $=$ & 855,929 & $/$ & $641,969.17$ \\
\hline
\end{tabular}

$\begin{aligned} \text { Cobertura de Intereses } & =\text { Utilidad Operativa } / \text { Gastos Financieros } \\ 86.82 & =514,254 \quad / \quad 5,923.24\end{aligned}$

Figura 118. Ratios Año 4 - Apalancamiento Financiero 
RENTABILIDAD

\begin{tabular}{|ccccc|}
\hline Margen Bruto & $=$ Utilidad Bruta & $/$ & Ventas Totales \\
58.11 & $=$ & 772,064 & $/$ & $1,328,608$ \\
\hline
\end{tabular}

\begin{tabular}{|ccccc|}
\hline $\begin{array}{c}\text { Margen de Utilidad } \\
\text { Neta }\end{array}$ & Utilidad Neta & $/$ & Ventas Totales \\
27.93 & $=$ & 371,081 & $/$ & $1,328,608$ \\
\hline
\end{tabular}

$\begin{gathered}\text { Retorno Sobre la } \\ \text { Inversiòn }(\text { ROA })\end{gathered}=$ Utilidad Neta $/$ Activos Totales

$43 \%=371,081 \quad / \quad 855,929$

\begin{tabular}{ccccc|}
$\begin{array}{c}\text { Retorno Sobre el } \\
\text { Capital (ROE) }\end{array}$ & $=$ & Utilidad Neta & $/$ & Capital de Accionistas \\
$137 \%$ & $=$ & 371,081 & $/$ & 270,888 \\
\hline
\end{tabular}

\begin{tabular}{|c|c|c|c|}
\hline $\begin{array}{l}\text { Retorno Sobre la } \\
\text { Inversiòn (ROA) }\end{array}$ & $=\quad$ Utilidad Neta & & Activos Totales \\
\hline $43 \%$ & $493,021,494,822$ & & $1,137,193,496,716$ \\
\hline
\end{tabular}

Figura 119. Ratios Año 4 - Rentabilidad 
13.19. Anexo $N^{\circ} 20$ - Ratios Año 5

\section{LIQUIDEZ}

\begin{tabular}{|ccccc|}
\hline $\begin{array}{c}\text { Disponibilidad } \\
\text { Inmediata }\end{array}$ & $=$ Caja y Banco & $/$ Pasivo Corriente \\
2.36 & $=580,644.07$ & $/$ & $246,094.42$ \\
\hline
\end{tabular}

Razón Corriente $=$ Activo Corriente $/$ Pasivo Corriente

3.80 $=\quad 934,277.41 \quad / \quad 246,094.42$

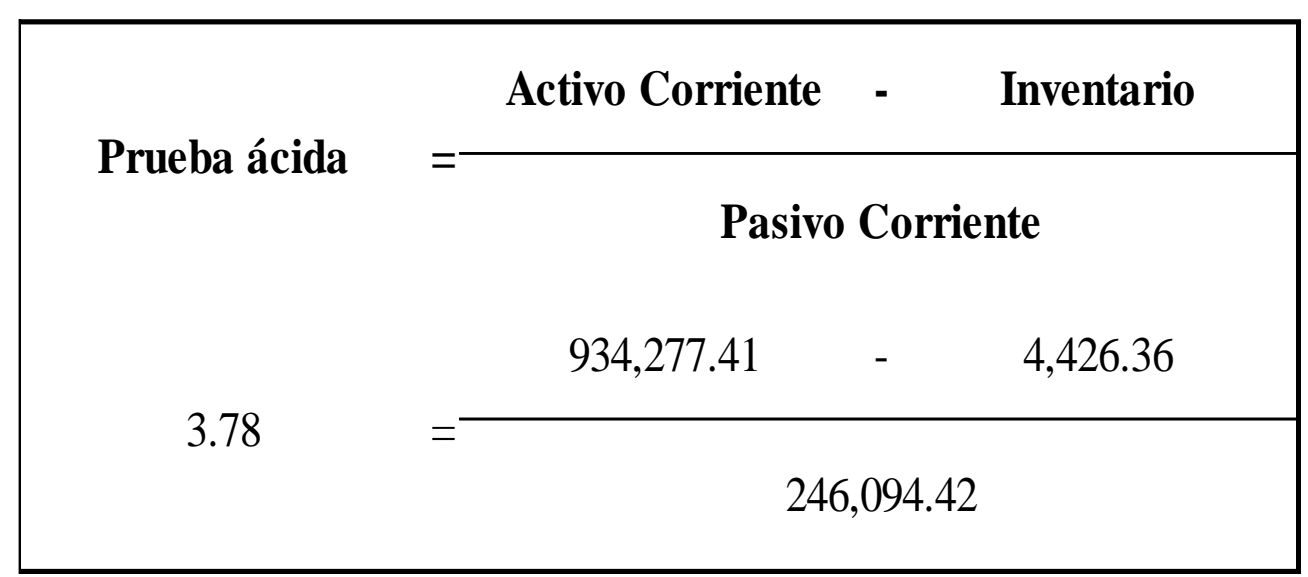

Figura 120. Ratios Año 5 - Liquidez 


\section{GESTION}

\begin{tabular}{|ccccc|}
\hline Rotación de Inventarios & $=$ & Costo de Venta & $/$ & Inventario \\
12.36 & $=$ & 54,699 & $/$ & $4,426.36$ \\
\hline
\end{tabular}

\begin{tabular}{|c|c|c|c|}
\hline \multirow{2}{*}{$\begin{array}{l}\text { Periodo Promedio de } \\
\text { Inventarios }\end{array}$} & \multicolumn{3}{|c|}{ Inventario } \\
\hline & Costo de Venta & I & 360 \\
\hline \multirow{2}{*}{29.13} & \multicolumn{3}{|c|}{$4,426.36$} \\
\hline & 54,699 & I & 360 \\
\hline
\end{tabular}

\begin{tabular}{|clccc|}
\hline Rotación de Activo Fijo & $=$ & Ventas & $/$ & Activo Fijo Neto \\
1.85 & $=$ & $1,677,186.13$ & $/$ & $908,302.11$ \\
& & & & \\
\hline
\end{tabular}

$\begin{array}{clcll}\text { Rotación de Activo } & = & \text { Ventas } & / & \text { Activo Total } \\ 1.59 & = & 1,677,186.13 & / & 1,051,683.71\end{array}$

Figura 121. Ratios Año 5 - Gestión 
APALANCAMIENTO FINANCIERO

\begin{tabular}{|ccccc|}
\hline Endeudamiento & $=$ Deuda Total & $/$ & Activo Total \\
23.91 & $=251,428.39$ & $/$ & $1,051,683.71$ \\
\hline
\end{tabular}

Deuda a Patrimonio $=$ Deuda Total $/$ Patrimonio

$1.31=1,051,684 \quad / \quad 800,255.32$

Multiplicador de Capital $=$ Total Activos / Patrimonio $1.31=1,051,684 \quad / \quad 800,255.32$

Cobertura de Intereses = Utilidad Operativa / Gastos Financieros $329.65=727,367 \quad / \quad 2,206.45$

Figura 122. Ratios Año 5 - Apalancamiento Financiero 
RENTABILIDAD

\begin{tabular}{|ccccc|}
\hline Margen Bruto & $=$ & Utilidad Bruta & $/$ & Ventas Totales \\
60.86 & $=$ & $1,020,797$ & $/$ & $1,677,186$ \\
\hline
\end{tabular}

\begin{tabular}{|ccccc|}
\hline $\begin{array}{c}\text { Margen de Utilidad } \\
\text { Neta }\end{array}$ & Utilidad Neta & $/$ & Ventas Totales \\
31.56 & $=$ & 529,367 & $/$ & $1,677,186$ \\
\hline
\end{tabular}

$\begin{aligned} & \text { Retorno Sobre la } \\ & \text { Inversiòn (ROA) }\end{aligned}=$ Utilidad Neta $/ \quad$ Activos Totales

$50 \%=529,367 \quad / \quad 1,051,684$

\begin{tabular}{|ccccc|}
\hline $\begin{array}{c}\text { Retorno Sobre el } \\
\text { Capital (ROE) }\end{array}$ & $=$ & Utilidad Neta & $/$ & Capital de Accionistas \\
$195 \%$ & $=$ & 529,367 & $/$ & 270,888 \\
\hline
\end{tabular}

$\begin{array}{ccccc}\begin{array}{c}\text { Retorno Sobre la } \\ \text { Inversiòn (ROA) }\end{array} & \text { Utilidad Neta } & / & \text { Activos Totales } \\ 50 \% & =887,847,660,311 \quad / & 1,763,869,332,334\end{array}$

Figura 123. Ratios Año 5 - Rentabilidad 


\subsection{Anexo $\mathbf{N}^{\circ} 21$ - Beta del Sector de Alimentos en EE.UU.}

Tabla 158

Beta de Sector de Alimentos de EEUU

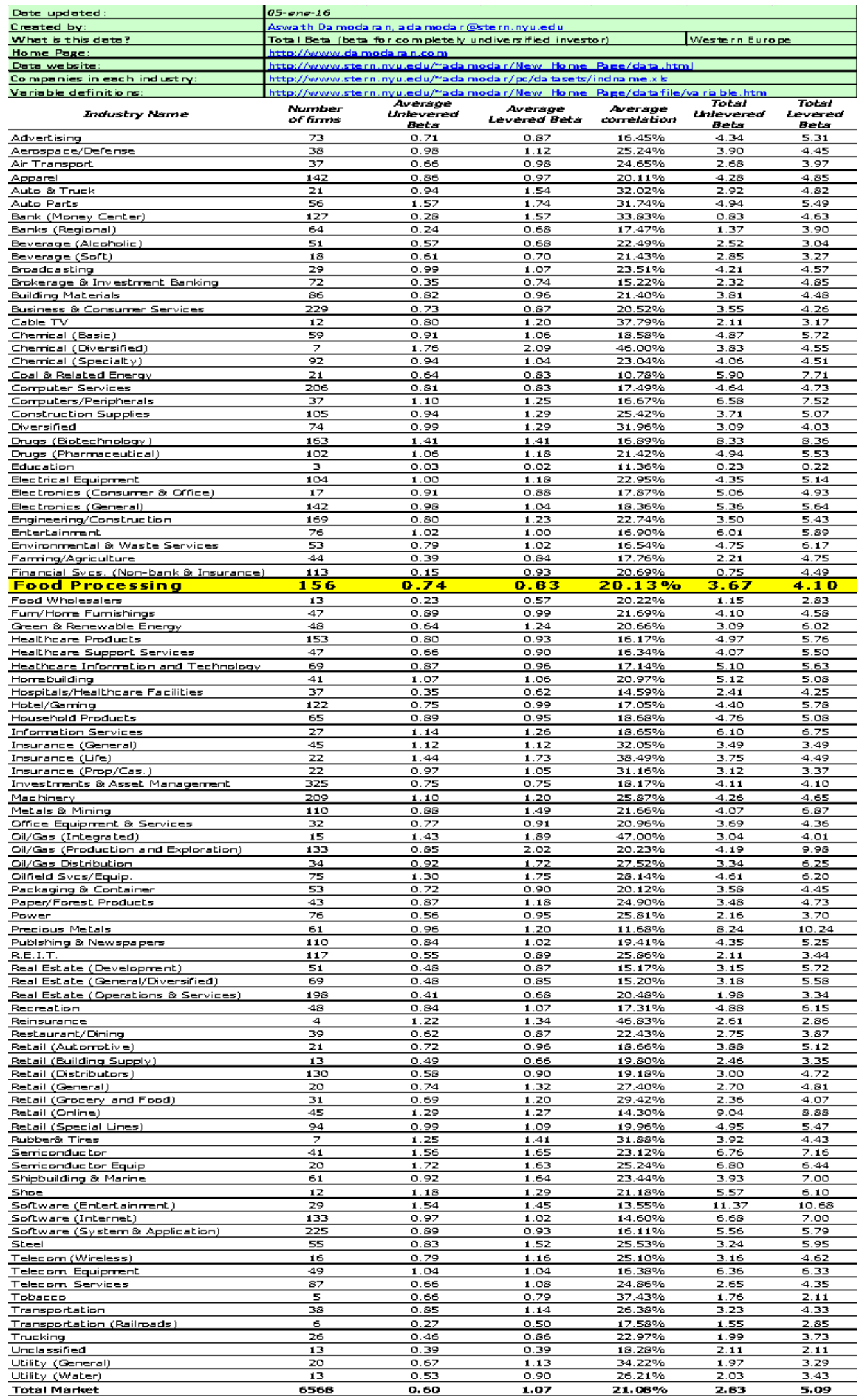


13.21. Anexo $\mathrm{N}^{\circ} 22$ - Afiche Publicitario - Papa Sano

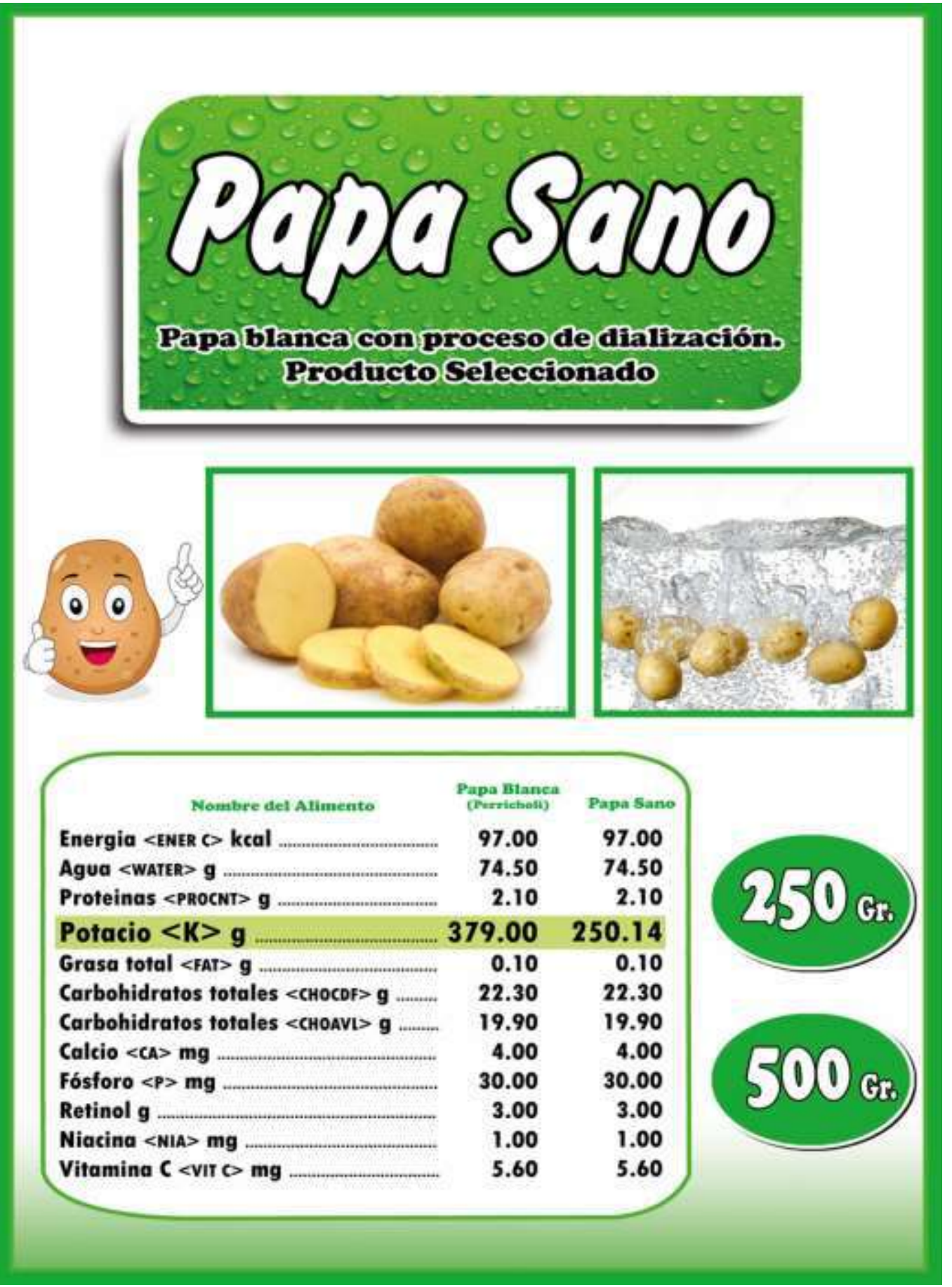

Figura 124. Afiche Publicitario - Papa Sano 


\title{
13.22. Anexo $\mathbf{N}^{\circ} \mathbf{2 3}$ - Extracto del Libro ¿Cuántos Años Viviré?
}

\author{
CAPITULO XI \\ ¿CUÁNDO EMPEZAMOS A DECLINAR?
}

Los humanos dejamos de crecer biológicamente entre los 25 y 27 años, porque la glándula pituitaria con el correr de los años disminuye su producción de HGH (Hormona del Crecimiento Humano), encargada de fortalecer y rejuvenecer nuestros tejidos y

"Cree en la juventud y no envejeceras. Duda $y$ perecerás". es a partir de entonces que se inicia una fase natural, intrinseca y universal de todo ser vivo: comenzamos a declinar. La Biologia moderna no ha podido resolver la comprensión de los mecanismos precisos por los cuales ocurre el envejecimiento.

Después de pasada la etapa de los 30 años el cuerpo humano comienza un declive en todas las funciones del organismo, aunque esto no sucede de forma inesperada y agresiva con el pasar de los años, la resistencia, la capacidad de metabolizar las grasas y otras funciones del cuerpo comienzan a degenerarse en forma moderada o leve con el tiempo

Es cuando se empieza a deteriorar el programa genético, dice el catedratico de Fisiologia Humana Francisco Mora. Jaime Miquel, ex director del Laboratorio de Envejecimiento de la NASA, dice que a esta edad comienza el cambio de la fisonomia: aumenta el peso, baja el metabolismo y los niveles de ciertas hormonas, aparecen cambios en los patrones de sueño, se pierde memoria

Si tomamos en cuenta nuestro sistema nervioso central, recien completamos nuestro desarrollo neuronal óptimo, alrededor de los 25 años, es decir que hasta esa edad seguimos creciendo en nuestra capacidad intelectual (no podemos estar envejeciendo entonces desde cierto punto de vista), a partir de la decada de los 20 , comenzarán los años más

Figura 125. Extracto del Libro ¿Cuántos Años Viviré? 
13.23. Anexo $\mathbf{N}^{\circ} \mathbf{2 4}$ - Gasto Mensual Promedio por Persona

Gasto Promedio Mensual por Persona, 2013

(Nuevos soles)
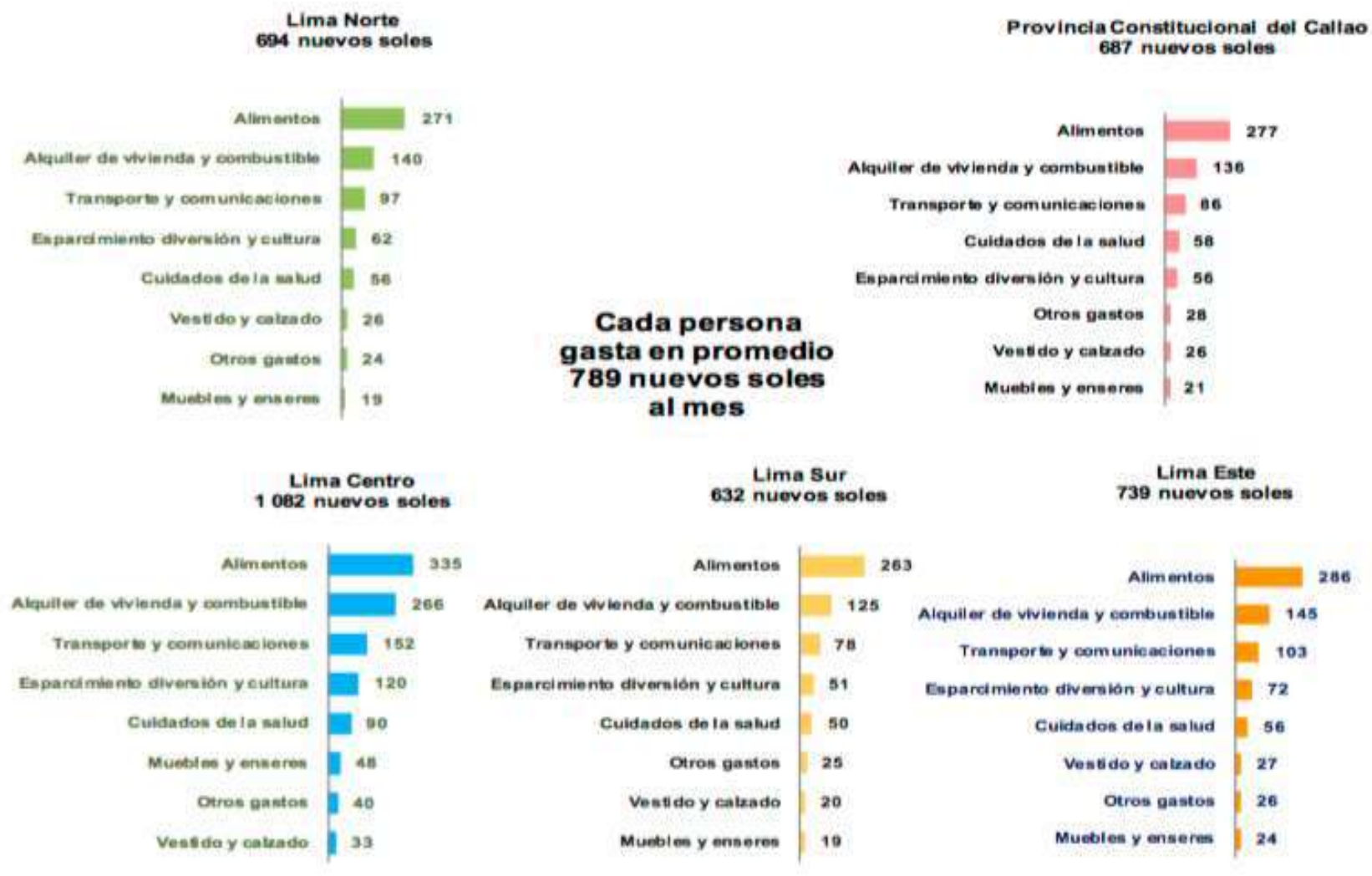

Figura 126 Gasto Mensual Promedio por Persona 
13.24. Anexo $\mathrm{N}^{\circ} 25$ - Licencias de Funcionamiento - Lima Metropolitana

Licencias de Apertura de Establecimientos, según Zona Geografica. 2013 (Número de lleenclas)

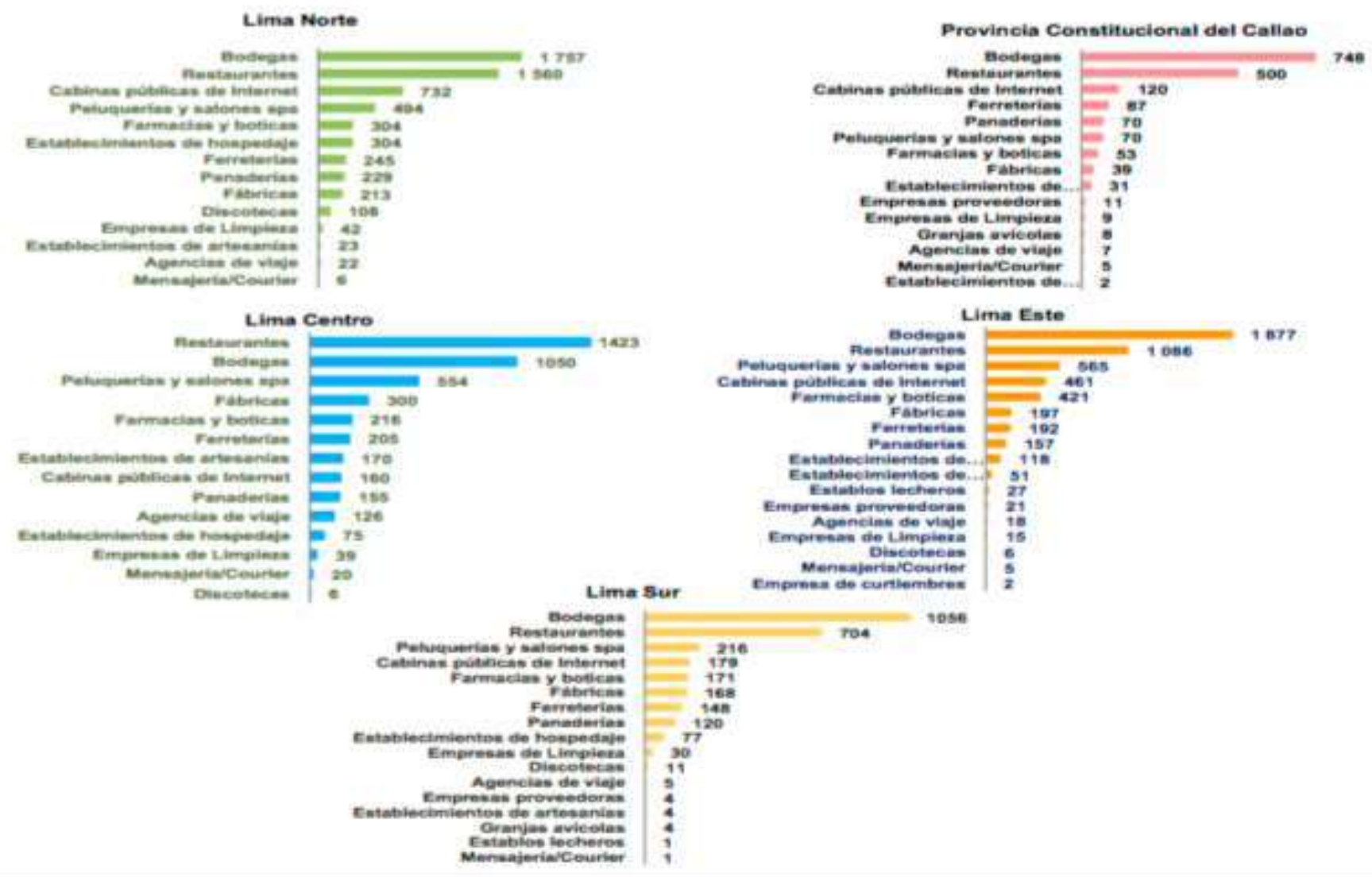

Figura 127 Licencias de Funcionamiento - Lima Metropolitana 
13.25. Anexo $N^{\circ} 26$ - Licencia a Bodegas - Lima Metropolitana

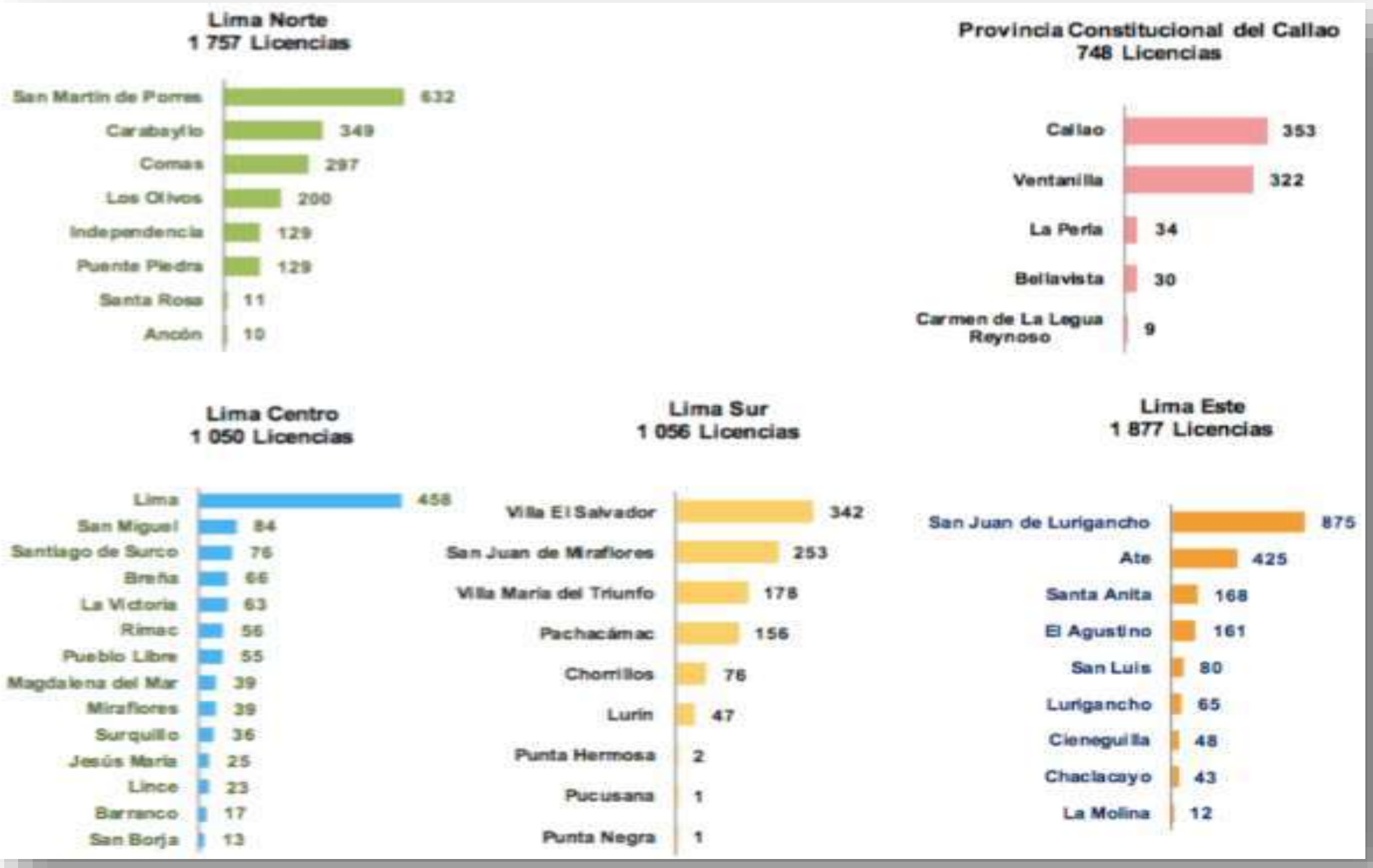

Figura 128 Licencia de Funcionamiento a Bodegas - Lima Metropolitana 
13.26. Anexo $N^{\circ} 27$ - Casas Naturistas - Zona 2

Tabla 159

Casas Naturistas - Zona 2

\section{CASAS NATURISTAS ZONA 2}

\begin{tabular}{|c|l|c|}
\hline \multicolumn{1}{|c|}{ DISTRITO } & \multicolumn{1}{|c|}{ EMPRESA } & \multicolumn{1}{|c|}{ CANTIDAD } \\
\hline \multirow{2}{*}{ LOS OLIVOS } & $\begin{array}{l}\text { Selva Andina Export } \\
\text { Distribuidor Independiente Walter Meza González } \\
\text { Productos Naturales y Terapias Alternativas } \\
\text { Maravi Natur } \\
\text { Vidatotal y Salud } \\
\text { Productos Naturales Anthony Pharma S.A.C. } \\
\text { Distribuidor Independiente Teoma }\end{array}$ & 7 \\
\hline SAN MARTIN DE PORRES & $\begin{array}{l}\text { Vida Saludable los Olivos } \\
\text { Bella \& Sana } \\
\text { Ganoterapia Victoria } \\
\text { Casa Naturista Reyes } \\
\text { Distribuidor Independiente Walter Meza González } \\
\text { Distribuidor Independiente Teoma } \\
\text { Inversiones Zambrano S.M. S.A.C. }\end{array}$ & \\
\hline INDEPENDENCIA & $\begin{array}{l}\text { Nuevas Tendencias del Siglo 21 } \\
\text { Distribuidor Independiente Teoma }\end{array}$ & 7 \\
\hline
\end{tabular}




\section{Bibliografía.}

1. Administración Estratégica

Décima Edición

Fred R. David

Editorial Pearson

2. Marketing

Decimocuarta Edición

Philio Kloter / Gary Armstrong

Editorial: Pearson

3. Contabilidad de Costos - Un enfoque Gerencial

Decimocuarta Edición

Charles T. Horngren / Srikant M. Datar / Madhav V. rajan

Editorial: Pearson

4. Proyectos de Inversión - Formulación y Evaluación

Segunda Edición

Nassir Sapag Chain

Editorial: Pearson

5. Dirección de Marketing

Philip Kotler, 2016, México,

Editorial: Pearson Education

Copyright Prentice Hall

6. ¿Cuántos Años Vivire?

Erneto E. Villalba Supka, 2012, Argentina,

Editorial: Dunken 


\section{Referencias Electrónicas}

1. ORGANIZACIÒN DE LAS NACIONES UNIDAD PARA LA ALIMENTACIÒN Y LA AGRICULTURA - FAO

http://www.fao.org/home/es/

2. ORGANIZACIÒN MUNDIAL DE LA SALUD - OMS

http://www.who.int/es/

3. INEI

http://www.inei.gob.pe/prensa/noticias/produccion-de-papa-crecio-45$\underline{7582 /}$

http://cde.peru21.pe/doc/0/0/1/8/5/185456.pdfhttp://semanaeconomica.com /article/servicios/educacion/160655-el-consumo-privado-en-el-2015cuales-son-los-sectores-que-resistiran-el-debil-crecimiento-economico/

http://www.inei.gob.pe/media/cifras_de_pobreza/pobreza_informetecnico2 $\underline{013 \_1 . p d f}$

https://www.inei.gob.pe/media/MenuRecursivo/publicaciones_digitales/Es t/Lib0932/index.htm

4. MINSA

http://www.minsa.gob.pe/index.asp?op=6

http://www.minsa.gob.pe/?op=51\&nota $=16193$

http://www.app.minsa.gob.pe/bsc/detalle indbsc.asp?lcind=5\&lcobj=1\&lc per $=1 \&$ lcfreg $=3 / 2 / 2015$

http://www.app.minsa.gob.pe/bsc/detalle_indbsc.asp?lcind=94\&lcobj=5\&l cper $=2 \&$ lcfreg $=8 / 9 / 2014$

http://www.dge.gob.pe/portal/docs/vigilancia/boletines/2014/03.pdf

http://www.minsa.gob.pe/estadisticas/estadisticas/Mortalidad/Macros.asp? $\underline{00}$

http://www.minsa.gob.pe/portada/prensa/notas_auxiliar.asp?nota=10044

5. MINISTERIO DE AGRICULTURA Y RIEGO

http://www.minagri.gob.pe/portal/

6. MINISTERIO DE TRANSPORTES Y COMUNICACIONES

http://www.proviasnac.gob.pe/Archivos/file/RVN_PERU_RTT_201309.p $\underline{\mathrm{df}}$

7. BANCO CENTRAL DE RESERVA DEL PERU

http://www.bcrp.gob.pe/

http://www.bcrp.gob.pe/docs/Publicaciones/Reporte-

Inflacion/2013/diciembre/reporte-de-inflacion-diciembre-2013-sintesis.pdf 
8. SISTEMA DE ABASTECIMIENTO Y PRECIOS - SISAP v 2.0

http://sistemas.minag.gob.pe/sisap/portal2/mayorista/

9. ASOCIACIÒN PERUANA DE EMPRESAS DE INVESTIGACIÒN DE MERCADO

http://apeim.com.pe/

http://apeim.com.pe/niveles.php

http://www.apeim.com.pe/wp-content/themes/apeim/docs/nse/APEIM NSE-2013

10. IPSOS PERÙ

http://www.ipsos-

apoyo.com.pe/sites/default/files/marketing_data/MKT_DATA_ninho_201 3.pdf

http://www.ipsosapoyo.com.pe/sites/default/files/marketing_data/Perfil_de _la_Bodega_y_Bodeguero_2012.pdf

http://www.ipsosapoyo.com.pe/sites/default/files/marketing_data/Mkt_Dat a_Perfiles_Zonales_2013.pdf

http://www.ipsosapoyo.com.pe/sites/default/files/marketing_data/Perfil_de 1_ama_de_casa_2013.pdf

11. TOTTUS

http://www.tottus.com.pe/tottus/

12. METRO - CENCOSUD

https://www.metro.com.pe/

13. PLAZA VEA

https://www.metro.com.pe/

14. MERCADO MAYORISTA MAKRO

http://www.makro.com.pe/

\section{AMERICA ECONOMICA}

http://apeim.com.pe/

16. DIARIO LA REPUBLICA

http://archivo.larepublica.pe/08-11-2014/hasta-60-peruanos-mueren-al-

mes-por-falta-de-donantesMINSA

http://archivo.larepublica.pe/09-03-2013/minsa-excesivo-consumo-de-sale-inadecuada-ingesta-de-agua-pueden-danar-el-rinon

\section{DIARIO PUBLIMETRO}

http://publimetro.pe/vida-estilo/noticia-donantes-organos-hay-73-mil-peru19750?ref=ecr

18. DIARIO EL COMERCIO

http://elcomercio.pe/lima/ciudad/lima-hay-al-menos-450-mil-afectadosenfermedad-renal-noticia-1797074 
19. KIDNEY \& UROLOGY FOUNDATION OF AMERICA INC.

http://www.kidneyurology.org/Library/Spanish/Metodos_de tratamiento para_la_insuficiencia_renal.php

20. FUNDACIÓN RENAL IÑIGO ÁLVAREZ DE TOLEDO

https://www.friat.es/wp-content/uploads/2013/12/Guia-para-el-control-def\%C3\%B3sforo-y-potasio.pdf

21. GAN - GASTRONOMÍA + NUTRICIÓN

http://gan-bcn.com/es/

22. GESTIOPOLIS

http://www.gestiopolis.com/philip-kotler-y-sus-estrategias-de-marketing/

23. ROBERTO ESPINOZA

http://robertoespinosa.es/2015/05/31/matriz-de-ansoff-estrategias-

crecimiento/

24. ANUNCIAR EN TELEVISIÓN: VENTAJAS, RECOMENDACIONES Y COSTOS

http://www.pqs.pe/actualidad/noticias/anunciar-en-television-ventajas-

recomendaciones-y-costos

http://www.pqs.pe/actualidad/noticias/anunciar-en-radio-ventajas-costos-yrecomendaciones

25. AMÉRICA TELEVISIÓN

http://www.comercial.americatv.com.pe/

26. SUPERINTENDENCIA DE BANCA, SEGUROS Y AFP

http://www.sbs.gob.pe/

27. DAMODARAN ONLINE: HOME PAGE FOR ASWATH

DAMODARAN

http://pages.stern.nyu.edu/ adamodar/

28. COMUNIDAD DE EMPRENDEDORES

WWW.emprendices.co

29. ¿Cuántos Años Viviré?

https://books.google.com.pe/books?id=JvbF2QCuRtYC\&pg=PA139\&lpg= PA139\&dq=catedr\%C3\%A1tico+de+Fisiolog\%C3\%ADa+Humana,+Fran cisco+Mora, $+\mathrm{a}+\mathrm{los}+30+\mathrm{a} \% \mathrm{C} 3 \% \mathrm{~B} 1 \mathrm{os}+\mathrm{se}+\mathrm{comienza}+\mathrm{a}+\mathrm{envejecer \& source}$ $=$ bl\&ots $=$ JGbdjgYom-

\&sig=Rce952_w_YxLzYgkHHyS1qBwC_U\&hl=es\&sa=X\&ved=0ahUK EwiXnfG8n83VAhVChZAKHVchA6AQ6AEINTAD\#v=onepage \&q=cate dr\%C3\%A1tico\%20de\%20Fisiolog\%C3\%ADa\%20Humana\%2C\%20Fran cisco $\% 20$ Mora $\% 2 \mathrm{C} \% 20 \mathrm{a} \% 20 \mathrm{los} \% 2030 \% 20 \mathrm{a} \% \mathrm{C} 3 \% \mathrm{~B} 1 \mathrm{os} \% 20 \mathrm{se} \% 20 \mathrm{comi}$ enza\%20a\%20envejecer\&f=false 